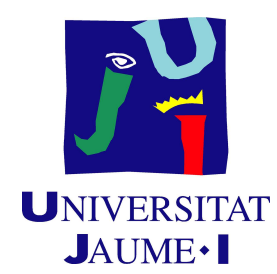

Escuela Superior de Tecnología y Ciencias Experimentales

Departamento de Ingeniería de Sistemas Industriales y Diseño

\title{
Propuesta y evaluación de tratamientos para la mejora de la eficiencia energética en el sector residencial mediante el desarrollo de experimentos económicos
}

\author{
TESIS DOCTORAL DE \\ Nieves García Martín \\ Bajo la dirección de \\ Enrique Belenguer Balaguer \\ Gerardo Sabater Grande
}

Castellón, marzo 2017 



\section{Resumen}

En esta tesis doctoral se ha realizado un estudio de diferentes métodos de reducción del consumo de energía a nivel residencial, clasificándolos en dos grandes grupos: métodos que aumentan la cantidad y calidad de la información recibida por el usuario en relación a su consumo, y métodos que incentivan económicamente el ahorro.

A lo largo del desarrollo de la tesis se han llevado a cabo tres experimentos diferentes, todos ellos respetando los principios y la metodología planteados por la economía experimental.

El primer experimento tuvo lugar en laboratorio. Su objetivo principal fue comparar la eficacia de diversos métodos informativos para la mejora del desempeño energético de los sujetos participantes. El entorno diseñado para ello fue una vivienda virtual simulada por ordenador; el método que resultó ser más eficaz durante las pruebas fue el uso de contadores inteligentes.

El segundo experimento consistió en la instalación de un contador inteligente en una serie de viviendas de la provincia de Castellón. El objeto en este caso fue el de confirmar la validez de la herramienta informativa de mayor éxito en un entorno menos artificial que el del laboratorio. La conclusión principal fue que las herramientas informativas en el ámbito real son ineficaces si no van acompañadas de algún tipo de incentivo.

En el tercer y último experimento, se ofreció a los sujetos participantes un incentivo económico a cambio de unos resultados de ahorro determinados, también en una serie de viviendas de la provincia de Castellón. Su objetivo principal fue comprobar si el incentivo económico es suficiente para obtener ahorros significativos en el consumo, y su resultado fue afirmativo.

Como complemento a los resultados anteriores y también como propuesta para ampliaciones posteriores, se plantea el desarrollo de una calificación del comportamiento de los usuarios en sus viviendas mediante la definición de una etiqueta energética. A partir de ella, se clasificaría a los habitantes en función de sus costumbres energéticas, independientemente de las características de la vivienda que ocupan. Por último, se proponen diversas formas de aplicación del incentivo económico asociado a la etiqueta energética. 


\section{Resum}

En esta tesi doctoral s'ha realitzat un estudi de diferents mètodes de reducció del consum d'energia a nivell residencial, classificant-los en dos grans grups: mètodes que augmenten la quantitat i qualitat de la informació rebuda per l'usuari en relació al seu consum, i mètodes que incentiven econòmicament l'estalvi.

Al llarg del desenvolupament de la tesi s'han dut a terme tres experiments diferents, tots ells respectant els principis i la metodologia plantejats per l'economia experimental.

El primer experiment va tindre lloc en laboratori. El seu objectiu principal va ser comparar l'eficàcia de diversos mètodes informatius per a la millora del comportament energètic dels subjectes participants. L'entorn dissenyat per als tests va ser una vivenda virtual simulada per ordinador; el mètode que va resultar ser més eficaç durant les proves va ser l'ús de comptadors intel.ligents.

El segon experiment va consistir en la installació d'un comptador intel-ligent en una sèrie de vivendes de la província de Castelló. L'objecte en este cas va ser el de confirmar la validesa de la ferramenta informativa de major èxit en un entorn menys artificial que el del laboratori. La conclusió principal va ser que les ferramentes informatives en l'àmbit real són ineficaços si no van acompanyades d'algun tipus d'incentiu.

En el tercer i últim experiment, es va oferir als subjectes participants un incentiu econòmic a canvi d'uns resultats d'estalvi determinats, també en una sèrie de vivendes de la província de Castelló. El seu objectiu principal va ser comprovar si l'incentiu econòmic és suficient per a obtindre estalvis significatius en el consum, i el seu resultat va ser afirmatiu.

Com a complement als resultats anteriors i també com a proposta per a ampliacions posteriors, es planteja el desenvolupament d'una qualificació del comportament dels usuaris en les seues vivendes per mitjà de la definició d'una etiqueta energètica. A partir d'ella, es classificaria els habitants en funció dels seus costums energètics, independentment de les característiques de la vivenda que ocupen. Finalment, es proposen diverses formes d'aplicació de l'incentiu econòmic associat a l'etiqueta energètica. 
In this doctoral thesis a study of different methods of energy consumption reduction at residential level has been carried out. The methods have been classified into two large groups: those that increase the quantity and quality of the information received by the user in relation to their consumption, and those that stimulate savings using an economic incentive.

Three different experiments have been performed throughout the development of the thesis, all of them following the principles and methodology formulated by the experimental economy.

The first experiment took place in the economic laboratory. Its main objective was to compare the effectiveness of various informative methods for the improvement of the participants' energy performance. The environment designed for it was a virtual home simulated by computer; the method that proved most effective during testing was the use of smart meters.

The second experiment consisted of the installation of a smart meter in a series of houses in the province of Castellón. The purpose in this case was to confirm the validity of the most successful information tool in a less artificial environment than the laboratory. The main conclusion was that information tools in the real world are ineffective if they are not accompanied by some kind of incentive.

In the third and last experiment, participants were offered an economic incentive in exchange of a specific amount of savings, also in a series of houses in the province of Castellón. Its main objective was to verify if the economic incentive is enough to obtain significant savings in consumption, and its result was affirmative.

As a complement to the previous results and also as a proposal for further enlargements, the development of a rating of the users' behaviour in their homes is proposed by defining an energy label. From it, the inhabitants would be classified according to their energetic habits, independently of the characteristics of the dwelling that they occupy. Finally, different forms of implementation of the economic incentive associated with the energy label are proposed. 


\section{Contenido}

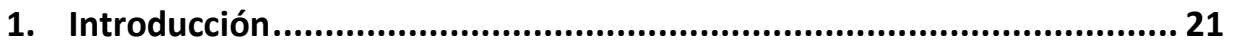

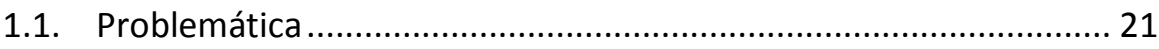

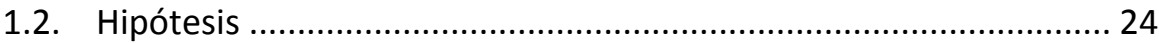

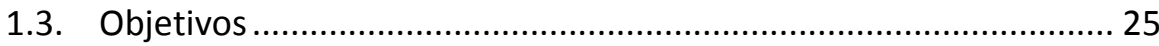

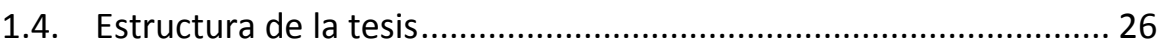

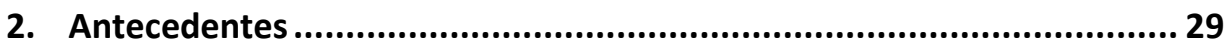

2.1. Legislación europea en eficiencia energética ................................. 29

2.1.1. Marco normativo de la política europea de eficiencia

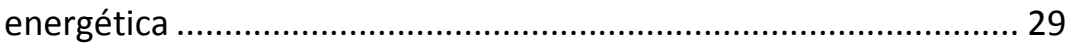

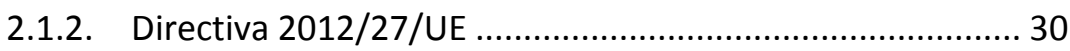

2.1.3. Directiva 2010/31/UE ......................................................... 31

2.1.4. Directiva Europea 2010/30/UE ....................................... 32

2.1.5. DIRECTIVA 2009/125/UE................................................... 32

2.1.6. Planes de eficiencia energética 2014-2020 ....................... 32

2.2. Legislación española en materia de eficiencia energética............... 33

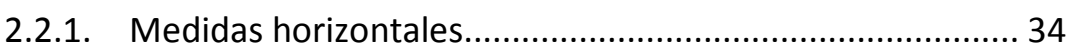

2.2.2. Medidas concretas para edificios ........................................ 36

2.3. Medida y evolución de la eficiencia energética mundial.................. 38

2.3.1. Evolución del consumo de energía primaria........................ 38

2.3.2. Evolución del consumo de energía final .............................. 39

2.3.3. Desagregación del consumo final por sectores .................. 40

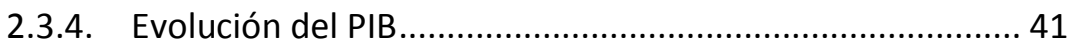

2.3.5. Evolución de la intensidad energética .................................. 42

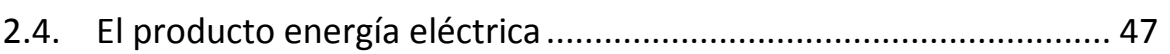

2.4.1. Elasticidad de la demanda ................................................ 48

2.4.2. Información del producto ................................................. 49

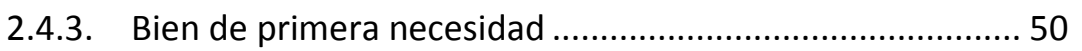

2.4.4. Efecto de los impuestos y otros recargos ........................... 51

2.4.5. Efectos medioambientales del consumo ............................ 51

2.5. Análisis del consumo energético en España ................................... 52

2.5.1. El consumo eléctrico en España......................................... 52

2.5.2. Contribución del sector residencial a la demanda............... 54

2.5.3. Proporción del consumo según equipos............................. 55 
2.5.4. El precio de la electricidad ................................................ 57

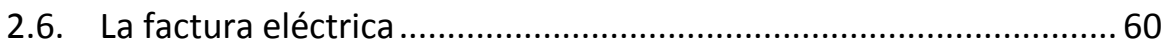

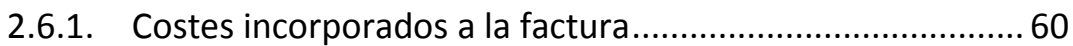

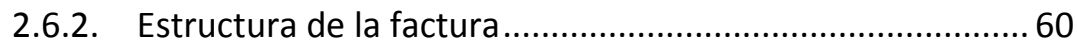

2.6.3. Dificultades para la interpretación de la factura ................. 63

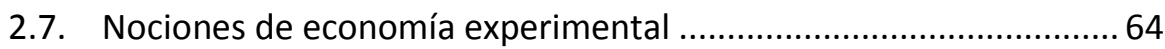

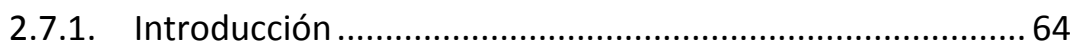

2.7.2. Pautas para la realización de un experimento económico. 68

2.7.3. Tratamiento estadístico de los resultados de las sesiones

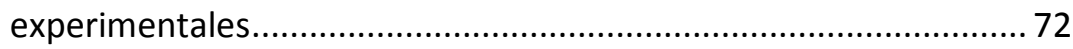

2.7.4. La economía experimental aplicada al campo energético.. 78

3. Brechas, barreras y políticas de eficiencia energética en el sector

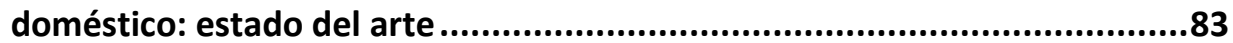

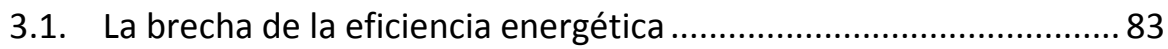

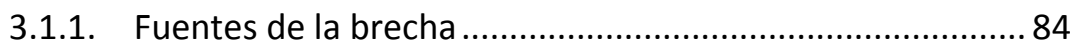

3.2. Barreras a la eficiencia energética ................................................... 89

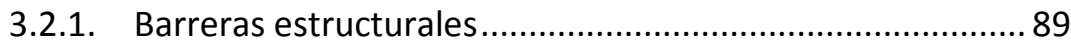

3.2.2. Barreras conductuales...................................................... 91

3.3. Recursos para la corrección de barreras estructurales..................... 93

3.3.1. Información del coste de la energía.....................................93

3.3.2. Internalización de externalidades ...................................... 94

3.4. Recursos para la corrección de barreras conductuales .................... 95

3.4.1. Minimización de la procrastinación ....................................95

3.4.2. Recompensas e incentivos ................................................ 96

3.4.3. Eliminación de la racionalidad limitada ..............................96

3.4.4. Aprovechamiento de las normas sociales.......................... 97

3.5. Políticas de eficiencia energética: tipología .......................................99

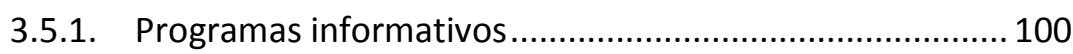

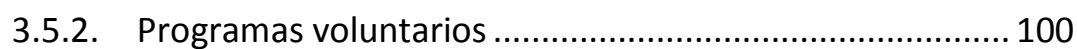

3.5.3. Incentivos financieros ....................................................... 100

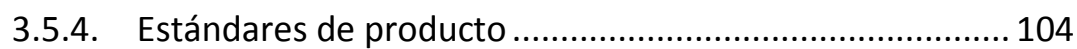

3.6. Políticas de eficiencia energética: ejemplos de aplicación ............. 104

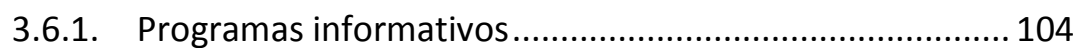

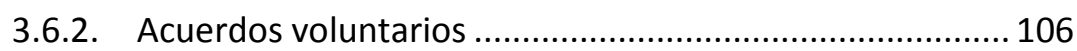

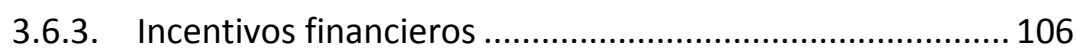

3.6.4. Estándares de eficiencia.................................................... 110 
4. La eficiencia energética en el sector residencial: estado del arte

4.1. Aumento de la eficiencia energética en el sector residencial mediante métodos informativos.

4.1.1. Tipología de los equipos consumidores y posibilidades de ahorro energético 113

4.1.2. Sistemas basados en la información............................... 115

4.1.3. Sistemas basados en la realimentación................................... 116

4.1.4. Tipos de realimentación .............................................. 117

4.2. Análisis de sistemas de realimentación en el sector residencial ... 118

4.2.1. Sistemas de realimentación de la información.................. 118

4.2.2. Sistemas de realimentación a través de la factura ............ 120

4.2.3. Sistemas de realimentación mediante prepago ................. 127

4.2.4. Sistemas de realimentación por contador inteligente ..... 128

4.2.5. Equipos de medida inteligente en el mercado ................. 129

5. Evaluación de métodos en laboratorio. Experimento 1...................... 139

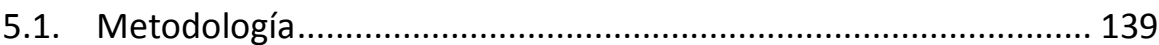

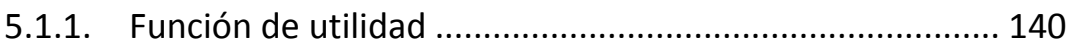

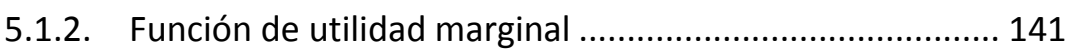

5.1.3. Aplicación de la función de utilidad en la economía

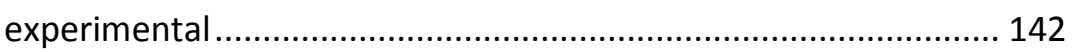

5.1.4. Aplicación de la función de utilidad al estudio .................. 143

5.2. Planificación de las sesiones experimentales ............................... 143

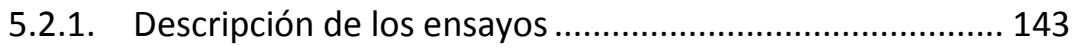

5.2.2. Descripción de los tratamientos .......................................... 144

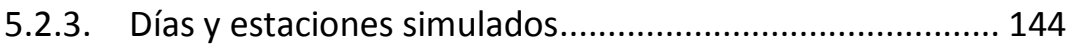

5.2.4. Descripción de la vivienda ................................................ 145

5.3. Desarrollo de las sesiones experimentales ................................... 147

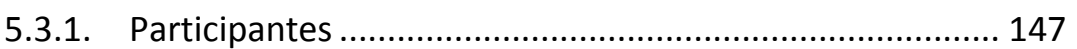

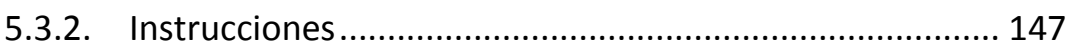

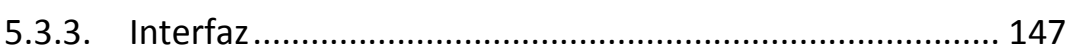

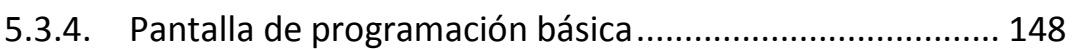

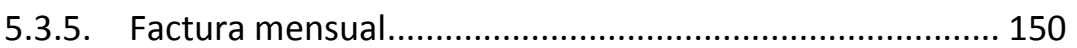

5.3.6. Desglose de la pantalla básica ........................................... 150 
5.3.7. Variaciones sobre la pantalla de programación básica..... 152

5.3.8. Pagos realizados a los sujetos .......................................... 156

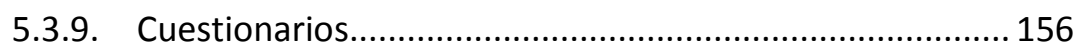

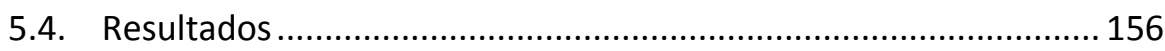

5.4.1. Consumo y beneficio eléctricos respecto al óptimo .......... 156

5.4.2. Consumo y beneficio eléctricos respecto al Tratamiento

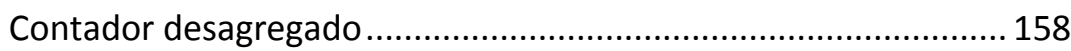

5.4.3. Consumo y beneficio eléctricos respecto al Tratamiento Básico 160

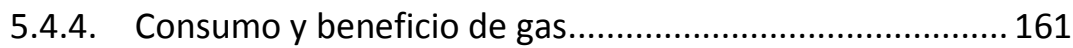

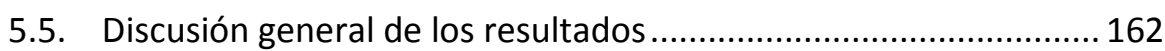

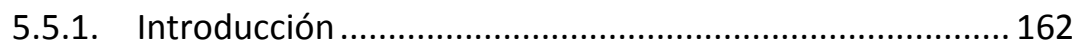

5.5.2. Sugestionabilidad de los sujetos ...................................... 163

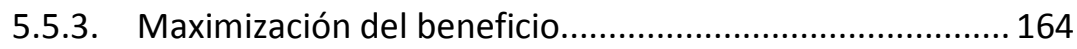

5.6. Discusión de los resultados por tratamiento ................................... 165

5.6.1. Contadores: Eficacia en la optimización ............................ 165

5.6.2. Consejos, Rankings y Básico: influencia de la presión a la baja en el consumo .................................................................... 168

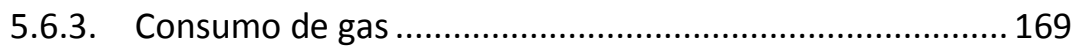

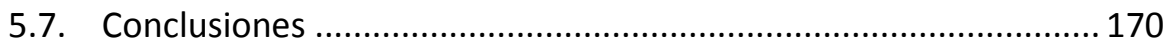

6. Evaluación del método informativo en campo: Experimento 2 …........173

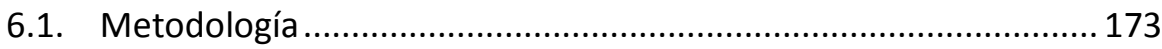

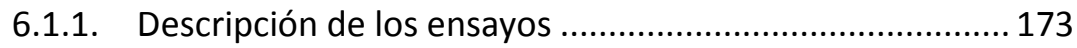

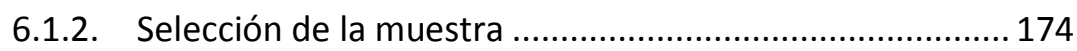

6.1.3. Descripción del dispositivo de medición onMeterDomo .. 175

6.1.4. Descripción de la aplicación de lectura onMeterApp ....... 177

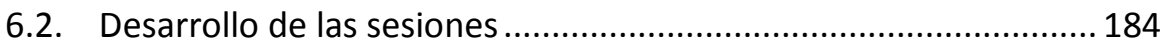

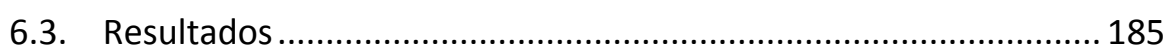

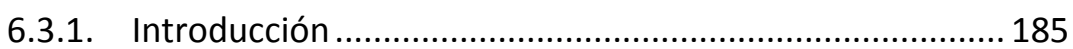

6.3.2. Estadísticos descriptivos .............................................. 186

6.3.3. Normalidad de las muestras .............................................. 187

6.3.4. Comparativa entre los dos grupos .................................. 187

6.3.5. Otras aportaciones de los participantes ............................ 189

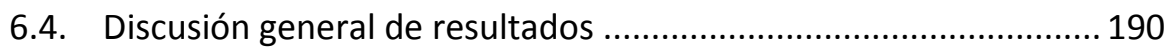

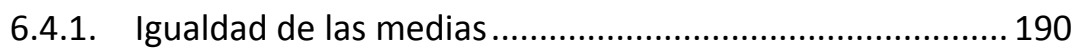

6.4.2. Validez de la herramienta informativa............................... 191 
6.4.3. Implicación de los usuarios .............................................. 192

6.4.4. Aportaciones de los usuarios ........................................... 192

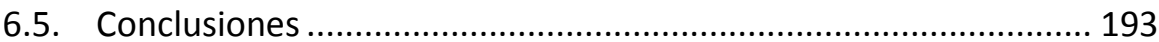

6.5.1. Necesidad de un incentivo............................................ 193

6.5.2. Las herramientas informativas puestas en marcha por la

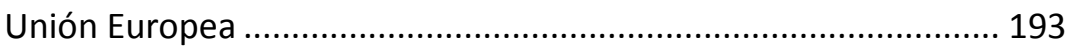

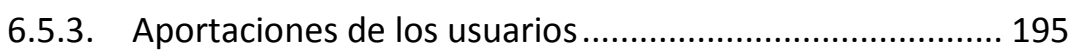

7. Evaluación del incentivo económico en campo: Experimento 3.......... 197

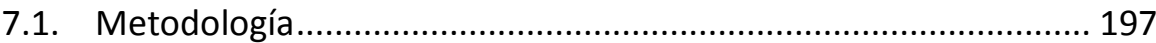

7.1.1. Descripción de los ensayos ........................................... 197

7.1.2. Objetivo de ahorro e incentivo aplicado .......................... 198

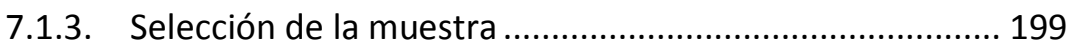

7.1.4. Diseño de la información semanal................................... 201

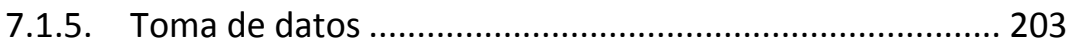

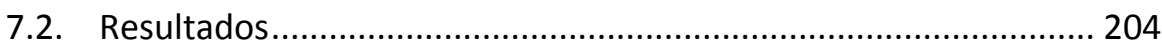

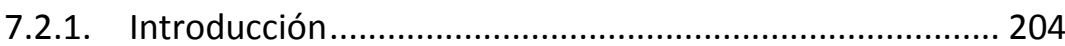

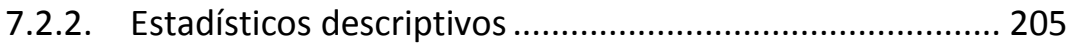

7.2.3. Normalidad de las muestras .......................................... 205

7.2.4. Comparativa de la variación de consumo entre grupos ... 206

7.2.5. Comparativa con el Grupo 0 ............................................. 209

7.2.6. Comportamientos individuales......................................... 209

7.2.7. Otras aportaciones de los participantes ........................... 210

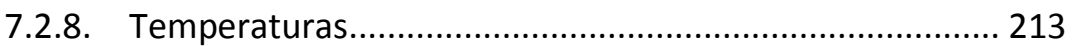

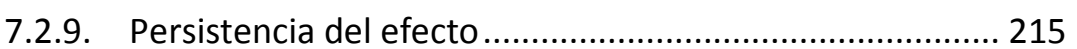

7.3. Discusión general de resultados .................................................. 216

7.3.1. Evolución de los consumos y ahorros ................................ 216

7.3.2. Influencia de la realimentación ........................................ 217

7.3.3. Validez de la herramienta informativa .............................. 217

7.3.4. Aportaciones de los participantes ..................................... 217

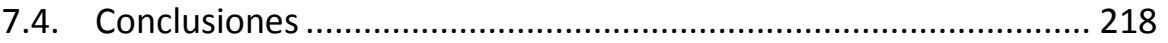

7.4.1. Importancia del incentivo financiero................................. 218

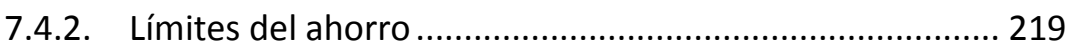

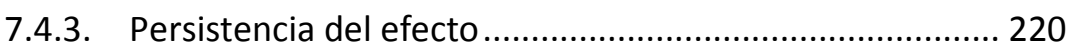

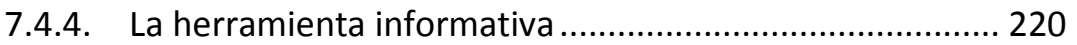


8. Propuesta de un índice de eficiencia del comportamiento energético en la vivienda

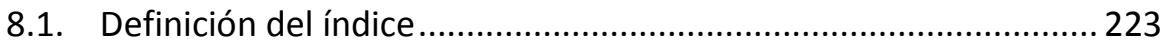

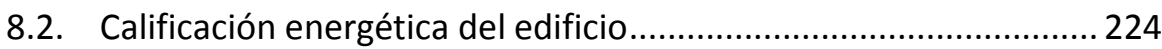

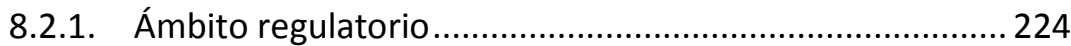

8.2.2. Cálculo de los valores del certificado ................................ 225

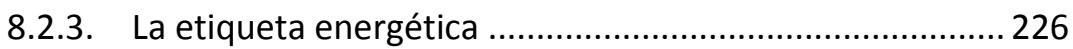

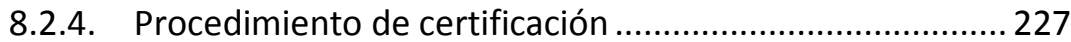

8.3. Calificación energética del uso de la vivienda................................. 231

8.3.1. Indicador de comportamiento energético....................... 231

8.3.2. Grado de similitud: clasificación en viviendas tipo ............ 232

8.3.3. Necesidad de un estudio estadístico de envergadura ...... 235

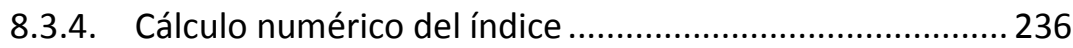

8.3.5. Definición de los escalones de la calificación..................... 236

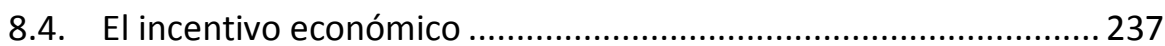

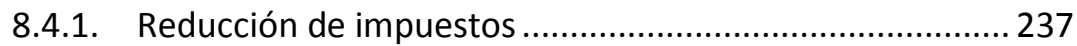

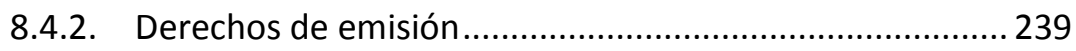

8.4.3. Modificación de la tarifa eléctrica...................................... 241

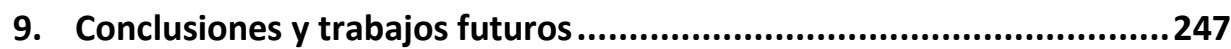

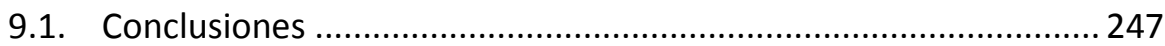

9.1.1. El problema medioambiental y el factor humano ............ 247

9.1.2. La información como herramienta de trabajo ................... 249

9.1.3. El incentivo económico como motor del cambio............... 251

9.1.4. Aplicabilidad del incentivo económico .............................. 253

9.1.5. Aplicabilidad de la economía experimental...................... 254

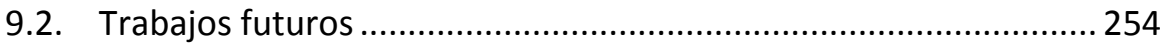

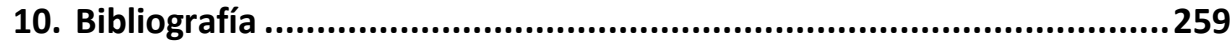

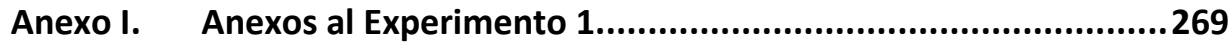

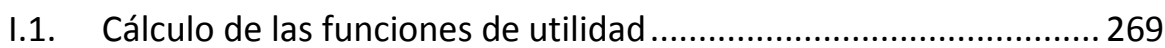

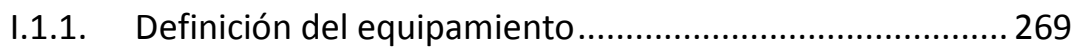

1.1.2. Cálculo de las funciones de utilidad de cada electrodoméstico, iluminación o equipo de climatización ............. 271

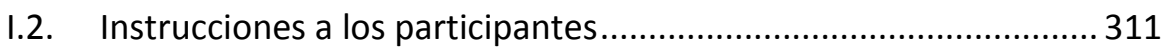


I.2.1. Instrucciones generales .................................................. 311

I.2.2. Pantalla de programación.............................................. 313

1.3. Estudio estadístico de los resultados experimentales.................... 315

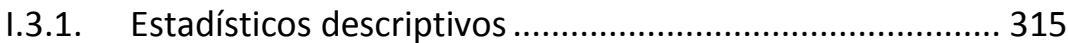

1.3.2. Comparativas internas al tratamiento. Wilcoxon.............. 326

1.3.3. Comparativas entre tratamientos. Mann-Whitney ........... 328

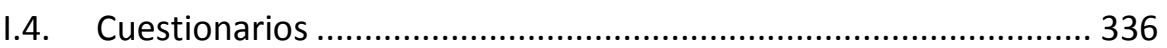

I.4.1. Cuestionario de concienciación medioambiental.............. 336

Anexo II. Anexos al Experimento 2

II.1. Carta y encuesta de selección ...................................................... 344

Anexo III. Anexos al Experimento 3 ................................................. 348

III.1. Carta y encuesta de selección del grupo I ................................... 348

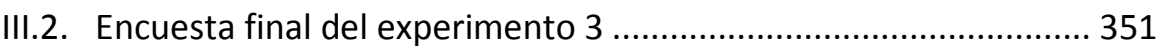

III.3. Comunicaciones vía mensaje de móvil o correo con los participantes

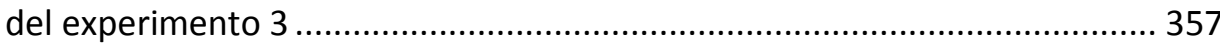

III.3.1. Comunicación de inicio del experimento, grupo I............. 357

III.3.2. Comunicación de inicio del experimento, grupo II ............ 358

III.3.3. Explicación de las gráficas, previa al inicio del experimento.

Vía mensaje de móvil, ambos grupos ........................................... 359

III.3.4. Comunicación de fin del experimento, vía mensaje de móvil,

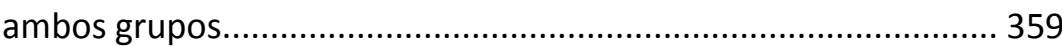

III.3.5. Resultados y solicitud de prolongación de acceso a la

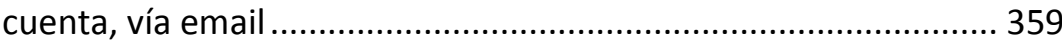

III.4. Estudio estadístico del experimento 3.......................................... 360

III.4.1. Estadísticos descriptivos de los consumos semanales y

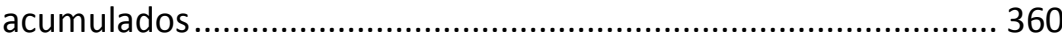

III.4.2. Estudios de normalidad de las muestras ........................... 364

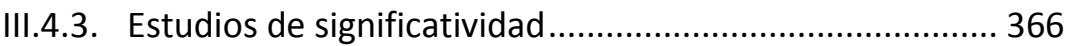

III.4.4. Otras aportaciones de los participantes ............................ 369 


\section{Índice de figuras}

Figura 1.1.- Aumento del consumo energético en el sector residencial en España. Fuente: IDAE ................................................................... 22

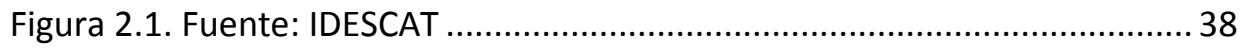

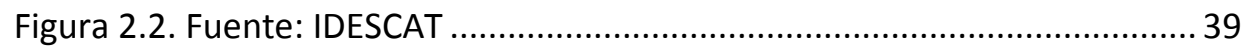

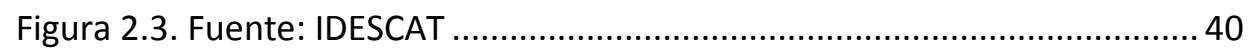

Figura 2.4. Distribución del consumo energético de energía final en el mundo (Fuente: [48] 40

Figura 2.5. Distribución del consumo energético de energía final en España

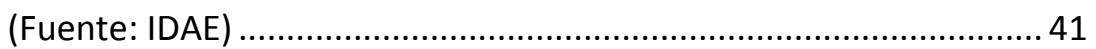

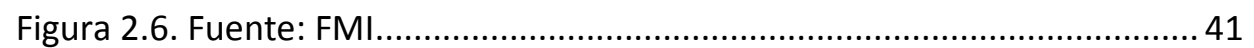

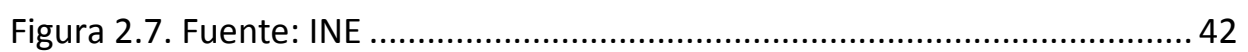

Figura 2.8. Cambios en los factores de intensidad energética por sector. Fuente:[79]......

Figura 2.9. Cambios en los factores de intensidad energética por sector. Fuente:[79]

Figura 2.10. Cambios en la intensidad mundial por sector, 2000-2014. Fuente: [79] 44

Figura 2.11. Intensidad primaria a paridad del poder de compra. Fuente: EnR/IDAE 44

Figura 2.12. Intensidad final a paridad del poder de compra. Fuente: EnR/IDAE

Figura 2.13. Comparativa europea de la intensidad energética del sector industrial. Fuente: EnR/IDAE. 45

Figura 2.14 Comparativa europea de la intensidad energética del sector transporte. Fuente: EnR/IDAE. 45

Figura 2.15. Comparativa europea de la intensidad final del sector servicios. Fuente: EnR/IDAE. 46 
Figura 2.16. Comparativa europea de la intensidad eléctrica del sector servicios. Fuente: EnR/IDAE

Figura 2.17. Comparativa europea de la intensidad final del sector doméstico. Fuente: EnR/IDAE.

Figura 2.18. Comparativa europea de la intensidad eléctrica del sector doméstico. Fuente: EnR/IDAE.

Figura 2.19.- Curva de la demanda. Fuente: IDAE... 52

Figura 2.20.- Curva de la demanda de invierno y verano. Fuente: IDAE 53

Figura 2.21.- Estructura de la generación diaria de energía eléctrica en España. Fuente: REE 54

Figura 2.22.- Estructura de la generación diaria de energía eléctrica en España. Fuente: REE. 55

Figura 2.23.- Consumo energético en el sector residencial español 57

Figura 2.24. Factura eléctrica 62

Figura 2.25.- Dato de energía consumida en la factura 63

Figura 3.1. Información del comportamiento energético respecto a los vecinos utilizada en la referencia [12] 98

Figura 3.2. Información adicional enviada en la referencia [12]... 99

Figura 3.3. Perfiles variables de precios de energía. Fuente: [68] 108

Figura 3.4. Efectos de diferentes políticas de eficiencia energética. Fuente: [112]

Figura 4.1.- Gráficos ensayados por Egan 122

Figura 4.2.- Gráficos ensayados por McLennan 123

Figura 4.3.- Gráficos ensayados por Carroll 123

Figura 4.4.- Gráficos ensayados por Carroll 124

Figura 4.5.- Histograma de consumo de la factura de Iberdrola 126

Figura 4.6.- Contador con tarjeta prepago. 127

Figura 4.7.- Publicidad de un contador inteligente. 128 


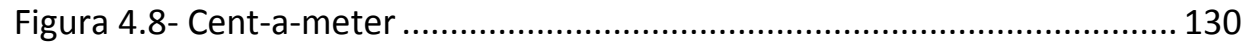

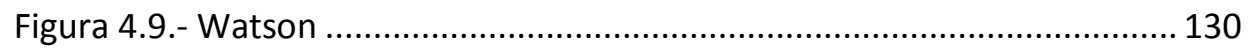

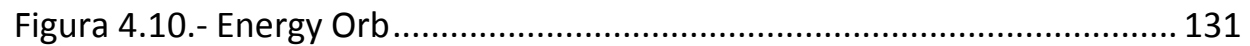

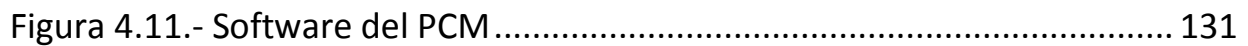

Figura 4.12.- ECOIS II …….......................................................................... 133

Figura 4.13.- Software experimento Karbo ....................................................... 133

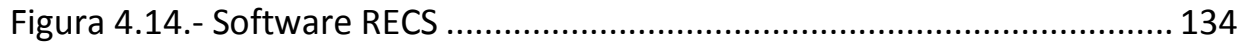

Figura 4.15.- Software experimento Wood.................................................. 135

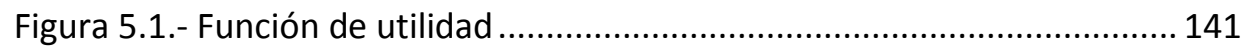

Figura 5.2- Funciones de utilidad y consumo asociado de la plancha.............. 142

Figura 5.3- Presentación del software a los participantes .............................. 147

Figura 5.4. Pantalla de programación básica..................................................... 149

Figura 5.5. - Pantalla de la factura mensual .................................................... 150

Figura 5.6.- Pantalla de programación Tratamiento Consejos .......................... 153

Figura 5.7.- Pantalla de programación Tratamiento Contador Único .............. 154

Figura 5.8.- Pantalla de programación Tratamiento Contador desagregado.. 154

Figura 5.9.- Pantalla específica Tratamiento Ranking .................................... 155

Figura 5.10.- Pantalla específica Tratamiento Ranking ................................... 155

Figura 5.11.- Valores porcentuales medios de consumo eléctrico mensual.. 157

Figura 5.12.- Valores porcentuales medios de beneficio eléctrico mensual. 158

Figura 5.13.- Valores porcentuales medios de consumo eléctrico mensual.. 159

Figura 5.14.- Valores porcentuales medios de beneficio eléctrico mensual.. 159

Figura 5.15.- Valores porcentuales medios de consumo eléctrico mensual.. 160

Figura 5.16.- Valores porcentuales medios de beneficio eléctrico mensual.. 160

Figura 5.17.- Comportamiento de los sujetos en el consumo de ACS ............. 161

Figura 5.18.- Comportamiento de los sujetos en la climatización de la vivienda 161 
Figura 6.1. Instalación del onMeterDomo en el cuadro eléctrico de la vivienda 176

Figura 6.2. Pantalla inicial del onMeterDomo.................................................. 179

Figura 6.3. Submenú Histórico de consumos ............................................... 179

Figura 6.4. Submenú Históricos de consumo. Gráfica diaria .......................... 180

Figura 6.5. Submenú Históricos de consumo. Consumo durante un periodo determinado 180

Figura 6.6. Submenú Factura estimada. Comparativa consumos / precios de la energía

Figura 6.7. Submenú Factura estimada. Precios de la energía consumida para distintas tarifas

Figura 6.8. Submenú Factura estimada, coste mensual de la energía

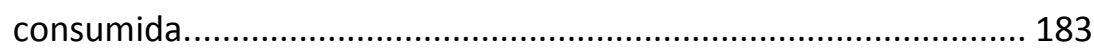

Figura 6.9. Submenú Potencia contratada. Auditoría energética................... 183

Figura 6.10. Comparativa entre las medias de consumo de los grupos onMeter y Control a lo largo de los tres periodos. 188

Figura 6.11. Página web con información mensual del consumo de una conocida distribuidora de energía eléctrica.

Figura 6.12. Grado de efectividad de las distintas políticas de eficiencia energética puestas en marcha por la Unión Europea. Fuente: [49] 195

Figura 7.1. Información del consumo semanal y comparativa con la misma semana del año anterior 202

Figura 7.2. Información del consumo total y comparativa con el del año anterior y con el resto de participantes. 202

Figura 7.3. Evolución del incremento de consumo a lo largo del experimento

Figura 7.4. Evolución del consumo acumulado del Grupo I entre los años 2015 y 2016 208

Figura 7.5. Evolución del consumo semanal del Grupo I 208

Figura 7.6. Ahorros obtenidos por cada participante individual del Grupo I.. 209 
Figura 7.7. Ahorros obtenidos por cada participante individual del Grupo II. 210

Figura 7.8 Comparativa entre las temperaturas medias y los consumos diarios de ambos Grupos en el año 2015. 214

Figura 7.9. Comparativa entre las temperaturas medias y los consumos diarios de ambos Grupos en el año 2016 214

Figura 7.10. Temperaturas medias diarias en los días del experimento de los

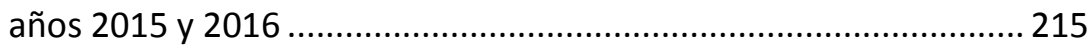

Figura 8.1. Etiqueta de eficiencia energética del edificio................................. 226

Figura 8.2. Ejemplo de distribución en frecuencia (total) de las emisiones totales generadas por un conjunto de viviendas seleccionadas a partir de las estadísticas del INE. Fuente: [51].

Figura 8.3. Formación gráfica de la escala de la calificación energética. Fuente: [51] 230

Figura 8.4. Desagregación del consumo en vivienda según fuentes energéticas. Fuente: Informe SPAHOUSEC. 


\section{Índice de tablas}

Tabla 2.1. Combinaciones de políticas de eficiencia energética en el sector de la edificación. Fuente: [102]

Tabla 2.2. Elasticidad de la demanda en el sector residencial 49

Tabla 2.3.- Consumo energético en el sector residencial español. Fuente: Informe Spahousec

Tabla 2.4.- Consumo energético en el sector residencial español por zona climática y tipo de vivienda. Fuente: Informe Spainhousec

Tabla 2.5. Tests de contraste de hipótesis 76

Tabla 5.1.- Consumo eléctrico del equipamiento de la vivienda ..... 145

Tabla 5.2. Consumo de gas en la vivienda. 146

Tabla 5.3.- Medias de consumo eléctrico 157

Tabla 5.4.- Valores medios de beneficio eléctrico mensual por estación....... 158

Tabla 6.1. Características socioeconómicas de las muestras. 175

Tabla 6.2. Calendario de sesiones 185

Tabla 6.3. Fechas de los cuatro periodos en que se divide el experimento ... 185

Tabla 6.4. Estadísticos descriptivos de todos los periodos 186

Tabla 6.5. Resultados de las pruebas de normalidad 187

Tabla 6.6.- Comparativa de los grupos onMeter y Control durante los 3 periodos del experimento

Tabla 6.7. Encuesta final experimento 2 189

Tabla 6.8. Encuesta final experimento 2 190

Tabla 7.1. Características socioeconómicas de los grupos I y II del experimento 3 200

Tabla 7.2. Estadísticos descriptivos del incremento global de consumo 205 
Tabla 7.3. Pruebas de normalidad de la variable Incremento global del

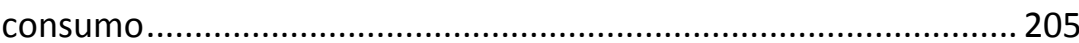

Tabla 7.4. Comparativa de resultados de los grupos 0, I y II a nivel global.... 206

Tabla 7.5. Resultados del test final para el Grupo I 212

Tabla 7.6. Resumen de los recursos utilizados por los participantes del Grupo I 213

Tabla 7.7. Resumen de la utilidad de la información semanal enviada según los participantes 213

Tabla 7.8. Resultados de la toma de datos posterior a la finalización del experimento 215

Tabla 8.1. Variables de las que depende el consumo de la vivienda 233

Tabla 8.2. Proporción de edificios según su calificación 238

Tabla 8.3. Clasificación IEEC de las viviendas de los Grupos I y II del

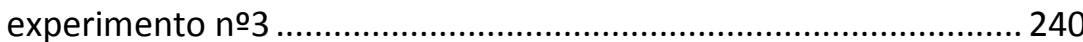

Tabla 8.4. Propuesta de pago de derechos de emisión. 241

Tabla 8.5. Costes unitarios de potencia y energía en la actualidad y modificación según propuesta........................................................ 242

Tabla 8.6. Importes de las facturas antes y después del cambio .....................244

Tabla I.1.- Resumen de valores en el punto óptimo del equipamiento y los

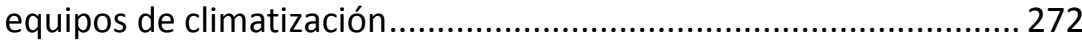

Tabla I.2.- Función de utilidad de la lavadora en el ciclo frío ............................ 275

Tabla I.3.- Función de utilidad de la lavadora en el ciclo 60…........................ 275

Tabla I.4.- Función de utilidad de la lavadora en el ciclo de 40 ...................... 276

Tabla I.5.- Función de utilidad de la lavadora en modo stand-by .................... 276

Tabla I.6.- Función de utilidad del lavavajillas en modo ECO ........................... 277

Tabla I.7.- Función de utilidad del lavavajillas en modo rápido ....................... 278

Tabla I.8.- Función de utilidad del lavavajillas en modo stand-by.................... 279

Tabla I.9.- Función de utilidad de la plancha ................................................... 279 
Tabla I.10.- Función de utilidad del televisor

Tabla I.11.- Función de utilidad del equipos de música ............................... 283

Tabla I.12.- Función de utilidad del ordenador fijo ................................... 283

Tabla I.13.- Función de utilidad del ordenador portátil .............................. 285

Tabla I.14.- Función de utilidad del calefactor en invierno........................... 286

Tabla I.15.- Función de utilidad del calefactor en verano ........................... 286

Tabla I.16.- Función de utilidad del horno en invierno ................................ 287

Tabla I.17.- Función de utilidad del horno en verano ................................. 287

Tabla I.18.- Función de utilidad del microondas en el desayuno.................... 288

Tabla I.19.- Función de utilidad del microondas el resto del día .................... 289

Tabla I.20.- Función de utilidad del tostador .............................................. 289

Tabla I.21.- Función de utilidad de la vitrocerámica .................................. 290

Tabla I.22.- Función de utilidad del ACS ................................................. 291

Tabla I.23.- Función de utilidad del ACS.................................................. 292

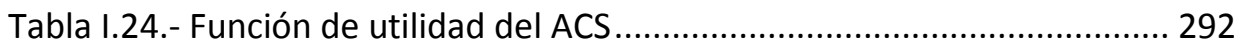

Tabla I.25.- Función de utilidad del ACS: combinaciones posibles ................. 293

Tabla I.26.- Programación de la calefacción y consumo asociado simplificado

Tabla I.27.- Función de utilidad de la calefacción en función de la temperatura de confort

Tabla III.1. Estadísticos descriptivos de los consumos semanales del Grupo I361

Tabla III.2. Estadísticos descriptivos de los consumos semanales del Grupo II

Tabla III.3. Estadísticos descriptivos de los consumos acumulados a lo largo del experimento por el Grupo I 363

Tabla III.4. Estadísticos descriptivos de los consumos acumulados a lo largo del experimento por el Grupo I ..................................................... 364

Tabla III.5. Normalidad de las muestras semanales .................................... 365 
Tabla III.6, Normalidad de las muestras acumuladas parciales........................ 366

Tabla III.7. Comparativa del consumo acumulado del Grupo I ......................... 366

Tabla III.8. Comparativa de consumos acumulados del Grupo II ......................367

Tabla III.9. Prueba de significatividad de la variable Incremento del consumo a lo largo del experimento

Tabla III.10. Comparativa del consumo semanal del Grupo I.......................... 368

Tabla III.11. Comparativa del consumo semanal del Grupo li.......................... 368

Tabla III.13. Recursos utilizados por los participantes del Grupo I para la consecución de su objetivo............................................................. 370 


\section{Introducción}

\subsection{Problemática}

La producción de energía eléctrica a partir de combustibles fósiles supone una fuente de emisión de contaminantes que contribuyen al efecto invernadero, a la disminución de la capa de ozono, al envenenamiento de suelos y acuíferos y a la alteración de los ecosistemas. El tratamiento de los residuos sólidos generados supone un problema añadido. Un tercer inconveniente de gravedad asociado al uso de estas fuentes es su previsible futuro agotamiento, que puede suponer a nivel mundial una crisis energética sin precedentes.

La dependencia de terceros países para el suministro de combustibles fósiles, por otra parte, supone un riesgo a la seguridad, al dependerse tanto de los países productores como de los de tránsito. El riesgo se acrecienta cuando se trata de regiones con problemas de estabilidad. En el caso de España, el 80 $\%$ de la energía primaria utilizada es importada.

Pese a los problemas enumerados en los párrafos anteriores, la demanda de energía primaria a nivel mundial no ha dejado de aumentar desde el principio de la Revolución Industrial. Hoy en día es impulsada principalmente 
por el crecimiento económico de algunos países emergentes, sobre todo China; en Europa, debido a la preocupación medioambiental y a la crisis económica de los últimos años, el aumento es menos significativo aunque también está presente. En cuanto a España, tanto en consumo de energía primaria como de energía final, la tendencia es contraria a la que se da a nivel mundial, apreciándose una contracción en el consumo, aunque con tendencia a la estabilización (Figura 2.3)

El estudio del consumo energético final a nivel global enmascara evoluciones y tendencias parciales que pueden ser importantes. Desagregando la demanda en España por sectores (transporte, industria, servicios y sector residencial), se observa que la demanda energética del sector residencial de nuestro país sigue una tendencia al alza, (ver Figura 1.1), pese al estancamiento originado por la crisis y a la reducción global del consumo. Teniendo en cuenta que el sector residencial supone un $17 \%$ del total del consumo energético en España, (25\% si se considera únicamente el consumo de energía eléctrica), su resistencia a la contracción lo convierte en un sector sobre el que es necesario incidir a la hora de diseñar políticas de eficiencia energética.

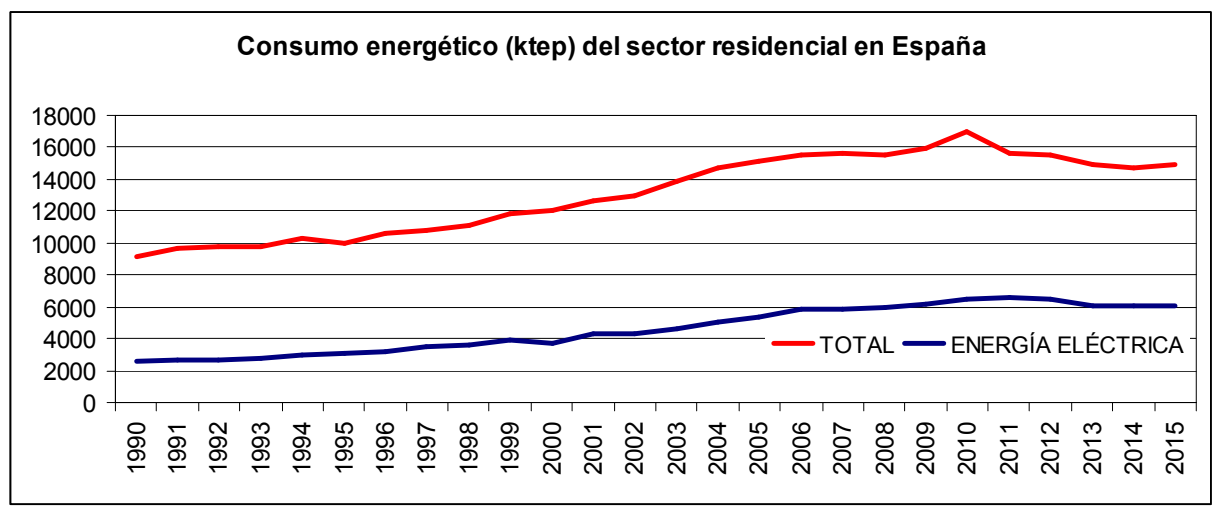

Figura 1.1.- Aumento del consumo energético en el sector residencial en España. Fuente: IDAE

La disminución en el consumo se puede conseguir por dos métodos: o bien reduciendo las actividades generadoras de consumo en valor absoluto, o bien aumentando la eficiencia energética de los equipos utilizados. Las políticas europeas relacionadas con el ahorro energético en los hogares se están enfocando, en su inmensa mayoría, hacia las mejoras técnicas en 
eficiencia energética tanto del equipamiento como de las envolventes térmicas, las instalaciones de climatización y las de ACS.

Sin embargo, se está detectando una diferencia importante entre el cálculo teórico y el resultado real del ahorro obtenido con estas mejoras. Diversos estudios ([125], [28], [26], [20 ], [58], [69], [89], [91]) achacan esta discrepancia al comportamiento de los habitantes, que no se ajusta a las predicciones. Como en cualquier otra actividad humana, los hábitos energéticos de los residentes son en parte automáticos, irracionales, y en general de difícil predicción, e influyen fuertemente en el consumo final de una vivienda, que puede diferir incluso en un factor de dos o más en función del comportamiento de sus habitantes [40].

Ello hace necesario un estudio detallado de la influencia del comportamiento humano en la efectividad de las medidas tomadas, de los problemas que genera la divergencia entre el comportamiento racional y el real y de los métodos más adecuados para reconducir este comportamiento a otro energéticamente más eficiente. Así, el problema de la eficiencia energética en el sector residencial se debe resolver necesariamente con la interacción de tres disciplinas aparentemente dispares: la psicología, la economía y la ingeniería.

En la literatura relativa a la eficiencia energética, los métodos de variación del comportamiento energético en el sector residencial se dividen en dos tipos: los que mejoran la información del usuario con respecto a su consumo, y los económicos, que incentivan hábitos más eficientes a base, de un modo u otro, de premiarlos económicamente.

Los métodos informativos deben darle al individuo las herramientas suficientes para capacitarles para reducir su consumo. Sin embargo, la mejora en el conocimiento del uso de la energía no implica de por sí la aparición del incentivo necesario para motivar al usuario a hacer el esfuerzo que ello supone.

En cuanto a los métodos económicos, éstos sí tienen la capacidad de influir considerablemente en el comportamiento de los individuos. Por eso, la combinación de un método informativo con uno financiero tiene una gran fuerza en la consecución de su objetivo: proporciona por una parte las herramientas necesarias para el ahorro y por otra, la motivación requerida para mantenerlo. 
De entre los métodos informativos, los que obtienen mejores resultados en los distintos estudios realizados hasta ahora son los que incluyen algún tipo de realimentación de la información, como tener en el hogar un contador con display que muestre el consumo instantáneo y el acumulado a lo largo de un mes, o disponer de un contador por electrodoméstico, o disponer de información comparativa sobre el comportamiento energético del resto del vecindario, o de una vivienda modelo. Las investigaciones son prometedoras, aunque las muestras que se utilizan en ellos tienen una dimensión enormemente variable y los distintos países en los que tienen lugar presentan grandes diferencias en cuanto a climatología y hábitos de consumo de la población. Todo ello dificulta las comparativas entre ellas, así como la deducción de conclusiones generales a todas.

En lo que se refiere a los métodos económicos, la bibliografía se centra principalmente en dos políticas: de un lado, se encuentra todo tipo de subvenciones, reducciones de impuestos y préstamos a bajo interés para la compra de equipos eficientes o para las mejoras de aislamiento de las viviendas; de otro lado, hay una literatura extensa en cuanto a la modificación de la curva de la demanda, con el objetivo principal de alisarla. Sin embargo, el uso de métodos económicos enfocados a la modificación del comportamiento apenas se nombra.

A lo largo del desarrollo de esta tesis, se estudiará la efectividad de la aplicación de diversos métodos informativos y económicos a la mejora de los hábitos energéticos de consumo en el sector residencial; tanto para el diseño de los experimentos como para el estudio de los resultados obtenidos se utilizará la metodología de la economía experimental.

\subsection{Hipótesis}

Se establece como primera hipótesis básica de trabajo que la capacidad de ahorro energético del habitante de una vivienda aumenta en función de la cantidad y la calidad de la información que se le proporciona en cuanto a su consumo instantáneo.

Se establece como segunda hipótesis básica de trabajo que la motivación más fuerte para los individuos, en lo que se refiere al ahorro energético, es de tipo económico. 
De las dos hipótesis básicas anteriores se deduce que la forma más eficaz de obtener ahorros energéticos importantes en la vivienda va a consistir en la combinación de un método informativo con uno financiero.

\subsection{Objetivos}

El primer objetivo de esta tesis es estudiar la eficacia de distintos métodos para disminuir el consumo energético en el sector residencial, sin reducir al mismo tiempo ni la confortabilidad de la vivienda ni el nivel de vida de sus ocupantes. Estos métodos se han aplicado del siguiente modo:

- Métodos puramente informativos experimentados en laboratorio. En este caso, se estudia de forma pormenorizada la eficacia de diversos métodos informativos (folletos informativos, uso de contadores inteligentes, discriminación horaria, información comparada con otros usuarios) mediante la simulación de una vivienda por ordenador. Esta simulación, diseñada específicamente para el desarrollo de este estudio, es utilizada por una serie de voluntarios, que hacen un consumo virtual de energía de forma que, en función de la información que tienen, maximizan el beneficio que obtienen de ella. La realización de los experimentos en laboratorio tiene por objetivo principal averiguar la eficacia comparada entre los diversos métodos, en un entorno controlado, con muestras de tamaños similares en condiciones similares, e independientemente de las variaciones climatológicas, la ubicación geográfica, las características de la vivienda etc. El objetivo de este ensayo es deducir de sus resultados el método o la combinación de métodos más eficaz para aplicarla en la realidad.

- Métodos puramente informativos experimentados en viviendas reales. En este caso, se implementa en viviendas reales el método que muestra mayor eficacia en el estudio anterior. El objetivo de esta segunda parte de la investigación es obtener datos reales de la combinación óptima estudiada previamente en laboratorio experimental.

- Mezcla del método informativo con un incentivo económico. Este último ensayo, también realizado en viviendas reales, tiene 
por objeto demostrar que la combinación de un método informativo con uno financiero tiene una fuerza mucho mayor en la consecución del objetivo de ahorro.

El segundo objetivo de esta tesis es reflexionar sobre la aplicabilidad del incentivo económico y proponer formas de llevarlo a la práctica. Para ello, se define un índice de eficiencia energética del uso de la vivienda y se muestra cómo utilizarlo para modificar la factura en función de éste.

El tercer objetivo es sacar conclusiones acerca de la aplicabilidad de la economía experimental en el estudio de las mejoras en eficiencia energética.

\subsection{Estructura de la tesis}

Esta tesis se divide en nueve capítulos, un índice bibliográfico y cuatro anexos. El primer capítulo es esta introducción; el contenido del resto de capítulos es el que se expone a continuación.

En el capítulo 2, se analiza la legislación existente respecto a la eficiencia energética, el mercado eléctrico español, el consumo eléctrico y la intensidad eléctrica a nivel mundial y particularizadas para el sector doméstico español, así como la estructura de la factura eléctrica y las dificultades de su interpretación.

En el capítulo 3, se describe el estado del arte relativo a los métodos informativos y económicos comentados anteriormente, así como el conjunto de barreras que impiden o dificultan el establecimiento exitoso de políticas de eficiencia energética en la vivienda, junto con algunos de los experimentos de campo y medidas políticas que se han utilizado o están en marcha para tratar de superarlas.

En el capítulo 4, se describe el estado del arte, particularizado para vivienda, de los métodos informativos que después se aplican en los capítulos 5,6 y 7.

Los tres capítulos siguientes, 5, 6 y 7, describen en detalle la metodología de cada uno de los experimentos llevados a cabo, así como sus resultados y las conclusiones que se derivan de ellos.

El capítulo 8 propone la definición de un índice de eficiencia energética en el uso de la vivienda, así como diversas formas de aplicación de éste. En primer lugar, se proponen métodos para clasificar las viviendas en distintos 
grupos, basados en la superficie de la vivienda, el número de habitantes, su ubicación y su índice de eficiencia energética del edificio. En segundo lugar, a partir de las viviendas tipo y de una serie de factores de corrección, se expone un método de cálculo del índice de eficiencia energética del comportamiento energético de los consumidores (IEEC). Por último, se sugieren diversas formas de compensar económicamente a las familias que obtengan IEEC de calificaciones elevadas.

El capítulo 9 contiene las conclusiones extraídas de esta tesis doctoral.

Por último, los anexos incluyen los datos y cálculos asociados a cada uno de los experimentos llevados a cabo, así como los estudios estadísticos en los que se apoyan. 


\section{Antecedentes}

\subsection{Legislación europea en eficiencia energética}

\subsubsection{Marco normativo de la política europea de eficiencia energética}

La Unión Europea, en el Consejo Europeo de marzo de 2007, aprobó una política integrada en materia de energía según la cual se compromete a alcanzar los siguientes objetivos de aquí a 2020: reducción de al menos un 20 $\%$ de las emisiones de gases de efecto invernadero con respecto a los niveles de 1990, una cuota del $20 \%$ del consumo de energía suministrada con renovables y una mejora de la eficiencia energética que permita un ahorro de un $20 \%$ con respecto a las previsiones para ese mismo año.

Los principales directivas relacionadas con estos objetivos se describen a continuación, y engloban los siguientes aspectos: la obligación de los estados miembros de establecer planes nacionales de eficiencia energética, la obligación de las empresas suministradoras a colaborar en la consecución de los objetivos de ahorro en los usos finales de la energía, y las certificaciones energéticas, tanto a nivel de edificio como a nivel de equipamiento. En los siguientes apartados se enumeran y describen brevemente estas directivas. 


\subsubsection{Directiva 2012/27/UE}

La piedra angular de la política de la Unión en materia de eficiencia energética es la La Directiva 2012/27/UE del Parlamento Europeo y del Consejo, de 25 de octubre de 2012 relativa a la eficiencia energética, por la que se modifican las Directivas 2009/125/CE y 2010/30/UE, y por la que se derogan las Directivas 2004/8/CE y 2006/32/CE. Tiene el propósito básico de encauzar a los Estados miembros hacia el cumplimiento de los objetivos de 2020.

En la Directiva 2012/27/UE se exige a los Estados miembros que establezcan objetivos indicativos nacionales de eficiencia energética para 2020, basados en el consumo de energía primario o final. Los Estados miembros tendrán que informar cada año sobre los avances alcanzados en los objetivos de eficiencia energética del país. Engloba entre otros los siguientes aspectos:

1.- Sistemas de obligaciones de eficiencia energética, que permite a los gobiernos imponer a los distribuidores de energía y/o empresas minoristas de venta de energía objetivos de reducción de consumo de sus clientes en un plazo determinado, siendo las propias empresas, por lo general, quienes pueden decidir qué procedimientos llevar a cabo para cumplir con estas obligaciones. Estos procedimientos pueden basarse en cambios tecnológicos, de comportamiento o económicos.

La elaboración de regímenes nacionales de obligaciones en materia de eficiencia energética o medidas equivalentes deben garantizar un ahorro anual de energía del 1,5\% para los usuarios finales. Otras medidas pueden ser, por ejemplo, acuerdos voluntarios o impuestos al $\mathrm{CO}_{2}$.

2.- Las auditorías energéticas deben ser fomentadas a todos los niveles: sector residencial, PYMES y grandes empresas, en este último caso se considerarán obligatorias al menos una vez cada 4 años, con la excepción de las empresas que dispongan de sistemas de gestión de la energía y medioambientales certificados

3.- En facturación y medición, se procurará, en la medida en la que sea técnicamente posible y financieramente soportable, la instalación de contadores que reflejen el consumo real de energía en el tiempo. En todo caso es necesaria la divulgación de información precisa en las facturas de la 
electricidad, a fin de capacitar a los consumidores y alentar un consumo energético más eficiente. Para ello, es requisito basar la factura en el consumo real y acompañarla de información sobre el consumo histórico.

4.- Se procurará promover la eficiencia energética de los pequeños clientes con información e incentivos financieros, por ejemplo incentivos fiscales, acceso a la financiación, ayudas o subvenciones, suministro de información, proyectos ejemplares o medidas de eficiencia energética.

5.- Los servicios energéticos serán fomentados y se procurará facilitar el acceso de las PYMES a ellos.

6.- En edificios, deben establecerse estrategias nacionales a largo plazo para fomentar la renovación del parque existente (inmuebles tanto residenciales como comerciales). Se acentuará la función ejemplarizante de los edificios públicos, tanto en lo que se refiere a mejoras en climatización como a compra de equipamiento altamente eficiente.

\subsubsection{Directiva 2010/31/UE}

La Directiva 2002/91/CE, hoy derogada, relativa a la eficiencia energética de los edificios (en particular, al aislamiento, al aire acondicionado y al uso de fuentes de energía renovables), y su sustituta, la Directiva 2010/31/UE de refundición, proporciona:

1.- Un método de cálculo de la eficiencia energética de los edificios,

2.- Unos requisitos mínimos para los edificios nuevos y los grandes edificios existentes, así como para las reformas grandes de edificios existentes.

3.- Regula la certificación energética. Los requisitos mínimos y la metodología a aplicar para el cálculo pueden ser específicas de naciones e incluso regiones dentro de una nación. El certificado de eficiencia energética debe incluir la eficiencia energética de un edificio y valores de referencia, para que los futuros compradores o arrendatarios puedan valorar su eficiencia energética. Cuando se construyan, vendan o alquilen edificios, locales o viviendas, debe entregarse a su nuevo ocupante una copia del certificado.

4.- Todos los edificios públicos construidos en Europa deben ser "nearly zero energy buildings" a partir del 31 de diciembre de 2018. Para los edificios de titularidad privada, la fecha límite es el 31 de diciembre de 2020. La definición de edificios energía casi cero es ambigua. 


\subsubsection{Directiva Europea 2010/30/UE}

La Directiva 2010/30/UE del parlamento europeo y del consejo de 19 de mayo de 2010 relativa a la indicación del consumo de energía y otros recursos por parte de los productos relacionados con la energía, mediante el etiquetado y una información normalizada, rige el etiquetado y la clasificación energética de los productos relacionados con la energía. Entre otras cosas:

1.- Describe el diseño general de la etiqueta y define de forma general también, las clases de eficiencia que deben considerarse.

2.- Estipula que la introducción del sistema de etiquetas debe ir acompañada de campañas informativas de carácter educativo y promocional

\subsubsection{DIRECTIVA 2009/125/UE}

La directiva 2009/125/UE del parlamento europeo y del consejo de 21 de octubre de 2009 por la que se instaura un marco para el establecimiento de requisitos de diseño ecológico aplicables a los productos relacionados con la energía, impone una serie de requisitos mínimos a una serie de productos relacionados con la energía, para que se puedan poner a la venta en la Unión Europea.

Los productos afectados son, entre otros: el stand-by (reglamento 1275/2008) de los equipos domésticos y de oficina, equipos de iluminación, televisiones, frigoríficos, congeladores, lavadoras, lavavajillas y fuentes de alimentación externa.

\subsubsection{Planes de eficiencia energética 2014-2020}

Cada país de la Unión Europea tiene la obligación de redactar por escrito su planificación para la consecución de los objetivos establecidos en el Consejo Europeo de marzo de 2007, cada 6 años. En el año 2014, todos los países plasmaron esos planes en los documentos denominados Planes de eficiencia energética 2014-2020, que sustituyen a los anteriores. Este apartado es un resumen de esas políticas, particularizadas para el sector de la edificación residencial.

Todas ellas son una mezcla de políticas, siendo las más comunes:

- Políticas informativas, incluyendo realimentación por la factura, información a los usuarios y contadores inteligentes 
- Regulaciones

- Acuerdos voluntarios

- Préstamos

- Subvenciones

- Reducciones de impuestos

- Obligaciones de eficiencia energéticas

Las combinaciones más habituales son las que se muestran en la tabla Tabla 2.1, extraída de la referencia [112]. Los dígitos indican el número de países que aplica esa combinación.

\begin{tabular}{|c|c|c|c|c|c|c|}
\hline & 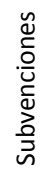 & 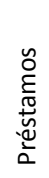 & 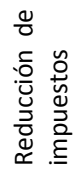 & 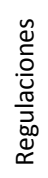 & 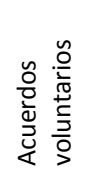 & 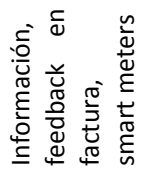 \\
\hline $\begin{array}{l}\text { Obligaciones de } \\
\text { efic. energética }\end{array}$ & \multirow[t]{5}{*}{4} & 4 & 1 & 1 & & 1 \\
\hline Subvenciones & & \multirow[t]{4}{*}{9} & 7 & 9 & 6 & 4 \\
\hline Préstamos & & & 2 & 7 & 6 & \\
\hline $\begin{array}{l}\text { Reducción de } \\
\text { impuestos }\end{array}$ & & & & 1 & 1 & \\
\hline Regulaciones & & & & & 2 & 6 \\
\hline
\end{tabular}

Tabla 2.1. Combinaciones de políticas de eficiencia energética en el sector de la edificación. Fuente: [102]

\subsection{Legislación española en materia de eficiencia energética}

La Ley 18/2014, de 15 de octubre contiene la transposición de la Directiva de Eficiencia Energética 2012/27/UE al ordenamiento jurídico español. En esta Ley 18/2014, España se compromete a un objetivo de ahorro energético acumulado de 15.979 ktep para el periodo 2014 a 2020.

La concreción de las medidas descritas en la Ley 18/2014 se encuentra en el Plan de Eficiencia Energética 2014-2020. Este Plan reformula el objetivo de 15.979 ktep de ahorro como una reducción anual acumulada de 571 ktep. El reparto por sectores es el siguiente:

- El 54,6\% (311,6 ktep/año) corresponde al sector Industria. La medida más importante es la adopción de las mejores tecnologías 
disponibles en equipos y procesos y, en menor medida, la implantación de sistemas de gestión energética.

- El 25,3\% (144,1 ktep/año) se alcanza mediante medidas en el sector Transporte, con actuaciones de movilidad urbana sostenible y planes de transporte al centro de trabajo, gestión de flotas de transporte por carretera o cursos de conducción eficiente. Los incentivos económicos incluyen el impuesto de registro basado en emisiones de $\mathrm{CO} 2$ y la promoción al cambio a vehículos más eficientes (Plan PIVE)

- El 15,3\% (87,1 ktep/año) está enfocado al sector Edificación y Equipamiento. Las medidas son la rehabilitación de la envolvente térmica de los edificios, la mejora de la eficiencia energética en instalaciones térmicas, de climatización y de ACS, iluminación, ascensores e instalaciones eléctricas. Se incluyen también medidas de mejora en instalaciones de frío, implantación de sistemas de domótica y renovación de electrodomésticos.

- El $5 \%$ restante (27,8 ktep/año), se alcanzará mediante medidas en los sectores Servicios Públicos (principalmente alumbrado exterior), Agricultura y Pesca y Comunicación.

En los apartados siguientes, se enumeran las medidas horizontales descritas en el Plan y se concretan posteriormente las específicamente adoptadas para edificios de viviendas.

\subsubsection{Medidas horizontales}

\subsubsection{El sistema de obligaciones de eficiencia energética}

Se establece, de acuerdo con el artículo 7 de la Directiva de Eficiencia Energética, un sistema de obligaciones en materia de eficiencia energética en la que los sujetos obligados son las empresas comercializadoras de gas y electricidad, los operadores de productos petrolíferos al por mayor y los operadores de gases licuados del petróleo al por mayor. Ellos quedan obligados a alcanzar en el año 2020 el objetivo de ahorro expresado en la Ley 8/2014, mediante la consecución anual a partir del año 2014 de un ahorro equivalente al 1,5 por ciento de sus ventas finales anuales de energía.

Este objetivo, según la reglamentación española, puede ser alcanzado por las empresas obligadas mediante un pago a un Fondo Nacional de 
Eficiencia Energética FNEE o por aportación de un certificado de eficiencia. En caso de pago al FNEE, el importe se calcula en función de la cuota de mercado correspondiente a cada sujeto obligado en el año calculado. En caso de aportación del certificado, aún está pendiente la publicación del catálogo de actuaciones, medidas de eficiencia energética y ahorros asociados que se puede emplear para hacerse merecedor del certificado.

El sistema de obligaciones se complementa con otras medidas, tales como mecanismos financieros, fiscalidad, acuerdos voluntarios, reglamentaciones, estándares y normas, sistemas de etiquetado energético, formación y campañas de información. La parte no subvencionada por los sujetos obligados se financiará con fondos públicos. El objetivo de ahorro queda repartido del siguiente modo [61] :

$40 \%$ Sujetos obligados (aportaciones al FNEE)

31\% Fondos FEDER (aportaciones al FNEE)

29\% Medidas alternativas (fiscales (Ley 15/2012), incentivos fiscales y financieros (PIVE, PIMA, PAREER), campañas de comunicación y otras medidas)

\subsubsection{Auditorías energéticas}

La obligación de realizar una auditoría será de aplicación a grandes empresas que ocupan a más de 250 personas y cuyo volumen de negocios anual excede de 50 millones de euros o cuyo balance general anual excede de 43 millones de euros. Las grandes empresas deben someterse a una auditoría energética como mínimo cada cuatro años a partir de la fecha de la auditoría energética anterior.

La auditoría, si es posible, debe analizar el coste del ciclo de vida del producto, y debe ser realizada por un organismo habilitado para este fin. Si la empresa tiene implantado un sistema de gestión energética o ambiental certificado por un organismo independiente y que incluya su propia auditoría energética, no es necesario que se someta a otra.

\subsubsection{Contadores y sistemas de información}

Los edificios con instalaciones centralizadas de climatización o ACS deben instalar contadores individuales o sistemas alternativos que permitan conocer el consumo individual. 
Se regula el contenido de las facturas, así como la obligatoriedad para las comercializadoras de ofrecer facturación electrónica on line, con información complementaria sobre el consumo histórico.

El plan de sustitución de equipos de medida de energía eléctrica sigue en marcha, debiéndose alcanzar la plena implantación de contadores que permitan discriminación horaria y telegestión para potencias contratadas de hasta $15 \mathrm{~kW}$ antes del 31 de diciembre de 2018.

\subsubsection{Información y formación}

Incluye campañas de publicidad en medios de difusión masiva (televisión, radio, prensa), difusión de folletos a repartir con la factura eléctrica, presencia permanente en Internet mediante la creación de un portal informativo en la web del IDAE (con un catálogo de publicaciones, boletines e informes estadísticos, bases de datos de ESE, de energías renovables, de aparatos de alta eficiencia energética, de electrodomésticos, producciones audiovisuales propias y servicios de información y formación al ciudadano).

\subsubsection{ESEs}

La figura de la Empresa de Servicios Energéticos (ESE) ha sido incorporada al ordenamiento jurídico español mediante el Real-Decreto Ley 6/2010, de 9 de abril, de medidas para el impulso de la recuperación económica y el empleo. Estas empresas proporcionan servicios de mejora de la eficiencia energética en la instalación de un usuario, asumiendo cierto grado de riesgo económico al hacerlo. El pago de los servicios prestados se basará (en parte o totalmente) en la obtención de mejoras de la eficiencia energética. Para la promoción de estas empresas, los Planes de Eficiencia Energética incluyen medidas de apoyo económico a su contratación, tales como el fondo JESSICA-FIDAE, de proyectos de desarrollo urbano sostenible o el PAREER, para la rehabilitación energética de edificios existentes del sector residencial.

\subsubsection{Medidas concretas para edificios}

En junio de 2014 se publicó la Estrategia a largo plazo para la rehabilitación energética en el sector de la edificación en España. En ella se concretan las siguientes medidas regulatorias para edificios: 
- Ley $8 / 2013$, de Rehabilitación, Regeneración y Renovación urbanas, enfocada al impulso de las actuaciones que conduzcan a la rehabilitación de los edificios, incluyendo las mejoras en eficiencia energética.

- Real Decreto $235 / 2013$, de 5 de abril, por el que se aprueba el procedimiento básico para la certificación de la eficiencia energética de los edificios.

- Real Decreto $238 / 2013$, de 5 de abril, por el que se modifican determinados artículos e instrucciones técnicas del Reglamento de Instalaciones Térmicas de los Edificios (RITE) de 20 de julio de 2007 para establecer mayores exigencias relativas al rendimiento energético de los equipos de generación de calor y frío, así como de los destinados al movimiento y transporte de fluidos

- Orden FOM/1635/2013, de 10 de septiembre, por la que se actualiza el Documento Básico DB-HE "Ahorro de Energía", del Código Técnico de la Edificación, aprobado por Real Decreto 314/2006, de 17 de marzo (BOE de 12 de septiembre de 2013).

Se concretan también las medidas de apoyo económico siguientes:

- Programa PAREER del Instituto para la Diversificación y Ahorro de la Energía (IDAE): "Programa de ayudas a proyectos integrales de ahorro y eficiencia energética en edificios de viviendas". Incluye ayudas para renovación de ventanas, fachadas, cubiertas, calderas, equipos de aire acondicionado, la incorporación de equipos para la medición individual de consumos de calefacción y agua caliente sanitaria, la sustitución de energía convencional por biomasa, por energía geotérmica, etc.

- Fondo JESSICA-F.I.D.A.E. Fondo de Inversión para financiar proyectos de eficiencia energética y energías renovables.

- Plan PIMA SOL, "Plan de Impulso al Medio Ambiente en el sector hotelero PIMA Sol", dirigido a la financiación de la rehabilitación energética de hoteles,

- Plan Estatal de fomento del alquiler de viviendas, la rehabilitación edificatoria, y la regeneración y renovación urbanas, 2013-2016, dirigido a la promoción de la rehabilitación de viviendas orientada a la mejora de la eficiencia energética (mejora de la envolvente térmica, instalación de sistemas de climatización y ACS, ascensores e iluminación). 


\subsection{Medida y evolución de la eficiencia energética mundial}

\subsubsection{Evolución del consumo de energía primaria}

La demanda mundial de energía primaria aumenta impulsada principalmente por las economías emergentes; en Europa, debido al menor crecimiento económico, a la crisis del consumo y a la preocupación medioambiental, la demanda ha aumentado en menor medida. En ninguno de los dos casos se da una reducción del consumo, que en realidad sería lo deseable. El aumento de la eficiencia energética sirve para reducir la velocidad de crecimiento, pero no es una herramienta suficiente para detenerlo.

Todas las fuentes principales de energía primaria (ver Figura 2.1), aumentan su consumo, aunque las mayores variaciones se dan en las energías renovables y el carbón. El aumento de uso de energías renovables se achaca a dos razones: reducen la dependencia energética de fuentes de energía externas e impulsan un mix energético más sostenible a largo plazo. El aumento en el uso del carbón, por su parte, viene impulsado por el consumo de China, que a su vez se debe al crecimiento económico del gigante asiático.

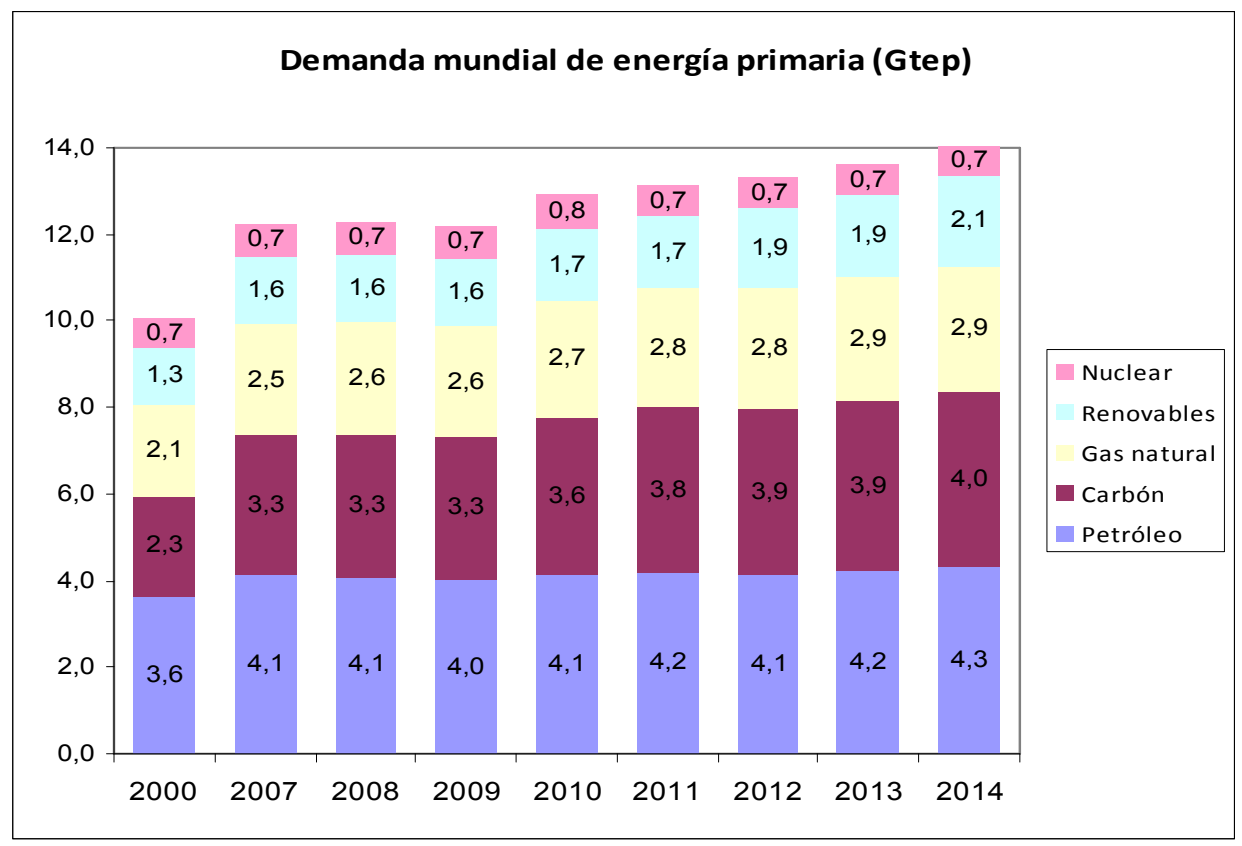

Figura 2.1. Fuente: IDESCAT 
En el caso de España, la demanda de energía primaria disminuye, pese a la salida del país de la crisis en el año 2013. Se observa una contracción importante del gas natural, debido a la variación de la regulación en materia de cogeneración de energía, así como una tendencia al aumento del consumo de carbón de importación, que también es un competidor importante para las centrales de ciclo combinado, lo que colabora a la reducción del consumo de gas. En el gráfico de la Figura 2.2 se muestra esa evolución, desagregada por fuente de energía primaria.

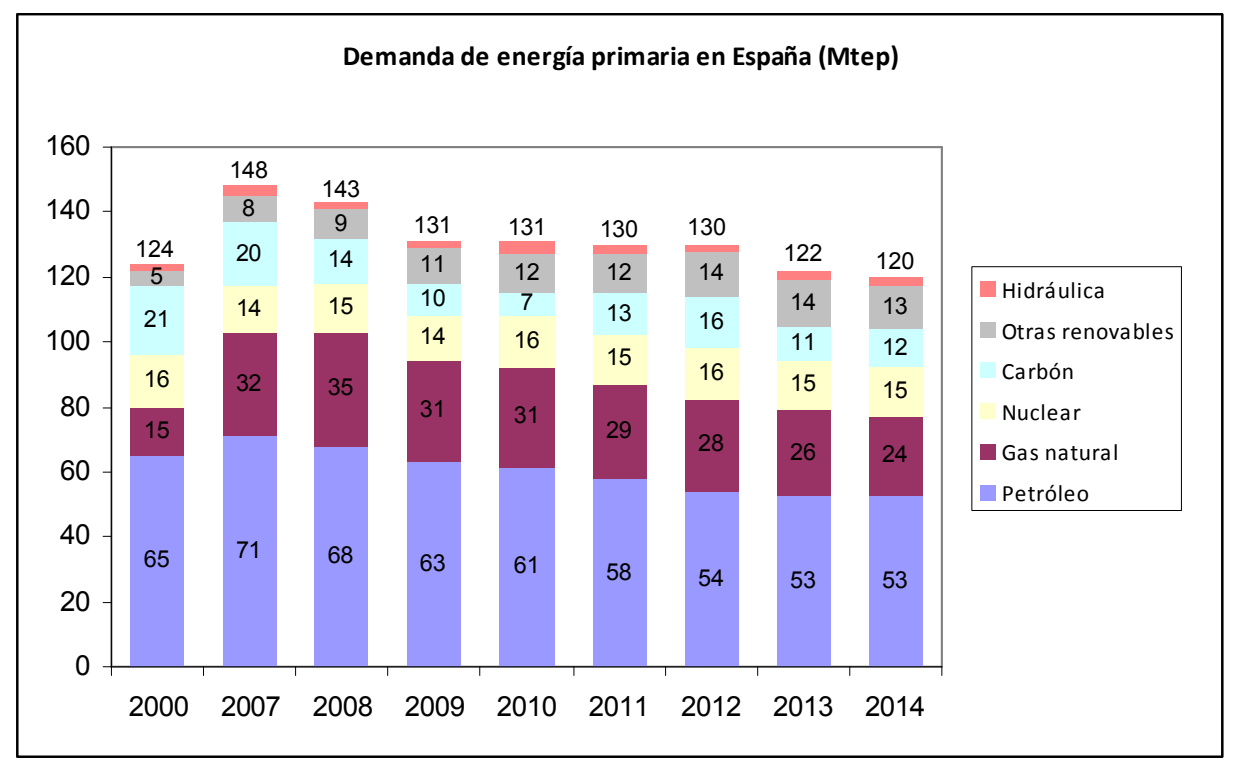

Figura 2.2. Fuente: IDESCAT

\subsubsection{Evolución del consumo de energía final}

Debido a los procesos de transformación requeridos para convertir la energía primaria en energía apta para el consumo, así como a las pérdidas en el transporte, la energía final disponible es menor que la primaria.

En cuanto al consumo de energía final en España, se muestra el desglose de consumo por sectores en la gráfica de la Figura 2.3. Al igual que en el caso de la energía primaria, la tendencia es contraria a la que se da a nivel mundial, apreciándose una contracción en el consumo durante los últimos años, aunque con tendencia a la estabilización. 


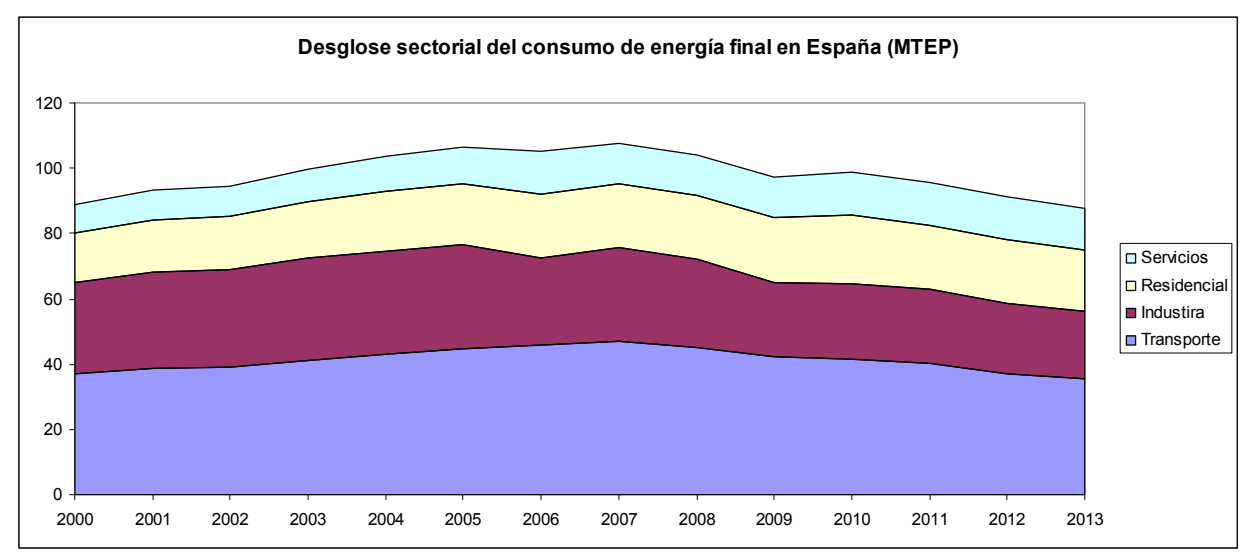

Figura 2.3. Fuente: IDESCAT

\subsubsection{Desagregación del consumo final por sectores}

La demanda de la energía eléctrica final se divide principalmente en cuatro sectores: transportes, industria, servicios y en el sector residencial. La distribución del consumo de energía final por sectores a nivel mundial se muestra en la Figura 2.4.

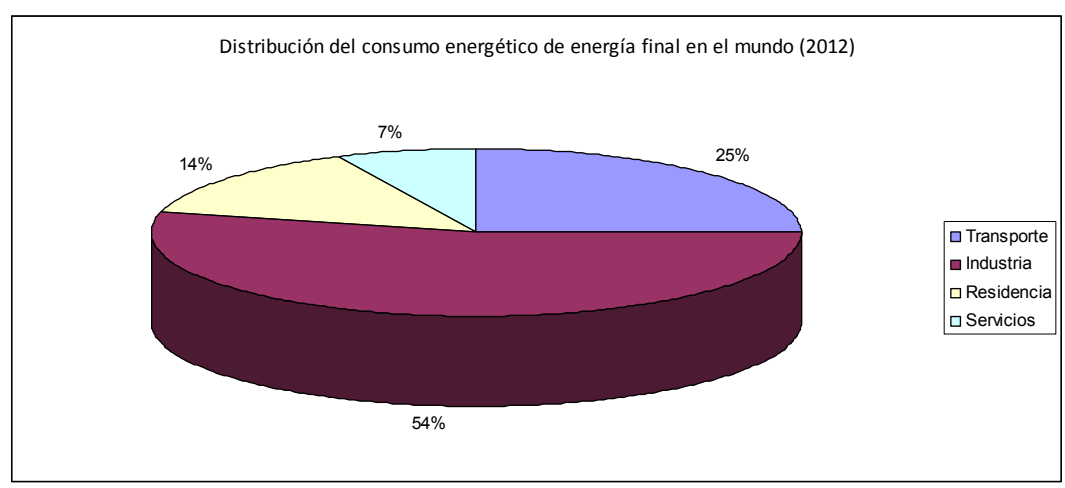

Figura 2.4. Distribución del consumo energético de energía final en el mundo (Fuente: [48]

En el caso de España, la distribución se muestra en la Figura 2.5 (Fuente: IDAE, datos del año 2008). Hay una diferencia apreciable en la proporción de transporte e industria, pero la contribución del sector doméstico es similar. 


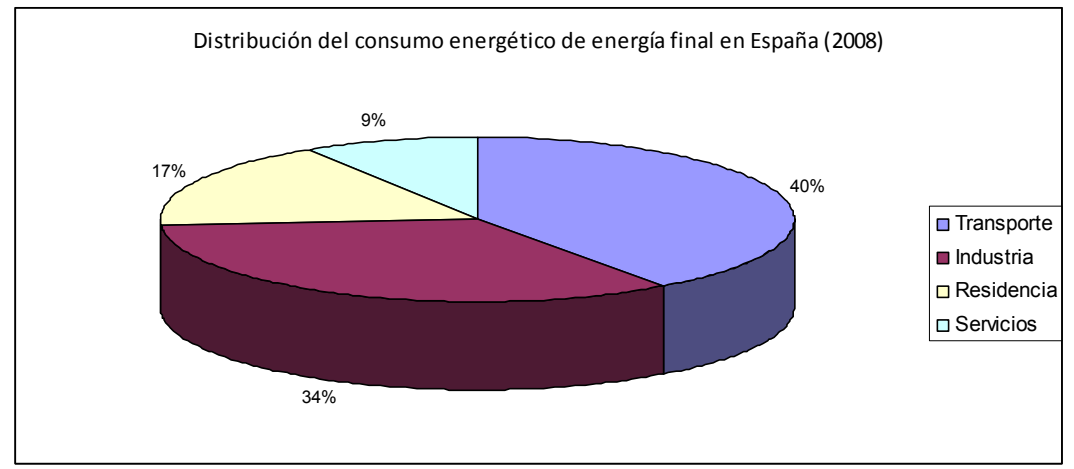

Figura 2.5. Distribución del consumo energético de energía final en España (Fuente: IDAE)

\subsubsection{Evolución del PIB}

La economía mundial como conjunto ha ido creciendo en los últimos años a un ritmo ligeramente superior al $3 \%$, siendo el crecimiento más rápido en las economías emergentes y más lento en las desarrolladas. Dentro de estas últimas se detectan variaciones apreciables entre unas y otras (Ver Figura 2.6).

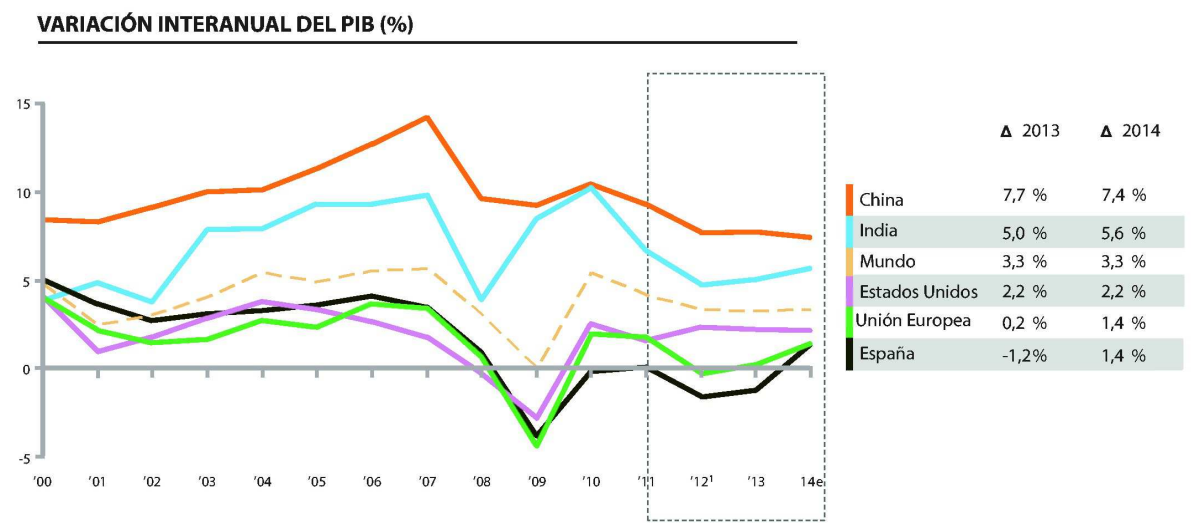

Fuente: Fondo Monetario Internacional (FMI); iNE; elaboración y análisis Fundación Repsol

Figura 2.6. Fuente: FMI

En el caso de España, la variación del PIB se refleja en el gráfico de la Figura 2.7. El final de la recesión se localiza en el año 2013, y desde ahí se observa una clara tendencia al alza del PIB del país. 


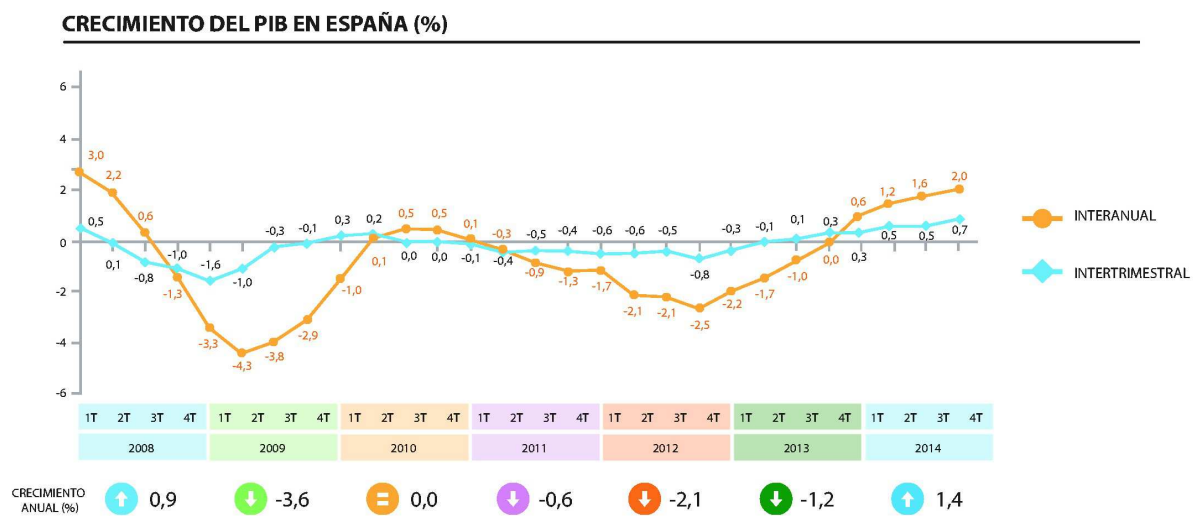

Fuente: Instituto Nacional de Estadistica (INE); elaboración y análisis Fundación Repsol. Los datos difieren del informe 2014 debido al cambio a la base 2010 de la serie numérica

Figura 2.7. Fuente: INE

\subsubsection{Evolución de la intensidad energética}

La medida de la eficiencia energética de un país en términos macroeconómicos se puede calcular a través de un parámetro denominado intensidad energética, que refleja la relación entre el consumo energético (E) y el volumen de la actividad económica. Para calcularla, se utiliza la siguiente fórmula, en la que se emplea el PIB como unidad de riqueza:

$$
I=\frac{E}{P I B}
$$

El objetivo de este sistema de medida es conocer cuántas unidades de energía son necesarias para producir una unidad de riqueza. Una intensidad energética baja supone el consumo de una cantidad reducida de energía para obtener una unidad de riqueza.

La intensidad energética se puede medir en términos de energía primaria o de energía final, así como desagregada en sus componentes: carbón, petróleo, gas natural, renovables y nuclear para la energía primaria, sectores industrial, terciario, transporte y residencial para la energía final. En el estudio siguiente se muestra la evolución de todos esos indicadores, a nivel mundial y, más pormenorizados, para el caso español.

EI PIB, como se comenta en el apartado 2.3.3, crece actualmente a un ritmo aproximado del $3 \%$, mientras que la demanda de energía primaria a nivel 
mundial lo hace a un ritmo de un $2 \%$. Gracias a ello, en términos globales la intensidad energética primaria mundial sigue un ritmo levemente decreciente (Ver Figura 2.8 y Figura 2.9)

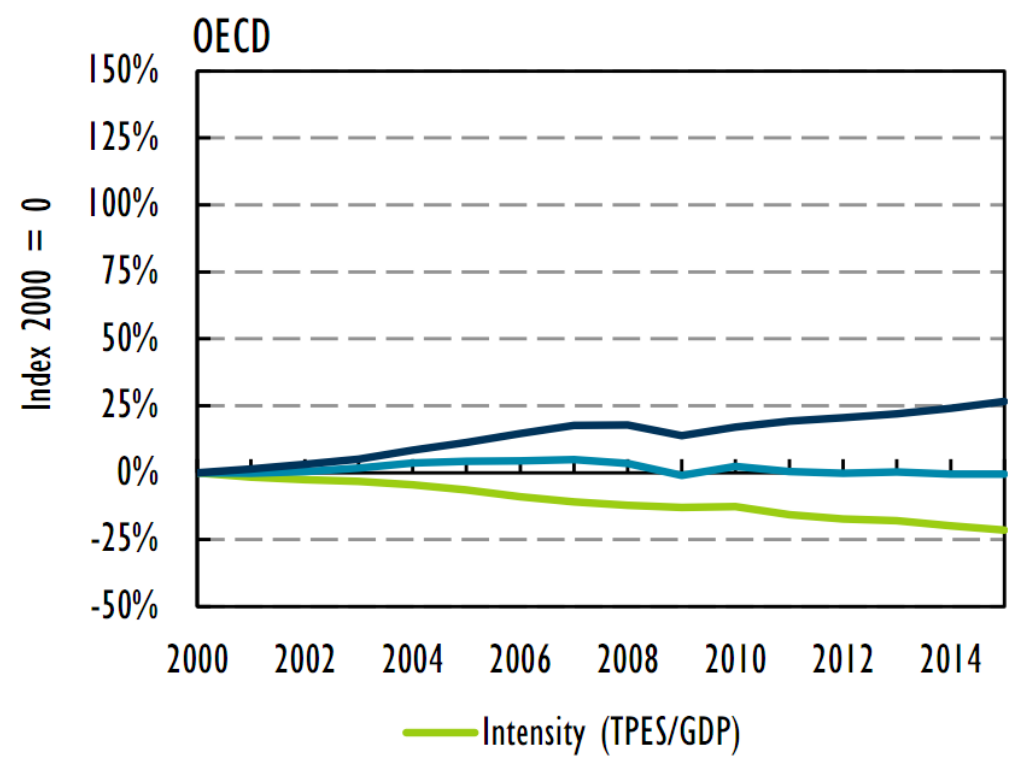

Figura 2.8. Cambios en los factores de intensidad energética por sector. Fuente:[79]

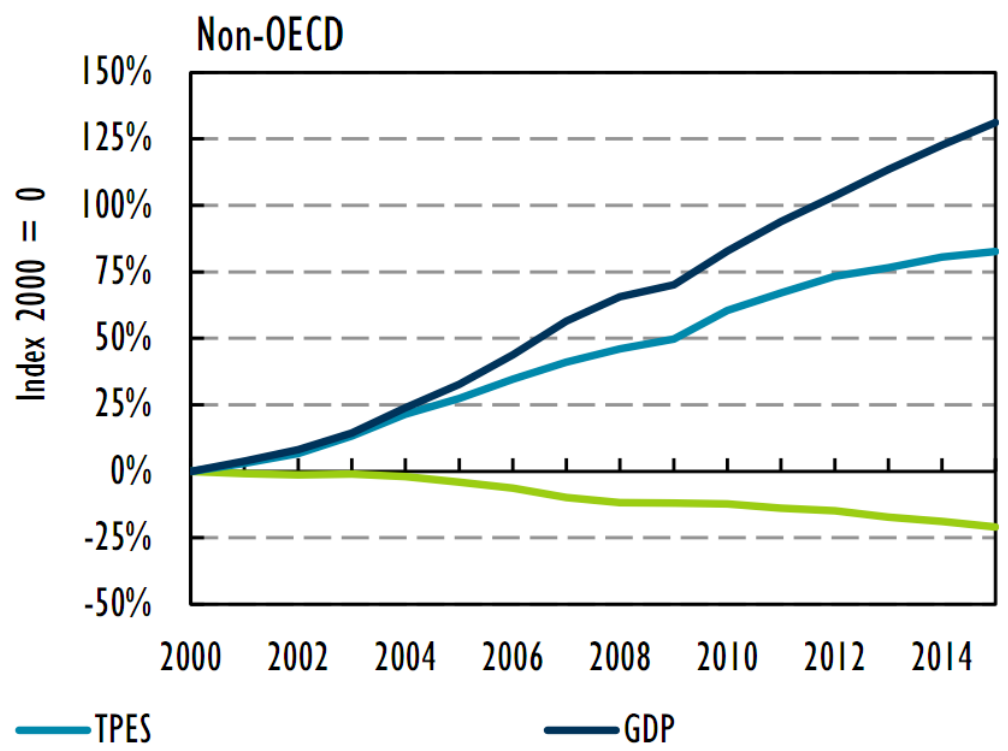

Figura 2.9. Cambios en los factores de intensidad energética por sector. Fuente:[79] 
Nótese como el parámetro intensidad energética informa acerca de la mejora en la eficiencia energética global, pero se requiere también, para tener una imagen global del problema energético, no perder de vista el parámetro del consumo. Si éste sigue aumentando, que es su tendencia durante los últimos años, por mucho que la intensidad energética se reduzca el problema del agotamiento de las fuentes de energía continúa agudizándose, aunque a una velocidad amortiguada por el aumento de la eficiencia energética.

La desagregación por usos, por otra parte, muestra un panorama distinto, con muy diferentes evoluciones en función del sector considerado (Ver Figura 2.10)

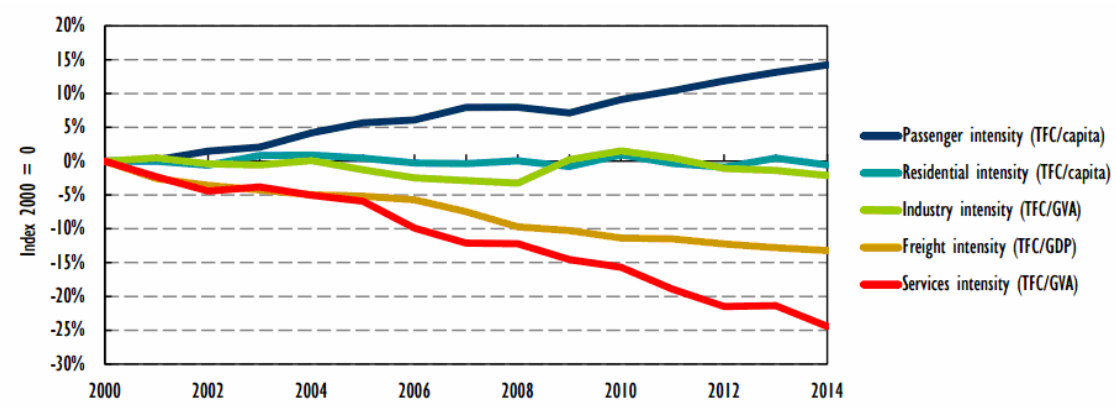

Figura 2.10. Cambios en la intensidad mundial por sector, 2000-2014. Fuente: [79]

Tanto en lo que se refiere a intensidad primaria (Figura 2.11) como a intensidad final (Figura 2.12), en la Unión Europea y sus países nos encontramos nuevamente con la tendencia a la baja que ha caracterizado a este parámetro durante los últimos años.

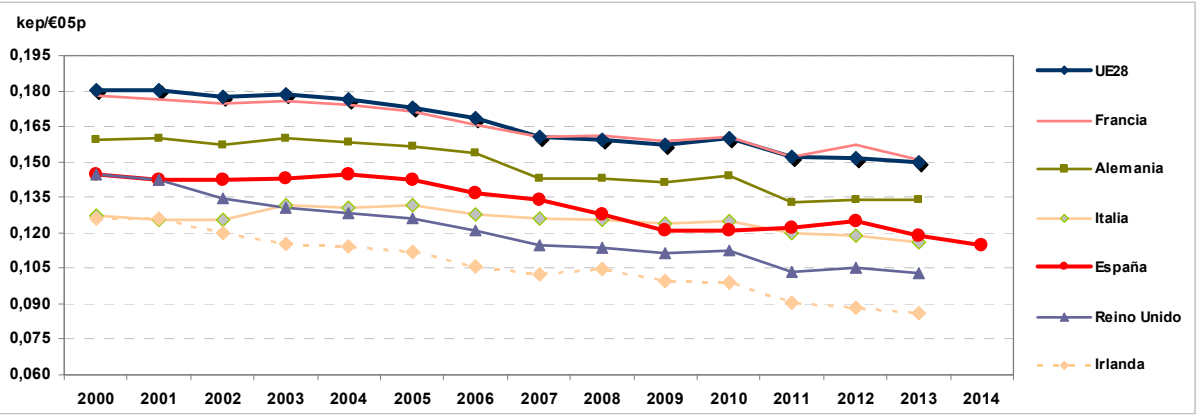

Figura 2.11. Intensidad primaria a paridad del poder de compra. Fuente: EnR/IDAE 


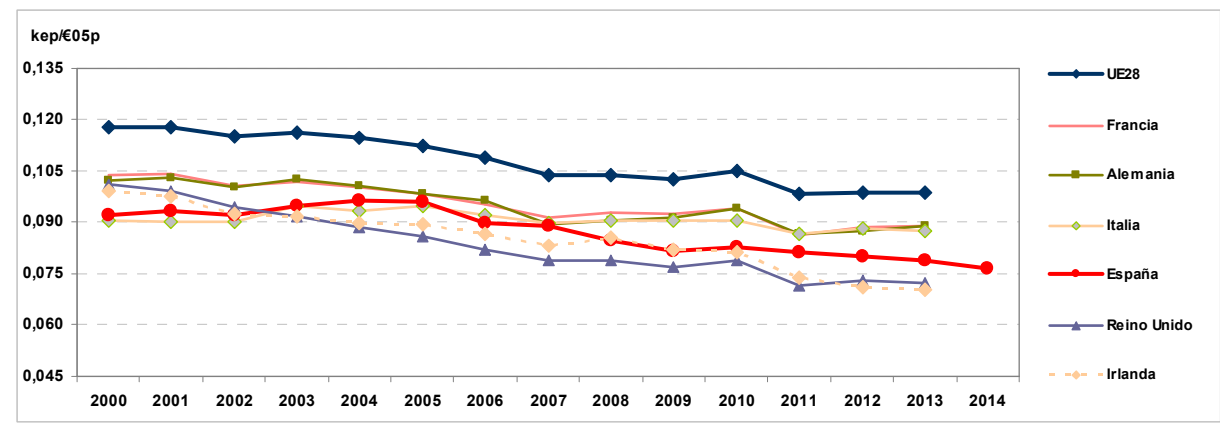

Figura 2.12. Intensidad final a paridad del poder de compra. Fuente: EnR/IDAE

Esta tendencia a la baja, aunque se mantiene, es diferente según el sector implicado, por lo que es conveniente estudiar las gráficas desagregadas por sectores (Figura 2.13 a Figura 2.18). En concreto, la intensidad energética final en el sector residencial y en energía eléctrica, proporciona el peor de los resultados (Figura 2.18).

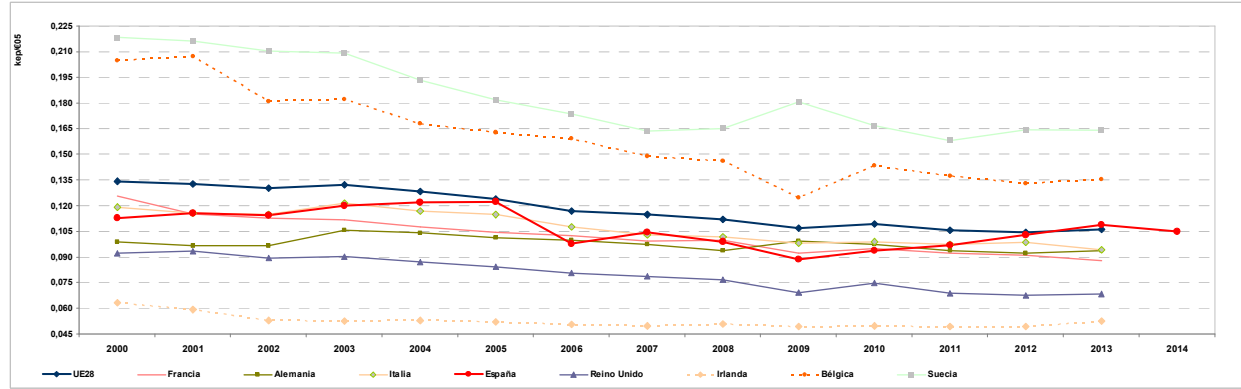

Figura 2.13. Comparativa europea de la intensidad energética del sector industrial. Fuente: EnR/IDAE

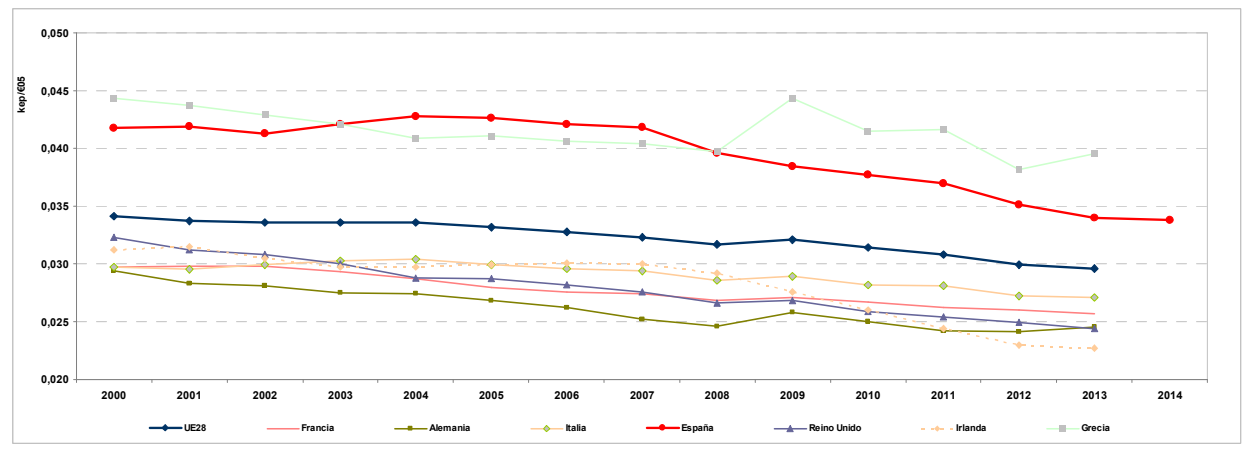

Figura 2.14 Comparativa europea de la intensidad energética del sector transporte. Fuente: EnR/IDAE 


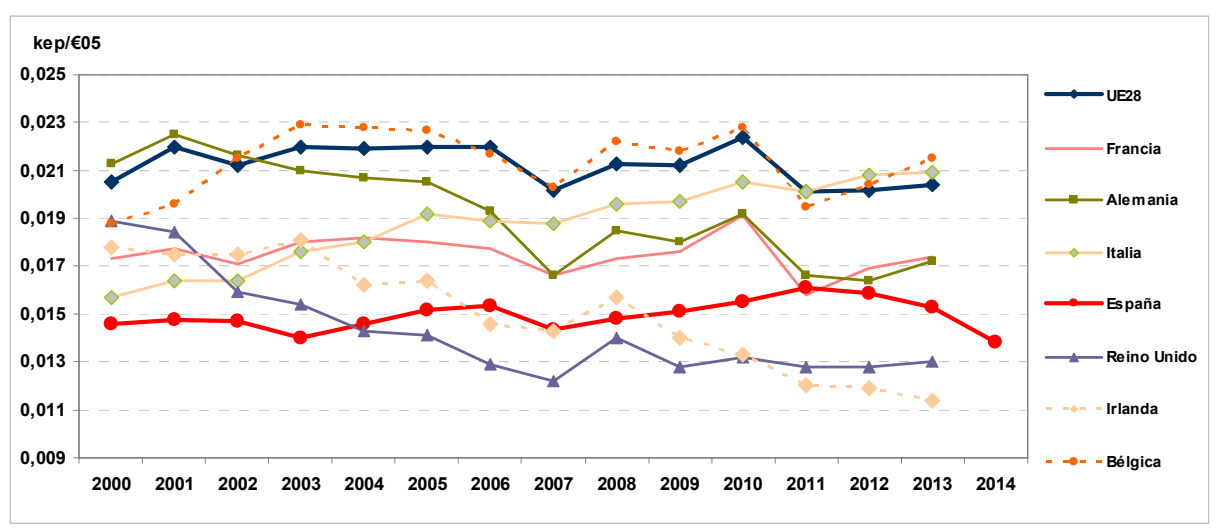

Figura 2.15. Comparativa europea de la intensidad final del sector servicios. Fuente: EnR/IDAE

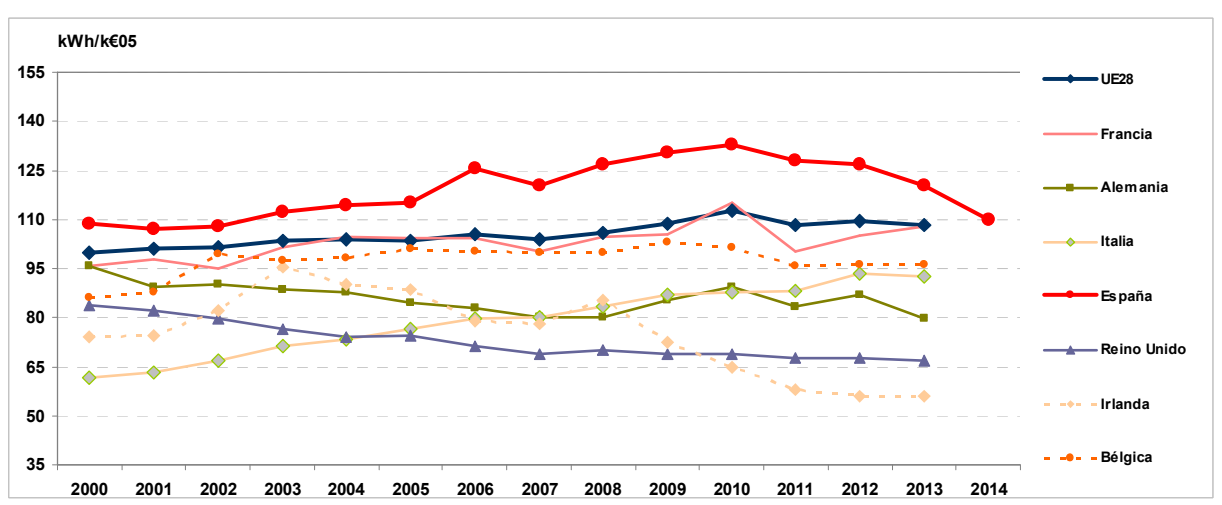

Figura 2.16. Comparativa europea de la intensidad eléctrica del sector servicios. Fuente: EnR/IDAE

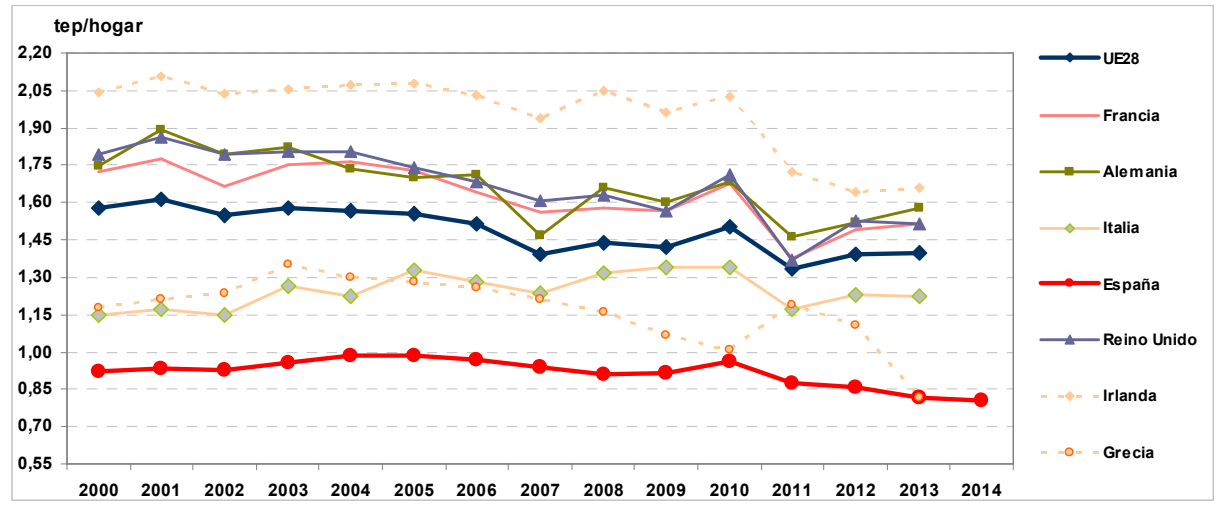

Figura 2.17. Comparativa europea de la intensidad final del sector doméstico. Fuente: EnR/IDAE 


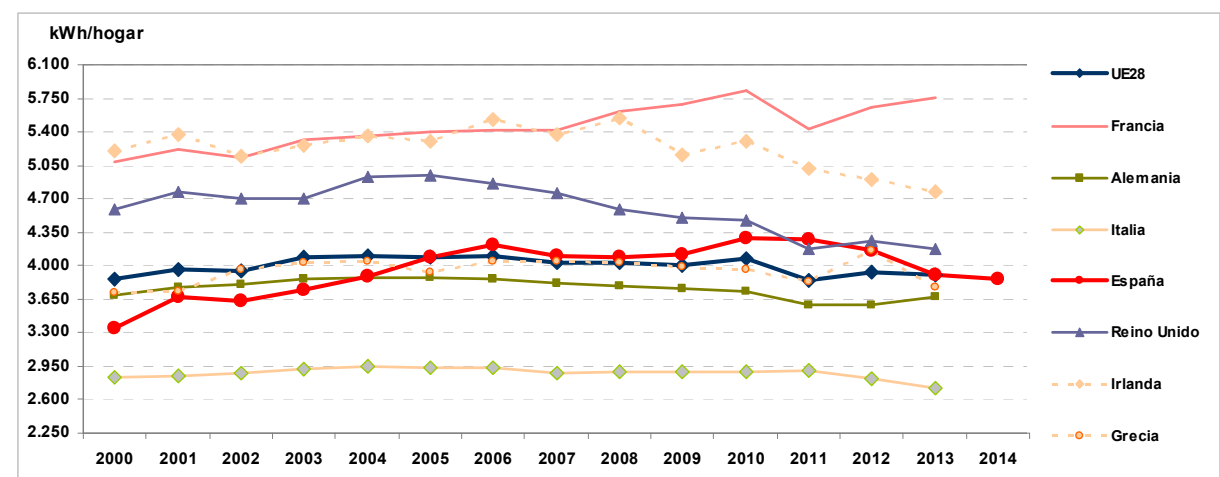

Figura 2.18. Comparativa europea de la intensidad eléctrica del sector doméstico. Fuente: EnR/IDAE

Estas gráficas muestran cómo, a pesar de que en conjunto nuestra posición en cuanto a intensidad energética en la UE es intermedia, al desagregar el consumo eléctrico en algunos sectores, pasamos a ser uno de los miembros con peores índices (sector servicios, Figura 2.16), o con índices con tendencia al alza en vez de a la baja (sector residencial, Figura 2.18). La necesidad de mejorar el desempeño del país en lo que se refiere a eficiencia energética en el sector residencial queda así acentuada.

\subsection{El producto energía eléctrica}

La energía eléctrica como producto de consumo en el sector doméstico presenta unas características especiales que deben tenerse en cuenta a la hora del planteamiento y análisis de posibles políticas de reducción del consumo o mejora de la eficiencia energética. Las connotaciones medioambientales y sociales que tiene el consumo de energía eléctrica diferencian en gran medida a este producto del resto por lo que su conocimiento detallado es fundamental para establecer las políticas más adecuadas.

Se plantean, a continuación, las características más relevantes que presenta la energía eléctrica como producto demandado en el sector doméstico. 


\subsubsection{Elasticidad de la demanda}

\subsubsection{Definición}

La elasticidad precio propio de la demanda se define como el grado de respuesta de la cantidad demandada de un bien o servicio ante un cambio en su precio. Se calcula del siguiente modo:

$$
\begin{gathered}
E P D=\frac{\% \text { variación en la cantidad demandada }}{\% \text { variación en el precio }} \\
E P D=\frac{\Delta Q_{d} / Q_{d}}{\Delta P / P}
\end{gathered}
$$

La EPD normalmente es negativa (variaciones positivas del precio suponen variaciones negativas de la demanda), pero habitualmente se registra en forma de valor absoluto.

La demanda de un bien se considera inelástica cuando los cambios en el precio tienen poca influencia en su demanda. Numéricamente hablando, esto se traduce en valores absolutos de EPD menores a 1. La demanda de un bien se considera elástica cuando los cambios en el precio influyen con fuerza en la demanda de ese bien, y suponen valores absolutos de EPD mayores a 1.

\subsubsection{Elasticidad de la demanda de energía eléctrica}

En el sector doméstico, el consumo de energía eléctrica en España tiene un comportamiento básicamente inelástico [87], es decir, las variaciones de precio afectan poco a la demanda de energía. Este comportamiento resulta coherente al considerar que en gran medida la energía eléctrica es un bien básico por lo que, al menos un consumo mínimo se debe realizar para mantener las condiciones elementales de confort y habitabilidad en el hogar. Este hecho también se ve reforzado al tener en cuenta que la energía eléctrica en la mayoría de los hogares no tiene sustitutos. En algunos casos podría pensarse, por ejemplo, en cambiar la calefacción eléctrica por gas u otro tipo de sustituciones pero son cambios que a causa de la necesidad de una fuerte inversión no se suelen realizar.

Se puede constatar también que al crecer el nivel económico o renta de los hogares la demanda se hace más elástica; la energía se utiliza no solo para 
cubrir las necesidades básicas sino también para otras actividades relacionadas con el ocio o la consecución de un mayor confort.

Puede concluirse, por lo tanto que la capacidad de adaptación de la demanda en el sector doméstico ante cambios en los precios de la energía es bastante limitada. No debe olvidarse tampoco que el precio de la energía viene determinado en la actualidad por la demanda del conjunto de sectores y no solo por el sector doméstico. De hecho el consumo doméstico en España representa aproximadamente el $17 \%$ o el $25 \%$ del total (considerando todas las fuentes de energía o únicamente la energía eléctrica respectivamente), por lo que su influencia en el establecimiento de los precios es reducida.

En la referencia [65], una revisión sobre la literatura al respecto de la elasticidad de la demanda, se proporcionan para ésta, en el campo residencial y sólo para la demanda de energía eléctrica, los valores que figuran en la Tabla 2.2 .

Estimación de la elasticidad de la demanda de energía eléctrica en el sector residencial

\begin{tabular}{cc}
\hline Rango en el corto plazo & Rango en el largo plazo \\
$0,14-0,44$ & $0,32-1,89$ \\
\hline
\end{tabular}

Tabla 2.2. Elasticidad de la demanda en el sector residencial

Donde se muestran los valores absolutos, siendo los reales negativos. Se observa en los valores que la elasticidad a corto plazo es pequeña, pero en el largo plazo aumenta, superando incluso el valor de 1.

\subsubsection{Información del producto}

Otra de las características que distinguen al producto energía eléctrica es la falta de información que tiene que afrontar el consumidor sobre diferentes aspectos del producto. Un consumo racional se basa en una buena información sobre el precio. Sin embargo, en el caso de la energía eléctrica en el sector doméstico, el consumidor no suele ser consciente ni del precio de la unidad de energía ni de la cantidad de energía consumida por los diferentes electrodomésticos. El coste del uso de cualquier electrodoméstico de la vivienda resulta desconocido para el consumidor por lo que no parece fácil que 
las señales de precio sean de utilidad para mejorar el comportamiento energético de los consumidores.

Por otro lado, es conocida la dificultad que tienen la mayoría de los consumidores para interpretar correctamente la factura eléctrica. Además, los datos de la factura corresponden a un periodo largo de tiempo por lo que resulta imposible relacionar el coste del producto con el uso del producto.

La información acerca del consumo propio de energía eléctrica es uno de los aspectos que requiere de una mejora sustancial en el futuro. La instalación de los contadores electrónicos o el uso de smart meters así como el desarrollo de etiquetas energéticas son aspectos que pueden perfeccionar en gran medida la información relativa al consumo de energía en el sector doméstico.

\subsubsection{Bien de primera necesidad}

Como producto esencial en cualquier hogar, la energía eléctrica se considera un bien de primera necesidad. A causa de ello, históricamente se ha tratado de regular el precio por parte de los gobiernos. La tendencia de liberalización actual propone considerar a la energía eléctrica como un bien de consumo más cuyo precio venga determinado por las leyes del mercado. Sin embargo, todavía se mantienen condiciones regulatorias como es el caso de la existencia de un bono social o de la tarifa PVPC en España. Aunque el precio de la energía en esta tarifa depende del precio del mercado mayorista liberalizado, el gobierno fija el precio final de la energía imponiendo, por tanto, límites a los beneficios empresariales de las empresas comercializadoras y distorsionando de alguna manera el funcionamiento del mercado.

Por otra parte, la importancia que en los últimos años ha adquirido el concepto de pobreza energética introduce más presión a la administración y a las empresas. Qué agente debe soportar el coste de la energía consumida por aquellos que no la pueden comprar es un debate que se mantiene en la actualidad.

En cualquier caso, el hecho de que la energía eléctrica se considere un bien de primera necesidad introduce o puede introducir condiciones regulatorias que afectan al funcionamiento del mercado y por tanto a su precio. 


\subsubsection{Efecto de los impuestos y otros recargos}

En la actualidad, y pese a que la energía está considerada como un bien básico, se aplica sobre la energía eléctrica el IVA general del $21 \%$ y un impuesto especial que se calcula como el $4,864 \%$ del consumo total y multiplicado por el factor 1,05113 . Sin embargo, como es bien sabido dentro del coste de la energía eléctrica se han ido incorporando progresivamente otros costes del sistema eléctrico que afectan al precio final. Hoy en día, el importe de la factura va destinado a las siguientes partidas:

- $\quad$ Costes del suministro eléctrico (49\%):

- Coste de producción de electricidad (31\%)

- Coste de redes de transporte y distribución (18\%)

- Impuestos, recargos y otros conceptos (51\%):

- Impuestos aplicados (21\%)

- Incentivos a las renovables, cogeneración y residuos (18\%)

- Otros costes regulados (12\%)

Es decir, más de la mitad del recibo de cualquier abonado no está vinculada a su consumo.

\subsubsection{Efectos medioambientales del consumo}

Las principales fuentes primarias no renovables de generación de energía eléctrica son el petróleo, el gas natural, la energía nuclear y el carbón; de entre ellas, la producción de energía eléctrica a partir de combustibles fósiles supone la emisión a la atmósfera de contaminantes como el dióxido de carbono, los óxidos de azufre y de nitrógeno, el metano, el monóxido de carbono, los metales pesados, las partículas en suspensión y los clorofluorocarbonos. Parte de estos contaminantes permanece en la atmósfera, contribuyendo al efecto invernadero y a la disminución de la capa de ozono; otros terminan depositándose en suelos, disolviéndose en los acuíferos o precipitando en forma de lluvia ácida, alterando los ecosistemas, reduciendo la biodiversidad y afectando a la salud de las personas.

Por otra parte, el tratamiento de los residuos sólidos generados en la producción también supone un problema importante; de entre ellos, los residuos nucleares son especialmente preocupantes, por su alta actividad 
radioactiva y su larga vida, no existiendo a día de hoy una solución satisfactoria para su eliminación.

Los combustibles fósiles, además, tienen un carácter limitado; a largo plazo, el aumento sostenido del consumo energético necesariamente devendrá en el agotamiento de estos recursos. Si hoy en día el control y la explotación de los yacimientos ya es fuente de tensiones sociales y conflictos bélicos, el impacto que puede suponer una crisis energética a nivel mundial para las generaciones futuras es muy grande.

\subsection{Análisis del consumo energético en España}

\subsubsection{El consumo eléctrico en España}

La demanda eléctrica en un país no es constante a lo largo del día, sino que tiene una evolución temporal cuyo nombre es curva de la demanda (Figura 2.19)

En esa curva puede verse cuál es el consumo instantáneo de energía eléctrica del conjunto del país, así como la evolución de éste a lo largo de las horas. En el eje de ordenadas se muestra la potencia, en el eje de abscisas se muestra la hora del día. La energía eléctrica total consumida por el país en un día entero se puede medir como el área bajo la curva.

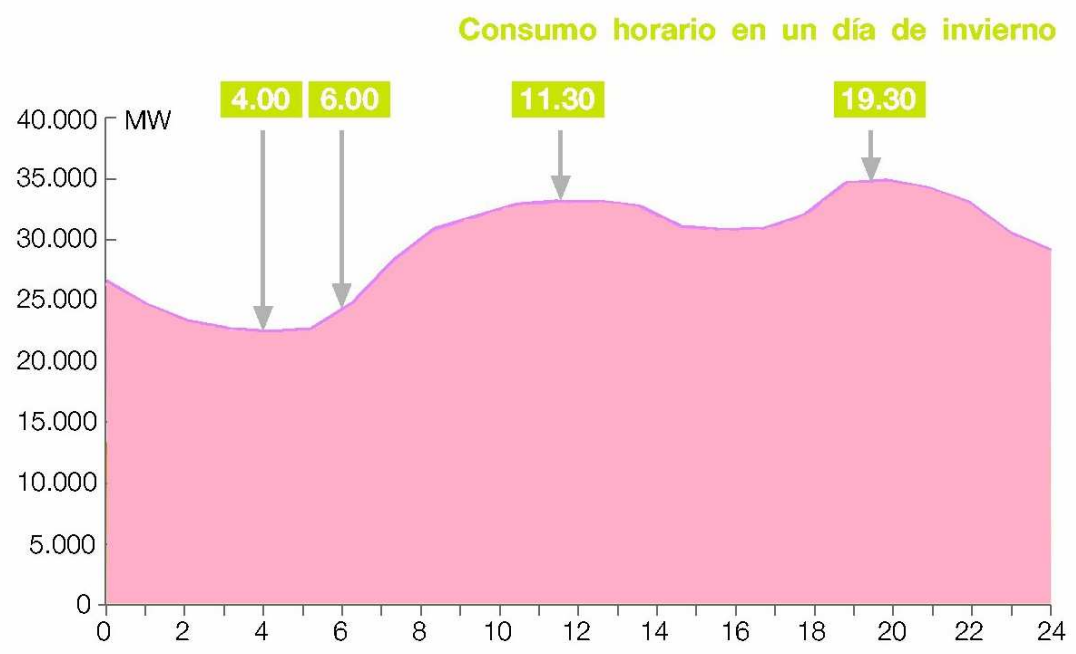

Figura 2.19.- Curva de la demanda. Fuente: IDAE 
La curva no se repite de un día para otro; le influyen mucho, además de las horas del día, la estacionalidad, el calendario laboral y las condiciones atmosféricas extremas. Por ejemplo, en verano el máximo se desplaza hacia las horas centrales del día, cuando la temperatura es más elevada (Figura 2.20)
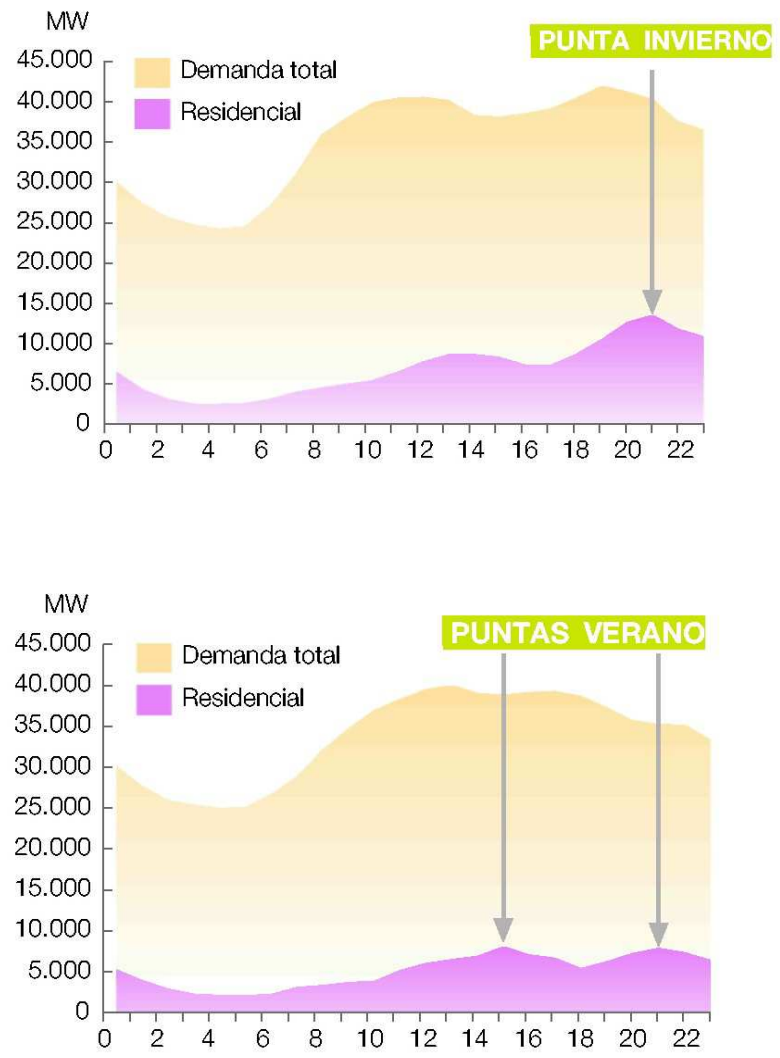

Figura 2.20.- Curva de la demanda de invierno y verano. Fuente: IDAE

Para poder atender a la demanda, el sistema eléctrico de un país debe tener instalada la suficiente cantidad de centrales generadoras como para que éstas puedan producir la demanda máxima, porque la energía eléctrica no puede almacenarse en grandes cantidades. Eso supone que, a mayor variabilidad de la curva, más sobredimensionado debe estar el sistema de generación. En la Figura 2.21 se puede ver el detalle de la estructura de generación en un día determinado. 


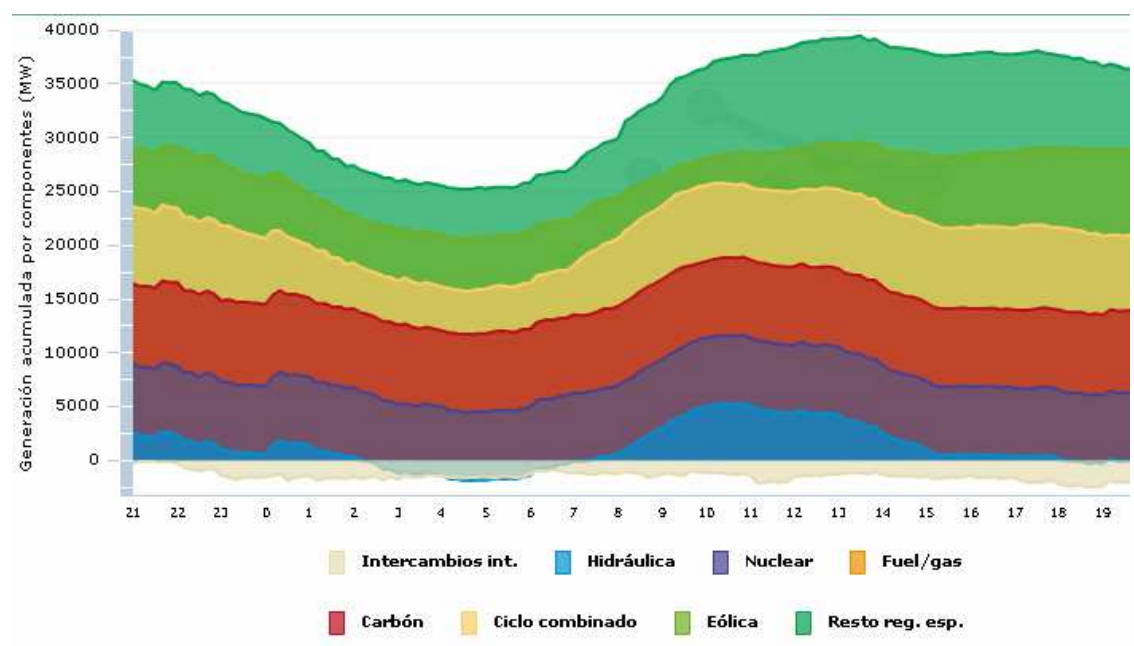

Figura 2.21.- Estructura de la generación diaria de energía eléctrica en España. Fuente: REE

Los planes nacionales sobre eficiencia energética tienen dos objetivos principales: reducir el consumo (es decir, bajar la curva de la demanda) e independizarlo de la hora (es decir, aplanar la curva). Ambos sirven para reducir la potencia instalada necesaria para atender toda la demanda.

\subsubsection{Contribución del sector residencial a la demanda}

Hay tres consumidores principales, que son el sector industrial, el sector servicios y el sector residencial. En la Figura 2.22 se puede ver la contribución aproximada de cada uno de ellos en cada instante de tiempo.

Consumo horario en un día de invierno

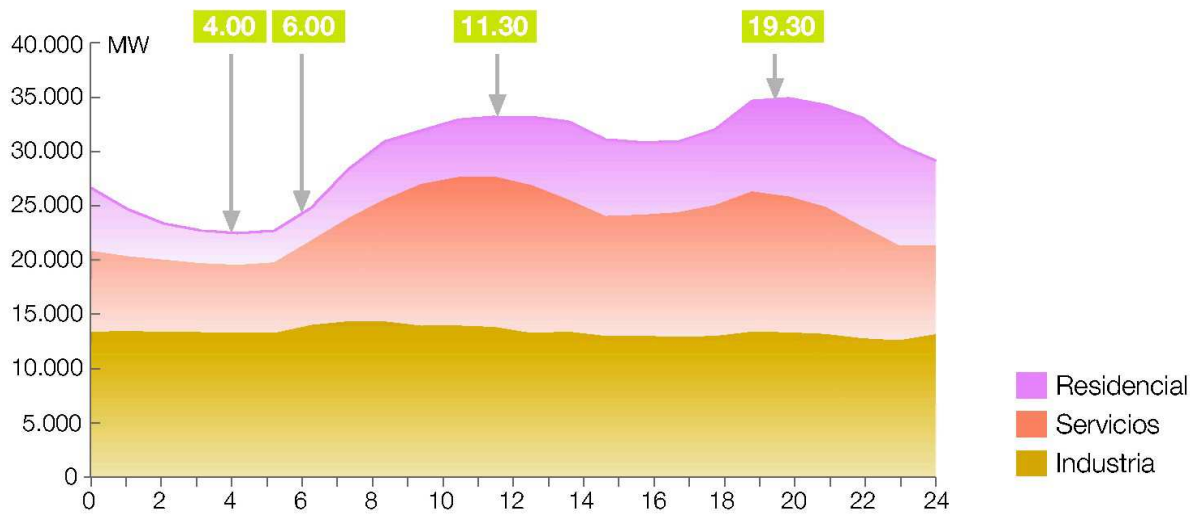


Figura 2.22.- Estructura de la generación diaria de energía eléctrica en España. Fuente: REE

Se aprecia cómo el consumo industrial es prácticamente constante, mientras que la parte residencial y de servicios tiene un fuerte componente horario. A partir de las 6 de la mañana, con el comienzo de la jornada, el consumo empieza a crecer; tiene un máximo hacia las 11:30 h, coincidencia de la actividad del sector servicios junto al uso de electrodomésticos en los hogares. Un segundo máximo hacia las 19:30 h coincide nuevamente la máxima actividad comercial con la vuelta al hogar de los trabajadores.

\subsubsection{Proporción del consumo según equipos}

En lo que se refiere a España, durante el año 2011, el consumo energético medio de un hogar español es de $10.521 \mathrm{kWh}$ al año. De este gasto, $6763,5 \mathrm{kWh}$ se debe al gasto de combustible; $3757,5 \mathrm{kWh}$ corresponde al gasto eléctrico, del cual $2330 \mathrm{kWh}$ pertenecen al gasto en electrodomésticos y el resto procede del gasto en iluminación, cocina, calefacción y agua caliente. Las tablas siguientes (Tabla 2.3. y Tabla 2.4), dan información detallada sobre cada tipo de equipamiento.

Consumo energético del conjunto del sector residencial español (2011)

\begin{tabular}{|c|c|c|c|c|c|}
\hline & \multicolumn{3}{|c|}{ Consumo (TJ) } & \multicolumn{2}{|c|}{ Consumo (\%) } \\
\hline & Eléctricos & Combustibles & Total & $\begin{array}{l}\text { Respecto } \\
\text { al } \\
\text { residencial } \\
\text { total } \\
\end{array}$ & $\begin{array}{c}\text { Respecto a } \\
\text { electrodomésticos }\end{array}$ \\
\hline Calefacción & 15907 & 272667 & 288574 & 47 & \\
\hline ACS & 16129 & 100114 & 116243 & 18,9 & \\
\hline Cocina & 20063 & 25588 & 45651 & 7,4 & \\
\hline Aire acondicionado & 5042 & 107 & 5149 & 0,8 & \\
\hline Iluminación & 25366 & & 25366 & 4,1 & \\
\hline Electrodomésticos & 133470 & & 133470 & 21,7 & \\
\hline Frigorífico & 40834 & & 40834 & & 30,6 \\
\hline Congelador & 8083 & & 8083 & & 6,1 \\
\hline Lavadora & 15812 & & 15812 & & 11,8 \\
\hline Lavavajillas & 8083 & & 8083 & & 6,1 \\
\hline Tv & 16263 & & 16263 & & 12,2 \\
\hline Secadora & 4469 & & 4469 & & 3,3 \\
\hline Horno & 11022 & & 11022 & & 8,3 \\
\hline Ordenadores & 9906 & & 9906 & & 7,4 \\
\hline Otros & 4707 & & 4707 & & 3,5 \\
\hline Stand-by & 14292 & & 14292 & & 10,7 \\
\hline
\end{tabular}


Tabla 2.3.- Consumo energético en el sector residencial español. Fuente: Informe Spahousec

Es importante, en lo que se refiere tanto al tipo como a la cantidad de consumo, la zona climática en la que se encuentra la residencia, así como el tipo de vivienda de la que se trate. Así queda patente en la Tabla 2.4.

Consumo anual medio por vivienda (kWh) que dispone del equipo (2011)

\begin{tabular}{cccccc}
\hline & \multicolumn{3}{c}{ Zona climática } & \multicolumn{2}{c}{ Tipo de vivienda } \\
\cline { 2 - 6 } & $\begin{array}{c}\text { Atlantico } \\
\text { Norte }\end{array}$ & Continental & Mediterráneo & Bloque & Unifamiliar \\
\hline Calefacción & 4018 & 7347 & 3975 & 2684 & 11215 \\
\hline ACS & 2039 & 2199 & 1639 & 1969 & 1671 \\
\hline Cocina & 1116 & 815 & 595 & 622 & 1007 \\
\hline Aire acondicionado & 751 & 235 & 140 & 152 & 207 \\
\hline iluminación & 354 & 329 & 474 & 399 & 434 \\
\hline electrodomésticos & 2641 & 2489 & 2559 & 2475 & 2626 \\
\hline frigorífico & 548 & 680 & 665 & 651 & 662 \\
congelador & 654 & 424 & 612 & 488 & 623 \\
lavadora & 332 & 254 & 272 & 274 & 273 \\
lavavajillas & 299 & 252 & 230 & 242 & 251 \\
tv & 67 & 144 & 116 & 119 & 119 \\
secadora & 269 & 237 & 260 & 258 & 252 \\
horno & 262 & 258 & 202 & 227 & 234 \\
\hline ordenadores & 123 & 160 & 140 & 140 & 156 \\
\hline otros & 44 & 39 & 22 & 35 & 20 \\
\hline Stand-by & 43 & 40 & 39 & 42 & 36 \\
\hline
\end{tabular}

Tabla 2.4.- Consumo energético en el sector residencial español por zona climática y tipo de vivienda. Fuente: Informe Spainhousec

De las tablas se deduce que, para el conjunto de España, casi la mitad del gasto total es en calefacción, y cerca de un $20 \%$ es ACS. Alrededor de la cuarta parte es en electrodomésticos, de los cuales el gasto mayor es en frigorífico, seguido por TV y lavadora. La 4a posición la tienen los sistemas de stand-by. En la Figura 2.23 se resumen las proporciones anteriores en forma gráfica. 


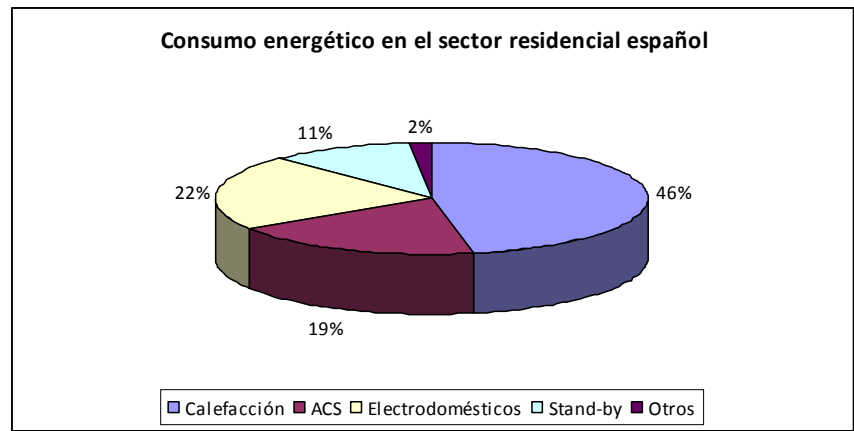

Figura 2.23.- Consumo energético en el sector residencial español

En la Europa de los 27 las proporciones de consumo son algo diferentes. Los equipos con consumos más elevados son:

- Los sistemas de calefacción eléctricos $(18,8 \%)$

- Los electrodomésticos fríos (15,3\%)

- $\operatorname{EI} \operatorname{ACS}(8,6 \%)$

- El stand by $(5,9 \%)$

\subsubsection{El precio de la electricidad}

El mercado eléctrico es el conjunto de mercados en los que se negocia la compra-venta de la energía eléctrica que circula por la red en España. El actual comenzó a ponerse en marcha en 1997, cuando entró en vigor la Ley del Sector Eléctrico. El año anterior ya se había firmado el llamado Protocolo Eléctrico entre el Ministerio de Industria y Energía y las principales empresas del sector, con lo que quedó anulado el Marco Legal Estable hasta entonces en vigor, que fijaba los precios en función de criterios políticos. Este relativamente nuevo sistema se basa en la competencia entre las empresas, y tiene como objetivo incrementar la calidad del suministro, la mejora del medio ambiente y conseguir que los precios se autorregulen en un mercado libre.

La regulación actual implica que muchas decisiones que antes eran tomadas por la Administración (como la autorización de construcción de nuevas centrales) ahora se dejan a criterio de las empresas, sin más limitaciones que las que establece la ley para cualquier instalación industrial. 
La Ley 54/1997, de 27 de noviembre, del Sector Eléctrico, establece que el mercado de producción es gestionado por dos Operadores: el Operador del Mercado (el Operador del Mercado Ibérico de Energía, Polo Español, S.A.$\mathrm{OMIE})$, que es el responsable de la gestión y liquidación de los mercados diario e intradiarios, y el Operador del Sistema (Red Eléctrica de España, S.A.- REE), que es el responsable de la gestión técnica y económica de los mercados de ajustes.

En este Mercado, los vendedores son los productores de electricidad (empresas generadoras), los comercializadores, los representantes del régimen especial y los titulares de unidades de oferta genérica de venta. Los compradores son los comercializadores de último recurso, los comercializadores, los consumidores directos en mercado y los titulares de unidades de oferta genérica de compra.

Diariamente, en lo que se denomina el mercado diario, los vendedores hacen ofertas de venta de determinadas cantidades de electricidad a determinado precio, para cada una de las horas del día siguiente. Al mismo tiempo, los compradores, directamente -en el caso de ser consumidores cualificados, actualmente sólo algunas grandes empresas- o indirectamente, a través de las compañías comercializadoras, hacen ofertas de compra.

La suma de las ofertas de compra configura una curva de demanda. Para cubrirla, se eligen las ofertas de venta más baratas, hasta satisfacer toda la demanda. El precio de la electricidad será el de la última oferta. Este proceso, denominado casación de la oferta y la demanda, está actualmente basado en un algoritmo denominado euphemia, aprobado para todos los mercados europeos.

Así, cada día de la semana, a las $12: 00$ h y tras la casación descrita anteriormente, se fija el precio y volumen de la energía para las 24 horas del día siguiente. Todo el proceso está gestionado por el operador de mercado, OMIE. Éste, a su vez, está supervisado por una comisión de representantes de los productores, distribuidores, comercializadores y consumidores cualificados.

También de forma diaria, se reúne el mercado intradiario, en el que se ajustan los programas de producción organizados el día anterior al consumo real del día en curso. 
El operador del sistema REE se encarga de comprobar la viabilidad técnica de los resultados del mercado, con el objetivo de garantizar la continuidad y la seguridad del suministro. A esto se le llama gestión de las restricciones técnicas del sistema, y supone pequeñas variaciones (del orden del 4-5\%), sobre la planificación original del operador de mercado. Actualmente, se encarga de esta labor Red Eléctrica de España, que se fundó para organizar todo lo relativo al transporte de electricidad.

La Comisión del Sistema Eléctrico protege los intereses de los consumidores y vela por la transparencia de todo el sistema. El Ministerio de Industria debe controlar el correcto funcionamiento de las actividades de producción y consumo de energía eléctrica.

Al precio de adquisición de la energía en el mercado diario y a las restricciones técnicas de operación, comentadas anteriormente, se le suman una serie de gastos, que son imputados al cliente a través de su factura eléctrica, y que sirven para el sostenimiento del sistema eléctrico y sus agentes. No aparecen en ella, pero se encuentran implícitos en los términos de energía y potencia.

Estos gastos extra se relacionan con: el margen de la comercializadora, los peajes de acceso, los pagos por capacidad, las pérdidas de transporte y distribución y la retribución a las operadoras.

Los peajes de acceso son un margen que cobra la compañía suministradora por el uso de sus redes, por las primas a las renovables y por los costes extrapeninsulares. Las compañías comercializadoras facturan este coste, que pagan a las suministradoras, a su vez a sus clientes.

Los pagos por capacidad se utilizan para incentivar la inversión y la disponibilidad de generación para cubrir la demanda en horas de punta del sistema a precios razonables. Los pagos por capacidad mantienen centrales con un funcionamiento muy bajo pero que son necesarias para la estabilidad del sistema. 


\subsection{La factura eléctrica}

\subsubsection{Costes incorporados a la factura}

El precio de la energía en el pool, las restricciones técnicas y servicios de operación se pagan según establezca el mercado horario, y se engloban dentro del término de energía de la factura.

El margen de la comercializadora es libre, y se engloba normalmente en el término de energía aunque puede encontrarse, según contratos, en el de potencia.

Los peajes de energía y potencia, los pagos por capacidad, las pérdidas de transporte y distribución, la retribución a las operadoras y el alquiler de equipos son términos regulados por ley. Todos menos el peaje de potencia, que se paga en el término de potencia, y el alquiler de equipos, que va aparte, se incluyen también dentro del término de energía.

A esto se añaden los impuestos municipales, el impuesto eléctrico y el IVA.

\subsubsection{Estructura de la factura}

Hasta 2009, el precio de la tarifa eléctrica para el sector doméstico estaba regulado por ley, y las facturas eran gestionadas por las compañías distribuidoras. Desde el 1 de julio de 2009, la actividad de suministro es ejercido en su totalidad por empresas comercializadoras en libre competencia.

Los consumidores con una potencia contratada no superior a $10 \mathrm{~kW}$, pueden acogerse a dos modalidades de contrato: pueden estar en el mercado libre, contratando la tarifa que les parezca más conveniente a cualquier comercializadora, o bien pueden continuar en el mercado regulado y contratar una tarifa llamada PVPC. En este último caso, necesariamente deben tener su contrato con una Comercializadora de Referencia (antes, CUR).

La tarifa PVPC (Precio Voluntario para el Pequeño Consumidor) sustituye a la anterior tarifa TUR, siendo ambas un sistema de fijación de precios establecido por el gobierno. La diferencia entre ellas es la forma de calcular el precio de la energía en cada caso. Con la entrada en vigor del PVPC, el precio de producción de la electricidad lo calcula OMIE de forma diaria en función de los precios por hora de la energía en el mercado eléctrico. 
Para los clientes que ya disponen de contador electrónico, la facturación se realiza en base al precio horario y al consumo horario real; para los que aún no disponen de este tipo de contadores, el cálculo se realiza en base al perfil de un consumidor promedio creado en base a patrones generales de comportamiento de los consumidores.

Existen tres modalidades de facturación dentro del PVPC: la tarifa general, la tarifa nocturna y la tarifa supervalle.

En una factura eléctrica encontramos los siguientes datos (ver Figura 2.24)

- Datos del contrato

- Datos del cliente

- Periodo de facturación

- Potencia contratada (máxima potencia que puede consumirse en un instante determinado)

- Tipo de tarifa contratada

- Datos de facturación

○ Fijos:

- Término de potencia (precio pagado por tener contratada una determinada potencia)

- Alquiler de equipos

- Impuesto sobre electricidad

○ Función del consumo

- Término de energía (precio pagado por el consumo total mensual de electricidad)

- IVA sobre el total

- Historial de consumo

- Gráfico de barras del consumo del año en curso

Es importante hacer hincapié en el hecho de que no todas las facturas contienen lecturas reales sino que, en ocasiones, son estimadas, y que en muchos casos son bimensuales. 


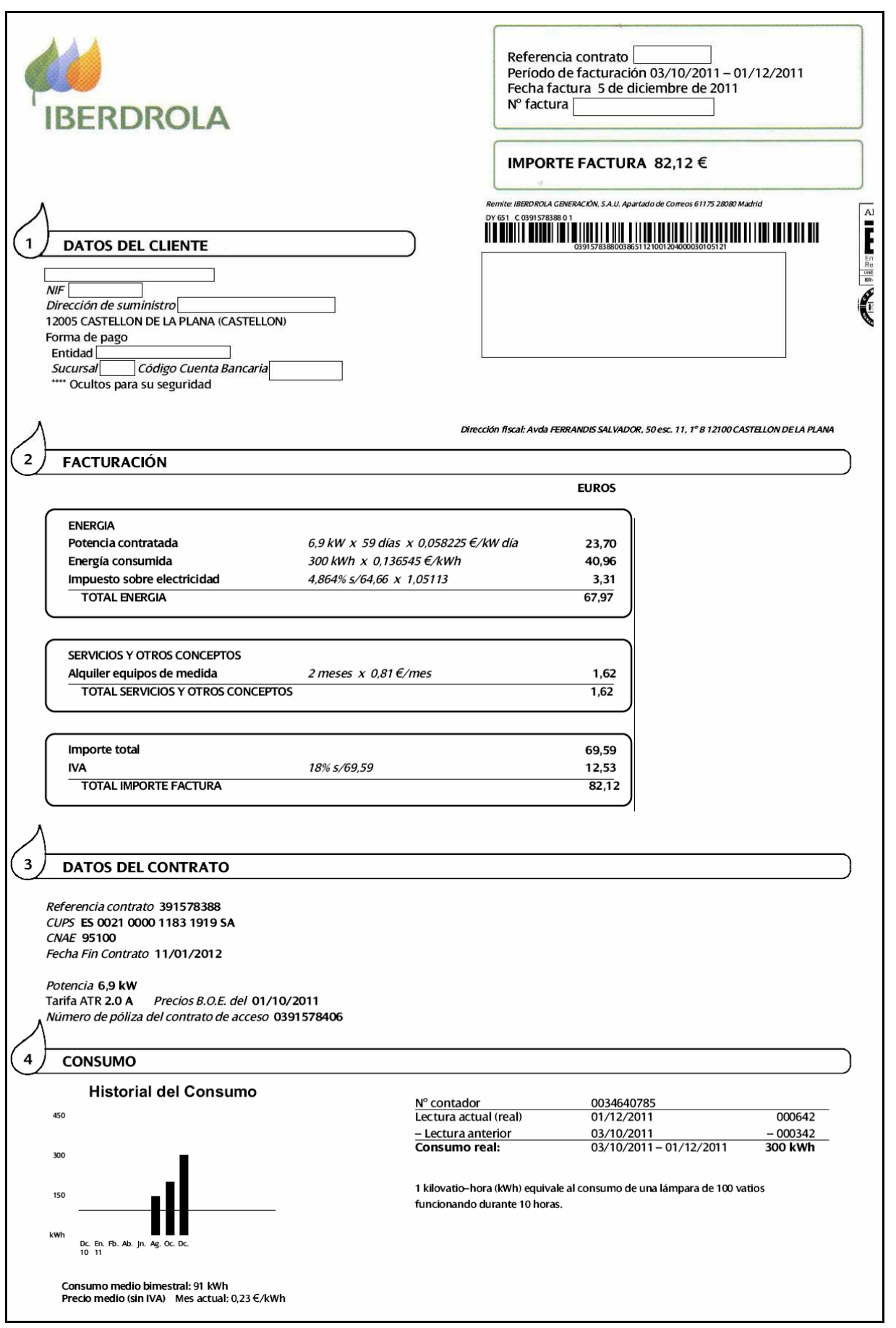

Figura 2.24. Factura eléctrica 


\subsubsection{Dificultades para la interpretación de la factura}

En una vivienda media, cada día del mes se llevan a cabo múltiples acciones que implican el consumo de energía. Estas acciones están asociadas a actividades muy diversas, relacionadas tanto con el ocio familiar como con las necesidades de alimentación, higiene y mantenimiento del hogar.

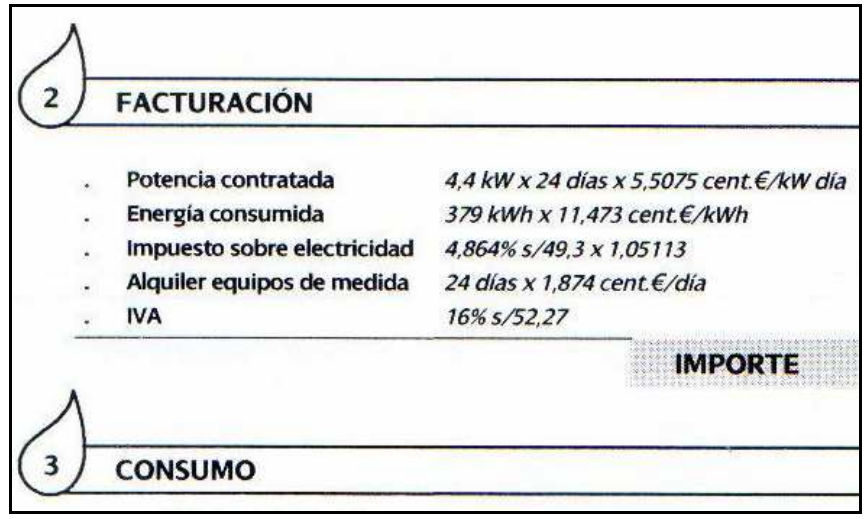

Figura 2.25.- Dato de energía consumida en la factura

Toda la información que recibe el usuario relacionado con todas esas acciones es una factura mensual o bimensual con un único dato de energía total consumida, representada en la Figura 2.25. El gasto asociado a cada una de las acciones anteriores es totalmente desconocido para el habitante de la vivienda: ¿Dónde está gastando más? ¿En la nevera, el lavaplatos, la TV, el horno, el microondas?... ¿Hay consumos fantasma que puede eliminar, como luces en habitaciones vacías o stand-by? ¿Sus vecinos consumen lo mismo que ellos? Una vivienda óptimamente eficiente, ¿consumiría mucho menos que ellos? Es imposible asociar la cantidad de energía consumida en un hogar con un comportamiento determinado de sus habitantes.

Supongamos que un ciudadano concienciado decide hacer pruebas a ciegas: en el consumo energético mensual influyen muchas cosas que no tienen que ver con el comportamiento energético de sus habitantes: de un mes para otro cambia la climatología, el número de horas de sol, el número de días laborables, etc. Incluso un usuario especialmente concienciado y especialmente exhaustivo, que anote los cambios que ha ido haciendo a lo largo de un mes entero, no podrá verlo reflejado en la factura de forma lo 
suficientemente precisa como para que pueda deducir cuánto ha influido en el total.

Otro problema asociado es el desconocimiento general de dónde invertir para maximizar el ahorro: ¿compro electrodomésticos más eficientes? ¿Será más eficaz variar mis hábitos energéticos? ¿Y si mejoro los cerramientos de la vivienda?

Es necesario, por tanto, el desarrollo de sistemas que permitan al usuario tomar decisiones basadas en datos inmediatos, precisos y fáciles de interpretar.

\subsection{Nociones de economía experimental}

\subsubsection{Introducción}

A lo largo del desarrollo de esta tesis, se habla mucho del concepto de economía experimental, estando todos los experimentos realizados en ella basados en su filosofía. Dado que el conocimiento de esta rama de la economía no está muy extendido fuera del ámbito de sus especialistas, en los siguientes apartados se da una noción básica de sus objetivos, su metodología y su aplicabilidad al campo de la eficiencia energética.

La economía experimental es una rama de la economía que consiste en la aplicación de ensayos experimentales, realizados en campo o en laboratorio, para la comprobación de teorías, predicciones y cuestiones económicas. Es una disciplina novedosa, que ha desarrollado un método experimental para la comprobación de teorías relacionadas con el comportamiento humano y social.

Los experimentos consisten a grandes rasgos en la simulación de un ambiente artificial determinado, (por ejemplo un mercado), dentro del cual un conjunto de sujetos experimentales toma una serie de decisiones de contenido económico, como puede ser comprar o vender en función del precio de determinado bien en cada momento. Los investigadores observan el comportamiento de los voluntarios sometidos a diferentes variaciones del ambiente artificial (por ejemplo, alteraciones en los precios de los bienes), y extraen conclusiones de las modificaciones de comportamiento observadas en cada variación aplicada. 
La economía experimental es una ciencia relativamente nueva. En los últimos años, su uso ha ido extendiéndose, abarcando no sólo la investigación de postulados estrictamente económicos sino también los de cualquier otra área del conocimiento con alguna relación con el comportamiento humano. El prestigio y la importancia de esta rama de la economía han ido aumentando, sobre todo a partir de la concesión de un premio Nobel a Vernon Smith, considerado el padre de la economía experimental.

La fácil aplicabilidad de la economía experimental a otros campos es una de sus ventajas más interesantes. La política macroeconómica, la microeconomía, las finanzas, la econometría, la neurociencia, la antropología y cualquier otra materia que tenga alguna relación con el comportamiento humano y social, se han beneficiado de la metodología de trabajo de la economía experimental [25]. Disciplinas tan aparentemente alejadas del comportamiento social como la ingeniería han encontrado también aplicación a esta nueva herramienta, en forma, por ejemplo, del estudio del funcionamiento del mercado eléctrico y el comportamiento de los agentes que lo forman.

Otra gran ventaja de la economía experimental es la sencillez con la que pueden testearse en laboratorio algunas situaciones que sería imposible ensayar en el mundo real, por las consecuencias que podrían suponer para la sociedad, por la cantidad de personas que podrían verse implicadas, o por el coste que llevaría asociado. Este es el caso, por ejemplo, de cualquier ensayo relacionado con la política macroeconómica o con los mercados energéticos.

\subsubsection{Metodología experimental}

La mayor parte de los experimentos económicos se realizan en laboratorio, utilizando como sujetos a voluntarios a los que se ofrece una remuneración económica a cambio de su colaboración. Los laboratorios de economía experimental suelen consistir en una sala, con una serie de al menos 30 mesas separadas entre sí por mamparas, tabiques o separadores, y con un ordenador en cada una de ellas. Los sujetos experimentales se sientan de forma que no pueden observarse entre sí.

Normalmente, en un experimento económico, se desea estudiar el efecto sobre las personas de ciertos cambios en el entorno que las rodea. Para ello, el método habitual de trabajo es dividir a los sujetos participantes en 
distintos grupos, y sumergir a cada grupo en un entorno muy similar pero con una cierta modificación sobre el de los demás. Comparando los resultados finales de cada grupo, se puede averiguar la influencia de esa modificación en particular sobre el comportamiento. A estos entornos parecidos pero diferentes se les llama tratamientos.

Los experimentadores, de forma previa al inicio del experimento, han diseñado las características del entorno, las reglas que lo rigen y el perfil de los sujetos participantes. Por su parte, los voluntarios saben que se encuentran en un entorno artificial, en el que deben jugar según las reglas acordadas, y saben también que su remuneración final será función de su desempeño a lo largo del experimento.

En el inicio de la sesión experimental, se explica de forma exhaustiva en qué consiste el experimento y cuáles son sus reglas; después, durante el desarrollo del experimento, se registra el comportamiento de los sujetos mientras éstos se encuentran inmersos en el entorno virtual que se ha creado para ellos. En la mayoría de los casos, este entorno está reproducido a través del ordenador. Por último, tras la finalización del experimento, se extraen conclusiones a partir de los datos obtenidos.

Las sesiones tienen una duración limitada en el tiempo, que normalmente se conoce con anticipación. Es habitual que se hagan varias rondas del mismo experimento, para dar ocasión a los sujetos de aprender a moverse en el entorno y comprender sus reglas.

Así, los experimentos en laboratorio son una forma sencilla, rápida y de bajo coste de efectuar comparaciones entre distintos escenarios, o explorar distintas opciones de actuación, que serían difíciles o imposibles de comparar en la realidad, con un control total sobre las variables que se desea testear.

En general, el experimentador procura que el entorno al que expone a los sujetos reproduzca hasta cierto punto las condiciones del mundo real. Por supuesto, el diseño correcto de la situación ficticia que, en laboratorio, emula de forma simplificada a la situación real, es de importancia capital. Sin embargo, los experimentos en laboratorio tienen como una de sus características principales la simplicidad de su planteamiento en comparación con la realidad, lo cual supone a la vez una gran ventaja y uno de sus mayores inconvenientes. 
Por una parte, la simplicidad permite a los sujetos experimentales controlar las reglas que rigen el experimento con facilidad y actuar de forma lógica con respecto a ellos, sin sentirse abrumados por un exceso de información o por la complejidad del entorno, y a los investigadores les permite asegurarse de que la única variación se encuentra en la variable que ellos manipulan. Por otra parte la simplicidad encierra el peligro de alejar al experimento y por tanto a sus resultados de la situación real que pretende estudiar, limitando en ocasiones la validez de sus resultados. De hecho, ésta es una de las críticas más repetidas a la validez de la economía experimental.

\subsubsection{Tipos de experimento}

La mayoría de los experimentos económicos tienen lugar en laboratorio, debido a sus características de simplicidad, control y replicabilidad. Por control se entiende la capacidad de manipulación de las variables que se estudian en el experimento, alterándolas a voluntad de forma que se pueda evaluar el efecto de los cambios. Por replicabilidad se entiende que los experimentos pueden repetirse en las mismas condiciones tantas veces como se desee.

Aunque en minoría por su dificultad de aplicación, los experimentos de campo también aparecen dentro del ámbito de la economía experimental. En el caso de los experimentos de campo, los sujetos también son voluntarios que se reclutan a cambio de una remuneración económica, y también son seleccionados de forma que cumplan las características necesarias para el experimento. La diferencia con los experimentos de laboratorio es que los de campo se llevan a cabo en la vida real o al menos en un entorno más natural, de forma que la observación realizada sea más realista y menos artificial. Aunque dificultada por el hecho de que la situación es menos controlable, en la medida de lo posible se intenta mantener el control sobre las variables objeto de estudio.

Se distinguen en total cuatro niveles de experimento:

Experimento de laboratorio. Se denomina así a aquél experimento en el que se desarrolla una situación ficticia, que sigue un conjunto de reglas determinadas por los investigadores y conocidas por los participantes, y en el que los sujetos son estudiantes.

Experimento de campo con carácter de artefacto. Experimento de laboratorio en el que los sujetos no son estudiantes. 
Experimento de campo enmarcado. Experimento en el que el entorno se vuelve más natural, sea por la tarea a realizar, o por la información que tienen los sujetos. Éstos conocen la naturaleza del experimento, y no son estudiantes.

Experimento de campo natural. Experimento de campo enmarcado en el que los sujetos no saben que forman parte de un experimento.

\subsubsection{Pautas para la realización de un experimento económico}

En los apartados siguientes se enumeran una serie de reglas básicas de la economía experimental a la hora de diseñar un experimento.

\subsubsection{Diseño del entorno}

De forma previa al inicio del experimento, deben tomarse una serie de decisiones relativas al entorno.

Debe decidirse si el experimento se realiza en laboratorio o en el mundo real. Como se ha comentado previamente, el entorno de laboratorio no puede pretender reproducir la complejidad del mundo real pero sí controlar fácilmente las variables que se desea estudiar. Por su parte, los experimentos reales suelen ser mucho más complejos de organizar y llevar a cabo, y el grado de control sobre ellos es más reducido. Sin embargo, sus resultados son más fiables porque el entorno no ha sido artificialmente simplificado.

En cuanto al entorno al que se somete a cada grupo particular de voluntarios, una norma básica de todo experimento es que entre dos tratamientos debe existir un único cambio. Si se efectúan dos modificaciones al mismo tiempo, no es posible evaluar qué parte de los efectos observados se debe a cada una de ellos. Generalmente uno de los tratamientos, llamado tratamiento base o control, es el que se utiliza como referencia para evaluar el efecto de la variación realizada en cada uno de los demás.

También debe concretarse el número de repeticiones que va a realizarse, y que debe ser suficiente para que el sujeto tenga tiempo de aprender a moverse e interactuar con el entorno, y no tan excesivo como para saturarle, aburrirle o desinteresarle. 


\subsubsection{Elaboración del manual de instrucciones}

Antes del inicio del experimento, los sujetos deben saber qué se espera de ellos y qué van a recibir a cambio. Para ello, debe redactarse un pequeño manual de instrucciones para los participantes. Las características de este manual deben ser las siguientes:

- Las instrucciones deben ser claras y concisas. Los participantes deberían entender todo el experimento sin necesidad de aclaraciones posteriores. En caso de que esas aclaraciones sean necesarias, conviene que se hagan públicamente, en voz alta, al inicio del experimento, para que todos los participantes partan de tener exactamente la misma información.

- Las instrucciones, en la medida de lo posible, no deben desvelar las intenciones de los investigadores: los sujetos deberían participar en los experimentos sin saber qué se espera en realidad de ellos. De esa forma, se evita en parte que sus objetivos se desplacen del incentivo monetario a otros relacionados con cumplir con las expectativas de los examinadores. Por la misma razón, la terminología utilizada no debe dar pistas ni tampoco influir en la actitud del sujeto ante el experimento. Por ejemplo, no debe especificar a qué grupo pertenece el sujeto o qué variable se está examinando.

- Los examinadores nunca deben mentir al sujeto experimental. Los experimentos económicos requieren de una credibilidad completa, desde el momento en que se depende de que el sujeto esté convencido de la relación entre sus acciones y su recompensa final, sin trucos ni trampas. Una relación de falta de veracidad, además, se extendería de unos experimentos a otros, por lo que se podría convertir en un problema con proyección de futuro.

\subsubsection{Selección de los sujetos experimentales}

De forma previa a la selección, es necesario saber qué perfil de sujeto experimental se desea. Muy a menudo se utilizan estudiantes de universidad para los experimentos de laboratorio, una decisión que es a veces ventajosa (las personas jóvenes tienen una curva de aprendizaje con una pendiente 
elevada, y para los estudiantes es suficiente un incentivo con un coste relativamente bajo), pero encierra un considerable peligro de sesgo: en función del tipo de experimento, pueden no representar correctamente a la población que se pretenda estudiar por la uniformidad de su edad o de sus conocimientos. También es más fácil que con otros colectivos que haya difusión de información entre ellos de unas sesiones a otras, dado que es probable que se conozcan entre sí. Es una cuestión a estudiar con cuidado en función del experimento.

También se debe establecer el número de sujetos experimentales con los que se va a trabajar, que en general vendrá limitado por el presupuesto y por el grado de complejidad creciente asociado a un número elevado de participantes. Una solución de compromiso suele estar en 30 participantes por grupo, un número suficientemente alto para que el tratamiento estadístico posterior llegue a resultados satisfactorios, y suficientemente bajo como para ser manejable.

\subsubsection{Organización de los participantes}

Existen dos formas de organizar a los participantes: en la primera, cada sujeto pertenece a un y solamente un tratamiento, y no puede trasladarse de uno a otro ni repetir el mismo experimento posteriormente perteneciendo a otro de los tratamientos. La forma de organización más habitual es ésta. Así se impide que los sujetos empleen lo aprendido en un tratamiento anterior para mejorar su desempeño en el siguiente, lo cual distorsionaría sus resultados en comparación con la sesión inicial, en la que los sujetos debían, inicialmente, aprender a manejarse en el nuevo entorno artificial.

El segundo sistema de organización es precisamente el opuesto, es decir, ir pasando a los sujetos de unos tratamientos a otros. Este sistema sólo debe emplearse si el experimento ha sido diseñado para ello, por ejemplo con la intención de estudiar la capacidad de aprendizaje de los sujetos.

\subsubsection{Motivación de los participantes}

Para que los sujetos se interesen por el entorno en el que se mueven, se le proporciona un incentivo, que en la mayor parte de las ocasiones es de tipo económico. Sin incentivos, los sujetos podrían tomar decisiones sin lógica, careciendo los resultados de validez. Esos incentivos deben ser lo bastante atractivos para que los participantes estén suficientemente motivados. 
Las características que debe tener el incentivo deben ser la contingencia, la dominancia y la monotonicidad. La contingencia se refiere a que la recompensa final obtenida debe ser función del comportamiento del sujeto a lo largo del experimento; la dominancia significa que los cambios de comportamiento del sujeto deben deberse fundamentalmente a cambios en el incentivo, sin que le influyan (o apenas) otras variables; y la monotonicidad se refiere a que un pago mayor debe ser siempre preferible a uno menor, sin que se alcance la saturación.

El pago económico a los participantes es una mejora de la economía experimental si se compara con el sistema habitual utilizado en psicología o sociología para los estudios de campo. En estas últimas disciplinas, generalmente los sujetos rellenan cuestionarios sobre un tema en cuestión y a partir de las respuestas los investigadores extraen conclusiones; es necesario creer en la sinceridad de las respuestas (incluso ante preguntas incómodas) y en que los sujetos no cambiarían sus respuestas si la situación de la que se habla pasara de hipotética a real. En los experimentos económicos, el sujeto trabaja por dinero, y es razonable pensar que elegirá la opción que le reporte más beneficios.

Pese a ello, parte de las críticas a la economía experimental vienen de considerar que en realidad hay otros motivos que hacen actuar a los sujetos al margen de su recompensa económica, como pueden ser complacer las expectativas del investigador o mantener el prestigio frente al resto de sujetos voluntarios.

\subsubsection{Control}

Se debe procurar, en la medida de lo posible, que la única variable que cambie es aquella que se está estudiando. Sin embargo, hay que tener en cuenta en cada caso las condiciones del experimento que se lleve a cabo; es relativamente fácil, en un experimento de laboratorio, emular las mismas condiciones de iluminación, temperatura, ruido, tiempos, brillo de la pantalla y cualquier otra variable del entorno. Sin embargo, en un experimento de campo, el control de las variables se vuelve más complicado. Aunque el diseño del experimento debe tratar de evitarlo en la medida de lo posible, según el tipo que sea deberá sacrificar parte del control a cambio de la ganancia en la naturalidad del entorno. 


\subsubsection{Independencia de las observaciones}

A la hora de analizar los resultados de las observaciones, la estadística de contraste trabaja con muestras relacionadas (variación en un mismo grupo entre el antes y el después de un tratamiento), y muestras independientes (diferencias entre grupos sometidos a distintos tratamientos). Con el objeto de que esa estadística se aplique correctamente, debe garantizarse la independencia entre grupos diferentes, es decir, debe impedirse la difusión de información entre unos grupos y otros. Nuevamente, esta regla es hasta cierto punto fácil de aplicar en laboratorio, pero en experimentos de campo puede ser más difícil de aplicar.

\subsubsection{Análisis de los datos}

La recogida de datos también debe planificarse cuidadosamente de forma previa a la realización del experimento. Los experimentos económicos, por su propia naturaleza, tienden a materializarse en forma de largas series de datos por sujeto y sesión; una correcta planificación previa evita que la digestión de toda la información obtenida sea innecesariamente compleja.

En realidad, pese a la cantidad de datos obtenida, generalmente las conclusiones son muy simples, y se basan en el tratamiento estadístico de los datos para obtener medias y variaciones significativas entre ellas.

\subsubsection{Tratamiento estadístico de los resultados de las sesiones experimentales}

En el presente apartado se hace un repaso rápido de los conceptos básicos de Estadística implicados en el análisis de los datos y se describen muy brevemente los tests de contraste de hipótesis que es habitual utilizar durante el desarrollo de un experimento económico. El carácter multidisciplinar de esta tesis aconseja la inclusión de esta información, formada por conceptos sobradamente conocidos por los economistas pero no necesariamente por expertos en otras áreas.

\subsubsection{Significatividad estadística y tests de contraste de hipótesis}

Cuando se trabaja con grandes cantidades de datos, agrupados según distintos criterios, es necesario el uso de herramientas estadísticas para estudiar sus características, tendencias, parecidos y diferencias. Reducir el 
problema a calcular las medias de cada grupo y compararlas entre sí no es válida; hay una componente de azar en cualquier agrupación de datos, y que puede suponer que dos medias sean diferentes por pura coincidencia, de la misma forma en que, si se tira al suelo un puñado de piedras, no se reparten de forma regular sobre éste sino que forman figuras $y$ agrupaciones caprichosas.

Para que exista la seguridad de que la diferencia entre dos grupos de datos no es azarosa sino el efecto de una razón determinada es para lo que se han desarrollado diferentes tests estadísticos, denominados en conjunto tests de contraste de hipótesis. Cuando estos tests prueban que la diferencia entre dos muestras tiene una razón de ser más allá de la casualidad, se dice que esa diferencia es estadísticamente significativa. Ninguna comparativa entre grupos que no tenga detrás el respaldo de la comprobación estadística de su significatividad tiene valor de prueba. Eso sí, la "prueba" siempre es de tipo probabilístico; no se puede probar con una certeza absoluta ni la significatividad ni la inexistencia de ella.

Los tests de contraste de hipótesis se basan en la prueba de verificación de la "hipótesis nula". Esto significa que parten de proponer una hipótesis HO (usualmente, que las muestras que se comparan proceden de poblaciones que son iguales entre sí), y calculan la probabilidad de que esa afirmación sea cierta. Si la probabilidad de que la hipótesis sea verdadera es muy reducida, se dice que la hipótesis nula debe ser rechazada, lo que es equivalente a decir que se acepta la hipótesis de que las poblaciones son diferentes.

Se denomina nivel de significación a la probabilidad de cometer un error al considerar cierta la hipótesis nula; el contraste de hipótesis, de hecho, consiste en calcular esa probabilidad. Por regla general, se utiliza el $5 \%$ como el nivel de significación o límite de probabilidad a partir del cual no se puede rechazar la hipótesis nula. Es decir, se considera que la hipótesis nula es falsa (y por tanto la proposición contraria es verdadera), cuando la probabilidad de que en realidad sea verdadera es menor al $5 \%$. Otros límites, usados menos frecuentemente, son el 1 y el $10 \%$.

La significatividad estadística existe únicamente cuando se puede rechazar la hipótesis nula y aceptar la alternativa. Cuando no se rechaza HO no se ha probado nada, sólo que faltan pruebas para rechazarla. Por eso los tests 
suelen estar enfocados al rechazo de H0, que sí es una prueba (estadística) de la diferencia entre las dos poblaciones.

La proposición contraria a la hipótesis nula se denomina hipótesis alternativa $\mathrm{H} 1$, y tiene un grado de indefinición mayor que la hipótesis nula; se puede formular como "la hipótesis nula es falsa" (las poblaciones son diferentes entre sí), en cuyo caso el contraste se denomina bilateral o de dos colas; o se puede formular especificando el sentido de la diferencia (una población es mayor o es menos que la otra), denominándose en este caso contraste unilateral o de una sola cola.

A la probabilidad de error de la hipótesis nula se le llama a veces $\alpha$ y otras veces $p$-valor, y en la práctica se da en tanto por uno. Es decir, la diferencia entre dos muestras se considerará estadísticamente significativa cuando el p-valor resultante de compararlas sea menor o igual a 0,05. En caso contrario ( $p$-valor $>0,05$ ), no se puede rechazar la hipótesis nula, por lo que las muestras no se pueden considerar significativamente diferentes.

Hipótesis nula HO:

Las muestras son iguales entre sí

$\mu 1=\mu 2 ;$

p-valor $>0,05$

Hipótesis alternativa bilateral $\mathrm{H} 1$ :

Las muestras son diferentes entre sí

$\mu 1 \neq \mu 2$

$p$-valor $\leq 0,05$

Hipótesis alternativa unilateral $\mathrm{H} 1$ :

Una muestra es mayor (o menor) que la otra

$\mu 1<\mu 2 \circ \mu 1>\mu 2$

$p$-valor $\leq 0,05$

Por ejemplo, se pueden comparar entre sí dos muestras de sujetos con problemas de alergia al polen, antes y después de haber sido sometidos a dos nuevos medicamentos, para comprobar la efectividad de éstos. Tras pasar el 
test de contraste de hipótesis a los resultados, se obtienen los siguientes resultados:

$$
\begin{aligned}
& \text { p-valor medicamento } 1=0,385 \\
& \text { p-valor medicamento } 2=0,036
\end{aligned}
$$

En el primero de los casos, no puede rechazarse la hipótesis nula por tener el p-valor un valor superior a 0,05. Al aceptarse la hipótesis nula, las medias antes y después de la ingesta del medicamento 1 deben considerarse iguales, no pudiéndose demostrar efectividad alguna del medicamento 1 frente a la alergia al polen.

En cambio, en el segundo caso, el p-valor es menor a 0,05; se rechaza la hipótesis nula de igualdad de las medias y se acepta la hipótesis alternativa: las medias antes y después de la ingesta del medicamento 2 son diferentes, y por tanto el medicamento 2 ha obrado algún efecto sobre los sujetos.

La significación estadística depende principalmente de tres variables: la diferencia entre las dos variables (a mayor diferencia, más probable es obtener un resultado estadísticamente significativo), y el tamaño de la muestra (a mayor tamaño de muestra, más fácil es detectar diferencias). También depende de la variabilidad de la respuesta (a mayor variabilidad entre las respuestas, más difícil será detectar una diferencia)

En los siguientes apartados, se describen las características de las muestras que aconsejan el uso de unos tests u otros, así como los tests de contraste de hipótesis utilizados en el desarrollo de esta tesis.

\subsubsection{La importancia de la normalidad de las muestras}

Existen muchos pruebas de contraste de hipótesis diferentes: $t$ de Student, Mann-Whitney o Kolmogorov-Smirnov son algunos ejemplos. El test de contraste de hipótesis que debe usarse en una situación determinada depende, entre otras cosas, de si las muestras presentan o no una distribución normal.

Las pruebas de contraste de hipótesis que comparan entre sí muestras normales se denominan tests paramétricos. En los tests paramétricos, se conoce el modelo de distribución de la población objeto de estudio (normalmente, se ha demostrado que es una distribución normal), y se 
desconocen algunos parámetros que se desea estimar a partir de los datos de la muestra.

Los tests que estudian muestras cuya distribución es diferente a la normal o con un número de datos pequeño, se denominan tests no paramétricos. En los tests no paramétricos, no se requiere conocer la distribución de la muestra, y al utilizarlos, se trabaja con estadísticos que no dependen de la distribución.

Tanto unos tests como otros son simples de usar y están disponibles en cualquier programa informático de cálculo estadístico, pero los no paramétricos son menos potentes (es menos probable que el test encuentre diferencias aunque las haya) que los establecidos para muestras normales. Por eso, el sistema habitual es utilizar los tests paramétricos siempre que sea posible, y los no paramétricos como la única alternativa cuando los primeros no son aplicables. En esta tesis, todos los cálculos estadísticos se han realizado con el programa IBM SPSS Statistics 19.

\subsubsection{Muestras relacionadas y muestras independientes}

El uso de unos tests u otros depende de si las muestras que se comparan presentan una distribución normal, pero también de si las muestras son independientes entre sí o están relacionadas.

Se dice que dos o más muestras son independientes entre sí cuando provienen de grupos diferentes (por ejemplo, las notas de una asignatura determinada de distintos grupos de estudiantes de un mismo nivel educativo). Se dice que las muestras están relacionadas cuando provienen de un mismo grupo (por ejemplo, las notas de dos asignaturas diferentes de un mismo grupo de estudiantes).

En la Tabla 2.5 se muestra un resumen de los tests que se van a utilizar en esta tesis en cada uno de los casos contemplados previamente.

Tipo de test a usar en función de las características de las muestras

\begin{tabular}{ccc}
\hline & Muestras independientes & Muestras relacionadas \\
\hline Distribución normal & T-test & T-test \\
\hline Otras distribuciones & Mann-Whitney & Wilcoxon \\
\hline
\end{tabular}

Tabla 2.5. Tests de contraste de hipótesis 


\subsubsection{Tests de normalidad}

La propia normalidad de una muestra se puede estudiar mediante dos tipos de prueba no paramétrica de contraste de hipótesis, llamadas test Kolmogorov-Smirnov y test de Shapiro-Wilk. Estas pruebas son sensibles a cualquier diferencia entre las dos poblaciones, no sólo en cuanto a la tendencia central sino también en cuanto a su forma. Para muestras pequeñas $(\mathrm{N}<50)$, se considera que el test de Shapiro-Wilk es el más robusto.

Es necesario pasar un test de normalidad a las muestras antes de cualquier otro, dado que del tipo de distribución depende la idoneidad de cada test para el estudio de las muestras.

En el test de Shapiro-Wilk, la hipótesis nula HO es que la muestra presenta una distribución normal, y por lo tanto, si el resultado del test es un p-valor mayor a 0,05 , se puede considerar que la muestra es normal.

El test de Kolmogorov-Smirnov determina la bondad del ajuste de dos distribuciones de probabilidad entre sí; si una de ellas es una distribución normal, permite averiguar si la muestra estudiada proviene de una población con ese tipo de distribución.

\subsubsection{Test $t$ de Student}

La prueba $t$ de Student es una prueba de contraste de hipótesis que puede utilizarse para comparar entre sí tanto muestras independientes como muestras relacionadas, siempre y cuando ambas tengan una distribución normal. La hipótesis nula $\mathrm{HO}$ en la prueba $\mathrm{t}$ es que las dos muestras comparadas tienen la misma media. Esta hipótesis se rechaza en el caso de que $p$-valor $\leq 0,05$, aceptándose en caso contrario.

La prueba $\mathrm{t}$ funciona del siguiente modo: si ambas muestras son similares, las diferencias entre ellas deberían ser aproximadamente normales también, y de media 0 . Si al calcular la media de las diferencias, el resultado no es consistente con una media de 0 , se rechaza la hipótesis nula.

\subsubsection{Test de Wilcoxon}

La prueba de Wilcoxon es una prueba de contraste de hipótesis que sirve para comparar entre sí dos muestras relacionadas. Es una prueba no paramétrica, que se puede utilizar para cualquier tipo de curva, no 
necesariamente normal. Este test compara entre sí las medianas de las dos muestras, y determina si su diferencia se debe o no al azar.

La prueba de Wilcoxon es menos exigente que la t de Student, por lo que sólo debe utilizarse si no puede usarse aquélla. En este caso se calculan las diferencias entre cada par de datos relacionados de ambas muestras. El test considera que, en caso de ser cierta la hipótesis nula, las diferencias negativas serían similares a las positivas, y mide la discrepancia del resultado con esa suposición.

La hipótesis nula se rechaza, como siempre, si $p \leq 0,05$. Es decir, queda demostrado que la diferencia entre dos muestras relacionadas es estadísticamente significativa cuando el resultado del test de Wilcoxon es un p-valor menor a 0,05.

\subsubsection{Test $U$ de Mann-Whitney}

La prueba de Mann-Whitney es una prueba de contraste de hipótesis para la comparación de dos muestras independientes. Como la anterior, es una prueba no paramétrica, válida para todo tipo de distribuciones. La hipótesis nula en este caso es que las dos muestras provienen de poblaciones idénticas; la hipótesis alternativa puede ser unilateral o bilateral y supone que la tendencia central de una población difiere de la otra, sin diferencias de forma o dispersión.

\subsubsection{La economía experimental aplicada al campo energético}

La economía experimental se ha estado utilizando para el estudio en el ámbito de la energía durante aproximadamente los últimos 40 años. Seguidamente se refieren distintos experimentos descritos en la literatura al respecto, que pueden clasificarse en dos categorías principales: experimentos en laboratorio y experimentos de campo. En general, cuatro son los aspectos básicos del campo de la energía que han sido o están siendo estudiados por la economía experimental en laboratorio: el diseño óptimo de los mercados eléctricos, la respuesta de la demanda, el papel de los mercados de futuro, y el desempeño de las diferentes formas posibles de subasta del mercado eléctrico diario.

Dentro de la categoría de experimentos de laboratorio, en [3] se describe un experimento de simulación acerca de la influencia de la respuesta 
de la demanda en el mercado eléctrico, para mostrar las variaciones en el equilibrio del mercado cuando se da en él un papel activo a la demanda. Para ello, se testearon en laboratorio tres entornos: uno de control, con precios fijos, y dos variaciones sobre precios dinámicos: un sistema de precios en tiempo real y uno de reducción de precios en horas punta cuya aparición se anunciaba con cierta antelación. La conclusión principal es que, con precios en tiempo real, los precios de la energía se aproximan a su óptimo teórico, mientras que, con el otro sistema, se reducen pero no con tanto éxito. En otro experimento del mismo autor [4], se estudia el efecto de distintas combinaciones de entornos tanto del lado de la demanda como del lado del suministro, pero con las conclusiones enfocadas también al lado de la demanda. En [13], se estudia el comportamiento de los consumidores ante dos diferentes formas de construcción de precios: precios dinámicos con descuentos por no consumir en horas pico, y precios dinámicos con sanciones por consumir en horas pico. El tratamiento 0 era de precio fijo. Sus hallazgos principales son dos: primero, que el sistema de precios dinámico es más eficiente que el fijo, y segundo, que los escenarios con sanciones son más efectivos en la reducción de las puntas de demanda que aquéllos en los que intervienen incentivos, pese a que no son los preferidos por los consumidores.

Siguiendo con los experimentos de laboratorio, en este caso enfocados al estudio de los posibles diseños del mercado eléctrico, en [108] se describen una serie de experimentos llevados a cabo en distintos países (Australia, Nueva Zelanda, Estados Unidos). Todos ellos consisten en el estudio de la viabilidad de diferentes formas de organización de un mercado eléctrico desregulado, descentralizado y/o privatizado, explorando en laboratorio si su funcionamiento es más eficiente que uno regulado.

El primero de ellos transcurre en Arizona, en 1984. la "Arizona Corporation Commission" (ACC) solicitó un estudio sobre desregulación del sector eléctrico. En este estudio, se aplicaron por primera vez experimentos económicos en sistemas eléctricos. El resultado de la investigación concluyó que era posible llevar a cabo la descentralización de las funciones del sistema eléctrico.

En [24] se describen una serie de experimentos de laboratorio con el objeto de estudiar cómo afecta la existencia de un mercado de futuros al funcionamiento del mercado al contado, llegando a la conclusión de que la introducción de un mercado de futuros reduce los precios. 
Otras investigaciones experimentales aplicadas a los mercados eléctricos, consistieron en distintos diseños de mercado para el Operador Independiente del Sistema de Nueva York. Las investigaciones se centraron en verificar el rendimiento de mercados que incorporan las restricciones técnicas de la red de transporte, tanto en la producción como en la entrega de la electricidad [123]

En cuanto a las comparativas entre distintas formas de subastas (doble continua, doble de precio uniforme, con regla de última oferta aceptada, con regla de última oferta rechazada, con diferente número de vendedores, con tope de precios o con y sin respuesta de la demanda), pueden revisarse, entre otros, [1], [101], [131].

Dentro la segunda categoría, los experimentos de campo, [14] realizó un experimento interesante, diseñado para determinar los efectos de diversas políticas sobre el consumo energético de los hogares. Se experimentó con los siguientes sistemas: elaboración de un folleto sobre medidas de ahorro energético, un feedback semanal del consumo del hogar, y una variación en el precio de la energía. Esta variación se obtuvo a base de devoluciones monetarias en función del desempeño de los hogares (reducciones de su consumo con respecto al mismo periodo del año anterior), que se consideró equivalente a la imposición de un sistema de escalones en los impuestos en función del desempeño logrado. Los resultados finales de este experimento mostraron que las políticas que envolvían modificaciones de precios obtenían mejores resultados que las informativas.

En cuanto al establecimiento de precios dinámicos, en 2010 se realizó una revisión exhaustiva de los más recientes experimentos de campo en este ámbito [56]. Como resumen de la revisión, que abarcó 15 experimentos diferentes, se llega a la conclusión de que la disminución de consumo, siempre hablando de la punta de carga y no del total de energía consumida, varía notablemente de unos ensayos a otros, principalmente en función del diseño del sistema de precios dinámico (tipo discriminación horaria o uso en tiempo real, número de escalones, variación de precios entre unas y otras, etc), la presencia o no de sistemas de climatización, e incluso la localización geográfica del experimento.

En resumen, en lo que se refiere al ámbito energético, la economía experimental en laboratorio se destaca como una herramienta más para la 
mejora de la comprensión de las políticas regulatorias, el funcionamiento de los mercados o la influencia relativa de los lados de la demanda y del suministro. Sus características de simpleza, rapidez y bajo coste ofrecen la oportunidad de analizar sin restricciones cuestiones tan complejas como el funcionamiento de las subastas, los mercados de futuros o el impacto de grandes cambios estructurales como la liberalización del mercado.

Los experimentos de campo, por su parte, y siempre en el ámbito energético, se han enfocado a temas principalmente relacionados con el comportamiento de los consumidores, un ámbito lo suficientemente simple, dentro de su complejidad, como para poder aislar de forma relativamente eficaz una variable determinada y poderla manipular en un entorno real. 


\section{Brechas, barreras y políticas de eficiencia energética en el sector doméstico: estado del}

\subsection{La brecha de la eficiencia energética}

La teoría económica tradicional postula que las decisiones tomadas por los seres humanos tienen un carácter puramente racional. Según esa teoría, y con el suficiente conocimiento de una situación determinada, la persona actuará de la forma que obtenga un resultado óptimo.

Basándonos en este principio, se supone que los ciudadanos, correctamente informados de las ventajas del ahorro energético y de cómo conseguirlo, reducirán su consumo.

Sin embargo, pese al incremento en el conocimiento del uso de la energía, a una actitud positiva frente al ahorro, y a la manifestada intención de ponerlo en práctica, los ciudadanos continúan en la práctica sin tomar medidas ni cambiar comportamientos relacionados con su consumo energético. No se trata simplemente de que los usuarios persigan intereses egoístas aunque 
hablen como personas altruistas, ya que este fenómeno aparece incluso cuando las mejoras energéticas benefician al usuario en términos económicos.

La discrepancia claramente observable entre el comportamiento presumible y el real de los usuarios de la energía eléctrica se conoce con el nombre de "energy efficiency gap" (brecha de la eficiencia energética). Una definición más precisa es ésta: es la diferencia entre el nivel actual de inversión en eficiencia energética, y el nivel calculado como de óptimo beneficio desde el punto de vista del consumidor [28].

En el debate actual sobre la eficiencia energética, el efecto de la mayoría de las medidas políticas que se aplican está basado en cálculos estimativos sobre los ahorros potenciales. Siendo así, necesariamente la respuesta conductual de las personas tiene que ser incorporada a este tipo de cálculos, para no sobreestimar los ahorros, para que los modelos sean más realistas y para que aumente la eficacia de las políticas energéticas [11].

En resumen, cualquier iniciativa política enfocada a la reducción del consumo energético debe tener en cuenta tanto la vertiente técnica del programa como la humana. A día de hoy, se han hecho y se están haciendo grandes esfuerzos en lo que se refiere a las mejoras técnicas tanto del equipamiento de la vivienda como en lo que se refiere a cerramientos, en muchos casos subvencionados por los estados; sin embargo, los incentivos para los cambios de comportamiento apenas aparecen en las directivas europeas relativas a la eficiencia energética.

En los siguientes apartados se describen, en este orden, las principales barreras de las que se nutre la brecha en la eficiencia energética, las barreras estructurales y conductuales que debe superar quien se enfrente a ella, y las distintas políticas que se están aplicando a nivel mundial para suprimirla. En estos dos últimos casos, los apartados están enfocados principalmente al sector residencial, objetivo principal de la tesis.

\subsubsection{Fuentes de la brecha}

Las fuentes que dan lugar a la brecha de la eficiencia energética son fundamentalmente tres: el llamado rebound effect, el free-rider effect, y, por último, el pre-bound effect ([21], [111], [66]). Todos ellos son descritos en este apartado. 
A estos tres efectos suele sumarse un cuarto problema, no menos importante, que viene del hecho de que la mayor parte de las evaluaciones se hacen sobre consumos estimados, no medidos [111]. Este hecho de por sí ya puede llevar a errores considerables entre las estimaciones y los hechos, no necesariamente debidas a una discrepancia real en los resultados. En la mayoría de las evaluaciones que juzgan el éxito o fracaso de determinada política, distintos autores tienen en cuenta diferentes variables, dan importancia a distintos aspectos del problema e interpretan de forma diferente los resultados. En resumen, la inexistencia de un proceso estandarizado de cálculo de los ahorros obtenidos resta credibilidad a las conclusiones de casi todos los estudios.

1.- Efecto rebote (Rebound effect). Las personas obtienen utilidad no de la energía en sí sino de aquello para lo que la emplean. Así que, cuando la eficiencia energética aumenta, con la consiguiente disminución del precio por uso, el efecto final es que los usuarios aumentan el consumo energético para aumentar la utilidad sin modificar el precio original. A esto se le ha dado en llamar "rebound effect" [11].

Se distinguen dos tipos de efecto rebote. En el primero, una innovación tecnológica hace que un producto sea más eficiente sin invertir más dinero; en el segundo, se mejora a propósito la eficiencia energética de un producto por necesidad y a cambio de invertir dinero en él (por ejemplo un cerramiento). [66]. En el segundo caso, al aumentar el precio del producto al tiempo que se disminuye sus costes posteriores en energía, el cálculo del efecto rebote se complica.

Desde otro punto de vista, el efecto rebote se divide en rebote directo (aumentar el consumo del bien que se abarata), y el indirecto (aumentar el consumo de otros bienes que supongan un consumo adicional de energía). Ambos procesos provienen del mismo fenómeno, explicado habitualmente a través de la curva de la demanda. Al disminuir el precio de un producto, o bien se aumenta su consumo o bien se dedica el dinero extra a aumentar el consumo de otro bien, hasta alcanzar un nuevo equilibrio en el balance precio / satisfacción.

La cuantificación del efecto rebote es extremadamente compleja, dado que es una relación entre lo que es (una magnitud relativamente fácil de conocer) y lo que debería ser (una magnitud que, en el mejor de los casos, es 
especulativa, cuando no directamente imposible de averiguar con una precisión razonable). La medida de lo que debería ser necesariamente está basada en estimaciones.

Aún así, se encuentran en la literatura diversos estudios que intentan la cuantificación aproximada de este efecto, principalmente centrados en climatización de la vivienda. En este caso, es relativamente fácil obtener una estimación del uso óptimo de la energía, basándose, por ejemplo, en su índice de eficiencia energética. Algunos ejemplos son:

En la referencia [71], los autores estiman un efecto rebote de entre un 20 y un $30 \%$ en un ensayo llevado a cabo sobre calefacción en 500 viviendas en Austria; en el texto [74] se describe un estudio sobre 79 viviendas que habían recibido asistencia financiera para la mejora de la calefacción de sus viviendas. El resultado es que efectivamente las viviendas redujeron su consumo, pero al mismo tiempo aumentaron, de media, 1ㅇF la temperatura de su termostato. Por lo tanto, se perdió alrededor de un $10 \%$ del ahorro potencial. Para la toma de datos, se analizaron las facturas eléctricas.

La referencia [90] describe un estudio, también solo sobre calefacción, sobre 11.000 viviendas en Alemania. En este caso, el estudio se hace a partir de la temperatura interior / kWh consumido. Sus conclusiones son dos:

- El nivel de ingresos influye en el efecto rebote, siendo éste mayor (49\%) para alquilados, considerados de ingresos bajos, que para propietarios, (12\%), considerados de ingresos altos

- Este hecho debe tenerse en cuenta a la hora de aplicar políticas de eficiencia energética destinadas a un tipo u otro de ciudadanos.

Un estudio de relevancia por el número de viviendas implicado es el que se describe en [11]. Se llevó a cabo en Holanda, sobre un conjunto de 560.000 viviendas, estudiando las diferencias encontradas entre la estimación teórica de consumo, dada por el índice de eficiencia energética de la vivienda, y el consumo real de ésta (sólo en términos de calefacción de la vivienda). Sus datos muestran que,

- Conforme el coste de calefactar disminuye, la diferencia entre la estimación teórica y el consumo real aumenta a favor del segundo, confirmando el efecto rebote. 
- Existen diferencias apreciables (27\%/41\%) entre el efecto rebote de propietarios y alquilados: el efecto es menor en las viviendas más ricas

- Al diseñarse una determinada política de eficiencia energética, debe tenerse en cuenta las características del grupo al que se destina.

Como media, el efecto rebote osciló entre un $41,3 \%$ para alquilados y un $26,7 \%$ para propietarios. Con esto deducen que el efecto es mayor en los consumidores con rentas más bajas, que son los que no han alcanzado aún su nivel de confort ideal. En esto coincide con otro experimento nombrado previamente [90] .

Pese a los resultados descritos hasta ahora, la magnitud del efecto rebote es un debate que persiste. La literatura al respecto va siendo considerable, pero en general es confusa y los términos de los que habla no terminan de estar perfectamente definidos. Además, las conclusiones numéricas en general o son poco fiables o no lo suficientemente globales. En general, se estima a nivel microeconómico efectos rebote que podrían oscilar entre el 20 y el $40 \%$, mientras que a nivel macroeconómico no existen estudios lo suficientemente profundos como para dar siquiera una estimación. [66].

Tampoco está suficientemente estudiada la magnitud relativa del impacto de las diferentes variables que influyen en él, tales como los ingresos medios de las familias. Identificar las variables de las que depende puede ayudar a refinar las políticas de eficiencia energética. Es posible que se esté dando a ciertas variables (como la superficie de la vivienda, el salario o el propio valor de la vivienda) un peso que, en realidad, no tienen. En la referencia [91] se estudia esta posibilidad en el ámbito de la calefacción de la vivienda.

Incluso hay autores que argumentan que el efecto rebote es sólo un componente de la eficiencia energética, de efectos muy variables y que, en realidad, deben computarse como una ganancia y no una pérdida. Puede ser en forma de innovación inducida (por ejemplo un sector que, al ver la mejora de uno próximo, mejora a su vez sus propios procesos) o crecimiento de la productividad; incluso si no es así, siempre se traduce en un aumento del bienestar, por lo que hay quien lo considera un beneficio y no una pérdida.

2.- Free-rider effect. Los free-riders son personas que habrían realizado las mejoras necesarias en eficiencia energética incluso en ausencia de 
subvenciones. La inversión que se realiza al subvencionarles se considera por ello una pérdida.

Si ya es difícil la cuantificación del efecto rebote, más complicada aún es la de este efecto, aunque existen algunos ensayos que lo hacen. Por ejemplo, en [85] se estima que hasta el $80 \%$ de los ahorros energéticos de ciertos programas provienen de free riders; según [88] entre el $50 \%$ y el $90 \%$ del ahorro es obtenido por free riders. En un estudio llevado a cabo en Estados Unidos, a partir de 40 programas de eficiencia energética llevados a cabo por distintas empresas, [53], se estiman pérdidas por efecto free-rider de entre un 0 y un $50 \%$ según el programa estudiado, con una media ponderada de un 12 $\%$.

La forma de medir este efecto es, en la mayoría de las ocasiones, mediante encuestas posteriores a la toma de decisiones en materia energética, por ejemplo preguntando si habrían tomado la misma medida en ausencia de subvenciones. En otros ensayos, como el que se describe en la referencia [92], el estudio se realiza por comparación de los consumidores implicados con otros de características similares sin acceso al programa de eficiencia energética.

3.- Prebound effect. Este efecto, descrito de forma muy reciente, consiste en la discrepancia hallada entre los valores estimados de consumo de energía de calefacción (a través del índice de eficiencia energética en la vivienda), y los reales. Es, en este caso, un problema que puede hacer sobrestimar los ahorros obtenidos con cualquier política de ahorro, si basa sus estimaciones en esos índices.

El estudio [11] afirma que el índice de eficiencia energética sobrestima las necesidades de calefacción, en aproximadamente un $16 \%$. Su sistema de cálculo consiste en la comparación de los índices con las facturas de gas.

Otro artículo que revela la existencia de este problema es el [121]. En él se describe un experimento llevado a cabo en Alemania, sobre 3400 viviendas, calculando la diferencia entre el consumo estimado por el índice y el consumo real medido. Como media, se hallaron diferencias de un $30 \%$ entre unos y otros, siendo menor el real que el estimado. 


\subsection{Barreras a la eficiencia energética}

El control del consumo energético se enfrenta a muchos obstáculos, que en general, por impedir alcanzar resultados energéticamente óptimos, se conocen con el nombre de barreras. Por una parte se encuentran las barreras estructurales y por otra las conductuales [110].

Para que las políticas de eficiencia energética tengan éxito, deben estar diseñadas de forma que minimicen las barreras estructurales y conductuales descritas en este apartado, y hacerlo de forma que los beneficios asociados a su aplicación superen los costes de implementarlas.

\subsubsection{Barreras estructurales}

Las barreras estructurales son defectos del mercado y obstáculos de tipo político sobre los que el usuario no tiene control, pero que influyen en sus decisiones y su comportamiento en las cuestiones energéticas.

En la literatura se nombran las siguientes barreras estructurales: ([118], [26], [110], [28]):

\subsubsection{Fallos del mercado.}

El primero de ellos es la falta de información sobre, por ejemplo, costes en tiempo real de la energía consumida, o consumo real, o tecnologías de energías renovables. La impredictibilidad de los precios hace que cualquier cálculo de, por ejemplo, el periodo de amortización de una inversión, sea inseguro para los pequeños consumidores.

El segundo se refiere al problema de la financiación: los tiempos de retorno de las inversiones en materia energética suelen ser excesivamente largos para ser acometidas por familias con ingresos medios.

El tercer problema, muy nombrado en la literatura, se suele denominar incentivos inapropiados o el problema del agente principal [28]. Consiste en la falta de discriminación a la hora de ofrecer incentivos económicos a los usuarios por parte de los gobiernos o las empresas; si no se personalizan para el tipo de usuario que los necesita, no pueden tener éxito. Hay múltiples ejemplos de ello: los dueños compran los electrodomésticos pero los alquilados pagan las facturas, por lo que los dueños no están incentivados a la compra de electrodomésticos eficientes; los constructores abaratarán el precio 
de la vivienda cuanto puedan, en vez de elegir los cerramientos o los sistemas de calefacción mejores aunque un poco más caros que elegirían los futuros dueños. Ocurre lo mismo con las cocinas de las viviendas de nueva construcción, que ya vienen con los electrodomésticos, seleccionados por la constructora principalmente por su precio y no por su eficiencia.

En la referencia [102] se describe un estudio relativo a este problema con respecto a cuatro usos finales de la energía en la vivienda: calefacción, refrigeración de alimentos, ACS e iluminación. Su forma de calcular la desviación del óptimo consiste en utilizar diversas bases de datos de tamaños de vivienda, tipo de equipamiento instalado en ella, valores medios de los consumos de éstos, y valores medios de los consumos de sus equivalentes energéticamente eficientes. Sus conclusiones son las siguientes: $25 \%$ de refrigeradores, $66 \%$ de sistemas de ACS, $48 \%$ de sistemas de calefacción y $2 \%$ de sistemas de iluminación están afectados por este problema.

El cuarto problema a considerar, último pero no menos importante, es la cuestión de las externalidades o costes no computados. Esto se refiere a las pérdidas asociadas con el uso de fuentes no eficientes, y que no constan en los balances económicos. [65]. Un ejemplo de ello es el coste social y medioambiental asociado a los combustibles fósiles: la ausencia de políticas regulatorias lleva a un sobreuso de energías polucionadoras. Se aconseja que, mediante políticas regulatorias, se internalicen esos costes ocultos para desincentivar el uso de este tipo de fuentes.

Otros costes no computados que deberían encarecer ciertas fuentes de energía son los siguientes: el problema de la dependencia de las importaciones, el de la diversificación limitada, los precios volátiles de la energía y los riesgos de seguridad que pueden afectar a los países productores y a los de tránsito, sobre todo si pertenecen a regiones con problemas de estabilidad.

\subsubsection{Barreras del mercado}

Las barreras del mercado, o falta de incentivo a la adopción o uso de un bien o servicio, se refieren principalmente a dos cuestiones. Por una parte, están relacionadas con la dificultad de acceso al capital por parte de los pequeños usuarios, al que se une la incertidumbre creada por la variabilidad del precio de la energía y del marco regulatorio relacionado con ella. 
Por otra parte, tienen que ver con la baja prioridad por las cuestiones energéticas por parte de los usuarios, dado que su precio es relativamente bajo comparado con otros bienes. En realidad, este bajo precio es artificial por varias razones: en primer lugar, porque no internaliza los costes medioambientales y de seguridad nombrados anteriormente; en segundo lugar, porque los precios se mantienen artificialmente bajos para proteger a la población con pocos recursos, y porque las tarifas reguladas impiden a los usuarios conocer los precios verdaderos [86].

\subsubsection{Obstáculos políticos y regulatorios.}

El marco regulatorio varía de forma inconsistente, por lo que los resultados de las inversiones no están garantizados en el medio plazo, lo que disuade a los posibles inversores. En España se pueden nombrar dos casos muy claros de este problema: el primero, la desaparición de la tarifa nocturna en el 2008, dejando a muchos usuarios sin poder amortizar las inversiones que hicieron para adaptarse a ella, y el segundo, la penalización al autoconsumo del 2015

\subsubsection{Barreras conductuales}

Las barreras conductuales se relacionan con la forma de ser de los seres humanos, y con el hecho de que, en muchos casos, su forma de actuar se desvía de la solución óptimamente eficiente.

Estas barreras son el objeto de estudio de la teoría de la economía conductual. En ella se detectan y describen varias tendencias del ser humano que tienen que ver con las desviaciones del comportamiento racional observadas, y son las que se enumeran y describen en este apartado. ([58], [65]).

Las barreras estudiadas por la economía del comportamiento afectan al comportamiento energético en dos vertientes relativamente independientes. Por una parte, influyen sobre las decisiones a la hora de invertir capital para el aumento de la eficiencia, sea en la adquisición de equipamiento más eficiente o en mejoras en la vivienda; por otra parte, influyen sobre la forma en la que el equipamiento, sea nuevo o usado, es utilizado. 


\subsubsection{Prospect theory o teoría prospectiva.}

Esta teoría describe cómo las personas toman sus decisiones en situaciones donde tienen que decidir entre alternativas que involucran riesgo. Dentro de la teoría prospectiva se habla de diversos fenómenos, tales como:

La procrastinación (status-quo bias) es la tendencia a diferir decisiones para hacer cambios, sobre todo cuando la complejidad de la información es grande y el tiempo invertido se prevé largo. También se interpreta como la costumbre de mantenerse en la opción por defecto, o el punto de referencia desde el que se juzga cualquier alternativa.

La aversión a la pérdida (loss aversion) consiste en dar más importancia a la inversión necesaria que a la ganancia futura obtenida de esa inversión. Es decir, si la ganancia fuera igual a la pérdida, se valoraría como más importante la pérdida. Un ejemplo de aversión a la pérdida es el siguiente: desde principios de los 80 se tenía la posibilidad de elegir balastos electrónicos en vez de convencionales para la iluminación fluorescente; sin embargo, y pese a que el periodo de amortización de la inversión era de menos de 2 años, tres cuartas partes de la población lo ignoró [84].

La aversión al riesgo (risk averse) es la tendencia, cuando la decisión a tomar conlleva un cierto riesgo de pérdidas, a preferir evitar un riesgo con probabilidad baja que afrontarlo con altas probabilidades de éxito. Esta tendencia es variable con el monto de la inversión original y del beneficio probable.

La reacción a recompensas $e$ incentivos (rewards and incentives) se refiere a que la respuesta conductual es mayor cuanto mayor es el incentivo aplicado. Sin embargo, la desaparición del incentivo conlleva la desaparición de la respuesta.

El Menosprecio temporal (temporal discounting) consiste en menospreciar un beneficio si éste se verá únicamente en el largo plazo. Esto se manifiesta en la preferencia por un beneficio pequeño pero inmediato a uno mayor pero más dilatado en el tiempo, o en la aversión a afrontar una inversión pequeña inmediata aunque en el futuro el beneficio acabe superando ampliamente a la inversión 


\subsubsection{Racionalidad limitada (bounded rationality)}

La racionalidad limitada es la inclinación, sobre todo en casos en los que la cantidad o complejidad de información adecuada es elevada, a escoger no la decisión óptima sino la primera válida para satisfacer los requerimientos mínimos deseados. En [106], se explica como una especie de sobrecarga cuando el número de opciones a elegir es excesiva. Un ejemplo es el ensayo descrito en [81] , en el que se compraba más un determinado bien cuando se daba a elegir entre 6 opciones que cuando se daban 24 opciones.

\subsubsection{El sesgo informativo (availability bias)}

Esta característica consiste en basar las decisiones en los testimonios fácilmente accesibles, sea por cercanía al usuario, por proximidad en el tiempo, o porque se han ido almacenando en la memoria y se tiene fácil acceso a su recuerdo. Suele ser una forma tendenciosa de tomar decisiones, dado que tiende a sobreestimar la frecuencia con la que aparece alguno de los casos.

\subsubsection{Respeto por las normas sociales (conform to social norms),}

Esta característica se manifiesta de dos formas diferentes. En primer lugar, consiste en la tendencia a aceptar y seguir normas aprobadas por la sociedad, y en segundo lugar, describe el hecho de que las personas tienden a evaluar su forma de actuar, sus posesiones o su bienestar no en términos absolutos sino relativos a los otros.

\subsection{Recursos para la corrección de barreras estructurales}

En este apartado, se presentan distintas alternativas para la corrección, o al menos la minimización del problema de las barreras estructurales para la disminución del consumo energético. Aunque parte de las barreras que se comentan en este apartado se ven también influenciadas por problemas del comportamiento, se ha intentado, en la medida de lo posible, independizar unos efectos de otros.

\subsubsection{Información del coste de la energía}

El hecho de que, al menos hasta ahora, el usuario pague un precio medio de la energía en vez de ver reflejado las oscilaciones de precio de ésta a 
lo largo del día, es un fallo de información de cara al usuario, que no puede optimizar su uso sin conocer estos precios. El precio por hora de la energía depende del mix necesario en cada momento del día, y viene reflejado por el precio de la energía más cara que es necesario utilizar en esa hora para cubrir la demanda nacional de energía. Es evidente que el usuario genera un sobreuso de la energía en las horas más caras y una falta de uso en las más baratas, siempre y cuando no conozca o no se le valore en la factura el momento de uso de la energía.

Para reflejar esos precios existen diferentes modos, que normalmente se resumen en dos: discriminación horaria (Time-of-Use TOU), y precio en tiempo real (Real-Time-Pricing, RTP). Hasta hace bien poco, era imposible aplicar a gran escala el RTP, dado que requiere del uso de contadores inteligentes; hoy en día está en período de implantación junto con la gradual penetración de estos contadores.

Existe una extensa bibliografía relativa al alisamiento de la curva de la demanda, lograda a base de tarifas de precios dinámicos (dinamic pricing) usando smart meters como sistema de información. En este caso se dan ahorros significativamente grandes en los picos, aunque también se reportan reducciones en los totales. Por ejemplo, en la referencia [33] se describe, en el transcurso de un experimento con smart meter en Irlanda entre 2009 y 2010, en el que se obtuvieron ahorros totales de alrededor de un $2,5 \%$, con puntas en las horas pico de hasta un $8,8 \%$. Otros experimentos similares se describen en la referencia [55] durante 2008-2009, con reducciones de pico de entre un 18 a un $33 \%$, usando como smart meter el Energy Orb. Existen también revisiones completas de experimentos anteriores, como la de [40], con resultados que oscilan, en los picos, entre el 5 y el $27 \%$ de reducción.

Algunos autores sugieren [119] que la reducción del gasto monetario conseguida mediante sistemas relacionados con la respuesta de la demanda incentivan además la compra de equipamiento más eficiente, ya que el mayor precio de estos elementos se ve compensado, en el largo plazo, por la reducción subsiguiente de la factura eléctrica

\subsubsection{Internalización de externalidades}

Se aconseja que, mediante políticas regulatorias, se internalicen los costes ocultos medioambientales de ciertas fuentes de energía para 
desincentivar el uso de este tipo de fuentes. Esto se puede conseguir imponiendo tasas a la tonelada de $\mathrm{CO}_{2}$ generada durante la extracción, producción, distribución y consumo de estos bienes [65].

Un ejemplo de ello es la imposición de un impuesto extra a los productos poco eficientes. Por ejemplo, en Portugal se ha establecido un impuesto que grava las lámparas poco eficientes (Decreto-Ley n.ㅇ 108/2007 de 12 de abril).

En la Unión Europea, se potencian las energías renovables frente a las convencionales usando, en parte, este sistema. Se conoce con el nombre de cuota obligatoria de certificados verdes, y se aplica en Suecia, Polonia, Rumanía, Reino Unido e Italia. Consiste en que los emisores contaminantes se ven obligados a comprar estos certificados, que son otorgados a los productores de energías renovables, que obtienen a través de ellos un ingreso adicional. Otros países gravan con impuestos las energías contaminantes, eximiendo de los pagos a las renovables.

\subsection{Recursos para la corrección de barreras conductuales}

La personalidad humana tiene las características enumeradas por la economía del comportamiento. Pueden ser, y de hecho son, un impedimento para la optimización de la eficiencia, pero también pueden ser aprovechadas en beneficio de ésta, siempre y cuando se utilicen adecuadamente y se diseñen las políticas de eficiencia energética teniéndolas en cuenta. Algunos ejemplos de esto pueden verse en los apartados siguientes.

\subsubsection{Minimización de la procrastinación}

En la medida de lo posible, las políticas deben pensarse de forma que subrayen las prácticas de ahorro que menos esfuerzo y cambio supongan a los usuarios [58]. Son especialmente interesantes las pequeñas modificaciones que se puedan dejar programadas por defecto (por ejemplo, animar a dejar las lavadoras, por defecto, en programas cortos y temperaturas bajas), o a cambiar el setting del televisor, que por defecto suele estar en pantalla demasiado brillante, que es como les gusta ponerlo en las tiendas de venta de electrodomésticos para que destaquen más mientras se encuentran en exposición. 
Un buen método para luchar contra la procrastinación es usar estrategias de compromiso (commitment devices). Por ejemplo, en la referencia [15], se describe un experimento de campo relativo a la eficacia del compromiso por parte de los abonados, en el que se obtuvieron reducciones de entre un 16 y un $25 \%$ entre los que se comprometieron a reducir un $20 \%$ su consumo (utilizando feedback como herramienta de ayuda).

\subsubsection{Recompensas e incentivos}

Sabemos que el comportamiento de los individuos está fuertemente influenciado por motivos económicos [95]: ahorrar dinero es un mensaje más atractivo, o al menos más poderoso, que el medioambiental. Por eso los métodos financieros tienen mucha fuerza en la consecución de los objetivos. Es conveniente, para que las campañas de reducción de consumo energético tengan el mayor éxito posible y sobre todo una permanencia superior a la duración del incentivo económico, unir a éste un mensaje emocional, asociado a las normas sociales comúnmente aceptadas, que aumente la persistencia del efecto [38]. El mensaje básico debería ser, por tanto, "vas a ahorrar energía y dinero" [35]

Una idea interesante es la que se describe en [21]. En este documento, el autor propone adjudicar a cada ciudadano una tarjeta con un número determinado de toneladas de $\mathrm{CO}_{2}$; cada vez que se compre electricidad, gas, gasolina o cualquier otro tipo de fuente energética, se resta de la tarjeta. Cuando ésta se acabe, se puede seguir comprando pero a un precio más caro; del mismo modo, el que tenga de sobra podría venderla. También se sugiere esta idea, (puntos para tarjetas-regalo o similar son efectivos en la modificación del comportamiento), en [38].

\subsubsection{Eliminación de la racionalidad limitada}

Debe procurarse simplificar tanto el mensaje por parte de las entidades como la acción necesaria por parte del usuario [58]. En el primer caso, esto quiere decir que es importante que la información sea simple, relevante y destacada antes que detallada y técnica [128]. En el segundo caso, podría aplicarse por ejemplo a través de la automatización de los elementos más complejos, como por ejemplo los termostatos o el encendido automático de diversos electrodomésticos en función del periodo tarifario. 
La empresa Con Edison (distribuidores en New York City y Westchester County), llevó a cabo durante el año 2015 entre sus clientes [35] un estudio de eficiencia. Su intención, entre otras, era estudiar y buscar soluciones válidas a algunas barreras que se encuentran habitualmente en la adopción de medidas de ahorro energético en el hogar: la falta de interés en adoptarlas por parte de los usuarios, el exceso de tiempo necesario para estudiar posibles modificaciones y hasta qué punto les benefician, su desconocimiento del mercado de ciertos productos (por ejemplo, placas solares o termostatos inteligentes), y la dificultad de elegir el que más les interesa debido a ese desconocimiento.

Señala que los métodos idóneos para cada uno de sus clientes son diferentes: los que están en régimen de alquiler no van a sufragar mejoras en los cerramientos de las viviendas, las viviendas nuevas no necesitan instalar termostatos inteligentes (ya los tienen), los habitantes de edificios no pueden instalar placas solares en su tejado (no lo tienen), etc. El hecho es que bombardear al usuario con sugerencias de mejoras que no son aplicables en su caso, hace que éste se sature y deje de hacer caso de los consejos.

Con Edison sugiere que debe buscarse un sistema de discriminar los tipos de mejoras y conectar a cada usuario exclusivamente con las que le vayan a resultar idóneas a su caso en particular, basándose en su perfil de uso de energía, sus datos demográficos, el tipo de vivienda, etc. Lo mismo es válido para los mensajes para la concienciación: deben ser específicos para cada tipo de usuario, no indiscriminados para toda la población.

En [28], se sugiere invertir en asistencia técnica para reducir el esfuerzo requerido por los usuarios para optimizar sus inversiones, sea en equipamiento eficiente o en mejoras de la vivienda. Esto ayuda a simplificar la toma de decisiones y además puede hacer que los usuarios se enfoquen en mejoras que, aunque para ellos sean pequeñas, para el conjunto de la población supongan reducciones considerables

\subsubsection{Aprovechamiento de las normas sociales}

En [9] y [12] se describe un experimento llevado a cabo por la compañía eléctrica estadounidense OPOWER. Esta compañía envía a sus usuarios información de su comportamiento energético con respecto al resto del vecindario de características similares, aplicando con ello la característica 
del comportamiento humano descrita como respeto a las normas sociales (Figura 3.1). El grupo de comparación son unas 100 viviendas próximas, con $\mathrm{m}^{2}$ similares, y mismo tipo de sistema de calefacción.

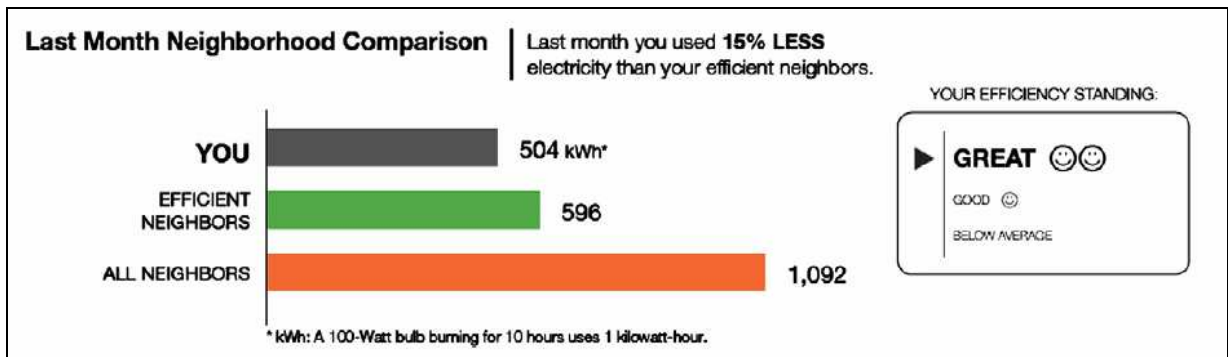

Figura 3.1. Información del comportamiento energético respecto a los vecinos utilizada en la referencia [12]

El estudio se ha llevado a cabo sobre unas 600.000 viviendas, entre grupo con tratamiento y grupo de control. Sus hallazgos son muy interesantes, destacando entre ellos estos 3:

1.- La persistencia del efecto es elevada. Pese a que la duración del experimento es ya de dos años, el efecto permanece o incluso se ha acentuado.

2.- El efecto es mayor cuanto mayor es la desviación original del consumo medio, reportándose diferencias, de entre un $6 \%$ extra de ahorro en el decil mayor y prácticamente un $0 \%$ en el decil menor.

3.- Aunque los usuarios con valores por debajo de la media de consumo prácticamente no redujeron su consumo, tampoco hubo efecto boomerang (no lo aumentaron para aproximarse a la media). Previendo esta posibilidad, la compañía añadió en estos casos una carita sonriente a la información enviada (aprovechando al hacerlo la característica del comportamiento humano conocida como social influence. Además, se clasificaba a las viviendas con las etiquetas de "excelente" (los que usan menos que el percentil 20), "bueno" (los que usan menos que la media sin ser excelentes), "por debajo de la media" (los que superaban la media). Los dos primeros recibían caritas (2 los excelentes, 1 los buenos), los terceros no. Pese a que la pertenencia a una etiqueta u otra sí influyó sustancialmente en los cambios de comportamiento, la etiqueta en sí no supuso ninguna influencia apreciable. Esto se estudió a partir de los excelentes y los buenos que se encontraban justo en el límite 
entre una categoría y otra, y entre cuyos comportamientos no se encontró diferencia alguna.

Además del envío de la información del consumo, también enviaban la figura siguiente, con información, personalizada según patrones de consumo de los clientes y sus características demográficas.

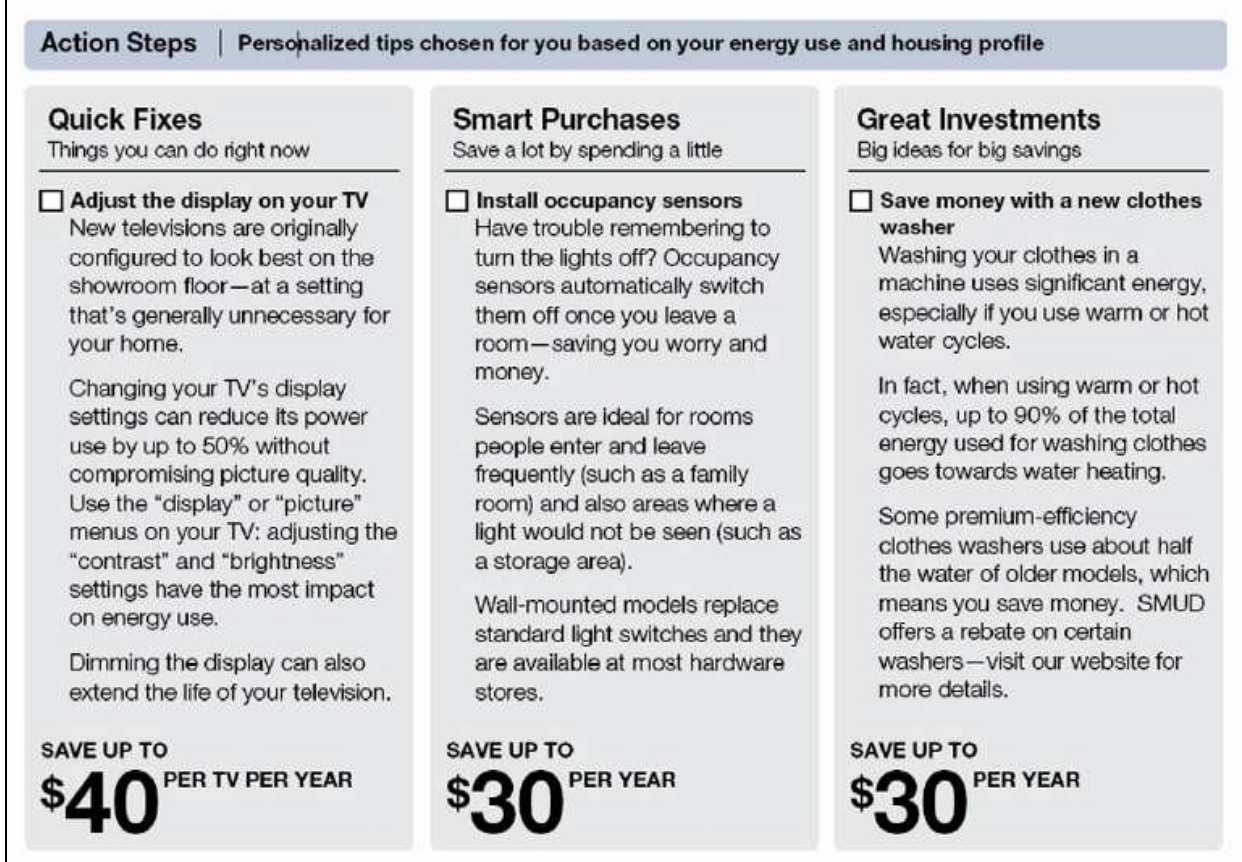

Figura 3.2. Información adicional enviada en la referencia [12]

En otros experimentos similares, aunque no tan extensos y largos como éste, se comenta la conveniencia del envío de información sobre el comportamiento en años anteriores, corregido por temperatura. [110].

\subsection{Políticas de eficiencia energética: tipología}

A lo largo de los últimos 40 años, gran cantidad de políticas de eficiencia energética han luchado contra el aumento del consumo. Aunque muy diferentes entre sí, en general todas ellas se pueden clasificar dentro de uno de estos cuatro tipos de política: programas informativos y de voluntariado, incentivos financieros y estándares de producto. 


\subsubsection{Programas informativos}

El objetivo de las políticas informativas es la reducción del consumo mediante el suministro de información relativa a ahorros potenciales en eficiencia energética [65]. Su intención es reducir el impacto de los fallos de mercado y los problemas en el comportamiento que se relacionan con defectos en la información, como la incertidumbre de las inversiones, la sobrecarga, la procrastinación o la aversión al riesgo y la pérdida.

Se engloban dentro de estas políticas recursos tales como: etiquetas energéticas de electrodomésticos y viviendas, distintas formas de feedback, medidores de energía inteligentes, auditorías energéticas (aplicadas en la industria) o campañas informativas.

La relación coste-efectividad de estas medidas no se encuentra en la literatura.

\subsubsection{Programas voluntarios}

En este caso, se trata de la aplicación de acuerdos voluntarios entre las empresas y el estado, en las que éstas se comprometen a una reducción porcentual determinada de su consumo energético, a cambio de recompensas tales como la buena publicidad de sus productos. Los objetivos a alcanzar están normalmente basados en reducciones de $\mathrm{CO}_{2}$ absolutas o por unidad de producto. Estos programas reducen el impacto de la procrastinación y otros componentes de la teoría prospectiva.

\subsubsection{Incentivos financieros}

Dentro de los incentivos financieros se engloban políticas muy diferentes, relacionadas con la falta de acceso al capital por parte de los usuarios, con el papel de las empresas suministradoras, y con la modificación de la curva de la demanda.

1.- El acceso al capital. En este apartado se engloban subvenciones, créditos fiscales, deducciones de impuestos, préstamos subvencionados y reembolsos. Se utilizan para minimizar barreras relacionadas con la falta de acceso al capital por parte de los pequeños usuarios, los tiempos de retorno excesivamente largos o la aversión al riesgo y a la pérdida. Todos ellos padecen el problema del rebound y del free-rider effect. 
Poco nombrado en la bibliografía, el aumento del precio de la energía a través de los impuestos que la gravan es evidentemente también un método de reducción del consumo energético. Al contrario que otros casos, no se presta a problemas de rebound effect o de free-riding effect, y promueve las mejoras tecnológicas. Además, según las teorías del comportamiento ya revisadas, la respuesta de los ciudadanos a las subidas de precios es mayor que su respuesta a las reducciones, debido al fenómeno de la aversión a la pérdida. Por otra parte, dado que la elasticidad de la demanda energética es pequeña, su potencial puede ser limitado, y el coste social de un aumento de impuestos en un bien de primera necesidad como es la energía, puede llegar a ser grande. ([36], [86])

\section{2.- Recompensas e incentivos}

La respuesta de la demanda (demand response) se define como el cambio en el comportamiento de los usuarios finales de la energía debido a cambios en el precio de la energía [6]. Este cambio puede darse de dos formas: modificaciones en la forma de la curva de la demanda o bien alteraciones de los consumos totales.

Si bien es fácil encontrar políticas de aplanamiento de la curva de la demanda basadas en recompensas económicas (discriminación horaria, por ejemplo), así como medidas indirectas para la reducción del consumo total, como subvenciones para mejoras de envolventes térmicas o compra de electrodomésticos más eficientes, no hay establecida ninguna medida política que recompense directamente la reducción del consumo total.

Existe poca literatura relativa al incentivo económico del comportamiento sostenible. Aparece el concepto feed-in-tarif, que se corresponde con bastante exactitud con uno de los objetivos de esta tesis, y que consiste en el establecimiento de una recompensa económica relativa al kWh ahorrado [19]. El sistema feed-in-tarif minimiza, por su naturaleza, el efecto rebote, dado que no incentiva la eficiencia energética sino directamente el ahorro.

El concepto feed-in-tarif se inspira en el sistema del mismo nombre utilizado en muchos países de la Unión Europea, incluido España, para impulsar las renovables. En este caso, consiste en que las energías renovables pueden elegir entre competir en el mercado libre con el resto, o bien vender 
con una tarifa regulada (feed-in-tariff) por el gobierno. Alemania también usa este sistema.

En el ámbito del ahorro energético, existen dos formas de aplicar el feed-in-tarif: compensando por kWh ahorrado o por la consecución de un determinado nivel (en tanto por cien) de ahorro. Al basar la recompensa en el ahorro anual de la vivienda y no en el consumo se mantiene un reto permanente, dado que, al pasar los años, la comparativa es siempre con un comportamiento más eficiente. Tampoco es inalcanzable si la tecnología continúa ofreciendo mejoras en la eficiencia energética de productos y cerramientos.

El mayor reto de este sistema es la cuantificación del ahorro obtenido. La medida del kWh consumido será real, pero la medida del kWh consumido en ausencia de incentivo es, por su naturaleza, necesariamente una estimación. Podría hacerse el cálculo a partir de los datos de consumo de la propia vivienda en años anteriores, corregida por diversos factores externos que pueden modificar el consumo independientemente del comportamiento (climatología, variación del número de miembros de la familia) [19].

3.- Las obligaciones de las empresas suministradoras. En los últimos años, los estados han empezado a obligar a las compañías suministradoras a tomar parte activa en los programas de ahorro energético enfocados a los usuarios finales. Estas obligaciones reciben en Europa el nombre de certificados blancos (white certificates) y, en Estados Unidos, programas de gestión de la demanda (demand-side management programs)

Los certificados blancos son obligaciones que las autoridades imponen a las empresas suministradoras de energía, de conseguir de sus abonados ahorros sustanciales en el consumo de energía. Las empresas energéticas deben obtener sus logros mediante proyectos de mejora de eficiencia del tipo que quieran y aplicados a cualquier sector al que suministran (industria, transporte, sector servicios o sector residencial).

En algunas ocasiones, se permite a las empresas comerciar con las ganancias de eficiencia obtenidas, de forma que si exceden sus objetivos puedan venderlos a otras empresas. En este caso, cada unidad de consumo energético reducida se acredita a través de un certificado blanco intercambiable. Teóricamente, al permitir el comercio de certificados blancos 
se asegura que las actuaciones de eficiencia energética sean desempeñadas por aquellos agentes que lo pueden hacer a mínimo coste.

Las compañías de distribución de electricidad y gas, son remuneradas por el coste y esfuerzo que deben incurrir para cumplir las metas propuestas por el regulador con una compensación monetaria por certificado blanco. Esta contribución se financia con un pequeño aumento en la tarifa de los clientes finales.

En Estados Unidos, sin existir la denominación certificado blanco, muchas legislaciones estatales tienen una regulación con la misma filosofía que ésta. Se obliga a las compañías suministradoras a llevar a cabo programas de eficiencia energética, que en este caso se conocen como programas de gestión de la demanda (demand-side management, DSM).

4.- ESCOs.- Las ESCOs (Energy Service Companies) son empresas de servicios energéticos que desarrollan, instalan y financian proyectos de eficiencia energética. Estas organizaciones permiten que las empresas enfoquen sus recursos a su actividad principal, mientras la ESCO se encarga de optimizar su desempeño energético.

5. La modificación de la curva de la demanda. Éste es uno de los pocos casos en los que las políticas de eficiencia ponen su atención, en parte, en el comportamiento de los individuos. Las políticas englobadas en este apartado tienen como objetivo el aplanamiento de la curva de la demanda, desplazando el consumo de las horas punta a las valle. Existen dos formas de conseguirlo: controlando la demanda desde el lado del suministrador, o variando los precios de forma que sea el consumidor el que desplace su consumo. Dentro de cada forma hay varias opciones:

- Control por parte del suministrador

- Programas de interrumpibilidad. Contratos con grandes usuarios a los que se puede cortar el suministro en periodos o bien punta de demanda o bien de precio de la electricidad muy elevado, evidentemente a cambio de una reducción en la factura.

- Control a distancia de los electrodomésticos. A cambio de una reducción en la tarifa, el usuario permite al suministrador interrumpir el funcionamiento de algunos de sus aparatos eléctricos durante los picos de demanda, por ejemplo el aire acondicionado 
- Control por parte del usuario (respuesta de la demanda o demandresponse)

- Precio en tiempo real. Consiste en cobrar la electricidad al precio real horario de la energía.

- Discriminación horaria. Consiste en dividir el día en franjas horarias (típicamente llano, punta y valle), y cobrar la energía a distinto precio en función de en qué franja horaria se realice el consumo.

En general, estos programas varían la forma de la curva pero tienen poca repercusión en el consumo total, dado que la mayoría de los consumos simplemente se desplazan de unos momentos del día a otros, no se anulan por completo.

\subsubsection{Estándares de producto}

En este tipo de políticas, se obliga a un mínimo nivel de eficiencia energética a un determinado producto que se pone a la venta en el mercado.

\subsection{Políticas de eficiencia energética: ejemplos de aplicación}

\subsubsection{Programas informativos}

1. Etiquetas energéticas. Uno de los programas insignia del gobierno de Estados Unidos de reducción de las emisiones de gases de invernadero por medio del uso eficiente de la energía es el sello voluntario Energy Star. Energy Star empezó como un programa de etiquetado voluntario para ordenadores y monitores. Hoy en día, puede encontrarse en más de 60 categorías de productos, incluidos los principales electrodomésticos, equipos de oficina, alumbrado y aparatos electrónicos para el hogar. También se utiliza para la categorización energética de viviendas y edificios comerciales e industriales.

En el experimento descrito en la referencia [63], se estima que esta medida supuso un ahorro de un 2,5\% del consumo eléctrico nacional en 2000. Sin embargo, en la referencia [64], tras una revisión de la literatura al respecto, se concluye que se requiere un estudio más profundo del método de valoración del coste-beneficio de la medida.

En Japón, el Top Runner Programm consiste en etiquetar todos los productos comprendidos en el programa, incluidas las importaciones, según su nivel de eficiencia energética comparado con el producto más eficiente del 
mercado en el momento en el que se definió el estándar "Top Runner" de ese producto. Sólo existen dos etiquetas: una verde si el producto alcanza el estándar Top Runner, o roja si no lo consigue. Hay una lista de 23 productos en el programa, entre los que se encuentran refrigeradores, aires acondicionados, lámparas fluorescentes, televisiones, ordenadores, calderas de calefacción, cocinas de gas y calentadores. No hay obligación legal de alcanzar el Top Runner, pero el Ministerio de Medio Ambiente puede divulgar los nombres de los productos que no lo hacen, con la consecuente mala publicidad para las empresas que los fabrican.

En Europa, la Directiva 2010/30/UE del parlamento europeo y del consejo de 19 de mayo de 2010 relativa a la indicación del consumo de energía y otros recursos por parte de los productos relacionados con la energía, mediante el etiquetado y una información normalizada, rige el etiquetado y la clasificación energética de los productos relacionados con la energía. También se limita por ley los máximos admisibles en stand-by.

2. Feedback. Este apartado está desarrollado con mucho detalle en el capítulo 4, por lo que aquí se obvia pese a su evidente importancia.

3. Auditorías energéticas. En Japón, se puede acceder a auditorías gratuitas para empresas pequeñas, y por una tarifa, para empresas medianas y grandes.

En Estados Unidos, se ofrece asistencia técnica en asuntos de eficiencia energética a las grandes empresas, así como auditorías gratuitas a las medianas y pequeñas. Según el estudio realizado en la referencia [8], las empresas en general juzgan los resultados de las auditorías en términos económicos, aplicando aquellas soluciones cuyo periodo de retorno de la inversión es de hasta un máximo de 15 meses, y rechazando todas las demás. En el caso particular del estudio, casi el $50 \%$ de las mejoras sugeridas fueron ignoradas por cuestiones económicas

En la Unión Europea, a través de la Directiva 2012/27/UE, las auditorías energéticas son obligatorias y periódicas para las grandes empresas. Además, se deben elaborar programas para fomentar la elaboración de auditorías energéticas en las PYME y los hogares. En el caso de que las PYME hayan celebrado acuerdos voluntarios de mejoras energéticas, se establecen ayudas para cubrir los costes de estas auditorías [64]. 


\subsubsection{Acuerdos voluntarios}

En Estados Unidos, a partir de 1992, el Estado empezó a firmar acuerdos voluntarios de reducción del consumo con grandes empresas, que participaban con la intención de mejorar su imagen pública. A día de hoy, ya no se admiten nuevas empresas, pero el acuerdo sigue en vigor para las que firmaron previamente.

Japón está reduciendo, en este caso a base de acuerdos voluntarios con las empresas fabricantes, los stand-by de los electrodomésticos. En el caso de refrigeradores, esta medida ha supuesto una reducción en su consumo medio de un 15\% entre 1979 y 1997; en otros electrodomésticos, se han alcanzado reducciones de hasta un $50 \%$ [80]

\subsubsection{Incentivos financieros}

1. Subvenciones, reducciones de impuestos, préstamos a bajo interés. En Estados Unidos, la ley de estímulo económico promulgada en febrero de 2009 estipula varias fuentes e incentivos de financiación para aumentar la eficiencia y alentar la adopción generalizada de tecnologías de energía renovable. Son, entre otros, subvenciones para realizar mejoras en climatización para familias de bajos recursos y para viviendas de protección oficial, reembolsos para usuarios que compren electrodomésticos eficientes y subsidios para la mejora en eficiencia energética de edificios gubernamentales. Se estima que las subvenciones para mejoras en climatización se tradujeron en una reducción en el consumo total de las viviendas participantes de un 21,9\% (climatización por gas) y un 10,5 \% (climatización eléctrica) en el periodo 19932003 [17].

Muchos países europeos han implementado incentivos en forma de reducción de impuestos para aislamiento y sistemas de calefacción en viviendas, por ejemplo en Francia 2007 (1,2 millones de viviendas beneficiadas), o para compras de electrodomésticos eficientes (Italia, Reino Unido). En otros países la reducción es en forma de subvenciones a la compra.

Se considera también eficiente, a veces incluso más que la subvención a la compra, la subvención a las empresas fabricantes siempre y cuando los productos que pongan a la venta cumplan unos niveles exigidos de eficiencia. Este método se aplica por ejemplo en California para la venta de equipos de 
climatización y en China, para la penetración de lámparas de bajo consumo [115]

En Corea y Japón se experimenta con una herramienta interesante. Consiste en la emisión de "puntos de carbono" para los compradores de equipos eficientes. Estos puntos pueden después canjearse por descuentos en distintas cosas, como bonos para transporte público, compras de otro equipamiento eficiente o pago de facturas energéticas. Es un programa voluntario para las empresas, pero las que se registran obtienen beneficios en publicidad y otros. En el caso de Japón, se encuentran reducciones de impuestos y préstamos a bajo interés para la construcción de edificios de alta eficiencia energética.

\section{Recompensas e incentivos}

En los Estados Unidos, [29], se llevó a cabo un programa de ahorro energético en industria (AEP Ohio), que, a una realimentación exhaustiva y a un seguimiento detallado, añade una compensación económica por kWh ahorrado, reportando ahorros de entre un 2,4 y un $8,6 \%$.

Existe también el caso de Toronto Hydro, que ofreció a sus clientes una devolución del $10 \%$ de su factura a los clientes (viviendas y negocios), que redujeran un $10 \%$ su consumo de un verano al siguiente [122], y que llegó a obtener resultados de ahorros de hasta un $20 \%$.

Ambos programas pueden considerarse ejemplos de aplicación del feedin-tariff.

China estableció en 2005 el programa top-1000 empresas consumidoras de energía [107], en el que las empresas participantes firmaron acuerdos voluntarios de reducción de consumo energético. Los objetivos en particular de cada empresa fueron fijados por el gobierno. Las empresas son recompensadas económicamente por cada tep ahorrado; las que no alcanzan sus objetivos, son sancionadas en forma de reducción de su prestigio. De forma previa al inicio del programa, las empresas recibieron información sobre autorrealización de auditorías energéticas, para que la propia empresa identificara sus oportunidades de ahorro. En algunos casos, fue una entidad externa la que realizó las auditorías, a cargo de la empresa auditada.

Otra política de recompensas, también establecida en China, [107], consiste en la clasificación de las empresas de alto consumo (como cementeras 
o de aluminio), según su nivel de eficiencia energética, en "estimuladas, permitidas, restringidas y eliminadas". A cada nivel se le asigna un precio progresivamente mayor del kWh. Esto no sólo estimula a las empresas a mejorar su desempeño energético sino que aumenta la financiación.

Por su parte, en Noruega, la empresa Trondheim Energy llevó a cabo un experimento en 2500 viviendas que consistió en un "precio fijo con opción de retorno" [68]. Con este sistema, los participantes compran un volumen determinado de energía a un precio preestablecido, calculado con referencia a los precios reales de la energía, y siguiendo un perfil variable a lo largo del año (ver Figura 3.3). Las desviaciones de consumo por encima de la cantidad preestablecida las paga el usuario al precio de mercado; las desviaciones por debajo, le son remuneradas por el suministrador al precio de mercado también. Este sistema tuvo una buena acogida por parte de los participantes.

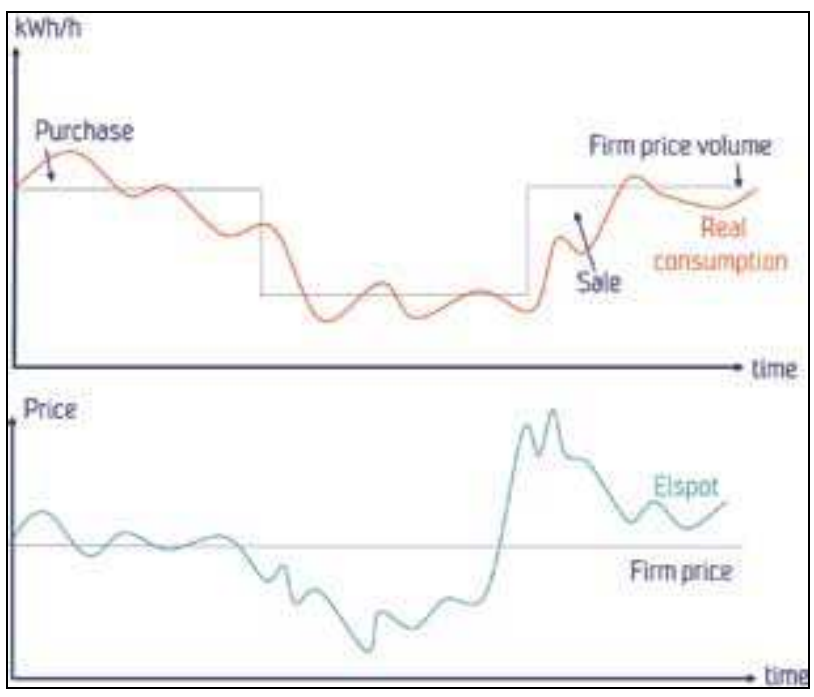

Figura 3.3. Perfiles variables de precios de energía. Fuente: [68]

3. Certificados blancos y gestión de la demanda: el papel de las empresas suministradoras. Estos certificados se están poniendo en marcha en Europa, estando ya operativos en algunos de sus países.

En el caso de Reino Unido, los comercializadores de gas y electricidad con más de 50.000 clientes domésticos están obligados a cumplir unos objetivos de reducción del consumo de sus clientes, fijados de forma particular para cada comercializador. Las multas en caso de incumplimiento se refieren a 
las licencias que necesitan los comercializadores para operar en el Reino Unido [70].

En el mercado italiano, cada certificado blanco obtenido equivale a la reducción de 1 tep del consumo final de energía. Una distribuidora puede alcanzar sus obligaciones de eficiencia energética generando certificados blancos con sus propios proyectos de reducción del consumo o bien adquiriendo certificados de otras empresas que han llevado a cabo este tipo de proyectos y que han excedido sus objetivos anuales. [70].

En el caso de Estados Unidos, los programas de gestión de la demanda consisten principalmente en información, asistencia técnica e incentivos financieros para la adopción de medidas de eficiencia energética. En los estados con más éxito en la aplicación de estas medidas se obtuvieron reducciones de uso de energía eléctrica de alrededor de un 6\% en 2000 [62].

California es un ejemplo paradigmático de la importancia del papel de estas empresas. Desde los años 80 , las empresas suministradoras californianas han estado implementando programas de eficiencia energética a gran escala. La financiación se realiza mediante un cargo en la factura eléctrica de 0,3 cents/kWh, que supone un 3\% aproximadamente de la factura total. En este caso, las distribuidoras reciben financiación en ciclos de tres años para llevar a cabo sus programas, y posteriormente son evaluadas, recibiendo bien premios bien penalizaciones por su desempeño [70].

4. Las compañías de servicios energéticos ESCOs. En el caso de Japón, desde el Estado se ofrecen incentivos financieros para facilitar el uso de las ESCOs en la mejora de la eficiencia energética de las empresas.

En algunas regiones de Estados Unidos y Canadá, desde 2009 se encuentra en funcionamiento el programa SEM (Strategic Energy Management), dentro de la que se engloban distintos programas de actuación. El primero de ellos es el Efficiency Vermont que, en la actualidad, se dedica principalmente a la venta de proyectos de eficiencia energética (mejoras en los procesos, en los ciclos de mantenimiento, y en el compromiso de los trabajadores con los cambios). Con ello, ayudan a los participantes a crear planes completos y de largo alcance, dando soporte técnico y financiero a las empresas para que alcancen sus objetivos energéticos [29]. Su previsión es una reducción de un $7,5 \%$ de consumo en dos años. 
El segundo, National Grid, provee también servicios de eficiencia energética siguiendo un esquema similar. Ambos ponen énfasis en la importancia de la adecuación de las soluciones a los casos particulares de cada una de las empresas participantes. Sus objetivos son las reducciones energéticas de esas empresas entre un 3 y un $5 \%$ de su consumo previo; su forma de atraer participantes es, nuevamente, el incentivo financiero en diversas formas.

\subsubsection{Estándares de eficiencia}

En Estados Unidos, los estándares de eficiencia en electrodomésticos están establecidos por ley desde la década de los 70. Son revisados y aumentados periódicamente en función de la aparición de innovaciones tecnológicas que mejoren su desempeño.

En el caso de Japón, los estándares existen pero son voluntarios. Cubren asuntos tales como la estanqueidad térmica de los cerramientos, los sistemas de iluminación, el ACS y los ascensores.

En cuanto a la UE, se han fijado mínimos de eficiencia para productos así como para edificios de nueva construcción a través de las distintas directivas de eficiencia energética descritas en el apartado 2.1.

\subsubsection{La combinación de políticas}

No sólo es necesario conocer el impacto de cada una de las posibles políticas a aplicar sino que también es importante saber qué relaciones las unen a la hora de aplicar varias de ellas al mismo tiempo. Con el objetivo de maximizar su efecto conjunto, es necesario saber si son complementarias, independientes o si se solapan sus efectos. La literatura con respecto a esta cuestión está aumentando, siendo una revisión muy reciente e interesante la de [112]. Según su revisión, las distintas políticas (aplicadas en grupos de dos), se relacionan del modo mostrado en la Figura 3.4. 


\begin{tabular}{|c|c|c|c|c|c|c|c|c|c|c|}
\hline \multicolumn{11}{|c|}{ Efectos de lalnteracción entre diferentes políticas de eficiencia energética } \\
\hline & 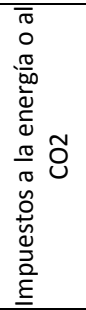 & 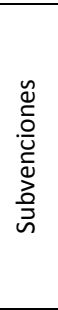 & 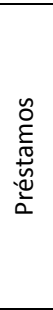 & 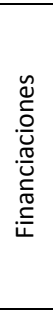 & 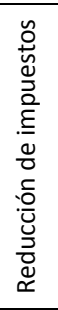 & 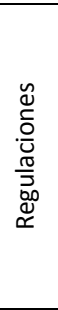 & 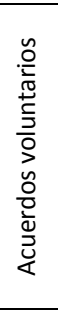 & 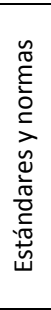 & 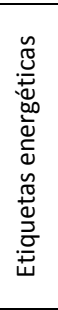 & 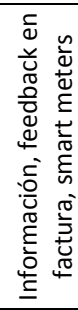 \\
\hline $\begin{array}{c}\text { Obligaciones de eficiencia } \\
\text { energética }\end{array}$ & + & - & - & - & - & 0 & - & + & + & + \\
\hline Impuestos a la energía o al CO2 & & + & + & + & + & + & + & + & + & + \\
\hline Subvenciones & & & - & - & - & 0 & 0 & + & + & + \\
\hline Préstamos & & & & - & - & 0 & 0 & + & + & + \\
\hline Financiaciones & & & & & - & 0 & 0 & + & + & + \\
\hline Reducción de impuestos & & & & & & 0 & 0 & + & + & + \\
\hline Regulaciones & & & & & & & - & + & + & + \\
\hline Acuerdos voluntarios & & & & & & & & + & + & + \\
\hline Estándares y normas & & & & & & & & & + & + \\
\hline Etiquetas energéticas & & & & & & & & & & + \\
\hline $\begin{array}{l}\text { +: Complementarias (Ahorros de } \\
0: \text { neutrales (Ahorros de la comb } \\
\text {-: Solapadas (Ahorros de la comb }\end{array}$ & $\begin{array}{l}\text { la comb } \\
\text { inación } \\
\text { inación }\end{array}$ & $\begin{array}{l}\text { inació } \\
\text { le pol } \\
\text { de pol }\end{array}$ & $\begin{array}{l}\text { de } p \\
\operatorname{cas} A \\
\text { cas } A\end{array}$ & $\begin{array}{l}\mathrm{i} \text { ícas } \\
\mathrm{B}=\mathrm{s} \\
\mathrm{B}<\mathrm{s}\end{array}$ & $\begin{array}{l}\mathrm{yB}> \\
\text { na d }\end{array}$ & $\begin{array}{l}\text { uma } \\
\text { ahor } \\
\text { ahor }\end{array}$ & $\begin{array}{l}\text { aho } \\
\text { A ye } \\
\text { A y }\end{array}$ & $\begin{array}{l}\text { o A y } \\
\text { ahorr } \\
\text { ahor }\end{array}$ & $\begin{array}{l}\text { I ah } \\
\text { B) } \\
\text { B) }\end{array}$ & ro B) \\
\hline
\end{tabular}

Figura 3.4. Efectos de diferentes políticas de eficiencia energética. Fuente: [112]

Donde: regulations se refiere a regulaciones en estándares de eficiencia energética mínima para productos y edificios, standards and norms se refiere a la regulación de la medición de esos estándares, y on-bill finance se refiere al pago de las mejoras en vivienda o equipamiento a través de la factura eléctrica y a plazos.

Siempre según el mismo autor, de la tabla se deducen las siguientes relaciones:

1.- Impuestos al $\mathrm{CO}_{2}$ es compatible con cualquier otra medida 
2.- La combinación de incentivos a la compra (reducciones de impuestos, subvenciones, obligaciones), con el acceso al capital (préstamos), se superponen, no siendo óptimo su uso conjunto.

3.- Las obligaciones se superponen con otros incentivos financieros

4.- Información y medidas de feedback refuerzan los efectos de cualquier otra política. Esto se debe a que influyen no en cuestiones económicas sino del comportamiento,

5.- Los estándares y normas son fundamentales para el establecimiento de cualquier otra política. 


\section{La eficiencia energética en el sector residencial: estado del arte}

\subsection{Aumento de la eficiencia energética en el sector residencial mediante métodos informativos}

4.1.1. Tipología de los equipos consumidores y posibilidades de ahorro energético

El consumo eléctrico en viviendas, excluyendo la calefacción, está determinado por dos factores principales:

- El Consumo fijo (Tipo y cantidad de electrodomésticos de los que se dispone), está relacionado con la superficie útil de la vivienda, el número de electrodomésticos del que se dispone, el número de miembros del hogar y la zona climática.

- El Consumo variable (Uso que los habitantes hacen de los electrodomésticos), está relacionado con el estilo de vida, los hábitos de consumo y los valores de los habitantes. Dos viviendas con el mismo consumo fijo pueden variar sustancialmente en el consumo variable, sin que ello implique un mayor grado de satisfacción en la vivienda de mayor consumo; simplemente puede ser un indicador de ineficacia en el 
uso del equipamiento. Por ejemplo, puede deberse a costumbres tales como dejar luces encendidas en habitaciones vacías, mantener la puerta del frigorífico abierta más tiempo del necesario, etc.

Para reducir el consumo fijo se aplican medidas técnicas de ahorro:

- Disminuir el número de electrodomésticos en el hogar

- Sustituir los electrodomésticos que se tienen por otros más eficientes

- Mejorar los cerramientos

- Generar electricidad propia

Está demostrado que las mejoras técnicas no son suficientes para garantizar reducciones de consumo, y que el consumo en hogares idénticos puede diferir en un factor de 2 o más dependiendo del comportamiento de los habitantes [40]. Además, no se considera económicamente rentable cambiar electrodomésticos en uso aunque se sustituyan por otros más eficientes, así que a corto plazo el potencial está en el cambio de hábitos en el consumo variable. A largo plazo el potencial sí es importante.

Para reducir el consumo variable, se aplican medidas de cambio de hábitos de consumo:

- Aprender formas más eficientes de llevar a cabo las mismas acciones

- Automatizar hábitos eficientes

Este trabajo de investigación está centrado en las medidas de reducción del consumo variable dentro del sector residencial, siempre y cuando no conlleven pérdida de la confortabilidad o del nivel de vida de sus habitantes. No se busca una reducción del tipo o la cantidad de electrodomésticos que cada usuario desee utilizar, sólo se intenta mostrarle cómo hacerlo eficientemente.

\subsubsection{Hábitos eficientes}

En función del tipo de equipamiento / electrodoméstico, el ahorro que se puede obtener de él puede ser de tipo técnico, actitudinal o ambos:

- Algunos electrodomésticos tienen poco margen de maniobra, y admiten poco más que ahorro energético en la compra: 
electrodomésticos fríos (neveras, congeladores...), electrodomésticos continuos (alarmas, relojes, módems...)

- Otros equipos tienen stand-by o modo de reposo: debe adquirirse el hábito de apagarlos por completo: televisores, equipos de música, DVDs, Blue-Ray, ordenadores

- Parte del equipamiento tiene un consumo que depende mucho del comportamiento de los habitantes, y además con mucho margen de variación: temperaturas de climatización, uso de termostatos programables, uso del agua caliente mínima necesaria para la higiene, uso de ropa abrigada en invierno y fresca en verano, cerrar/abrir puertas y ventanas, así como persianas y toldos, temperaturas de lavado, máximas cargas por ciclo, uso de lámparas más eficientes, apagado de luces innecesarias, cambio de hábitos de cocinado (uso de olla exprés, uso de microondas en vez de horno, hervir la cantidad mínima necesaria de agua, apagar las cocinas y los hornos con unos minutos de antelación),

Dada la importancia de la variación provocada por las diferencias en los hábitos, es necesario buscar métodos para educar en comportamientos energéticamente eficientes; esos métodos deben probar su eficacia inmediata y también la persistencia de su efecto.

A su vez, los cambios en los hábitos de consumo se pueden incentivar utilizando tres métodos diferentes: basados en la información, basados en la economía o basados en la realimentación.

\subsubsection{Sistemas basados en la información}

Consisten en proporcionar a los usuarios información sobre cuestiones importantes a la hora de comprar nuevos electrodomésticos, y sobre formas de utilizar de forma eficiente el equipamiento y los electrodomésticos del hogar

Características deseables:

- Implicar emociones y motivar

- Ser directo y simple

- Mantenerse en el tiempo

- Ser lo más específica posible 
Por sí mismos no son demasiado eficaces, o lo son sólo en el corto plazo. Las campañas informativas (Vattenfall's Task, Eskilstuna Project y otros), parecen tener influencia (reducciones de un 3\% aproximadamente), pero no hay persistencia del efecto; sólo duran unos días.

Únicamente parecen tener cierta capacidad de influencia en cambios de comportamiento las campañas informativas llevadas a cabo en las escuelas, donde al parecer los alumnos transmiten a sus padres la información obtenida y son más insistentes a la hora de aplicarla.

Donde sí pueden tener más eficacia es como complemento a un sistema de realimentación; en ese caso, le sirven al usuario como fuente de inspiración y de ideas para probar comportamientos más eficientes, sugeridos por esas campañas informativas.

\subsubsection{Sistemas basados en la realimentación}

Los métodos realimentados consisten en proporcionar al usuario información sobre su consumo, de forma que éste pueda cambiar su comportamiento y comprobar cómo este cambio se refleja en el consumo.

La realimentación es un método de aprendizaje que consiste en hacer saber al usuario, tan instantáneamente como sea posible, qué resultados tienen sus acciones. Así puede experimentar distintos comportamientos, ver qué resultados obtiene con cada uno de ellos, aprender de sus errores, seleccionar los métodos más eficientes para hacer las cosas, y ser consciente en todo momento del consumo energético que se está produciendo en su hogar.

Cualquier sistema de realimentación debe cumplir unas características básicas para tener éxito:

- Seguir inmediatamente a la acción

- Producirse con una periodicidad elevada

- Mantenerse en el tiempo

- Presentarse de forma atractiva, simple y fácil de entender

- Incluir comparaciones (con uno mismo, con el vecindario, con un hogar patrón...) 


\subsubsection{Tipos de realimentación}

Realimentación directa.- Consiste en una realimentación inmediata, obtenida a través de un medidor en tiempo real. Se obtienen, según experimentos, ahorros entre un 5 y un 15\% ([5], [42], [80], [75], [82], [129]). La información sobre la persistencia del cambio es variable, pero en general parece que, aún con cierta tendencia a la baja, el efecto es persistente. Se cree que será más útil para consumidores de mayor cantidad de energía que para los de menor.

Realimentación indirecta.- Es una realimentación procesada de alguna forma, como por ejemplo en la factura. En general, es mucho menos inmediata que la anterior, por lo que se pueden esperar logros menores. De hecho, los resultados de los experimentos arrojan unos valores de ahorros del 0 al $10 \%$. ([15], [46], [97], [73], [79], [127])

Realimentación desagregada.- Es un tipo especial de realimentación directa en el que se muestra el gasto de cada electrodoméstico por separado. Ahora mismo es relativamente cara y complicada, pero sus resultados son buenos [124].

Cualquiera de los métodos de realimentación mejora sus resultados si se combina con una campaña informativa sobre métodos de ahorro y hábitos derrochadores

\subsubsection{Métodos de realimentación directa}

Contador básico.- Los usuarios chequean regularmente su contador. Requiere mucho interés por parte del usuario [72]

Medida en tiempo real (smart meter).- Muestra, al alcance de la vista, el consumo instantáneo, el medio, el histórico, etc ([5], [42], [80], [75], [82], [129])

Alarma.- Es similar al anterior pero no muestra valores sino que alerta de ciertas cosas, como ([57], [83]):

- Se está consumiendo por encima de un límite

- La temperatura exterior es suficientemente buena para quitar la climatización

- Ha cambiado el periodo tarifario 


\subsubsection{Métodos de realimentación indirecta}

Factura informativa (total o por electrodoméstico).- Consiste en aumentar la cantidad de información entregada con la factura, en forma de históricos de consumo, comparaciones con otros hogares similares, etc. ( [46], [97], [73], [127])

Tarjeta pre-pago.- Consiste en comprar una tarjeta prepago e introducirla en un contador que se tiene en casa. Permite el uso de electricidad hasta que se agota el crédito ([31], [42], [105])

\subsubsection{Realimentación desagregada}

Consiste en poner un medidor independiente por electrodoméstico o por grupo de ellos ([93], [124]). De momento, es un método caro y complejo de instalar. Una versión más factible es el uso de un software que sea capaz de distinguir cada electrodoméstico ([24], [59]). Pese a las dificultades técnicas de aplicación, es evidente que es un método con el potencial de aumentar el ahorro obtenido.

\subsection{Análisis de sistemas de realimentación en el sector residencial}

\subsubsection{Sistemas de realimentación de la información}

En general los métodos informativos no se clasifican dentro de los realimentados. Sin embargo, hay formas de organizar la información de forma que ésta sea realimentada. Por ejemplo, algunos estudios generan herramientas interactivas para recabar datos de los usuarios a la vez que se les proporciona información realimentada. Para ello, normalmente en una página web, el usuario debe introducir una serie de datos que se le solicitan: algunos para caracterizar el hogar (superficie, tipo de vivienda, número de miembros, renta anual etc), y otros sobre el equipamiento (principalmente, el tipo y marca de los electrodomésticos de los que se dispone).

A partir de ahí, el programa genera automáticamente, para el investigador, una base de datos de consumos de los hogares; y para el usuario, una comparativa de sus gastos con los del resto así como una serie de consejos de ahorro personalizados en base al equipamiento de su hogar. 
El usuario puede introducir los cambios que se han sugerido (en los ensayos reales lo más habitual es sugerirle la compra de electrodomésticos más eficientes), y el programa le muestra las variaciones que sus actos generan en las facturas posteriores.

Es un buen sistema si se utiliza como apoyo a otros métodos de realimentación, pero por sí mismo tiene un par de desventajas importantes: uno, que requiere un grado de implicación importante por parte del usuario (en general, los cuestionarios son demasiado largos y pesados), y en segundo lugar las sugerencias de ahorro están demasiado orientadas a la compra de electrodomésticos, y nada a los hábitos de consumo. Sin embargo, la interactividad siempre es buena, y se puede producir espontáneamente el deseo de averiguar más sugerencias de ahorro mientras se está experimentando con alguno de los otros métodos.

En los siguientes subapartados se resumen algunos de los experimentos realizados en este ámbito.

\subsubsection{Experimento Benders [16]}

Consistió en el envío de un cuestionario vía web junto con información personalizada. Los usuarios debían contestar una serie de preguntas sobre el equipamiento de su vivienda, la orientación de ésta, el número de miembros etc.

Las características de la muestra son las siguientes:

- Ciudad-Groningen, The Netherlands

- Tipología vivienda: Con conexión a Internet

- $\quad$ № participantes: 347 en el inicio, 190 al final

Los ensayos incluyeron el cuestionario inicial, una serie de consejos de ahorro personalizados en base al equipamiento particular de la vivienda, y un sistema de realimentación vía software que consistía en que el usuario podía ensayar distintos métodos de ahorro por ordenador (por ejemplo, cambiar las lámparas incandescentes por otras de bajo consumo), y comprobar los ahorros obtenidos con ello antes de llevar las modificaciones a la práctica.

Los ensayos se realizaron durante el año 2006, obteniéndose unos ahorros del $8,7 \%$ 
Los resultados de ahorro de hasta un $8,7 \%$ no son realistas, dado que se trata únicamente de lo que se podría conseguir si se realizaran los cambios, pero no prueba que éstos se llevaron posteriormente a cabo. Además, una gran cantidad de participantes renunció debido a la complejidad de los cuestionarios, por lo que las personas extremadamente concienciadas están sobrerrepresentadas

\subsubsection{Experimento Karbo and Fjordbak [82]}

El planteamiento es similar al anterior, mediante cuestionario vía web. Las características de la muestra son las siguientes:

Ciudad: Dinamarca

№ participantes: 5300 hogares daneses

Los ensayos incluyeron el cuestionario inicial, una serie de consejos de ahorro personalizados en base al equipamiento particular de la vivienda, y un sistema de realimentación vía software que consistía en que el usuario podía ensayar distintos métodos de ahorro por ordenador (por ejemplo, cambiar las lámparas incandescentes por otras de bajo consumo), y comprobar los ahorros obtenidos con ello antes de llevar las modificaciones a la práctica.

Los ensayos se realizaron durante el año 2004, obteniéndose unos ahorros del $10 \%$ (calculado por el programa, si se siguen sus directrices)

Al igual que el ensayo anterior, requiere mucha dedicación e interés del usuario

\subsubsection{Sistemas de realimentación a través de la factura}

El método consiste en añadir información del consumo a la factura, de forma que el usuario pueda ir conociendo sus hábitos de consumo energético y actuar en función de ellos. La información referida en la factura, para tener un impacto máximo, debe tener las siguientes características:

- Ser clara y comprensible

- Mostrarse en forma preferiblemente gráfica

- $\quad$ No excederse en la cantidad de información

- Contener información sobre posibles medidas de ahorro, en forma de acciones concretas 
- Contener comparación con una referencia:

- Con otros hogares similares

- Con él mismo en años previos

- Con un hogar patrón

- Tener una periodicidad elevada y mantenerse en el tiempo

- Incluir información de circunstancias excepcionales, como tiempo atmosférico fuera de lo normal

- No enfocarse en cálculos de consumo

El sistema de facturas es interesante, pero tiene un par de limitaciones importantes. En primer lugar, hoy en día, entre el momento en que se realiza el consumo y el momento en el que se ve reflejado en la factura pueden llegar a pasar 2 meses; puede servir como toque de advertencia si se nota una variación de consumo al alza, pero es una advertencia muy general. En segundo lugar, la factura aporta datos de consumo total, de forma que es imposible discernir el efecto relativo de cada una de las acciones tomadas en el hogar durante los dos meses anteriores.

\subsubsection{Gráficos utilizados}

Egan [46], en un ensayo muy citado posteriormente, prueba la satisfacción de los usuarios y el grado de comprensión de éstos con respecto a los gráficos mostrados en la Figura 4.1. Los gráficos elegidos para el ensayo no son especialmente fáciles de comprender para la mayoría de los usuarios, que además eligieron como preferido el gráfico $\mathrm{C}$. 


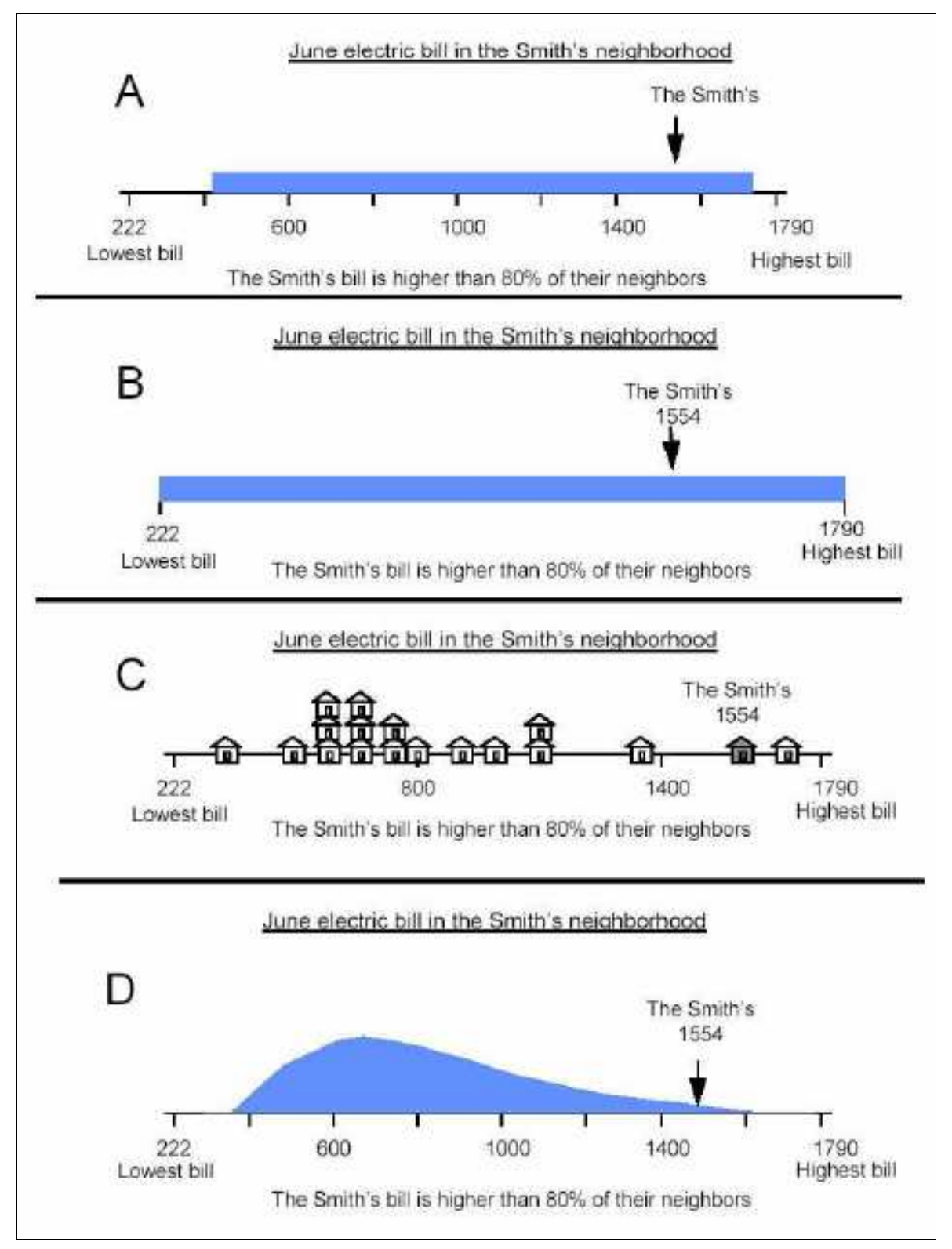

Figura 4.1.- Gráficos ensayados por Egan 
En un informe redactado en 2005 por McLennan Magasanik Associates [97], se sugieren gráficos como el de la Figura 4.2, mucho más simples y fáciles de comprender.

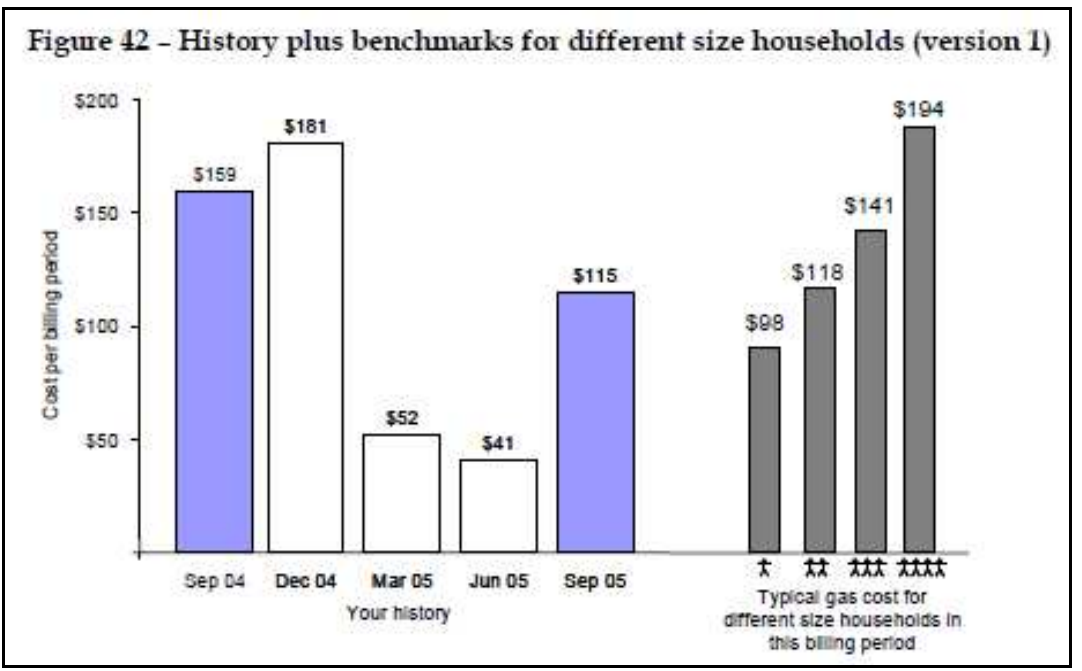

Figura 4.2.- Gráficos ensayados por McLennan

En un tercer informe, [33], se muestran los pertenecientes a la Figura 4.3 y la Figura 4.4:

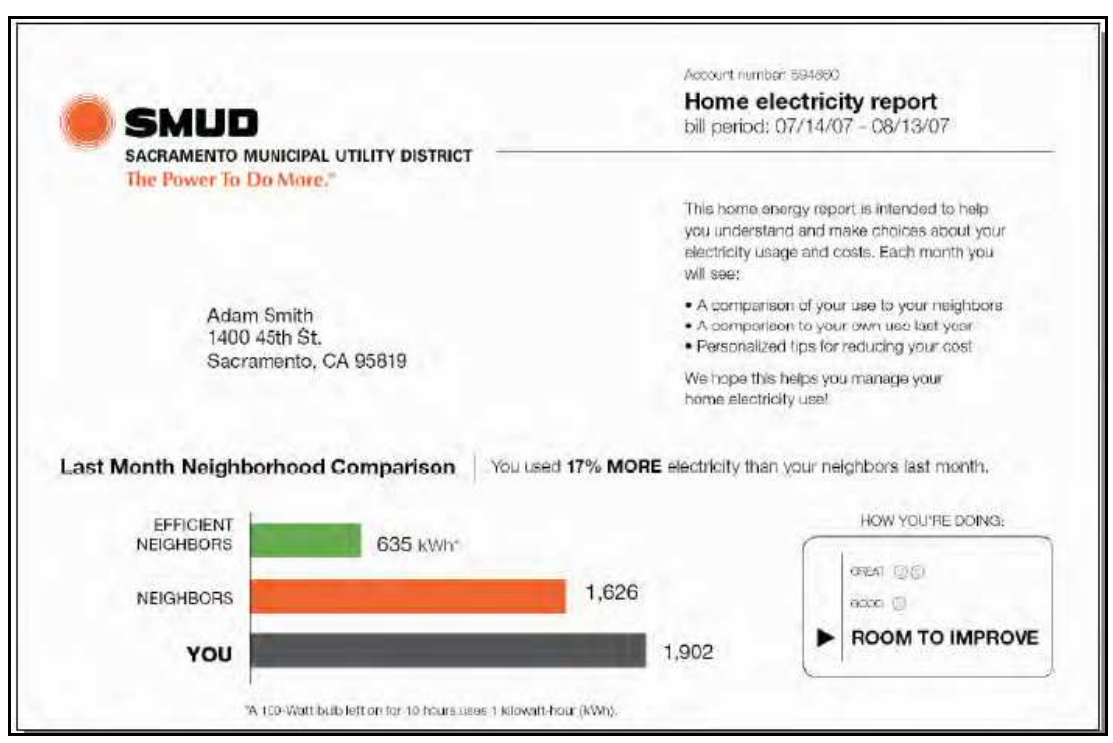

Figura 4.3.- Gráficos ensayados por Carroll 


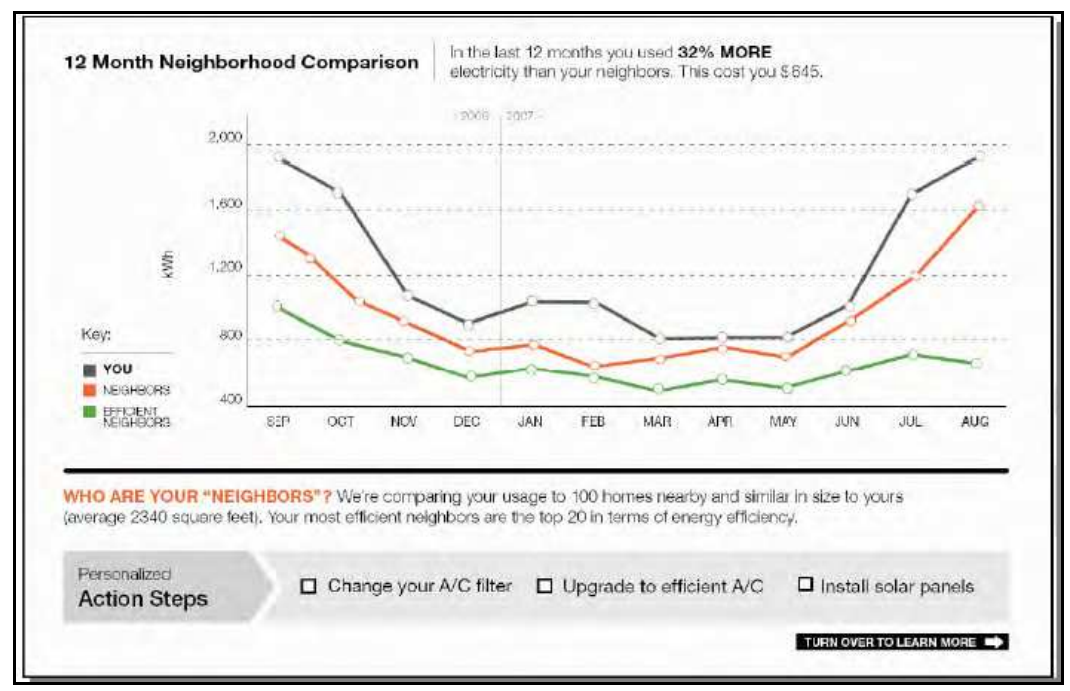

Figura 4.4.- Gráficos ensayados por Carroll

\subsubsection{Resultados de algunos ensayos en vivienda}

\section{Haakana et al [72]}

Se realizó sobre una muestra de 105 hogares en Finlandia. Los habitantes leían sus contadores y enviaban la información a los autores. Con esta información, se realizaron y reenviarion a los participantes una serie de gráficos mensuales, independientes de la factura, conteniendo:

- Comparación con casas similares

- Comparación con el resto de los hogares objeto del estudio

- Coste del consumo energético realizado

- Consejos de ahorro

Mediante este sistema, se obtuvieron los ahorros siguientes:

- Eléctricos $11-16 \%$

- Combustible 6\%

Arvola et al. [10]

Se realizó sobre una muestra de 696 hogares en Helsinki. Consistió en el envío de facturas basadas en datos reales, conteniendo 
- Comparaciones de los consumos con los del mismo mes del año anterior

- Información sobre formas de ahorro

Se obtuvieron niveles de ahorro respecto al grupo de control de entre el 1 y el $4,7 \%$

\section{Wilhite and Ling [127]}

Se realizó sobre una muestra de 1450 hogares de Oslo, a los que se enviaron, junto con la factura, distintas combinaciones de frecuencia, comparación con históricos y consejos.

Se obtuvieron ahorros de entre un 7,5 y un $10 \%$

\section{Garay and Lindholm [62]}

Se realizó sobre una muestra de 600 hogares de Helsinborg. Consistió en la comparación de los consumos del hogar con un patrón, así como el envío de una serie de estadísticas de consumo.

No se obtuvieron niveles de ahorro significativos.

\section{Dünnholff and Duscha [44]}

Se realizó sobre una muestra de 4500 hogares en Heidelberg. Consistió en la comparación de los consumos del hogar con un patrón, así como el envío de una serie de consejos de ahorro. Previamente al inicio del estudio, se llevó a cabo una auditoría personal sobre el consumo de la vivienda.

Se obtuvieron niveles de ahorro de hasta un $5 \%$

\section{Henryson et al [73]}

Se realizó en Oslo (1989/92).Consistió en el envío de seis facturas anuales, con un gráfico de barras de los consumos realizados en los 2 años previos, y junto con una serie de consejos de ahorro.

Se obtuvieron niveles de ahorro de hasta un $10 \%$

\subsubsection{Directiva 2006/32/EC}

Pese a las limitaciones de la realimentación por factura, ésta incluye una información fundamental; tanto es así que la Unión Europea obliga a las compañías eléctricas a proporcionar a sus usuarios una serie de datos 
enfocados a la realimentación. Esto se hace a través de la Directiva 2006/32/EC, del Parlamento Europeo y del Consejo, de 5 de abril de 2006, sobre la eficiencia del uso final de la energía y los servicios energéticos, en su Artículo 13:

- La facturación debe basarse en el consumo real de energía

- La facturación basada en consumo real debe tener la frecuencia suficiente como para permitir que los clientes regulen su propio consumo de energía

- Los distribuidores o las comercializadoras deben facilitar al cliente final, de forma clara y comprensible:

- Los precios reales actuales y el consumo real de energía

- La comparación con el consumo durante el mismo periodo del año anterior, preferiblemente de forma gráfica

- La comparación con un usuario de energía medio, perteneciente a la misma categoría de usuario, si es posible

- Direcciones de Internet donde puede encontrarse información sobre medidas de mejora de la eficiencia energética

En concreto, Iberdrola ha interpretado esta directiva como muestra la Figura 4.5. Otras comercializadoras (Unión Fenosa, Gas Natural y otros), muestran gráficos similares.

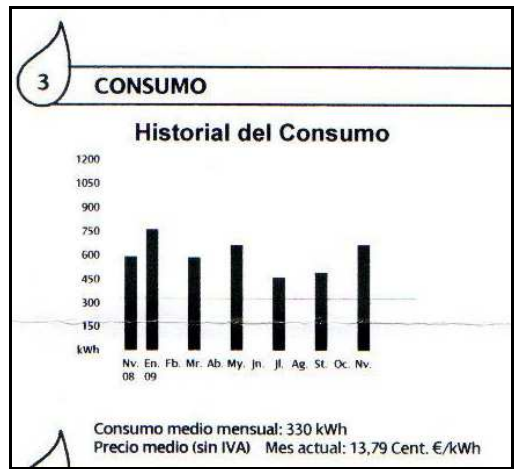

Figura 4.5.- Histograma de consumo de la factura de Iberdrola 


\subsubsection{Sistemas de realimentación mediante prepago}

Consiste en una tarjeta que se introduce en un contador inteligente, 0 un código que se teclea en éste, según países (Figura 4.6). Es un sistema similar al de los móviles de tarjeta prepago. Se utiliza en algunos países, como Gran Bretaña, Irlanda del Norte, Sudáfrica, Argentina, Bélgica, Tasmania. En otros es completamente inexistente, aparentemente debido a las regulaciones en materia de desconexión eléctrica.

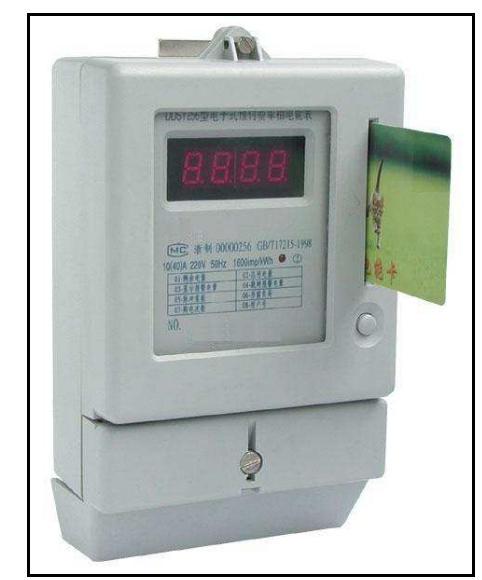

Figura 4.6.- Contador con tarjeta prepago

Tiene como ventaja principal, desde el punto de vista del usuario, que da mucho control sobre el gasto. De hecho, sus usuarios principales son familias de ingresos bajos que, con este sistema, no abultan inconscientemente una deuda importante con la compañía eléctrica sino que son conscientes del crédito restante en todo momento.

Proporciona realimentación inmediata como mínimo a través del control del crédito restante, que va bajando. El contador suele incluir información relevante para el ahorro: consumo instantáneo, consumo acumulado, gasto hasta el momento o crédito restante.

Tiene inconvenientes importantes: para empezar, las tarifas, de momento, son mayores, debido principalmente al precio del contador, que es relativamente sofisticado, y al precio de su instalación. Pero el problema más grave es que hay un riesgo importante de desconexión. 
Se han sugerido las siguientes propuestas de solución a esos inconvenientes: en lo que se refiere a la tarifa, se da por supuesto que la generalización del uso de contadores inteligentes reducirá el precio.

En cuanto al problema de las desconexiones, se sugieren varias posibilidades:

- Ampliación de sistemas de pago (móvil, tarjeta, internet)

- Créditos de emergencia, a abonar al comprar la tarjeta siguiente

- Política de no desconexión nocturna, a abonar al comprar la tarjeta siguiente

- Cambio remoto de prepago a crédito

4.2.3.1. Resultados relativos al uso de este sistema:

Irlanda del Norte [105].- Se estiman ahorros del 3\%

Ontario (Compañía Woodstock Hydro, [42]).- Ahorros 15-20\%. En este caso, el contador incluye información de consumo instantáneo, etc.

\subsubsection{Sistemas de realimentación por contador inteligente}

Se entiende por contador inteligente (smart meter) un equipo de medición de energía, con una pantalla situada en un lugar visible que proporciona información de consumo al usuario. Existen contadores diseñados específicamente para esta función y existen aplicaciones por ordenador o vía móvil que, conectados a un medidor situado en el contador de la vivienda, muestran la información en pantalla.

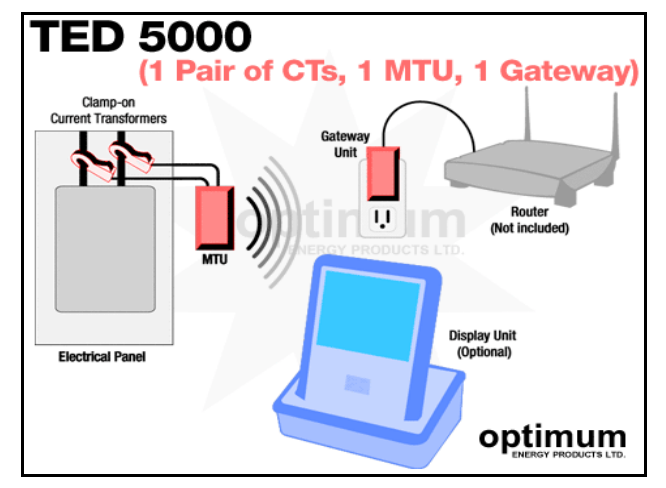

Figura 4.7.- Publicidad de un contador inteligente 
Éste es un sistema de realimentación muy prometedor, como se muestra en los resultados de experimentos en el apartado 4.2.5.2. Sus ventajas principales son:

- La realimentación es instantánea: eso multiplica su potencial como método de aprendizaje

- La información es simple: una gráfica que varía, un precio que aumenta constantemente...

- Si es por Internet, puede incluir comparativas con otros hogares

- Se mantiene en el tiempo, lo que mejora la persistencia

Tiene como inconvenientes que aún es un método caro, y que no discrimina la influencia de cada electrodoméstico en el montante total, salvo por la perturbación inicial.

\subsubsection{Equipos de medida inteligente en el mercado}

Existe hoy en día una gran variedad de contadores inteligentes comerciales. Casi todos muestran consumo instantáneo y acumulado, coste en euros e históricos de todos los tipos. Varían bastante en el diseño, por lo que a continuación se describen algunos de ellos.

\section{Cent-a-meter}

Su monitor es portátil, siendo su aspecto similar al de la Figura 4.8. El propio usuario puede realizar la instalación completa, dado que no necesita la conexión de ningún tipo de cableado. Los valores de potencia y energía se calculan a partir del consumo de intensidad de corriente de la vivienda, medida mediante transformador de intensidad. Ello reduce los costes de instalación. Además, no necesita cables.

Su precio es de 250 euros, y sus características pueden consultarse en http://www.centameter.co.nz

Muestra:

- consumo de potencia con históricos

- gas efecto invernadero

- temperatura, humedad 
- alarma, de valor programable, de pico de demanda

- coste eléctrico total con históricos

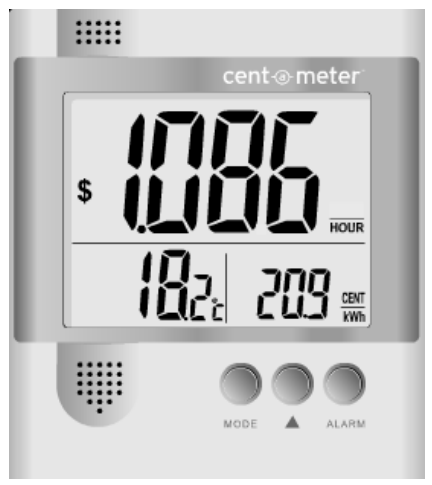

Figura 4.8-Cent-a-meter

\section{Watson}

Su monitor es portátil, su aspecto se muestra en la Figura 4.9. Como el cent-a-meter y muchos otros de este tipo, mide la intensidad consumida y calcula potencias y energías únicamente a partir de ese dato.

No necesita cables (tiene un radio de acción de 50 metros). Muestra, cambiando con un botón, bien kWh, bien coste.

Cambia de color en función de si el gasto es bajo (azul), medio (violeta) o alto (rojo)

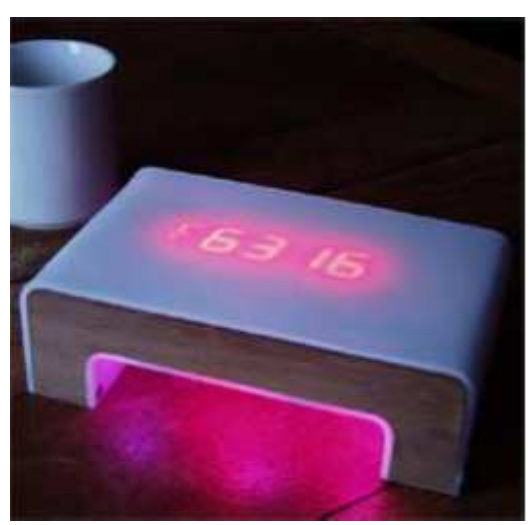

Figura 4.9.- Watson

\section{Energy Orb}


Se ilumina en distintos colores en función de la tarifa del momento (Figura 4.10). Pulsa y cambia de color para dar diferentes avisos. Puede verse en http://www.ambientdevices.com/about-us/energy-products

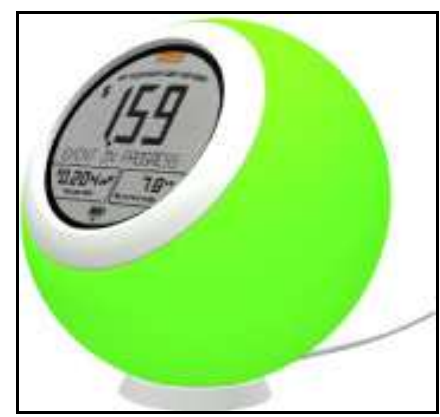

Figura 4.10.- Energy Orb

PCM (Power Cost Energy Monitor)

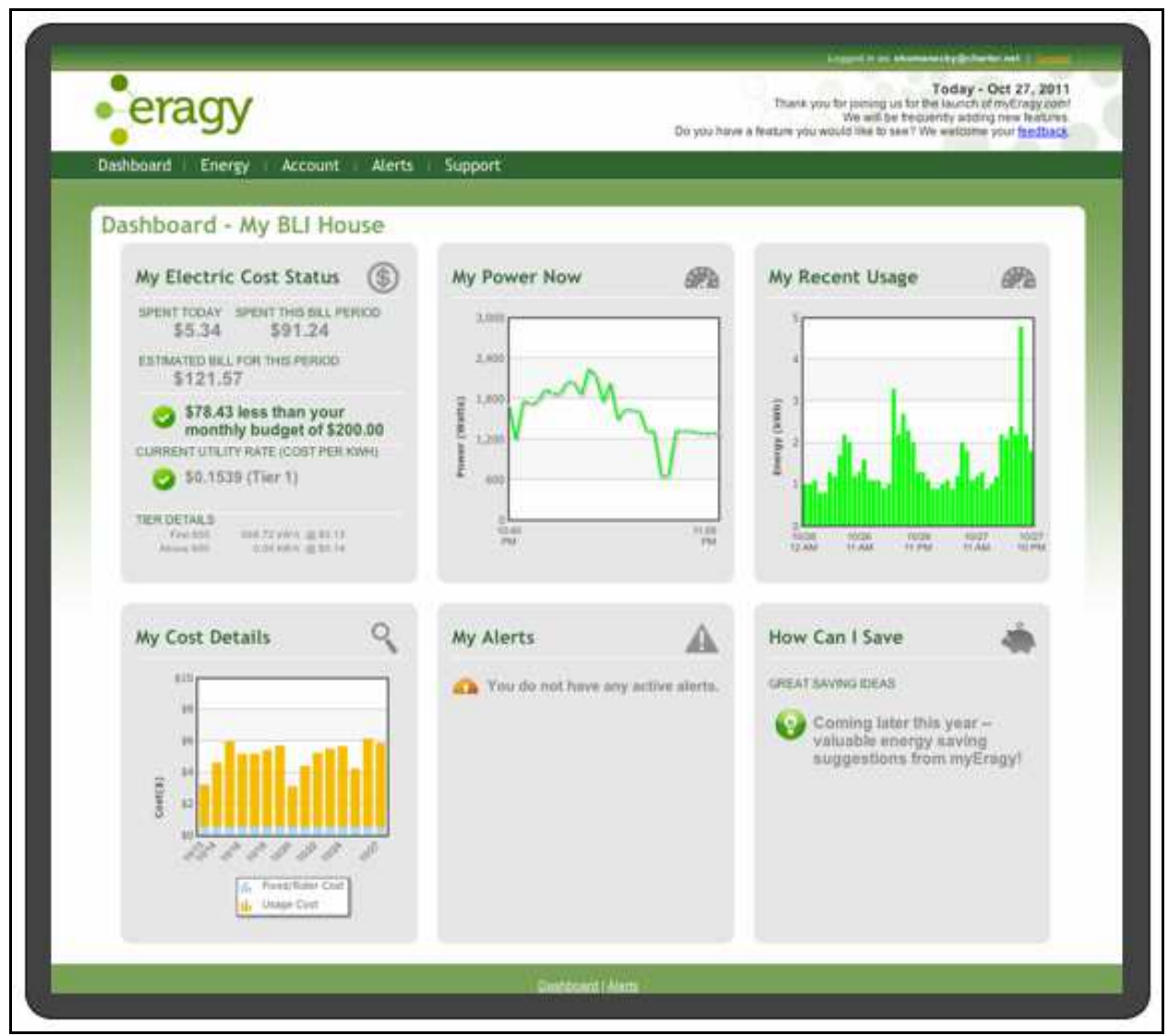

Figura 4.11.- Software del PCM 
Muestra (en dólares y en $\mathrm{kWh}$ ):

- Consumo instantáneo

- Consumo total

- Consumo previsto

- Temperatura exterior

Es sin cable y portable, aunque también incluye software (puede consultarse la información básica en la pantalla del propio contador, pero puede ampliarse esta información en el ordenador con gráficas de consumo, históricos, previsión del valor de la factura, etc: Figura 4.11). Puede verse en http://www.bluelineinnovations.com/Products/power-cost-energy-monitorwifi-gateway/myEragy/

\subsubsection{Diseños realizados para experimentos específicos}

En los experimentos que se describen en los apartados siguientes, se usan tanto contadores inteligentes comerciales como diseños propios. Los primeros tienen la ventaja de la facilidad de su adquisición, los segundos permiten al investigador un diseño perfectamente ajustado a las observaciones que desea realizar. En general, los diseños específicos se consultan en pantallas de ordenador, mientras que los diseños comerciales tienen sus propias pantallas.

Otra diferencia importante entre ellos es el método de toma de medidas, que, en el caso de los comerciales, es en su inmensa mayoría un simple toroide en la entrada de la alimentación, es decir, obtiene toda la información de la medida de la intensidad sin tener en cuenta ni la tensión ni el factor de potencia.

Algunos de los diseños específicos se describen brevemente a continuación, junto con una muestra del diseño de la pantalla informativa.

\section{ECOIS II [124]}

Incluye medida de calefacción, e incluye medida independiente de cada equipo. Graba el número de veces que se actúa sobre cada botón para estudiar posteriormente las preferencias de los usuarios en cuanto a la información. Incluye notas simples sobre métodos de ahorro específicos de ese equipo. Puede verse el aspecto de la pantalla en la Figura 4.12. 


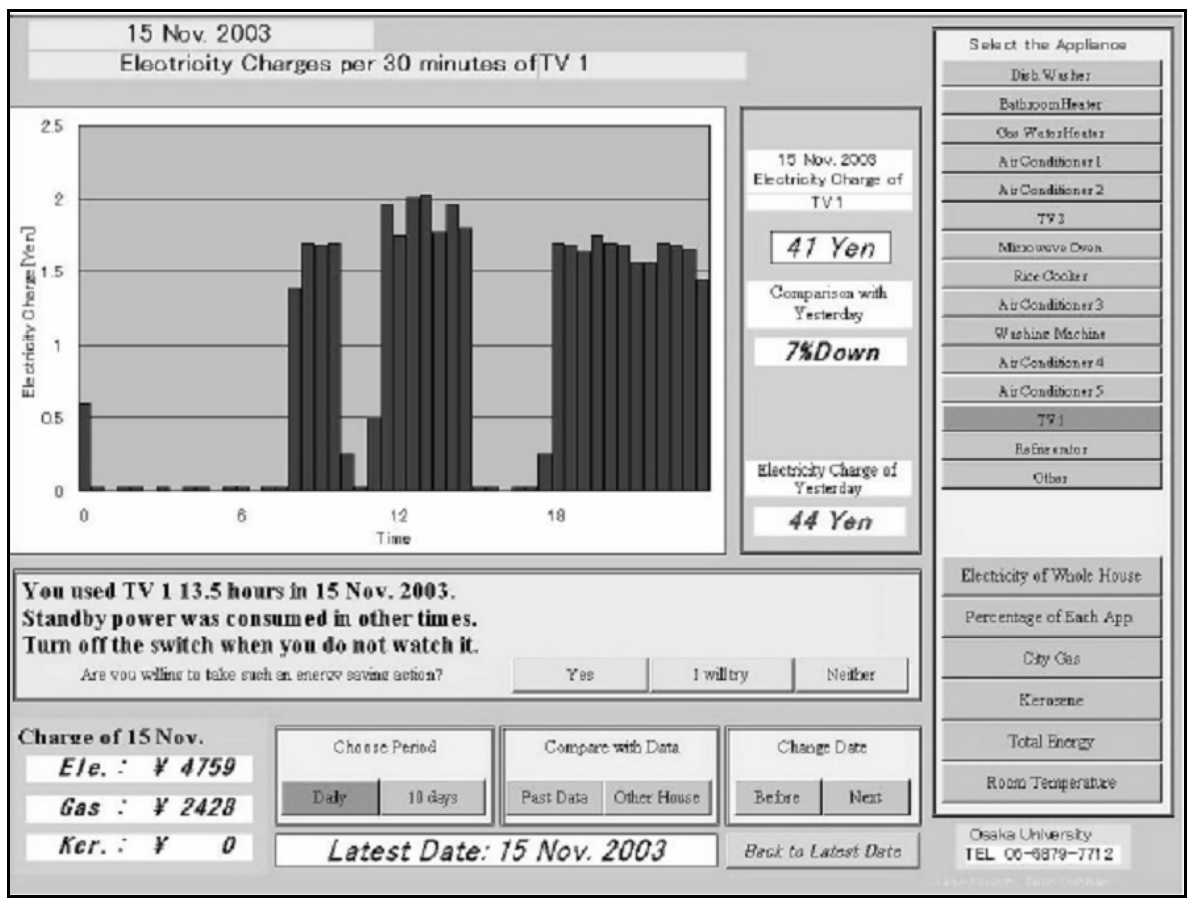

Figura 4.12.- ECOIS II

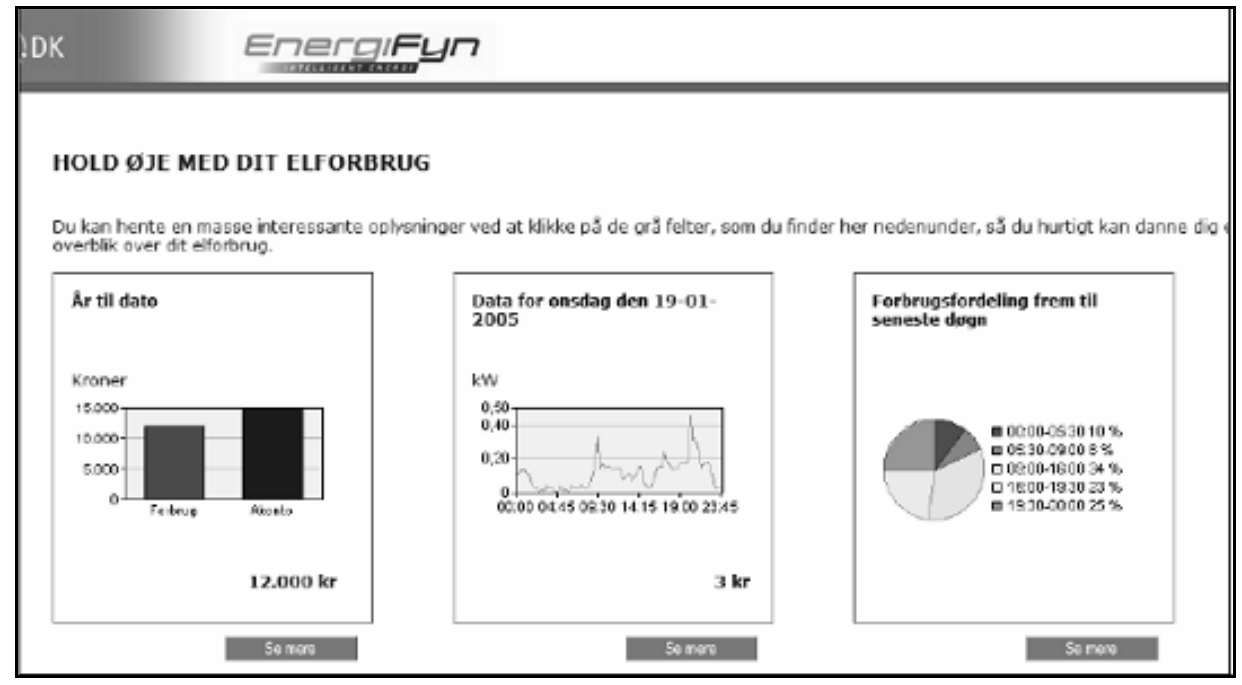

Figura 4.13.- Software experimento Karbo 


\section{Experimento Karbo / Fjordbak [80]}

Los smart meters se comunican con un ordenador central. Los resultados se pueden consultar por Internet. Las medidas se toman cada 15 minutos, vía radio, a un concentrador local. La pantalla principal es similar a la que se muestra en la Figura 4.13.

\section{RECS (residential electricity cost speedometer) [42]}

El software fue desarrollado durante los años 90, por lo que es menos sofisticado en cuanto a su presentación que los anteriores (Figura 4.14). Mide:

- Consumo de la vivienda

- Consumo de distintas cargas, como nevera, lavaplatos, calefacción, ACS, lavadora, secadora, luces y enchufes

- Base: horas, días, meses, años

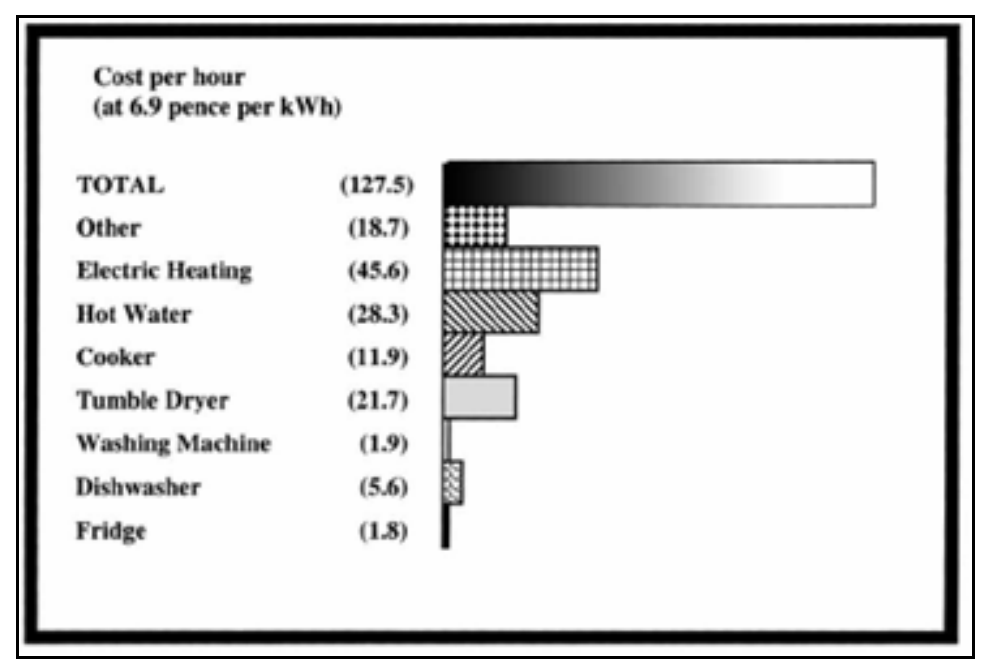

Figura 4.14.- Software RECS

\section{Experimento Wood / Newborough [129]}

Diferencia entre los consumos por evento, los diarios y los semanales (Figura 4.15). No muestra potencia para no confundir al usuario. 


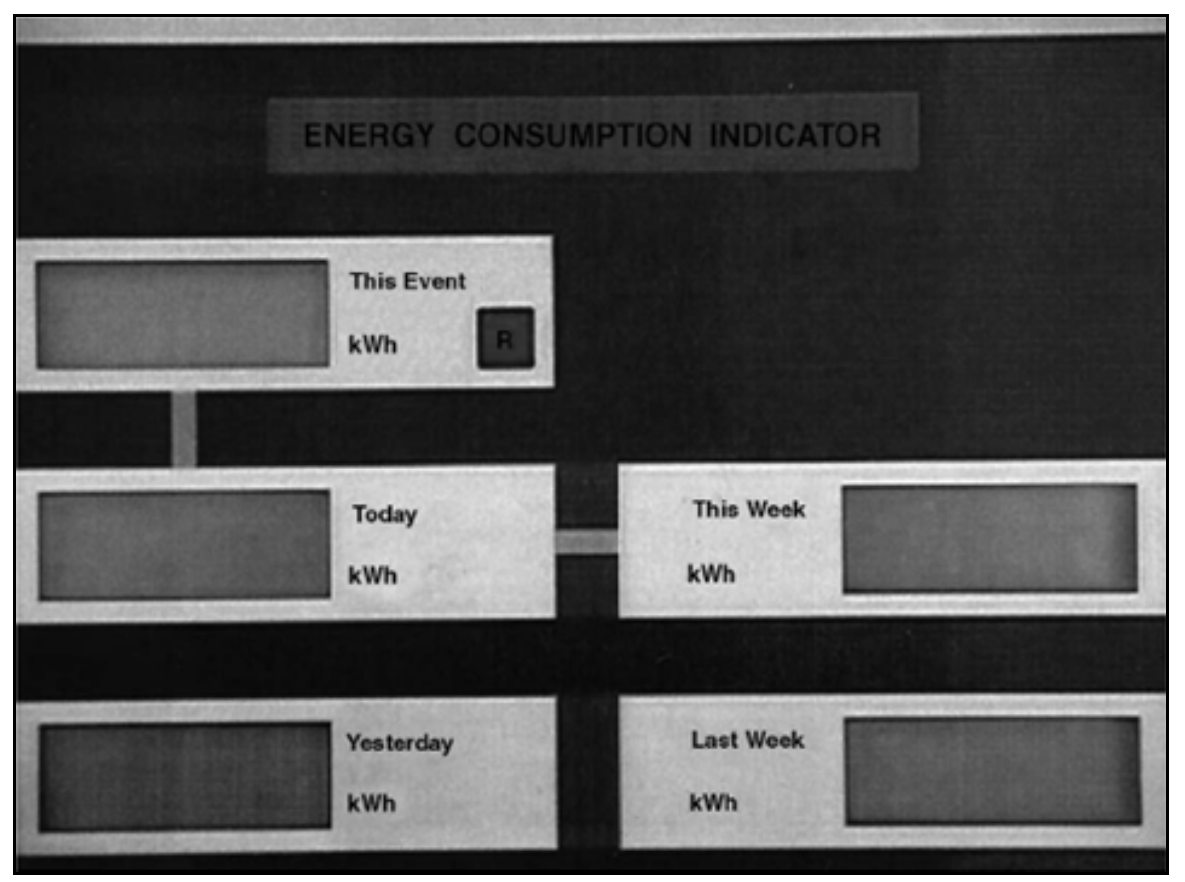

Figura 4.15.- Software experimento Wood

4.2.5.2. Resultados de algunos ensayos en vivienda

En este apartado se describe brevemente las características de algunos ensayos realizados, así como los niveles de ahorro obtenidos y el tipo de contador inteligente utilizado. Los contadores están descritos en los dos apartados anteriores.

\section{Ueno et al [124]}

El contador inteligente utilizado es el ECOIS II, de diseño propio. EI ensayo se realizó en Osaka, para una tipología vivienda de $140 \mathrm{~m}^{2}$, pareja casada con de 1 a 3 hijos. El número de participantes fue de 10 familias más un grupo de control de 9 familias.

Se llevó a cabo durante el año 2002, con un total de 56 días. Se realizó en invierno y sólo en días laborables para minimizar inflluencias externas. Fue monitorizado cada electrodoméstico por separado, así como también la calefacción de manera independiente.

Los ahorros obtenidos alcanzan un $12 \%$. Las reducciones en stand-by fueron considerables, una vez los usuarios fueron conscientes de ese gasto 


\section{Kelsey, González ([83)]}

El contador inteligente utilizado es el Eco-eye y Watson. Se realizó en (Gran Bretaña), en viviendas con 3 o más habitaciones y para familias con niños pequeños. Sólo participaron 6 familias.

No se dan resultados de ahorros obtenidos, pero aparecen una serie de observaciones de interés, como son las siguientes:

- El uso disminuyó con el tiempo, porque, según los participantes, una vez se sabe lo que gasta cada electrodoméstico, es innecesario seguir consultándolo.

- En algunos casos, se incorporó a la rutina diaria, utilizándolo para comprobar que no queda nada encendido de noche o al salir todos de casa.

- Todos prefirieron el Watson, que cambia de color.

\section{Karbo y Larsen [82]}

El contador inteligente es de diseño propio, cuyo diseño requiere conexión a Internet. Se llevó a cabo en 3000 hogares de Dinamarca

\section{The Hydro-One pilot [75]}

El contador inteligente es una marca comercial, el PCM. El ensayo dio comienzo en el año 2006, y tuvo una duración de 2,5 años. El estudio se realizó paralelamente en 5 regiones distintas: Barrie, Brampton, Lincoln, Peterborough y Timmins, y en total se tomaron datos de 400 participantes.

Los ahorros obtenidos fueron los siguientes: en hogares sin calefacción eléctrica: 8,2 \%; en hogares con calefacción eléctrica: $1,2 \%$. No incluía información de consejos de ahorro de ningún tipo; cuantifica el añadido de éstos en una mejora del ahorro de un 7-10 \%. El impacto fue cuantificado con respecto a los consumos del año previo,

Incluye una serie de observaciones de interés, como son las siguientes: recomienda una medición separada del consumo en calefacción, y hay una persistencia considerable de los niveles de ahorro en el tiempo

\section{Ontario Hydro [42]}

El contador inteligente utilizado es el RECS (diseño propio). El ensayo se realizó durante el año 1992, con una duración de 60 días. Fue llevado a cabo 
en Ontario, Canadá, para una muestra de 25 hogares + grupo de control + grupo ciego (total 100 hogares). El grupo de control sabía que estaban midiendo su consumo).

Se obtuvieron ahorros de un $12,9 \%$. Como observación a tener en cuenta, el ensayo indica un decrecimiento en el ahorro con el tiempo,

\section{Wood and Newborough [129]}

El contador inteligente es de diseño propio. Fue llevado a cabo en Gran Bretaña, para 44 familias, en 3 grupos: Control, Sólo información, Información + Contador Inteligente.

El ensayo sólo medía cocina, y tuvo una duración de 4 meses, con unos meses previos para tener información de consumos, durante el año 2003. Se obtuvieron ahorros de entre un 10 y $23 \%$, en el grupo con información y contador inteligente.

\section{Alahmad et al [5]}

Utilizaron dos tipos de contador inteligente, ambos de marcas comerciales: Aztech y PCM. Fue llevado a cabo en Omaha, Nebraska. El número de participantes fue de 151 hogares + 95 en grupo de control

El ensayo se realizó durante dos años, del 2007 al 2009. Se obtuvieron ahorros de un $12 \%$ en el PCM pero aumento de consumo en el Aztech

Hay varias observaciones interesantes en el artículo, como son las siguientes:

- Se proporciona una página web para dudas de los participantes y con información sobre medidas básicas de ahorro energético.

- El hecho de pedir participantes voluntarios hace que las personas concienciadas (que son las que menos pueden reducir su consumo), estén sobrerrepresentadas en la muestra.

\section{Faruqui and Wood [57]}

El contador inteligente es una marca comercial, el Energy Orb. El ensayo se realizó durante el año 2008, para 62 hogares, e incluyó, además del contador inteligente, discriminación horaria, información por carta del consumo del mes previo e información por carta de los métodos de ahorro. 


\section{Evaluación de métodos en laboratorio. Experimento 1.}

\subsection{Metodología}

Los experimentos económicos suelen utilizar dinero en efectivo para incentivar a los sujetos que participan en ellos, y se utilizan, con apoyo de la estadística, para testear, en un entorno simple y controlado, el comportamiento económico de los individuos en determinadas situaciones.

En este estudio en particular, se han utilizado las instalaciones de economía experimental del Departamento de Economía de la Facultad de Ciencias Jurídicas y Económicas de la Universidad Jaume I para llevar a cabo un experimento económico consistente en simular el comportamiento energético de los sujetos en una vivienda virtual, y obtener datos de las variaciones de comportamiento obtenidas variando la información suministrada a éstos. Este experimento económico en concreto es considerablemente novedoso en dos aspectos independientes: su metodología y su objeto de estudio.

En cuanto a la metodología utilizada, el entorno virtual desarrollado para la realización de los experimentos, descrito en los apartados siguientes, es considerablemente más complejo que ninguno de los diseñados hasta ahora. 
El número de decisiones a tomar por el sujeto a lo largo de las sesiones, la cantidad de información que se le suministra y la complejidad de las modificaciones de comportamiento necesarias para la obtención de resultados mensurables, no han sido nunca intentadas en laboratorio antes, al menos no con éxito. El haber obtenido resultados significativos en un entorno tan complejo para el sujeto, abre un nuevo campo de investigación en la economía experimental, basado en el uso de simulaciones más complejas y por tanto más próximas al mundo real.

En cuanto al objeto del estudio, las modificaciones del comportamiento energético en la vivienda en función del tipo de información suministrado, nunca ha sido antes ensayado en forma de experimento económico. Ello abre por tanto también una nueva vía de investigación en el campo de la ingeniería: cualquier método de ahorro energético puede ensayarse de forma sencilla, en un plazo de tiempo breve y con un presupuesto económico reducido, en laboratorio; los resultados obtenidos se probarán, en el resto de experimentos, en forma de ensayos en viviendas reales; sin embargo, gracias a la experimentación previa en laboratorio se pueden obtener muchas observaciones importantes previas a bajo coste.

En los apartados siguientes se hace un resumen de la teoría básica de la economía experimental, que luego es utilizada para el desarrollo del experimento.

\subsubsection{Función de utilidad}

Una función de utilidad es una función que mide la satisfacción obtenida por un consumidor cuando disfruta de cierta cantidad de bienes. Es decir, es la medida del dinero que una persona estaría realmente dispuesta a pagar por el uso de un bien. Cuanto más vital es un bien, mayor es su utilidad. Cuantas menos unidades se poseen de un mismo bien, más valor tiene la unidad actual.

La función de utilidad cuantifica de forma objetiva la necesidad que tiene una persona de determinado producto. La cuantificación se hace en forma de dinero, y mide cuánto estaría verdaderamente dispuesta una persona a pagar por recibir un servicio o comprar un producto.

A mayor cantidad de un bien, menor la utilidad de la unidad siguiente; la función, como muestra la Figura 5.1, es siempre creciente pero tiende a la saturación en un número determinado de unidades del bien. 


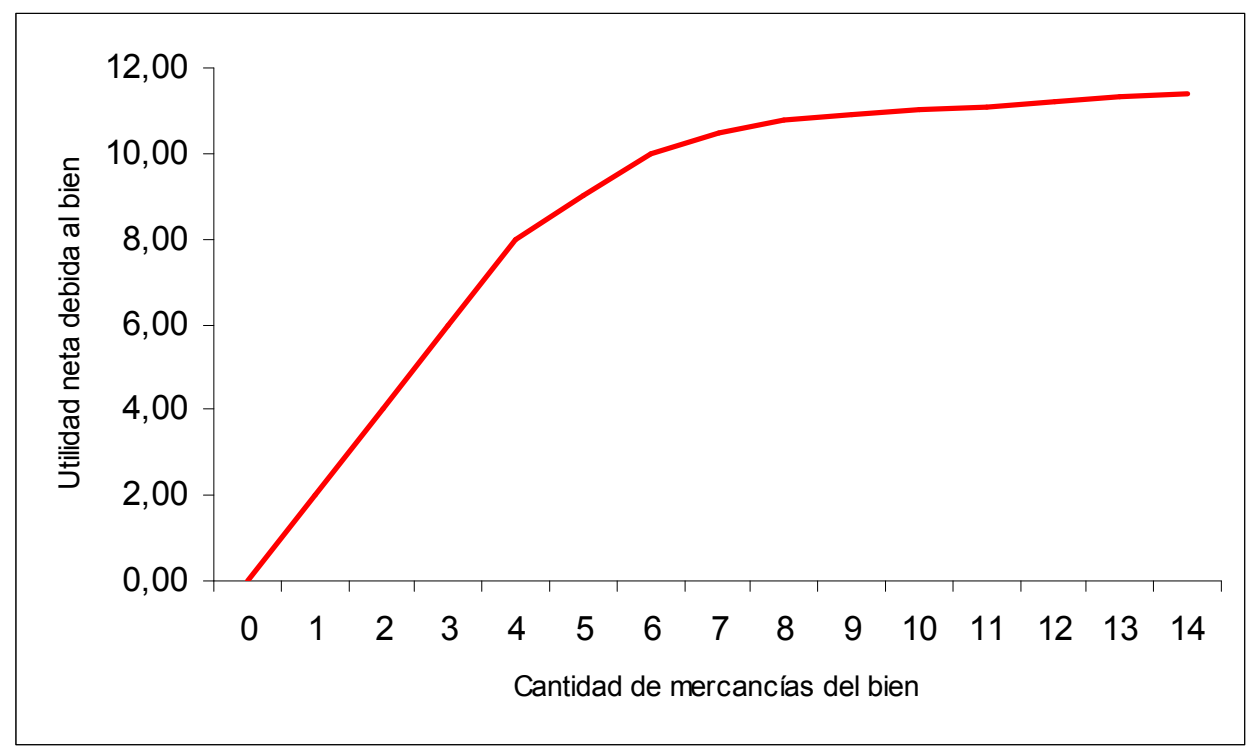

Figura 5.1.- Función de utilidad

Es decir, la función en su tramo inicial tiene una fuerte pendiente positiva ya que, si el consumidor carece de un bien, el hecho de incrementar su consumo aumenta mucho su satisfacción. En cambio, a partir de la saturación, ésta se vuelve prácticamente constante.

Al ser una función creciente, la primera derivada, parcial si se trata de una función de varias variables, es positiva $\left(f^{\prime}\left(Q_{i}\right)=\partial U / \partial Q i>0\right)$. Sin embargo, debido a su forma, la segunda derivada parcial es negativa. $\left(f^{\prime \prime}\left(Q_{i}\right)=\partial^{2} U / \partial Q i^{2}\right.$ $<0)$.

\subsubsection{Función de utilidad marginal}

Es el valor que se otorga a cada unidad adicional de un bien, o variación de la utilidad ante un cambio infinitesimal en la cantidad consumida de un bien: $U_{M Q 1}=\partial U / \partial Q i$. Su valor depende de la forma específica de $U$, aunque siempre:

Su valor es positivo (recordemos que $\left.f^{\prime}(Q i)=\partial U / \partial Q i>0\right)$

Su forma es decreciente (recordemos que $\left.f^{\prime \prime}(Q i)=\partial^{2} U / \partial Q i^{2}<0\right)$ 


\subsubsection{Aplicación de la función de utilidad en la economía experimental}

La utilidad de un bien es, en resumen, una forma simple de cuantificar el grado de satisfacción obtenido por el uso repetido de ese bien. La función de utilidad de cualquier bien es, en la realidad, diferente para cada persona, y depende de sus intereses personales. Por ejemplo, para algunas personas la utilidad de un equipo de música será mayor que la de un televisor; para otras ocurrirá al contrario.

Cada uso de un bien supone, a su vez, un gasto asociado, en este caso en forma de consumo energético; si cuantificamos la utilidad de un bien en euros, podemos calcular el beneficio final obtenido por su uso como la diferencia entre la satisfacción que produce (es decir, su utilidad), y el gasto que supone (es decir, el consumo energético). A esta diferencia la llamaremos beneficio.

\section{Beneficio $=$ Utilidad - Coste}

Dadas las formas combinadas de la función de utilidad y la de gasto, existe una combinación óptima, en la que la diferencia entre utilidad y gasto, es decir el beneficio, es máxima. Por ejemplo, en la Figura 5.2 se muestra la función de utilidad de un electrodoméstico, comparada con el consumo eléctrico que supone. En el eje de abscisas se muestra el número de unidades de uso de este electrodoméstico, y en el de ordenadas, el dinero asociado tanto a utilidad como a gasto. Es evidente que, en este caso, el beneficio máximo está en un uso semanal, coincidiendo con el punto de inflexión de la curva de utilidad.

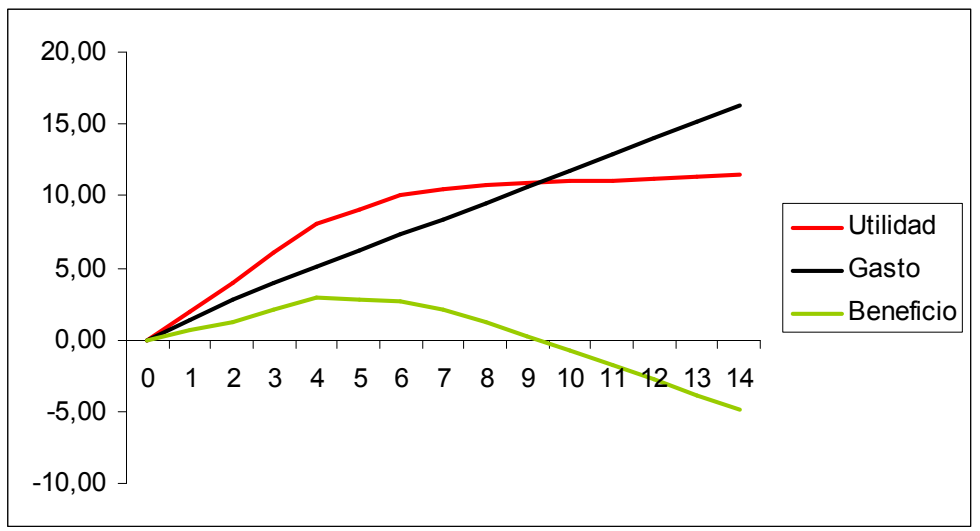

Figura 5.2- Funciones de utilidad y consumo asociado de la plancha 


\subsubsection{Aplicación de la función de utilidad al estudio}

En las sesiones experimentales realizadas para este estudio, los voluntarios conocen en cada momento el nivel de utilidad, medida en euros virtuales, que obtienen con una combinación determinada de electrodomésticos. Así como el valor de la utilidad se suministra por igual a todos los participantes, la información sobre el consumo energético del sujeto será diferente para cada grupo: ésta es la base que nos permite observar las diferencias de comportamiento en función de los sistemas de realimentación utilizados, así como determinar cómo afecta el tipo de información a la capacidad del voluntario de optimizar su comportamiento.

Las funciones de utilidad de cada electrodoméstico se han definido situando los máximos beneficios en lo que se ha considerado un uso razonable de los electrodomésticos, y un beneficio prácticamente nulo en un uso nulo o claramente excesivo. El cálculo exacto de la función de utilidad y el consumo de cada electrodoméstico puede consultarse en el Anexo I.

\subsection{Planificación de las sesiones experimentales}

\subsubsection{Descripción de los ensayos}

Los experimentos consisten en la simulación del comportamiento energético de una familia a lo largo de un año y medio. Cada mes estará representado por un único día tipo; lo que el sujeto decida para ese día se repetirá para los restantes 29 días del mes. Los días tipo se irán alternando: 3 de invierno, que representarán 3 meses, 3 de verano, y así sucesivamente. En cada día tipo, el participante tiene que seleccionar los electrodomésticos que quiere utilizar, el modo y el número de usos semanales o diarios.

El valor de la utilidad se le muestra al sujeto al lado de cada electrodoméstico, cuando selecciona el uso que va a hacer de él. La utilidad será función del número de usos semanales o el número de horas diarias que se utilice.

Al terminar el "mes", es decir, cuando el sujeto termine de rellenar un día tipo, se le presentará una factura eléctrica y una de gas, correspondientes al mes que acaba de rellenar. En ella verá también la utilidad total obtenida con su comportamiento mensual, así como el beneficio correspondiente al 
periodo. Al participante se le pagará, al final del experimento, una cantidad de dinero proporcional al beneficio obtenido.

\subsubsection{Descripción de los tratamientos}

En los experimentos de laboratorio se han probado seis tipos de tratamiento diferentes. Cada uno se llevó a cabo en una sesión independiente, con una duración aproximada de 2 horas. Los tratamientos probados, y la información ofrecida a los participantes en cada uno de ellos, fueron los siguientes:

- Tratamiento Básico: Una factura eléctrica y de gas por mes.

- Tratamiento Consejos: Una factura eléctrica y de gas por mes, junto con un conjunto de consejos de buenos hábitos energéticos, repetidos todos los meses.

- Tratamiento Contador Único: Una factura eléctrica y de gas por mes, junto con un contador inteligente que muestra el consumo instantáneo del conjunto del hogar, en kWh, o céntimos de euro.

- Tratamiento Contador Desagregado: Una factura eléctrica y de gas por mes, junto con un conjunto de contadores inteligentes, que muestra el consumo instantáneo de cada grupo de electrodomésticos por separado, en kWh o céntimos de euro.

- Tratamiento ranking: Una factura eléctrica y de gas por mes, junto con información comparativa con el comportamiento de los demás usuarios del sistema. Este tratamiento se repitió en dos sesiones diferentes, dado que, al existir información de la actuación del resto de participantes, el grupo completo sólo supone una observación independiente.

\subsubsection{Días y estaciones simulados}

En principio se tenía la intención de simular tanto días laborables como festivos, tanto de invierno como de verano. Finalmente, se decidió, para simplificar el entorno, simular únicamente días laborables. Cada día laborable programado por el sujeto se consideraba un mes completo (multiplicando los consumos por 30 días).

Se fueron alternando 3 "meses" laborables de invierno, que simulaban una estación, con 3 de verano, hasta completar un total de 18 meses. 


\subsubsection{Descripción de la vivienda}

\subsubsection{Estancias}

La vivienda es un hogar formado por tres miembros (padre, madre y un hijo). Dispone de salón, cocina independiente, dos habitaciones y un cuarto de baño. La calefacción y el ACS son de gas, todo el resto de electrodomésticos e iluminación son eléctricos. No hay aire acondicionado.

\subsubsection{Electrodomésticos, iluminación y climatización}

\begin{tabular}{|c|c|c|c|}
\hline \multirow{2}{*}{\multicolumn{2}{|c|}{ Electrodoméstico }} & \multicolumn{2}{|c|}{ Consumo } \\
\hline & & kWh/ciclo & kW \\
\hline Calefactor & & 1 & \\
\hline Horno & & 1,5 & \\
\hline \multirow{2}{*}{ Microondas } & Desayuno & 0,0389 & \\
\hline & Comida / cena & 0,29 & \\
\hline Tostador & & 0,092 & \\
\hline Vitrocerámica & & 0,24 & \\
\hline \multirow{4}{*}{ Lavadora } & ciclo frío & 0,12 & \\
\hline & ciclo 40은 & 0,19 & \\
\hline & ciclo 60을 & 0,45 & \\
\hline & stand-by & & 0,00145 \\
\hline \multirow{3}{*}{ Lavaplatos } & Ciclo rápido & 0,68 & \\
\hline & ciclo ECO & 0,88 & \\
\hline & stand-by & & 0,00214 \\
\hline Plancha & & 0,224 & \\
\hline \multirow{2}{*}{ TV } & & & 0,135 \\
\hline & stand-by & & 0,0024 \\
\hline \multirow{2}{*}{ Minicadena } & & & 0,008 \\
\hline & stand-by & & 0,004 \\
\hline Ordenador & & & 0,165 \\
\hline \multirow{2}{*}{ Portátil } & & & 0,028 \\
\hline & stand-by & & 0,015 \\
\hline \multirow{3}{*}{ Alumbrado } & Cocina & & 0,04 \\
\hline & Salón & & 0,024 \\
\hline & Habitaciones & & 0,012 \\
\hline
\end{tabular}

Tabla 5.1.- Consumo eléctrico del equipamiento de la vivienda 
Todos los participantes disponen exactamente del mismo equipamiento, con las mismas características y el mismo consumo eléctrico para todos ellos. Dado que la oferta de cada tipo de electrodoméstico existente es grande y la diferencia en consumo dentro de cada tipo en algunos casos es considerable (por ejemplo televisiones, en función del tamaño de la pantalla y el tipo de tecnología, o frigoríficos en función de su volumen y de si tienen o no congelador), se ha decidido seleccionar unas marcas y modelos determinados, razonablemente modernos, y de clases energéticas en el margen en el que se fabrican en estos momentos.

Ese equipamiento y su consumo asociado son los indicados en las Tabla 5.1 y Tabla 5.2 .

Consumo de gas de la vivienda

\begin{tabular}{|c|c|c|c|}
\hline \multirow{2}{*}{\multicolumn{2}{|c|}{ Tipo de consumo }} & \multicolumn{2}{|c|}{ Consumo } \\
\hline & & kWh/ciclo & $\mathrm{kW}$ \\
\hline \multirow{3}{*}{ ACS } & Ducha 1 & 0,96 & \\
\hline & Ducha 2 & 1,44 & \\
\hline & Baño & 4,15 & \\
\hline \multirow{15}{*}{ Calefacción } & 150 & & 0,425 \\
\hline & 160 & & 0,46 \\
\hline & 170 & & 0,5 \\
\hline & 180 & & 0,54 \\
\hline & 190 & & 0,58 \\
\hline & 20 은 & & 0,62 \\
\hline & 210 & & 0,67 \\
\hline & 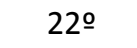 & & 0,73 \\
\hline & $23 ㅇ$ & & 0,79 \\
\hline & $24 \stackrel{\circ}{0}$ & & 0,85 \\
\hline & 25 은 & & 0,92 \\
\hline & 260 & & 0,99 \\
\hline & 270 & & 1,07 \\
\hline & 280 & & 1,16 \\
\hline & 290 & & 1,25 \\
\hline
\end{tabular}

Tabla 5.2. Consumo de gas en la vivienda 


\subsection{Desarrollo de las sesiones experimentales}

\subsubsection{Participantes}

En cada una de las sesiones experimentales participaron un total de 30 voluntarios, es decir, un total de $30 \times 6=180$ sujetos.

\subsubsection{Instrucciones}

Al inicio de cada sesión se programó una presentación de una media hora para explicar a los sujetos el uso del software (Figura 5.3). El contenido de esta presentación puede consultarse en el Anexo I.

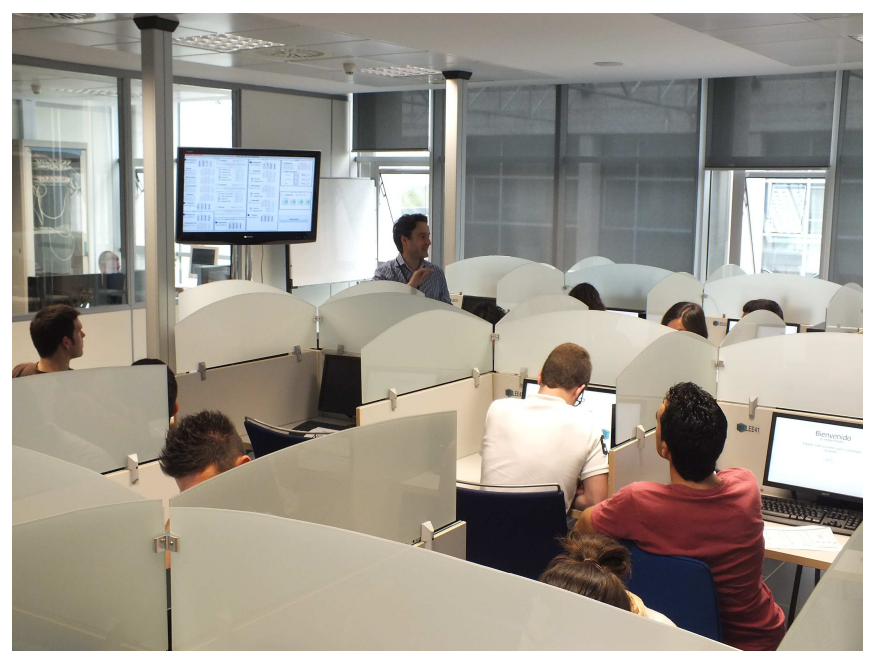

Figura 5.3- Presentación del software a los participantes

\subsubsection{Interfaz}

El interfaz diseñado para la realización de los experimentos de laboratorio consiste en dos pantallas, una (la Pantalla de Programación) en la que los sujetos programan su comportamiento energético en el hogar durante un día tipo, y otra (la Pantalla de Factura) en la que se les muestra las facturas eléctricas y de gas asociadas a ese comportamiento, junto con el beneficio final obtenido, que es una simple resta: la Utilidad menos el Gasto.

Hay una tercera pantalla, que sólo aparece en los tratamientos de ranking, en la que se informa de la posición en la que ha quedado el sujeto con respecto a la media y al mejor de su grupo. 
La Pantalla de Programación es diferente para cada uno de los tratamientos, pero la variación es mínima, y consiste únicamente en el añadido, a la Pantalla de Programación Básica, de la información asociada a cada uno de los métodos de realimentación.

\subsubsection{Pantalla de programación básica}

Es la pantalla principal del programa (ver Figura 5.4). En ella se ve un día tipo (laborable invierno o laborable verano). Los electrodomésticos están agrupados por estancias (cocina, habitaciones, salón y baños), y en cada uno de ellos puede programarse el número de horas en las que se encuentra en marcha, si se queda o no en stand-by, el tipo de ciclo que se utiliza y otros detalles. Además, en los días de invierno, hay un programador para la temperatura de la calefacción.

Hay electrodomésticos con usos en forma de ciclo, como la lavadora o el lavaplatos. Están presentados de forma que el usuario puede elegir el tipo de ciclo y el número de ciclos por semana. Otros electrodomésticos se usan por horas, como la TV o el equipo de música. Estos últimos se seleccionan y calculan por horas. También hay electrodomésticos que no admiten manipulación, como el módem-router o el refrigerador, que se mantienen en marcha las 24 horas del día. De entre los electrodomésticos, los que se prestan a tener modo de espera también tienen una tecla de selección de apagado total.

El sujeto debe decidir qué electrodomésticos utiliza en un periodo determinado, durante cuántas horas o ciclos y con o sin apagado total, y, una vez hecho, él mismo da paso al siguiente periodo pulsando la tecla "Siguiente".

Una vez el sujeto da paso al siguiente periodo, el programa simulará un mes completo multiplicando el consumo de un día por los 30 días del mes; el resultado de esta operación se utilizará para el cálculo de la factura mensual. 


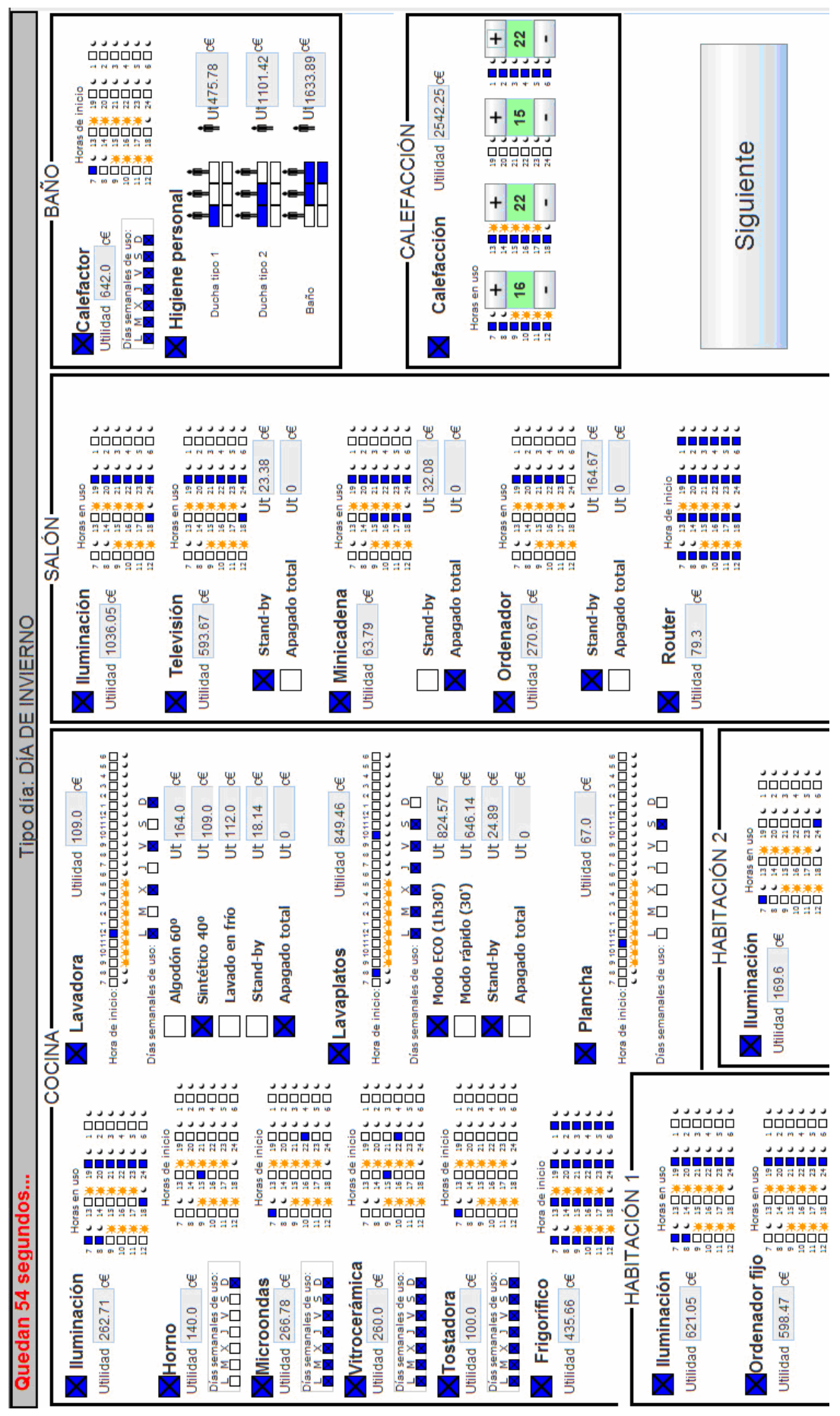

Figura 5.4. Pantalla de programación básica 


\subsubsection{Factura mensual}

Es la pantalla que se muestra seguidamente a la de programación (Figura 5.5. ). Contiene: el coste en energía eléctrica y de gas, la utilidad total obtenida, y el beneficio del periodo. También se muestra un histograma con el comportamiento de los últimos seis meses.

Esta pantalla es común a todos los escenarios.

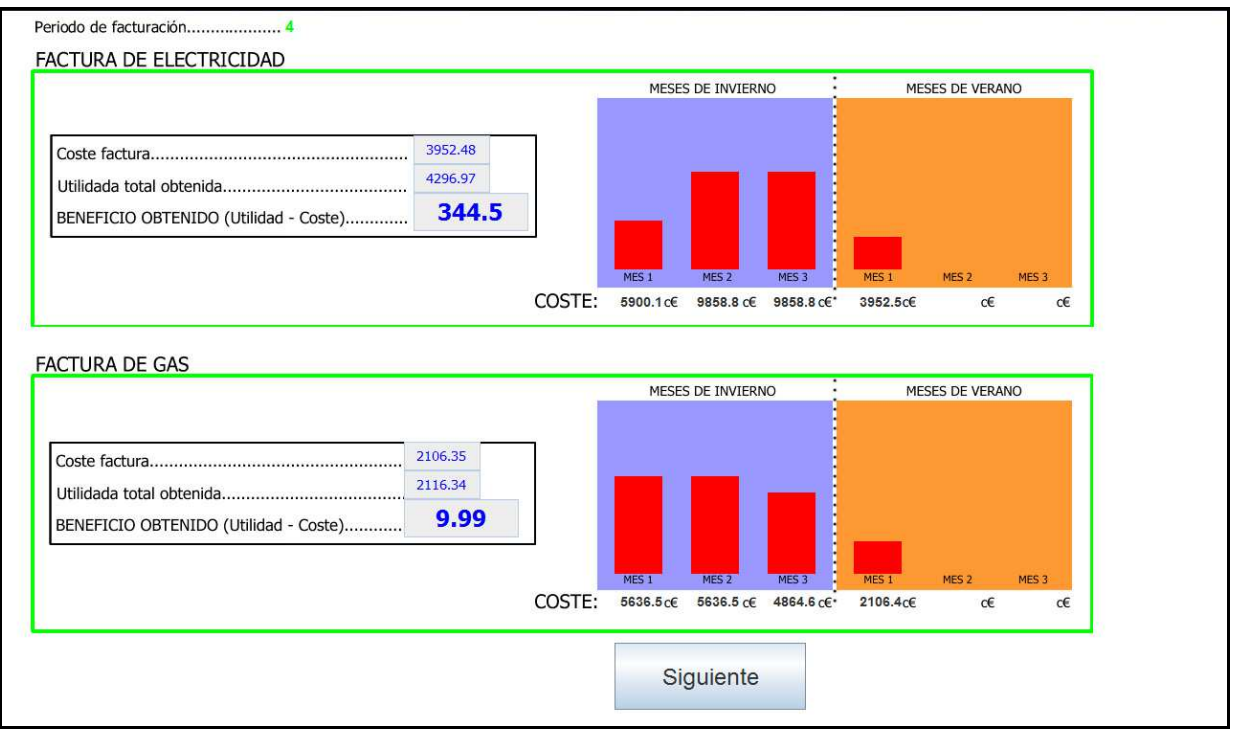

Figura 5.5. - Pantalla de la factura mensual

Puede consultarse el cálculo de los valores incluidos en la factura en el Anexol.

\subsubsection{Desglose de la pantalla básica}

\subsubsection{Iluminación}

Existen 4 puntos de selección de iluminación: en la cocina, el salón, la habitación de los padres y la del hijo. Todos funcionan de la misma forma: al seleccionar su uso (pulsando en el cuadrado de la derecha del nombre), se selecciona por defecto la luz encendida las 24 horas del día. El sujeto debe apagar la luz en las horas en las que no quiera que ésta permanezca encendida. Hay un icono al lado de cada hora, mostrando si es de día o de noche. 
5.3.6.2. Horno, microondas, vitrocerámica, tostadora, plancha y calefactor

Todos funcionan de la misma forma: primero se selecciona su uso, después el número de días de la semana que va a utilizarse, y después la o las horas del día en las que va a ponerse. Por ejemplo, se puede poner la plancha los sábados a las 12:00, lo cual supondría un uso de un ciclo semanal, o se puede poner la vitrocerámica los lunes, martes y miércoles a las 12:00 y a las 20:00, para hacer la comida y la cena esos tres días de la semana. Eso supondría un uso de 6 ciclos por semana.

\subsubsection{Lavadora y lavaplatos}

Permiten elegir los días y horas de uso, como el grupo del horno, pero además hay que seleccionar el tipo de programa con el que se va a lavar. También se puede elegir entre dejarlas en stand-by (con el piloto destellando cuando terminan), o apagarlas con el botón de on/off (casilla "apagado total").

\subsubsection{Frigorífico y MODEM/router}

Tanto uno como otro son electrodomésticos sin posibilidad de manipulación por parte del sujeto. Aparecen en la pantalla, en la que se muestra su consumo, pero no permiten ningún tipo de elección, dado que necesariamente se encuentran encendidos las 24 horas del día. Suponen un consumo energético del que no se puede prescindir.

\subsubsection{Ordenador fijo, TV, equipo de música, ordenador portátil}

Se selecciona el número de horas que se desea usar y el stand-by o el apagado total. En el caso del ordenador, el stand-by significa dejarlo encendido y cerrar la pantalla, y en el televisor y equipo de música, dejarlos preparados para encenderlos con el mando a distancia.

\subsubsection{Higiene personal}

En los ideogramas, la primera columna representa al padre, la segunda a la madre y la tercera al niño. Cada uno de ellos puede elegir hasta dos lavados diarios, del tipo que deseen. La primera ducha es enjabonándose con el grifo cerrado, la segunda con el grifo abierto. La caldera es de gas, luego el gasto correspondiente a este término se encontrará en la factura de gas. 


\subsubsection{Calefacción}

Se puede elegir la temperatura (así como encender o apagar la calefacción), en 4 tramos diferentes del día. Por ejemplo, para bajarla por la noche o apagarla si se sale de casa durante muchas horas. Este término también pertenece a la factura de gas. Sólo aparecerá en los días de invierno; en los de verano desaparece.

\subsubsection{Variaciones sobre la pantalla de programación básica}

\subsubsection{Tratamiento Consejos}

El interfaz de la pantalla de programación es exactamente igual al básico, pero añade un pequeño cuadro en el que se muestran, uno por uno, una serie de consejos energéticos (Figura 5.6). Cuando el sujeto ha visto todos ellos, puede programar su comportamiento mensual de la forma habitual.

Los consejos programados son los siguientes:

- No dejes en stand-by los equipos cuando no los utilices: apágalos totalmente

- El microondas gasta mucho menos que el horno, y en él se puede cocinar prácticamente las mismas comidas

- No planches muy a menudo: procura acumular ropa suficiente para al menos 1 hora de plancha

- Acuérdate de apagar las luces al salir de las habitaciones

- Aprovecha la luz natural

- Apaga el ordenador, la TV y el equipo de música cuando no los utilices

- En la lavadora, programa ciclos cortos con agua fría o templada

- Aprovecha al máximo la capacidad de carga de la lavadora

- Es mucho más ahorrativo ducharse que bañarse

- Cierra el grifo de la ducha mientras te enjabonas

- Usa ropa cálida en invierno: no hace falta más de 18-22 C de temperatura de día o 16 o de noche 
- Usa ropa fresca en verano: no hace falta menos de 250 C de temperatura de día

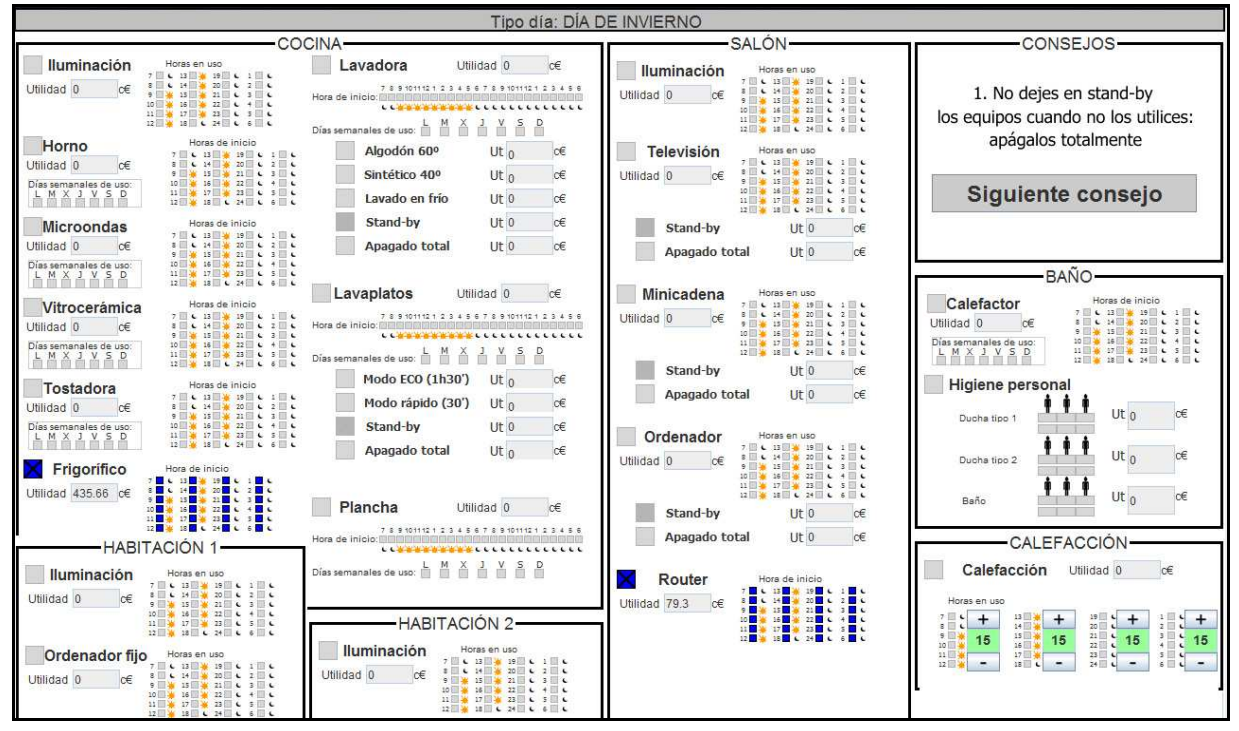

Figura 5.6.- Pantalla de programación Tratamiento Consejos

\subsubsection{Tratamiento Contador}

El interfaz de la pantalla de programación es exactamente igual al básico, pero añade un cuadro con un contador inteligente, que permite seleccionar el consumo en kWh o céntimos de euro (Figura 5.7). El contador varía instantáneamente según se van poniendo en marcha o anulando los diferentes electrodomésticos.

\subsubsection{Tratamiento Contador Desagregado}

Es exactamente igual al anterior, pero el cuadro incluye cinco contadores independientes (Figura 5.8): alumbrado, cocina, gas, ocio y otros. (Otros incluye lavadora, lavaplatos, plancha y calefactor; ocio incluye TV, música y ordenadores) 


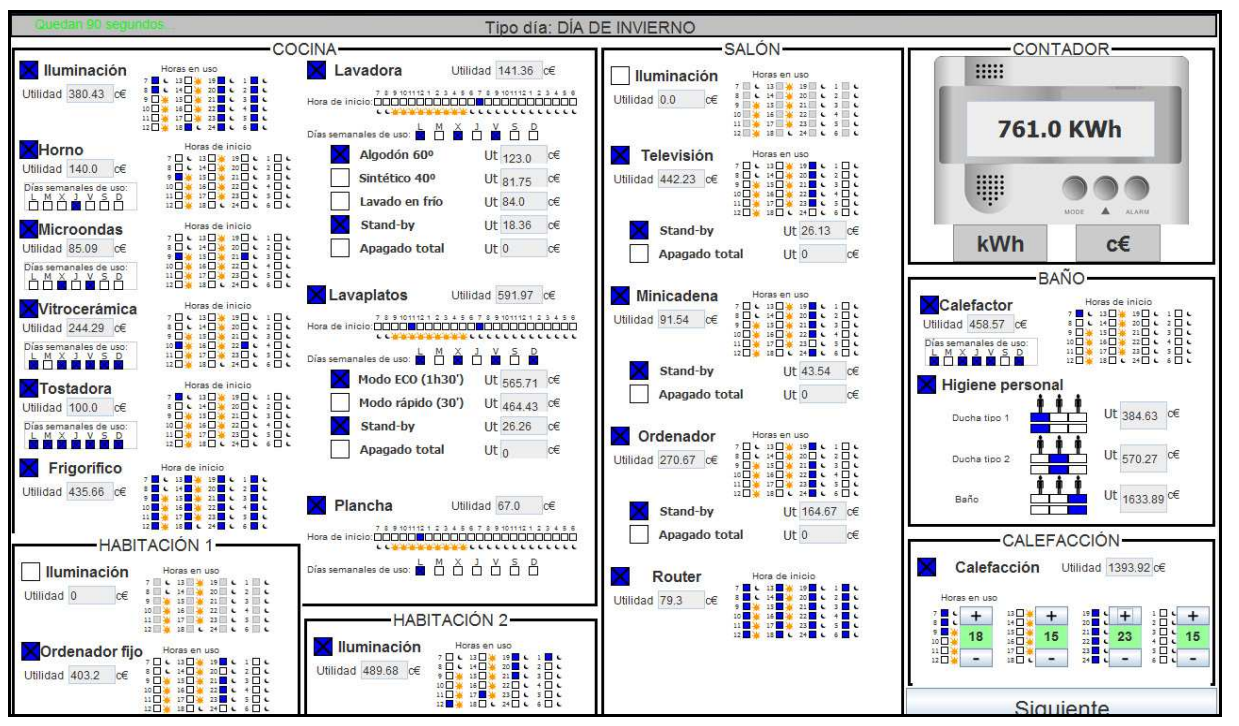

Figura 5.7.- Pantalla de programación Tratamiento Contador Único

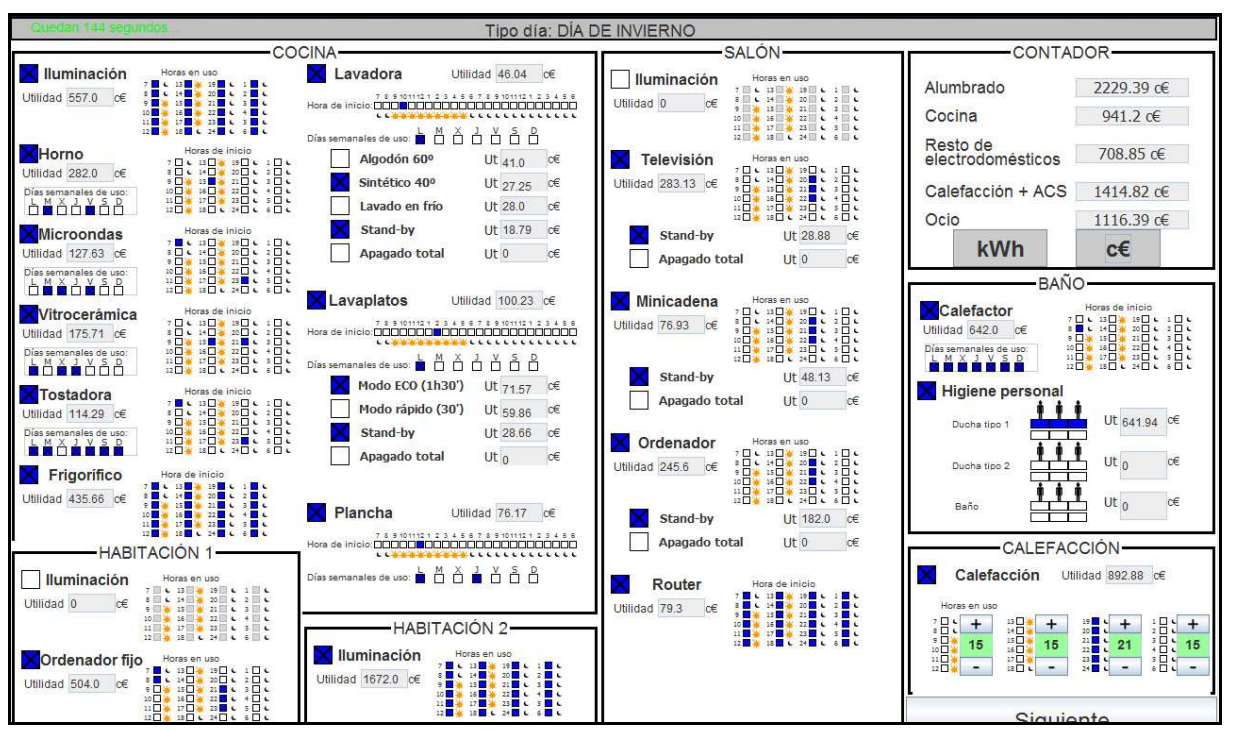

Figura 5.8.- Pantalla de programación Tratamiento Contador desagregado 


\subsubsection{Tratamiento ranking}

Es el único escenario con 3 pantallas por periodo. En este caso, la pantalla de programación es exactamente igual a la básica, pero, tras la factura, se añade una tercera pantalla (Figura 5.9 y Figura 5.10 ) en la que se muestra el comportamiento del sujeto en relación al resto de participantes:

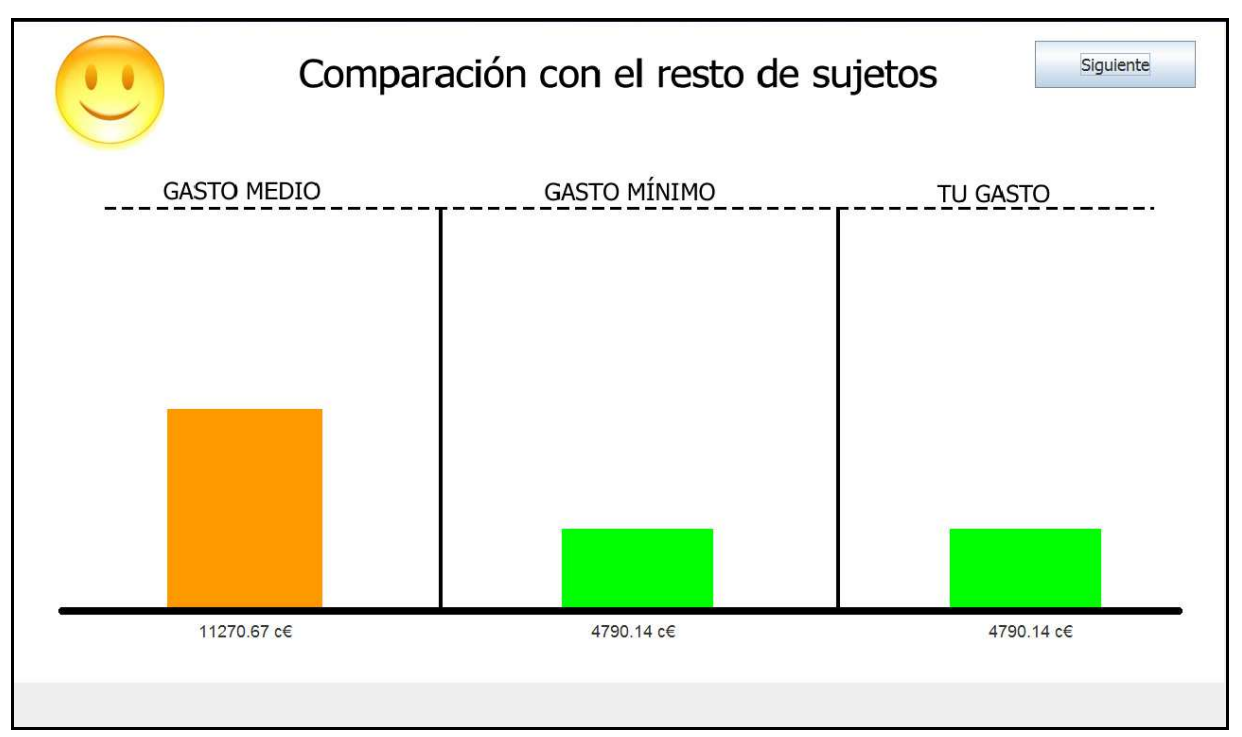

Figura 5.9.- Pantalla específica Tratamiento Ranking

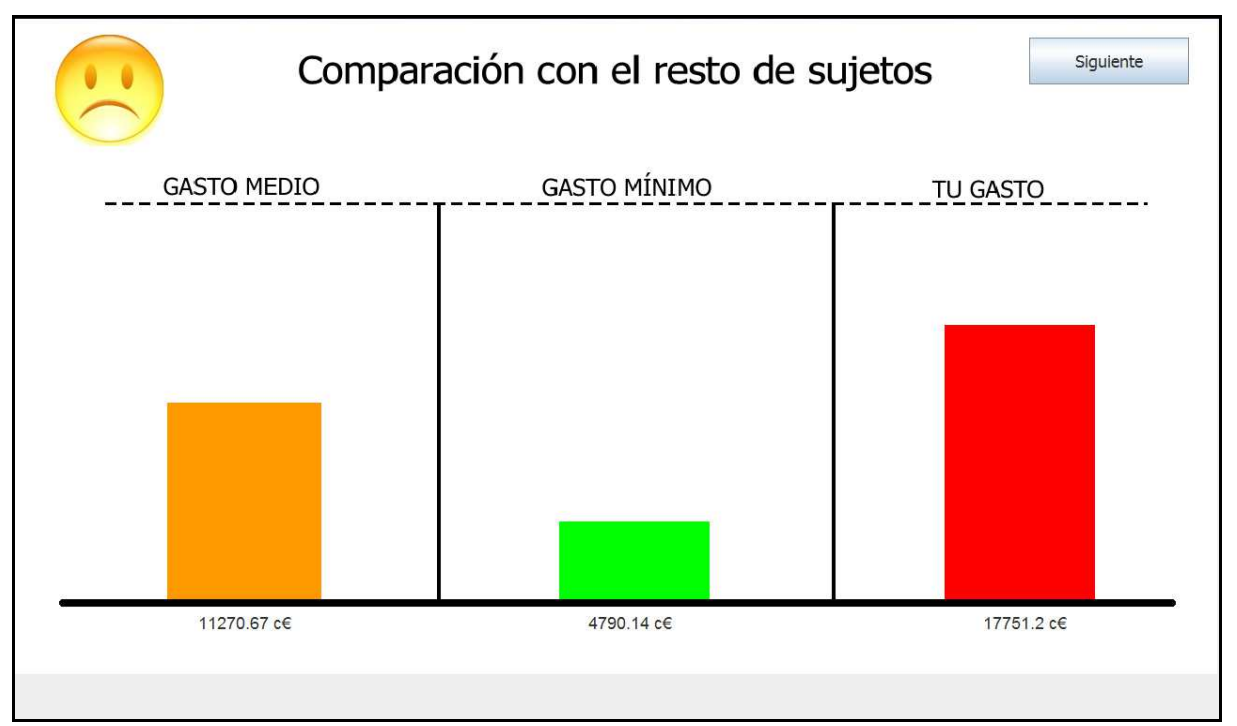

Figura 5.10.- Pantalla específica Tratamiento Ranking 


\subsubsection{Pagos realizados a los sujetos}

En los experimentos de laboratorio de economía experimental se suele trabajar con una moneda virtual y un factor de conversión, previamente conocido, entre la moneda virtual utilizada en las simulaciones y el euro. El dinero que se paga a los sujetos es el resultado de multiplicar la cantidad virtual que ha obtenido con su actuación por el factor de conversión.

Con objeto de mantener el mayor contacto posible con la realidad, y que el montante de las facturas se pareciera al que realmente se tiene en el hogar, la moneda virtual utilizada en este experimento concreto coincide con el euro real por un factor de 1 .

Así, los consumos de los distintos electrodomésticos están calculados en euros virtuales (que en realidad coinciden con los reales); las funciones de utilidad, al estar deducidas de éstos, también. Los beneficios en la pantalla de la factura, dado que son la resta de la utilidad menos el consumo, son también euros reales.

Para la realización de los pagos se utiliza un factor de corrección de 0,1 , de forma que el pago monetario obtenido por el estudiante fue el resultado de sumar los beneficios de los 18 meses y dividirlos por 10 .

\subsubsection{Cuestionarios}

Con el objeto de averiguar si los tipos de comportamiento tenían que ver con la personalidad y la concienciación energética de los sujetos, se solicitó a los participantes que rellenaran, al acabar la sesión experimental, los cuestionarios incluidos en el Anexo I.4.

\subsection{Resultados}

\subsubsection{Consumo y beneficio eléctricos respecto al óptimo}

Las tablas y figuras siguientes muestran los resultados numéricos de los experimentos de laboratorio, algunas en valores absolutos y otras calculadas en forma porcentual respecto a un comportamiento denominado óptimo. Este óptimo consiste en una combinación de electrodomésticos tal que proporciona el beneficio monetario mayor posible, y representaría, en la vida real y para ese equipamiento, una confortabilidad máxima en la vivienda sin derroche energético. 
En la Figura 5.11 y la Tabla 5.3 siguientes se muestran los resultados de cada uno de los tratamientos, así como la diferencia entre el comportamiento eléctrico óptimo y el resto. La significatividad estadística de las diferencias se demuestra en el Anexo I.3.

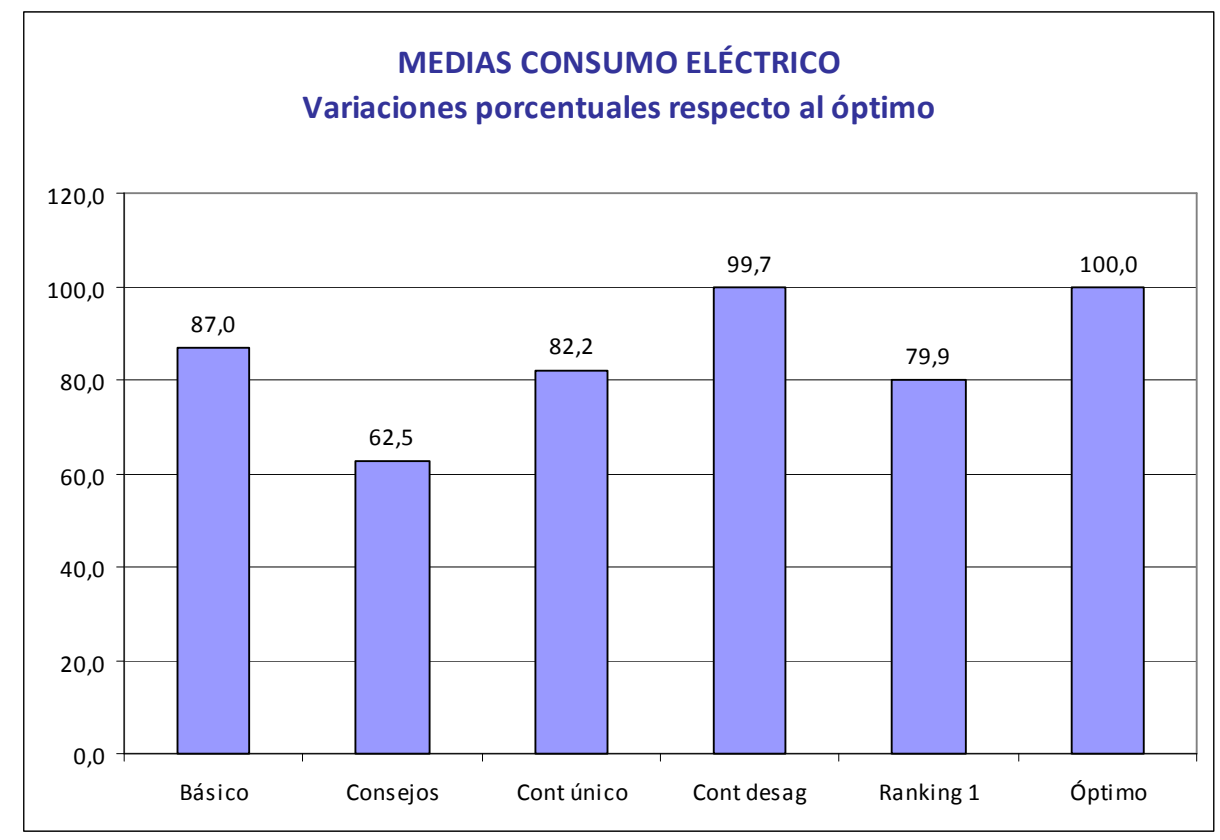

Figura 5.11.- Valores porcentuales medios de consumo eléctrico mensual

Medias de consumo eléctrico mensual (c€)

\begin{tabular}{cccc}
\hline & Tratamiento & Invierno & Verano \\
\hline T1 & Básico & 3603,8 & 3123,7 \\
T2 & Consejos & 2636,1 & 2200,7 \\
T3 & Contador único & 3427,6 & 2930,4 \\
T4 & Contador desagregado & 4054,7 & 3658,8 \\
T8 & Rankings & 3412,8 & 2685,1 \\
T0 / T7 & Óptimo & 4150,1 & 3586,4 \\
\hline
\end{tabular}

Tabla 5.3.- Medias de consumo eléctrico

Seguidamente, por su importancia a la hora de extraer conclusiones, se muestran también valores absolutos y comparados de beneficio eléctrico. Las figuras siguientes (Figura 5.12., Tabla 5.4) indican los resultados de cada uno de los experimentos, y su significatividad estadística se demuestra en el Anexo I.3. 


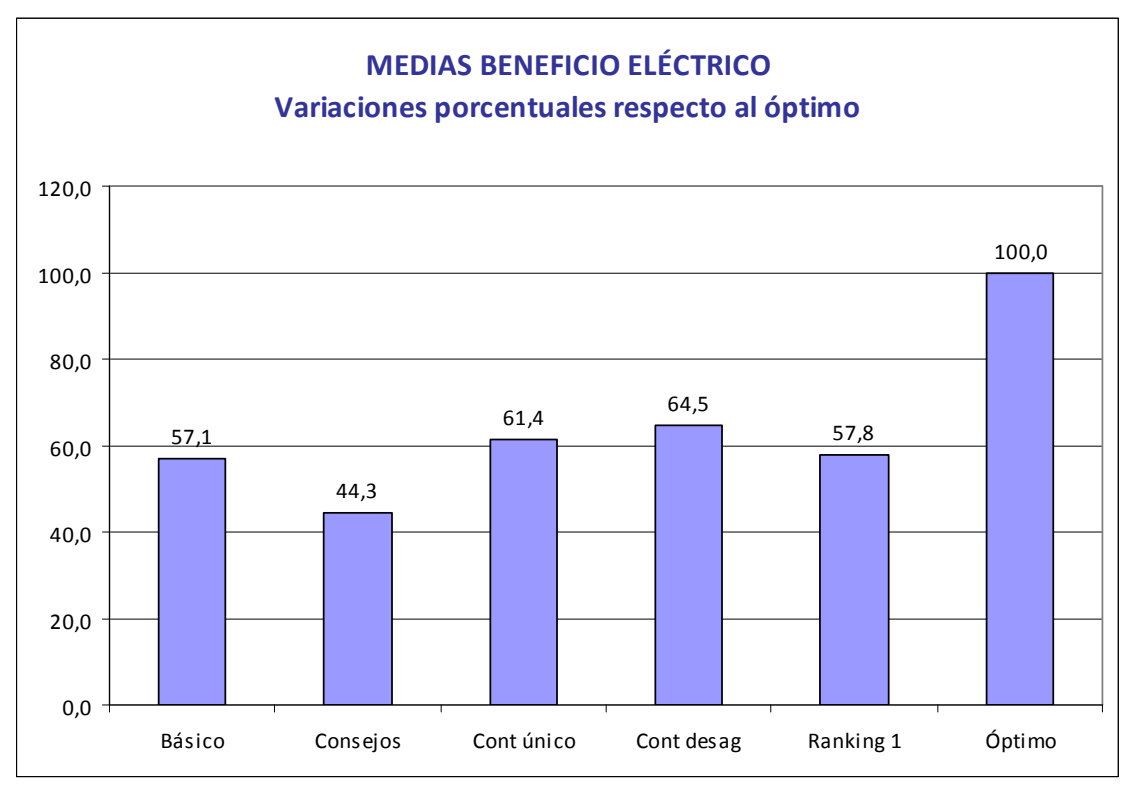

Figura 5.12.- Valores porcentuales medios de beneficio eléctrico mensual

Medias de beneficio eléctrico (c€)

\begin{tabular}{cccc}
\hline & Tratamiento & Invierno & Verano \\
\hline T1 & Básico & 539,1 & 464,1 \\
T2 & Consejos & 417,9 & 361 \\
T3 & Contador único & 571,9 & 509,7 \\
T4 & Contador desagregado & 589,6 & 548,9 \\
T8 & Rankings & 549,2 & 508 \\
T0 / T7 & Óptimo & 941,3 & 941,3 \\
\hline
\end{tabular}

Tabla 5.4.- Valores medios de beneficio eléctrico mensual por estación

\subsubsection{Consumo y beneficio eléctricos respecto al Tratamiento Contador desagregado}

Utilizando los mismos valores de las tablas Tabla 5.3 y la Tabla 5.4 , se pueden calcular comparativas de eficacia con respecto al tratamiento contador desagregado. Los resultados se muestran en la Figura 5.13. El análisis estadístico de las diferencias, que en todos los casos son significativas, se encuentra en el Anexo I.3. El mismo tipo de cálculo, realizado con la variable Beneficios, arroja los resultados mostrados en la Figura 5.14. 


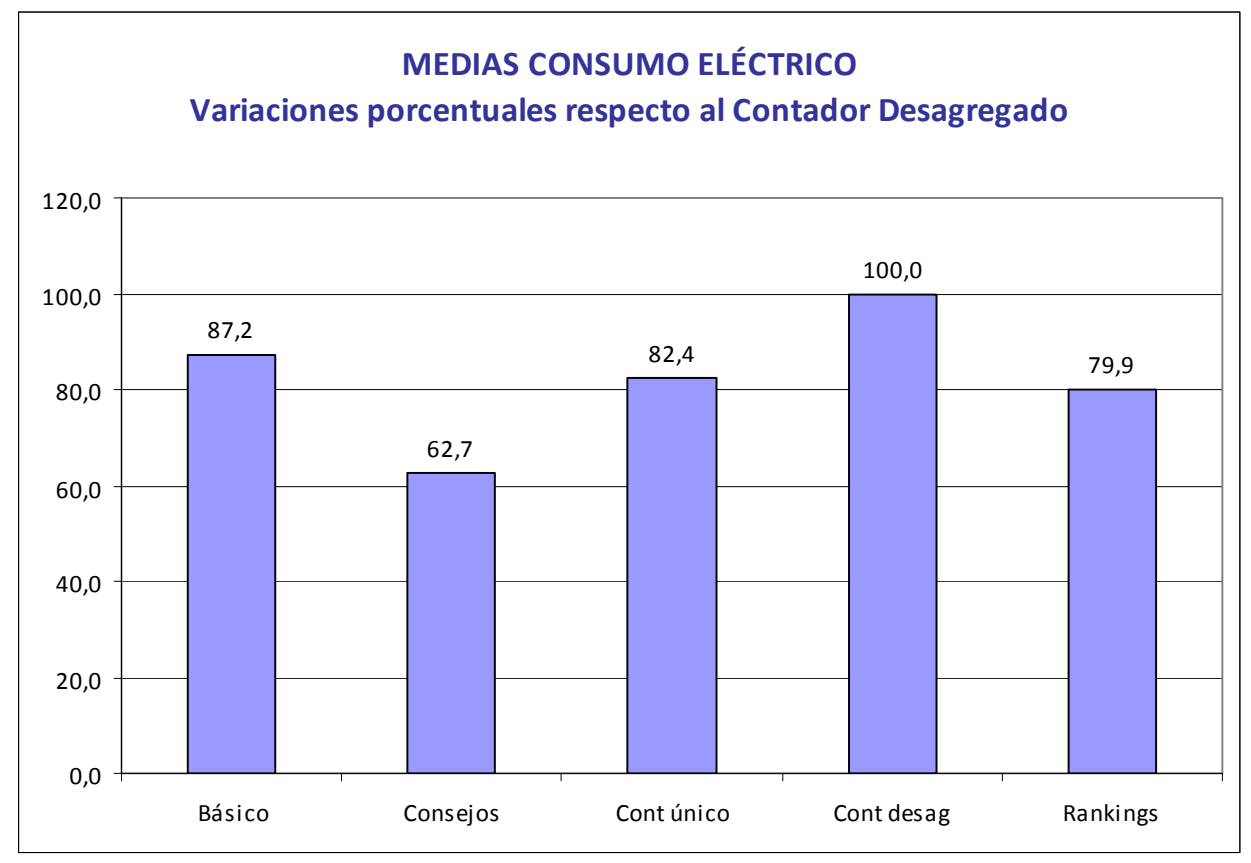

Figura 5.13.- Valores porcentuales medios de consumo eléctrico mensual

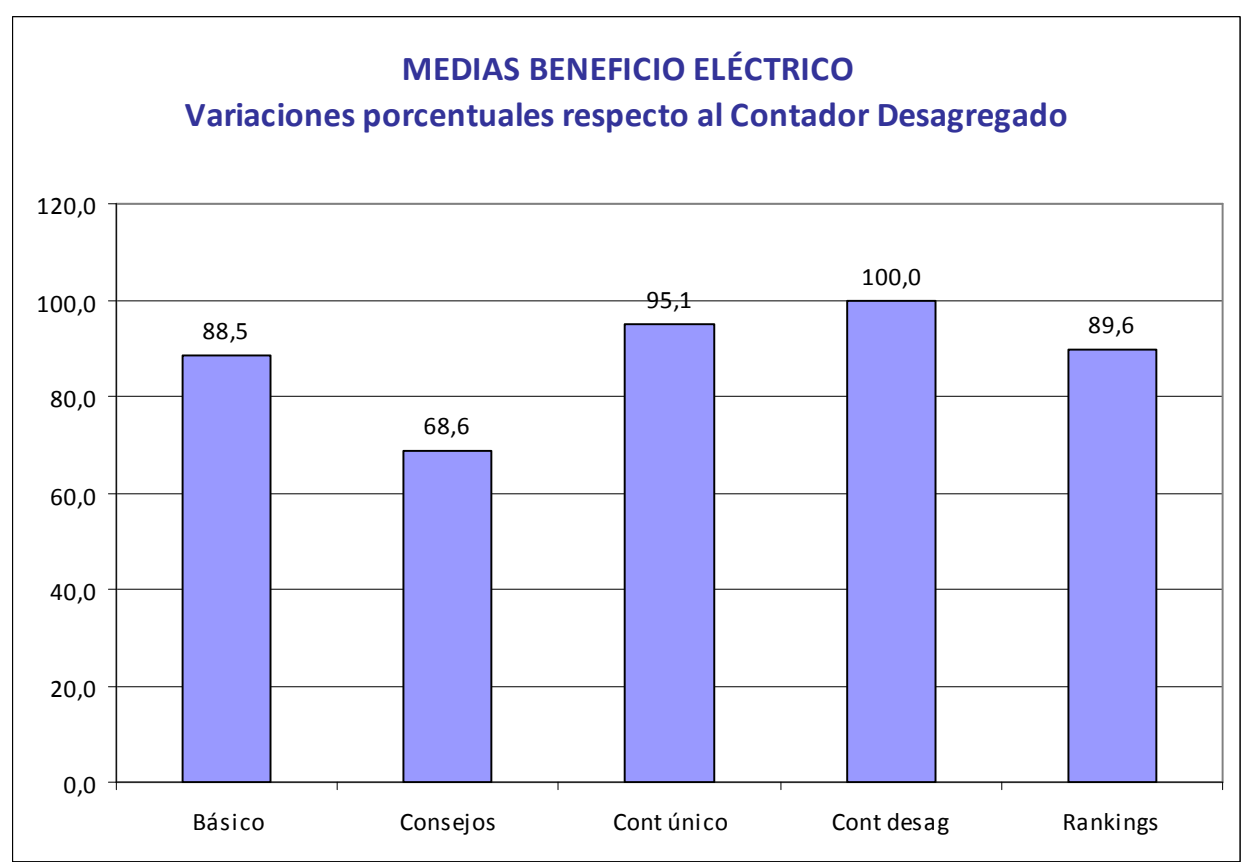

Figura 5.14.- Valores porcentuales medios de beneficio eléctrico mensual 


\subsubsection{Consumo y beneficio eléctricos respecto al Tratamiento Básico}

En cuanto a comparativas entre tratamientos, por último se muestran las relaciones entre los tres tratamientos más pobres (Básico, Consejos y Ranking), en relación al básico (Figura 5.15 y Figura 5.16).

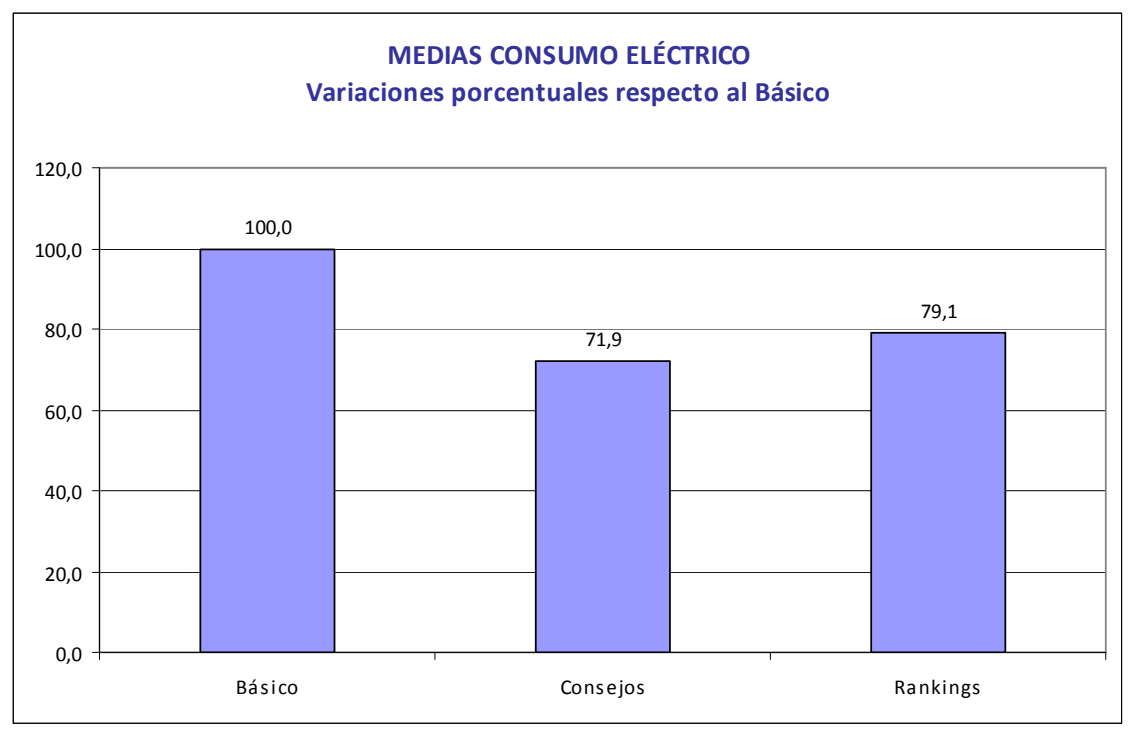

Figura 5.15.- Valores porcentuales medios de consumo eléctrico mensual

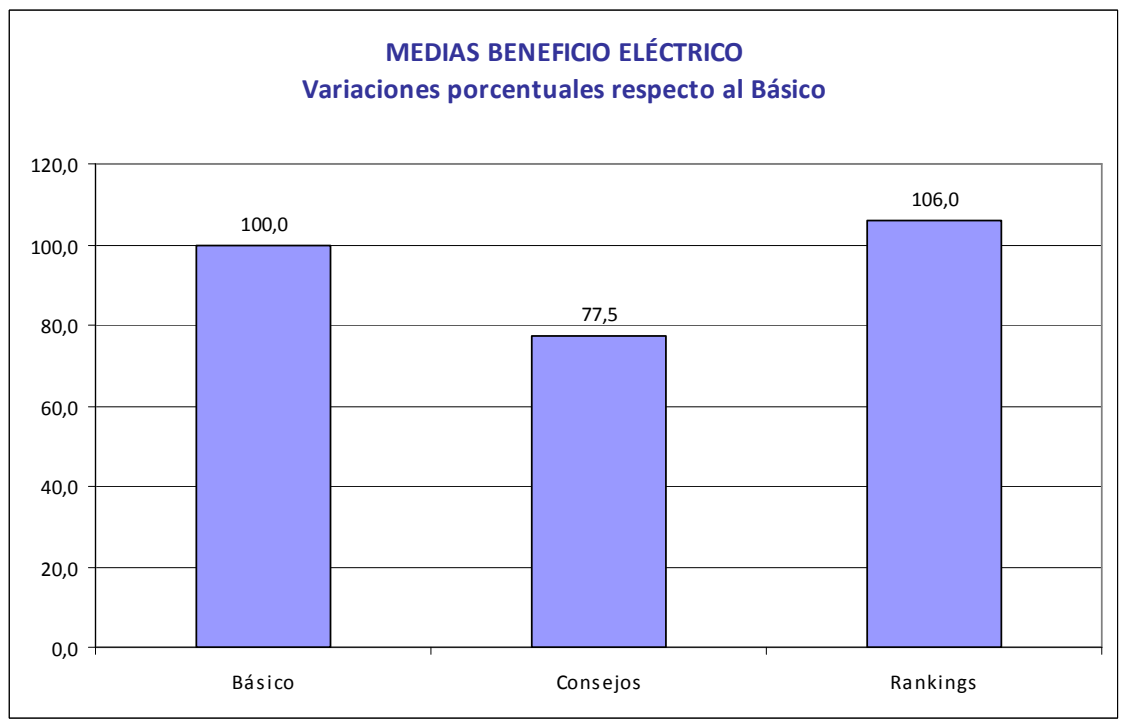

Figura 5.16.- Valores porcentuales medios de beneficio eléctrico mensual 


\subsubsection{Consumo y beneficio de gas}

Las gráficas siguientes (Figura 5.17 y Figura 5.18) muestran los resultados en el consumo de gas, desagregados en los dos elementos que lo consumen: el ACS durante todo el año, la calefacción únicamente en invierno.

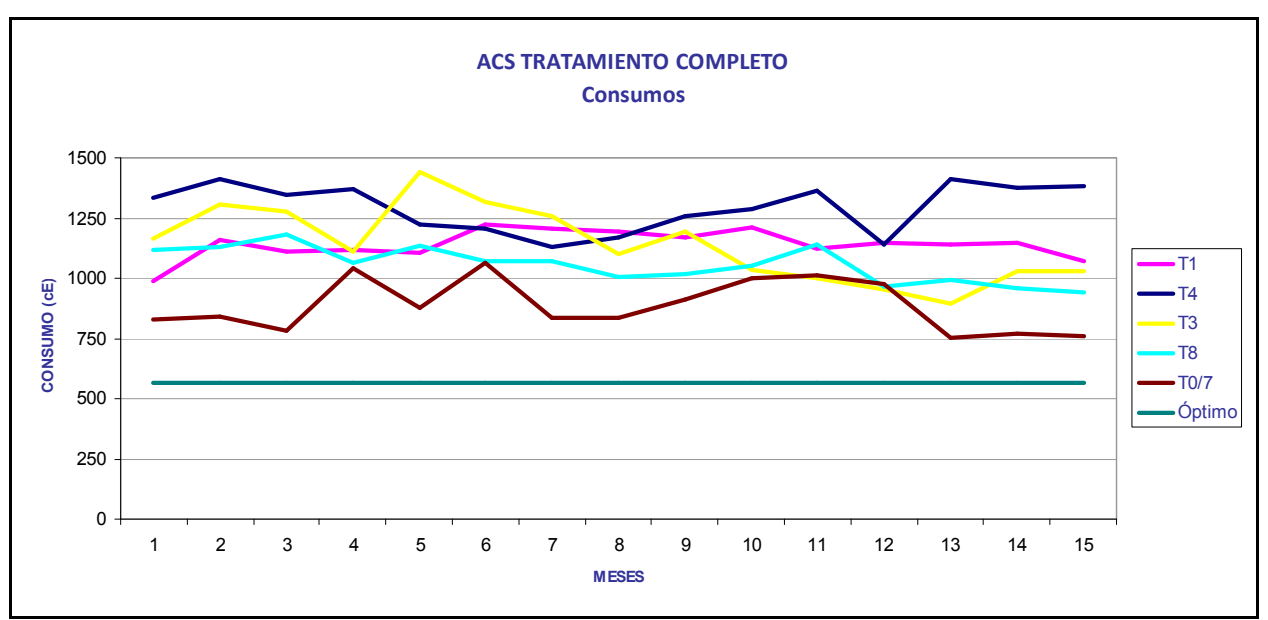

Figura 5.17.- Comportamiento de los sujetos en el consumo de ACS

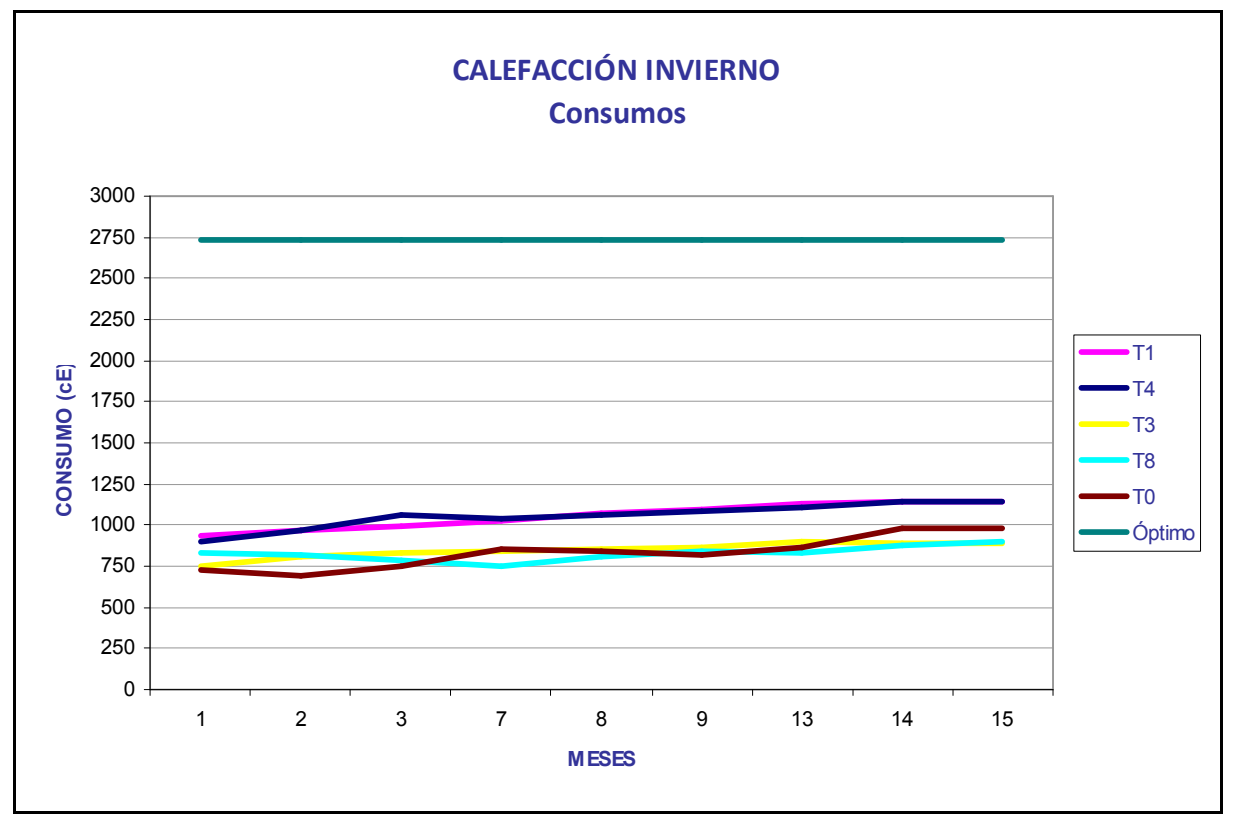

Figura 5.18.- Comportamiento de los sujetos en la climatización de la vivienda 
En ambas figuras se muestra en un color determinado cada uno de los tratamientos en cada uno de los meses en los que se utiliza el equipo; así mismo, se muestra el valor del comportamiento óptimo, en este caso no del conjunto del equipamiento en general sino de cada equipo en particular. En el ACS los meses de uso son correlativos del 1 al 15; en la calefacción se muestran sólo los meses de invierno, esto es, los meses 1, 2, 3, 7, 8, 9, 13, 14 y 15.

\subsection{Discusión general de los resultados}

\subsubsection{Introducción}

En la Figura 5.11 y la Tabla 5.3 se aprecia claramente que todos los comportamientos, en todos los tratamientos, son avaros y no derrochadores, pese a que el experimento se diseñó bajo la idea de que los sujetos, por desconocimiento y por hábito, serían más derrochadores que ahorrativos. Sin embargo, la realidad es que en general el resultado ha sido exactamente el contrario.

Pese a que el comportamiento de partida no ha sido el esperado en ninguno de los casos, la influencia del tipo de realimentación con el que se ha realizado cada tratamiento es evidente tanto en la comparativa con el óptimo (Figura 5.11) como en la comparación entre sí de los distintos escenarios.

La interpretación de estos resultados se vuelve, eso sí, algo más compleja, dado que el comportamiento idóneo desde el punto de vista práctico resulta ser el más consumista y no el menos; sin embargo, la influencia de la información aportada a los sujetos modifica claramente su comportamiento en una serie de aspectos que se estudian y cuantifican en los siguientes subapartados.

Para los siguientes análisis, se va a estudiar dos influencias básicas que marcan el comportamiento de los grupos, y que se enumeran seguidamente:

Por una parte, el fenómeno sugestión, que marca una tendencia a la baja del consumo que se aprecia sobre todo en los tratamientos con menor grado de realimentación (Básico, Consejos y Rankings). Este fenómeno se describe en el apartado Sugestionabilidad de los sujetos.

Por otra parte, el objetivo egoísta de maximizar el beneficio obtenido al final de los experimentos, que marca una tendencia al alza del consumo (es decir, una aproximación eficaz al óptimo), que caracteriza el comportamiento 
de los tratamientos con una realimentación más eficaz (Contadores Desagregados y Contadores Únicos). Este objetivo se describe en el apartado Maximización del beneficio.

\subsubsection{Sugestionabilidad de los sujetos}

El estudio demuestra, de forma inesperada pero muy clara, que el comportamiento de los individuos se ha visto fuertemente influenciado por la sugestión de que se esperaba de ellos un comportamiento energéticamente eficiente.

Aunque los participantes fueron advertidos de que su beneficio monetario máximo sería obtenido mediante un uso razonable de los electrodomésticos, los resultados muestran de forma significativa que su comportamiento peca de exceso de ahorro en todos los casos, pese a ir ello en contra de sus propios intereses.

Si entendemos por sugestión el proceso psicológico mediante el cual, al emitir una información determinada, se puede guiar o modificar el comportamiento de las personas, el hecho de que el sujeto sepa que está participando en un experimento sobre eficiencia energética le sugestiona a comportarse de forma energéticamente irreprochable; si entendemos por home-grown values a los valores adquiridos por la educación en el hogar de los participantes, en el caso de este experimento los sujetos claramente actuaron bajo la idea preconcebida de que el comportamiento energéticamente eficiente es el más ahorrativo posible.

La suma de estos dos fenómenos (la sugestión generada por el título del experimento unida a una educación según la cual el comportamiento energéticamente eficiente es el más ahorrativo posible), ha generado un comportamiento, más que ahorrador, avaro.

Desde el primer momento, un objetivo importante de este estudio es aprender más sobre la parte irracional del comportamiento humano en el ámbito energético de la vivienda: la gran influencia de la sugestionabilidad a lo largo de las sesiones evidencia hasta qué punto debe tomarse esa irracionalidad en cuenta a la hora de diseñar estrategias de ahorro energético.

En la realidad la complejidad del entorno energético es tal que al usuario le es imposible actuar de forma tan energéticamente eficiente, y además el sujeto no se encuentra tan presionado por el entorno en cuanto a su 
comportamiento energético. Aún así, este experimento, realizado en el entorno más simple del laboratorio, muestra cómo los sujetos, en determinadas circunstancias, actúan voluntariamente en contra de sus propios intereses, representados por los beneficios obtenidos al final del experimento.

\subsubsection{Maximización del beneficio}

Todo el estudio está diseñado para optimizar el comportamiento energético sin modificar el grado de confortabilidad de la vivienda, es decir, no se busca reducir el uso del equipamiento sino optimizar la forma en que se utiliza.

En lo que se refiere al experimento realizado, esto se traduce en conseguir que se maximice el beneficio obtenido, no en minimizar el consumo a cualquier coste. Maximizar el beneficio significa obtener la máxima utilidad posible (es decir, lograr la máxima satisfacción posible en el uso del equipamiento), con el menor consumo posible (es decir, de la forma más eficaz posible).

En el mundo real, esto sería equivalente a utilizar los electrodomésticos que se desee, en la cantidad y de la manera que cada individuo prefiera (máxima satisfacción), de la forma más eficaz (mínimo consumo).

A largo plazo, este planteamiento no garantiza pero sí hace más probable que la modificación del comportamiento se mantenga. Si se obtienen reducciones del consumo a base de sacrificar el confort, es decir, si se reducen tanto el consumo como la utilidad, es más probable que se abandone. Si se obtienen reducciones del consumo sin sacrificios y con la recompensa añadida de la reducción en la factura eléctrica, es decir, si se reduce el consumo manteniendo casi constante la utilidad, las probabilidades de que la modificación del comportamiento se mantenga son evidentemente mayores.

En una parte de los siguientes análisis, se va a cuantificar la eficacia de cada tratamiento en función de su grado de aproximación al óptimo, no de su grado de ahorro. Aparentemente, esto es contrario al objetivo del estudio, dado que el óptimo (Figura 5.11) es el comportamiento más consumista; sin embargo, hay que tener en cuenta que, en un entorno realista, el comportamiento de partida va a ser en general derrochador.

Si el comportamiento es avaro, el grado de satisfacción es bajo, por lo que no se cumplen los objetivos finales; si el comportamiento es derrochador, 
el consumo es innecesariamente elevado, por lo que tampoco se cumple el objetivo. Ambas situaciones se resuelven tendiendo al óptimo, que maximiza la satisfacción manteniendo el consumo bajo control.

Si un tipo de realimentación es capaz de conseguir que los sujetos se aproximen más al óptimo, es razonable suponer que lo conseguirá tanto si el punto de partida es avaro, como ha ocurrido en el laboratorio, como si es derrochador, que es lo que sucede en la realidad. En un caso u otro, el grado de aproximación, en valor absoluto, muestra la eficacia de la realimentación a la hora de corregir comportamientos, sean al alza o a la baja. Y en ambos casos la aproximación al óptimo equivale a maximizar el beneficio.

\subsection{Discusión de los resultados por tratamiento}

Se va a dividir los resultados de los experimentos en dos grandes grupos: maximizadores del beneficio (Contadores), y minimizadores del consumo (Rankings, Consejos y Básico). Dentro de cada grupo, se comentan los resultados independientes de cada tratamiento.

\subsubsection{Contadores: Eficacia en la optimización}

\subsubsection{Contadores desagregados}

Los resultados experimentales en cuanto al consumo (Figura 5.11) muestran que el único caso en el que el comportamiento ha sido prácticamente igual al óptimo (en un 99,7 \%) es el escenario T4 (Contador Desagregado): este sistema de realimentación es el que más ayuda a optimizar el comportamiento energético.

En el caso que nos ocupa, esa optimización supone un consumo mayor, lo que se debe al comportamiento avaro de partida de todos los sujetos. Sin embargo, ese ajuste al óptimo indica que la cantidad de información suministrada es suficiente para racionalizar y optimizar de forma objetiva el comportamiento energético del individuo.

En un entorno realista, con un comportamiento derrochador, la modificación del comportamiento consistiría en una corrección a la baja del consumo, en busca, al igual que en estos experimentos, del óptimo real, y con información suficiente como para llevarla a cabo con éxito. 
La comparativa de la eficacia de este método con respecto al resto de los tratamientos se muestra en la Figura 5.13. Llama la atención en esta Figura 5.13el hecho de que la diferencia en consumo con el contador único es muy acentuada; más, incluso, que con el tratamiento Básico.

\subsubsection{Contadores únicos: variable beneficios}

Observando la Figura 5.11 de comparativa de consumos con el óptimo, se tienen los siguientes porcentajes, en orden de mayor a menor proximidad al óptimo:

\begin{tabular}{|c|c|}
\hline 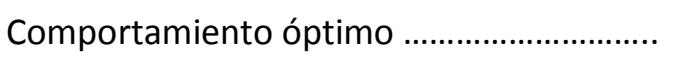 & $100 \%$ \\
\hline Tratamiento Contador Desagregado............. & $99,7 \%$ \\
\hline 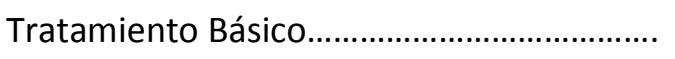 & $87 \%$ \\
\hline 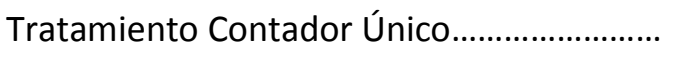 & $82,2 \%$ \\
\hline 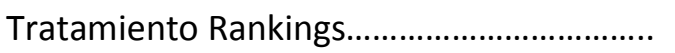 & $79,9 \%$ \\
\hline
\end{tabular}

Es decir, si tomamos como medida del éxito de un tratamiento su proximidad en consumo al óptimo, resulta ser más eficaz el tratamiento básico que la información suministrada por el contador único, resultado claramente ilógico.

La variable Consumo se ha utilizado hasta ahora para estudiar el comportamiento de los sujetos y su grado de éxito. En un experimento de eficiencia energética, parece el punto más razonable sobre el que basar las conclusiones.

Sin embargo, la misma cantidad de consumo se puede conseguir utilizando de forma racional los electrodomésticos necesarios para vivir confortablemente y no más que éstos, o utilizando de forma irracional esos mismos electrodomésticos, derrochando en unos y ahorrando excesivamente en otros, pero de forma que, casualmente, la suma del conjunto de los consumos sea similar. En otras palabras, estudiando únicamente la variable 
Consumo no se cuantifica correctamente el grado de éxito de los participantes en el experimento.

Para tener una visión de conjunto completa, sobre todo en lo que se refiere al tratamiento Contador Único, es necesario revisar conjuntamente dos variables: Consumos y Beneficios. Una misma cantidad de consumo puede suponer beneficios mayores o menores, en función de la combinación de electrodomésticos de la que provenga. La eficacia de un tratamiento, desde el punto de vista egoísta de un sujeto, es al fin y al cabo su grado de éxito en conducirle a maximizar su beneficio.

A la vista de la Figura 5.12 sí se puede afirmar que la eficacia de los dos métodos de realimentación por contador es elevada. Dado que el objetivo final del sujeto es maximizar el dinero obtenido al final del experimento, el éxito de ambos tratamientos es similar en cuanto a su capacidad de proporcionar la información necesaria para actuar en función de los intereses propios del sujeto.

Aún así, hay una diferencia significativa entre ellos, tanto en lo que se refiere a consumos como en lo que se refiere a beneficios, a favor del Contador Desagregado. En cuanto a las diferencias comentadas anteriormente con el tratamiento Básico, ahora sí se aprecia cómo, a pesar de que el consumo del Básico es mayor que el del Contador Único, su beneficio es más pequeño.

Para comparar con más precisión el efecto del Contador Desagregado con el resto, nos fijamos en la Figura 5.14. El grado de eficacia en la maximización del beneficio de los diferentes comportamientos, comparadas con el mejor y en orden de mayor a menor, es la siguiente:

\begin{tabular}{|c|c|}
\hline Tratamiento Contador Desagregado............. & $100 \%$ \\
\hline 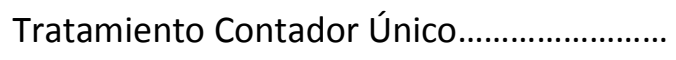 & $95,1 \%$ \\
\hline Tratamiento Rankings......................................... & $89,6 \%$ \\
\hline 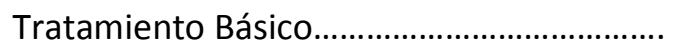 & $88,5 \%$ \\
\hline
\end{tabular}


Es decir, la diferencia en grado de éxito en su proximidad al comportamiento óptimo entre el Contador Desagregado y el Contador Único es de cinco puntos porcentuales.

\subsubsection{Consejos, Rankings y Básico: influencia de la presión a la baja en el consumo}

\subsubsection{Sugestionabilidad de los tratamientos}

Los tres tratamientos con una realimentación pobre se caracterizan por presentar un nivel bajo de beneficios (Figura 5.12.); sin embargo, las diferencias entre ellos en cuanto a consumos son considerables. En los tres ha primado la influencia irracional de la sugestión, pero de forma proporcional al tipo de información proporcionado.

Tratamiento Básico.- No se caracteriza por un consumo a la baja especialmente pequeño (comparado con el resto de tratamientos). Su valor proporcional respecto al óptimo es de un $87 \%$, el segundo más alto (Figura 5.11). Si tomamos este valor como referencia de la medida de la sugestión generada por el título del proyecto, podemos estimar el efecto generado por el resto de tratamientos de baja realimentación.

Tratamiento Consejos.- La presión a la baja del consumo generada por la repetición de los Consejos obtiene una exageración del efecto sugestión de un $28 \%$ respecto al tratamiento Básico (Figura 5.15). No significa esto que la eficacia del tratamiento de por sí sea elevada, dado que el objetivo final del estudio no es incentivar el ahorro por encima de cualquier otra consideración sino incentivar el ahorro manteniendo la confortabilidad.

Ese $28 \%$ está contabilizando principalmente, de nuevo, la sugestionabilidad del ser humano y no la eficacia del tratamiento, dado que, a efectos de la variable Beneficio, el tratamiento Consejos también es el que da peores resultados: un $22 \%$ por debajo con respecto al beneficio del tratamiento básico (Figura 5.16).

Tratamiento Rankings.- El tratamiento Rankings incluye un método de sugestión algo diferente al resto, que consiste en acentuar la diferencia del sujeto con la media de su grupo, para ver si esto modifica su comportamiento.

En ella se puede ver que en efecto existe una tendencia de los sujetos a aproximarse a la media de consumo, tanto por encima como por debajo. Este 
método de influencia reduce el consumo (un $21 \%$ respecto al básico), y sin embargo no es en absoluto perjudicial para los beneficios (un 6\% superiores al básico). Ambos resultados lo convierten en un método muy recomendable, por sus buenos resultados y por la facilidad de su aplicación.

\subsubsection{Consumo de gas}

Todas las conclusiones anteriores se han referido al estudio del comportamiento energético en el consumo de electricidad en la vivienda. En este apartado se discute el comportamiento particular de los sujetos en los que se refiere al consumo de gas.

El consumo de gas en invierno está formado por el ACS y la calefacción; en verano, únicamente por el ACS. La Figura 5.17 y Figura 5.18 muestran el consumo de calefacción en invierno y el consumo de ACS a lo largo de los 18 meses de tratamiento.

Ambos consumos parecen haber sido demasiado complicados de interpretar para los sujetos. En el ACS, el formato de selección de uso es diferente al del resto del equipamiento de la vivienda, y el número de combinaciones a probar, elevado. En las gráficas se aprecia cómo el comportamiento de todos los grupos es errático y no muestra el menor grado de aprendizaje. Además, es el único caso en el que la media de uso está por encima y no por debajo del óptimo (Figura 5.17).

En cuanto a la calefacción, el sistema de programación de la caldera ha resultado ser demasiado complicado de comprender, incluso con la ayuda de los contadores. Por esa razón, dado que supone un consumo considerable, la mayoría ha optado por no utilizar la calefacción o infrautilizarla. En la Figura 5.18 se detecta a simple vista el grado de infrautilización con respecto al óptimo y la escasa diferencia entre los distintos tratamientos. En ella, el óptimo está representado mediante una línea horizontal; los meses representados en el eje de abscisas son sólo los de invierno dado que en verano no se podía utilizar la calefacción.

En ensayos posteriores será necesario por tanto redefinir y simplificar el método de programación de ambos elementos para obtener resultados significativos en el consumo de gas. Es importante obtener datos ajustados de las formas de comportamiento en ambos apartados, dado que la calefacción y el ACS son los mayores consumidores de energía dentro del sector residencial. 
En cuanto a los resultados de este trabajo en particular, gracias a que la electricidad se ha medido y facturado independientemente del gas, se pueden extraer también conclusiones independientes de ambos tipos de energía.

\subsection{Conclusiones}

En estas conclusiones se van a comentar valores numéricos de las modificaciones de comportamiento logradas con los diferentes tratamientos. No se debe perder de vista que estos grados de variación se han obtenido en una simulación relativamente simple por ordenador; no son directamente aplicables a la realidad, que es mucho más compleja y en la que influyen factores, tanto medioambientales como sociales, que no han sido tenidos en cuenta en laboratorio. Sin embargo, la dirección de la influencia de estos efectos, así como la importancia relativa entre ellos, sí son extrapolables a la realidad.

La concienciación medioambiental de los ciudadanos es un punto fundamental a la hora de diseñar cualquier campaña de ahorro energético. Se obtienen reducciones en el consumo energético de hasta trece puntos porcentuales en laboratorio únicamente mediante la sugestión de los sujetos, sin ninguna otra indicación de cuál debe ser su comportamiento. La reducción alcanza 31,4 puntos porcentuales cuando se realimenta esta concienciación mediante la repetición de mensajes relativos al ahorro energético.

Esa concienciación, sin otra información añadida, obtiene reducciones a costa del sacrificio del ciudadano, como indica el escaso éxito en la maximización de los beneficios de este tipo de tratamientos. Es necesario, por tanto, reforzar la concienciación medioambiental con métodos que den al ciudadano herramientas para conseguir esos mismos niveles de ahorro sin pérdida de confortabilidad. Para ello se han mostrado como altamente eficaces los dos tratamientos con contadores inteligentes, que han obtenido los valores más altos de éxito en lo que se refiere a la obtención de beneficios monetarios.

El tratamiento por rankings obtiene buenos resultados tanto en reducciones de consumo como en maximización de beneficios, sólo un $10 \%$ por debajo del tratamiento con contador desagregado. Además de ser un método eficaz, tiene la ventaja de ser, hoy en día, muy fácil de aplicar: en vecindarios en los que las compañías suministradoras han instalado 
contadores con lectura telemática, añadir este tipo de información a las facturas eléctricas apenas supondría un coste adicional. El valor que se use como referencia, además, puede ser la media del vecindario o bien la media con una residencia energéticamente eficiente, lo que puede incitar más al usuario a buscar la reducción de su factura.

Es necesario desarrollar métodos más sofisticados de apoyo a la reducción del consumo energético en calefacción y ACS, que claramente han sido los más difíciles de entender para los sujetos. En el entorno del laboratorio, y en previsión de ensayos posteriores, se debe simplificar la interfaz a este respecto; en el ámbito de la realidad, sería conveniente redactar una serie de consejos, simples de entender y fáciles de aplicar, antes de utilizar (o unidos a) un método más sofisticado de medida del consumo. 


\section{Evaluación del método informativo en campo: Experimento 2}

\subsection{Metodología}

\subsubsection{Descripción de los ensayos}

Este segundo experimento económico es el primero de los realizados en vivienda. Fue diseñado para testear en el mundo real la aplicabilidad de uno de los tratamientos con mejores resultados del experimento de laboratorio: el tratamiento contador único.

Consiste en la instalación de un contador inteligente llamado onMeterDomo en un conjunto de hogares de características similares, junto con una aplicación para smartphone y tableta mediante la cual el usuario puede consultar sus datos de consumo instantáneo, sus históricos de consumo, el precio horario de la energía, el valor de su siguiente factura eléctrica, y otros.

El objeto de este segundo experimento es la evaluación de la modificación del comportamiento obtenida exclusivamente mediante una aplicación informativa exhaustiva, completa e instantánea del consumo 
energético de la vivienda. El único incentivo económico contenido en este experimento es la rebaja en la factura eléctrica conseguida por los usuarios en base a los ahorros obtenidos.

Durante el periodo total de duración del experimento, y con la intención de aislar los resultados de posibles variaciones climatológicas $u$ otras variables externas, se registran los datos de dos grupos de voluntarios, uno de ellos con el onMeter instalado y el segundo sin él. Una vez recopilados los datos de ambos grupos, la variable de comparación será la variación de consumo en ambos grupos antes y después de instalado el elemento de medida en uno de ellos.

\subsubsection{Selección de la muestra}

Los sujetos participantes en el experimento fueron convocados a través de la carta y la encuesta mostradas en el Anexo II. Esta carta se envió, vía email, a toda la comunidad educativa y asociaciones de amigos de la Universitat Jaume I de Castelló, durante el mes de junio del año 2015.

De entre los voluntarios se seleccionó en principio una muestra de treinta participantes, tomando como criterio principal la mayor similitud posible entre sus viviendas, su equipamiento y el número de habitantes. A este grupo se le conoce en las tablas y gráficos siguientes como el Grupo I o Grupo onMeter.

Por diversos problemas durante la instalación del onMeterDomo, (en algunos casos no cabía en el cuadro de protección de la vivienda, en otros fue imposible conseguir la comunicación del dispositivo con la red Wifi de la vivienda, en otros hubo fallos sostenidos de comunicación entre la red WiFi y el servidor), finalmente la muestra quedó reducida a 22 participantes, cuyas características más relevantes se muestran en la Tabla 6.1.

Por otra parte, los sujetos del grupo de control fueron seleccionados con criterios de selección similares (carta a la comunidad educativa solicitando voluntarios, viviendas de características parecidas, etc), por lo que las muestras tienen características parecidas. A esta muestra se la nombra en las siguientes tablas y gráficos como Grupo II o Grupo de Control.

En la Tabla 6.1, se muestran las características de cada muestra en función de los datos que se han considerado relevantes. 
Distribución de la muestra según superficie de la vivienda (m2)

\begin{tabular}{cccc}
\hline & $90-120$ & $121-150$ & $151-500$ \\
Grupo I (onMeter) & $86 \%$ & $14 \%$ & $0 \%$ \\
Grupo II (Control) & $77 \%$ & $4 \%$ & $19 \%$ \\
\hline \multicolumn{5}{c}{ Distribución de la muestra según tipo de vivienda } \\
\hline \multicolumn{5}{c}{ Unifamiliar } & Adosado & Edificio \\
Grupo I (onMeter) & $0 \%$ & $14 \%$ & $86 \%$ \\
Grupo II (Control) & $17 \%$ & $8 \%$ & $75 \%$ \\
\hline Distribución de la muestra por número de habitantes \\
\hline \\
\hline
\end{tabular}

Tabla 6.1. Características socioeconómicas de las muestras

\subsubsection{Descripción del dispositivo de medición onMeterDomo}

El onMeterDomo es un equipo domótico que se sitúa en el cuadro eléctrico del local o residencia. Toma medidas de los parámetros fundamentales del consumo y las envía a un servidor a través de la red Wifi de la vivienda. En el servidor, los datos son tratados y puestos a disposición del usuario a través de una aplicación para smartphone.

El onMeterDomo, cuyo aspecto se muestra en la llustración 1 , está preparado para acoplarse al carril DIN del cuadro eléctrico de la instalación, de forma que, una vez instalado, queda oculto junto a los elementos de mando y protección. Se puede instalar en cualquier tipo de local o vivienda siempre que sea monofásica, con alimentación en corriente alterna de $230 \mathrm{~V} 50 \mathrm{~Hz}$, y de 
hasta un máximo de $11500 \mathrm{~W}$ de potencia. También se requiere la existencia de una red WiFi para la transmisión de datos.

La toma de medida de intensidad se realiza mediante una pequeña pinza amperimétrica que abraza al conductor de fase a la salida del IGA (Interruptor General Automático). Las únicas conexiones eléctricas que se requieren (y que deben ser realizadas por un técnico electricista), son la conexión del sensor de corriente al onMeterDomo, y la alimentación de éste a tensión (Figura 6.1). Para la alimentación a tensión, debe conectarse el onMeterDomo a la salida de alguno de los interruptores magnetotérmicos secundarios del

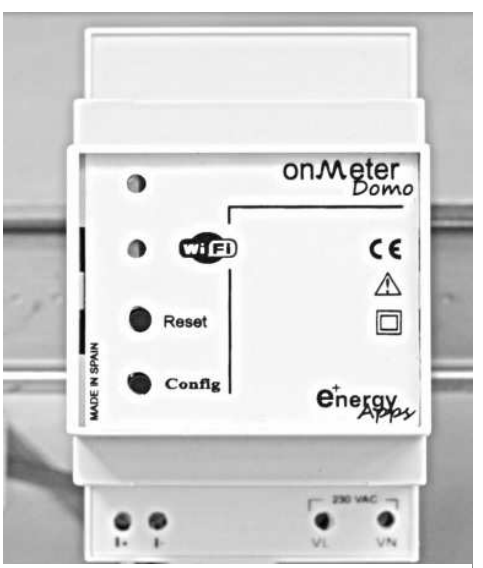

Ilustración 1. onMeterDomo cuadro de alimentación.

La toma de medida de tensión se realiza mediante un divisor resistivo que se encuentra en el interior del dispositivo. A partir de las ondas de tensión y la de intensidad se puede calcular el $\cos \varphi$, la potencia activa, la energía consumida y cualquier otro parámetro eléctrico del consumo que se considere necesario. Los valores calculados son enviados al servidor cada 3 segundos.

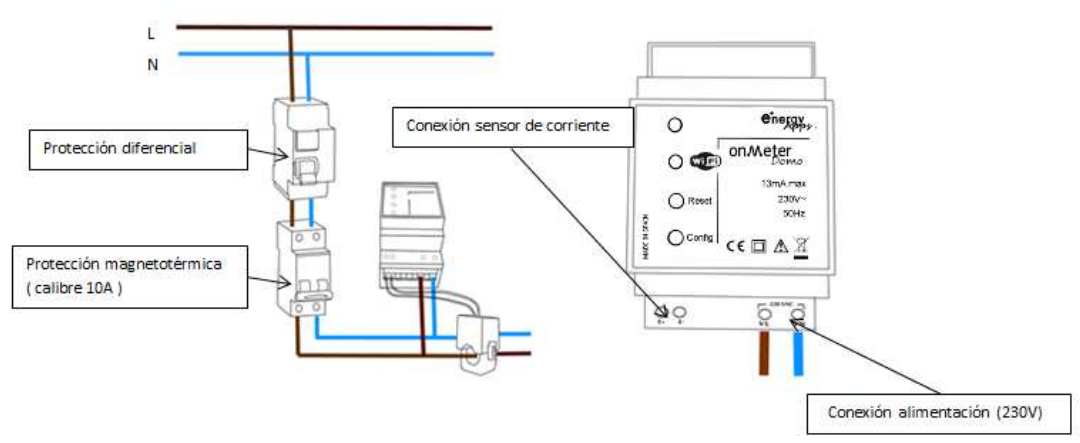

Figura 6.1. Instalación del onMeterDomo en el cuadro eléctrico de la vivienda 


\subsubsection{Descripción de la aplicación de lectura onMeterApp}

La aplicación para el uso del onMeterDomo por parte del usuario, llamada onMeterApp, puede descargarse e instalarse tanto en smartphone como en tablet. La pantalla de inicio se muestra en la Figura 6.2. En esta pantalla se da la medida instantánea, en tiempo real, de la potencia consumida. El dato va variando con el tiempo; cualquier modificación que se haga en el consumo instantáneo de la vivienda, por ejemplo encender una luz o poner la lavadora en marcha, se refleja con un retardo máximo de 3 segundos en esta pantalla.

La información contenida en esta pantalla inicial se ve completada por la información que puede obtenerse del resto de submenús que se ven en la parte derecha: histórico de consumos, factura estimada y potencia contratada. Los tres botones restantes (configuración red WiFi, añadir un nuevo OnMeter y Logout), son para necesidades de configuración y salida de la aplicación.

Pinchando en el menú Histórico de consumos se entra en la pantalla de la Figura 6.3. En ella, se puede seleccionar un periodo determinado (el día de hoy, el de ayer, una semana, un mes, un día cualquiera o un periodo cualquiera), en los que ver el consumo en el hogar.

Al seleccionar un día determinado, se muestra una gráfica pormenorizada del consumo instantáneo en $\mathrm{W}$, del día completo si ya ha transcurrido, o de la parte transcurrida si es el día en curso (Figura 6.4). En cualquiera de los dos casos, se puede ampliar el detalle de cualquier parte de la gráfica, del ancho que se desee, simplemente abarcando la zona con dos dedos. En la gráfica de la Figura 6.4 se ha ampliado el periodo desde las 6:48 hasta las 8:28. Además, tocando cualquier punto de la gráfica, el programa muestra la hora exacta y el consumo instantáneo de ese punto. En la Figura 6.4, se ha pinchado en el instante 07:51:29, en el que el consumo instantáneo es de 2167,4 W. Esta última característica es común a todas las gráficas de la aplicación.

Además de la gráfica, se añaden otros tres datos: la energía total en kWh consumida durante el día, su coste si la tarifa contratada es PVPC, y su coste si la tarifa contratada es PVPC con tarifa nocturna. 
El botón Consumo instantáneo devuelve al usuario a la pantalla de inicio (Figura 6.2), y el botón Históricos de consumo, le lleva nuevamente al submenú de Históricos (Figura 6.3).

Aún dentro del submenú Históricos de consumo, en el caso de seleccionar un periodo mayor a un día, la pantalla muestra una gráfica con la potencia media de cada uno de los días abarcados, así como una gráfica con los mínimos y máximos diarios. (Figura 6.5). El resto de datos son similares a los de la Figura 6.4.

El tercer botón mostrado en la Figura 6.2 es Factura estimada. En este submenú se calculan costes de la energía consumida en función de la tarifa que se tenga contratada.

Dentro de ese submenú existen a su vez varias opciones. La primera de ellas consiste en la comparación, para un día determinado, del perfil de consumo del usuario y el perfil del coste de la tarifa eléctrica por hora (Figura 6.6).

Gracias a esta comparativa, el usuario puede determinar si la mayoría de sus consumos son en horas punta o valle y decidir, en función de esa distribución, la tarifa eléctrica que más le convenga.

La segunda opción del menú Factura estimada muestra, en forma de gráfica, el precio de la energía consumida por hora para cada una de las tarifas contempladas (PVPC, PVPC tarifa nocturna, y tarifa plana). En este caso, La tarifa plana puede ser definida por el usuario dentro de la aplicación, para hacerla coincidir con la que tiene contratada.

La tercera y última opción del submenú Factura estimada contiene la misma información que la de la Figura 6.7 pero para un mes completo en vez de un único día. (Figura 6.8). Si se trata del mes en curso, la pantalla da una estimación a partir del consumo de los días ya transcurridos; si el mes ya ha vencido, hace el cálculo sobre los valores reales.

El tercer botón informativo de la pantalla inicial mostrada en la Figura 6.2 se denomina Potencia contratada. Entrando en él, se accede a una pantalla en la que se pueden introducir los datos exactos de la tarifa eléctrica contratada por el usuario. A partir de esta información, de la de las tarifas actualizadas PVPC y PVPC nocturna, y de los consumos previos del usuario, el 
programa realiza una sencilla auditoría energética de la instalación ( Figura 6.9).

Los puntos que revisa son los siguientes:

- Comparativa de la potencia máxima consumida con la potencia contratada. En caso de que la primera sea inferior a la segunda, aconseja un cambio en la tarifa para ajustar el término de potencia.

- Comparativa del precio del término de energía para las tres tarifas con las que trabaja el programa: PVPC, PVPC tarifa nocturna, tarifa plana.

- Consumo de base. En este caso, se mide el consumo fantasma de la vivienda, producido normalmente por la suma de los stand-by de los electrodomésticos que los tengan.

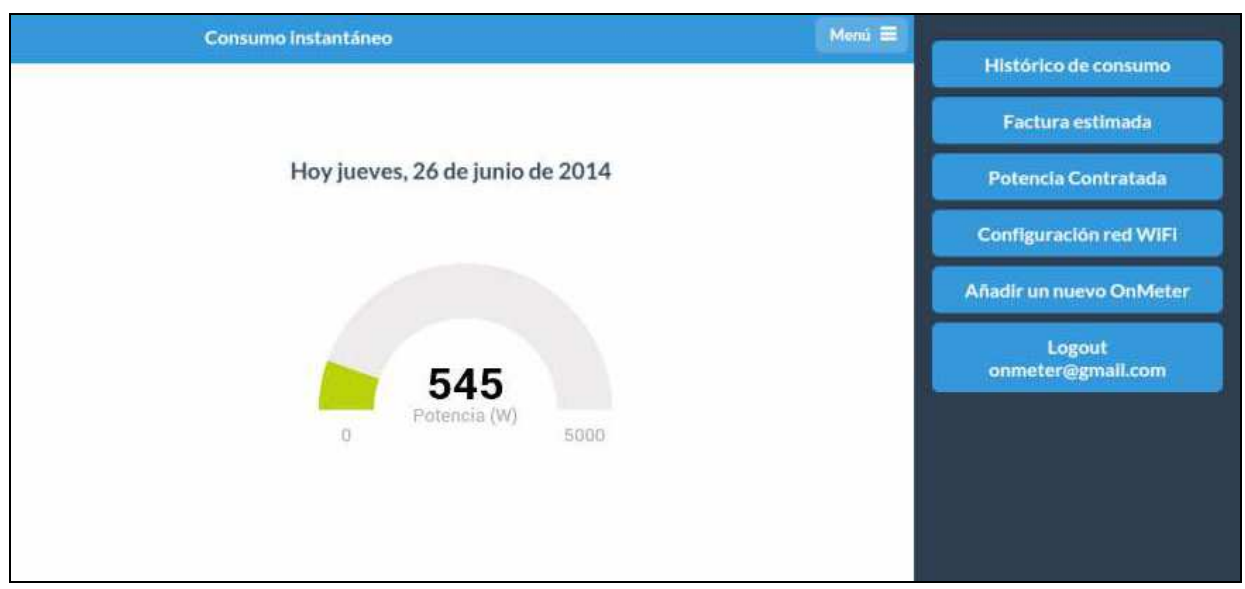

Figura 6.2. Pantalla inicial del onMeterDomo

X Selecciona un día

2014-01-30

Ver consumo

Selecciona un mes

$\because$ Selecciona un periodo

Figura 6.3. Submenú Histórico de consumos 


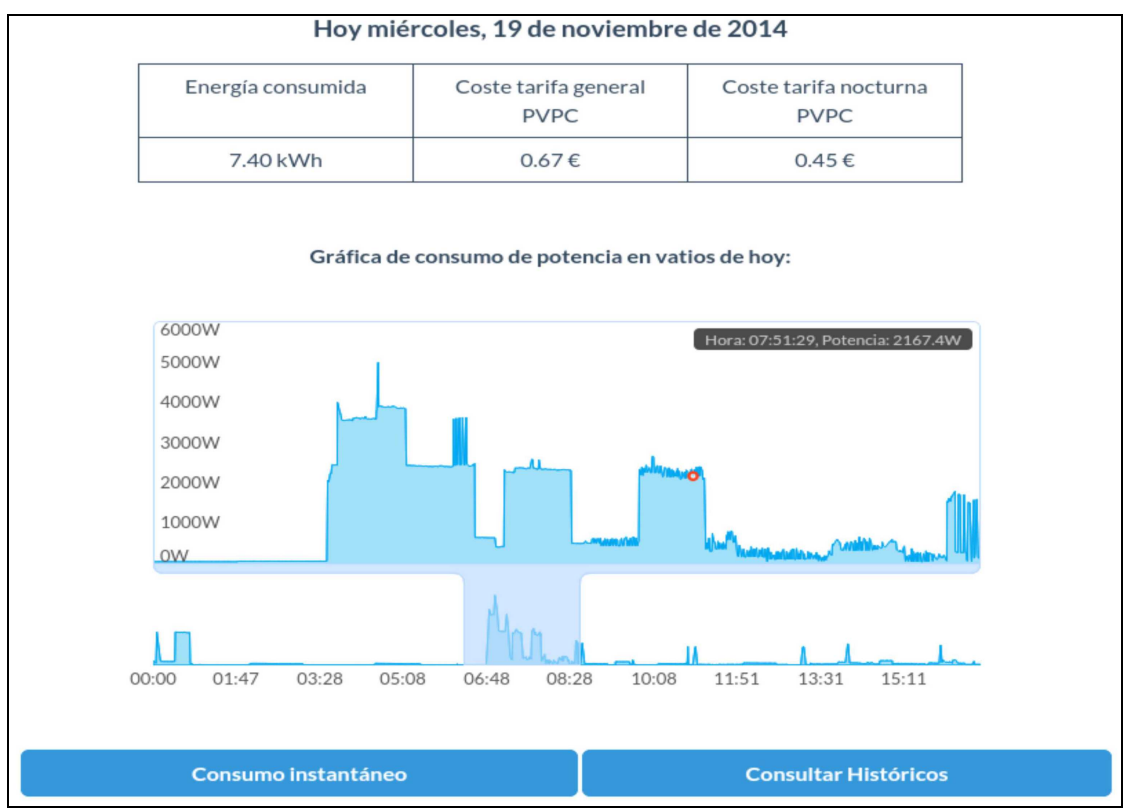

Figura 6.4. Submenú Históricos de consumo. Gráfica diaria

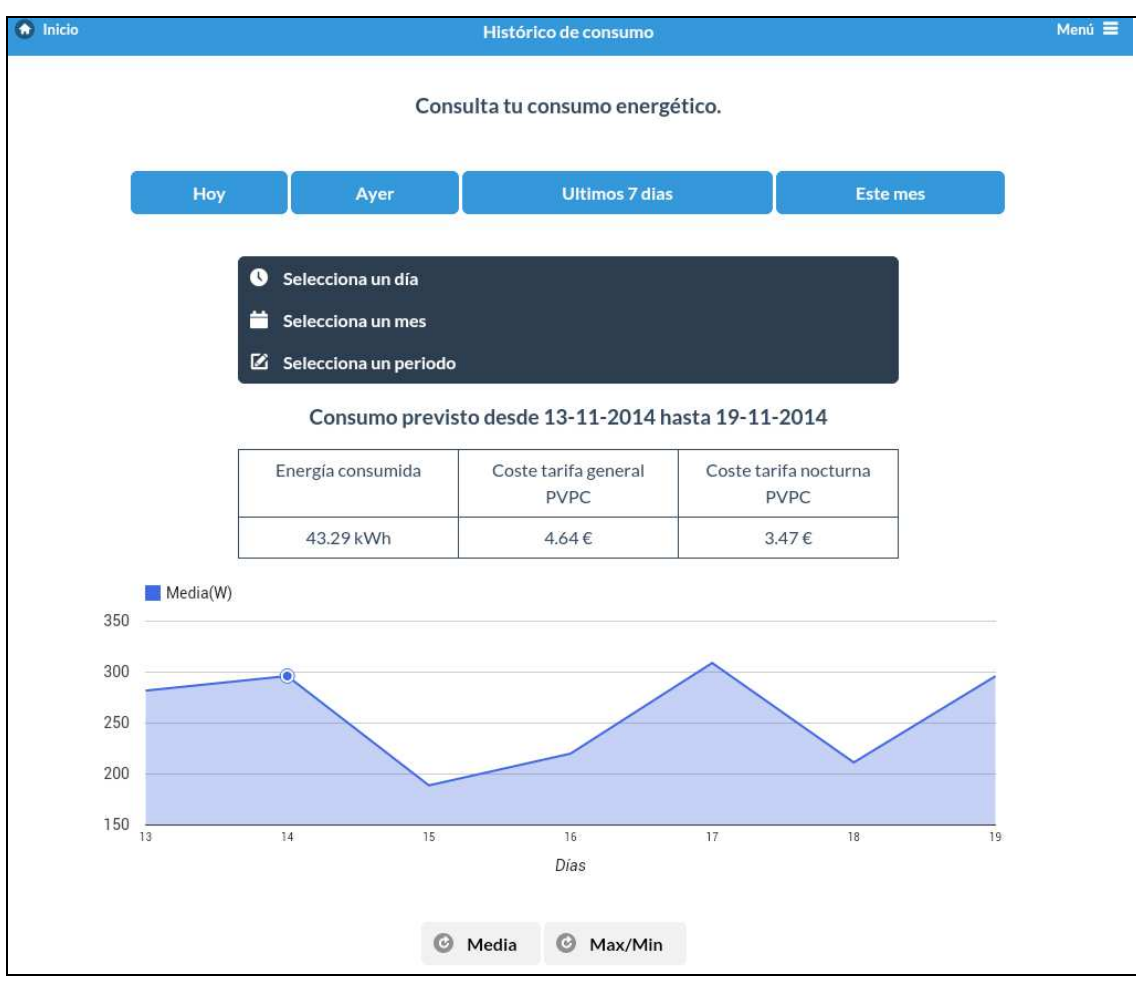

Figura 6.5. Submenú Históricos de consumo. Consumo durante un periodo determinado 


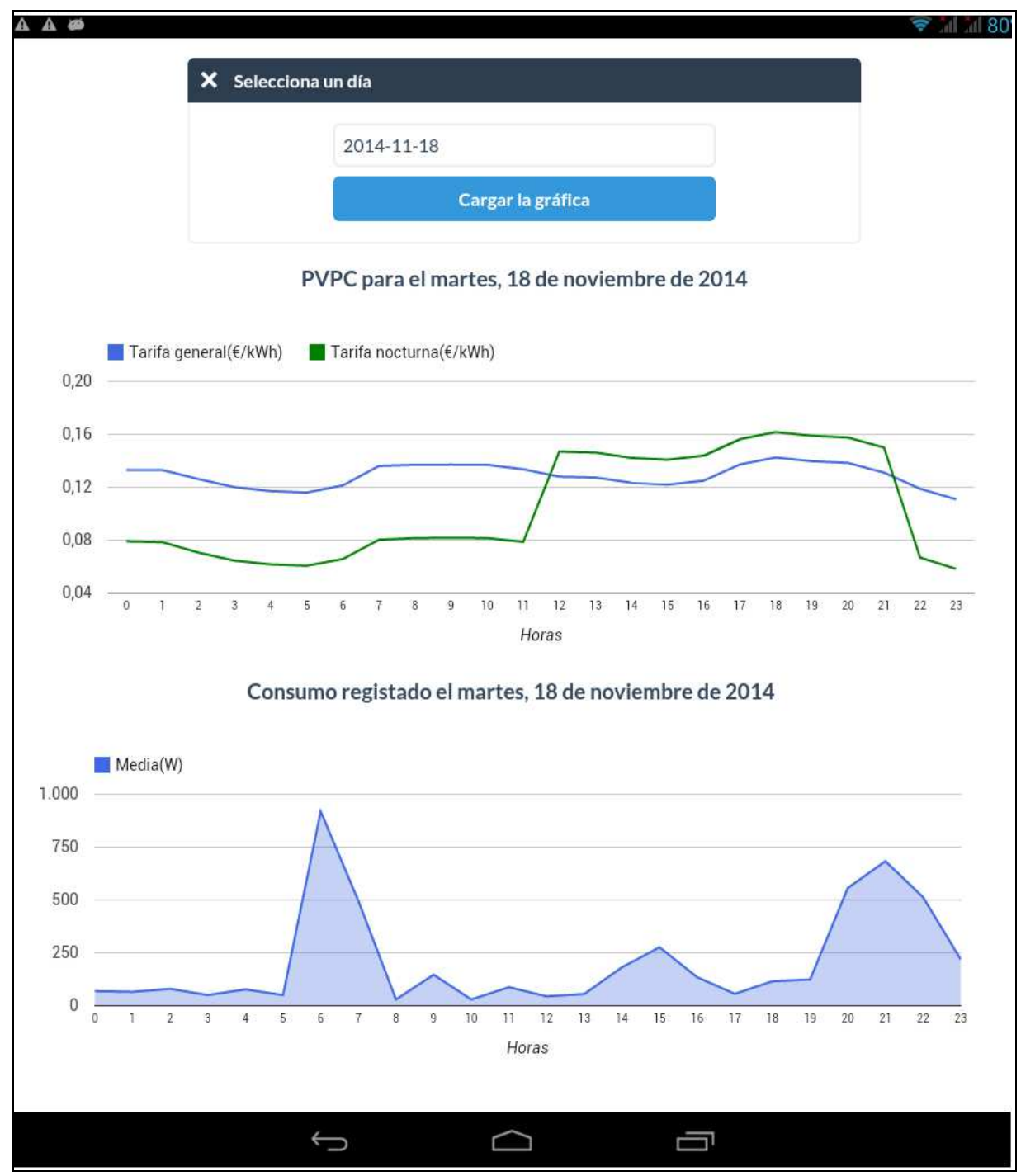

Figura 6.6. Submenú Factura estimada. Comparativa consumos / precios de la energía 


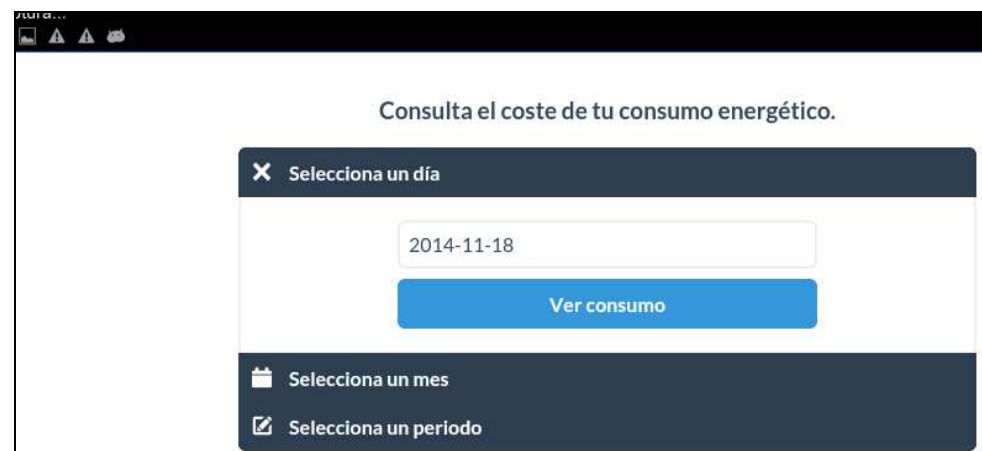

\section{F}

Consumo para el martes, 18 de noviembre de 2014

\begin{tabular}{|c|c|c|}
\hline $\begin{array}{c}\text { Coste tarifa general } \\
\text { PVPC }\end{array}$ & $\begin{array}{c}\text { Coste tarifa nocturna } \\
\text { PVPC }\end{array}$ & Coste tarifa plana \\
\hline $0.65 €$ & $0.53 €$ & $0.76 €$ \\
\hline
\end{tabular}

0,16

Coste tarifa general(€) $\quad$ Coste tarifa nocturna(€)

Coste tarifa contratada(€)

0,12

0,08

0,04

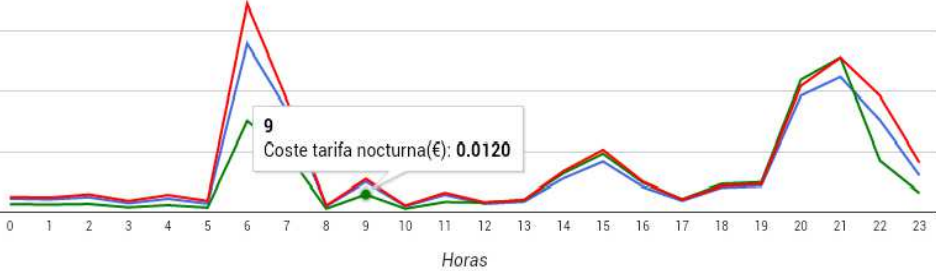

$\hookrightarrow \quad \square$

Figura 6.7. Submenú Factura estimada. Precios de la energía consumida para distintas tarifas 


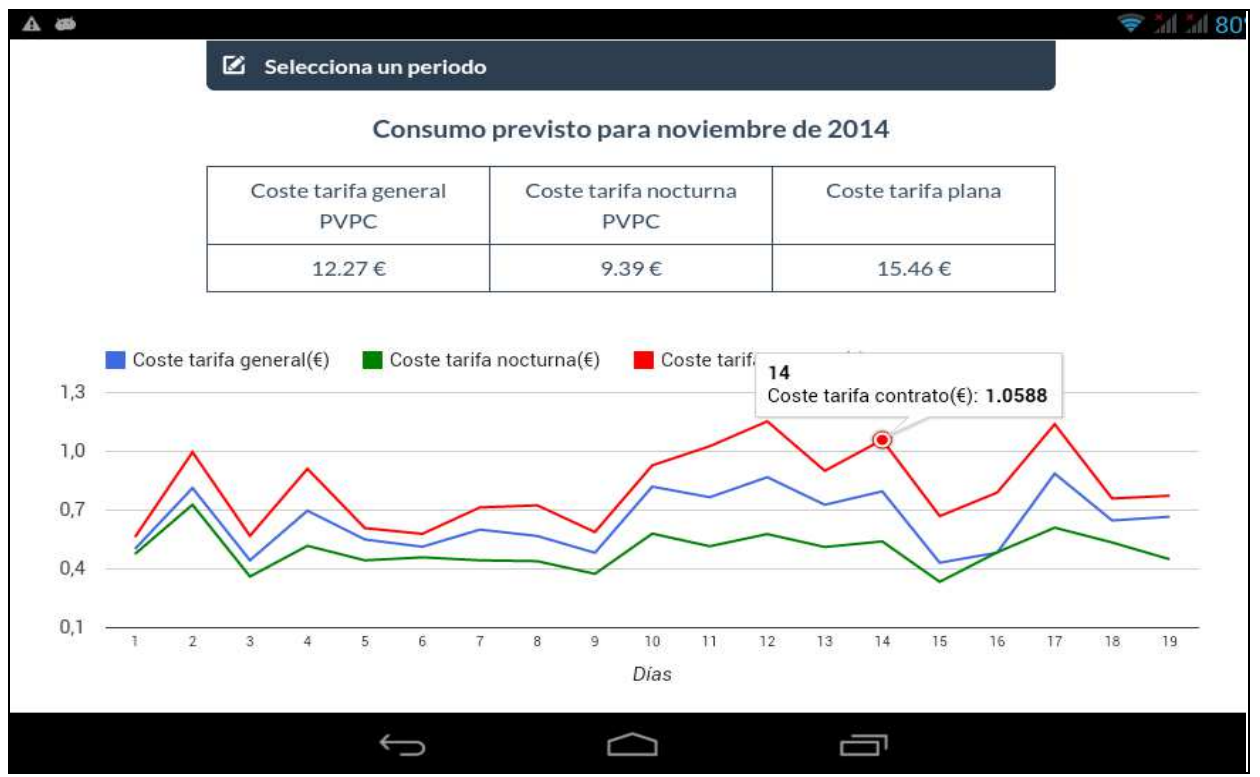

Figura 6.8. Submenú Factura estimada, coste mensual de la energía consumida.

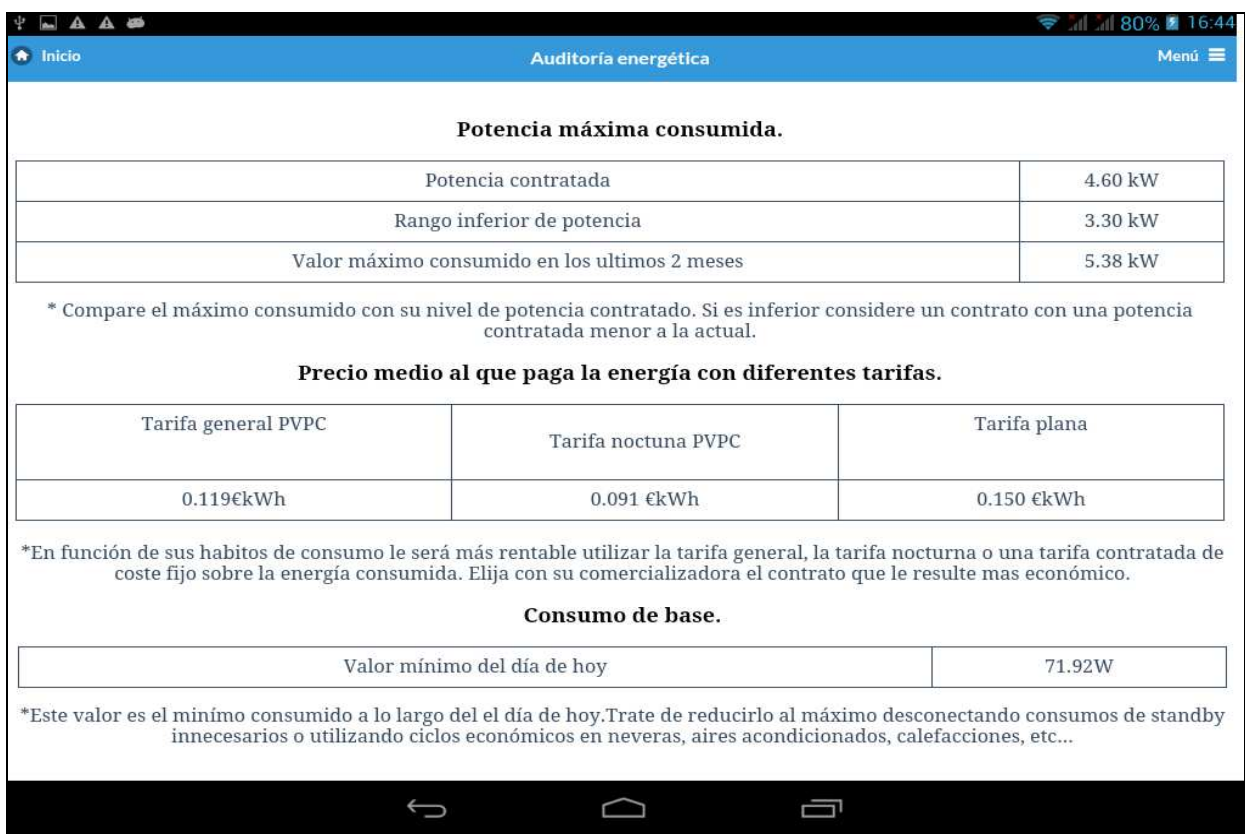

Figura 6.9. Submenú Potencia contratada. Auditoría energética 


\subsection{Desarrollo de las sesiones}

El periodo de instalación de los medidores inteligentes onMeterDomo se prolongó durante los meses de octubre y noviembre del año 2015. Desde el momento en que fue instalado en cada vivienda, el equipo empezó a enviar datos al servidor. Por lo tanto, se dispone de medidas de todos los participantes desde, como mínimo, el 17 de noviembre de 2015, fecha en la que se instaló y comprobó el último de los dispositivos.

La aplicación onMeterApp, imprescindible para que la información de los onMeterDomo llegue al usuario, fue distribuida a la vez a todos los participantes el día 18 de diciembre de 2015, fecha en la que se dio inicio al experimento. Los datos tomados entre el 17 de noviembre y el 18 de diciembre son por tanto conocidos por los investigadores pero no por los sujetos experimentales. Este conjunto de 31 días de medidas, tomadas sin conocimiento de los participantes, se utilizó posteriormente como base para juzgar el desempeño de los sujetos durante los periodos siguientes.

A partir del día 18 de diciembre se tomaron datos de forma continuada hasta el 26 de febrero de 2016, momento en que, a causa de un problema en los servidores, empezó a fallar la toma de datos. Los problemas se prolongaron de manera intermitente hasta el 26 de marzo, día desde el que la aplicación volvió a funcionar con normalidad. En la Tabla 6.2 se muestran los días con medidas válidas así como los que hubieron de ser desechados. Las medidas válidas se reparten en 3 periodos claramente diferenciados: el previo al reparto de la aplicación onMeterApp, el periodo diciembre 2015 a marzo 2016 y el último, del 26 de mayo a 26 de junio. En realidad este último periodo es más largo, pero se decidió desechar las medidas tomadas a partir de las vacaciones escolares, dado que un número indeterminado de participantes cambia a su residencia de verano aproximadamente en esas fechas.

En cuanto al grupo de control, se tomaron datos de consumo de los tres periodos del experimento 2. En este caso, los datos se obtuvieron de la página web de una única compañía distribuidora. En esta página, entrando con el identificador de cada usuario, se pueden descargar los datos de consumo horarios, diarios, semanales o mensuales del abonado. En el caso de este experimento, se descargaron los datos de consumo diarios, en Wh, de los días 17 noviembre a 26 de febrero, 10 a 30 de marzo, y 26 de mayo a 26 de junio. 


\begin{tabular}{|l|lllll|}
\hline & $1 a 7$ & 8 a 14 & 15 a 21 & 22 a 28 & $29-31$ \\
\cline { 2 - 5 } OCT & & & & \\
NOV & & & & \\
DIC & & & & \\
ENE & & & & \\
FEB & & & & \\
MAR & & & & \\
ABR & & & & \\
MAY & & & & \\
JUN & & & & \\
\hline
\end{tabular}

Periodo instalación onMeterDomo

Periodo 0 previo a la distribución de la app

Días con medidas válidas

Días con medidas defectuosas

Tabla 6.2. Calendario de sesiones

\subsection{Resultados}

\subsubsection{Introducción}

Para la evaluación del comportamiento de los integrantes del grupo onMeter, se procedió del siguiente modo: en primer lugar, se compararon los consumos medios de los participantes de ambos grupos durante el mes previo al experimento (periodo 0), en el que ninguno de los dos tuvo acceso a sus consumos. Se toma como hipótesis de trabajo que la diferencia relativa entre las medias, en ausencia de la instalación del onMeterDomo, se habría mantenido estable a lo largo del tiempo. La variable de comparación es el incremento de consumo.

Para que los periodos sean comparables entre sí, es aconsejable que tengan el mismo número de días, al menos aproximadamente. Por eso, se ha dividido la toma de datos en 3 subperiodos, cuyas fechas se pueden consultar en la Tabla 6.3

Fechas de los cuatro periodos del experimento

\begin{tabular}{ll}
\hline Periodo 0 & 17 nov a 17 de dic de 2015 \\
Periodo I & 18 dic 2015 a 26 ene de 2016 (excepto 24dic a 1ene) \\
Periodo II & 27 ene a 26 feb \\
Periodo III & 23 may a 26 jun \\
\hline
\end{tabular}

Tabla 6.3. Fechas de los cuatro periodos en que se divide el experimento 
En segundo lugar, se compararon los consumos medios de los dos grupos durante los tres periodos del experimento en los que la onMeterApp estuvo instalada (periodos I, II y III). Cualquier desviación en las medias relativas de ambos grupos sobre el periodo 0 se interpreta como resultado de la instalación del onMeterDomo y su app.

En todos los apartados siguientes, las variables se denominan de la siguiente forma:

- Grupo con el onMeterDomo instalado: Grupo onMeter o Grupo I

- Grupo de control: Grupo Control o Grupo II

- Toma de medidas previa a la distribución del onMeterApp: Periodo

0

- Primer periodo del experimento: Periodo I

- Segundo periodo del experimento: Periodo II

- Tercer periodo del experimento: Periodo III

\subsubsection{Estadísticos descriptivos}

Las muestras del grupo onMeter tienen las características mostradas en la Tabla 6.4.

Estadísticos descriptivos de la variable global incremento del consumo

\begin{tabular}{ccccc}
\hline & $\begin{array}{c}\text { Incremento } \\
\text { Periodo }\end{array}$ & Media (kWh) & $\begin{array}{c}\text { Desviación } \\
\text { típica (kWh) }\end{array}$ & N \\
\hline Grupo & I-0 & $-46,99$ & 101,37 & 22 \\
onMeter & II-0 & $-34,41$ & 93,11 & 22 \\
& III-0 & 15,47 & 141,48 & 22 \\
\hline \multirow{3}{*}{ Grupo Control } & I-0 & $-24,79$ & 49,07 & 46 \\
& II-0 & $-8,76$ & 40,89 & 46 \\
\hline
\end{tabular}

Tabla 6.4. Estadísticos descriptivos de todos los periodos 


\subsubsection{Normalidad de las muestras}

Se rechaza la hipótesis de normalidad de la mayoría de las distribuciones del grupo onMeter ( $p$-valor $<0,005$ ), aunque las del grupo de control sí lo son excepto en un caso. Los resultados se muestran en la Tabla 6.5.

Pruebas de normalidad de la variable global Incremento del consumo

\begin{tabular}{cccc}
\hline & $\begin{array}{c}\text { Incremento } \\
\text { Periodo }\end{array}$ & $\begin{array}{c}\text { Kolmogorov- } \\
\text { Smirnov }\end{array}$ & Shapiro-Wilk \\
\hline \multirow{3}{*}{ Grupo onMeter } & I-0 & 0,003 & 0,003 \\
& II-0 & 0,004 & 0,015 \\
Grupo Control & III-0 & 0,086 & 0,132 \\
\hline & II-0 & 0,159 & 0,285 \\
& III-0 & 0,114 & 0,038 \\
\end{tabular}

Tabla 6.5. Resultados de las pruebas de normalidad

Al no poderse demostrar la normalidad de una parte de las muestras, los tests aplicados en los apartados siguientes son no paramétricos.

\subsubsection{Comparativa entre los dos grupos}

Los resultados finales de las comparativas entre los dos grupos no muestran, en ninguno de los periodos, diferencia alguna entre los grupos. En la Tabla 6.6 se muestran las medias, la variación en tanto por cien entre los dos grupos, así como la significatividad de las comparativas. En la Figura 6.10 se muestra la comparativa gráfica entre las medias.

Como se puede observar en la Tabla 6.6, las diferencias porcentuales entre las muestras son muy pequeñas; oscilan entre un $-1 \%$ y un $+1 \%$ aproximadamente. Además, no son significativas en ninguno de los casos ( $p$ valor siempre cercano a 1 ).

Resultados globales comparados Grupos I y II 


$\begin{array}{ccccc}\text { Periodo } & \text { Consumo } & \text { Incremento } & \text { Ahorro } & \text { p-valor (Mann- } \\ & \text { medio }(\mathrm{kWh}) & (\mathrm{kWh}) & (\%) & \text { Whitney) }\end{array}$

\begin{tabular}{|c|c|c|c|c|c|}
\hline Grupo & 0 & 280,91 & 24 & -869 & \multirow{4}{*}{0,550} \\
\hline onMeter & I & 305,33 & 24,42 & - & \\
\hline Grupo & 0 & 296,55 & \multirow{2}{*}{24,79} & \multirow{2}{*}{$-8,36$} & \\
\hline Control & 1 & 321,34 & & & \\
\hline \multirow{2}{*}{$\begin{array}{c}\text { Grupo } \\
\text { onMeter }\end{array}$} & 0 & 280,91 & \multirow{2}{*}{11,26} & \multirow{2}{*}{$-4,01$} & \multirow{4}{*}{0,643} \\
\hline & II & 292,17 & & & \\
\hline Grupo & 0 & 296,55 & \multirow{2}{*}{8,76} & \multirow{2}{*}{$-2,95$} & \\
\hline Control & II & 305,30 & & & \\
\hline \multirow{2}{*}{$\begin{array}{c}\text { Grupo } \\
\text { onMeter }\end{array}$} & 0 & 280,91 & \multirow[t]{2}{*}{$-22,94$} & \multirow[t]{2}{*}{8,17} & \multirow{4}{*}{0,723} \\
\hline & III & 257,97 & & & \\
\hline Grupo & 0 & 296,55 & \multirow{2}{*}{$-27,55$} & \multirow{2}{*}{9,29} & \\
\hline Control & III & 269,00 & & & \\
\hline
\end{tabular}

Tabla 6.6.- Comparativa de los grupos onMeter y Control durante los 3 periodos del experimento La comparación se ha llevado a cabo a través del test de Mann-Whitney, dado que la mitad de las muestras no tienen una distribución normal.

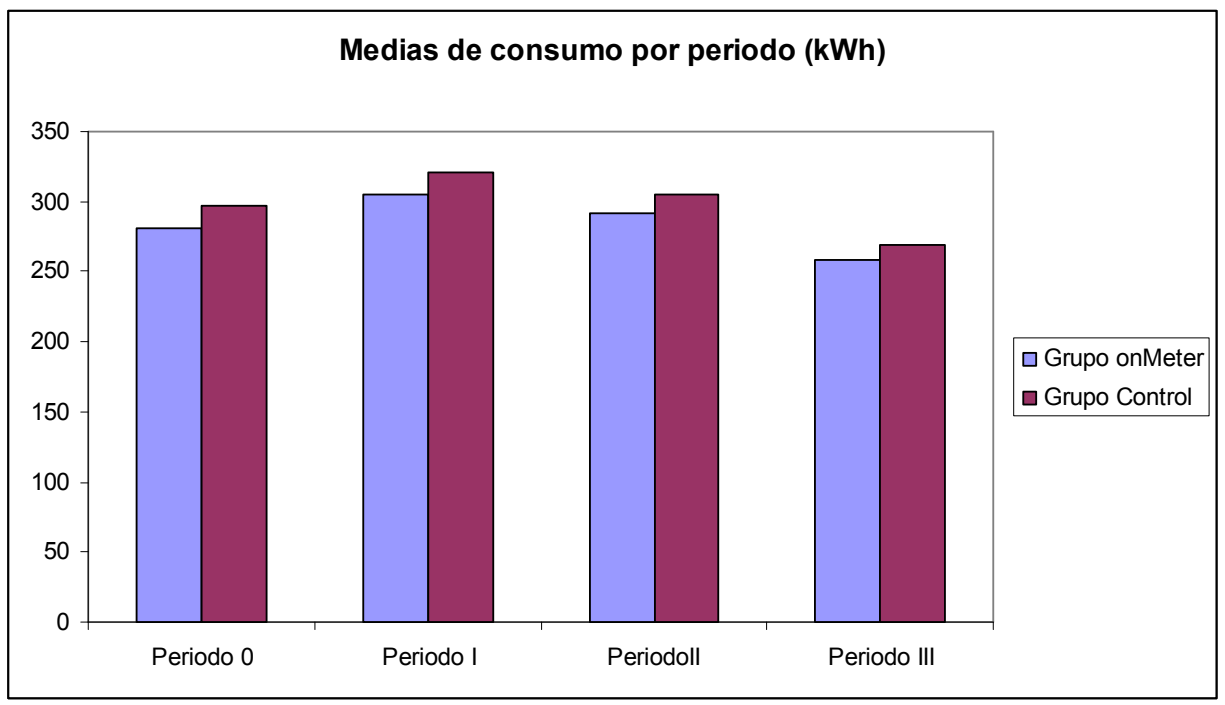

Figura 6.10. Comparativa entre las medias de consumo de los grupos onMeter y Control a lo largo de los tres periodos. 


\subsubsection{Otras aportaciones de los participantes}

Una vez terminado el experimento y ya en el periodo de retirada de los onMeterDomo, se solicitó a los participantes que rellenaran una encuesta acerca de su participación en el experimento. Sólo contestaron a la encuesta 9 de los participantes originales, pudiéndose revisar sus contestaciones en las dos siguientes tablas (Tabla 6.7 y Tabla 6.8)

Encuesta final experimento 2

\begin{tabular}{|c|c|}
\hline \multicolumn{2}{|l|}{ ¿Considera que el medidor le ayuda a ahorrar? } \\
\hline Poco & 0 \\
\hline Regular & 4 \\
\hline Mucho & 3 \\
\hline No sé & 2 \\
\hline \multicolumn{2}{|l|}{ ¿Le parece importante reducir el uso de energía en el hogar? } \\
\hline Esencial & 6 \\
\hline Importante & 3 \\
\hline Poco importante & 0 \\
\hline Totalmente innecesario & 0 \\
\hline \multicolumn{2}{|l|}{ ¿Considera eficiente su comportamiento energético de los últimos años? } \\
\hline $\begin{array}{lll} & P o c o\end{array}$ & 0 \\
\hline Regular & 5 \\
\hline Mucho & 4 \\
\hline No sé & 0 \\
\hline \multicolumn{2}{|l|}{ ¿Consulta su factura eléctrica cuando la recibe? } \\
\hline El coste total & 1 \\
\hline El coste total y el gasto en $\mathrm{kWh}$ & 0 \\
\hline El coste total, el gasto en kWh y el histórico de consumos & 8 \\
\hline No la miro & 0 \\
\hline \multicolumn{2}{|l|}{ Si desea ahorrar energía, ¿por qué razón/razones? } \\
\hline Economía personal & 9 \\
\hline Economía nacional & 0 \\
\hline Agotamiento de fuentes de energía & 5 \\
\hline Cambio climático & 6 \\
\hline \multicolumn{2}{|l|}{ ¿Tiene alguno de estos problemas para conseguir ahorros? } \\
\hline No sé qué hacer para ahorrar & 2 \\
\hline No puedo comprobar qué efecto tienen los cambios que hago & 1 \\
\hline No tengo referencias de lo que es normal gastar, así que no sé si ahorro & \\
\hline o derrocho & 3 \\
\hline Los cambios que podría hacer me cuestan más dinero que lo que ahorro & 3 \\
\hline
\end{tabular}

Tabla 6.7. Encuesta final experimento 2 
Encuesta final experimento 2

Es difícil ver cómo afectan aparatos discontinuos como nevera/termo

No tengo el hábito de entrar, pero me permite ver qué consume más

No hemos hecho un uso muy continuado de la aplicación

Observaciones Ayuda mucho a saber el consumo real de cada

acerca del electrodoméstico

medidor No vivim obsessionats per l'estalvi energètic, però procurem no malgastar en la despesa elèctrica

$A$ veces me ha hecho pensar en algunos picos que he visto y no sé qué son

Me ha servido para confirmar mis sospechas y pasar a modificar las bombillas de algunas luces

\begin{tabular}{cl}
\hline & Cambio de compañía suministradora, cambio de bombillas \\
& No (repetido 4 veces) \\
& La principal mesura d'estalvi és el canvi progressiu per \\
¿Ha tomado & làmpades LED \\
$\begin{array}{c}\text { alguna } \\
\text { medida }\end{array}$ & Sustituiremos los downlights de la cocina por LEDs \\
inspirada en & Sustituiremos el termo eléctrico y el frigorífico por otros más \\
su uso? & eficientes \\
& Cambiar potencia contratada y tipo de tarifa \\
& Sí, todas relacionadas con cambio de hábitos para ajustarse a \\
& Uso del horno más moderado \\
\hline
\end{tabular}

Tabla 6.8. Encuesta final experimento 2

\subsection{Discusión general de resultados}

\subsubsection{Igualdad de las medias}

La igualdad de las medias de los grupos I y II a lo largo de todos los periodos, demuestra que la instalación del onMeterDomo junto con su aplicación no ha supuesto ninguna mejora en el desempeño energético de los participantes. A pesar de que los resultados no han coincidido con lo que se esperaba inicialmente, lo cierto es que demuestran claramente que una herramienta informativa, por completa que sea, no es suficiente para garantizar una reducción del consumo por parte de los abonados. 


\subsubsection{Validez de la herramienta informativa}

La onMeterApp incluye una enorme cantidad de información acerca tanto del consumo en sí como de su coste. Utilizando únicamente la información incluida en la pantalla inicial (Figura 6.2), el usuario ya puede conocer de primera mano la potencia instantánea consumida por cada uno de los electrodomésticos y equipos de su vivienda, sin más que encenderlos o apagarlos sucesivamente; puede detectar también consumos fantasma simplemente desconectándolo todo.

Entrando en los sucesivos submenús, a través de los históricos de consumo, el usuario puede detectar defectos en cualquiera de los electrodomésticos de la vivienda, a través de la detección de picos extraños en las curvas o subidas bruscas del consumo instantáneo. Puede saber, por comparación, qué equipamiento es el mayor consumidor, y plantearse la posibilidad de cambiarlo por uno más eficiente.

Puede localizar consumos fantasma a través de los mínimos de consumo nocturnos, y reducirlos a cero por el simple procedimiento de apagar los electrodomésticos que los provocan. Puede incluso revisar, antes de salir de casa, si se ha dejado una luz, un ordenador o un sistema de calefacción en marcha.

Eso en cuanto a los consumos; en cuanto a las facturas, la aplicación puede asesorar al usuario acerca de la conveniencia de cambiar de tarifa o de potencia contratada en función de las características de su consumo, o incluso pasarse a un sistema de tarifa nocturna.

En resumen, la cantidad de información que puede obtenerse a partir de la onMeterApp, y sólo se han nombrado algunas de sus posibilidades, es más que de sobra para acometer mejoras tanto en el comportamiento energético como en la modernización del equipamiento de la vivienda.

Se puede objetar que la herramienta es demasiado compleja para la mayoría de los usuarios, y que el exceso de información que contiene, en vez de inspirar, satura; sin embargo, el usuario tiene la opción de ignorar los submenús y centrarse exclusivamente en la pantalla inicial, un único número que ya contiene, en sí, información más que suficiente para ponerse a trabajar con ella. 


\subsubsection{Implicación de los usuarios}

Una cuestión es la calidad y cantidad de la información suministrada, y otra cuestión, fundamental en este caso, es el interés de los participantes en ella y en aplicarla para la reducción de su consumo. El poco interés mostrado por los sujetos en el uso de la aplicación se demostró durante los periodos en los que falló la comunicación con el servidor. El primero de los periodos de fallo duró 10 días, pero el segundo duró 52 días. Durante ese tiempo, al abrir la aplicación, ésta informaba de fallo de comunicación con el servidor. Pese a que ese mensaje de error se mantuvo permanentemente en la pantalla de la aplicación durante 52 días, ni uno sólo de los participantes del experimento se quejó de la falta de funcionamiento de la aplicación durante todo ese tiempo.

\subsubsection{Aportaciones de los usuarios}

En la encuesta final repartida a los participantes (Tabla 6.7, Tabla 6.8), y pese al escaso número de respuestas obtenidas, se aprecian algunos detalles de interés.

En cuanto a la percepción del consumo eléctrico en el propio hogar, los participantes, si se les habla en términos generales, consideran importante su reducción pero si hablan de ellos mismos, les parece que su comportamiento propio es razonablemente eficiente. Entre las razones que se esgrimen para desear ahorrar energía, hay unanimidad en la importancia que tiene el ahorro para la economía personal, y un interés medio en las razones medioambientales.

En cuanto a su implicación en el conocimiento de su propio consumo, muestran casi unanimidad: todos menos uno afirman revisar todos los datos relevantes de su factura eléctrica (coste, consumo en kWh e históricos) cuando la reciben, lo que es un resultado sorprendente.

En las preguntas relativas al medidor, el test es poco significativo (no sé, regular y mucho están uniformemente repartidas), pero los comentarios sobre en qué les ha ayudado sí son interesantes, porque muestran que no ha habido prácticamente ningún uso del medidor relativo al cambio de comportamiento, a excepción de la reducción en el uso del horno. Todas las medidas que los participantes afirman haber tomado están relacionadas, o bien con ajustes de su tarifa eléctrica a su consumo, o bien de mejoras en el equipamiento. 
Finalmente, los problemas relacionados con el ahorro están repartidos de forma regular entre todas las posibilidades sugeridas.

\subsection{Conclusiones}

\subsubsection{Necesidad de un incentivo}

En el primero de los experimentos realizados durante la elaboración de la tesis, llevado a cabo en laboratorio, (ver Capítulo 5), se premió económicamente a los sujetos que lograban, en una vivienda simulada, obtener ahorros en su consumo energético. Los resultados fueron muy buenos, obteniéndose reducciones significativas del consumo con la combinación del incentivo económico y la realimentación de la información.

Sin embargo, en este segundo experimento, ningún incentivo económico fue aplicado. Pese a la cantidad y calidad de la información suministrada a los participantes, no hubo ninguna variación significativa en su comportamiento, a excepción de algunos sujetos que, durante la instalación, detectaron algún defecto en la instalación eléctrica de la vivienda que subsanaron en ese momento. Es más, los participantes ni siquiera se tomaban la molestia de abrir la aplicación y mirar su consumo.

Parece, a la vista de los resultados de este experimento con métodos informativos, que, siendo éstos suficientemente exhaustivos, dan a los usuarios herramientas suficientes para capacitarles para reducir su consumo. El problema de estos métodos es que no incluyen el incentivo necesario para motivar al usuario a hacer el esfuerzo que ello supone.

\subsubsection{Las herramientas informativas puestas en marcha por la Unión Europea}

En la Unión Europea, y en virtud de la normativa en vigor, se están llevando a cabo campañas de sustitución de los contadores tradicionales por contadores de alta tecnología, capaces de dar medidas instantáneas de consumo. A su vez, las compañías distribuidoras y comercializadoras están poniendo esta información, en forma de gráficas y hojas de cálculo, a disposición de sus clientes (Figura 6.11). 
1.

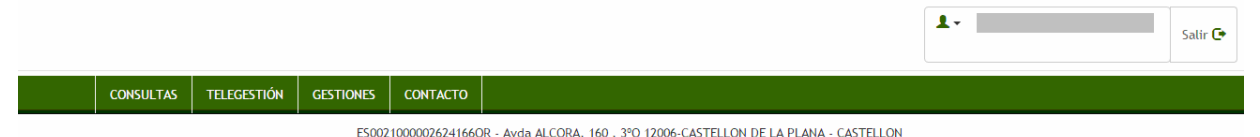

ES50210000026241660R - AVda ALCORA, 160, 3ㅇ 12006-CASTELLON DE LA PLANA - CASTELLON

Mi consumo - mensual

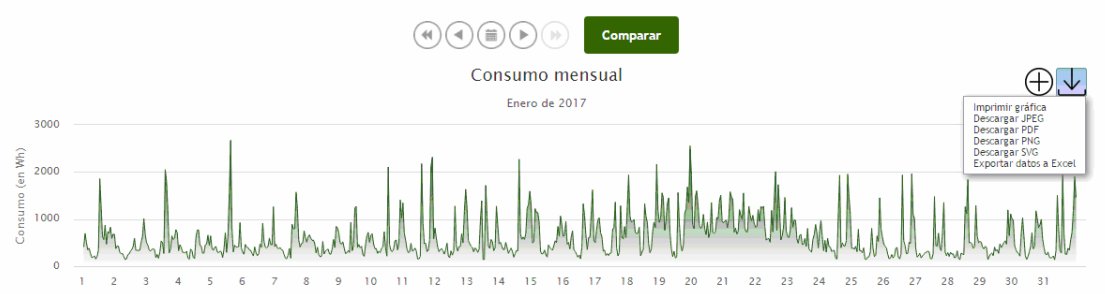

Figura 6.11. Página web con información mensual del consumo de una conocida distribuidora de energía eléctrica.

En un estudio llevado a cabo por El Energy Efficiency Watch, que analiza los resultados de los Planes Nacionales de Eficiencia Energética de los países miembros de la Unión Europea [49], y tras una serie de entrevistas contestadas por más de 1100 expertos de todos los países de la Unión, se confeccionó la Figura 6.12, en la que se muestra el grado de éxito de cada una de las políticas de la Unión Europea de los últimos años (siempre según la percepción de los expertos que contestaron a la entrevista).

Uno de los objetivos de la introducción de smart metering es proporcionar a los abonados una herramienta útil para la disminución de su consumo energético; sin embargo, la efectividad de esta iniciativa no está siendo, al menos según la percepción de los expertos, demasiado buena. En la Figura 6.12, se aprecia cómo el smart metering está considerado, junto a los impuestos sobre la energía, como una de las medidas políticas de menor efectividad de todas las aplicadas.

Con este experimento y el siguiente se demuestra que el problema no se encuentra en la cantidad de la información que se proporciona al usuario, sino en la voluntad de éste de, primero, acceder a esa información, y segundo, utilizarla en pro de la eficiencia energética.

Teniendo en cuenta el desembolso económico y las dificultades técnicas que supone la sustitución de todos los contadores y su implementación en una red que proporcione medidas a corto plazo a todos sus usuarios, es necesario 
implantar las medidas necesarias para que esta política alcance su máxima eficacia.

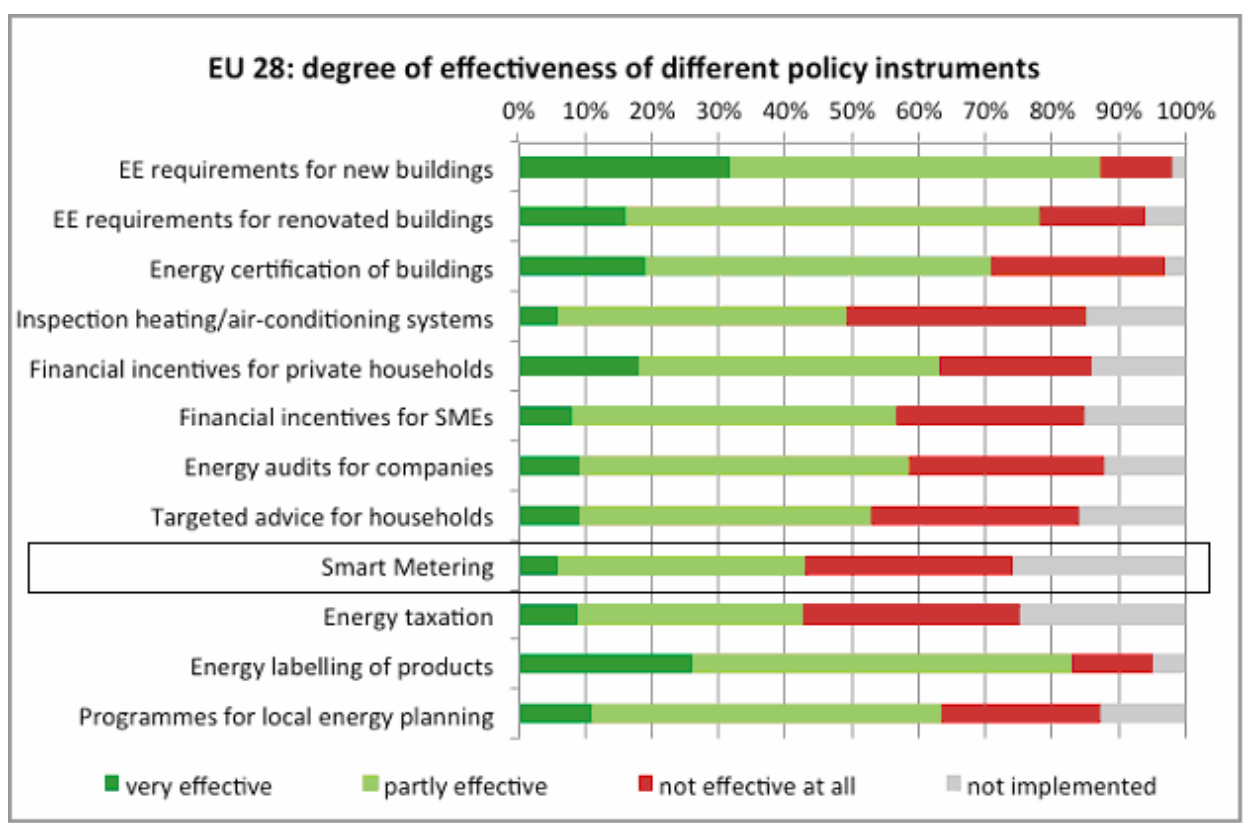

Figura 6.12. Grado de efectividad de las distintas políticas de eficiencia energética puestas en marcha por la Unión Europea. Fuente: [49]

\subsubsection{Aportaciones de los usuarios}

Dos conclusiones interesantes se extraen de las encuestas realizadas al fin del experimento. La primera de ellas viene de la unanimidad en la importancia que tiene el ahorro energético para la economía personal de los participantes. Uno de los problemas principales de las medidas de ahorro energético a nivel residencial es que las mejoras que se realicen, sean del tipo que sean, a la hora de la verdad apenas se reflejan en una factura eléctrica en la que pesan más los términos no variables (término de potencia, alquiler de equipos, impuestos), que la parte relacionada con el consumo. Si uno de los principales incentivos para los usuarios es el ahorro económico que les generan las medidas de eficiencia energética, pero cualquier medida que tomen apenas les repercute económicamente, la configuración de la factura eléctrica es claramente desincentivadora para el ahorro energético. 
La segunda conclusión está relacionada con la forma en la que se ha utilizado el medidor. El hecho de que la mayoría de modificaciones que se han hecho o que se proyectan hacer estén relacionadas con un cambio en la tarifa eléctrica $o$ en el equipamiento por otro más eficiente explica por qué ha habido tan poco uso de éste. En realidad, los usuarios sí lo han utilizado, pero no de forma continuada sino en una especie de auditoría inicial de su vivienda, en la que se ha detectado por una parte el equipamiento a sustituir y por otra la conveniencia o no de un cambio de tarifa. Una vez hecho esto, a la herramienta no se le ha dado ningún otro uso. Por tanto, para que un medidor sea efectivo de forma continuada, debe mostrarse a sus usuarios formas de utilizarlo que vayan más allá de esa evaluación inicial, y deben buscarse herramientas que promuevan una consulta periódica. 


\section{Evaluación del incentivo económico en campo: Experimento 3}

\subsection{Metodología}

\subsubsection{Descripción de los ensayos}

El tercer experimento llevado a cabo es el segundo de los realizados en vivienda. Consiste en el estudio de la modificación del comportamiento en el consumo eléctrico conseguida a base de remunerar económicamente el ahorro obtenido. Para ello, se reclutó a un conjunto de voluntarios a los que se ofreció una recompensa dineraria a cambio de conseguir un ahorro determinado en su consumo eléctrico, medido en relación a su propio consumo en los mismos meses del año anterior. Para que los participantes tuvieran una referencia de si estaban logrando los objetivos establecidos en la convocatoria, se les envió semanalmente información de su desempeño. A este grupo de le denominó Grupo de pago o Grupo I.

Al igual que en el experimento 2 , se hizo necesario evitar la influencia en los resultados de posibles variaciones externas tales como la climatología. Para ello, se reclutó un grupo de control (grupo II) al que no se ofreció ningún tipo 
de recompensa, pero que recibió la misma información semanal que el primer grupo. El objetivo de enviar la misma información a ambos grupos fue que el resultado de ahorro obtenido por el grupo I sobre el II fuera resultado exclusivo de la variable económica, sin que se pudiera achacar parte de su éxito mayor al que fueran informados de su actuación.

Con el objeto de evaluar la posible influencia de la información entregada a los grupos I y II, se reclutó a un tercer grupo, llamado grupo ciego (Grupo 0). Este grupo no supo de su participación en el experimento hasta después de concluido éste, y desde luego no fue informado semanalmente de su comportamiento. Por lo tanto, es un grupo válido para la valoración de la influencia de la variable información sobre los otros dos grupos.

Una vez recopilados todos los datos, se comparó la evolución en el comportamiento de cada grupo con respecto a sí mismo en los meses anteriores, y con respecto a los demás en los mismos meses.

En el caso de este experimento, los datos de los consumos fueron tomados directamente de la cuenta personal de cada participante en la página web de su compañía distribuidora. En esta página se pueden consultar y descargar datos horarios, diarios, semanales o mensuales de cualquier abonado que tenga instalado un contador electrónico. Para ello, previamente al inicio del experimento, los miembros de los grupos I y II facilitaron sus contraseñas de acceso.

\subsubsection{Objetivo de ahorro e incentivo aplicado}

El objetivo del grupo I fue conseguir un ahorro sostenido en el consumo eléctrico de su vivienda, durante los meses de octubre, noviembre y diciembre del año 2016, con respecto al consumo de los mismos meses del año 2015. Como incentivo para ese ahorro, se ofreció una remuneración en metálico, de valor linealmente variable entre 0 euros para ahorros nulos o negativos, y 100 euros para el ahorro máximo, un $10 \%$ sobre el consumo de las mismas fechas del año anterior.

Debido a la temperatura anormalmente cálida del otoño del año 2015, se previó la posibilidad de que el consumo del año en curso, por razones únicamente climatológicas, fuera mayor que el del anterior, y por tanto fuera especialmente difícil obtener un ahorro considerable. Por ello, y dado que la remuneración era proporcional al ahorro, se decidió poner un límite de ahorro 
máximo relativamente bajo, un $10 \%$, para no desincentivar a los que obtuvieran resultados no demasiado buenos durante las primeras semanas.

El grupo II, como grupo de control, no dispuso de ningún incentivo monetario. En cuanto al grupo 0 , ni siquiera tuvo conocimiento de la realización del experimento hasta una vez concluido éste.

Se dio libertad a los grupos I y II para diseñar su propia estrategia de ahorro, sin dar información alguna ni consejos de ahorro energético de ningún tipo. Posteriormente al estudio, se preguntó en una encuesta si sus logros se habían conseguido a base de modificaciones del comportamiento, cambios en el equipamiento de la vivienda u otros métodos.

\subsubsection{Selección de la muestra}

Los sujetos participantes en el experimento fueron convocados a través de la carta y la encuesta mostradas en el Anexo III.1. Esta carta se envió, vía email, a toda la comunidad educativa y asociaciones de amigos de la Universitat Jaume I de Castelló, durante el mes de septiembre del año 2016.

De entre los voluntarios se seleccionó en principio una muestra de sesenta participantes, tomando como criterio principal la mayor similitud posible entre sus viviendas, su equipamiento y el número de habitantes. Los criterios de selección ideales fueron los siguientes:

- Clientes de una misma comercializadora eléctrica

- Vivienda ocupada durante los últimos dos años, de forma permanente

- Superficie de la vivienda entre 90 y $120 \mathrm{~m}^{2}$

- Número de habitantes entre 3 y 4

- Ubicación en la ciudad de Castellón

- Vivienda situada en edificio de viviendas

- Sistema de calefacción por gas

- Cocina eléctrica

A partir de los criterios de selección enumerados, se seleccionó a los participantes para que la muestra fuera lo más homogénea posible, aunque también en función de la disponibilidad de voluntarios. Los únicos requisitos 
imprescindibles fueron los dos primeros, excepto que el criterio de pertenencia a una misma comercializadora se consideró innecesario para el grupo 0 .

Debido a diversos problemas posteriores, principalmente falta de datos de algunos participantes en la página web de la compañía distribuidora durante algunos días o semanas del experimento, la muestra quedó reducida a 50 participantes ( 25 en el Grupo I y 25 en el Grupo II). Sus características socioeconómicas se muestran en la Tabla 7.1, junto con las del grupo 0.

Distribución de la muestra según superficie de la vivienda (m2)

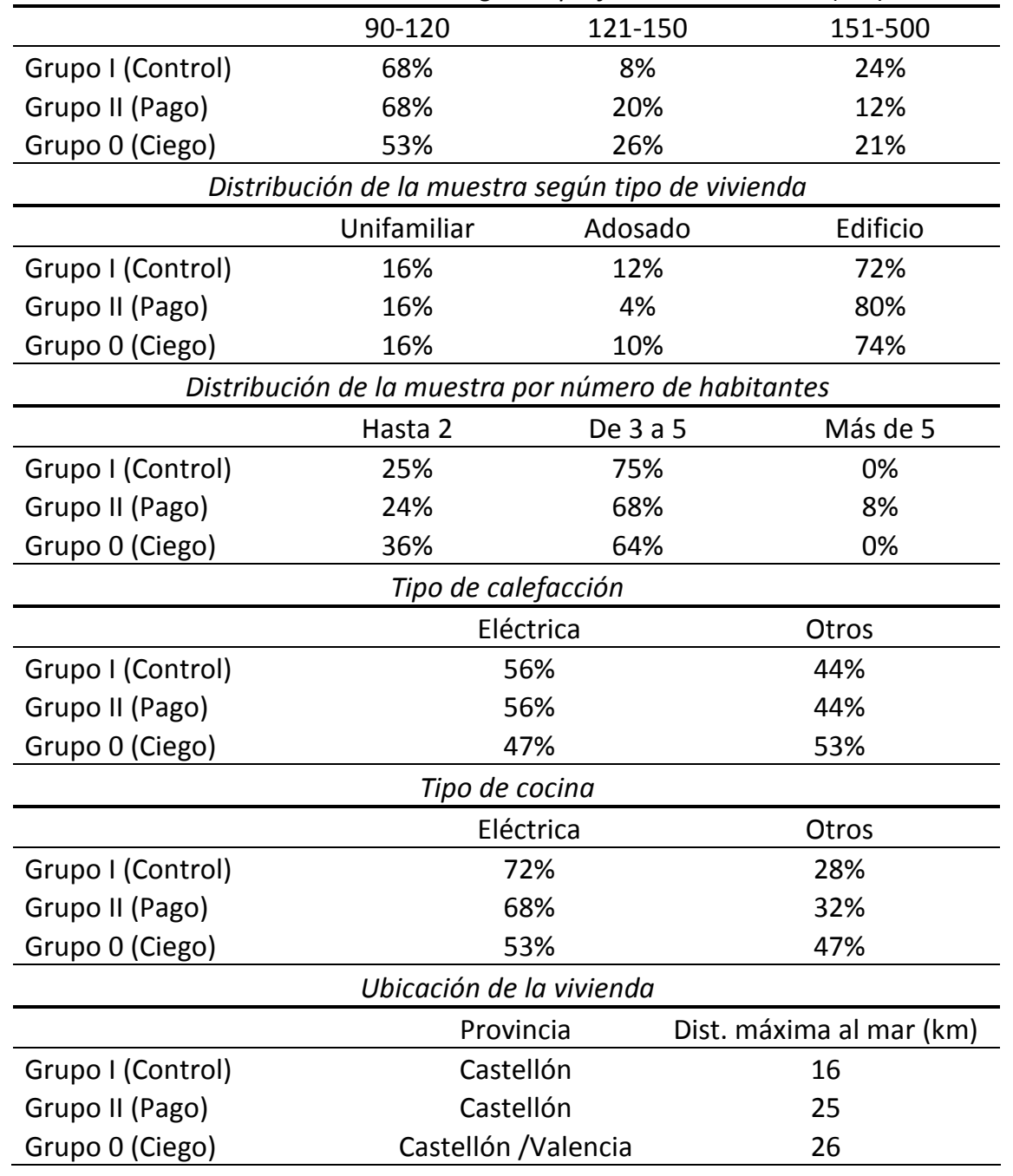

Tabla 7.1. Características socioeconómicas de los grupos I y II del experimento 3 


\subsubsection{Diseño de la información semanal}

Dado que la duración del experimento era inicialmente de tres meses, se consideró necesario establecer un buen sistema de realimentación de la información que no dejara exclusivamente en manos de los participantes el ser conscientes del ahorro obtenido hasta entonces.

Aunque en teoría el sistema de realimentación ya existe y es suficientemente sofisticado y con información sobrada para cualquier necesidad de los participantes (los datos de consumo de la página web de la compañía suministradora, con actualización diaria e información sobre consumos horarios, diarios y mensuales durante al menos dos años), la experiencia adquirida durante el experimento 2 llevó a considerar conveniente el envío periódico de un paquete informativo diseñado para contener una realimentación limitada, de un tipo eminentemente básico.

El paquete informativo consta de dos gráficas con información tanto del consumo semanal como del total. La primera gráfica (Figura 7.1) contiene información sobre el consumo de la semana anterior y su comparativa con los mismos siete días del año 2015, para dar a los sujetos una idea de su desempeño semanal en el experimento. De este modo, en caso de haber modificado algún patrón de comportamiento o algún equipamiento de la vivienda durante ese periodo, podían tener una idea de la repercusión en su consumo. Se consideró que ésta sería para ellos la información más útil a la hora de emprender modificaciones, dada su proximidad en el tiempo (se enviaba en cuanto acababa la semana que se estaba valorando).

Como en realidad el experimento consistía en el ahorro sostenido desde el inicio, se envió una segunda gráfica con el consumo acumulado desde el principio del experimento y su comparativa con el mismo periodo del año anterior (Figura 7.2). Esto se hizo para mantener en los participantes el interés por alcanzar el objetivo propuesto por el incentivo, dado que las variaciones en el consumo semanal pueden ser engañosas con respecto a la consecución de los objetivos finales. De este modo, los participantes tenían un recordatorio semanal del objetivo real a alcanzar. 


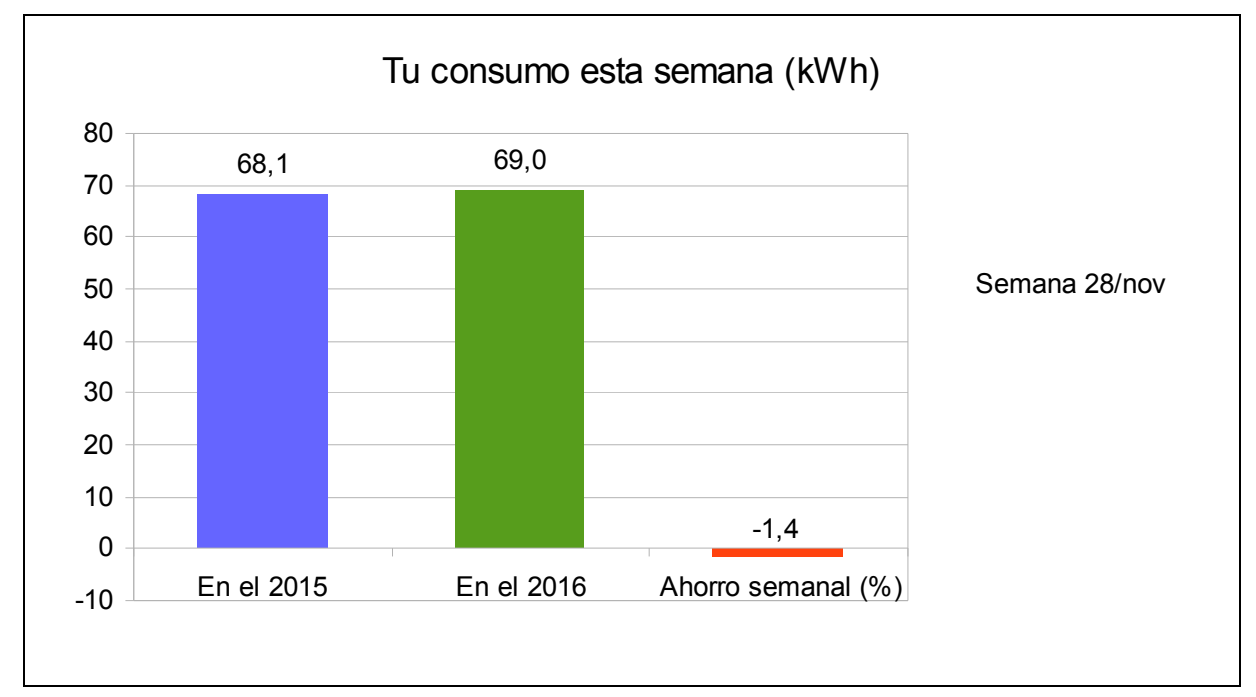

Figura 7.1. Información del consumo semanal y comparativa con la misma semana del año anterior

Además de estas dos gráficas, se envió también información sobre la actuación del resto de participantes del grupo al que pertenecía cada uno (Figura 7.2). Según varios experimentos comentados en el apartado 4.2, éste es un dato que suele interesar y motivar a los participantes en este tipo de experimentos.

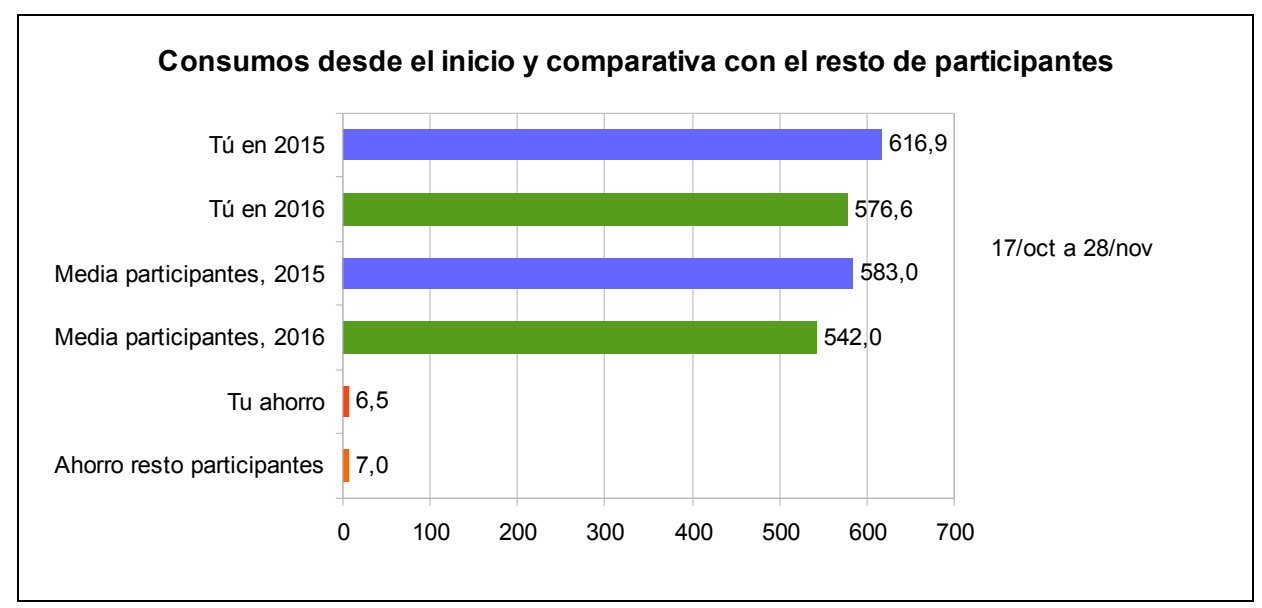

Figura 7.2. Información del consumo total y comparativa con el del año anterior y con el resto de participantes 
Todo el envío de información se realizó directamente al smartphone de cada participante, a través de mensaje, dado que es la forma de comunicación que requiere menos esfuerzo por su parte. Además, se procuró que la información fuera simple de leer y fácil de interpretar.

El formato se diseñó de forma que cupiera en la pantalla del móvil sin necesidad de ampliar, mover o girar la imagen (Ilustración 2).

El lunes de cada semana, se recogían los datos de la semana previa. Como está demostrado que la realimentación es más efectiva cuanto más cerca se produce en el tiempo, las gráficas mostradas en la llustración 2 se enviaban ese mismo día, tanto al grupo I como al grupo II.

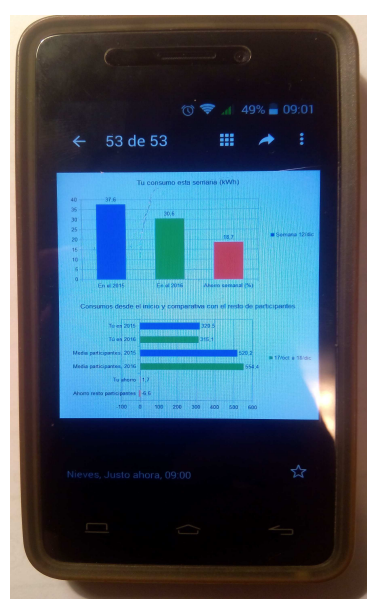

Ilustración 2. Vista de las gráficas en smartphone

\subsubsection{Toma de datos}

El experimento fue diseñado para ser llevado a cabo preferiblemente en una zona cálida y en los meses o bien de otoño o bien de primavera, las estaciones menos extremas en cuanto a temperaturas. La razón principal fue independizar, en la medida de lo posible, el consumo eléctrico de las condiciones climatológicas. Al ser la calefacción uno de los principales consumidores de energía de la vivienda, tomar datos en la época en la que menos se usa hace aumentar la homogeneidad de la muestra.

Los participantes de los grupos I y II fueron reclutados durante el mes de septiembre y la primera quincena de octubre del año 2016. Antes del inicio del experimento, se descargaron sus datos de consumo diarios de los meses de octubre, noviembre y diciembre del año 2015 de la página web de la compañía suministradora.

El experimento tuvo su comienzo el día 17 de octubre (lunes) y se dio por terminado el 18 de diciembre (domingo). El envío de información semanal dio comienzo el 24 de octubre de 2016, primer lunes posterior al día de inicio del experimento. A partir de ese momento, el lunes de cada semana se enviaban los datos de la semana previa.

Este procedimiento se repitió semanalmente hasta el lunes 12 de diciembre, fecha en la que se envió la última gráfica semanal y se advirtió a 
todos los participantes de la finalización del experimento con fecha domingo 18 de diciembre. También se les solicitó que estuvieran atentos a su correo, en el que recibirían, con fecha aproximada 21 de diciembre, sus resultados finales. Todas estas comunicaciones se encuentran en el Anexo III.3.

Una vez terminado el experimento, se solicitó a todos los participantes que continuaran permitiendo el acceso a sus datos de la página web durante un par de meses más. El objetivo de la recopilación de este último conjunto de datos es evaluar el efecto de la desaparición del incentivo económico sobre el consumo del grupo I.

\subsection{Resultados}

\subsubsection{Introducción}

Para la evaluación del comportamiento de los integrantes de los grupos I y II, se comparó la actuación de cada grupo con su periodo equivalente del año anterior. Se toma como hipótesis de trabajo que, en ausencia del incentivo económico, las diferencias entre el año 2015 y el año 2016 serían similares en ambos grupos, ya que ambos habrían estado sometidos a las mismas variaciones medioambientales o de otros tipos. La variable de comparación utilizada es el incremento de consumo entre los años 2015 y 2016; está calculada de forma que los incrementos negativos suponen ahorros en el año 2016 con respecto al 2015.

En todos los casos, se tienen dos formas de agrupar los datos, que coinciden con las que se utilizaron para enviar a los sujetos experimentales: consumos semanales independientes, y consumos acumulados desde el inicio del experimento. En todos los apartados siguientes, se denominan de la siguiente forma:

- Grupo sin ningún tipo de información ni incentivo económico: Grupo 0 o Grupo ciego

- Grupo con incentivo económico e información semanal por mensaje de móvil: Grupo I o Grupo de pago

- Grupo sin incentivo económico pero con información semanal por mensaje de móvil: Grupo II o Grupo de control 


\subsubsection{Estadísticos descriptivos}

Los estadísticos descriptivos de los consumos pormenorizados (semanales y acumulados por semana), se muestran en el Anexo III.4.1. En la Tabla 7.2 se dan los estadísticos descriptivos de la variable de comparación global utilizada, que es el incremento de consumo entre los años 2015 y 2016, en $\mathrm{kWh}$, para el periodo completo del experimento (17 de octubre a 18 de diciembre en ambos años).

Estadísticos descriptivos de la variable Incremento global del consumo (kWh)

\begin{tabular}{ccccc}
\hline & Media & $\begin{array}{c}\text { Desviación } \\
\text { típica }\end{array}$ & Mínimo & Máximo \\
Grupo I & $-41,01$ & 139,98 & $-345,3$ & 391,1 \\
Grupo II & 34,16 & 99,63 & $-133,82$ & 325,6 \\
Grupo 0 & 32,05 & 67,11 & $-94,75$ & 147,80 \\
\hline
\end{tabular}

Tabla 7.2. Estadísticos descriptivos del incremento global de consumo

\subsubsection{Normalidad de las muestras}

La normalidad de las muestras se verificó a través de los tests de Kolmogorov-Smirnov y Shapiro-Wilk. Los resultados del $p$-valor de la variable global se muestran en la Tabla 7.3; los resultados para los valores parciales de la variable se pueden consultar en el Anexo III.4.2.

\begin{tabular}{ccc} 
Pruebas de normalidad de la variable Incremento global del consumo \\
\hline & Kolmogorov-Smirnov & Shapiro-Wilk \\
Grupo I & 0,2 & 0,09 \\
Grupo II & 0,049 & 0,005 \\
Grupo 0 & 0,025 & 0,002 \\
\hline
\end{tabular}

Tabla 7.3. Pruebas de normalidad de la variable Incremento global del consumo

A la vista de los resultados mostrados en la Tabla 7.3, se rechaza la hipótesis de normalidad de los datos de los Grupos 0 y II. Por ello, los tests aplicados en el siguiente desarrollo son del tipo no paramétrico, adecuados para la comparación de este tipo de muestras. Los resultados parciales muestran una mezcla similar a la de los globales, pudiéndose demostrar la falta de normalidad de aproximadamente la mitad de ellas (ver en Anexo III.4.2). 


\subsubsection{Comparativa de la variación de consumo entre grupos}

Entre los años 2015 y 2016 hay una variación negativa del consumo (un decremento del consumo) del grupo I, al tiempo que se registra una variación del consumo positiva (un aumento del consumo) tanto en el grupo II de control como en el grupo ciego 0. Los resultados finales se resumen en la Tabla 7.4. Son significativas las diferencias del grupo de pago con respecto a cualquiera de los otros dos ( $p$ valor 0,013 y 0,09 respectivamente), no son significativas las diferencias entre los grupos ciego y de control ( $p$-valor 0,594$)$.

Resultados globales comparados

\begin{tabular}{|c|c|c|c|c|c|c|c|}
\hline & & \multirow{2}{*}{$\begin{array}{c}\text { Consumo } \\
\text { medio (kWh) }\end{array}$} & \multirow{2}{*}{$\begin{array}{l}\text { Incremento } \\
\text { medio (kWh) }\end{array}$} & \multirow{2}{*}{$\begin{array}{c}\text { Ahorro } \\
(\%)\end{array}$} & \multicolumn{3}{|c|}{ p-valor (Mann-Whitney) } \\
\hline & & & & & $I-I I$ & $\mathrm{I}-0$ & II-0 \\
\hline \multirow{2}{*}{ Grupo I } & 2015 & 582,99 & \multirow{2}{*}{$-41,01$} & \multirow{2}{*}{7,03} & \multirow{2}{*}{0,013} & \multirow{2}{*}{0,009} & \multirow{2}{*}{-} \\
\hline & 2016 & 541,978 & & & & & \\
\hline \multirow{2}{*}{ Grupo II } & 2015 & 520,2 & \multirow{2}{*}{34,16} & \multirow{2}{*}{$-6,57$} & \multirow{2}{*}{0,013} & \multirow{2}{*}{-} & \multirow{2}{*}{0,594} \\
\hline & 2016 & 554,362 & & & & & \\
\hline \multirow{2}{*}{ Grupo 0} & 2015 & 570,93 & \multirow{2}{*}{32,06} & \multirow{2}{*}{$-5,62$} & \multirow{2}{*}{ - } & \multirow{2}{*}{0,009} & \multirow{2}{*}{0,594} \\
\hline & 2016 & 602,99 & & & & & \\
\hline
\end{tabular}

Tabla 7.4. Comparativa de resultados de los grupos 0, I y II a nivel global

Mientras el grupo II de control aumentaba un 6,6 \% su consumo en el periodo estudiado, el grupo I, con incentivo monetario, lo redujo en un $7 \%$. Tomando al grupo de control como referencia del comportamiento en ausencia de tratamiento, la reducción en consumo del grupo I con respecto a lo que hubiera sido su comportamiento esperable en el año 2016 es de un 14,6 $\%$.

La evolución a lo largo del experimento de esta variable puede verse en la Figura 7.3, en la que se muestra el incremento de consumo del año 2016 respecto al 2015 para los dos grupos a lo largo de las semanas que dura éste. En el caso del Grupo I, se aprecia desde la primera semana un decremento sostenido del consumo; en el caso del Grupo II, el grupo de control, se observa una variación más irregular. 


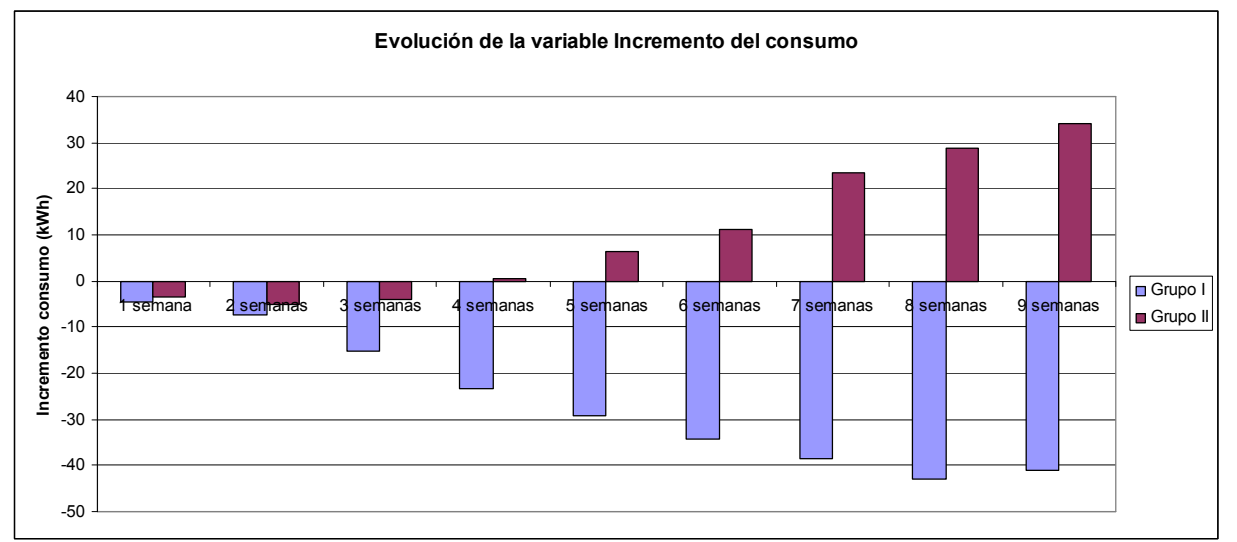

Figura 7.3. Evolución del incremento de consumo a lo largo del experimento

La variable Incremento del consumo a lo largo del experimento es significativa en la mayor parte de las semanas (ver Tabla III.9 en el Anexo III.4.3).

En cuanto a la variación del consumo total para el Grupo I a lo largo del experimento, ésta se muestra en la Figura 7.4. Las barras muestran el consumo acumulado en cada semana, en los años 2015 y 2016; la línea, el ahorro obtenido en tanto por cien. El objetivo marcado por el experimento, un $10 \%$, está indicado por una línea horizontal.

Los ahorros acumulados rozan el $10 \%$ durante las semanas centrales del experimento, aunque finalmente se reducen al $7 \%$. Las variaciones acumuladas son en su mayoría significativas (ver Tabla III.7 Anexo III.4.3)

En cuanto al comportamiento semanal, el ahorro llega a superar el $12 \%$ en las semanas 3 y 4 (Figura 7.5). Sin embargo, en las últimas semanas se reducen sustancialmente. La significatividad de las diferencias semanales se muestra en la Tabla III.8 del Anexo III.4.3. 


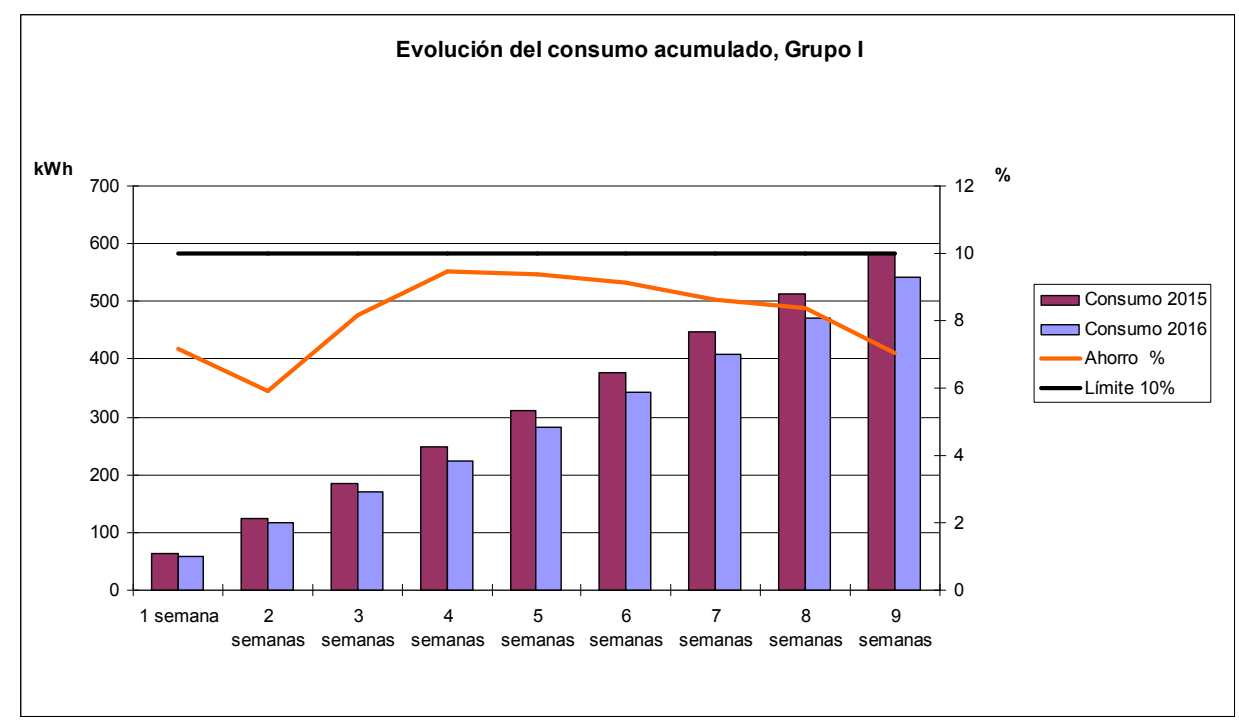

Figura 7.4. Evolución del consumo acumulado del Grupo I entre los años 2015 y 2016

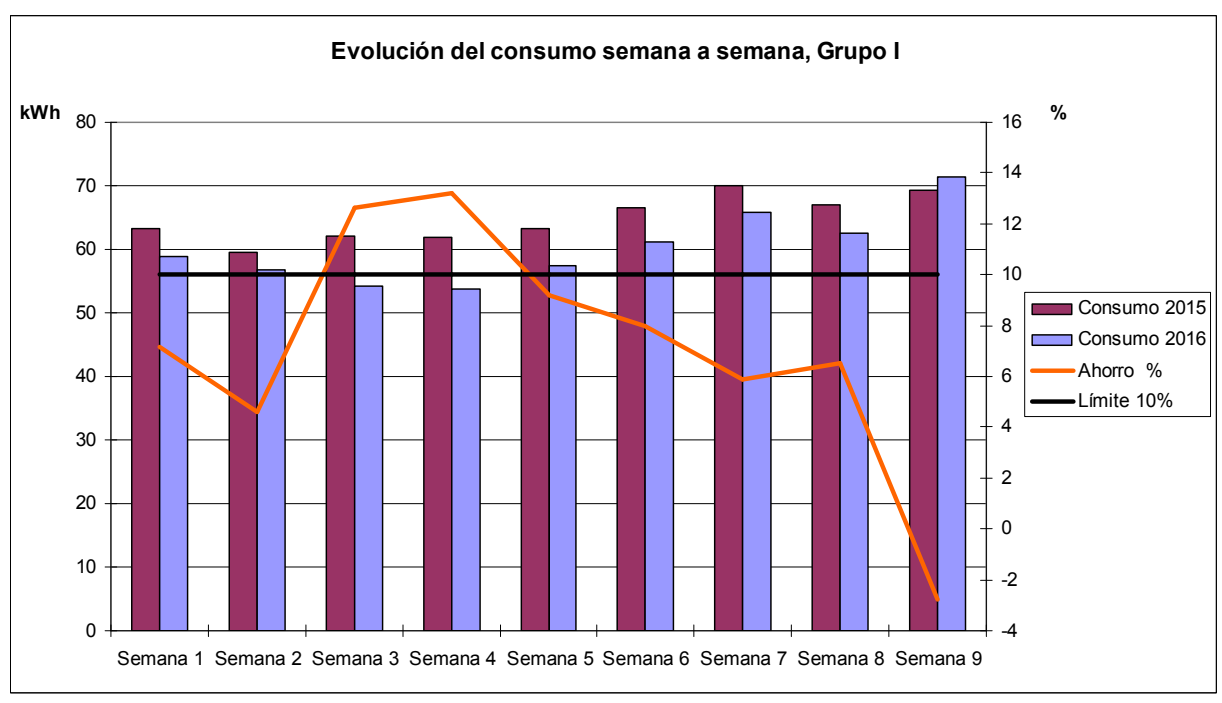

Figura 7.5. Evolución del consumo semanal del Grupo I 


\subsubsection{Comparativa con el Grupo 0}

La necesidad del grupo ciego nace de la posible influencia de la realimentación en el grupo de control. Gracias a su reclutamiento, es posible analizar independientemente los efectos de la remuneración y de la realimentación.

Como puede verse en los resultados mostrados en Tabla 7.4, la influencia de la realimentación en el grupo de control ha sido nula: la evolución en el tiempo es similar para los grupos 0 y II, siendo no significativa la pequeña diferencia que hay entre ellos.

\subsubsection{Comportamientos individuales}

Para el estudio de la evolución individual del comportamiento de los miembros del Grupo I, se parte del dato del ahorro del año 2016 respecto al 2015.

En la Figura 7.6. se muestra un resumen del grado de éxito individual en la consecución del experimento. La línea horizontal marca el límite de ahorro del $10 \%$. Como se aprecia en ella, 7 participantes no consiguieron ahorro alguno y, de hecho, consumieron más en el 2016 que en el 2015; otros 7 tuvieron un éxito moderado, reduciendo el consumo pero sin alcanzar el objetivo deseado, y 11 participantes fueron capaces de superar el objetivo.

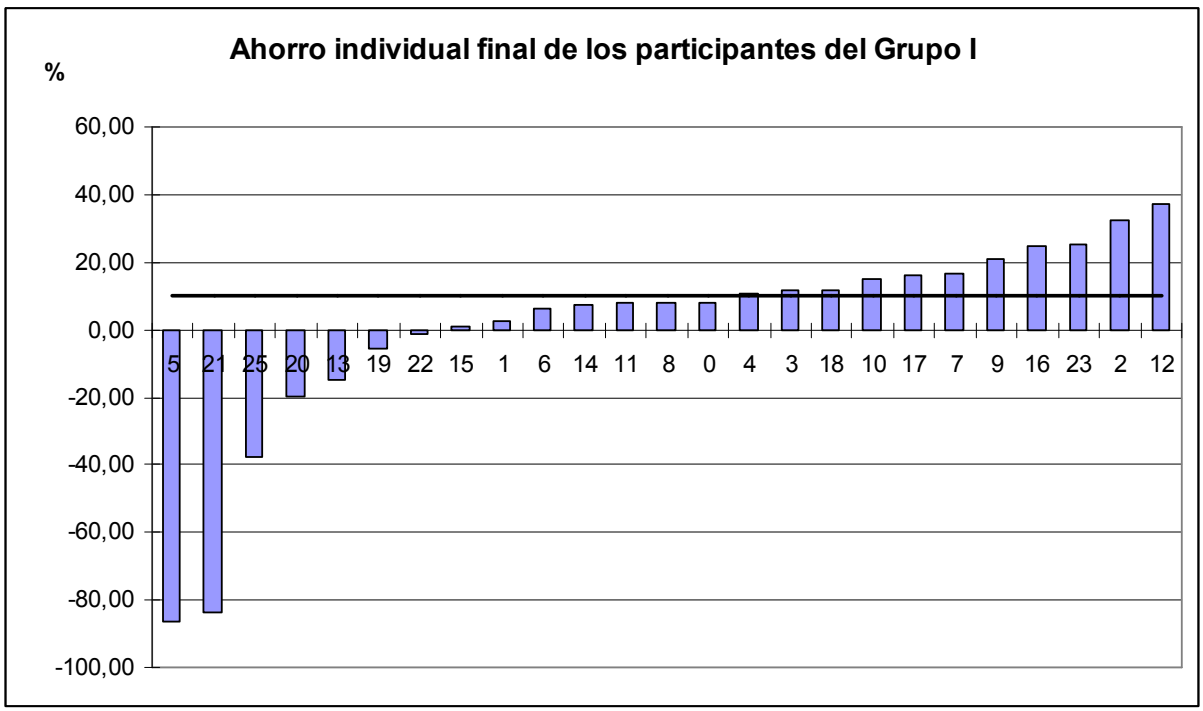

Figura 7.6. Ahorros obtenidos por cada participante individual del Grupo I 
En el caso del Grupo II, son 15 sujetos los que consumen más durante el 2016 que en el 2015; 7 de ellos tienen un éxito parcial en la consecución del objetivo, y únicamente 3 superan éste. La gráfica se muestra en la Figura 7.7. La escala del eje $Y$ se ha mantenido igual a la de la Figura 7.6 para facilitar la comparativa entre ambas. Los datos numéricos en los que se basan ambas gráficas se encuentran en el Anexo III.

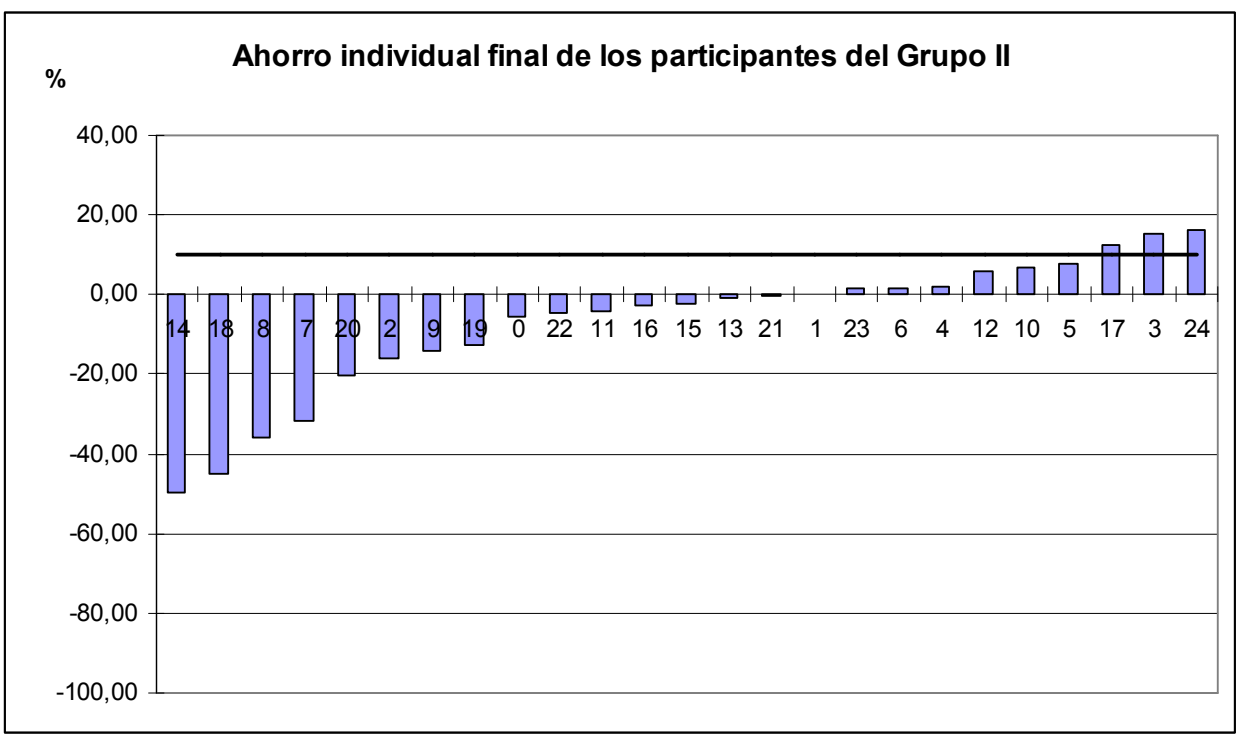

Figura 7.7. Ahorros obtenidos por cada participante individual del Grupo II

\subsubsection{Otras aportaciones de los participantes}

Una vez terminado el experimento, se pasó a todos los participantes un cuestionario de concienciación medioambiental basada en la escala NEP (New Environmental Paradigm) [45], un test utilizado para estudios en los que las diferencias en las creencias 0 actitudes pueden explicar ciertos comportamientos. La escala se construye a partir de las respuestas a 15 preguntas que se pueden consultar en el Anexo III.2. Al test de concienciación se agregaron dos preguntas sobre el experimento que también se pueden consultar allí. 
A partir de las calificaciones obtenidas, se subdividió a los sujetos del Grupo I en dos subgrupos del mismo tamaño, encontrándose la nota de corte en el identificador 7. Los sujetos con nota mayor a la de este identificador son los de mayor concienciación según el test, los de notas menores, los de menor concienciación. Como añadido a esta calificación, se preguntó a los sujetos si querían donar sus ganancias a una ONG dedicada a temas medioambientales, a lo que todos (excepto dos sujetos con una ganancia de $0 €$ ), contestaron que no.

En la Tabla 7.5 se muestra este grupo ordenado por calificación, incluyéndose los resultados finales de los individuos para correlacionar su actitud con sus consumos. No todos los participantes contestaron, por lo que sólo se representa a los 21 que lo hicieron.

Los números de la columna "sistema de ahorro" son las respuestas a la siguiente pregunta:

"La diferencia entre los resultados de este año y del pasado, tanto si has consumido más como si has consumido menos, ¿a qué crees que se ha debido? (Puedes marcar varios puntos)".

1.- Cambios en el equipamiento

2.- Cambios en el comportamiento de los miembros de la familia

3.- Pura casualidad

4.-Otros

El test $U$ de Mann-Whitney, aplicado para comparar a los dos subgrupos, en cada una de las semanas del experimento por separado así como al consumo acumulado en cada uno de los periodos, no muestra ninguna diferencia significativa entre ellos.

En cuanto al sistema de ahorro, hay prácticamente unanimidad en la herramienta utilizada, "cambios de comportamiento de los miembros de la familia". Sólo dos de los entrevistados no la nombran, siendo uno de ellos de los que no obtuvieron recompensa alguna.

El segundo sistema más nombrado es el de "cambios en el equipamiento de la vivienda", en 7 ocasiones, la mayoría de ellas acompañando al cambio de comportamiento. 
Respuestas al test final, Grupo I

\begin{tabular}{cccccc}
\hline Ident. & $\begin{array}{c}\text { Ahorro total } \\
(\%)\end{array}$ & Recompensa $(€)$ & Nota test & ¿Donaría...? & $\begin{array}{c}\text { Sistema de } \\
\text { ahorro }\end{array}$ \\
\hline 6 & 6,5 & 65,4 & 6,8 & No & 1,3 \\
11 & 7,8 & 78,2 & 6,67 & No & 2 \\
20 & $-20,0$ & 0 & 6,27 & No & 2 \\
21 & $-83,8$ & 0 & 6,27 & Sí & 1,4 \\
14 & 7,4 & 73,7 & 6,13 & No & 1,2 \\
10 & 14,7 & 100 & 6 & No & 2 \\
12 & 37,0 & 100 & 6 & No & 2 \\
16 & 24,9 & 100 & 6 & No & 2 \\
2 & 32,1 & 100 & 5,47 & No & 2 \\
8 & 7,9 & 78,6 & 5,47 & No & 2 \\
\hline 7 & 16,7 & 100 & 5,33 & No & 1,2 \\
\hline 25 & $-37,8$ & 0 & 5,33 & Sí & 2 \\
18 & 11,8 & 100 & 5,2 & No & 2 \\
15 & 1,1 & 10,8 & 5,2 & No & 1,2 \\
23 & 25,0 & 100 & 5,2 & No & 2 \\
3 & 11,6 & 100 & 5,07 & No & 2 \\
0 & 7,9 & 78,7 & 5,07 & No & 2 \\
9 & 20,9 & 100 & 6 & No & 2 \\
4 & 10,9 & 100 & 4,53 & No & 1,2 \\
19 & $-5,7$ & 0 & 4,13 & No & 1,2 \\
17 & 16,1 & 100 & 4 & No & 2 \\
\hline
\end{tabular}

Tabla 7.5. Resultados del test final para el Grupo I

Para evitar en la medida de lo posible que los sujetos adornaran las respuestas si se les preguntaba de forma previa al cobro de la recompensa, un par de semanas después de recibido el dinero, se amplió esta pregunta por mensaje de móvil, añadiendo estas otras:

1.- ¿Qué cambios hiciste en concreto para reducir tu consumo?

2.- ¿Te ayudaron las gráficas que enviaba semanalmente? Y si es así, ¿qué parte de ellas mirabas más? 
Las respuestas se muestran en el Anexo III.4.4 tal cual fueron enviadas por los participantes; en las Tabla 7.6 y Tabla 7.7 se muestran de forma resumida.

Recursos utilizados por los participantes del grupo I para la consecución del objetivo de ahorro

\begin{tabular}{cc}
\hline Recurso utilizado & $\begin{array}{c}\text { Número de veces } \\
\text { que se menciona }\end{array}$ \\
\hline Apagado de luces innecesarias & 10 \\
Optimización del uso de los electrodomésticos & 8 \\
Concienciación de la familia & 6 \\
Desenchufado de los aparatos no utilizados & 4 \\
Optimización de la climatización & 4 \\
Mejoras en el equipamiento & 2 \\
\hline
\end{tabular}

Tabla 7.6. Resumen de los recursos utilizados por los participantes del Grupo I

Uso de la información semanal enviada al Grupo I

\begin{tabular}{lcc}
\hline $\begin{array}{l}\text { ¿Fue } \\
\text { útil? }\end{array}$ & ¿Qué gráfica mirabas más? & $\begin{array}{c}\text { Número de veces } \\
\text { que se menciona }\end{array}$ \\
\hline Sí & & 15 \\
No & Ahorro semanal & 0 \\
\hline & Ahorro total & 11 \\
& Página web de la compañía suministradora & 4 \\
& Comparativas & 1 \\
& & 1 \\
\hline
\end{tabular}

Tabla 7.7. Resumen de la utilidad de la información semanal enviada según los participantes

En este caso, las mejoras en el equipamiento se reducen de 7 apariciones a 2, siendo la práctica totalidad de los recursos nombrados relativos a cambios en el comportamiento.

\subsubsection{Temperaturas}

La comparativa entre temperaturas medias y consumos se muestra en la Figura 7.8 y la Figura 7.9. No hay nada reseñable en ellas, aparte de la evidente dependencia inversa entre ambas. 


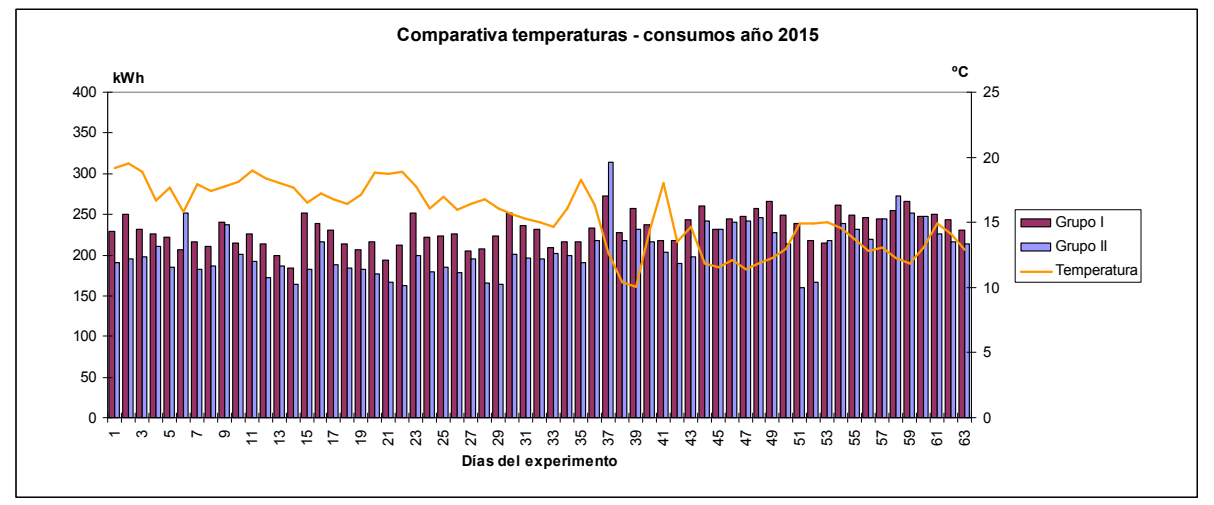

Figura 7.8 Comparativa entre las temperaturas medias y los consumos diarios de ambos Grupos en el año 2015.

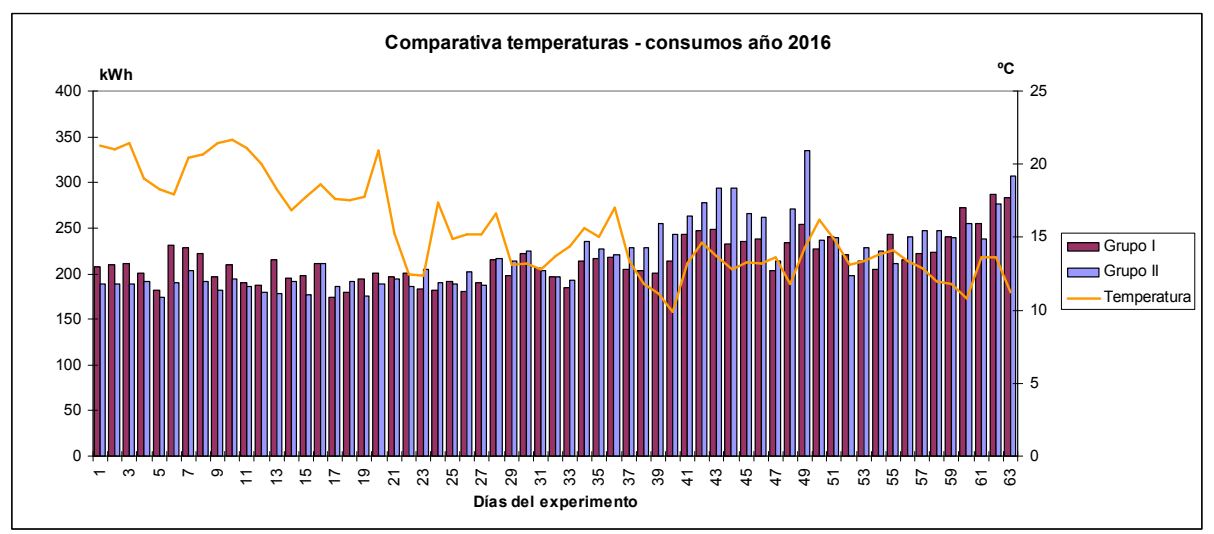

Figura 7.9. Comparativa entre las temperaturas medias y los consumos diarios de ambos Grupos en el año 2016

Las diferencias en temperaturas entre un año y otro tampoco son especialmente significativas (Figura 7.10). Si asumimos que, entre los 13 y los 23 C es innecesario el uso de la calefacción o el aire acondicionado, se aprecia también en la Figura 7.10 que la parte de climatización apenas se ha utilizado durante el experimento. Esto es importante, dado que la fuente energética para la climatización de parte de las viviendas es gas natural, por lo que el uso de éste podría haber distorsionado los resultados comparados de todos los participantes. 


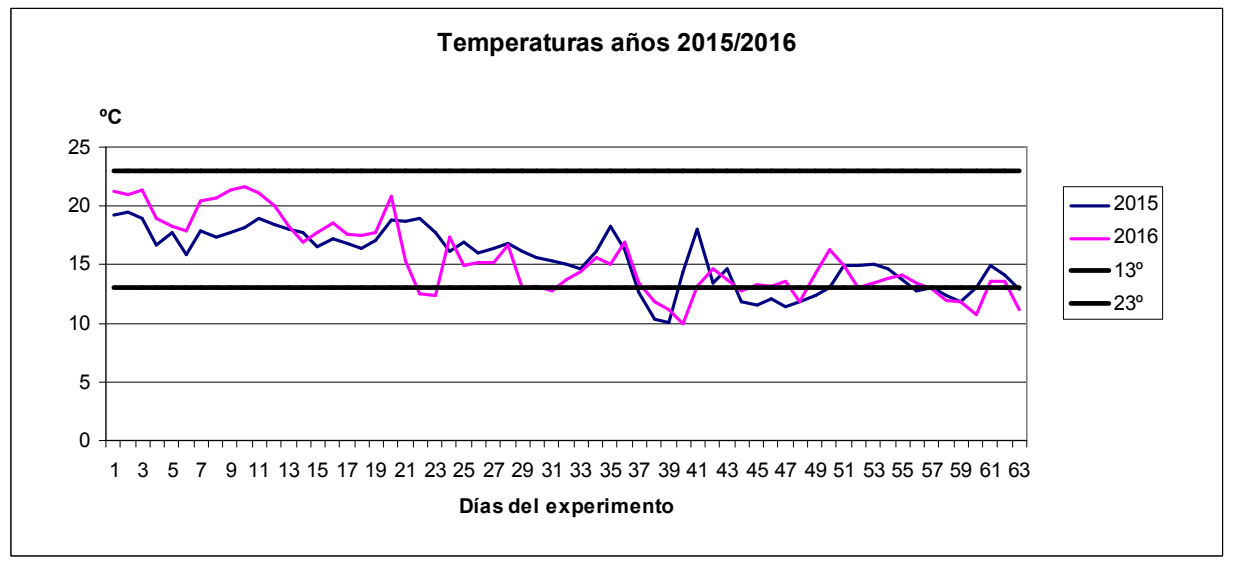

Figura 7.10. Temperaturas medias diarias en los días del experimento de los años 2015 y 2016

\subsubsection{Persistencia del efecto}

Tras la finalización del experimento, se solicitó a todos los participantes que mantuvieran abiertas sus cuentas de la compañía suministradora para seguir tomando datos y tener la oportunidad de comprobar la persistencia del efecto durante los meses posteriores.

Esta situación se mantuvo durante los meses de enero y febrero del año 2017, tras lo que se dio aviso finalmente a los sujetos para que cambiaran su contraseña, dando por terminada así esta última parte del experimento. Los resultados pueden consultarse en la Tabla 7.8.

Resultados del periodo posterior a la finalización del experimento

\begin{tabular}{|c|c|c|c|c|c|c|c|}
\hline & & \multicolumn{2}{|c|}{ Consumo (kWh) } & \multicolumn{2}{|c|}{ Incremento ( $k W h$ ) } & \multirow{2}{*}{$\begin{array}{c}\text { Ahorro } \\
\text { (\%) }\end{array}$} & \multirow{2}{*}{$\begin{array}{l}\text { p-valor } \\
\text { (Mann- } \\
\text { Whitney) }\end{array}$} \\
\hline & & Medio & Total & Medio & Total & & \\
\hline Grupo & Ene-Feb 2016 & 640 & 14079,7 & & & & \multirow{4}{*}{0,039} \\
\hline I & Ene-Feb 2017 & 660,7 & 14534,8 & 20,7 & 455,2 & $-3,23$ & \\
\hline Grupo & Ene-Feb 2016 & 573,2 & 12610,4 & & & & \\
\hline II & Ene-Feb 2017 & 652,2 & 14349,2 & 79 & 1738,8 & $-13,79$ & \\
\hline
\end{tabular}

Tabla 7.8. Resultados de la toma de datos posterior a la finalización del experimento 
La significatividad de la variable Incremento del Consumo continúa siendo significativa, siendo en este caso el resultado del test de Mann-Whitney un $\mathrm{p}$-valor $=0,039$.

A la vista de los resultados, y pese al empeoramiento de la variable ahorro, se mantiene una diferencia considerable (un 10,2\%) entre ambos grupos, llegándose con ello a la conclusión de que la persistencia a corto plazo existe. Sin embargo, el efecto se va reduciendo (de 14,6 a 10,2 \%), por lo que no está garantizado en el medio / largo plazo.

\subsection{Discusión general de resultados}

\subsubsection{Evolución de los consumos y ahorros}

Tanto la Tabla 7.4 como la Figura 7.3 y la Figura 7.4 muestran el éxito del experimento a la hora de obtener ahorros significativos en el consumo eléctrico. Aparecen en ellas ahorros que oscilan entre un máximo de 9,45\% y un total de $7,03 \%$, pese a que el Grupo de Control obtuvo como resultado final un ahorro negativo (es decir, un incremento) de un $-6,6 \%$.

Si asumimos que el comportamiento de ambos grupos hubiera sido similar en ausencia de incentivo, el grupo I hubiera consumido en 2016 un 6,6 $\%$ más que en 2015. Calculando a partir de esa premisa, el ahorro del Grupo I con respecto a su consumo estimado en el año 2016 es en realidad de un 14,6 $\%$.

Las variaciones en el consumo entre los años 2015 y 2016 son significativas en prácticamente todos los casos, confirmando la influencia del incentivo en los resultados del Grupo I. Este resultado avala la eficacia del incentivo aplicado.

El comportamiento semanal del Grupo I muestra variaciones que, durante la etapa intermedia del experimento, superan el objetivo establecido, alcanzándose una punta de ahorro durante la semana 4 de un $13,23 \%$ respecto al año anterior.

Sin embargo, en las últimas semanas se reduce sustancialmente el ahorro obtenido. Este resultado es probablemente el efecto combinado del abandono por parte tanto de los sujetos con peores resultados como de los sujetos con éxito muy superior al límite establecido. 


\subsubsection{Influencia de la realimentación}

Los resultados obtenidos por el grupo ciego son muy similares a los obtenidos por el grupo de control. Este resultado refuerza y confirma las conclusiones del experimento no 2: en ausencia de incentivo externo, la realimentación no implica modificación alguna del comportamiento.

\subsubsection{Validez de la herramienta informativa}

La herramienta informativa se diseñó para ser simple, para llegar al usuario sin necesidad de que éste hiciera ningún esfuerzo, y para ser periódica.

Dado el éxito del experimento en la consecución de su objetivo, se considera que las premisas de las que parte esta herramienta informativa (simpleza en la información, comparativa con uno mismo, facilidad de acceso por parte de los participantes y periodicidad) son fundamentales en la consecución de los objetivos.

Desde la perspectiva de los participantes, la herramienta informativa fue útil (Tabla 7.7). La mayoría de ellos utilizaba como herramienta de trabajo la comparativa semanal con ellos mismos, por lo que esta herramienta cumplió con el objetivo para el que había sido diseñada. El consumo total también es nombrado por varios sujetos. Sin embargo, la comparativa con el resto del grupo apenas se nombra.

Sin embargo, una parte de los participantes fracasó en su intento por disminuir su consumo. Parte de ese fracaso es achacable a la excesiva simplicidad de la gráfica, que al fin y al cabo sólo ofrece un dato semanal de consumo, lo cual realmente es poca información.

\subsubsection{Aportaciones de los participantes}

Es especialmente interesante la comparación entre los recursos utilizados para el ahorro entre los participantes de los experimentos 2 y 3 . En el primer caso (apartado 6.3.5), la práctica totalidad de formas de ahorro nombradas por los participantes se relacionaba o bien con cambios en el equipamiento o bien con modificaciones en el contrato con la compañía suministradora. Evidentemente, para los participantes en el experimento 3 una modificación de contrato no era un recurso válido, pero sí lo habría sido, al igual que para los del 2, cualquier cambio en el equipamiento. Sin embargo, este tipo de modificación apenas es nombrado por los sujetos experimentales 
(Tabla 7.6). Uno de los hallazgos más interesantes de este experimento 3 es que la mayoría de las reducciones en el consumo se han obtenido por cambios de comportamiento de los sujetos experimentales.

Además, las variaciones de comportamiento en general son muy simples y conocidas por todos: apagado de luces y televisiones que no se usan, eliminación de los stand-by por desenchufado del equipamiento que lo presenta, optimización en el uso de lavadoras y otros electrodomésticos blancos, y, en general, concienciación de la familia en la aplicación de estas medidas tan básicas. Esto, nuevamente, muestra el potencial de la actitud de los usuarios a la hora de obtener reducciones de consumo significativas.

También es interesante, al repasar la Tabla 7.5, el hecho de que, independientemente de la nota obtenida en el test, ninguno de los participantes se ha mostrado interesado en la donación del dinero recibido a una ONG relacionada con el cambio climático. Las únicas excepciones son dos participantes que no consiguieron ahorro alguno.

\subsection{Conclusiones}

Varias conclusiones interesantes se desprenden de este experimento y de su comparación con el número 2 , que se comentan en los siguientes apartados.

\subsubsection{Importancia del incentivo financiero}

Los niveles de ahorro obtenidos por el Grupo I han sido considerables, demostrándose claramente con ello dos cosas: primera, que un incentivo lo bastante grande es suficiente para obtener ahorros significativos sin demasiadas dificultades, y segunda, que la información con realimentación no es suficiente (el grupo II no ha actuado en absoluto pese a tener la misma información que el Grupo I, y el experimento 2 no obtuvo ningún resultado pese a que la herramienta informativa era marcadamente superior a la del experimento 3 ).

En segundo lugar, es importante recordar que, aunque se ha dado libertad a los participantes de obtener sus resultados de la forma que desearan, es significativo el hecho de que la mayoría de ellos achaca sus ahorros a variaciones de su comportamiento, sin necesidad de realizar cambios en el equipamiento de la vivienda. Ello da una idea de la importancia que 
tiene la actitud de los usuarios en cuanto a su comportamiento energético, una variable que apenas se tiene en cuenta en los planes de eficiencia energética.

Por otra parte, el hecho de que este experimento tenga una duración limitada es la razón evidente de que la mayoría de los participantes haya obtenido ahorros sustanciales mediante cambios en el comportamiento y no en el equipamiento de la vivienda: a corto plazo, los cambios en el equipamiento son más costosos que los beneficios obtenidos como resultado del ahorro. Sin embargo, en el caso de que un sistema de este tipo se estableciese a gran escala y durante gran cantidad de tiempo, la inversión en equipamiento más eficiente se vería también incentivada, lo que podría redundar en un ahorro energético extra.

También es fundamental tener en cuenta que lo que se valora en este experimento no es el aumento en la eficiencia energética del participante sino la reducción de su consumo total. Este detalle es importante, aunque la mayoría de las medidas aplicadas en la política nacional no lo tienen en cuenta. Las subvenciones a la compra de electrodomésticos más eficientes o a la mejora de los cerramientos encierran el peligro del efecto rebote, que en esos casos aparece o bien en forma de compra de más electrodomésticos o bien en aumento de la temperatura de confort. Evidentemente aumentar la eficiencia puede ayudar a disminuir el consumo, pero sólo si se aplica teniendo como objetivo final esa reducción. Y para ello, es necesario incentivar el ahorro.

Por último, es importante comentar que el incentivo financiero tal como se ha establecido para el pequeño grupo de sujetos participantes, evidentemente no es aplicable a gran escala. Por la complejidad de la aplicación práctica del incentivo financiero, se dedica a él un apartado independiente, el 8.4, en el que se aborda este problema con detalle y se sugieren diversos métodos de aplicación.

\subsubsection{Límites del ahorro}

Los participantes se pueden clasificar en función de su grado de éxito, como se aprecia en la Figura 7.6, en tres grupos: los que superan el límite marcado, los que no lo alcanzan pero tienen beneficios, y los que fracasan, consumiendo más en el año 2016 que en el 2015.

Pese a que el ahorro total del grupo de pago como conjunto no alcanzó el límite del $10 \%$, buena parte de los participantes sí lo superó ampliamente. 
Esto significa claramente que el potencial del incentivo económico es mayor de lo inicialmente supuesto, ya que los que superaron el límite perdieron el incentivo. Por otra parte, otros participantes se desanimaron por su falta de resultados $\mathrm{y}$, aparentemente, abandonaron el experimento.

La aplicación de este sistema de incentivos debe diseñarse entonces teniendo en cuenta estas dos premisas básicas: mantener un objetivo mínimo suficientemente bajo para no desanimar a los menos hábiles para la reducción de su consumo, pero con un máximo lo bastante alto para empujar hasta límites mayores a los más capacitados para la reducción de su consumo.

Estos abonados menos hábiles requieren además algún tipo de ayuda extra, dado que ni con un incentivo importante son capaces de alcanzar el éxito. Puede ser, por ejemplo, en forma de una herramienta informativa más completa que la ofrecida en el experimento, o en forma de auditoría energética individualizada. Para los más ahorrativos, un sistema de derechos de emisión o similar (ver apartado 8.4.2) sería el ideal para mantener el incentivo.

\subsubsection{Persistencia del efecto}

Según los resultados del apartado 7.2.9, la persistencia durante los dos primeros meses posteriores a la finalización del experimento es considerable. Probablemente se debe a la automatización de algunos gestos que antes no se tenía, tales como el apagado de luces al salir de las habitaciones, uno de los sistemas de ahorro más nombrados por los participantes.

Aún así, la persistencia sólo se ha demostrado durante los dos meses posteriores a la aplicación del incentivo, y en ese periodo sufre una reducción de un 4\%; probablemente se requieran refuerzos periódicos para evitar, pasados periodos de tiempo mayores, el retorno al comportamiento previo.

\subsubsection{La herramienta informativa}

En tercer lugar, la herramienta informativa que acompañe al incentivo económico debe diseñarse muy cuidadosamente para informar sin saturar, ni por exceso de información ni por frecuencia excesiva. El sistema ideal podría ser una aplicación similar a la del experimento 2 , con el añadido de un mensaje automático semanal enviado al smartphone o a la tablet del abonado. Este mensaje contendría un mínimo resumen de su comportamiento, similar al del 
experimento 3: comparándolo con el de años anteriores y relacionándolo con su éxito o fracaso a la hora de conseguir los objetivos que le correspondan según el incentivo económico que finalmente se haya diseñado.

De forma automática, esta herramienta debería añadir a la información del consumo, una mínima batería de consejos individualizados en función del desempeño particular del abonado. La individualización de este tipo de información es importante: dar consejos de forma indiscriminada contribuye a la saturación y al desinterés por parte de quien los recibe. Por ejemplo, para individuos con ahorros por debajo de los objetivos, se pueden añadir sugerencias de ahorro; para los que están por encima, mensajes de felicitación, y para los que están fracasando, el consejo de acceder a la auditoría energética de la propia aplicación o a una externa que les ayude. Con una herramienta lo suficientemente sofisticada, los consejos de ahorro se pueden individualizar aún más, ya que es posible, a través de la curva de consumo individual, detectar e identificar algunos problemas típicos, como electrodomésticos con consumos excesivos o presencia de consumos fantasma de la vivienda.

Las compañías suministradoras y sus certificados blancos podrían tener aquí un papel importante, dado que son las que tienen acceso a todos los datos de los abonados relacionados con su consumo, junto con su número de teléfono y correo electrónico. Ello evitaría la necesidad de instalar un medidor extra en cada vivienda, y daría la posibilidad de tener una aplicación estándar para todos los abonados, que se iría optimizando con el tiempo y la experiencia adquirida. 


\section{Propuesta de un índice de eficiencia del comportamiento energético en la vivienda}

\subsection{Definición del índice}

Para la instauración de cualquier tipo de incentivo, sea informativo o económico, relacionado con el desempeño energético de los residentes, es imprescindible contar con una forma de evaluar éste. Para ello, se propone en este capítulo el establecimiento de un índice de eficiencia energética del uso de la vivienda (IEEC), mediante el cual se calificaría a las viviendas en función de la eficiencia energética de los hábitos de consumo de sus habitantes. Los posibles incentivos asociados se establecerían a partir de esa calificación, al igual que está proyectado hacerse con la etiqueta energética del edificio.

La etiqueta energética con su índice y la letra de la clasificación aparecerían mensualmente en la factura eléctrica del contribuyente, informándole de la eficacia de su comportamiento energético durante el mes transcurrido.

La familiaridad de los ciudadanos con los índices de calificación en forma de letra y asociados a la conocida etiqueta energética, presente hoy día en muchos ámbitos cotidianos (electrodomésticos, edificios, neumáticos, aire 
acondicionado, calderas, ventanas y otros), hace muy interesante una presentación similar de la calificación de su comportamiento. La lectura e interpretación de este índice se ha convertido en un lenguaje universal; una etiqueta energética con el formato estándar apareciendo en la factura y marcando al abonado en la letra $G$ es un sistema muy gráfico de calificar su comportamiento.

Dado que ya hay en vigor un sistema de calificación energética del edificio, en buena parte aprovechable para el nuevo índice que va a definirse, el capítulo comienza haciendo una revisión de su ámbito regulatorio y sus fundamentos de cálculo. Posteriormente, define el nuevo índice a partir del anterior y de otras variables que le afectan. Por último, se proponen distintas alternativas posibles para la aplicación de un incentivo económico tomando como base el IEEC.

Queda fuera del ámbito de esta tesis, por su complejidad, una clasificación pormenorizada de las viviendas y una definición precisa del cálculo de este índice; únicamente se pretende sentar las bases de un sistema posible, cuyo desarrollo se realizaría en trabajos posteriores.

\subsection{Calificación energética del edificio}

\subsection{1. Ámbito regulatorio}

Las exigencias relativas a la certificación energética de edificios se establecieron por primera vez en la Directiva 2002/91/CE del Parlamento Europeo y del Consejo, de 16 de diciembre de 2002. Fueron transpuestas al ordenamiento jurídico español en el Real Decreto 47/2007, de 19 de enero, mediante el que se aprobó un Procedimiento básico para la certificación de eficiencia energética de edificios de nueva construcción.

Posteriormente, la Directiva 2002/91/CE fue modificada por la Directiva 2010/31/UE del Parlamento Europeo y del Consejo, de 19 de mayo de 2010, relativa a la eficiencia energética de los edificios. Esta circunstancia hizo necesario transponer de nuevo al ordenamiento jurídico español las modificaciones que introduce con respecto a la Directiva modificada.

En vez de añadir una nueva disposición que modificara el Real Decreto 47/2007 añadiéndole las nuevas exigencias, se derogó el Real Decreto 47/2007 
y se redactó un nuevo Real Decreto que incluyó una refundición de la parte válida del 47/2007.

Este nuevo Real Decreto es el 235/2013, de 5 de abril, por el que se aprueba el procedimiento básico para la certificación de la eficiencia energética de los edificios. Con la entrada en vigor de este último, se incorpora el Procedimiento básico para la certificación de eficiencia energética de edificios existentes.

A partir de la entrada en vigor del RD 235/2013, (el 1 de junio de 2013), queda establecida la obligación de poner a disposición de los compradores o usuarios de los edificios un certificado de eficiencia energética que incluya información sobre la eficiencia energética de un edificio y un valor de referencia. Se incluyen edificios de nueva construcción y edificios o partes de edificios existentes, como viviendas o locales, que se vendan o alquilen. Tanto los edificios residenciales como los de oficinas o locales comerciales se encuentran bajo el ámbito de aplicación de esta normativa. Quedan exentos edificios industriales y agrícolas, religiosos, construcciones provisionales y monumentos o edificios patrimoniales.

\subsubsection{Cálculo de los valores del certificado}

La eficiencia energética del edificio se determina calculando o midiendo el consumo de energía necesaria para satisfacer anualmente la demanda energética del edificio en unas condiciones normales de funcionamiento y ocupación. Esa demanda incluye las necesidades de calefacción, refrigeración, ventilación, producción de agua caliente sanitaria y, en su caso, (en vivienda no) iluminación, con el fin de mantener las condiciones de confort térmico y lumínico así como la calidad del aire interior. No incluye el consumo en electrodomésticos, equipos de ocio, o iluminación en el caso de vivienda. Tampoco contiene referencia alguna al número de habitantes (se considera en edificios de viviendas un nivel de ocupación de 1 persona por cada $33,3 \mathrm{~m}^{2}$, que es el valor medio de ocupación según el censo de ocupación 1991-2000 del INE).

Bajo la denominación "edificio" se entiende tanto un edificio completo como cualquiera de sus locales o viviendas de forma independiente.

La valoración considera los siguientes factores:

- Disposición y orientación del edificio 
- Características térmicas de todas sus envolventes

- Instalaciones térmicas (generadores de calefacción, generadores de refrigeración, instalaciones de ACS)

- Zona climática

- Tipo de vivienda (unifamiliar / bloque)

\subsubsection{La etiqueta energética}

La obtención del certificado de eficiencia energética otorga el derecho de utilización, durante el periodo de validez del mismo (10 años), de la etiqueta de eficiencia energética, cuyos contenidos se muestran en la Figura 8.1.

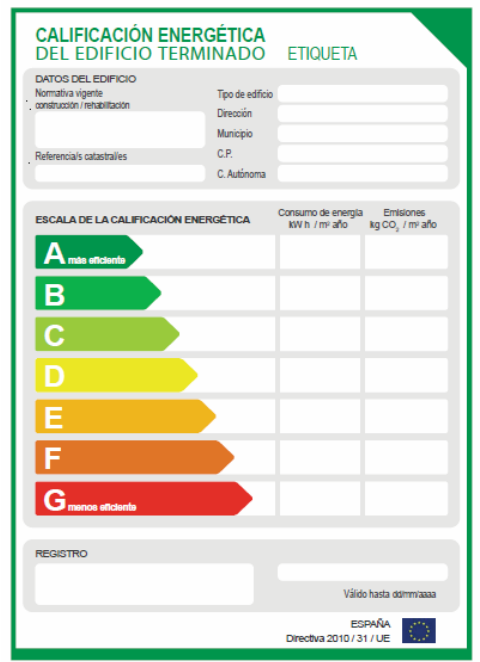

Figura 8.1. Etiqueta de eficiencia energética del edificio

La etiqueta contiene los datos básicos del edificio, el consumo calculado de energía primaria consumida en $\mathrm{kWh} / \mathrm{m}^{2}$.año, la emisión anual en $\mathrm{kg} \mathrm{CO}_{2} /$ $\mathrm{m}^{2}$. año, y la valoración del edificio examinado, en una escala de letras.

La escala de letras va de la A (la más eficiente) a la G (la menos eficiente). La calificación se realiza por comparativa con un edificio patrón, de características similares al examinado: la misma forma, tamaño, orientación, zonificación interior, uso de cada espacio, e iguales obstáculos remotos que el edificio objeto. Así, un edificio con una calificación A se prevé que tenga un 
consumo mucho menor al del edificio de referencia y uno con calificación $\mathrm{G}$, un consumo mucho mayor.

En cuanto a las calidades constructivas, el edificio de referencia presenta unas calidades constructivas en fachada, suelo, cubierta y elementos de sombra, instalaciones de iluminación e instalaciones térmicas que cumplan respectivamente los requisitos de eficiencia energética del CTE-DB-HE1, CTE-DB-HE3, CTE-DB-HE2 y del CTE-DB-HE4. Así como, en los casos necesarios, la contribución fotovoltaica mínima exigida por el CTE-DB-HE5.

\subsubsection{Procedimiento de certificación}

El procedimiento de certificación requiere tomar decisiones respecto a tres asuntos:

- El indicador que va a usarse para comparar edificios

- El grado de similitud entre los edificios que se comparan

- La escala de calificación

Todos estos puntos se detallan en los apartados siguientes.

\subsubsection{Indicadores de comportamiento energético}

Los indicadores de comportamiento energético se utilizan para comparar entre sí el comportamiento energético de edificios de características parecidas. Se obtienen de la energía consumida por el edificio para satisfacer sus necesidades de climatización, ventilación e iluminación. Los indicadores que se utilizan en la edificación son, en concreto, los siguientes:

- Las emisiones anuales de $\mathrm{CO}_{2}$ por $\mathrm{m}^{2}$ de superficie útil del edificio

- La energía primaria anual en $\mathrm{kWh}$ por $\mathrm{m}^{2}$ de superficie útil del edificio

- El desglose de las dos anteriores para cada uno de los servicios principales del edificio

Para establecer los límites de las clases de eficiencia energética, se trabaja con estos índices. Se necesita conocer:

- Los indicadores del edificio objeto del estudio I dificio $_{\text {- }}$ 
- El valor medio de indicador correspondiente a un edificio de nueva planta, conforme a la reglamentación vigente en el año $2006, I_{\text {reglamentario }}$

- El valor medio del indicador de los edificios similares pertenecientes al parque edificatorio existente en el año 2006, $\mathrm{I}_{\text {stock }}$

\subsubsection{Grado de similitud}

En el caso de edificios no destinados a viviendas, (oficinas, hospitales, etc), el criterio establecido para considerar similares dos edificios es que tengan la misma forma, dimensión, orientación de las fachadas y relación vidrio / muro. Y por supuesto que se encuentren en la misma zona climática.

Sin embargo, en el caso de edificios de viviendas, que es el caso contemplado en esta tesis, debido a la homogeneidad que existe tanto en lo relativo al tipo de espacios en el interior de las viviendas como en la utilización de los mismos, se distingue simplemente entre edificios de bloques y edificios unifamiliares, siempre teniendo en cuenta que los edificios a comparar se encuentren en la misma zona climática.

\subsubsection{Cálculo de los escalones de la calificación en edificios} de viviendas

Para el establecimiento de los límites de las clases en edificios de vivienda se utiliza el llamado escenario de comparación, que es una previsión de cómo serán los indicadores energéticos de los edificios construidos en el año base (2006). Se partió de las siguientes hipótesis: la tipología sería similar a la de años anteriores, y las calidades constructivas de las envolventes y los sistemas de climatización, ventilación e iluminación seguirán los mínimos indicados en el CTE.

Así, los escalones de la calificación se definieron a partir de un parque edificatorio virtual conformado por una muestra de edificios representativa de acuerdo con las estadísticas del INE sobre construcción de edificios de nueva planta.

Tras la selección de las tipologías de vivienda más habituales (14 tipos de viviendas unifamiliares y 11 de bloques de viviendas), se calculó su demanda energética con el programa LIDER, simulando las mismas viviendas tipo con 
diferentes calidades de envolventes, sistemas de climatización y ACS, con la fachada principal orientada en cuatro orientaciones diferentes, y en 12 localidades diferentes, representativas de las diferentes zonas climáticas de invierno y verano.

Como resultado, se obtuvo una distribución en frecuencias de emisiones y consumos para cada uno de los climas posibles.

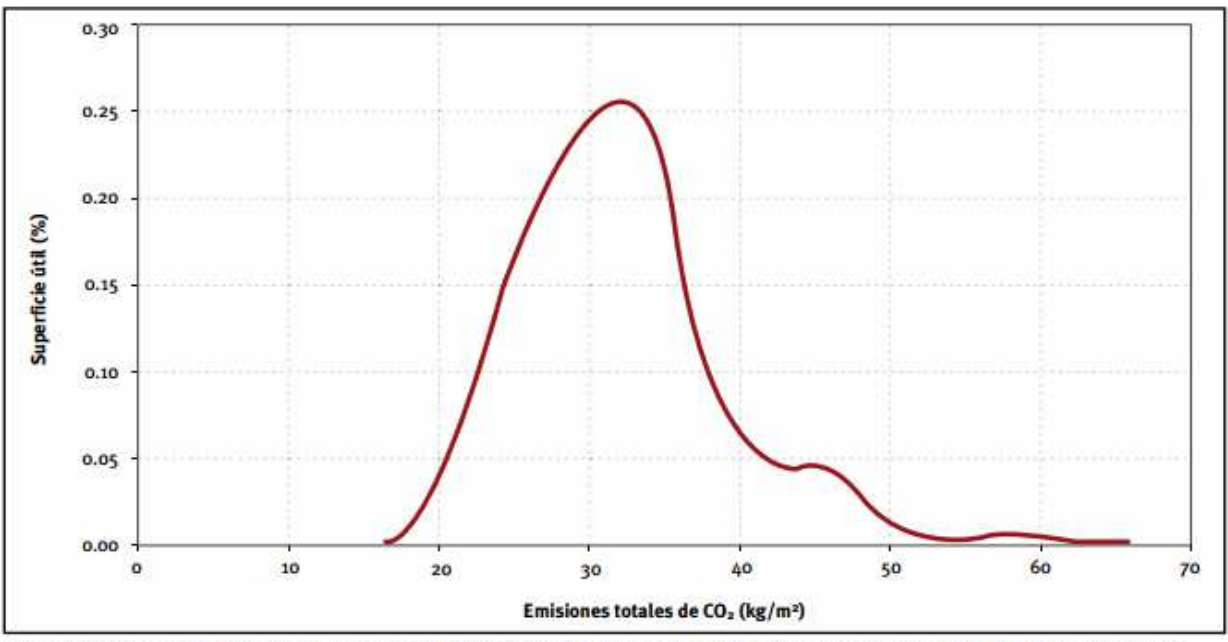

Figura 1 Distribución en frecuencias de las emisiones totales de $\mathrm{CO},\left(\mathrm{kg} / \mathrm{m}^{2}\right)$ de los edificios de viviendas unifamiliares situados en Madrid que cumplen estrictamente el $\mathrm{CTE}$-HE

Figura 8.2. Ejemplo de distribución en frecuencia (total) de las emisiones totales generadas por un conjunto de viviendas seleccionadas a partir de las estadisticas del INE. Fuente: [51]

Esas mismas frecuencias se pueden representar de forma acumulada como en la Figura 8.3. A partir de la curva de frecuencias acumuladas en cada uno de los climas representados, es posible definir las clases siguiendo los criterios siguientes:

- En las clases C y D estará el $90 \%$ de los edificios que cumplan estrictamente el CTE-HE ( $35 \%$ en clase C y $55 \%$ en clase D).

- Del $10 \%$ restante, el $5 \%$ que representa a los edificios más eficientes estará en la clase B, mientras que el $5 \%$ de los edificios menos eficientes estará en la clase $E$. Se entiende que el ancho de las clases $E$ y $F$ no precisa de una definición precisa, ya que no se contempla que haya edificios nuevos que puedan entrar en la clase $\mathrm{F}$. 
- El ancho de la clase B se ha determinado sabiendo que a la clase $A$ deben acceder aquellos edificios que estarían inicialmente en la clase B si hubieran cumplido estrictamente el CTE pero que han experimentado una mejora de su eficiencia energética similar a la que les supone a los edificios de clase $\mathrm{C}$ pasar a clase $\mathrm{B}$.

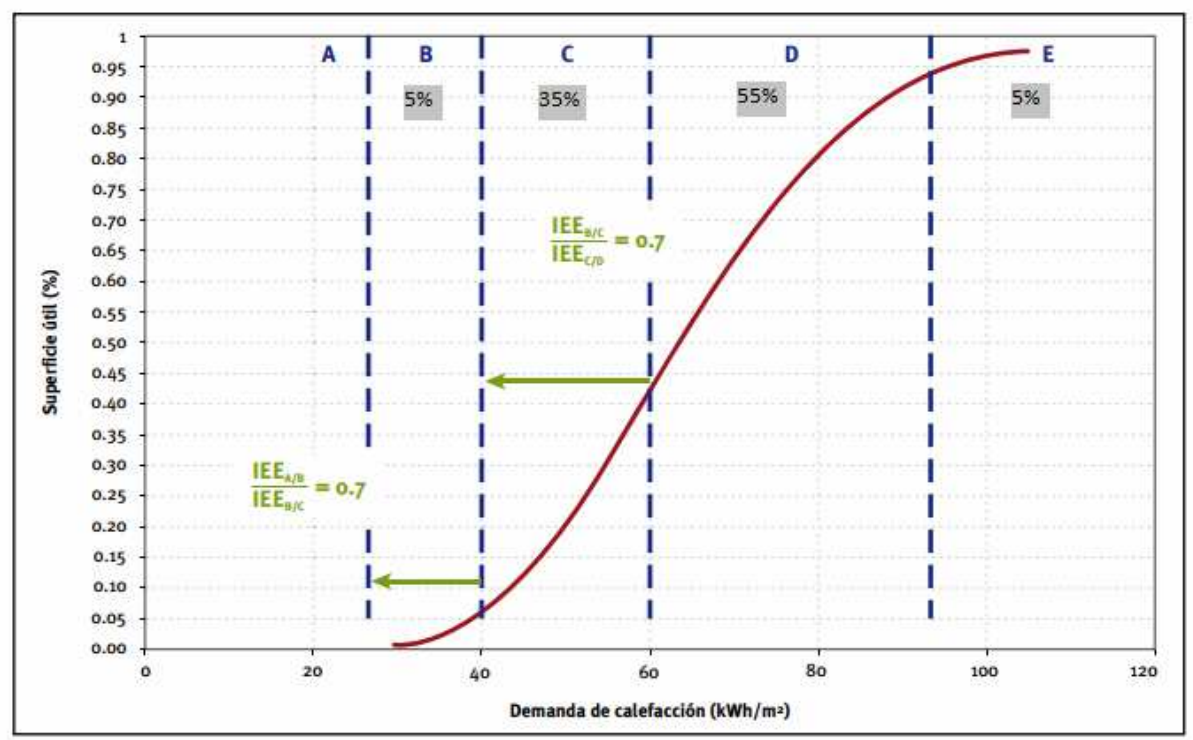

Figura 8.3. Formación gráfica de la escala de la calificación energética. Fuente: [51]

En resumen, el sistema de cálculo tuvo las siguientes fases:

- Selección de viviendas tipo representativas del parque edificatorio español (unifamiliares y en bloque por separado)

- Obtención de sus indicadores energéticos para distintas zonas climáticas, orientaciones y calidades de construcción

- Clasificación matemática en función del resultado

\subsubsection{Directrices para elaborar la escala}

Partiendo de las directrices para la elaboración de la escala de calificación energética para edificios, y dando por supuesto que al menos algunas de ellas serán válidas para la nueva calificación: 
1. La escala debe diferenciar claramente unas actitudes de otras; no tiene sentido que la mayoría de los abonados recaigan en la misma escala.

2. Debe tener sensibilidad a las mejoras, es decir, debe ser relativamente fácil cambiar de escala.

3. Debe ser posible, aunque sea difícil, alcanzar la calificación A

4. Debe ser estable, es decir, permanecer invariable durante una cantidad razonable de tiempo.

5. Debe ser consistente con los objetivos de su establecimiento, y ayudar a obtenerlos

\subsection{Calificación energética del uso de la vivienda}

El objetivo de la calificación energética del uso de la vivienda es valorar el comportamiento de sus habitantes en relación a su consumo energético. La eficiencia en el uso se determina midiendo la energía consumida por los habitantes de la vivienda a lo largo de un periodo determinado, y comparándolo con una vivienda patrón. Los consumos incluyen climatización, ACS, iluminación y electrodomésticos, y se consideran todas las posibles fuentes de energía, aunque se incide principalmente en la combinación electricidad - gas.

Para definir la calificación, el siguiente desarrollo se basa e imita en la medida de lo posible el desarrollo del índice de eficiencia energética en edificio, con el que está fuertemente relacionado.

\subsubsection{Indicador de comportamiento energético}

En el caso del uso de la vivienda, el indicador de comportamiento energético más sencillo de usar es el término de energía, es decir, los kWh mensuales consumidos por los habitantes de la vivienda.

Para tener en cuenta que la energía utilizada puede ser de distintas fuentes, (principalmente eléctrica, gas natural, productos petrolíferos y energías renovables, ver Figura 8.4), deberá sumarse la contribución al total de cada uno de ellos, excepto en el caso de energías renovables. Por tanto, la variable a utilizar para la valoración del comportamiento energético debería ser la siguiente: 


$$
\mathrm{I}=\mathrm{kWh} \mathrm{h}_{\text {eléctricos }}+\mathrm{kWh} \mathrm{h}_{\text {gas }}+\mathrm{kWh} \mathrm{h}_{\text {prodpetroliferos }}
$$

Los dos primeros datos se obtienen fácilmente de las lecturas de los contadores respectivos de cada abonado; la dificultad de obtención del tercero hace aconsejable, al menos en una primera aproximación, no tenerlo en cuenta, como se comenta en el apartado 8.3.2. Se requiere en cualquiera de los casos la colaboración de las empresas comercializadoras para la obtención de este dato.

De esta forma se elimina el problema de las diferentes fuentes energéticas utilizadas para climatización y ACS utilizadas en vivienda, que dificultaría considerablemente las comparativas. La posible mayor eficacia de unos sistemas respecto a otros, como veremos posteriormente, quedará solventada gracias al uso de los valores calculados en la certificación energética del edificio, que ya incluyen en sus cálculos el sistema de calefacción / ACS utilizado en la vivienda objeto del estudio.

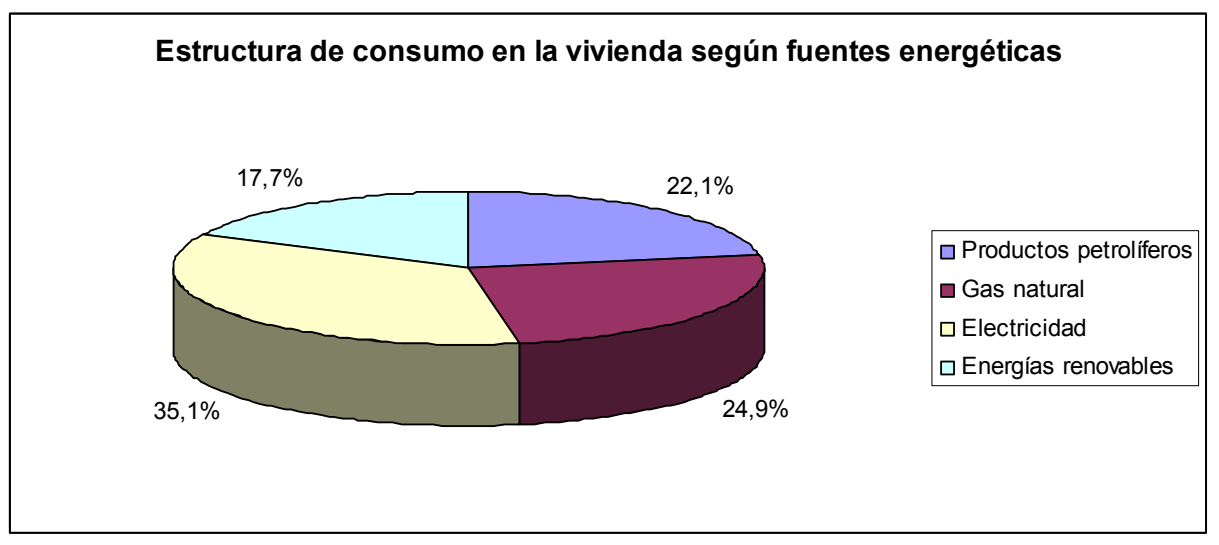

Figura 8.4. Desagregación del consumo en vivienda según fuentes energéticas. Fuente: Informe SPAHOUSEC

\subsubsection{Grado de similitud: clasificación en viviendas tipo}

Para empezar, es necesario definir, al igual que se describe en la calificación energética del edificio, una serie de viviendas tipo que sirvan de referencia para la clasificación de la vivienda objeto de estudio. Para ello, es necesario determinar las variables que, independientemente del comportamiento de los habitantes, afectan al consumo. 
Múltiples artículos estudian la relación de diversas variables con el consumo total de una vivienda ([96], [94], [67], [104], [130], [120], [43]). En el artículo [96] se enumeran las más nombradas en la bibliografía, independientemente del comportamiento de sus habitantes. Estas variables se resumen en la Tabla 8.1 :

Variables de las que depende el consumo de una vivienda

\begin{tabular}{cc}
\multicolumn{1}{c}{ Variable } & $\begin{array}{c}\text { No de veces } \\
\text { que se nombra }\end{array}$ \\
\hline Características constructivas de la vivienda & 13 \\
\hline Tipo de vivienda & 7 \\
Superficie & 8 \\
Ubicación & 5 \\
Edad de la vivienda & 6 \\
Sistema de calefacción & 5 \\
Zona climática & 11 \\
\hline Características de los habitantes & 8 \\
\hline Número de habitantes & 4 \\
Composición del hogar & 12 \\
\hline Régimen de propiedad & \\
\hline Ingresos & 12 \\
\hline Características de los electrodomésticos & 8 \\
\hline Parque de electrodomésticos & \\
\hline
\end{tabular}

Tabla 8.1. Variables de las que depende el consumo de la vivienda

\section{- Características constructivas y superficie}

De la enumeración de la Tabla 8.1, todas las características constructivas de la vivienda están englobadas en el certificado de eficiencia energética del edificio y por tanto pueden valorarse a partir de éste. Se tomará de esta parte, como único dato de partida para el establecimiento de la vivienda tipo, el consumo en $\mathrm{kWh} / \mathrm{m}^{2}$.año estimado por la calificación energética, que ya tiene en cuenta la zona climática, la edad del edificio, la ubicación, el tipo de vivienda y el sistema de climatización.

Como el consumo estimado por la calificación energética se da por unidad de superficie, se incluirá la influencia de esta variable por simple multiplicación de ambos términos. Con ello, no será necesario tenerla en 
cuenta de forma separada, dado que su influencia principal se relaciona con la climatización. Se desprecia de momento su influencia en la iluminación, aunque es una cuestión que debería estudiarse en detalle en una segunda revisión del sistema.

El consumo estimado es una variable continua, por lo que será necesario definir una serie de escalones para las viviendas tipo. Posteriormente, las desviaciones del consumo real con respecto al de la vivienda tipo se calcularán mediante la aplicación de un factor de corrección.

Con el uso de este término para la definición de las viviendas tipo, se desacopla la variación en el consumo de la calidad de los cerramientos, sistema de climatización, edad del edificio, etc. Ello lo hace especialmente útil para la calificación de los hábitos con independencia de las condiciones de habitabilidad de las viviendas.

- Características de los habitantes

En cuanto a las características de los habitantes, la variable de mayor precisión a usar es sin duda la composición del hogar, dado que no requiere la misma cantidad de energía un niño que un adulto; sin embargo, dada la dificultad de acceso a esta información, se ha considerado preferible tomar como única variable a tener en cuenta el número de habitantes de la vivienda, independientemente de su edad.

- Características de los electrodomésticos

Por lo que respecta a las características y propiedad de los electrodomésticos, no se considera una variable válida de clasificación en viviendas tipo. Por el contrario, se interpreta como uno de los posibles elementos sobre los que el usuario puede incidir a la hora de disminuir su consumo, sea por medio de la sustitución por equivalentes de mayor calificación energética, sea por reducción en el uso. Por lo tanto, no se tienen en cuenta a la hora de definir las viviendas tipo, aunque evidentemente influirán en los consumos totales.

Con esta simplificación se premia a las viviendas con los electrodomésticos más eficientes (o con las que disponen de menos cantidad absoluta de ellos). Además, limita en parte la aparición del efecto rebote, que consiste en aprovechar el ahorro en la factura para comprar otros productos, que pueden ser también consumidores de energía. 
- Fuentes de energía

Por último, conviene separar en viviendas tipo independientes del resto, las que incluyen uso de productos petrolíferos (ver Figura 8.4). La dificultad de acceso a los consumos de los usuarios hace inviable, al menos en una primera aproximación, tenerlos en cuenta. Por tanto, en este caso no se calificaría más que el consumo eléctrico de la vivienda, y los usuarios sólo serían comparados en cuanto a ésta. En todos los demás casos, la calificación se hará de forma conjunta al consumo de electricidad y gas.

Como resumen, las viviendas tipo serían establecidas a partir de los siguientes criterios:

- Consumo estimado según la calificación energética del edificio

- Superficie

- $\quad$ № de habitantes

- Fuentes energéticas

Es decir, una vez pasado el consumo estimado a kWh/año y separadas las viviendas con uso de fuentes de energía fósil, únicamente dependería del consumo estimado y del número de habitantes.

\subsubsection{Necesidad de un estudio estadístico de envergadura}

La inexistencia de una base de datos cruzada de las variables establecidas en el apartado 8.3.2 hace necesario un estudio estadístico a nivel nacional del consumo real de las viviendas de los distintos tipos establecidos. Sería necesario para ello cruzar las siguientes bases de datos:

- Consumo energético en la vivienda, dato en poder de las compañías comercializadoras

- Calificación energética de las viviendas, junto con su superficie, presentes en el Registro oficial de certificados de eficiencia energética en edificios, competencia de las distintas comunidades autónomas

- Número de habitantes de la vivienda, padrón municipal de habitantes, responsabilidad de los Ayuntamientos.

Un estudio pormenorizado previo de este tipo sería imprescindible para el establecimiento de este índice; pero tiene además otras aplicaciones. 
Por ejemplo, sería de gran ayuda para investigar la precisión del cálculo teórico de las necesidades energéticas realizado por los programas de calificación energética del edificio, que, según algunos autores ([11], [111]), está sobredimensionado.

\subsubsection{Cálculo numérico del índice}

Una vez establecidas las viviendas tipo a partir de los criterios establecidos en el apartado 8.3.2, y realizado el estudio estadístico descrito en el apartado 8.3.3, el valor de consumo medio de energía en una vivienda tipo determinada sería la base sobre la que calcular el desempeño de una vivienda en particular.

El cálculo podría ser tan simple como éste:

$$
I E E C=\frac{\text { Consumo propio }(k W h)}{\text { Consumo viviendatipo }(k W h)}
$$

Este valor puede utilizarse directamente en la factura eléctrica, para comparar el consumo de la vivienda en cuestión con la media de sus pares. Éste es un recurso muy utilizado en la literatura relativa a la reducción del consumo en vivienda por métodos informativos, aunque la vivienda de comparación con la que se ha trabajado no es demasiado precisa, dado que no existen bases de datos tan pormenorizadas como la descrita en el apartado 8.3.3. También puede indicarse con una etiqueta energética, que contendría los datos básicos de la vivienda, el consumo en kWh mensuales, y la calificación energética obtenida. La letra podría variar mensualmente.

\subsubsection{Definición de los escalones de la calificación}

Una vez definidas las viviendas tipo, así como conocidos los consumos de las viviendas por medición directa, para la definición de los escalones se seguiría un procedimiento similar al de la calificación energética del edificio, descrito en el apartado 8.2.4.3.

Es decir, para cada vivienda-tipo, se llevaría a cabo la siguiente secuencia:

1. Cálculo de la distribución en frecuencia acumulada de los kWh consumidos por el conjunto de viviendas incluidos en la definición de una vivienda tipo en particular (Figura 8.2) 
2. Situación de las escalas sobre la distribución en frecuencia acumulada (ligeramente corregido con respecto a la escala de la calificación en edificio [51]), de forma que se cumpla que :

a. El $80 \%$ de las viviendas se sitúan en las clases C (13\%), D $(27 \%)$ y $E(40 \%)$

b. El $20 \%$ restante se reparte por igual en las clases mejores y peores: $\mathrm{B}$ y $\mathrm{F} 8 \%$, A y G $2 \%$ cada uno.

La primera clasificación sería entonces puramente estadística, al contrario que en el caso del índice de eficiencia energética en el edificio, que parte de un parque virtual de viviendas calculadas por ordenador. La razón es la pura y simple falta de datos que permita una simulación fiable de los comportamientos, y la necesidad de que los datos reales casen razonablemente bien desde el primer momento con los límites teóricos que se establezcan.

Los datos para la definición de los límites de las escalas se calcularían para cada mes de un año determinado, y tras esto se mantendrían fijos durante un periodo de tiempo razonablemente largo, típicamente 10 años. Las fronteras límite en kWh deberán ser corregidas por temperatura anualmente.

\subsection{El incentivo económico}

El tercer experimento llevado a cabo durante la realización de esta tesis, el estudio del incentivo económico, ha resultado ser finalmente el de mayor éxito. Sin embargo, su aplicabilidad práctica es compleja, dado que podría requerir por parte de las Administraciones públicas un esfuerzo financiero considerable.

Como finalización de este capítulo se sugieren algunos métodos posibles para la implementación de un incentivo económico que se establecería en base a la calificación energética IEEC obtenida. Para ello, se describen tres posibilidades: reducción de impuestos, imposición de una cuota de $\mathrm{CO}_{2}$, y ajuste de la factura eléctrica al consumo.

\subsubsection{Reducción de impuestos}

En España, el $85 \%$ de las viviendas certificadas hasta ahora con la calificación de eficiencia energética en edificio han obtenido una calificación $E$, F o G. Sólo un $11 \%$ han obtenido una calificación $D$, que es la más baja de la 
gama de las viviendas con consumos menores al del edificio patrón. En la tabla, se muestran los resultados del registro de calificaciones en consumo para edificios existentes. El registro por emisiones es ligeramente diferente, pero los porcentajes son similares. La tabla está basada en datos del Ministerio de Energía, Industria y Turismo de julio del año 2015 [50].

\begin{tabular}{ccc}
\multicolumn{3}{c}{ Registro de calificaciones por consumo (año 2015) } \\
\hline Letra & Número de edificios & Proporción \\
\hline A & 1.435 & $0 \%$ \\
B & 7.508 & $1 \%$ \\
C & 43.582 & $3 \%$ \\
D & 151.690 & $11 \%$ \\
E & 693.802 & $52 \%$ \\
F & 142.860 & $11 \%$ \\
G & 301.863 & $22 \%$ \\
\hline
\end{tabular}

Tabla 8.2. Proporción de edificios según su calificación

Para la promoción de una buena calificación energética del edificio, se están tomando medidas de reducción del IBI para viviendas energéticamente eficientes. En concreto, el Real Decreto 233/2013, que regula el Plan Estatal de fomento del alquiler de viviendas, la rehabilitación edificatoria y la regeneración y renovación urbanas, 2013-2016 (prorrogado hasta el fin del año 2017 por el Real Decreto 637/2016), establece subvenciones de hasta el $35 \%$ del presupuesto de la mejora. Además, el Gobierno ha modificado la ley del 2004 de Haciendas locales para permitir a los Ayuntamientos la rebaja en el Impuesto sobre Bienes Inmuebles (IBI) de las viviendas que puedan demostrar unas calificaciones energéticas entre las letras $A$ ( $20 \%$ de reducción) y E ( $4 \%$ de reducción). Sin embargo, como es competencia de los Ayuntamientos, serán éstos quienes decidan o no trasladar esta posibilidad a sus ordenanzas municipales.

Del mismo modo que puede regularse que una buena calificación energética del edificio suponga una reducción del IBI, puede establecerse ese mismo sistema para una buena calificación energética del comportamiento. Dado que este impuesto lo pagan los propietarios de las viviendas, este sistema podría funcionar también, correctamente publicitado, como un incentivo al cambio a electrodomésticos de alta eficiencia en las viviendas en régimen de alquiler. 
EI IBI no es el único impuesto sobre el que se puede trabajar; en la factura eléctrica, y pese a que la electricidad se considera un bien de primera necesidad, el Impuesto sobre el Valor Añadido (IVA) es de un $21 \%$, que además se aplica sobre un importe al que se ha aplicado previamente un impuesto sobre electricidad (5,11 \%). Reducciones en el IVA aplicado en la factura aumentarían el efecto reductor de la disminución del consumo en la propia factura. Sin embargo, el efecto obtenido a través del IVA es pequeño (ver ejemplo de aplicación en apartado 8.4.3)

\subsubsection{Derechos de emisión}

El comercio de derechos de emisión es un instrumento de mercado que se utiliza para el control de las emisiones de efecto invernadero. Actualmente existen diversos mercados de emisión que afectan a distintos países y a diferentes contaminantes. Uno de los más importantes es el Régimen de Comercio de Derechos de Emisión de la Unión Europea, (Directiva 2003/87/CE, transpuesta al ordenamiento jurídico español por la Ley 1/2005), que cubre las emisiones de $\mathrm{CO}_{2}$ de actividades tales como centrales térmicas, instalaciones de combustión térmica de potencias superiores a $20 \mathrm{MW}$, refinerías, cemento, cerámica, vidrio, papeleras y otras.

En este mercado, un gobierno establece un límite sobre la cantidad total del gas contaminante que puede ser emitido, y asigna unos derechos de emisión determinados a cada una de las actividades afectadas por la regulación. Esos derechos de emisión se pueden comprar y vender; las empresas que emitan menos de lo estipulado, pueden vender a las que superen su asignación.

El comercio de derechos de emisión se ve como un sistema más eficiente que la actuación a través de los impuestos, aunque hay críticas a la dificultad de la asignación inicial de derechos, así como al cálculo del techo de emisiones.

Con el mismo sistema de organización que a nivel de grandes empresas, se puede asignar a cada vivienda un límite a la cantidad equivalente de $\mathrm{CO}_{2}$ emitida. Como se pretende desincentivar el derroche, pero no gravar injustamente peores condiciones de habitabilidad o mayor número de habitantes del hogar, esta asignación se debería calcular para cada una de las viviendas tipo descritas anteriormente. Así quedaría compensado el hecho de 
que las residencias con peores envolventes térmicas requieren más energía para climatizarse, o que las familias con mayor número de miembros consumen necesariamente más.

Dentro de una misma vivienda tipo, los hogares con consumos inferiores a la media dispondrían de derechos de emisión que vender, con el consiguiente beneficio económico. Las viviendas con consumos por encima de la asignación recibirían una penalización a través de la necesidad de comprar los derechos necesarios para compensar el exceso.

Para desarrollar el concepto con un ejemplo, se ha calculado el IEEC de los participantes de los grupos I y II del experimento no 3 en función de su consumo, suponiendo que todos ellos pertenecen a una misma vivienda tipo. Los resultados se muestran en la Tabla 8.3.

Calificación de las viviendas de los Grupos I y II del experimento ํㅡ 3

\begin{tabular}{ccc}
\hline $\begin{array}{c}\text { Calificación } \\
\text { IEEC }\end{array}$ & $\begin{array}{c}\text { No de viviendas de la } \\
\text { calificación en la muestra }\end{array}$ & $\begin{array}{c}\text { Consumo mensual } \\
\text { medio (kWh) }\end{array}$ \\
\hline A & 1 & 57 \\
B & 4 & 84 \\
C & 6 & 123 \\
D & 14 & 163 \\
E & 20 & 290 \\
F & 4 & 490 \\
G & 1 & 680 \\
\hline
\end{tabular}

Tabla 8.3. Clasificación IEEC de las viviendas de los Grupos I y II del experimento no3

Se ha considerado por simplificación que todos los habitantes con la misma calificación consumen lo mismo, (la media de los participantes con la misma letra), aunque evidentemente en la realidad hay diferencias entre unos y otros. La calificación se ha llevado a cabo sobre la distribución estadística de la muestra, usando el procedimiento descrito en el apartado 8.3.5.

La asignación de $\mathrm{CO}_{2}$ se calcularía de forma que las viviendas que se encuentren justo en la frontera entre las calificaciones $D$ y la $E$ no paguen ni reciban dinero. En el caso del ejemplo, ese valor se corresponde con una 
emisión de $48,8 \mathrm{~kg}$ de $\mathrm{CO}_{2}$. A partir de ahí, simplemente el $\mathrm{kg}$ extra de $\mathrm{CO}_{2}$ se grava con una cantidad a determinar. Por ejemplo, la Tabla 8.4 se ha confeccionado para un precio de $1 €$ el $\mathrm{kg}$ de $\mathrm{CO}_{2}$ en exceso o defecto.

Propuesta de pago de derechos de emisión

\begin{tabular}{|c|c|c|c|c|c|}
\hline $\begin{array}{c}\text { Calif. } \\
\text { Vivienda }\end{array}$ & $\begin{array}{c}\text { № de viv del } \\
\text { tipo }\end{array}$ & $\begin{array}{c}\text { Consumo } \\
\text { mensual } \\
(\mathrm{kWh})\end{array}$ & $\begin{array}{c}\text { Equivalencia } \\
\text { en } \mathrm{kg} \mathrm{CO}_{2}\end{array}$ & $\begin{array}{c}\text { Exceso sobre } \\
\text { el valor } \\
\text { neutro }\end{array}$ & Ganancia $(€)$ \\
\hline$A$ & 1 & 57 & 12,17 & 36,63 & 29,3 \\
\hline B & 4 & 84 & 17,94 & 30,86 & 24,69 \\
\hline $\mathrm{C}$ & 6 & 123 & 26,27 & 22,53 & 18,02 \\
\hline $\mathrm{D}$ & 14 & 163 & 34,82 & 13,98 & 11,19 \\
\hline Frontera & - & 226,5 & 48,8 & 0 & 0 \\
\hline E & 20 & 290 & 61,94 & $-13,14$ & $-10,51$ \\
\hline $\mathrm{F}$ & 4 & 490 & 104,66 & $-55,86$ & $-44,69$ \\
\hline G & 1 & 680 & 145,24 & $-96,44$ & $-77,15$ \\
\hline \multicolumn{5}{|c|}{ Total recaudado $(€)$} & 49,15 \\
\hline
\end{tabular}

Tabla 8.4. Propuesta de pago de derechos de emisión

Por supuesto, el ejemplo es una simplificación pensada únicamente para ilustrar el concepto de derechos de emisión en la vivienda, y para ver cómo beneficia a los ahorradores, perjudica a los derrochadores y, si se calcula con rigor, se autofinancia. En caso de llevarse a la práctica, sería necesario un estudio mucho más riguroso de los consumos, de la frontera más apropiada, y desde luego requeriría previamente la definición de las viviendas tipo así como la calificación energética de los hogares afectados.

\subsubsection{Modificación de la tarifa eléctrica}

Veamos el problema de la tarifa eléctrica a través de un ejemplo numérico. Supongamos una vivienda con las siguientes características: 245 $\mathrm{kWh} /$ mes en el año 2015, tarifa PVPC, 5,5 kW de potencia contratada, y una reducción de consumo de un 10\% durante el año 2016.

Tal como está diseñada una factura eléctrica hoy día, el $60 \%$ de su importe se dedica a pagar el término relacionado con la energía, siendo el $40 \%$ restante un pago fijo formado por la parte de potencia y de alquiler de equipos. Debido a ello, una reducción de consumo de un $10 \%$ en la vivienda 
del ejemplo se traduce en una disminución de un 5,5\% en el importe de la factura. En el caso del ejemplo, en valor absoluto el abonado habría pasado de pagar 56,1€ a pagar $53 €$. Es decir, sólo se habría ahorrado 3,1 €.

En este apartado se propone una factura que deje de depender de términos fijos y varíe de forma lineal con la energía consumida; de esta forma, reflejaría mejor el comportamiento de los abonados. Para ello, es necesario unificar los costes unitarios del peaje de potencia, el margen de la comercializadora, el peaje de la energía y el coste de la energía en un único factor. (Se muestra un ejemplo simplificado en la Tabla 8.5).

Costes unitarios actuales y reducidos según el sistema propuesto

\begin{tabular}{|c|c|c|c|c|c|c|c|}
\hline \multicolumn{2}{|r|}{ Potencia contratada $(\mathrm{kW})$} & 4,4 & 5,5 & 6,6 & 7,7 & 8,8 & 9,9 \\
\hline \multirow{6}{*}{$\begin{array}{l}\text { Costes } \\
\text { unitarios } \\
\text { actuales }\end{array}$} & Peaje de potencia ( $€ /$ kW·día) & \multicolumn{6}{|c|}{0,103944} \\
\hline & Comercializadora (€/kW·día) & \multicolumn{6}{|c|}{0,010929} \\
\hline & Peaje energía $(€ / k W h)$ & \multicolumn{6}{|c|}{0,044027} \\
\hline & Coste energía (€/kWh) & \multicolumn{6}{|c|}{0,055472} \\
\hline & Impuesto sobre la energía & \multicolumn{6}{|c|}{$5,11 \%$} \\
\hline & Alquiler equipos ( $€ /$ mes) & \multicolumn{6}{|c|}{0,79671} \\
\hline \multicolumn{2}{|c|}{ Coste unitario global propuesto ( $€ / \mathrm{kWh})$} & 0,18 & 0,2 & 0,21 & 0,23 & 0,24 & 0,26 \\
\hline
\end{tabular}

Tabla 8.5. Costes unitarios de potencia y energía en la actualidad y modificación según propuesta

Este factor o coste unitario global multiplicaría la energía consumida para obtener el importe total de la factura. Con este sistema, el cálculo de la factura, incluyendo todos los conceptos excepto el IVA, se calcularía simplemente como:

Importe total factura $=$ Energía $(\mathrm{kWh}) \cdot$ Coste unitario global $(€ / \mathrm{kWh})$

Supongamos ahora dos viviendas con un consumo mensual de $500 \mathrm{kWh}$. Una de ellas está ocupada por una unidad familiar de 6 miembros, y es una casa antigua, grande y con aislamientos térmicos deficientes. La otra es una vivienda pequeña pero nueva, con buen aislamiento y en la que vive una unidad familiar de 2 miembros. Es evidente que la primera es más eficiente en su comportamiento, aunque no se aprecie en el consumo. Si el precio de la 
energía es el mismo para ambas, no se está valorando de manera adecuada el uso que se hace de ellas.

Para poder comparar con justicia el desempeño de dos viviendas, éstas deben ser iguales entre sí en cuanto al número de miembros, calidad de los cerramientos y superficie. Por tanto, el coste unitario debería ser un valor específico para cada vivienda tipo. Al comparar viviendas iguales, sí se puede afirmar que consumos mayores están asociados a costumbres más derrochadoras.

Utilizando el mismo ejemplo que en el apartado 8.4.2, se ha calculado el importe de las facturas de cada una de las viviendas de la muestra, agrupadas por su IEEC. El importe (antes de impuestos) se muestra, tanto para el sistema actual de facturas como para el sistema propuesto, en la Tabla 8.6. El "sistema actual" está calculado para una tarifa PVPC de un solo tramo; el "sistema propuesto" está calculado multiplicando el consumo por el coste unitario global propuesto.

En la Tabla 8.3 se puede ver la diferencia de consumo entre la clase A y la $G$ de la misma vivienda tipo. Por otra parte, en la Tabla 8.6 se puede ver cómo esa variación de consumo repercute en la factura tanto para el sistema de cálculo actual como para el propuesto. Por ejemplo, para las viviendas con 4,4 kW de potencia contratada, una vivienda A pasaría de pagar 22,7€ a pagar $9,99 €$ por el mismo consumo, mientras que una vivienda $G$ pasa de pagar $87,85 €$ a pagar $119,14 €$.

El "coste unitario global propuesto" se ha calculado en las tablas de forma que los usuarios cuyo consumo esté justo en la frontera entre las clases $D$ y $E$, mantengan el mismo importe de factura. Las de menor consumo con respecto a ésta (tipos A, B, C, D,) la reducen de forma sustancial (ver Tabla 8.6), mientras que las demás ( $E, F$ y $G$ ) la aumentarían. Otras viviendas tipo requerirían otros "costes unitarios globales", calculados según el mismo sistema.

En cualquiera de las potencias contratadas, la vivienda $G$ paga más de $100 €$ mensuales más que la de calificación $A$, cuando previamente pagaba unos $65 €$ más. Es decir, se pueden obtener niveles de incentivo económico del mismo orden que el que se ha utilizado en el experimento no 3 de esta tesis ( $50 €$ mensuales en el mejor de los casos), sin perder recaudación total de 
dinero. Además, si el IEEC aparece en la factura, el consumidor $\mathrm{G}$ será sabedor de esa diferencia, cosa que con el sistema actual no ocurre.

Importe de la factura con el sistema actual y con el coste unitario global propuesto (€)

\begin{tabular}{|c|c|c|c|c|c|c|c|}
\hline \multirow{2}{*}{ IEEC } & \multirow{2}{*}{$\begin{array}{l}\text { Cálculo de } \\
\text { la factura } \\
\text { según } \\
\text { sistema... }\end{array}$} & \multicolumn{6}{|c|}{ Potencia contratada $(\mathrm{kW})$} \\
\hline & & 4,4 & 5,5 & 6,6 & 7,7 & 8,8 & 9,9 \\
\hline \multirow{2}{*}{ A } & Actual & 22,70 & 26,68 & 30,67 & 34,65 & 38,63 & 42,62 \\
\hline & Propuesto & 9,99 & 10,94 & 11,90 & 12,86 & 13,82 & 14,77 \\
\hline \multirow{2}{*}{ B } & Actual & 25,52 & 29,50 & 33,49 & 37,47 & 41,46 & 45,44 \\
\hline & Propuesto & 14,72 & 16,13 & 17,54 & 18,95 & 20,36 & 21,77 \\
\hline \multirow{2}{*}{$\mathrm{C}$} & Actual & 29,60 & 33,58 & 37,57 & 41,55 & 45,54 & 49,52 \\
\hline & Propuesto & 21,55 & 23,62 & 25,68 & 27,75 & 29,82 & 31,88 \\
\hline \multirow{2}{*}{$\mathrm{D}$} & Actual & 33,78 & 37,77 & 41,75 & 45,74 & 49,72 & 53,70 \\
\hline & Propuesto & 28,56 & 31,30 & 34,03 & 36,77 & 39,51 & 42,25 \\
\hline \multirow{2}{*}{$E$} & Actual & 47,06 & 51,05 & 55,03 & 59,02 & 63,00 & 66,99 \\
\hline & Propuesto & 50,81 & 55,68 & 60,55 & 65,42 & 70,30 & 75,17 \\
\hline \multirow{2}{*}{$\mathrm{F}$} & Actual & 67,98 & 71,97 & 75,95 & 79,93 & 83,92 & 87,90 \\
\hline & Propuesto & 85,85 & 94,08 & 102,31 & 110,54 & 118,78 & 127,01 \\
\hline \multirow{2}{*}{ G } & Actual & 87,85 & 91,84 & 95,82 & 99,81 & 103,79 & 107,77 \\
\hline & Propuesto & 119,14 & 130,56 & 141,98 & 153,41 & 164,83 & 176,26 \\
\hline \multirow{4}{*}{ Totales } & Actual & 2076 & 2276 & 2475 & 2674 & 2873 & 3072 \\
\hline & Propuesto & 2077 & 2276 & 2475 & 2674 & 2873 & 3072 \\
\hline & Variación & & & & & & \\
\hline & $\begin{array}{c}\text { en la } \\
\text { recaudación }\end{array}$ & 0 & 0 & 0 & 0 & 0 & 0 \\
\hline
\end{tabular}

Tabla 8.6. Importes de las facturas antes y después del cambio

Este cálculo no pretende en absoluto ser exhaustivo ni directamente aplicable tal como está hecho; está demasiado simplificado. Es únicamente una propuesta para investigaciones futuras, y a la vez un cálculo simplificado para mostrar que el potencial del incentivo a través de la factura existe, que es considerable y que puede estar autofinanciado. Esto último lo demuestra los totales de la Tabla 8.6: la suma recaudada por la comercializadora con el sistema actual y con el sistema propuesto es exactamente la misma. 
Este sistema no sólo permite un incentivo económico autofinanciado; además, es más justo que el que se encuentra establecido hoy en día, dado que repercute el coste de las redes, los operadores, y el consumo energético extra en mayor medida no sobre los mayores consumidores sino sobre los mayores derrochadores de cada una de las clases en las que se ha dividido a la población. Recuérdese que los pertenecientes a las clases $A$ y $G$ tienen viviendas cuyas necesidades energéticas en climatización y ACS son iguales, luego las diferencias de consumo entre ellas vienen de variaciones en sus hábitos energéticos o en el tipo y cantidad de electrodomésticos que utilizan.

Si además este factor o coste unitario fluctúa como el actual en función del precio real de la energía en cada momento, al repercutir con más fuerza en el importe final de la factura, es un incentivo extra al aplanamiento de la curva de la demanda.

El cálculo exhaustivo del coste unitario de una factura de este tipo está ligado a la definición del IEEC, a la clasificación de las viviendas tipo, y al conocimiento preciso de los consumos ligados a éstas. Queda fuera del ámbito de esta tesis por la magnitud del trabajo que supone, pero lleva asociado un gran potencial de ahorro energético y de justicia social. 


\section{Conclusiones y trabajos futuros}

\subsection{Conclusiones}

\subsubsection{El problema medioambiental y el factor humano}

El problema medioambiental asociado al uso de combustibles fósiles como fuente de energía primaria (emisión de gases de efecto invernadero, contaminación de acuíferos, gestión de los residuos, agotamiento de los recursos, dependencia de terceros países) hace necesaria la reducción del consumo energético a nivel global. Pese a ser este hecho sobradamente conocido, el consumo energético a nivel mundial no ha dejado de aumentar desde el inicio de la Revolución Industrial, al principio impulsado principalmente por los países occidentales, hoy en día por las potencias emergentes.

La persistencia del problema energético y su evidente gravedad ha impulsado a los países desarrollados a poner en marcha una serie de políticas para reducir el consumo o al menos contener su crecimiento. Estas políticas están enfocadas a los cuatro principales consumidores de energía final en el mundo: industria (54\% de la energía final consumida), transportes ( $25 \%$ ), sector residencial (14 \%) y sector terciario (7 \%). [48]. En España las 
proporciones son difrerentes: un $34 \%$ corresponde a la industria, un $40 \%$ al transporte, un $17 \%$ al sector residencial y el $9 \%$ al sector terciario (IDAE, datos del 2008).

En los que se refiere al sector residencial, y a pesar de todo el esfuerzo realizado en la promoción del ahorro de energía y en el aumento de la eficiencia energética, las previsiones de ahorro no cuadran con los resultados obtenidos. La diferencia entre ambas se ha venido a conocer con el nombre de brecha de la eficiencia energética, y su existencia se achaca al factor humano y a la irracionalidad de su comportamiento

La brecha se manifiesta principalmente a través de dos efectos, observados en multitud de ocasiones aunque difíciles de traducir en términos monetarios. Son el efecto rebote y el efecto free-rider. Cualquier política que pretenda la reducción del consumo en términos absolutos debe tener presente el primero; cualquier política que implique un desembolso financiero debe tratar de impedir la aparición del segundo.

Algunos ejemplos de las diversas políticas relacionadas con la cuestión energética que se han aplicado hasta ahora son las siguientes: los sistemas de obligaciones de eficiencia energética, los requisitos mínimos de eficiencia energética en productos de todo tipo y edificios tanto residenciales como del sector terciario, las etiquetas de eficiencia energética, los incentivos económicos para mejora de envolturas térmicas en edificios o para la sustitución de productos de baja eficiencia energética, las campañas de concienciación en medios públicos, y la mejora en los sistemas de medición y de información al cliente final.

La mayoría de estas políticas están más enfocadas al aumento de la eficiencia que a la reducción del consumo en valor absoluto. Lo primero no implica necesariamente lo segundo en un entorno en el que diariamente salen al mercado nuevos productos consumidores de energía, y en el que no se pone ningún freno al efecto rebote. El aumento de la eficiencia energética debería entenderse como una herramienta para lograr la reducción en el consumo, no como un fin en sí misma.

Esta tesis está enfocada a la reducción del consumo absoluto en el sector residencial, obtenida principalmente mediante el cambio de comportamiento en el uso del equipamiento de ésta. A lo largo de su desarrollo, se demuestra el potencial de ahorro que se encuentra oculto en 
este ámbito, se prueban distintas herramientas para potenciarlo e incentivarlo, y se sugieren diversos sistemas para aplicar esas mismas herramientas a nivel de política gubernamental.

\subsubsection{La información como herramienta de trabajo}

En el caso particular del sector residencial, uno de los problemas básicos con los que se enfrenta el usuario a la hora de reducir su consumo energético es la falta de información con la que se encuentra en cuanto al consumo instantáneo y diario de cada uno de los equipos que utiliza en el hogar. De todas las acciones llevadas a cabo a lo largo de como mínimo un mes, la única información que recibe es un valor en kWh equivalente al conjunto de todas las decisiones energéticas tomadas a lo largo de 30 días.

Es necesaria la generación de una herramienta informativa exhaustiva e instantánea para que el usuario aprenda los comportamientos más eficientes con respecto a cada uno de los equipos de su vivienda. Debe ser exhaustiva porque una vivienda la componen muchos equipos diferentes, que en muchas ocasiones están actuando de forma simultánea, por lo que se requiere información suficiente para discernir entre ellos; debe ser instantánea para que el usuario sea capaz de aprender, por el método ensayo-error, qué equipamiento consume más, o qué forma de uso le permitiría utilizar óptimamente cada uno de ellos. Difícilmente lo averiguará si no conoce el efecto de sus acciones hasta un mes después de haberlas ejecutado.

A lo largo del desarrollo de esta tesis, se ha probado la eficacia de la herramienta informativa de varias formas diferentes. También han quedado patentes sus limitaciones.

Durante la realización del experimento no 1 , se probaron en laboratorio diversos métodos informativos, con el objetivo de seleccionar el mejor de entre ellos y probarlo posteriormente en viviendas reales. Como resumen, se pueden extraer las siguientes conclusiones a partir de los resultados obtenidos:

- Los sujetos son capaces de moverse en un entorno complejo y averiguar rápidamente las reglas que lo rigen si están adecuadamente informados.

- Los contadores inteligentes son una herramienta informativa con un gran potencial de ayuda al usuario; el grado de conocimiento del 
consumo propio que puede alcanzarse gracias a ellos es grande y sofisticado, permitiendo al individuo actuar de forma razonada y optimizar su actuación incluso en contra de la presión externa.

- En ausencia de información sobre el consumo pero en un ambiente de gran presión hacia la eficiencia energética, los individuos tienden a comportarse como creen que se espera de ellos, en vez de intentar maximizar su propio beneficio. La concienciación medioambiental podría por tanto ser una herramienta útil para la reducción del consumo energético, aunque hoy en día se está lejos de alcanzar en el mundo real el nivel de presión social necesario para ello.

- La cuestión de la climatización es especialmente difícil de entender por parte de los usuarios, por lo que requiere, en el caso real, un tratamiento especial. Éste podría consistir, por ejemplo, en un conjunto de consejos simples para su optimización, añadidos al sistema de información elegido.

- La influencia de la actuación del grupo en el que se engloba el sujeto es considerable, por lo que la comparación con los pares puede ser una herramienta útil. Además, con la información con la que cuentan las compañías suministradoras hoy día, es muy fácil añadirla a la factura; de hecho, algunas compañías ya lo hacen, aunque la comparativa se hace sin tener en cuenta las diferentes características de las viviendas, su número de miembros ni otros datos relevantes para el consumo.

Una vez concluido el experimento no 1 y a la vista de sus resultados, se diseñó un contador inteligente específico para ser puesto en marcha en un conjunto de viviendas de características similares en la provincia de Castellón. El sistema elegido para el diseño fue el de contador integral. El objetivo de este segundo experimento fue comprobar, en el mundo real, un sistema informativo que había probado en laboratorio su capacidad para conseguir ahorros significativos en el consumo.

Durante varios meses, se tomaron medidas de consumo del grupo con el contador inteligente y de un segundo grupo de control. En todo ese tiempo, no se aprecia prácticamente ninguna diferencia en la variación de consumo del grupo con contador y la del grupo sin él; las variaciones en porcentaje no superan en ningún caso el $1 \%$ y desde luego la diferencia, además de reducida, no muestra ninguna significatividad. Queda patente además el desinterés de los usuarios por la herramienta, no consultada por ninguno de ellos durante semanas. 
Como resumen, se pueden extraer las siguientes conclusiones de este experimento y de su relación con el anterior:

- La presencia de una herramienta informativa, aunque supone un aumento del conocimiento del uso de la energía, no implica necesariamente una reducción del consumo. Para obtener una reducción del consumo, a la herramienta informativa debe añadírsele un incentivo al ahorro.

- Un incentivo económico sumado a la herramienta informativa es eficaz, como demuestra el experimento $n=1$. En él, a los participantes se les pagaba en función de su desempeño energético, una cuestión que quedó enmascarada hasta la realización de este segundo experimento.

- Una presión social lo suficientemente fuerte es eficaz, como demuestra el experimento $n$ ㅇ 1 . Pero esta presión social no es eficaz o no tiene la suficiente fuerza en el mundo real, como demuestra el experimento $\mathrm{n}$ - 2 .

- Las herramientas informativas que se están desarrollando por ley (contadores inteligentes de medida de energía eléctrica, mejoras en la información suministrada en las facturas, información actualizada en la página web de las compañías suministradoras), no son consideradas por los expertos de entre las más efectivas (apartado 6.5.2, Figura 6.12). La razón posiblemente sea la misma que la que se deduce de este experimento: el aumento de información es eficaz como herramienta, pero es inútil si no existe una motivación para su uso.

\subsubsection{El incentivo económico como motor del cambio}

La tercera parte de la tesis ha consistido en el desarrollo del experimento no 3, el segundo de los realizados en vivienda. En este caso, se ha simplificado la herramienta informativa y se ha cambiado su diseño; también se ha añadido un incentivo económico para comprobar el efecto de éste. El objetivo final de cara a los sujetos participantes ha sido la consecución de un ahorro sostenido de un $10 \%$ en su consumo eléctrico a lo largo de los meses de octubre, noviembre y diciembre del año 2016; su incentivo, un pago lineal de 0 a 100 euros en función del ahorro total obtenido.

En el caso de este último experimento, los resultados han sido significativos, alcanzándose niveles de ahorro que, en el caso del grupo completo llegan a superar el límite del $10 \%$ en alguna de las semanas, aunque 
finalmente se reducen a un $7 \%$. Estos datos son referidos al comportamiento de los sujetos con respecto a sí mismos durante el año anterior; si se comparan con el comportamiento del grupo de control, la diferencia global entre ellos se dispara al $14,6 \%$.

Si se particulariza para los individuos participantes, se detectan diez casos con ahorro superior al $10 \%$, aunque también fracasos sonoros: siete casos de aumento en vez de reducción del consumo.

Como resumen de los resultados obtenidos, se pueden extraer las siguientes conclusiones de este experimento y de su relación con los anteriores:

- Un incentivo económico puede ser suficiente para que los usuarios consigan niveles de ahorro importantes, aunque será necesario afinar, en experimentos futuros, el importe mínimo requerido para que funcione.

- La herramienta informativa por sí sola no es suficiente: el grupo de control no obtiene ningún nivel de ahorro, y de hecho consume más durante la realización del experimento que en el año anterior, pese a contar con la misma información que el grupo incentivado económicamente.

- Una parte de los usuarios ya dispone de los conocimientos necesarios para obtener esos ahorros, dado que con una realimentación tan pobre como la ofrecida les basta para conseguir su objetivo.

- Otra parte de los usuarios es incapaz de obtener ahorros por sí mismos. La necesidad de una herramienta informativa de calidad se hace patente para estos casos; la que se desarrolló para este tercer experimento ha resultado claramente insuficiente para ellos. Otros recursos, tales como las auditorías energéticas y los consejos individualizados, pueden enfocarse también a los casos de este tipo.

- Los usuarios encuentran utilidad en la realimentación y la consultan, según indican los tests de finalización. Sin embargo, la influencia de los pares no parece tener un gran efecto: no se nombra apenas en los tests de finalización, ni ha influido en la actuación del grupo de control.

- La mayoría del ahorro en el experimento no 3 se ha obtenido por cambios de comportamiento, lo que demuestra el potencial que contiene éste. Además, el potencial es mayor de lo que se supone: hay 
sujetos con capacidades de reducción de consumo que superan ampliamente la barrera artificial del $10 \%$.

- El efecto es persistente en el corto plazo: tras la finalización del experimento, la diferencia entre ambos grupos con respecto al año anterior se mantiene. Sin embargo, se observa una amortiguación del $14,6 \%$ al $10,23 \%$ en la reducción.

- Este tipo de incentivos premia el ahorro, no el aumento de la eficiencia, por lo que reduce la influencia del efecto rebote.

\subsubsection{Aplicabilidad del incentivo económico}

En esta tesis se plantea la posibilidad de definir un índice de eficiencia energética de los hábitos de consumo de los residentes en vivienda, unida a una serie de incentivos económicos basados en la calificación energética obtenida. Las etiquetas energéticas ya existentes tanto para edificios como para productos, son consideradas según los expertos [49] como una de las políticas europeas de eficiencia energética de mayor éxito. Por ello, y por la familiaridad de los ciudadanos con ellas, una etiqueta energética del comportamiento es una manera idónea de calificar éste.

Esta etiqueta debe permitir comparar viviendas de las mismas calidades constructivas y equipos de climatización, situadas en zonas climáticas equivalentes y con una superficie y un nivel de ocupación iguales, con una vivienda tipo de las mismas características. De esta forma, podrá compararse el consumo entre ellas, premiar a las más eficientes o castigar el consumo extra de las más derrochadoras.

Se propone, una vez realizada la calificación de la vivienda, el establecimiento de alguno de los siguientes incentivos económicos:

- Reducción de ciertos impuestos, tales como el IBI. Esta medida ya se está implantando, aunque asociada al índice de eficiencia energética del edificio

- Comercio de derechos de emisión. Esta medida también existe ya, en este caso aplicada a la emisión de las grandes empresas consumidoras. Aquí se propone establecer una emisión determinada para cada vivienda tipo, y permitir el tráfico de derechos de emisión desde las más eficientes a las menos. 
- Modificación de la factura eléctrica. En este caso, se sugiere hacer depender las tarifas eléctricas no de términos fijos como la potencia sino exclusivamente del consumo eléctrico mensual. De esta forma, las modificaciones del comportamiento energético tendrían un reflejo más realista en el precio que los usuarios pagan por ellas. En este caso, el precio del kWh puede estar también asociado a la calificación energética de la vivienda, lo cual multiplicaría el efecto del incentivo.

Con los incentivos económicos del tipo comercio de derechos de emisión y modificación de la factura eléctrica, se evita dejar en las arcas públicas el peso de la financiación de las medidas de eficiencia energética.

\subsubsection{Aplicabilidad de la economía experimental}

A lo largo de los tres experimentos realizados en esta tesis, se han respetado las premisas y la metodología de trabajo de la economía experimental. Gracias a ella, se ha determinado en laboratorio la aplicabilidad y el probable grado de éxito de diversas herramientas informativas, y en campo la eficacia tanto de los métodos informativos como de la mezcla de los métodos informativos con los incentivos económicos.

Los resultados, aunque no en todos los casos han coincidido con las expectativas previas que se tenía de ellos, han sido consistentes entre sí, significativos y de aplicación a nivel de la política medioambiental de la Unión Europea, lo que avala el interés de esta herramienta para éste y otros estudios en el campo de la energía.

\subsection{Trabajos futuros}

Tras las conclusiones obtenidas en esta tesis doctoral, quedan abiertas nuevas líneas de investigación, tales como:

\section{Relativas a la economía experimental en laboratorio}

- En lo que se refiere a la economía experimental en laboratorio, se ha abierto una línea de investigación novedosa en cualquiera de sus múltiples ámbitos de aplicación, al haber quedado demostrado a través del experimento no 1 que los sujetos experimentales son capaces de manejarse en entornos virtuales más complejos de lo que nunca se han usado hasta ahora.

- En lo que se refiere específicamente al ámbito de esta tesis, dada la limitación de tiempo, presupuesto y espacios, se probaron una serie de 
tratamientos en un grupo de estudiantes. Queda abierta la posibilidad de organizar otros conjuntos de sesiones experimentales, probando las siguientes variaciones:

- Idénticos escenarios para una población más diversa, formada por ejemplo por miembros de asociaciones de vecinos, para confirmar que los resultados obtenidos son consistentes en ámbitos diferentes.

- Un escenario nuevo consiste en la aplicación de un sistema dinámico de precios.

- Un escenario consistente en la comparación con el IEEC, y con incentivos similares a los propuestos con éste: presión social de la etiqueta y la comparación con los pares, factura asociada al consumo, derechos de emisión y variaciones en los impuestos. Todos ellos combinados con la información proporcionada por distintos tipos de contadores inteligentes, a la búsqueda de la combinación de métodos que demuestre mayor eficacia.

\section{Relativas a la economía experimental en campo}

Los experimentos realizados en campo tienen dos inconvenientes principales: la dificultad de su gestión, y el presupuesto que suponen. Debido a ello, y a pesar del esfuerzo realizado durante el desarrollo de esta tesis, quedan muchas líneas de investigación abiertas en este ámbito.

- En primer lugar, y en relación con los contadores inteligentes, es fundamental profundizar en un diseño óptimo de la herramienta de comunicación con el usuario. Se requieren en este aspecto nuevos experimentos, para determinar:

- La cantidad idónea de información

- La forma más adecuada de presentarla

- La influencia de los mensajes recordatorios, y su periodicidad ideal

- La posibilidad de programar consejos de ahorro individualizados a partir de las lecturas de consumo 
- En segundo lugar, y en relación a los incentivos, quedan abiertas las siguientes líneas de investigación:

- Si es monetario, debe explorarse cuáles son las cantidades de dinero adecuadas para la movilización de los usuarios. Ello permitirá decidir si este tipo de incentivo se puede llevar a cabo mediante un cambio simple, a través de los impuestos, o si requiere un sistema más complejo, que incluya la generación de un sistema autofinanciado.

- Si es social, qué formas de presión son las más adecuadas y hasta qué punto influyen en el comportamiento.

- Por último, la persistencia de los incentivos, sean informativos, sociales o económicos, es un tema en permanente discusión. Es necesaria la organización de una toma de datos a lo largo de al menos un año con posterioridad a la realización de los experimentos, para conocer con detalle su evolución.

\section{Relativas al IEEC}

- El desarrollo exhaustivo y completo del IEEC, cuya existencia permitiría la calificación precisa del comportamiento energético de los abonados en sus viviendas. Ello supone, de forma previa a cualquier otra consideración, un estudio estadístico en profundidad que permita el estudio de la relación entre superficie de la vivienda, número de miembros, calidad de la envolvente térmica, zona climática y consumo energético.

- El estudio de la aplicabilidad del IEEC a diversos sistemas de incentivos tanto sociales como económicos:

- En cuanto a los incentivos sociales, es interesante el estudio del grado de presión social que supone para los abonados el recibir su calificación energética mensual y conocer con precisión su consumo referido al resto de viviendas con iguales características a la suya.

- Dentro de los incentivos económicos asociados a la calificación IEEC, es fundamental el estudio en profundidad del sistema de facturas idóneo para reflejar con más precisión los excesos de consumo energético sin afectar ni a la recaudación total ni a la justicia social, siendo al mismo 
tiempo económicamente viable. El sistema de derechos de emisión a nivel residencial, con una estructura similar a la sugerida para la factura eléctrica, también es una línea de investigación futura de gran interés. 


\section{Bibliografía}

[1] Abbink, K., Brandts, J., \& McDaniel, T. (2003). Asymmetric Demand Information in Uniform and Discriminatory Call Auctions: An Experimental Analysis Motivated by Electricity Markets. Journal of Regulatory Economics, 23(2), 125-144

[2] Abrahamse W,StegL, VlekC, RothengatterT. A review of intervention studies aimed at household energy conservation. JEnvironPsychol 2005;25:273-91.

[3] Adilov, N., Schuler, R.E. Schulze, W. and D.E. Toomey. 2004. "The Effect of customer participation in electricity markets: An experimental analysis of alternative market structures." Proceedings of the 37th Annual Hawaii International Conference on System Sciences.

[4] Adilov, N., Schuler, R.E. Schulze, W., Toomey D.E. and R.Z. Zimmerman. 2005. "Market structure and the predictability of electricity system line flows: An experimental analysis." Presented at 38th Annual Hawaii International Conference on Systems Science, Waikoloa, HI.

[5] Alahmad, Wheeler, Schwer, Eiden, Brumbaugh, "A Comparative Study of Three Feedback Devices for Residential Real-Time Energy Monitoring", IEEE Transactions on industrial electronics, vol. 59, No. 4, april 2012

[6] Albadi, M.H., El-Saadany, E.F., (2008). A summary of demand response in electricity markets. Electric Power Systems Research 78 (2008) 1989-1996

[7] Almeida, Fonseca, Schlomann, Feilberg, "Characterization of the household electricity consumption in the EU, potential energy savings and specific policy recommendations", Energy and Buildings 43 (2011) 1884-1894 
[8] Anderson, Soren T. and Newell, Richard G., Information Programs for Technology Adoption: The Case of Energy-Efficiency Audits, , September 2002, Resources for the Future

[9] Allcott, Hunt, Social norms and energy conservation, Journal of Public Economics 95 (2011 10821095)

[10] Arvola A, Uutela $A$ and Anttila $U$ (1994) Billing feedback as a means of encouraging conservation of electricity in households: a field experiment in Helsinki. Energy and the consumer, Finnish Ministry of Trade and Industry

[11] Aydin Erdal, Kok Nils, Brounen Dirk, Energy Efficiency and Household Behavior: The Rebound Effect in the Residential Sector, October 24, 2015

[12] Ayres, I., Raseman, S., \& Shih, A. (2013). Evidence from two large field experiments that peer comparison feedback can reduce residential energy usage. Journal of Law, Economics, and Organization, 29, 992-1022

[13] Barreda, García, Pavan, Sabater, "Demand response in experimental electricity markets", Revista Internacional de Sociología (RIS) Special Issue Behavioral on and Experimental Economics Vol. 70, extra 1, 127-165, marzo 2012

[14] Battalio, R.C., Kagel, J., Winkler, R.C. and R.A. Winett.1979. "Residential electricity demand: An experimental analysis." Review of Economics and Statistics 61(2):180-189. http://dx.doi.org/10.2307/1924585

[15] Becker, Lawrence J. Joint effect of feedback and goal setting on performance: A field study of residential energy conservation. Journal of Applied Psychology, Vol 63(4), Aug 1978, 428-433

[16] Benders, Kok, Moll, Wiersma, Noorman, "New approaches for household energy conservation-In search of personal household energy budgets and energy reduction options", Energy Policy 34 (2006) 3612-3622

[17] Berry, L., Schweitzer, M., 2003. Metaevaluation of National Weatherization Assistance Program Based on State Studies, 1993-2002. ORNL/CON-488. Oak Ridge National Laboratory, Oak Ridge, TN

[18] Bertoldi, Atanasiu, "Electricity Consumption and Efficiency Trends in European Union, Status Report 2009", JRC, ie (Institute for Energy)

[19] Bertoldi P., Rezessy S., and Boza-Kiss B., Rewarding energy savings rather than energy efficiency: Exploring the concept of a feed-in tariff for energy savings, Energy Policy Volume 56, May 2013, Pages 526-535

[20] Bertoldi P., Serrenho T., Zangheri P., Consumer Feedback Systems: How Much Energy Saving Will They Deliver and for How Long?, 2016 ACEEE Summer Study on Energy Efficiency in Buildings

[21] Boardman, Brenda, Creating a Virtuous Circle for Climate Change with Consumers, Manufacturers and Sufficiency, Energy efficiency in domestic appliances and lighting proceedings of the 4th international conference, eedal'06 21-23 June 2006, London, United Kingdom

[22] Brandon, Lewis, "Reducing household energy consumption: a qualitative and quantitative field study", Journal of Environmental Psychology_1999., pp. 75-85

[23] Brandts J. , La economía experimental y la economía del comportamiento, Instituto de Análisis Económico (CISC), Barcelona Junio 2007

[24] Brandts, J., P. Pezanis-Christou y A. Schram (en prensa), "Competition with Forward Contracts: A Laboratory Analysis Motivated by Electricity Market Design", Economic Journal. 
[25] Brañas, P., Barreda, I. Experimentos en economía.

[26] Brenan, Timothy J., Behavioural economics and energy efficiency regulation, Resources for the Future, July 2016

[27] Brophy Haney, A., Jamasb, T. and M.G. Pollitt. 2009. "Smart metering and electricity demand: Technology, economics and international experience." Cambridge Working Papers in Economics, number 0905.

[28] Brown, Marilyn A., Market failures and barriers as a basis for clean energy policies, Energy Policy 29 (2001) 1197-1207:

[29] Burgess, J., Cross, M., Baker, G. Puja Vohra, The Second Generation of Strategic Energy Management Programs, 2015 ACEEE Summer Study on Energy Efficiency in Industry

[30] Calificación de la eficiencia energética de los edificios. Ministerio de Industria, Energía y Turismo; Ministerio de Fomento, IDAE.

[31] Casarin, Nicollier, "Prepaid Meters in Electricity. A Cost-Benefit Analysis", available at http://www.sandiego.edu/business/documents/Casarin.pdf

[32] Carroll, Ed and Mark Brown. 2009. "Research to Inform Design of Residential Energy Use Behavior Change Pilot." Conservation Improvement Program Presentation for the Minnesota Office of Energy Security. (July) Franklin Energy.

[33]Carroll, Ed, Eric Hatton, and Mark Brown. 2009. "Residential Energy Use Behavior Change Pilot." CMFS project code B21383. (April) Franklin Energy.

[34] Cialdini, Robert B., Carl A. Kallgren, and Raymond R. Reno. 1991. A Focus Theory of Normative Conduct: a Theoretical Refinement and Reevaluation of the Role of Norms in Human Behavior. In Advances in Experimental Social Psychology, ed. M. P. Zanna 24, 201-234. New York, NY: Academic.

[35] Con Edison, CONnectED Home Platforms, Demonstration Project, 2015

[36] Conchado, A. and P. Linares. 2010. "Estimación de los beneficios de la gestión activa de la demanda. Revisión del estado del arte y propuestas." Cuadernos Económicos de ICE 79: 187-212.

[37] Craig, S. and McCann, J. (1978). Assessing communications effects on energy conservation. Journal of Consumer Research 5(2): 82-88.

[38] Customer Engagement Committee, Staff Report on the Work of the Customer Engagement Committee, Reforming the Energy Vision (REV) Working Group I: Customer Engagement July 8, 2014

[39] Delmas, M. A., Fischlein, M., and Asensio, O. I. (2013). Information strategies and energy conservation behavior: A meta-analysis of experimental studies from 1975 to 2012. Energy Policy, 61, 729739

[40] Darby S. The effectiveness of feedback on energy consumption. Oxford, United Kingdom, http://www.defra.gov.uk/ENVIRONMENT/climatechange/uk/ energy/research/pdf/energyconsumpfeedback.pdf; April, 2006.

[41] Darby, "Social learning and public policy: Lessons from an energy-conscious village", Energy Policy 34 (2006) 2929-2940

[42] Dobson and Griffin, Ontario Hydro, "Conservation Effect of Immediate Electricity Cost Feedback on Residential Consumption Behaviour", available at http://aceee.org/proceedingspaper/ss92/panel10/paper06 
[43] Druckman, Jackson, "Household energy consumption in the UK: a highly geographically and socio-economically disaggregated model", Energy Policy, Volume 36, Issue 8, August 2008, Pages 3177-3192

[44] Dünnhoff, E., \& Duscha, M. (2008). Efficient building blocks for energy counseling aimed at reducing electricity consumption in private households. Study by the ifeu (Institut für Energie-und Umweltforschung), Heidelberg (in press)

[45] Dunlap, R. E., Van Liere, K. D., Mertig, A. G., \& Jones, R. E. (2000). New Trends in Measuring Environmental Attitudes: Measuring endorsement of the New Ecological Paradigm: A revised NEP Scale. Journal of Social Issues, 56(3), 425-442. doi: 10.1111/0022-4537.00176

[46] Egan, Kempton, Eide, Lord, Payne. 1996. "How Customers Interpret and Use Comparative Graphics of Their Energy Use". In the Proceedings of the 1996 AC'EEE Summer Study on Energy E@ciency in Buildings. Berkeley, CA: American Council for an Energy-Efficient Economy.

[47] Ehrhardt-Martinez, K., K. Donnelly, and J. Laitner (2010). Advanced metering initiatives and residential feedback programs: A meta-review for household electricity-saving opportunities. Technical Report E105, American Council for an Energy Efficient Economy.

[48] EIA, (Energy Information Administration, U.S.), "International Energy Outlook 2016", DOE/EIA0484(2016) I May 2016

[49] Energy-Efficiency-Watch project "How to make Europe Number 1 in Energy Efficiency. Key results from the Energy-Efficiency-Watch-Project", Brochure presented by the Energy-Efficiency-Watch project

[50]. ESTADO DE LA CERTIFICACIÓN ENERGÉTICA DE LOS EDIFICIOS DATOS CCAA (3o informe) Ministerio de Industria, Energía y Turismo; Ministerio de Fomento, IDAE.

[51] Escala de calificación energética. Edificios de nueva construcción. IDAE

[52] Escala de calificación energética. Edificios existentes. IDAE

[53] Eto J., Kito S., Shown L., Sonnenblick R., Where Did the Money Go? The Cost and Performance of the Largest Commercial Sector DSM Programs, Lawrence Berkeley National Laboratory, Berkeley, 1995

[54] Faruqui, A., Sergici, S., Sharif, A. 2010. The impact of informational feedback on energy consumption-A survey of the experimental evidence. Energy, 35, 1598- 1608

[55] Faruqui, A., Sergici, S. 2011. Dynamic pricing of electricity in the mid-Atlantic region: econometric results from the Baltimore gas and electric company experiment. Journal of Regulatory Economics, 40, 82-109

[56] A. Faruqui and S. Sergici. "Household response to dynamic pricing of electricity: A survey of the experimental evidence," SSRN Report no. 1134132, Social Science Research Network, January 10, 2009. http://papers.ssrn.com/sol3/papers.cfm?abstract id=1134132

[57] Faruqui and Wood, "Quantifying the benefits of dynamic pricing in the mass market", 2008, Edison Electric Institute

[58] Frederiks E., Stenner K., Hobman E., Household energy use: Applying behavioural economics to understand consumer decision-making and behaviour. Renewable and Sustainable Energy Reviews 41(2015)1385-1394

[59] Firth , Lomas, Wright, Wall, "Identifying trends in the use of domestic appliances from household electricity consumption measurements", Energy and Buildings 40 (2008) 926-936 
[60] Fischer, C. 2008. Feedback on household electricity consumption: a tool for saving energy? Energy Efficiency, 1, 79-104

[61] FUNSEAM, "El sistema español de obligaciones de eficiencia energética. un análisis crítico de la transposición de la directiva de eficiencia energética", Mayo 2015

[62] Garay J and Lindholm P (1995) Statistics on the energy bill: better control for the customer. International Energy Program Evaluation Conference, Chicago, August 22-25, 1995

[63] Geller H., Harrington P., Rosenfeld A, Tanishima S., Unander F., Polices for increasing energy efficiency: Thirty years of experience in OECD countries, Energy Policy 34 (2006) 556-573

[64] Gillingham, Newell, and Palmer, ENERGY EFFICIENCY POLICIES: A Retrospective Examination, 2006

[65] Gillingham, Newell, Palmer, (2009) Energy efficiency economics and policy, Energy Efficiency Economics and Policy, working paper 15031

[66] Gillingham, Rapson, and Wagner, The Rebound Effect and Energy Efficiency Policy, Resources for the Future 2014

[67] Gram-Hanssen, Kofod, Petersen, "Different Everyday Lives: Different Patterns of Electricity Use", Pannels of the 2004 ACEEE Summer Study on Energy Efficiency in Buildings

[68] Grande, O.S., H. Saele, and I. Graabak. 2008. Market based demand response research project summary. SINTEF Energy Research

[69] Greening, Greene, Difiglio, Energy efficiency and consumption - the rebound effect - a survey, Energy Policy 28 (6-7) (2000) 389-401

[70] Grupo de trabajo de "certificados blancos", "Documentación de grupo de trabajo "certificados blancos"”, Asociación de Empresas de Eficiencia Energética A3e. Año 2011

[71] Haas, R. and P. Biermayr (2000). The rebound effect for space heating empirical evidence from Austria. Energy Policy 28 (6), 403-410

[72] Haakana, Sillanpää and Talsi, "The Effect of Feedback and Focused Advice on Household EnergyConsumption", Panel4-ID38-p11, available

at: http://www.eceee.org/library/conference proceedings/eceee Summer Studies/1997/Panel 4/p4 6

[73]Henryson, Hakansson, Pyrko, "Energy efficiency in buildings through information - Swedish Perspective", Energy Policy 28 (2000) 169-180

[74] Hirst, E., D. White, and R. Goeltz (1985). Indoor temperature changes in retrofit homes. Energy 10 (7), 861-870

[75] Hydro One, Summary-The Impact of Real-Time Feedback on Residential Electricity Consumption: The Hydro-One Pilot, 2006.

[76] IDAE, "Proyecto sech-spahousec: Análisis del consumo energético del sector residencial en España", julio 2011

[77] IDAE, Informe anual de intensidades energéticas, año 2014,

[78] Iyer, Kempton, Payne," Comparison Groups as a Tool for Evaluating Energy Efficiency Programs: An Analysis of ENERGY STAR@ Billing Comparison Groups"

[79] Internacional Energy Agency, "energy efficiency market report 2016" 
[80] International Energy Agency (IEA), 2002. Energy Efficiency Update-Japan. International Energy Agency, Paris, France www.iea.org/pubs/newslett/eneff/jp.pdf

[81] lyngar, S. and Lepper, M. (2000). When choice is demotivating: can one desire too much of a good thing? Journal of Personality and Social Psychology 79(6): 995-1006

[82] Karbo, Larsen, "Use of online measurement data for electricity savings in Denmark", ECEEE 2005 Summer study - Panel 1. strategies and integrated policies, pp. 161-164

[83] Kelsey, González, "Understanding the Use and Adoption of Home Energy Meters", available at www.eco-eye.co.uk/academic/KelseyGonzalez.pdf

[84] Koomey, J., Sanstad, A.H., Shown, L.J., 1996. Energy-efficiency lighting: market data, market imperfections, and policy success. Contemporary Economic Policy 14(3), 98-111.)

[85] Krietler V. 1991. On customer choice and free ridership in utility programs. CONF-910807. Presented at Int. Energy Program Eval. Conf., 5th, Chicago

[86] Labandeira X. , Linares P. , Energy Efficiency: Economics and Policy, Journal of Economic Surveys - March 2010

[87] Labandeira, Labeaga and López-Otero, Estimation of Elasticity Price of Electricity with Incomplete Information, Economics for Energy, Working Paper 01/2010

[88] Loughran D., J. Kulick, Demand-side management and energy efficiency in the United States, Energy Journal 25 (1) (2004) 19-41

[89] Lopes M.A.R., C.H. Antunes, N. Martins, Energy behaviours as promoters of energy efficiency: A 21st century review, Renewable and Sustainable Energy Reviews 16 (2012) 4095-4104

[90] Madlener, R. and M. Hauertmann (2011). Rebound effects in german residential heating: Do ownership and income matter? Working Paper

[91] Majcen, D., L. Itard, and H. Visscher (2013). Actual and theoretical gas consumption in Dutch dwellings: What causes the differences? Energy Policy 61, 460-471.

[92] Malm E., 1996, An Actions-Based Estimate of the Free Rider Fraction in Electric Utility DSM Programs, The energy journal, Vol. 17, № 3

[93] Mansouri, Newborough, "Dynamics of Energy Use in UK Households: End-use monitoring of Electric Cookers", Panel III, 08

[94] Mansouri, Newborough, Probert, "Energy consumption in UK households: Impact of domestic electrical appliances", Applied Energy, Volume 54, Issue 3, July 1996, ages 211-285

[95] McKenzie-Mohr D., Promoting Sustainable Behavior: An Introduction to Community-Based Social Marketing, Journal of Social Issues, Vol. 56, No. 3, 2000, pp. 543-554

[96] McLoughlin, F. et al., Characterising domestic electricity consumption patterns by dwelling and occupant socio-economic variables: An Irish case study, Energy Buildings (2012),

[97] McLennan Magasanik Associates Pty Ltd, "Showing comparative energy consumption information on customers' bills: Report to Queensland Department of Energy", December 2005

[98] Mendiluce M. y Linares P., Análisis de la evolución de la intensidad energética en España, Economics for Energy

[99] Ministerio de Fomento, "Estrategia a largo plazo para la rehabilitación energética en el sector de la edificación en españa en desarrollo del artículo 4 de la directiva 2012/27/ue". 
[100] Ministerio de Industria, Energía y Turismo, "Plan Nacional de Eficiencia Energética 2014-2020"

[101] Mount, T., Schulze, W., Thomas, R. J., \& Zimmerman, R. (2001). Testing the Performance of Uniform Price and Discriminative Auctions (No. 01-18). Power Systems Engineering Research Center (PSERC). Retrieved from http://www.pserc.wisc.edu/

[102] Murtishaw S, Sathaye J. 2006. Quantifying the effect of the principal-agent problem on US residential use. Work. Pap. LBNL-59773, Lawrence Berkeley Natl. Lab.

[103] Nielsen, "How to get the birds in the bush into your hand", Energy Policy, Nov-1993, pp.11331144

[104] O’Dohertya, Lyonsa, Richard S.J., "Energy-Using Appliances and Energy-Saving Features: Determinants of Ownership in Ireland", Elsevier, Applied Energy Volume 85, Issue 7, July 2008, Pages 650662 Mar-2006

[105] Owen, Ward, "Smart Meters : Commercial, Policy and Regulatory Drivers", Sustainability first,

[106] Pollitt and Shaorshadze, The Role of Behavioural Economics in Energy and Climate Policy, December 2011, EPRG Working Paper 1130, Cambridge Working Paper in Economics 1165

[107] Price, L., X. Wang and J. Yun. 2009. The Challenge of reducing Energy Consumption of the Top1000 Largest Industrial Enterprises in China. Draft paper submitted for the 2009 summer study of the ECEEE.

[108] Rassenti, S., V. Smith y B. Wilson (2002), "Using Experiments to Inform the Privatization/Deregulation Movement in Electricity", The Cato Journal, 22, invierno 2002.

[109] Rassenti, S., V. Smith y B. Wilson (2003), "Controlling Market Power and Price Spikes in Electricity Networks: demand-side bidding", Proceedings of the National Academy of Science, 100, 29983003.

[110] Reiss, Peter, and Matthew White (2008). "What Changes Energy Consumption? Prices and Public Pressure." RAND Journal of Economics, Vol. 39, No. 3 (Autumn), pages 636-663

[111] Rosenow J., Galvin , Evaluating the evaluations: Evidence from energy efficiency programmes in Germany and the UK. Energy and Buildings 62 (2013), 450-458

[112] Rosenow, J., Fawcett, T., Eyre, N., Oikonomou, N. (2016): Energy efficiency and the policy mix. Building Research \& Information. DOI 10.1080/09613218.2016.1138803

[113] Rosenow, J., Platt, R., Demurtas, A., 2014. Fiscal impacts of energy efficiency programmes - the example of solid wall insulation investment in the UK. Energy Policy. DOI: 10.1016/j.enpol.2014.08.007

[114] Rosin, Hõimoja, Möller, Lehtla, "Residential Electricity Consumption and Loads Pattern Analysis", 978-1-4244-6981-9/10/\$26.00 C2010 IEEE

[115] de la Rue du Can S., N. Shah, A. Phadke, Country Review of Energy-Efficiency Financial Incentives in the Residential Sector, 2011, Ernest Orlando Lawrence Berkeley National Laboratory

[116] Schultz, P. Wesley, Jessica M. Nolan, Robert B. Cialdini, Noah J. Goldstein, and Vladas Griskevicius. 2007. The Constructive, Destructive, and Reconstructive Power of Social Norms. Psychological Science 18, $429-34$.

[117] Shogren, F. and Taylor, L. (2008). On behavioral-environmental economics. Review of Environmental Economics and Policy 2(1): 26-44

[118] Sovacool, Benjamin K. 2009. The importance of comprehensiveness in renewable electricity and energy-efficiency policy. Energy Policy 37 (2009) 1529-1541 
[119] Spees K., L. Lave, Demand response and electricity market efficiency, Electricity J. 20 (2007) 69-85

[120] Steemers, GeunYoungYun, "Household energy consumption: a study of the role of occupants", building research \& information (2009) 37(5-6), 625-637

[121] Sunikka-Blank M., \& Galvin R. (2012) Introducing the prebound effect: the gap between performance and actual energy consumption, Building Research \& Information, 40:3, 260-273

[122] TCH, Toronto Hydro Corporation. 2007. Toronto Businesses Cut Summertime Power Consumption by Almost $90 \mathrm{MW}$

[123] R. Thomas, T. Mount, R. Zimmerman, W. Schulze, R. Schuler, L. Chapman, "Testing the Effects of Price Responsive Demand on Pay-as-Offered and Soft-Cap Electricity Auctions," 35th Annual Hawaii International Conference on System Sciences (HICSS'02) - vol. 2,pp.54, 2002

[124] Ueno, Inada, Saeki, Tsuji, "Effectiveness of displaying energy consumption data in residential houses. Analysis on how the residents respond", ECEEE 2005 Summer study, panel 6. dynamics of consumption , pp. 1289-1299

[125] U.S. Department of Energy, Washington, DC 20585, Behavioral Economics Applied to Energy Demand Analysis: A Foundation, October 2014, Independent Statistics \& Analysis www.eia.gov

[126] Williams, Matthews, "Scoping the potential of monitoring and control technologies to reduce energy use in homes", 1-4244-0861-X/07/\$25.00 2007 IEEE

[127] Wilhite, H., Ling, R., 1995. Measured energy savings from a more informative energy bill. Energy and Buildings 22, 145-155

[128] Wilson, C. and Dowlatabadi, H. (2007). Models of decisionmaking and residential energy use. Annual Review of Environmental Resources 32: 169-203)

[129] Wood, Newborough, "Dynamic energy-consumption indicators for domestic appliances: environment, behaviour and design", Energy and Buildings 35 (2003) 821-841

[130] Yohanis, Mondol, Wright, Norton, "Real-life energy use in the UK: How occupancy and dwelling characteristics affect domestic electricity use", Elsevier, Energy and Buildings, Volume 40, Issue 6, 2008, Pages 1053-1059

[131] R. D. Zimmerman, R. J. Thomas, D. Gan, C. Murillo-Sánchez, "An Internet-Based Platform for Testing Generation Scheduling Auctions", in Proceedings of the Hawaii International Conference On System Sciences, January 6-9,1997 


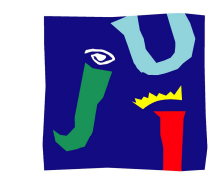

UNIVERSITAT

JAUME• |

Escuela Superior de Tecnología y Ciencias Experimentales

Departamento de Ingeniería de Sistemas Industriales y Diseño

Propuesta y evaluación de tratamientos para la mejora de la eficiencia energética en el sector residencial mediante el desarrollo de experimentos económicos

\author{
Anexos \\ TESIS DOCTORAL DE \\ Nieves García Martín \\ Bajo la dirección de \\ Enrique Belenguer Balaguer \\ Gerardo Sabater Grande
}

Castellón, marzo 2017 



\section{Anexo I. Anexos al Experimento 1}

\section{I.1. Cálculo de las funciones de utilidad}

\section{I.1.1. Definición del equipamiento}

\section{l.1.1.1. Electrodomésticos}

Los electrodomésticos están agrupados en función del modo de uso, en tres grupos que se calculan de forma diferente:

Electrodomésticos de uso por hora.- Son electrodomésticos en los que el usuario tiene libertad para escoger el número diario de horas de uso que quiere darle, como la TV o la iluminación. Estos electrodomésticos se seleccionan y calculan por horas.

Electrodomésticos de uso por ciclo.- Son electrodomésticos cuya duración está preestablecida, como una lavadora o un lavaplatos, que funcionan por ciclos. En este caso, el usuario tiene libertad de elegir el número de ciclos diarios y semanales que desea.

Electrodomésticos no manipulables.- Son electrodomésticos que están permanente en marcha, como el frigorífico o el módem. El usuario no tiene 
ningún control sobre ellos, aunque tienen un consumo y una utilidad asociados.

Unos pocos electrodomésticos, como el calefactor, son estacionales, por lo que su función de utilidad varía en invierno y verano.

\section{I.1.1.2. Iluminación}

La iluminación puede seleccionarse por horas. Tanto en invierno como en verano, al lado de la casilla de selección aparece un símbolo de sol o luna en función de si a esa hora es de día o de noche.

Por defecto, todas las casillas de iluminación están activadas, simulando el hecho de que hay que hacer un esfuerzo consciente para apagar la luz al salir de las habitaciones.

Se han definido los siguientes puntos de luz:

Cocina.- 2 lámparas de bajo consumo de $20 \mathrm{~W}$ cada una

Habitación 1.- 2 lámparas incandescentes de 60 W cada una

Habitación 2.- 2 lámparas incandescentes de $60 \mathrm{~W}$ cada una

Salón.- 8 lámparas incandescentes de 60 W cada una

\section{l.1.1.3. Equipos de climatización}

Se ha simplificado al máximo el funcionamiento de la caldera de calefacción. Se ha querido desagregar el efecto de ésta en el conjunto, dado que es uno de los consumos más importantes y uno, a la vez, de los más complejos. Por esa razón se ha simulado una caldera de gas, con consumo independiente al del resto del hogar, junto con factura independiente.

\section{I.1.1.4. Precios de la energía}

Los precios de la energía, en valores del año 2012, que se han utilizado, son:

\section{Electricidad:}

Precio TUR.................................0,159937 €/kWh

IVA ................................................ $21 \%$

Total precio kWh........................P = 19,352377 c€ / kWh 
Gas

Precio kWh

$0,05810345 € / k W h$

IVA.

$21 \%$

Total precio kWh $0,0703051745 \mathrm{c€} / \mathrm{kWh}$

\section{I.1.1.5. Stand-by}

Los electrodomésticos susceptibles de tener un stand-by (lavadora y lavavajillas, ordenadores, todo lo relacionado con el ocio), tienen una casilla de selección para el stand-by. Por defecto se encuentra activada.

En principio, el sujeto no tiene ningún aliciente para eliminar el standby; de hecho, el no hacerlo le supone una utilidad determinada. Ahora bien, ésta está calculada de forma que en realidad, si no se desactiva la casilla, el beneficio es negativo.

\subsubsection{Cálculo de las funciones de utilidad de cada electrodoméstico, iluminación o equipo de climatización}

Todas las utilidades están calculadas en céntimos de euro mensuales. Los electrodomésticos generan unos beneficios que son proporcionales al grado de necesidad básica que supone el electrodoméstico. Además, si un electrodoméstico se puede programar en distintos ciclos, el beneficio máximo sólo se obtiene con el ciclo más ahorrativo.

En concreto, se han calculado utilidades de forma que los beneficios máximos (utilizando de forma óptima todos los electrodomésticos) sean los siguientes:

Calefacción supone un beneficio de 150 c€

Lavadora, vitrocerámica, ACS e iluminación, 75 c€

Lavaplatos, plancha, horno, microondas, tostadora, $50 \mathrm{c€}$

Ocio, horno en verano, 25 c€ 


\begin{tabular}{ccccc} 
Electrodoméstico & Ciclos & Llano & Utilidad & Beneficio \\
\hline Lavadora & Frío & 37,16 & 112,16 & 75 \\
Lavaplatos & Rápido & 368,47 & 418,47 & 50 \\
Plancha & & 17,34 & 67,34 & 50 \\
TV & & 313,51 & 338,51 & 25 \\
Equipo música & & 22,47 & 47,47 & 25 \\
Ord fijo & & 478,97 & 503,97 & 25 \\
Ord portátil & & 80,99 & 105,99 & 25 \\
Horno & Invierno & 232,23 & 282,23 & 50 \\
& Verano & 232,23 & 257,23 & 25 \\
Microondas & Desayuno & 21,08 & 71,08 & 50 \\
Tostador & Otros & 112,24 & 162,24 & 50 \\
Vitrocerámica & & 49,85 & 99,85 & 50 \\
ACS & & 130,05 & 205,05 & 75 \\
& Ducha 1 & 520,19 & 595,19 & 75 \\
Iluminación & Cocina & 69,67 & 144,67 & 75 \\
& Salón & 418,01 & 493,01 & 75 \\
Calefacción & Habitaciones & 348,34 & 423,34 & 75 \\
& Central & 6989 & 7160 & 171 \\
& Calefactor & 540 & 690 & 150 \\
\hline
\end{tabular}

Tabla I.1.- Resumen de valores en el punto óptimo del equipamiento y los equipos de climatización

Por último, los stand-by se calculan de forma que, aunque el participante pueda sentir cierta satisfacción al no molestarse en apagar un electrodoméstico, el beneficio salga ligeramente negativo (prácticamente 0 ) al ser el consumo del mismo orden que la utilidad.

\section{I.1.2.1. Simbología y unidades de medida}

En todas las tablas que siguen, se utiliza la siguiente simbología y las unidades de medida aquí indicadas: 
$\mathrm{S}=4$ semanas $/$ mes

$\mathrm{N}=$ Número de ciclos/semana

$\mathrm{C}=$ consumo medio del electrodoméstico, en $\mathrm{kWh} / \mathrm{ciclo}$

$P=$ precio del $k W h$ incluyendo impuestos $=19,352377$ céntimos de euro

$\mathrm{G}=$ gasto mensual en céntimos de euro $=\mathrm{C} * \mathrm{~N} * \mathrm{~S} * \mathrm{P}$

$\mathrm{U}=$ utilidad en céntimos de euro

$\mathrm{B}=$ beneficio (utilidad - gasto)

$\mathrm{CS}=$ Consumo del stand-by, en $\mathrm{kW}$

$\mathrm{H}=$ horas mensuales en stand-by (si no se selecciona la opción Apagado Total)

GS = Gasto mensual en stand-by en céntimos de euro

En la columna "gasto" se calcula el precio de la energía en c€ en función del número de horas diarias de uso o del número de ciclos por semana, según el tipo de electrodoméstico.

En la columna "utilidad", se calcula la utilidad en c€ de forma que sea máxima en el uso más razonable y menor en cualquier otro. El uso que se ha considerado más razonable está marcado en color gris. La forma de la función de utilidad es la siguiente: 2 líneas rectas de pendientes diferentes; la primera parte de 0 y alcanza su máximo en el uso más razonable; la segunda parte de ahí y termina, a la altura del uso

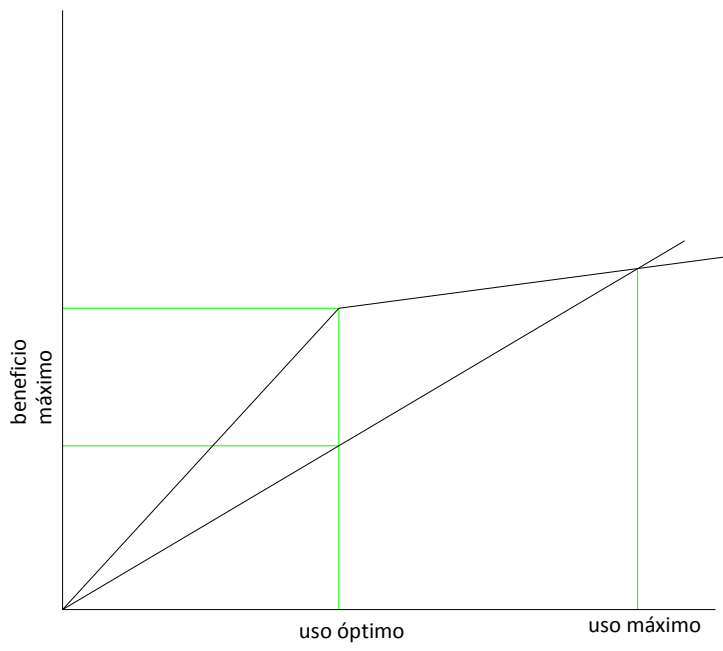
máximo, coincidiendo casi con el gasto en ese punto. Es decir, su forma es similar a la de la figura en todos los casos.

En la columna "beneficio" se calcula en c€ la diferencia entre utilidad y gasto. 


\section{l.1.2.2. Lavadora}

Este electrodoméstico tiene un uso en forma de ciclo, siendo su consumo un número determinado de $\mathrm{kWh} / \mathrm{ciclo}$. Dentro de la lavadora, existen 3 posibles ciclos, unos más ahorrativos que otros. La lavadora, al igual que todos los electrodomésticos de uso por ciclo, está programada de forma que el usuario puede elegir el número de ciclos por semana y el tipo de ciclo.

Para este electrodoméstico, vamos a permitir un uso máximo semanal de 14 ciclos ( 2 veces al día). Este punto marcará el beneficio 0 . Usos mayores, que no tienen mucho sentido, se impiden por programación mediante la inutilización de las casillas "hora de inicio".

Se ha decidido arbitrariamente que, en la vivienda tipo en la que nos encontramos, el número de habitantes es tal que sólo es necesario poner la lavadora 4 veces por semana. Se calcula el valor de la utilidad de tal forma que el beneficio sea máximo si y sólo si se usa 4 veces por semana y en el ciclo más ahorrador. En cualquier otra combinación, el beneficio será menor.

Con estas premisas, la definición de las funciones de utilidad queda como sigue:

\begin{tabular}{cccccc} 
Ciclo & Consumo & Ciclos/semana & Gasto & Utilidad & Beneficio \\
\hline Frío & 0,12 & 0 & 0 & 0 & 0 \\
Frío & 0,12 & 1 & 9,29 & 28 & 18,71 \\
\hline Frío & 0,12 & 2 & 18,58 & 56 & 37,42 \\
\hline Frío & 0,12 & 3 & 27,87 & 84 & 56,13 \\
\hline Frío & 0,12 & 4 & 37,16 & 112 & 74,84 \\
\hline Frío & 0,12 & 5 & 46,45 & 113,8 & 67,35 \\
\hline Frío & 0,12 & 6 & 55,73 & 115,6 & 59,87 \\
\hline Frío & 0,12 & 7 & 65,02 & 117,4 & 52,38 \\
Frío & 0,12 & 8 & 74,31 & 119,2 & 44,89 \\
Frío & 0,12 & 9 & 83,6 & 121 & 37,4 \\
Frío & 0,12 & 10 & 92,89 & 122,8 & 29,91 \\
Frío & 0,12 & 11 & 102,18 & 124,6 & 22,42 \\
Frío & 0,12 & 12 & 111,47 & 126,4 & 14,93
\end{tabular}




\begin{tabular}{cccccc} 
Frío & 0,12 & 13 & 120,76 & 128,2 & 7,44 \\
Frío & 0,12 & 14 & 130,05 & 130 & $-0,05$ \\
\hline
\end{tabular}

Tabla I.2.- Función de utilidad de la lavadora en el ciclo frío

\begin{tabular}{|c|c|c|c|c|c|}
\hline Ciclo & Consumo & Ciclos/semana & Gasto & Utilidad & Beneficio \\
\hline $60 \circ$ & 0,45 & 0 & 0 & 0 & 0 \\
\hline $60 \circ$ & 0,45 & 1 & 34,83 & 41 & 6,17 \\
\hline 60 은 & 0,45 & 2 & 69,67 & 82 & 12,33 \\
\hline $60 \circ$ & 0,45 & 3 & 104,5 & 123 & 18,5 \\
\hline $60 \circ$ & 0,45 & 4 & 139,34 & 164 & 24,66 \\
\hline 60 은 & 0,45 & 5 & 174,17 & 196,4 & 22,23 \\
\hline 60 은 & 0,45 & 6 & 209,01 & 228,8 & 19,79 \\
\hline $60 \circ$ & 0,45 & 7 & 243,84 & 261,2 & 17,36 \\
\hline 60 은 & 0,45 & 8 & 278,67 & 293,6 & 14,93 \\
\hline $60 \circ$ & 0,45 & 9 & 313,51 & 326 & 12,49 \\
\hline 60 은 & 0,45 & 10 & 348,34 & 358,4 & 10,06 \\
\hline $60 \%$ & 0,45 & 11 & 383,18 & 390,8 & 7,62 \\
\hline $60 \%$ & 0,45 & 12 & 418,01 & 423,2 & 5,19 \\
\hline 60 은 & 0,45 & 13 & 452,85 & 455,6 & 2,75 \\
\hline $60 \circ$ & 0,45 & 14 & 487,68 & 488 & 0,32 \\
\hline
\end{tabular}

Tabla I.3.- Función de utilidad de la lavadora en el ciclo 60 응

\begin{tabular}{|c|c|c|c|c|c|}
\hline Ciclo & Consumo & Ciclos/semana & Gasto & Utilidad & Beneficio \\
\hline 40 은 & 0,19 & 0 & 0 & 0 & 0 \\
\hline 40 은 & 0,19 & 1 & 14,71 & 27,25 & 12,54 \\
\hline 40 은 & 0,19 & 2 & 29,42 & 54,5 & 25,08 \\
\hline 40 은 & 0,19 & 3 & 44,12 & 81,75 & 37,63 \\
\hline 40 은 & 0,19 & 4 & 58,83 & 109 & 50,17 \\
\hline 40 은 & 0,19 & 5 & 73,54 & 118,7 & 45,16 \\
\hline 40 은 & 0,19 & 6 & 88,25 & 128,4 & 40,15 \\
\hline 40 은 & 0,19 & 7 & 102,95 & 138,1 & 35,15 \\
\hline
\end{tabular}




\begin{tabular}{|c|c|c|c|c|c|}
\hline 40 은 & 0,19 & 8 & 117,66 & 147,8 & 30,14 \\
\hline 40응 & 0,19 & 9 & 132,37 & 157,5 & 25,13 \\
\hline 40 은 & 0,19 & 10 & 147,08 & 167,2 & 20,12 \\
\hline 40 은 & 0,19 & 11 & 161,79 & 176,9 & 15,11 \\
\hline 40 은 & 0,19 & 12 & 176,49 & 186,6 & 10,11 \\
\hline 40 은 & 0,19 & 13 & 191,2 & 196,3 & 5,1 \\
\hline 40 은 & 0,19 & 14 & 205,91 & 206 & 0,09 \\
\hline
\end{tabular}

Tabla I.4.- Función de utilidad de la lavadora en el ciclo de 40 o

\begin{tabular}{ccccc}
$\begin{array}{c}\text { Consumo } \\
\text { Stand-by }\end{array}$ & $\begin{array}{c}\text { Horas } \\
\text { Stand-by }\end{array}$ & $\begin{array}{c}\text { Gasto } \\
\text { stand-by }\end{array}$ & $\begin{array}{c}\text { Utilidad } \\
\text { stand-by }\end{array}$ & Beneficio \\
\hline 0,00145 & 720 & 20,2 & 19 & $-1,2$ \\
0,00145 & 712 & 19,98 & 18,79 & $-1,19$ \\
0,00145 & 704 & 19,75 & 18,57 & $-1,18$ \\
0,00145 & 696 & 19,53 & 18,36 & $-1,17$ \\
0,00145 & 688 & 19,31 & 18,14 & $-1,16$ \\
0,00145 & 680 & 19,08 & 17,93 & $-1,15$ \\
0,00145 & 672 & 18,86 & 17,71 & $-1,14$ \\
0,00145 & 664 & 18,63 & 17,50 & $-1,13$ \\
0,00145 & 656 & 18,41 & 17,29 & $-1,12$ \\
0,00145 & 648 & 18,18 & 17,07 & $-1,11$ \\
0,00145 & 640 & 17,96 & 16,86 & $-1,1$ \\
0,00145 & 632 & 17,73 & 16,64 & $-1,09$ \\
0,00145 & 624 & 17,51 & 16,43 & $-1,08$ \\
0,00145 & 616 & 17,29 & 16,21 & $-1,07$ \\
0,00145 & 608 & 17,06 & 16 & $-1,06$ \\
\hline
\end{tabular}

Tabla I.5.- Función de utilidad de la lavadora en modo stand-by

Al tener más utilidad, lavar en el ciclo menos ahorrador, esto puede engañar al sujeto, que prefiera en principio lavar a 60ㅇ, y puede servir como consejo de ahorro para cualquiera. Este mismo sistema se utiliza en todos los electrodomésticos con varias posibilidades de uso. 


\subsubsection{Lavavajillas}

Este electrodoméstico tiene un uso en forma de ciclo, siendo su consumo un número determinado de $\mathrm{kWh} / \mathrm{ciclo}$. Dentro del lavavajillas, existen 2 posibles ciclos, unos más ahorrativos que otros. El lavavajillas, al igual que todos los electrodomésticos de uso por ciclo, está programada de forma que el usuario puede elegir el número de ciclos por semana y el tipo de ciclo.

Para este electrodoméstico, vamos a permitir un uso máximo semanal de 14 ciclos ( 2 veces al día). Este punto marcará el beneficio 0 . Usos mayores, que no tienen mucho sentido, se impiden por programación mediante la inutilización de las casillas "hora de inicio".

Se ha decidido arbitrariamente que, en la vivienda tipo en la que nos encontramos, el número de habitantes es tal que sólo es necesario poner el lavavajillas 7 veces por semana. Se calcula el valor de la utilidad de tal forma que el beneficio sea máximo si y sólo si se usa 7 veces por semana y en el ciclo más ahorrador. En cualquier otra combinación, el beneficio será menor.

Con estas premisas, la definición de las funciones de utilidad queda como sigue:

\begin{tabular}{cccccc} 
Ciclo & Consumo & Ciclos/semana & Gasto & Utilidad & Beneficio \\
\hline Modo ECO & 0,88 & 0 & 0 & 0 & 0 \\
Modo ECO & 0,88 & 1 & 68,12 & 71,57 & 3,45 \\
Modo ECO & 0,88 & 2 & 136,24 & 143,14 & 6,9 \\
Modo ECO & 0,88 & 3 & 204,36 & 214,71 & 10,35 \\
Modo ECO & 0,88 & 4 & 272,48 & 286,29 & 13,8 \\
Modo ECO & 0,88 & 5 & 340,6 & 357,86 & 17,26 \\
Modo ECO & 0,88 & 6 & 408,72 & 429,43 & 20,71 \\
Modo ECO & 0,88 & 7 & 476,84 & 501,00 & 24,16 \\
Modo ECO & 0,88 & 8 & 544,96 & 565,71 & 20,75 \\
Modo ECO & 0,88 & 9 & 613,08 & 630,43 & 17,35 \\
Modo ECO & 0,88 & 10 & 681,2 & 695,14 & 13,94 \\
Modo ECO & 0,88 & 11 & 749,32 & 759,86 & 10,53 \\
Modo ECO & 0,88 & 12 & 817,44 & 824,57 & 7,13 \\
Modo ECO & 0,88 & 13 & 885,56 & 889,29 & 3,72 \\
Modo ECO & 0,88 & 14 & 953,69 & 954 & 0,31 \\
\hline
\end{tabular}

Tabla I.6.- Función de utilidad del lavavajillas en modo ECO 


\begin{tabular}{cccccc} 
Ciclo & Consumo & Ciclos/semana & Gasto & Utilidad & Beneficio \\
\hline Modo rápido & 0,68 & 0 & 0 & 0 & 0 \\
Modo rápido & 0,68 & 1 & 52,64 & 59,86 & 7,22 \\
Modo rápido & 0,68 & 2 & 105,28 & 119,71 & 14,44 \\
Modo rápido & 0,68 & 3 & 157,92 & 179,57 & 21,66 \\
Modo rápido & 0,68 & 4 & 210,55 & 239,43 & 28,87 \\
Modo rápido & 0,68 & 5 & 263,19 & 299,29 & 36,09 \\
Modo rápido & 0,68 & 6 & 315,83 & 359,14 & 43,31 \\
Modo rápido & 0,68 & 7 & 368,47 & 419,00 & 50,53 \\
Modo rápido & 0,68 & 8 & 421,11 & 464,43 & 43,32 \\
Modo rápido & 0,68 & 9 & 473,75 & 509,86 & 36,11 \\
Modo rápido & 0,68 & 10 & 526,38 & 555,29 & 28,9 \\
Modo rápido & 0,68 & 11 & 579,02 & 600,71 & 21,69 \\
Modo rápido & 0,68 & 12 & 631,66 & 646,14 & 14,48 \\
Modo rápido & 0,68 & 13 & 684,3 & 691,57 & 7,27 \\
Modo rápido & 0,68 & 14 & 736,94 & 737 & 0,06 \\
\hline
\end{tabular}

Tabla I.7.- Función de utilidad del lavavajillas en modo rápido

\begin{tabular}{ccccc} 
Consumo Stand-by & $\begin{array}{c}\text { Horas Stand- } \\
\text { by }\end{array}$ & $\begin{array}{c}\text { Gasto Stand- } \\
\text { by }\end{array}$ & $\begin{array}{c}\text { Utilidad } \\
\text { Stand-by }\end{array}$ & Beneficio \\
\hline 0,00214 & 720 & 29,82 & 29 & $-0,82$ \\
0,00214 & 712 & 29,49 & 28,66 & $-0,83$ \\
0,00214 & 704 & 29,16 & 28,31 & $-0,84$ \\
0,00214 & 696 & 28,82 & 27,97 & $-0,85$ \\
0,00214 & 688 & 28,49 & 27,63 & $-0,86$ \\
0,00214 & 680 & 28,16 & 27,29 & $-0,88$ \\
0,00214 & 672 & 27,83 & 26,94 & $-0,89$ \\
0,00214 & 664 & 27,5 & 26,60 & $-0,9$ \\
0,00214 & 656 & 27,17 & 26,26 & $-0,91$ \\
0,00214 & 648 & 26,84 & 25,91 & $-0,92$ \\
0,00214 & 640 & 26,51 & 25,57 & $-0,93$ \\
0,00214 & 632 & 26,17 & 25,23 & $-0,95$ \\
0,00214 & 624 & 25,84 & 24,89 & $-0,96$ \\
0,00214 & 616 & 25,51 & 24,54 & $-0,97$
\end{tabular}




\subsubsection{Plancha}

Este electrodoméstico tiene un uso en forma de ciclo, siendo su consumo un número determinado de $\mathrm{kWh} / \mathrm{ciclo}$. Dentro del lavavajillas, existen 2 posibles ciclos, unos más ahorrativos que otros. El lavavajillas, al igual que todos los electrodomésticos de uso por ciclo, está programada de forma que el usuario puede elegir el número de ciclos por semana y el tipo de ciclo.

Se ha decidido arbitrariamente que, en la vivienda tipo en la que nos encontramos, el número de habitantes es tal que sólo es necesario poner poner la plancha 1 vez por semana, durante 1 hora. Eso supone un consumo por uso de $0.224 \mathrm{kWh} /$ ciclo. No se dan más opciones que un planchado de 1 hora, así que en este caso sólo hay un modo de uso. No se permiten más de 7 planchas por semana.

En este caso no existe la posibilidad de stand-by.

\begin{tabular}{cccccc} 
Ciclo & consumo & Usos/semana & Gasto & Utilidad & Beneficio \\
\hline 1 hora & 0,224 & 0 & 0 & 0 & 0 \\
1 hora & 0,224 & 1 & 17,34 & 67 & 49,66 \\
\hline 1 hora & 0,224 & 2 & 34,68 & 76,17 & 41,49 \\
1 hora & 0,224 & 3 & 52,02 & 85,33 & 33,31 \\
1 hora & 0,224 & 4 & 69,36 & 94,50 & 25,14 \\
1 hora & 0,224 & 5 & 86,7 & 103,67 & 16,97 \\
1 hora & 0,224 & 6 & 104,04 & 112,83 & 8,79 \\
1 hora & 0,224 & 7 & 121,38 & 122 & 0,62 \\
\hline
\end{tabular}

Tabla I.9.- Función de utilidad de la plancha

\subsubsection{Ocio}

Dentro del apartado denominado ocio se encuentran la TV, los ordenadores y el equipo de música. Todos ellos disponen de stand-by o modo de espera, y todos se seleccionan por número de horas diarias de uso. Inicialmente, se hizo un cálculo diferente del número de horas óptimo en función de si el día era laborable o festivo; finalmente, al decidirse la 
eliminación de los días festivos, fue suficiente con una única función de utilidad.

\begin{tabular}{|c|c|c|c|c|c|}
\hline Equipo & Consumo & Horas & Gasto & Utilidad & Beneficio \\
\hline & 135 & 0 & 0 & 0 & 0 \\
\hline & 135 & 1 & 78,377 & 84,75 & 6,4 \\
\hline & 135 & 2 & 156,75 & 169,5 & 13 \\
\hline & 135 & 3 & 235,13 & 254,25 & 19 \\
\hline & 135 & 4 & 313,51 & 339 & 25 \\
\hline & 135 & 5 & 391,89 & 416,1 & 24 \\
\hline & 135 & 6 & 470,26 & 493,2 & 23 \\
\hline & 135 & 7 & 548,64 & 570,3 & 22 \\
\hline & 135 & 8 & 627,02 & 647,4 & 20 \\
\hline & 135 & 9 & 705,39 & 724,5 & 19 \\
\hline & 135 & 10 & 783,77 & 801,6 & 18 \\
\hline & 135 & 11 & 862,15 & 878,7 & 17 \\
\hline \multirow[t]{13}{*}{ TV } & 135 & 12 & 940,53 & 955,8 & 15 \\
\hline & 135 & 13 & 1018,9 & 1032,9 & 14 \\
\hline & 135 & 14 & 1097,3 & 1110 & 13 \\
\hline & 135 & 15 & 1175,7 & 1187,1 & 11 \\
\hline & 135 & 16 & 1254 & 1264,2 & 10 \\
\hline & 135 & 17 & 1332,4 & 1341,3 & 8,9 \\
\hline & 135 & 18 & 1410,8 & 1418,4 & 7,6 \\
\hline & 135 & 19 & 1489,2 & 1495,5 & 6,3 \\
\hline & 135 & 20 & 1567,5 & 1572,6 & 5,1 \\
\hline & 135 & 21 & 1645,9 & 1649,7 & 3,8 \\
\hline & 135 & 22 & 1724,3 & 1726,8 & 2,5 \\
\hline & 135 & 23 & 1802,7 & 1803,9 & 1,2 \\
\hline & 135 & 24 & 1881,1 & 1881 & $-0,1$ \\
\hline Equipo & $\begin{array}{l}\text { Consumo } \\
\text { Stand-by }\end{array}$ & $\begin{array}{c}\text { Horas } \\
\text { Stand-by }\end{array}$ & $\begin{array}{l}\text { Gasto } \\
\text { stand-by }\end{array}$ & $\begin{array}{l}\text { Utilidad } \\
\text { stand-by }\end{array}$ & Beneficio \\
\hline \multirow[t]{4}{*}{ TV } & 0,0024 & 24 & 33,4409 & 33 & $-0,44091$ \\
\hline & 0,0024 & 23 & 32,0475 & 31,625 & $-0,42254$ \\
\hline & 0,0024 & 22 & 30,6542 & 30,25 & $-0,40417$ \\
\hline & 0,0024 & 21 & 29,2608 & 28,875 & $-0,38579$ \\
\hline
\end{tabular}




\begin{tabular}{ccccc}
0,0024 & 20 & 27,8674 & 27,5 & $-0,36742$ \\
0,0024 & 19 & 26,4741 & 26,125 & $-0,34905$ \\
0,0024 & 18 & 25,0807 & 24,75 & $-0,33068$ \\
0,0024 & 17 & 23,6873 & 23,375 & $-0,31231$ \\
0,0024 & 16 & 22,2939 & 22 & $-0,29394$ \\
0,0024 & 15 & 20,9006 & 20,625 & $-0,27557$ \\
0,0024 & 14 & 19,5072 & 19,25 & $-0,2572$ \\
0,0024 & 13 & 18,1138 & 17,875 & $-0,23882$ \\
0,0024 & 12 & 16,7205 & 16,5 & $-0,22045$ \\
0,0024 & 11 & 15,3271 & 15,125 & $-0,20208$ \\
0,0024 & 10 & 13,9337 & 13,75 & $-0,18371$ \\
0,0024 & 9 & 12,5403 & 12,375 & $-0,16534$ \\
0,0024 & 8 & 11,147 & 11 & $-0,14697$ \\
0,0024 & 7 & 9,7536 & 9,625 & $-0,1286$ \\
0,0024 & 6 & 8,36023 & 8,25 & $-0,11023$ \\
0,0024 & 5 & 6,96686 & 6,875 & $-0,09186$ \\
0,0024 & 4 & 5,57348 & 5,5 & $-0,07348$ \\
0,0024 & 3 & 4,18011 & 4,125 & $-0,05511$ \\
0,0024 & 2 & 2,78674 & 2,75 & $-0,03674$ \\
0,0024 & 1 & 1,39337 & 1,375 & $-0,01837$ \\
0,0024 & 0 & 0 & 0 & 0 \\
\hline
\end{tabular}

Tabla I.10.- Función de utilidad del televisor

\begin{tabular}{llllll} 
Equipo & Consumo & Horas & Gasto & Utilidad & Beneficio \\
\hline Equipo & 7,74 & 0 & 0 & 0 & 0 \\
música & 7,74 & 1 & 4,4936 & 9,6 & 5,1 \\
& 7,74 & 2 & 8,9872 & 19,2 & 10 \\
& 7,74 & 3 & 13,481 & 28,8 & 15 \\
& 7,74 & 4 & 17,974 & 38,4 & 20 \\
& 7,74 & 5 & 22,468 & 48 & 26 \\
& 7,74 & 6 & 26,962 & 51,1579 & 24 \\
& 7,74 & 7 & 31,455 & 54,3158 & 23 \\
& 7,74 & 8 & 35,949 & 57,4737 & 22 \\
& 7,74 & 9 & 40,443 & 60,6316 & 20 \\
\hline
\end{tabular}




\begin{tabular}{|c|c|c|c|c|}
\hline 7,74 & 10 & 44,936 & 63,7895 & 19 \\
\hline 7,74 & 11 & 49,43 & 66,9474 & 18 \\
\hline 7,74 & 12 & 53,923 & 70,1053 & 16 \\
\hline 7,74 & 13 & 58,417 & 73,2632 & 15 \\
\hline 7,74 & 14 & 62,911 & 76,4211 & 14 \\
\hline 7,74 & 15 & 67,404 & 79,5789 & 12 \\
\hline 7,74 & 16 & 71,898 & 82,7368 & 11 \\
\hline 7,74 & 17 & 76,392 & 85,8947 & 9,5 \\
\hline 7,74 & 18 & 80,885 & 89,0526 & 8,2 \\
\hline 7,74 & 19 & 85,379 & 92,2105 & 6,8 \\
\hline 7,74 & 20 & 89,872 & 95,3684 & 5,5 \\
\hline 7,74 & 21 & 94,366 & 98,5263 & 4,2 \\
\hline 7,74 & 22 & 98,86 & 101,684 & 2,8 \\
\hline 7,74 & 23 & 103,35 & 104,842 & 1,5 \\
\hline 7,74 & 24 & 107,85 & 108 & 0,2 \\
\hline $\begin{array}{l}\text { Consumo } \\
\text { Stand-by }\end{array}$ & $\begin{array}{l}\text { Horas } \\
\text { Stand-by }\end{array}$ & $\begin{array}{l}\text { Gasto } \\
\text { stand-by }\end{array}$ & $\begin{array}{l}\text { Utilidad } \\
\text { stand-by }\end{array}$ & Beneficio \\
\hline 0,004 & 24 & 55,7348 & 55 & $-0,73485$ \\
\hline 0,004 & 23 & 53,4126 & 52,7083 & $-0,70423$ \\
\hline 0,004 & 22 & 51,0903 & 50,4167 & $-0,67361$ \\
\hline 0,004 & 21 & 48,768 & 48,125 & $-0,64299$ \\
\hline 0,004 & 20 & 46,4457 & 45,8333 & $-0,61237$ \\
\hline 0,004 & 19 & 44,1234 & 43,5417 & $-0,58175$ \\
\hline 0,004 & 18 & 41,8011 & 41,25 & $-0,55113$ \\
\hline 0,004 & 17 & 39,4788 & 38,9583 & $-0,52052$ \\
\hline 0,004 & 16 & 37,1566 & 36,6667 & $-0,4899$ \\
\hline 0,004 & 15 & 34,8343 & 34,375 & $-0,45928$ \\
\hline 0,004 & 14 & 32,512 & 32,0833 & $-0,42866$ \\
\hline 0,004 & 13 & 30,1897 & 29,7917 & $-0,39804$ \\
\hline 0,004 & 12 & 27,8674 & 27,5 & $-0,36742$ \\
\hline 0,004 & 11 & 25,5451 & 25,2083 & $-0,3368$ \\
\hline 0,004 & 10 & 23,2229 & 22,9167 & $-0,30619$ \\
\hline 0,004 & 9 & 20,9006 & 20,625 & $-0,27557$ \\
\hline 0,004 & 8 & 18,5783 & 18,3333 & $-0,24495$ \\
\hline 0,004 & 7 & 16,256 & 16,0417 & $-0,21433$ \\
\hline
\end{tabular}




\begin{tabular}{|c|c|c|c|c|c|}
\hline & 0,004 & 6 & 13,9337 & 13,75 & $-0,18371$ \\
\hline & 0,004 & 5 & 11,6114 & 11,4583 & $-0,15309$ \\
\hline & 0,004 & 4 & 9,28914 & 9,16667 & $-0,12247$ \\
\hline & 0,004 & 3 & 6,96686 & 6,875 & $-0,09186$ \\
\hline & 0,004 & 2 & 4,64457 & 4,58333 & $-0,06124$ \\
\hline & 0,004 & 1 & 2,32229 & 2,29167 & $-0,03062$ \\
\hline & 0,004 & 0 & 0 & 0 & 0 \\
\hline \multicolumn{6}{|c|}{ Tabla I.11.- Función de utilidad del equipos de música } \\
\hline Equipo & C & $\mathrm{H}$ & G & $\mathrm{U}$ & B \\
\hline \multirow{25}{*}{$\begin{array}{l}\text { Ordenador } \\
\text { fijo }\end{array}$} & 165 & 0 & 0 & 0 & 0 \\
\hline & 165 & 1 & 95,794 & 100,8 & 5 \\
\hline & 165 & 2 & 191,59 & 201,6 & 10 \\
\hline & 165 & 3 & 287,38 & 302,4 & 15 \\
\hline & 165 & 4 & 383,18 & 403,2 & 20 \\
\hline & 165 & 5 & 478,97 & 504 & 25 \\
\hline & 165 & 6 & 574,77 & 598,474 & 24 \\
\hline & 165 & 7 & 670,56 & 692,947 & 22 \\
\hline & 165 & 8 & 766,35 & 787,421 & 21 \\
\hline & 165 & 9 & 862,15 & 881,895 & 20 \\
\hline & 165 & 10 & 957,94 & 976,368 & 18 \\
\hline & 165 & 11 & 1053,7 & 1070,84 & 17 \\
\hline & 165 & 12 & 1149,5 & 1165,32 & 16 \\
\hline & 165 & 13 & 1245,3 & 1259,79 & 14 \\
\hline & 165 & 14 & 1341,1 & 1354,26 & 13 \\
\hline & 165 & 15 & 1436,9 & 1448,74 & 12 \\
\hline & 165 & 16 & 1532,7 & 1543,21 & 11 \\
\hline & 165 & 17 & 1628,5 & 1637,68 & 9,2 \\
\hline & 165 & 18 & 1724,3 & 1732,16 & 7,9 \\
\hline & 165 & 19 & 1820,1 & 1826,63 & 6,5 \\
\hline & 165 & 20 & 1915,9 & 1921,11 & 5,2 \\
\hline & 165 & 21 & 2011,7 & 2015,58 & 3,9 \\
\hline & 165 & 22 & 2107,5 & 2110,05 & 2,6 \\
\hline & 165 & 23 & 2203,3 & 2204,53 & 1,3 \\
\hline & 165 & 24 & 2299,1 & 2299 & $-0,1$ \\
\hline
\end{tabular}

Tabla I.12.- Función de utilidad del ordenador fijo 


\begin{tabular}{llllll} 
Equipo & Consumo & Horas & Gasto & Utilidad & Beneficio \\
\hline Ordenador & 27,9 & 0 & 0 & 0 & 0 \\
portátil & 27,9 & 1 & 16,198 & 21,2 & 5 \\
& 27,9 & 2 & 32,396 & 42,4 & 10 \\
& 27,9 & 3 & 48,594 & 63,6 & 15 \\
& 27,9 & 4 & 64,792 & 84,8 & 20 \\
& 27,9 & 5 & 80,99 & 106 & 25 \\
& 27,9 & 6 & 97,188 & 120,895 & 24 \\
& 27,9 & 7 & 113,39 & 135,789 & 22 \\
& 27,9 & 8 & 129,58 & 150,684 & 21 \\
& 27,9 & 9 & 145,78 & 165,579 & 20 \\
& 27,9 & 10 & 161,98 & 180,474 & 18 \\
& 27,9 & 11 & 178,18 & 195,368 & 17 \\
& 27,9 & 12 & 194,38 & 210,263 & 16 \\
& 27,9 & 13 & 210,57 & 225,158 & 15 \\
& 27,9 & 14 & 226,77 & 240,053 & 13 \\
& 27,9 & 15 & 242,97 & 254,947 & 12 \\
& 27,9 & 16 & 259,17 & 269,842 & 11 \\
27,9 & 17 & 275,36 & 284,737 & 9,4 \\
27,9 & 18 & 291,56 & 299,632 & 8,1 \\
27,9 & 19 & 307,76 & 314,526 & 6,8 \\
27,9 & 20 & 323,96 & 329,421 & 5,5 \\
27,9 & 21 & 340,16 & 344,316 & 4,2 \\
27,9 & 22 & 356,35 & 359,211 & 2,9 \\
27,9 & 23 & 372,55 & 374,105 & 1,6 \\
27,9 & 24 & 388,75 & 389 & 0,2 \\
\hline Consumo & Horas & Gasto & Utilidad & \\
Stand-by & Stand-by & stand-by & stand-by & Beneficio \\
& 24 & 209,006 & 208 & $-1,00567$ \\
& 0,015 & 23 & 200,297 & 199,333 & $-0,96377$ \\
0,015 & 22 & 191,589 & 190,667 & $-0,92187$ \\
0,015 & 21 & 182,88 & 182 & $-0,87996$ \\
0,015 & 20 & 174,171 & 173,333 & $-0,83806$ \\
& 015 & 19 & 165,463 & 164,667 & $-0,79616$ \\
& & & & &
\end{tabular}




\begin{tabular}{lllll}
0,015 & 18 & 156,754 & 156 & $-0,75425$ \\
0,015 & 17 & 148,046 & 147,333 & $-0,71235$ \\
0,015 & 16 & 139,337 & 138,667 & $-0,67045$ \\
0,015 & 15 & 130,629 & 130 & $-0,62854$ \\
0,015 & 14 & 121,92 & 121,333 & $-0,58664$ \\
0,015 & 13 & 113,211 & 112,667 & $-0,54474$ \\
0,015 & 12 & 104,503 & 104 & $-0,50284$ \\
0,015 & 11 & 95,7943 & 95,3333 & $-0,46093$ \\
0,015 & 10 & 87,0857 & 86,6667 & $-0,41903$ \\
0,015 & 9 & 78,3771 & 78 & $-0,37713$ \\
0,015 & 8 & 69,6686 & 69,3333 & $-0,33522$ \\
0,015 & 7 & 60,96 & 60,6667 & $-0,29332$ \\
0,015 & 6 & 52,2514 & 52 & $-0,25142$ \\
0,015 & 5 & 43,5428 & 43,3333 & $-0,20951$ \\
0,015 & 4 & 34,8343 & 34,6667 & $-0,16761$ \\
0,015 & 3 & 26,1257 & 26 & $-0,12571$ \\
0,015 & 2 & 17,4171 & 17,3333 & $-0,08381$ \\
0,015 & 1 & 8,70857 & 8,66667 & $-0,0419$ \\
0,015 & 0 & 0 & 0 & 0 \\
\hline
\end{tabular}

Tabla I.13.- Función de utilidad del ordenador portátil

\section{I.1.2.6. Calefactor}

Es un electrodoméstico estacional, por lo que su función de utilidad es diferente en invierno y verano. Se considera electrodoméstico de ciclo.

\begin{tabular}{cccccc}
\multicolumn{6}{c}{ Invierno } \\
\hline Ciclo & consumo & Usos/semana & Gasto & Utilidad & Beneficio \\
\hline Único & 1 & 0 & 0 & 0 & 0 \\
& 1 & 1 & 77,41 & 91,71 & 14,30 \\
& 1 & 2 & 154,82 & 183,43 & 28,61 \\
& 1 & 3 & 232,23 & 275,14 & 42,91 \\
& 1 & 4 & 309,64 & 366,86 & 57,22 \\
& 1 & 5 & 387,05 & 458,57 & 71,52 \\
& 1 & 6 & 464,46 & 550,29 & 85,83 \\
& 1 & 7 & 541,87 & 642,00 & 100,13 \\
& 1 & 8 & 619,28 & 707,43 & 88,15
\end{tabular}




\begin{tabular}{ccccc}
\hline 1 & 9 & 696,69 & 772,86 & 76,17 \\
1 & 10 & 774,10 & 838,29 & 64,19 \\
1 & 11 & 851,50 & 903,71 & 52,21 \\
1 & 12 & 928,91 & 969,14 & 40,23 \\
1 & 13 & 1006,32 & 1034,57 & 28,25 \\
1 & 14 & 1083,73 & 1100,00 & 16,27 \\
\hline
\end{tabular}

Tabla I.14.- Función de utilidad del calefactor en invierno

Verano

\begin{tabular}{cccccc}
\hline Ciclo & consumo & Usos/semana & Gasto & Utilidad & Beneficio \\
\hline & 1 & 0 & 0,00 & 0,00 & 0,00 \\
& 1 & 1 & 77,41 & 77,41 & 0,00 \\
& 1 & 2 & 154,82 & 154,82 & 0,00 \\
& 1 & 3 & 232,23 & 232,23 & 0,00 \\
& 1 & 4 & 309,64 & 309,64 & 0,00 \\
& 1 & 5 & 387,05 & 387,05 & 0,00 \\
& 1 & 6 & 464,46 & 464,46 & 0,00 \\
& 1 & 7 & 541,87 & 541,87 & 0,00 \\
& 1 & 8 & 619,28 & 619,28 & 0,00 \\
& 1 & 9 & 696,69 & 696,69 & 0,00 \\
& 1 & 10 & 774,10 & 774,10 & 0,00 \\
& 1 & 11 & 851,50 & 851,50 & 0,00 \\
& 1 & 12 & 928,91 & 928,91 & 0,00 \\
& 1 & 13 & 1006,32 & 1006,32 & 0,00 \\
& 1 & 14 & 1083,73 & 1083,73 & 0,00 \\
\hline
\end{tabular}

Tabla I.15.- Función de utilidad del calefactor en verano

\section{I.1.2.7. Horno}

Como el horno es un electrodoméstico de mucho gasto, he considerado como uso razonable dos vez por semana en invierno (ya que calienta la cocina), y el mismo en verano pero con utilidades menores.

\begin{tabular}{cccccc} 
Ciclo & consumo & $\begin{array}{c}\text { Uso } \\
\text { semanal }\end{array}$ & Gasto & Utilidad & Beneficio \\
\hline único & 2 & 0 & 0,00 & 0,00 & 0,00 \\
& 2 & 1 & 116,11 & 140,00 & 23,89
\end{tabular}




\begin{tabular}{|c|c|c|c|c|c|}
\hline & 2 & 2 & 232,23 & 282,00 & 49,77 \\
\hline & 2 & 3 & 348,34 & 393,92 & 45,57 \\
\hline & 2 & 4 & 464,46 & 505,83 & 41,38 \\
\hline & 2 & 5 & 580,57 & 617,75 & 37,18 \\
\hline & 2 & 6 & 696,69 & 729,67 & 32,98 \\
\hline & 2 & 7 & 812,80 & 841,58 & 28,78 \\
\hline & 2 & 8 & 928,91 & 953,50 & 24,59 \\
\hline & 2 & 9 & 1045,03 & 1065,42 & 20,39 \\
\hline & 2 & 10 & 1161,14 & 1177,33 & 16,19 \\
\hline & 2 & 11 & 1277,26 & 1289,25 & 11,99 \\
\hline & 2 & 12 & 1393,37 & 1401,17 & 7,80 \\
\hline & 2 & 13 & 1509,49 & 1513,08 & 3,60 \\
\hline & 2 & 14 & 1625,60 & 1625,00 & $-0,60$ \\
\hline \multicolumn{6}{|c|}{ Tabla I.16.- Función de utilidad del horno en invierno } \\
\hline \multicolumn{6}{|c|}{ Verano } \\
\hline Ciclo & consumo & Usos/semana & Gasto & Utilidad & Beneficio \\
\hline \multirow{15}{*}{ único } & 1,5 & 0 & 0 & 0 & 0 \\
\hline & 1,5 & 1 & 116,11 & 130 & 13,89 \\
\hline & 1,5 & 2 & 232,23 & 257 & 24,77 \\
\hline & 1,5 & 3 & 348,34 & 371 & 22,66 \\
\hline & 1,5 & 4 & 464,46 & 485 & 20,54 \\
\hline & 1,5 & 5 & 580,57 & 599 & 18,43 \\
\hline & 1,5 & 6 & 696,69 & 713 & 16,31 \\
\hline & 1,5 & 7 & 812,8 & 827 & 14,2 \\
\hline & 1,5 & 8 & 928,91 & 941 & 12,09 \\
\hline & 1,5 & 9 & 1045,03 & 1055 & 9,97 \\
\hline & 1,5 & 10 & 1161,14 & 1169 & 7,86 \\
\hline & 1,5 & 11 & 1277,26 & 1283 & 5,74 \\
\hline & 1,5 & 12 & 1393,37 & 1397 & 3,63 \\
\hline & 1,5 & 13 & 1509,49 & 1511 & 1,51 \\
\hline & 1,5 & 14 & 1625,6 & 1625 & $-0,6$ \\
\hline
\end{tabular}

Tabla I.17.- Función de utilidad del horno en verano 


\section{I.1.2.8. Microondas}

Para el microondas, he diferenciado el uso para desayuno (un ciclo de $38,9 \mathrm{Wh} / \mathrm{ciclo}$, que equivale a calentar el café con leche durante $40 \mathrm{~s}$ para 3 personas), del uso para comidas (un ciclo de $290 \mathrm{Wh} /$ ciclo, que se corresponde a una comida cocinada durante 15 minutos). Para saber si el sujeto está "cocinando" el desayuno o la comida, la primera selección entre las 7 y las 10 de la mañana se considerará desayuno; cualquier otra selección en ese horario o en otro se considerará preparación de la comida.

\begin{tabular}{cccccc} 
Ciclo & consumo & Usos/semana & Gasto & Utilidad & Beneficio \\
\hline & 0,0389 & 0 & 0 & 0 & 0 \\
& 0,0389 & 1 & 3,01 & 10,1428571 & 7,13 \\
Desayuno & 0,0389 & 2 & 6,02 & 20,2857143 & 14,26 \\
(horas & 0,0389 & 3 & 9,03 & 30,4285714 & 21,39 \\
entre 7y & 0,0389 & 4 & 12,04 & 40,5714286 & 28,53 \\
10 ) & 0,0389 & 5 & 15,06 & 50,7142857 & 35,66 \\
& 0,0389 & 6 & 18,07 & 60,8571429 & 42,79 \\
& 0,0389 & 7 & 21,08 & 71 & 49,92 \\
\hline
\end{tabular}

Tabla I.18.- Función de utilidad del microondas en el desayuno

\begin{tabular}{|c|c|c|c|c|c|}
\hline Ciclo & consumo & $\begin{array}{l}\text { Usos/semar } \\
\text { (hay qu } \\
\text { sumarlos } \\
\text { los } \\
\text { anteriores) }\end{array}$ & Gasto & Utilidad & Beneficio \\
\hline \multirow{12}{*}{$\begin{array}{c}\text { Comida o } \\
\text { cena } \\
\text { (cualquier } \\
\text { hora una } \\
\text { vez } \\
\text { elegido el } \\
\text { desayuno) }\end{array}$} & 0,29 & 0 & 0 & 0 & 0 \\
\hline & 0,29 & 1 & 22,45 & 32,4 & 9,95 \\
\hline & 0,29 & 2 & 44,9 & 64,8 & 19,9 \\
\hline & 0,29 & 3 & 67,35 & 97,2 & 29,85 \\
\hline & 0,29 & 4 & 89,8 & 129,6 & 39,8 \\
\hline & 0,29 & 5 & 112,24 & 162 & 49,76 \\
\hline & 0,29 & 6 & 134,69 & 178,89 & 44,2 \\
\hline & 0,29 & 7 & 157,14 & 195,78 & 38,64 \\
\hline & 0,29 & 8 & 179,59 & 212,67 & 33,08 \\
\hline & 0,29 & 9 & 202,04 & 229,56 & 27,52 \\
\hline & 0,29 & 10 & 224,49 & 246,44 & 21,96 \\
\hline & 0,29 & 11 & 246,94 & 263,33 & 16,4 \\
\hline
\end{tabular}




\begin{tabular}{lllll}
0,29 & 12 & 269,39 & 280,22 & 10,84 \\
0,29 & 13 & 291,83 & 297,11 & 5,28 \\
0,29 & 14 & 314,28 & 314 & $-0,28$ \\
\hline
\end{tabular}

Tabla I.19.- Función de utilidad del microondas el resto del día

\section{l.1.2.9. Tostadora}

El uso óptimo se establece en un uso diario, que se corresponde con usar la tostadora 3 veces cada día (el consumo diario está ya multiplicado por 3 usos, correspondientes a las tostadas de los 3 habitantes de la casa)

\begin{tabular}{cccccc} 
Ciclo & consumo & Usos/semana & Gasto & Utilidad & Beneficio \\
\hline & 0,092 & 0 & 0 & 0 & 0 \\
& 0,092 & 1 & 7,12 & 14,29 & 7,16 \\
& 0,092 & 2 & 14,24 & 28,57 & 14,33 \\
& 0,092 & 3 & 21,37 & 42,86 & 21,49 \\
& 0,092 & 4 & 28,49 & 57,14 & 28,66 \\
& 0,092 & 5 & 35,61 & 71,43 & 35,82 \\
& 0,092 & 6 & 42,73 & 85,71 & 42,98 \\
3tostadas & 0,092 & 7 & 49,85 & 100,00 & 50,15 \\
& 0,092 & 8 & 56,97 & 102,86 & 45,88 \\
& 0,092 & 9 & 64,1 & 105,71 & 41,62 \\
& 0,092 & 10 & 71,22 & 108,57 & 37,35 \\
& 0,092 & 11 & 78,34 & 111,43 & 33,09 \\
& 0,092 & 12 & 85,46 & 114,29 & 28,83 \\
& 0,092 & 13 & 92,58 & 117,14 & 24,56 \\
& 0,092 & 14 & 99,7 & 120 & 20,3 \\
\hline
\end{tabular}

Tabla I.20.- Función de utilidad del tostador

\subsubsection{Vitrocerámica}

Se considera de media un ciclo de media hora de uso para la preparación de la comida, los primeros 10 minutos a toda potencia y los 20 últimos, a fuego bajo. 


\begin{tabular}{cccccc} 
Ciclo & consumo & Usos/semana & Gasto & Utilidad & Beneficio \\
\hline \multirow{6}{*}{ Comida o } & 0,24 & 0 & 0 & 0 & 0 \\
& 0,24 & 1 & 18,58 & 29,29 & 10,71 \\
& 0,24 & 2 & 37,16 & 58,57 & 21,41 \\
& 0,24 & 3 & 55,73 & 87,86 & 32,12 \\
& 0,24 & 4 & 74,31 & 117,14 & 42,83 \\
& 0,24 & 5 & 92,89 & 146,43 & 53,54 \\
& 0,24 & 6 & 111,47 & 175,71 & 64,24 \\
& 0,24 & 7 & 130,05 & 205,00 & 74,95 \\
& 0,24 & 8 & 148,63 & 212,86 & 64,23 \\
& 0,24 & 9 & 167,2 & 220,71 & 53,51 \\
& 0,24 & 10 & 185,78 & 228,57 & 42,79 \\
& 0,24 & 11 & 204,36 & 236,43 & 32,07 \\
& 0,24 & 12 & 222,94 & 244,29 & 21,35 \\
& 0,24 & 13 & 241,52 & 252,14 & 10,63 \\
& 0,24 & 14 & 260,1 & 260 & $-0,1$ \\
\hline
\end{tabular}

Tabla I.21.- Función de utilidad de la vitrocerámica

\section{I.1.2.11. No manipulables}

Están dentro del grupo los electrodomésticos que no admiten manipulación alguna, sino que están constantemente en marcha. No suponen gasto ni beneficio; la utilidad en ellos coincide con el gasto.

Para el frigorífico:

Consumo en kWh mensuales $=33,5 \mathrm{~W} * 24 \mathrm{~h} * 28 \mathrm{~d}=22,5 \mathrm{kWh}$ mensuales.

Gasto en céntimos de euro $=22,5 \mathrm{kWh} * 19,352377 \mathrm{c} € / \mathrm{kWh}=435,66 \mathrm{c€}$

Utilidad $=435,66 \mathrm{c} €$

Beneficio $=435,66-435,66=0$

Para el módem-router: 
Consumo en kWh mensuales $=6,1 \mathrm{~W} * 24 \mathrm{~h} * 28 \mathrm{~d}=4,1 \mathrm{kWh}$ mensuales.

Gasto en céntimos de euro $=4,1 \mathrm{kWh} * 19,352377 \mathrm{c} € / \mathrm{kWh}=79,3 \mathrm{c} €$

Utilidad $=79,3 c €$

Beneficio $=79,3-79,3=0$

\subsubsection{ACS}

En este caso, también se puede ajustar el consumo a kWh/ciclo. Para ello, vamos a suponer los siguientes valores:

Potencia caldera $23 \mathrm{~kW}$

Ducha 1.- (Cerrando el grifo para enjabonarse)..... $50+100$ segundos

Ducha 2.- (Grifo abierto todo el tiempo) $50+175$ segundos

Baño.$.50+600$ segundos

(Todos los casos incluyen $50 \mathrm{~s}$, que es el tiempo en el que el grifo está abierto previamente hasta que se calienta el agua)

\begin{tabular}{cccccc} 
Ciclo & Consumo & Ciclos/semana & Gasto & Utilidad & Beneficio \\
\hline Ducha 1 & 0,96 & 0 & 0 & 0 & 0 \\
Ducha 1 & 0,96 & 1 & 27 & 30,57 & 3,57 \\
Ducha 1 & 0,96 & 2 & 53,99 & 61,14 & 7,14 \\
Ducha 1 & 0,96 & 3 & 80,99 & 91,71 & 10,71 \\
Ducha 1 & 0,96 & 4 & 107,99 & 122,27 & 14,29 \\
Ducha 1 & 0,96 & 5 & 134,99 & 152,84 & 17,86 \\
Ducha 1 & 0,96 & 6 & 161,98 & 183,41 & 21,43 \\
\hline Ducha 1 & 0,96 & 7 & 188,98 & 213,98 & 25 \\
Ducha 1 & 0,96 & 8 & 215,98 & 238,36 & 22,38 \\
Ducha 1 & 0,96 & 9 & 242,97 & 262,74 & 19,76 \\
Ducha 1 & 0,96 & 10 & 269,97 & 287,11 & 17,14 \\
Ducha 1 & 0,96 & 11 & 296,97 & 311,49 & 14,52 \\
Ducha 1 & 0,96 & 12 & 323,97 & 335,87 & 11,9 \\
Ducha 1 & 0,96 & 13 & 350,96 & 360,25 & 9,29 \\
Ducha 1 & 0,96 & 14 & 377,96 & 384,63 & 6,67 \\
\hline
\end{tabular}

Tabla I.22.- Función de utilidad del ACS 


\begin{tabular}{cccccc} 
Ciclo & Consumo & Ciclos/semana & Gasto & Utilidad & Beneficio \\
\hline Ducha 2 & 1,44 & 0 & 0 & 0 & 0 \\
Ducha 2 & 1,44 & 1 & 40,5 & 41,92 & 1,43 \\
Ducha 2 & 1,44 & 2 & 80,99 & 83,85 & 2,86 \\
Ducha 2 & 1,44 & 3 & 121,49 & 125,77 & 4,29 \\
Ducha 2 & 1,44 & 4 & 161,98 & 167,70 & 5,71 \\
Ducha 2 & 1,44 & 5 & 202,48 & 209,62 & 7,14 \\
Ducha 2 & 1,44 & 6 & 242,97 & 251,55 & 8,57 \\
Ducha 2 & 1,44 & 7 & 283,47 & 293,47 & 10 \\
Ducha 2 & 1,44 & 8 & 323,97 & 333,01 & 9,05 \\
Ducha 2 & 1,44 & 9 & 364,46 & 372,56 & 8,1 \\
Ducha 2 & 1,44 & 10 & 404,96 & 412,10 & 7,14 \\
Ducha 2 & 1,44 & 11 & 445,45 & 451,64 & 6,19 \\
Ducha 2 & 1,44 & 12 & 485,95 & 491,19 & 5,24 \\
Ducha 2 & 1,44 & 13 & 526,45 & 530,73 & 4,29 \\
Ducha 2 & 1,44 & 14 & 566,94 & 570,27 & 3,33 \\
\hline & \multicolumn{7}{c}{ Tabla I.23.- Función de utilidad del ACs } & & \\
Ciclo & Consumo & Ciclos/semana & Gasto & Utilidad & Beneficio \\
\hline Baño & 4,15 & 0 & 0 & 0 & 0 \\
Baño & 4,15 & 1 & 116,71 & 117,18 & 0,48 \\
Baño & 4,15 & 2 & 233,41 & 234,37 & 0,95 \\
Baño & 4,15 & 3 & 350,12 & 351,55 & 1,43 \\
Baño & 4,15 & 4 & 466,83 & 468,73 & 1,9 \\
Baño & 4,15 & 5 & 583,53 & 585,91 & 2,38 \\
Baño & 4,15 & 6 & 700,24 & 703,10 & 2,86 \\
Baño & 4,15 & 7 & 816,95 & 820,28 & 3,33 \\
Baño & 4,15 & 8 & 933,65 & 936,51 & 2,86 \\
Baño & 4,15 & 9 & 1050,36 & 1052,74 & 2,38 \\
Baño & 4,15 & 10 & 1167,07 & 1168,97 & 1,9 \\
Baño & 4,15 & 11 & 1283,77 & 1285,20 & 1,43 \\
Baño & 4,15 & 12 & 1400,48 & 1401,43 & 0,95 \\
Baño & 4,15 & 13 & 1517,19 & 1517,66 & 0,48 \\
Baño & 4,15 & 14 & 1633,89 & 1633,89 & 0 \\
\hline & & & & \\
\hline
\end{tabular}

Tabla I.24.- Función de utilidad del ACS 
En ese caso, cada ciclo supone un gasto energético de:

Ducha 1.- $23 \mathrm{~kW} * 150 \mathrm{~s} * 1 \mathrm{~h} / 3600 \mathrm{~s}=0,96 \mathrm{kWh} / \mathrm{ciclo}$

Ducha 2.- $23 \mathrm{~kW} * 225 \mathrm{~s} * 1 \mathrm{~h} / 3600 \mathrm{~s}=1,44 \mathrm{kWh} / \mathrm{ciclo}$

Baño.- 23 kW*650s*1h/3600s = 4,15 kWh/ciclo

\begin{tabular}{ccccc}
$\begin{array}{c}\text { Combinaciones } \\
\text { posibles por persona } \\
\text { y semana }\end{array}$ & $\begin{array}{c}\text { Casilla marcada en } \\
\text { el prog (por } \\
\text { persona) }\end{array}$ & Gasto & Utilidad & Beneficio \\
\hline 7 duchas 1 & 1 ducha 1 & 188,98 & 213,98 & 25 \\
14 duchas 1 & 2 duchas 1 & 377,96 & 384,63 & 6,67 \\
7 duchas $1+7$ & 1 ducha 1 y 1 ducha & & & \\
duchas 2 & 2 & 472,45 & 475,78 & 3,33 \\
7 duchas $1+7$ baños & 1 ducha 1 y 1 baño & 1005,93 & 1007,59 & 1,67 \\
7 duchas 2 & 1 ducha 2 & 283,47 & 293,47 & 10 \\
14 duchas 2 & 2 duchas 2 & 566,94 & 570,27 & 3,33 \\
7 duchas $2+7$ & & & & \\
baños & 1 ducha 2 +1 baño & 1100,42 & 1101,42 & 1 \\
7 baños & 1 baño & 816,95 & 820,28 & 3,33 \\
14 baños & 2 baños & 1633,89 & 1633,89 & 0 \\
\hline
\end{tabular}

Tabla I.25.- Función de utilidad del ACS: combinaciones posibles

\subsubsection{Calefacción}

La calefacción debe contabilizarse en función del número de horas de uso diarias y de la temperatura de calefacción. La calefacción va a ser de gas natural; se va a hacer una factura de gas sólo de este concepto. Se supone, para el cálculo de la función, que la potencia de la calefacción aumenta un $8 \%$ el consumo energético por grado de temperatura de confort extra.

Dado que la calefacción parece el bien más básico de todos, le he dado un beneficio máximo de 150 euros. Se ha considerado óptimo (con beneficio máximo) el siguiente uso: 16 horas de calefacción a una temperatura de entre 18 y $22 \circ$, y 8 horas (las nocturnas), a una temperatura de entre 15 y 160 . El uso nocturno supone un beneficio de $30 \mathrm{c} €$, que se suman a los $120 \mathrm{c} €$ de beneficio del uso diurno. Si en vez de ese sistema se deja la calefacción entre 18 y $22^{\circ} \mathrm{C}$ las 24 horas del día, el beneficio es menor pero también alto: $80 \mathrm{c} €$. Si se va 
incrementando la temperatura de confort, los beneficios van cambiando en esta proporción:

\begin{tabular}{cc} 
Temp de confort (o- $)$ & Potencia caldera 24 horas $(\mathrm{kW})$ \\
\hline 15 & 0,425 \\
16 & 0,46 \\
17 & 0,5 \\
18 & 0,54 \\
19 & 0,58 \\
20 & 0,62 \\
21 & 0,67 \\
22 & 0,73 \\
23 & 0,79 \\
24 & 0,85 \\
25 & 0,92 \\
26 & 0,99 \\
27 & 1,07 \\
28 & 1,16 \\
29 & 1,25 \\
\hline
\end{tabular}

Tabla I.26.- Programación de la calefacción y consumo asociado simplificado

En cuanto a temperaturas superiores, dan también beneficio máximo en $16+8$ horas, pero el beneficio es menor dado que no se consigue mayor confort y sí mayor gasto. El beneficio va descendiendo desde 23ㅇ C (60 céntimos de euro) hasta $29^{\circ} \mathrm{C}$ (0 céntimos). No se permiten temperaturas superiores a 29 o ni inferiores a 15ㅇ.

Temperatura entre 23 y $24^{\circ}$ C, 16 horas de uso......80 c€ (sumados a los 30 nocturnos, $110 \mathrm{c} €)$

Temperatura entre 23 y 25 ㅇ C, 24 horas de uso......50 c€

Temperatura entre 26 y $29^{\circ}$ C, 16 horas de uso...... Bajando de 50 a $10 \mathrm{c} €$

Temperatura entre 26 y $29 \circ$ C, 24 horas de uso......Bajando de 25 a 0 c€

Las tablas correspondientes al uso óptimo, con los máximos señalados en amarillo, son las siguientes: 


\begin{tabular}{|c|c|c|c|c|c|}
\hline $\begin{array}{c}\text { Temp de } \\
\text { confort }\end{array}$ & C & $\mathrm{H}$ & G & $U$ & B \\
\hline & & 0 & 0 & 0 & 0 \\
\hline & & 1 & 89,64 & 93,39 & 3,75 \\
\hline & & 2 & 179,28 & 186,78 & 7,5 \\
\hline & & 3 & 268,92 & 280,17 & 11,25 \\
\hline & & 4 & 358,56 & 373,56 & 15 \\
\hline & & 5 & 448,2 & 466,95 & 18,75 \\
\hline & & 6 & 537,83 & 560,33 & 22,5 \\
\hline & & 7 & 627,47 & 653,72 & 26,25 \\
\hline & & 8 & 717,11 & 747,11 & 30 \\
\hline & & 9 & 806,75 & 834,94 & 28,19 \\
\hline & & 10 & 896,39 & 922,77 & 26,38 \\
\hline & & 11 & 986,03 & 1010,59 & 24,56 \\
\hline \multirow[t]{13}{*}{150} & 425 & 12 & 1075,67 & 1098,42 & 22,75 \\
\hline & & 13 & 1165,31 & 1186,25 & 20,94 \\
\hline & & 14 & 1254,95 & 1274,07 & 19,13 \\
\hline & & 15 & 1344,59 & 1361,90 & 17,31 \\
\hline & & 16 & 1434,23 & 1449,73 & 15,5 \\
\hline & & 17 & 1523,86 & 1537,55 & 13,69 \\
\hline & & 18 & 1613,5 & 1625,38 & 11,87 \\
\hline & & 19 & 1703,14 & 1713,21 & 10,06 \\
\hline & & 20 & 1792,78 & 1801,03 & 8,25 \\
\hline & & 21 & 1882,42 & 1888,86 & 6,44 \\
\hline & & 22 & 1972,06 & 1976,69 & 4,62 \\
\hline & & 23 & 2061,7 & 2064,51 & 2,81 \\
\hline & & 24 & 2151,34 & 2152,34 & 1 \\
\hline
\end{tabular}

Tabla I.27.- Función de utilidad de la calefacción en función de la temperatura de confort

\begin{tabular}{cccccc}
$\begin{array}{c}\text { Temp de } \\
\text { confort }\end{array}$ & $\mathrm{C}$ & $\mathrm{H}$ & $\mathrm{G}$ & $\mathrm{U}$ & $\mathrm{B}$ \\
\hline 169 & 460 & 0 & 0 & 0 & 0 \\
& & 1 & 97,02 & 100,77 & 3,75 \\
& 2 & 194,04 & 201,54 & 7,5 \\
& 3 & 291,06 & 302,31 & 11,25 \\
& 4 & 388,08 & 403,08 & 15 \\
\hline
\end{tabular}




\begin{tabular}{|c|c|c|c|c|c|}
\hline & & 5 & 485,11 & 503,86 & 18,75 \\
\hline & & 6 & 582,13 & 604,63 & 22,5 \\
\hline & & 7 & 679,15 & 705,40 & 26,25 \\
\hline & & 8 & 776,17 & 806,17 & 30 \\
\hline & & 9 & 873,19 & 901,38 & 28,19 \\
\hline & & 10 & 970,21 & 996,59 & 26,38 \\
\hline & & 11 & 1067,23 & 1091,80 & 24,56 \\
\hline & & 12 & 1164,25 & 1187,00 & 22,75 \\
\hline & & 13 & 1261,27 & 1282,21 & 20,94 \\
\hline & & 14 & 1358,3 & 1377,42 & 19,13 \\
\hline & & 15 & 1455,32 & 1472,63 & 17,31 \\
\hline & & 16 & 1552,34 & 1567,84 & 15,5 \\
\hline & & 17 & 1649,36 & 1663,05 & 13,69 \\
\hline & & 18 & 1746,38 & 1758,26 & 11,88 \\
\hline & & 19 & 1843,4 & 1853,46 & 10,06 \\
\hline & & 20 & 1940,42 & 1948,67 & 8,25 \\
\hline & & 21 & 2037,44 & 2043,88 & 6,44 \\
\hline & & 22 & 2134,47 & 2139,09 & 4,63 \\
\hline & & 23 & 2231,49 & 2234,30 & 2,81 \\
\hline & & 24 & 2328,51 & 2329,51 & 1 \\
\hline $\begin{array}{l}\text { Temp de } \\
\text { confort }\end{array}$ & C & $\mathrm{H}$ & G & U & B \\
\hline \multirow[t]{13}{*}{170} & 500 & 0 & 0 & 0 & 0 \\
\hline & & 1 & 105,46 & 109,21 & 3,75 \\
\hline & & 2 & 210,92 & 218,42 & 7,5 \\
\hline & & 3 & 316,37 & 327,62 & 11,25 \\
\hline & & 4 & 421,83 & 436,83 & 15 \\
\hline & & 5 & 527,29 & 546,04 & 18,75 \\
\hline & & 6 & 632,75 & 655,25 & 22,5 \\
\hline & & 7 & 738,2 & 764,45 & 26,25 \\
\hline & & 8 & 843,66 & 873,66 & 30 \\
\hline & & 9 & 949,12 & 977,31 & 28,19 \\
\hline & & 10 & 1054,58 & 1080,95 & 26,37 \\
\hline & & 11 & 1160,04 & 1184,60 & 24,56 \\
\hline & & 12 & 1265,49 & 1288,24 & 22,75 \\
\hline
\end{tabular}




\begin{tabular}{cccc}
13 & 1370,95 & 1391,89 & 20,94 \\
14 & 1476,41 & 1495,53 & 19,13 \\
15 & 1581,87 & 1599,18 & 17,31 \\
16 & 1687,32 & 1702,82 & 15,5 \\
17 & 1792,78 & 1806,47 & 13,69 \\
18 & 1898,24 & 1910,11 & 11,87 \\
19 & 2003,7 & 2013,76 & 10,06 \\
20 & 2109,16 & 2117,41 & 8,25 \\
21 & 2214,61 & 2221,05 & 6,44 \\
22 & 2320,07 & 2324,70 & 4,63 \\
23 & 2425,53 & 2428,34 & 2,81 \\
24 & 2530,99 & 2531,99 & 1 \\
\hline
\end{tabular}

\begin{tabular}{|c|c|c|c|c|c|}
\hline $\begin{array}{l}\text { Temp de } \\
\text { confort }\end{array}$ & C & & G & U & B \\
\hline \multirow[t]{20}{*}{180} & 540 & 0 & 0 & 0 & 0 \\
\hline & & 1 & 113,89 & 121,39 & 7,5 \\
\hline & & 2 & 227,79 & 242,79 & 15 \\
\hline & & 3 & 341,68 & 364,18 & 22,5 \\
\hline & & 4 & 455,58 & 485,58 & 30 \\
\hline & & 5 & 569,47 & 606,97 & 37,5 \\
\hline & & 6 & 683,37 & 728,37 & 45 \\
\hline & & 7 & 797,26 & 849,76 & 52,5 \\
\hline & & 8 & 911,16 & 971,16 & 60 \\
\hline & & 9 & 1025,05 & 1092,55 & 67,5 \\
\hline & & 10 & 1138,94 & 1213,94 & 75 \\
\hline & & 11 & 1252,84 & 1335,34 & 82,5 \\
\hline & & 12 & 1366,73 & 1456,73 & 90 \\
\hline & & 13 & 1480,63 & 1578,13 & 97,5 \\
\hline & & 14 & 1594,52 & 1699,52 & 105 \\
\hline & & 15 & 1708,42 & 1820,92 & 112,5 \\
\hline & & 16 & 1822,31 & 1942,31 & 120 \\
\hline & & 17 & 1936,2 & 2051,20 & 115 \\
\hline & & 18 & 2050,1 & 2160,10 & 110 \\
\hline & & 19 & 2163,99 & 2268,99 & 105 \\
\hline
\end{tabular}




$\begin{array}{llll}20 & 2277,89 & 2377,89 & 100 \\ 21 & 2391,78 & 2486,78 & 95 \\ 22 & 2505,68 & 2595,68 & 90 \\ 23 & 2619,57 & 2704,57 & 85 \\ 24 & 2733,47 & 2813,47 & 80\end{array}$

\begin{tabular}{|c|c|c|c|c|c|}
\hline $\begin{array}{l}\text { Temp de } \\
\text { confort }\end{array}$ & C & & G & $U$ & B \\
\hline \multirow{25}{*}{190} & \multirow{25}{*}{580} & 0 & 0 & 0 & 0 \\
\hline & & 1 & 122,33 & 129,83 & 7,5 \\
\hline & & 2 & 244,66 & 259,66 & 15 \\
\hline & & 3 & 366,99 & 389,49 & 22,5 \\
\hline & & 4 & 489,32 & 519,32 & 30 \\
\hline & & 5 & 611,66 & 649,16 & 37,5 \\
\hline & & 6 & 733,99 & 778,99 & 45 \\
\hline & & 7 & 856,32 & 908,82 & 52,5 \\
\hline & & 8 & 978,65 & 1038,65 & 60 \\
\hline & & 9 & 1100,98 & 1168,48 & 67,5 \\
\hline & & 10 & 1223,31 & 1298,31 & 75 \\
\hline & & 11 & 1345,64 & 1428,14 & 82,5 \\
\hline & & 12 & 1467,97 & 1557,97 & 90 \\
\hline & & 13 & 1590,3 & 1687,80 & 97,5 \\
\hline & & 14 & 1712,63 & 1817,63 & 105 \\
\hline & & 15 & 1834,97 & 1947,47 & 112,5 \\
\hline & & 16 & 1957,3 & 2077,30 & 120 \\
\hline & & 17 & 2079,63 & 2194,63 & 115 \\
\hline & & 18 & 2201,96 & 2311,96 & 110 \\
\hline & & 19 & 2324,29 & 2429,29 & 105 \\
\hline & & 20 & 2446,62 & 2546,62 & 100 \\
\hline & & 21 & 2568,95 & 2663,95 & 95 \\
\hline & & 22 & 2691,28 & 2781,28 & 90 \\
\hline & & 23 & 2813,61 & 2898,61 & 85 \\
\hline & & 24 & 2935,94 & 3015,94 & 80 \\
\hline
\end{tabular}




\begin{tabular}{|c|c|c|c|c|c|}
\hline $\begin{array}{l}\text { Temp de } \\
\text { confort }\end{array}$ & C & & G & U & B \\
\hline \multirow{25}{*}{20 은 } & \multirow{25}{*}{620} & 0 & 0 & 0 & 0 \\
\hline & & 1 & 130,77 & 138,27 & 7,5 \\
\hline & & 2 & 261,54 & 276,54 & 15 \\
\hline & & 3 & 392,3 & 414,80 & 22,5 \\
\hline & & 4 & 523,07 & 553,07 & 30 \\
\hline & & 5 & 653,84 & 691,34 & 37,5 \\
\hline & & 6 & 784,61 & 829,61 & 45 \\
\hline & & 7 & 915,37 & 967,87 & 52,5 \\
\hline & & 8 & 1046,14 & 1106,14 & 60 \\
\hline & & 9 & 1176,91 & 1244,41 & 67,5 \\
\hline & & 10 & 1307,68 & 1382,68 & 75 \\
\hline & & 11 & 1438,44 & 1520,94 & 82,5 \\
\hline & & 12 & 1569,21 & 1659,21 & 90 \\
\hline & & 13 & 1699,98 & 1797,48 & 97,5 \\
\hline & & 14 & 1830,75 & 1935,75 & 105 \\
\hline & & 15 & 1961,51 & 2074,01 & 112,5 \\
\hline & & 16 & 2092,28 & 2212,28 & 120 \\
\hline & & 17 & 2223,05 & 2338,05 & 115 \\
\hline & & 18 & 2353,82 & 2463,82 & 110 \\
\hline & & 19 & 2484,58 & 2589,58 & 105 \\
\hline & & 20 & 2615,35 & 2715,35 & 100 \\
\hline & & 21 & 2746,12 & 2841,12 & 95 \\
\hline & & 22 & 2876,89 & 2966,89 & 90 \\
\hline & & 23 & 3007,66 & 3092,66 & 85 \\
\hline & & 24 & 3138,42 & 3218,42 & 80 \\
\hline
\end{tabular}

\begin{tabular}{cllllll}
$\begin{array}{c}\text { Temp de } \\
\text { confort }\end{array}$ & C & & H & \multicolumn{1}{c}{ G } & \multicolumn{1}{c}{ U } & \multicolumn{1}{c}{ B } \\
\hline 210 & 670 & 0 & 0 & 0 & 0 \\
& 1 & 141,31 & 148,81 & 7,5 \\
& 2 & 282,63 & 297,63 & 15 \\
& 3 & 423,94 & 446,44 & 22,5 \\
& & 565,25 & 595,25 & 30 \\
\hline
\end{tabular}




\begin{tabular}{lllll}
5 & 706,57 & 744,07 & 37,5 \\
6 & 847,88 & 892,88 & 45 \\
7 & 989,19 & 1041,69 & 52,5 \\
8 & 1130,51 & 1190,51 & 60 \\
9 & 1271,82 & 1339,32 & 67,5 \\
10 & 1413,13 & 1488,13 & 75 \\
11 & 1554,45 & 1636,95 & 82,5 \\
12 & 1695,76 & 1785,76 & 90 \\
13 & 1837,07 & 1934,57 & 97,5 \\
14 & 1978,39 & 2083,39 & 105 \\
15 & 2119,7 & 2232,20 & 112,5 \\
16 & 2261,01 & 2381,01 & 120 \\
17 & 2402,33 & 2517,33 & 115 \\
18 & 2543,64 & 2653,64 & 110 \\
19 & 2684,95 & 2789,95 & 105 \\
20 & 2826,27 & 2926,27 & 100 \\
21 & 2967,58 & 3062,58 & 95 \\
22 & 3108,89 & 3198,89 & 90 \\
23 & 3250,21 & 3335,21 & 85 \\
24 & 3391,52 & 3471,52 & 80 \\
\hline
\end{tabular}

\begin{tabular}{cccccc}
$\begin{array}{c}\text { Temp de } \\
\text { confort }\end{array}$ & C & H & G & U & B \\
\hline 229 & 730 & 0 & 0 & 0 & 0 \\
& 1 & 153,97 & 161,47 & 7,5 \\
& 2 & 307,94 & 322,94 & 15 \\
& 3 & 461,9 & 484,41 & 22,5 \\
& 4 & 615,87 & 645,87 & 30 \\
& 5 & 769,84 & 807,34 & 37,5 \\
& 6 & 923,81 & 968,81 & 45 \\
& 7 & 1077,78 & 1130,28 & 52,5 \\
& 8 & 1231,75 & 1291,75 & 60 \\
& 9 & 1385,71 & 1453,22 & 67,5 \\
& 10 & 1539,68 & 1614,68 & 75 \\
& 11 & 1693,65 & 1776,15 & 82,5 \\
& & & &
\end{tabular}




\begin{tabular}{ccccc}
12 & 1847,62 & 1937,62 & 90 \\
13 & 2001,59 & 2099,09 & 97,5 \\
14 & 2155,56 & 2260,56 & 105 \\
15 & 2309,52 & 2422,03 & 112,5 \\
\hline 16 & 2463,49 & 2583,49 & 120 \\
17 & 2617,46 & 2732,46 & 115 \\
18 & 2771,43 & 2881,43 & 110 \\
19 & 2925,4 & 3030,40 & 105 \\
20 & 3079,37 & 3179,37 & 100 \\
21 & 3233,33 & 3328,34 & 95 \\
22 & 3387,3 & 3477,30 & 90 \\
23 & 3541,27 & 3626,27 & 85 \\
24 & 3695,24 & 3775,24 & 80 \\
\hline
\end{tabular}

\begin{tabular}{|c|c|c|c|c|c|}
\hline $\begin{array}{l}\text { Temp de } \\
\text { confort }\end{array}$ & C & $\mathrm{H}$ & G & $U$ & B \\
\hline \multirow[t]{19}{*}{230} & 790 & 0 & 0 & 0 & 0 \\
\hline & & 1 & 166,62 & 171,62 & 5 \\
\hline & & 2 & 333,25 & 343,25 & 10 \\
\hline & & 3 & 499,87 & 514,87 & 15 \\
\hline & & 4 & 666,49 & 686,49 & 20 \\
\hline & & 5 & 833,12 & 858,12 & 25 \\
\hline & & 6 & 999,74 & 1029,74 & 30 \\
\hline & & 7 & 1166,36 & 1201,36 & 35 \\
\hline & & 8 & 1332,99 & 1372,99 & 40 \\
\hline & & 9 & 1499,61 & 1544,61 & 45 \\
\hline & & 10 & 1666,23 & 1716,23 & 50 \\
\hline & & 11 & 1832,86 & 1887,86 & 55 \\
\hline & & 12 & 1999,48 & 2059,48 & 60 \\
\hline & & 13 & 2166,1 & 2231,10 & 65 \\
\hline & & 14 & 2332,73 & 2402,73 & 70 \\
\hline & & 15 & 2499,35 & 2574,35 & 75 \\
\hline & & 16 & 2665,97 & 2745,97 & 80 \\
\hline & & 17 & 2832,6 & 2908,85 & 76,25 \\
\hline & & 18 & 2999,22 & 3071,72 & 72,5 \\
\hline
\end{tabular}




\begin{tabular}{ccccc}
19 & 3165,84 & 3234,59 & 68,75 \\
20 & 3332,47 & 3397,47 & 65 \\
21 & 3499,09 & 3560,34 & 61,25 \\
22 & 3665,71 & 3723,21 & 57,5 \\
23 & 3832,34 & 3886,09 & 53,75 \\
24 & 3998,96 & 4048,96 & 50 \\
\hline
\end{tabular}

\begin{tabular}{|c|c|c|c|c|c|}
\hline $\begin{array}{l}\text { Temp de } \\
\text { confort }\end{array}$ & C & $\mathrm{H}$ & G & $U$ & B \\
\hline \multirow{25}{*}{230} & \multirow{25}{*}{790} & 0 & 0 & 0 & 0 \\
\hline & & 1 & 166,62 & 171,62 & 5 \\
\hline & & 2 & 333,25 & 343,25 & 10 \\
\hline & & 3 & 499,87 & 514,87 & 15 \\
\hline & & 4 & 666,49 & 686,49 & 20 \\
\hline & & 5 & 833,12 & 858,12 & 25 \\
\hline & & 6 & 999,74 & 1029,74 & 30 \\
\hline & & 7 & 1166,36 & 1201,36 & 35 \\
\hline & & 8 & 1332,99 & 1372,99 & 40 \\
\hline & & 9 & 1499,61 & 1544,61 & 45 \\
\hline & & 10 & 1666,23 & 1716,23 & 50 \\
\hline & & 11 & 1832,86 & 1887,86 & 55 \\
\hline & & 12 & 1999,48 & 2059,48 & 60 \\
\hline & & 13 & 2166,1 & 2231,10 & 65 \\
\hline & & 14 & 2332,73 & 2402,73 & 70 \\
\hline & & 15 & 2499,35 & 2574,35 & 75 \\
\hline & & 16 & 2665,97 & 2745,97 & 80 \\
\hline & & 17 & 2832,6 & 2908,85 & 76,25 \\
\hline & & 18 & 2999,22 & 3071,72 & 72,5 \\
\hline & & 19 & 3165,84 & 3234,59 & 68,75 \\
\hline & & 20 & 3332,47 & 3397,47 & 65 \\
\hline & & 21 & 3499,09 & 3560,34 & 61,25 \\
\hline & & 22 & 3665,71 & 3723,21 & 57,5 \\
\hline & & 23 & 3832,34 & 3886,09 & 53,75 \\
\hline & & 24 & 3998,96 & 4048,96 & 50 \\
\hline
\end{tabular}




\begin{tabular}{|c|c|c|c|c|c|}
\hline $\begin{array}{l}\text { Temp de } \\
\text { confort }\end{array}$ & C & $\mathrm{H}$ & G & $U$ & B \\
\hline & & 0 & 0 & 0 & 0 \\
\hline & & 1 & 179,28 & 184,28 & 5 \\
\hline & & 2 & 358,56 & 368,56 & 10 \\
\hline & & 3 & 537,83 & 552,83 & 15 \\
\hline & & 4 & 717,11 & 737,11 & 20 \\
\hline & & 5 & 896,39 & 921,39 & 25 \\
\hline & & 6 & 1075,67 & 1105,67 & 30 \\
\hline & & 7 & 1254,95 & 1289,95 & 35 \\
\hline & & 8 & 1434,23 & 1474,23 & 40 \\
\hline & & 9 & 1613,5 & 1658,50 & 45 \\
\hline & & 10 & 1792,78 & 1842,78 & 50 \\
\hline & & 11 & 1972,06 & 2027,06 & 55 \\
\hline \multirow[t]{13}{*}{240} & 850 & 12 & 2151,34 & 2211,34 & 60 \\
\hline & & 13 & 2330,62 & 2395,62 & 65 \\
\hline & & 14 & 2509,89 & 2579,89 & 70 \\
\hline & & 15 & 2689,17 & 2764,17 & 75 \\
\hline & & 16 & 2868,45 & 2948,45 & 80 \\
\hline & & 17 & 3047,73 & 3123,98 & 76,25 \\
\hline & & 18 & 3227,01 & 3299,51 & 72,5 \\
\hline & & 19 & 3406,29 & 3475,04 & 68,75 \\
\hline & & 20 & 3585,56 & 3650,56 & 65 \\
\hline & & 21 & 3764,84 & 3826,09 & 61,25 \\
\hline & & 22 & 3944,12 & 4001,62 & 57,5 \\
\hline & & 23 & 4123,4 & 4177,15 & 53,75 \\
\hline & & 24 & 4302,68 & 4352,68 & 50 \\
\hline
\end{tabular}

\begin{tabular}{cccccc}
$\begin{array}{c}\text { Temp de } \\
\text { confort }\end{array}$ & C & H & G & U & B \\
\hline 25 o & 920 & 0 & 0 & 0 & 0 \\
& & 1 & 194,04 & 199,04 & 5 \\
& 2 & 388,08 & 398,08 & 10 \\
& & 3 & 582,13 & 597,13 & 15 \\
\hline
\end{tabular}




\begin{tabular}{|c|c|c|c|c|c|}
\hline & & 4 & 776,17 & 796,17 & 20 \\
\hline & & 5 & 970,21 & 995,21 & 25 \\
\hline & & 6 & 1164,25 & 1194,25 & 30 \\
\hline & & 7 & 1358,3 & 1393,30 & 35 \\
\hline & & 8 & 1552,34 & 1592,34 & 40 \\
\hline & & 9 & 1746,38 & 1791,38 & 45 \\
\hline & & 10 & 1940,42 & 1990,42 & 50 \\
\hline & & 11 & 2134,47 & 2189,47 & 55 \\
\hline & & 12 & 2328,51 & 2388,51 & 60 \\
\hline & & 13 & 2522,55 & 2587,55 & 65 \\
\hline & & 14 & 2716,59 & 2786,59 & 70 \\
\hline & & 15 & 2910,63 & 2985,63 & 75 \\
\hline & & 16 & 3104,68 & 3184,68 & 80 \\
\hline & & 17 & 3298,72 & 3374,97 & 76,25 \\
\hline & & 18 & 3492,76 & 3565,26 & 72,5 \\
\hline & & 19 & 3686,8 & 3755,55 & 68,75 \\
\hline & & 20 & 3880,85 & 3945,85 & 65 \\
\hline & & 21 & 4074,89 & 4136,14 & 61,25 \\
\hline & & 22 & 4268,93 & 4326,43 & 57,5 \\
\hline & & 23 & 4462,97 & 4516,72 & 53,75 \\
\hline & & 24 & 4657,01 & 4707,01 & 50 \\
\hline $\begin{array}{c}\text { Temp de } \\
\text { confort }\end{array}$ & C & $\mathrm{H}$ & G & $U$ & B \\
\hline \multirow[t]{11}{*}{260} & 990 & 0 & 0 & 0 & 0 \\
\hline & & 1 & 208,81 & 211,93 & 3,13 \\
\hline & & 2 & 417,61 & 423,86 & 6,25 \\
\hline & & 3 & 626,42 & 635,79 & 9,38 \\
\hline & & 4 & 835,23 & 847,73 & 12,5 \\
\hline & & 5 & 1044,03 & 1059,66 & 15,62 \\
\hline & & 6 & 1252,84 & 1271,59 & 18,75 \\
\hline & & 7 & 1461,64 & 1483,52 & 21,88 \\
\hline & & 8 & 1670,45 & 1695,45 & 25 \\
\hline & & 9 & 1879,26 & 1907,38 & 28,12 \\
\hline & & 10 & 2088,06 & 2119,31 & 31,25 \\
\hline
\end{tabular}




\begin{tabular}{|c|c|c|c|c|c|}
\hline & & 11 & 2296,87 & 2331,25 & 34,38 \\
\hline & & 12 & 2505,68 & 2543,18 & 37,5 \\
\hline & & 13 & 2714,48 & 2755,11 & 40,62 \\
\hline & & 14 & 2923,29 & 2967,04 & 43,75 \\
\hline & & 15 & 3132,1 & 3178,97 & 46,87 \\
\hline & & 16 & 3340,9 & 3390,90 & 50 \\
\hline & & 17 & 3549,71 & 3596,58 & 46,88 \\
\hline & & 18 & 3758,51 & 3802,26 & 43,75 \\
\hline & & 19 & 3967,32 & 4007,95 & 40,63 \\
\hline & & 20 & 4176,13 & 4213,63 & 37,5 \\
\hline & & 21 & 4384,93 & 4419,31 & 34,37 \\
\hline & & 22 & 4593,74 & 4624,99 & 31,25 \\
\hline & & 23 & 4802,55 & 4830,67 & 28,13 \\
\hline & & 24 & 5011,35 & 5036,35 & 25 \\
\hline $\begin{array}{l}\text { Temp de } \\
\text { confort }\end{array}$ & C & $\mathrm{H}$ & G & U & B \\
\hline \multirow[t]{18}{*}{$27^{\circ}$} & 1070 & 0 & 0 & 0 & 0 \\
\hline & & 1 & 225,68 & 228,18 & 2,5 \\
\hline & & 2 & 451,36 & 456,36 & 5 \\
\hline & & 3 & 677,04 & 684,54 & 7,5 \\
\hline & & 4 & 902,72 & 912,72 & 10 \\
\hline & & 5 & 1128,4 & 1140,90 & 12,5 \\
\hline & & 6 & 1354,08 & 1369,08 & 15 \\
\hline & & 7 & 1579,76 & 1597,26 & 17,5 \\
\hline & & 8 & 1805,44 & 1825,44 & 20 \\
\hline & & 9 & 2031,12 & 2053,62 & 22,5 \\
\hline & & 10 & 2256,8 & 2281,80 & 25 \\
\hline & & 11 & 2482,48 & 2509,98 & 27,5 \\
\hline & & 12 & 2708,16 & 2738,16 & 30 \\
\hline & & 13 & 2933,83 & 2966,33 & 32,5 \\
\hline & & 14 & 3159,51 & 3194,51 & 35 \\
\hline & & 15 & 3385,19 & 3422,69 & 37,5 \\
\hline & & 16 & 3610,87 & 3650,87 & 40 \\
\hline & & 17 & 3836,55 & 3873,68 & 37,12 \\
\hline
\end{tabular}




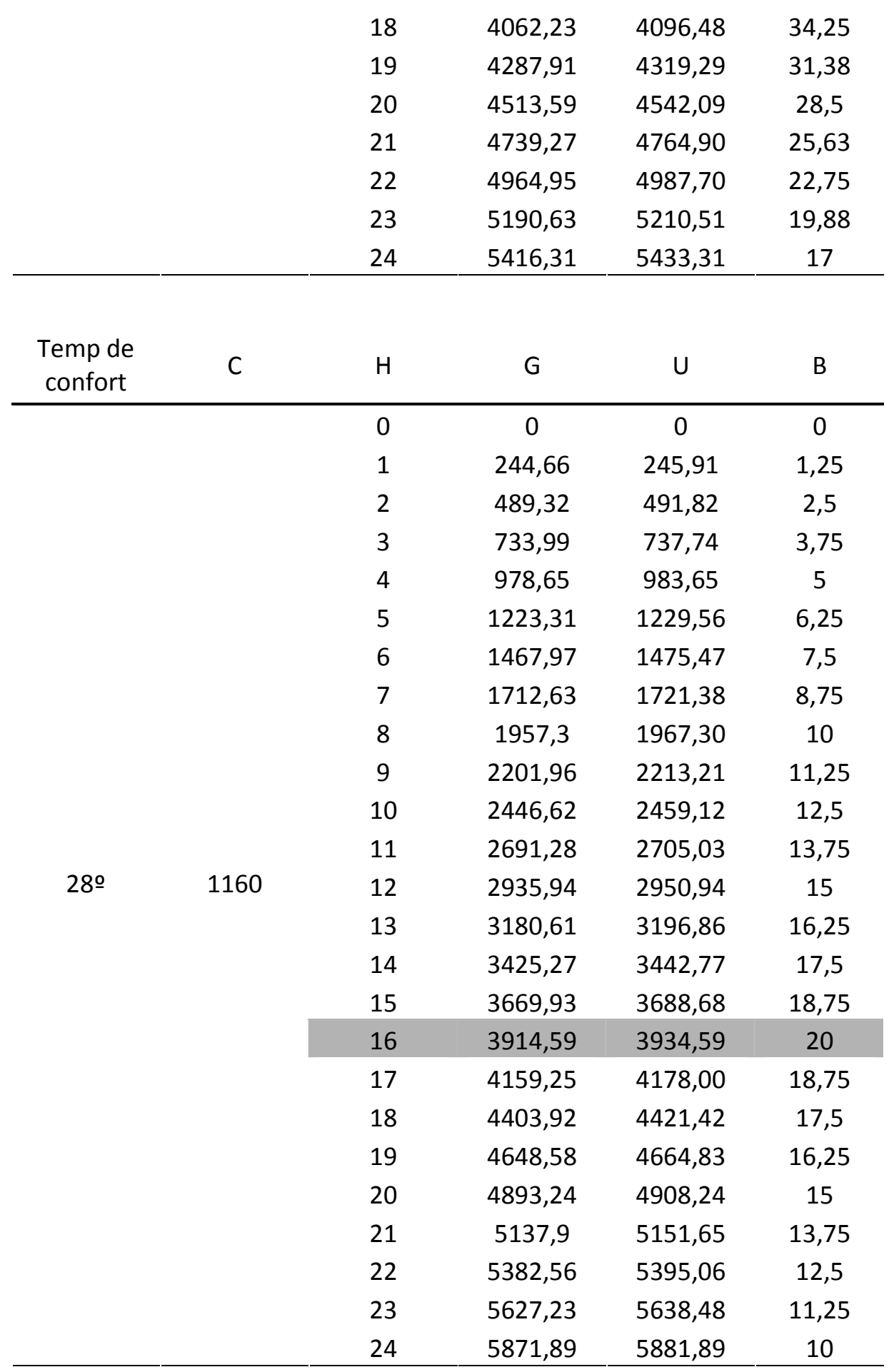




\begin{tabular}{|c|c|c|c|c|c|}
\hline $\begin{array}{l}\text { Temp de } \\
\text { confort }\end{array}$ & C & $\mathrm{H}$ & G & $U$ & B \\
\hline & & 0 & 0 & 0 & 0 \\
\hline & & 1 & 263,64 & 264,27 & 0,63 \\
\hline & & 2 & 527,29 & 528,54 & 1,25 \\
\hline & & 3 & 790,93 & 792,81 & 1,88 \\
\hline & & 4 & 1054,58 & 1057,08 & 2,5 \\
\hline & & 5 & 1318,22 & 1321,35 & 3,13 \\
\hline & & 6 & 1581,87 & 1585,62 & 3,75 \\
\hline & & 7 & 1845,51 & 1849,89 & 4,38 \\
\hline & & 8 & 2109,16 & 2114,16 & 5 \\
\hline & & 9 & 2372,8 & 2378,42 & 5,63 \\
\hline & & 10 & 2636,44 & 2642,69 & 6,25 \\
\hline & & 11 & 2900,09 & 2906,96 & 6,88 \\
\hline \multirow[t]{13}{*}{290} & 1250 & 12 & 3163,73 & 3171,23 & 7,5 \\
\hline & & 13 & 3427,38 & 3435,50 & 8,13 \\
\hline & & 14 & 3691,02 & 3699,77 & 8,75 \\
\hline & & 15 & 3954,67 & 3964,04 & 9,38 \\
\hline & & 16 & 4218,31 & 4228,31 & 10 \\
\hline & & 17 & 4481,95 & 4490,70 & 8,75 \\
\hline & & 18 & 4745,6 & 4753,10 & 7,5 \\
\hline & & 19 & 5009,24 & 5015,49 & 6,25 \\
\hline & & 20 & 5272,89 & 5277,89 & 5 \\
\hline & & 21 & 5536,53 & 5540,28 & 3,75 \\
\hline & & 22 & 5800,18 & 5802,68 & 2,5 \\
\hline & & 23 & 6063,82 & 6065,07 & 1,25 \\
\hline & & 24 & 6327,47 & 6327,47 & 0 \\
\hline
\end{tabular}

\section{I.1.1.1. Iluminación}

En principio, debería ser un elemento muy estacional; sin embargo, como el día simulado es laborable, en realidad no hay grandes diferencias en el grado de uso que se ha considerado. 
Invierno

\begin{tabular}{lccccc}
\hline \multirow{2}{*}{ Estancia } & \multicolumn{5}{c}{ Laborable } \\
\cline { 2 - 6 } & $\mathrm{C}$ & $\mathrm{H}$ & $\mathrm{G}$ & $\mathrm{U}$ & $\mathrm{B}$ \\
\hline & 40 & 0 & 0 & 0 & 0 \\
& 40 & 1 & 23,2 & 48,3 & 25,1 \\
& 40 & 2 & 46,4 & 96,7 & 50,2 \\
& 40 & 3 & 69,7 & 145 & 75,3 \\
& 40 & 4 & 92,9 & 165 & 71,7 \\
Cocina & 40 & 5 & 116 & 184 & 68,1 \\
& 40 & 6 & 139 & 204 & 64,5 \\
& 40 & 7 & 163 & 223 & 60,9 \\
& 40 & 8 & 186 & 243 & 57,3 \\
& 40 & 9 & 209 & 263 & 53,7 \\
& 40 & 10 & 232 & 282 & 50,1 \\
40 & 11 & 255 & 302 & 46,5 \\
& 40 & 12 & 279 & 322 & 42,9 \\
40 & 13 & 302 & 341 & 39,3 \\
& 40 & 14 & 325 & 361 & 35,7 \\
40 & 15 & 348 & 380 & 32,1 \\
& 40 & 16 & 372 & 400 & 28,5 \\
40 & 17 & 395 & 420 & 24,9 \\
40 & 18 & 418 & 439 & 21,3 \\
40 & 19 & 441 & 459 & 17,7 \\
40 & 20 & 464 & 479 & 14,1 \\
& 40 & 21 & 488 & 498 & 10,5 \\
40 & 22 & 511 & 518 & 6,86 \\
& 40 & 23 & 534 & 537 & 3,26 \\
& 40 & 24 & 557 & 557 & $-0,3$ \\
\hline & & & &
\end{tabular}

\section{Verano}

\begin{tabular}{cccccc}
\hline \multirow{2}{*}{ Estancia } & \multicolumn{6}{c}{ Laborable } \\
\cline { 2 - 6 } & $\mathrm{C}$ & $\mathrm{H}$ & $\mathrm{G}$ & $\mathrm{U}$ & $\mathrm{B}$ \\
\hline Cocina & 40 & 0 & 0 & 0 & 0 \\
& 40 & 1 & 23,2 & 61 & 37,8
\end{tabular}




\begin{tabular}{ccccc}
40 & 2 & 46,4 & 122 & 75,6 \\
40 & 3 & 69,7 & 141,77 & 72,1 \\
40 & 4 & 92,9 & 161,55 & 68,7 \\
40 & 5 & 116 & 181,32 & 65,2 \\
40 & 6 & 139 & 201,09 & 61,8 \\
40 & 7 & 163 & 220,86 & 58,3 \\
40 & 8 & 186 & 240,64 & 54,9 \\
40 & 9 & 209 & 260,41 & 51,4 \\
40 & 10 & 232 & 280,18 & 48 \\
40 & 11 & 255 & 299,95 & 44,5 \\
40 & 12 & 279 & 319,73 & 41,1 \\
40 & 13 & 302 & 339,5 & 37,6 \\
40 & 14 & 325 & 359,27 & 34,2 \\
40 & 15 & 348 & 379,05 & 30,7 \\
40 & 16 & 372 & 398,82 & 27,3 \\
40 & 17 & 395 & 418,59 & 23,8 \\
40 & 18 & 418 & 438,36 & 20,4 \\
40 & 19 & 441 & 458,14 & 16,9 \\
40 & 20 & 464 & 477,91 & 13,5 \\
40 & 21 & 488 & 497,68 & 10 \\
40 & 22 & 511 & 517,45 & 6,55 \\
40 & 23 & 534 & 537,23 & 3,1 \\
40 & 24 & 557 & 557 & $-0,3$ \\
\hline & & & &
\end{tabular}

Verano/Invierno

\begin{tabular}{cccccc}
\hline \multirow{2}{*}{ Estancia } & \multicolumn{5}{c}{ Laborable } \\
\cline { 2 - 6 } Salón & $\mathrm{C}$ & $\mathrm{H}$ & $\mathrm{G}$ & $\mathrm{U}$ & $\mathrm{B}$ \\
& 240 & 0 & 0 & 0 & 0 \\
& 240 & 1 & 139,34 & 164,33 & 24,996 \\
& 240 & 2 & 278,67 & 328,67 & 49,992 \\
& 240 & 3 & 418,01 & 493,00 & 74,989 \\
& 240 & 4 & 557,35 & 628,76 & 71,413 \\
& 240 & 5 & 696,69 & 764,52 & 67,838 \\
& 240 & 6 & 836,02 & 900,29 & 64,263 \\
& 240 & 7 & 975,36 & 1036,05 & 60,688 \\
& & & & \\
\hline \multirow{5}{*}{309}
\end{tabular}




\begin{tabular}{ccccc}
240 & 8 & 1114,7 & 1171,81 & 57,113 \\
240 & 9 & 1254 & 1307,57 & 53,537 \\
240 & 10 & 1393,4 & 1443,33 & 49,962 \\
240 & 11 & 1532,7 & 1579,10 & 46,387 \\
240 & 12 & 1672 & 1714,86 & 42,812 \\
240 & 13 & 1811,4 & 1850,62 & 39,237 \\
240 & 14 & 1950,7 & 1986,38 & 35,661 \\
240 & 15 & 2090,1 & 2122,14 & 32,086 \\
240 & 16 & 2229,4 & 2257,90 & 28,511 \\
240 & 17 & 2368,7 & 2393,67 & 24,936 \\
240 & 18 & 2508,1 & 2529,43 & 21,361 \\
240 & 19 & 2647,4 & 2665,19 & 17,785 \\
240 & 20 & 2786,7 & 2800,95 & 14,21 \\
240 & 21 & 2926,1 & 2936,71 & 10,635 \\
240 & 22 & 3065,4 & 3072,48 & 7,0597 \\
240 & 23 & 3204,8 & 3208,24 & 3,4845 \\
240 & 24 & 3344,1 & 3344 & $-0,0907$ \\
\hline
\end{tabular}

En el alumbrado de las habitaciones, como la iluminación de ambas es la misma (2 lámparas $60 \mathrm{~W}$ ), se suman las horas de las 2.

Verano /Invierno

\begin{tabular}{cccccc}
\hline \multirow{2}{*}{ Estancia } & \multicolumn{5}{c}{ Laborable } \\
\cline { 2 - 6 } habitaciones & $\mathrm{C}$ & $\mathrm{H}$ & $\mathrm{G}$ & $\mathrm{U}$ & $\mathrm{B}$ \\
& 120 & 0 & 0 & 0 & 0 \\
& 120 & 1 & 69,669 & 84,8 & 15,131 \\
& 120 & 2 & 139,34 & 169,60 & 30,263 \\
& 120 & 3 & 209,01 & 254,40 & 45,394 \\
& 120 & 4 & 278,67 & 339,20 & 60,526 \\
& 120 & 5 & 348,34 & 424,00 & 75,657 \\
& 120 & 6 & 418,01 & 489,68 & 71,673 \\
& 120 & 7 & 487,68 & 555,37 & 67,689 \\
& 120 & 8 & 557,35 & 621,05 & 63,704 \\
& 120 & 9 & 627,02 & 686,74 & 59,72 \\
& 120 & 10 & 696,69 & 752,42 & 55,735 \\
& 120 & 11 & 766,35 & 818,11 & 51,751 \\
& 120 & 12 & 836,02 & 883,79 & 47,767
\end{tabular}




\begin{tabular}{lcccc}
120 & 13 & 905,69 & 949,47 & 43,782 \\
120 & 14 & 975,36 & 1015,16 & 39,798 \\
120 & 15 & 1045 & 1080,84 & 35,814 \\
120 & 16 & 1114,7 & 1146,53 & 31,829 \\
120 & 17 & 1184,4 & 1212,21 & 27,845 \\
120 & 18 & 1254 & 1277,89 & 23,861 \\
120 & 19 & 1323,7 & 1343,58 & 19,876 \\
120 & 20 & 1393,4 & 1409,26 & 15,892 \\
120 & 21 & 1463 & 1474,95 & 11,908 \\
120 & 22 & 1532,7 & 1540,63 & 7,9233 \\
120 & 23 & 1602,4 & 1606,32 & 3,939 \\
120 & 24 & 1672 & 1672,00 & $-0,0454$ \\
\hline
\end{tabular}

\section{I.2. Instrucciones a los participantes}

\section{I.2.1. Instrucciones generales}

El propósito de esta sesión experimental es estudiar el comportamiento energético de los individuos en el hogar. Durante su desarrollo, tendrás que simular la actividad de una familia en cuanto a su consumo eléctrico en el hogar durante varios meses.

Durante la sesión experimental verás una pantalla en la que deberás seleccionar, para un día tipo, el uso que quieres darle a cada uno de los electrodomésticos del hogar.

Cada electrodoméstico que utilices te proporcionará una ganancia en euros, pero a la vez te supondrá un gasto energético. Al final del experimento, ganarás la diferencia entre el precio que pagamos por el uso de cada electrodoméstico y el gasto que ello supone. Dicha cantidad se te pagará en efectivo de manera confidencial inmediatamente después. Adicionalmente y sólo por participar te corresponde un pago fijo de $5 €$.

Es muy importante que preguntes (alzando la mano) todas las dudas que te surjan a lo largo de la sesión. Fuera de esas preguntas, cualquier tipo de comunicación con los demás participantes en la sesión está totalmente prohibida y sujeta a expulsión de la sesión.

En el programa vas a simular el comportamiento energético de una familia a lo largo de un año y medio. Cada mes estará representado por un 
único día tipo; lo que decidas para ese día se repetirá para los restantes 29 días del mes. Los días tipo se irán alternando: 3 de invierno, que representarán 3 meses, 3 de verano, y así sucesivamente.

En cada día tipo, tendrás que seleccionar los electrodomésticos que quieres utilizar, el modo y el número de usos semanales o diarios. Por cada uso que hagas de un electrodoméstico te pagaremos un precio determinado, llamado utilidad, pero a la vez te supondrá un gasto energético, en euros también. Tu ganancia final dependerá de la diferencia entre la utilidad que obtengas y el gasto que ello suponga.

En la pantalla de simulación del día tipo, se muestran los electrodomésticos y el alumbrado de la vivienda. Uno por uno, deberás ir seleccionando los que quieres utilizar y en qué medida. Al lado de cada uno de ellos, cuando los selecciones, puedes ver la utilidad que tienen, es decir, el precio que pagamos por su uso. La utilidad será función del número de usos semanales o el número de horas diarias que se utilice; el gasto también. Las casillas elegidas se vuelven de color azul. Las no elegidas permanecen blancas.

Parte de los electrodomésticos se seleccionan por horas, por ejemplo el alumbrado o la TV. En cada uno de ellos, el número de horas que selecciones se considerará igual todos los días de ese mes. Por ejemplo, si eliges ver la TV durante 8 horas al día, la verás 8 horas al día durante todo el mes en curso. Al presentarte la factura mensual, el gasto que se haga en este tipo de electrodomésticos se multiplicará por 30 para simular los 30 días del mes

En otros electrodomésticos, como la lavadora, se selecciona tanto el número de usos semanales como el número de usos diario. Por ejemplo, eligiendo martes y jueves a las 12:00 y a las 4:00, se está eligiendo un uso total de 4 veces por semana. Al presentarte la factura mensual, el gasto que se haga en los electrodomésticos que se eligen por semana, como la lavadora, se multiplicarán por 4 para simular las 4 semanas del mes.

La calefacción se encuentra dividida en 4 tramos horarios; puedes elegir la temperatura que quieres en cada uno de esos tramos y las horas en las que vas a tenerla en marcha.

Por último, existen electrodomésticos en los que no puedes hacer nada, como el frigorífico. Se trata de electrodomésticos que permanecen encendidos las 24 horas del día. 
En todos los casos, la utilidad que se muestra en pantalla ya se corresponde con la utilidad mensual.

Al decidir qué electrodomésticos vas a utilizar y en qué grado, ten en cuenta que la vivienda está ocupada por una familia de 3 miembros (padre, madre y un hijo); la mejor forma de maximizar tus ganancias es hacer un uso razonable de la energía teniendo en cuenta este hecho.

Al terminar el "mes", es decir, cuando termines de rellenar un día tipo, se te presentará una factura eléctrica y una de gas, correspondientes al mes que acabas de rellenar. En ella verás también la utilidad total que has obtenido con tu comportamiento mensual. Tu objetivo final debe ser maximizar la diferencia entre la utilidad total y el precio de la factura, que será el dinero que ganes al terminar el experimento.

\subsubsection{Pantalla de programación}

En la parte de arriba de la pantalla se muestra el tipo de día: invierno o verano. Esto influye en la calefacción, que desaparece en verano, y en las horas de luz, que cambian.

El resto de la pantalla se encuentra dividida en estancias: la cocina, las habitaciones, el salón y el baño. En cada una de ellas se encuentran los electrodomésticos básicos que suelen ubicarse en ellas. Cada electrodoméstico tiene una serie de casillas de selección, que se van a explicar seguidamente.

El uso de cualquier electrodoméstico se selecciona para empezar pulsando el cuadrado de selección que se encuentra a la derecha de su nombre. Mientras no se seleccione la casilla se encuentra de color blanco; al seleccionarla, se vuelve de color azul.

Con esa selección no es suficiente para que funcione: una vez seleccionado el electrodoméstico se debe programar lo que se va a hacer con él, es decir, en función del tipo que sea, el número de horas, el de días de la semana, la hora de inicio u otros. Los colores de las casillas de programación funcionan del mismo modo que las de uso: blanco no seleccionado, azul seleccionado. 
El electrodoméstico no está en funcionamiento hasta que no se hayan pulsado tanto las casillas de uso como las de programación. En cuanto está en funcionamiento, su casilla de Utilidad muestra el valor total de ésta.

\subsubsection{Iluminación}

Existen 4 puntos de selección de iluminación: en la cocina, el salón, la habitación de los padres y la del hijo. Todos funcionan de la misma forma: al seleccionar su uso (pulsando en el cuadrado de la derecha del nombre), se selecciona por defecto la luz encendida las 24 horas del día, lo que se ve en el programa porque todos los cuadrados de selección de hora están de color azul. El alumno debe apagar la luz en las horas en las que no quiera que ésta permanezca encendida. Hay un icono al lado de cada hora, mostrando si es de día o de noche.

I.2.2.2. Horno, microondas, vitrocerámica, tostadora, plancha y calefactor

Todos funcionan de la misma forma: primero se selecciona su uso, después el número de días de la semana que va a utilizarse, y después la o las horas del día en las que va a ponerse. Por ejemplo, se puede poner la plancha los sábados a las 12:00, lo cual supondría un uso de un ciclo semanal, o se puede poner la vitrocerámica los lunes, martes y miércoles a las 12:00 y a las 20:00, para hacer la comida y la cena esos tres días de la semana. Eso supondría un uso de 6 ciclos por semana.

\subsubsection{Lavadora y lavaplatos}

Permiten elegir los días y horas de uso, como el grupo del horno, pero además hay que seleccionar el tipo de programa con el que se va a lavar. También se puede elegir entre dejarlas en stand-by (con el piloto destellando cuando terminan), o apagarlas con el botón de on/off (casilla "apagado total").

\subsubsection{Frigorífico y MODEM/router}

Están pero no dejan hacer nada con ellos, dado que se encuentran encendidos las 24 horas del día. Supondrán un consumo energético del que no se puede prescindir. 
1.2.2.5. Ordenador fijo, $T V$, equipo de música, ordenador portátil

Se selecciona el número de horas que se desea usar y el stand-by o el apagado total. En el caso del ordenador, el stand-by significa dejarlo encendido y cerrar la pantalla, y en el TV y equipo de música, dejarlos preparados para encenderlos con el mando a distancia.

\subsubsection{Higiene personal}

En los muñequitos, la primera columna se refiere al padre, la segunda a la madre y la tercera al niño. Cada uno de ellos puede elegir hasta dos lavados diarios, del tipo que deseen. La primera ducha es enjabonándose con el grifo cerrado, la segunda con el grifo abierto. La caldera es de gas, luego el gasto correspondiente a este término se encontrará en la factura de gas.

\subsubsection{Calefacción}

Se puede elegir la temperatura (así como encender o apagar la calefacción), en 4 tramos diferentes del día. Por ejemplo, para bajarla por la noche o apagarla si se sale de casa durante muchas horas. Este término también pertenece a la factura de gas. Sólo aparecerá en los días de invierno; en los de verano desaparece.

\section{I.3. Estudio estadístico de los resultados experimentales}

\section{I.3.1. Estadísticos descriptivos}

Estadísticos descriptivos. Consumos

Tratamiento 1.- Básico

\begin{tabular}{cccccc} 
Sesión & N & Mínimo & Máximo & Media & Desv. típ. \\
\hline Mes 1 & 30 & 1357,08 & 6364,92 & 3129,13 & 1022,27 \\
Mes 2 & 30 & 1686,78 & 6389,37 & 3382,24 & 1111,39 \\
Mes 3 & 30 & 1909,32 & 6238,72 & 3351,83 & 1030,36 \\
Mes 4 & 30 & 1296,31 & 4809,83 & 2839,83 & 884,1 \\
Mes 5 & 30 & 1296,31 & 4735,3 & 2928,48 & 946,28 \\
Mes 6 & 30 & 1296,31 & 6387,95 & 3158,17 & 1269,46 \\
Mes 7 & 30 & 1864,93 & 6713,07 & 3695,19 & 1361,65 \\
Mes 8 & 30 & 1889,69 & 6890,77 & 3667,38 & 1271,41
\end{tabular}




\begin{tabular}{cccccc} 
Mes 9 & 30 & 1964,01 & 7483,61 & 3832,64 & 1332,38 \\
Mes 10 & 30 & 882,47 & 6340,79 & 3131,59 & 1267,06 \\
Mes 11 & 30 & 1296,31 & 6790,18 & 3112,66 & 1171,5 \\
Mes 12 & 30 & 1296,31 & 6665,17 & 3185,87 & 1083,44 \\
Mes 13 & 30 & 2000,23 & 7574,27 & 3675,95 & 1257,58 \\
Mes 14 & 30 & 2002,62 & 8823,04 & 3859,97 & 1443,22 \\
Mes 15 & 30 & 1996,6 & 8823,04 & 3840,01 & 1470,25 \\
Mes 16 & 30 & 1296,31 & 8655,85 & 3329,74 & 1382,21 \\
Mes 17 & 30 & 1296,31 & 8697,92 & 3242 & 1430,32 \\
Mes 18 & 30 & 1285,38 & 8940,59 & 3184,92 & 1463,87 \\
Media del & 30 & 1651,06 & 6112,5 & 3287,73 & 961,59 \\
invierno 1 & & & & & \\
Media del & 30 & 1296,31 & 5085,1 & 2975,49 & 985,66 \\
verano 1 & & & & & \\
Media del & 30 & 1906,21 & 7029,15 & 3731,74 & 1292,58 \\
invierno 2 & & & & & \\
Media del & 30 & 1296,31 & 6589,94 & 3143,37 & 1131,85 \\
verano 2 & & & & & \\
$\begin{array}{c}\text { Media del } \\
\text { invierno 3 }\end{array}$ & 30 & 2081,67 & 8406,78 & 3791,98 & 1375,59 \\
$\begin{array}{c}\text { Media del } \\
\text { verano 3 }\end{array}$ & 30 & 1296,31 & 8764,79 & 3252,22 & 1415,78 \\
$\begin{array}{c}\text { Media } \\
\text { Inviernos }\end{array}$ & 30 & 1962,23 & 6258,68 & 3603,81 & 1098,16 \\
$\begin{array}{c}\text { Media } \\
\text { Veranos }\end{array}$ & 30 & 1296,31 & 6639,89 & 3123,69 & 1091,9 \\
Media total & 30 & 1793,66 & 6449,29 & 3363,75 & 1059,77 \\
\hline & & & & & \\
\hline
\end{tabular}

Estadísticos descriptivos. Consumos

\begin{tabular}{lccccc}
\hline & \multicolumn{4}{c}{ Tratamiento 2.- Consejos } \\
Sesión & N & Mínimo & Máximo & Media & Desv. típ. \\
\hline Mes 1 & 23 & 1530,06 & 5807,61 & 3235,6 & 1115,14 \\
Mes 2 & 23 & 1729,78 & 7556,93 & 3013,33 & 1297,59 \\
Mes 3 & 23 & 1431,87 & 4959,79 & 3031,44 & 1073,24 \\
Mes 4 & 23 & 1233,05 & 8362,68 & 2702,26 & 1613,31 \\
Mes 5 & 23 & 609,3 & 11276,77 & 2659,84 & 2111,62
\end{tabular}




\begin{tabular}{cccccc} 
Mes 6 & 23 & 729,28 & 4514,5 & 2416,08 & 980,79 \\
Mes 7 & 23 & 1094,67 & 8945,45 & 3294,97 & 1569,11 \\
Mes 8 & 23 & 940,13 & 14210,67 & 3559,64 & 2633 \\
Mes 9 & 23 & 983,41 & 10466,97 & 3408,86 & 1835,27 \\
Mes 10 & 23 & 1032,07 & 7737,86 & 2993,25 & 1744,66 \\
Mes 11 & 23 & 1006,58 & 13289,02 & 3353,8 & 2821,8 \\
Mes 12 & 23 & 1341,48 & 12164,37 & 3245,86 & 2541,52 \\
Mes 13 & 23 & 1426,14 & 9841,28 & 3843,64 & 1965,14 \\
Mes 14 & 23 & 818,91 & 9562,6 & 3980,33 & 2400,2 \\
Mes 15 & 23 & 1564,45 & 11352,82 & 3577,14 & 2387,3 \\
Mes 16 & 23 & 848,6 & 8213,76 & 2803,39 & 1668,49 \\
Mes 17 & 23 & 1229,3 & 8122,78 & 2773,1 & 1644,04 \\
Mes 18 & 23 & 1152,12 & 7682,55 & 2886,22 & 1761,95 \\
Media del & 23 & 1600,74 & 6002,78 & 3093,45 & 1024,13 \\
invierno 1 & & & & & \\
Media del & 23 & 958,31 & 8051,32 & 2592,73 & 1455,83 \\
verano 1 & & & & & \\
Media del & 23 & 1006,07 & 11207,7 & 3421,15 & 1964,1 \\
invierno 2 & & & & & \\
Media del & 23 & 1254,09 & 8471,01 & 3197,63 & 2184,3 \\
verano 2 & & & & & \\
Media del & 23 & 1396,69 & 9283,92 & 3800,37 & 2164,94 \\
invierno 3 & & & & & \\
Media del & 23 & 1118,12 & 8006,36 & 2820,9 & 1649,47 \\
verano 3 & & & & & \\
Media & 23 & 1334,5 & 8831,47 & 3438,33 & 1531,83 \\
Inviernos & & & & & \\
Media & 23 & 1184,34 & 6686,36 & 2870,42 & 1480,83 \\
Veranos & & & & & \\
Media total & 23 & 1259,42 & 7758,91 & 3154,37 & 1464,79 \\
\hline
\end{tabular}

Estadísticos descriptivos. Consumos

\begin{tabular}{cccccc}
\hline & \multicolumn{5}{c}{ Tratamiento 3.- Contador desagregado } \\
\cline { 2 - 6 } Sesión & $\mathrm{N}$ & Mínimo & Máximo & Media & Desv. típ. \\
\hline Mes 1 & 30 & 1852,94 & 9273,4 & 3989,32 & 1684,41 \\
Mes 2 & 30 & 603,8 & 9632,16 & 4022,29 & 2058,17
\end{tabular}




\begin{tabular}{cccccc} 
Mes 3 & 30 & 1869,19 & 7994,01 & 4147,42 & 1797,93 \\
Mes 4 & 30 & 1418,97 & 8010,85 & 3650,78 & 1696,14 \\
Mes 5 & 30 & 1213,96 & 9061,55 & 3613,31 & 1740,57 \\
Mes 6 & 30 & 1101,4 & 8962,06 & 3609,96 & 1641,08 \\
Mes 7 & 30 & 1297,46 & 9100,29 & 3952,18 & 1712,28 \\
Mes 8 & 30 & 1457,86 & 9311,62 & 3978,74 & 1782,02 \\
Mes 9 & 30 & 1652,92 & 9183,57 & 4080,52 & 1695,43 \\
Mes 10 & 30 & 1643,31 & 7958,8 & 3636,24 & 1405,46 \\
Mes 11 & 30 & 1866,95 & 7124,06 & 3602,13 & 1263,3 \\
Mes 12 & 30 & 1692,23 & 7140,47 & 3587,75 & 1283,96 \\
Mes 13 & 30 & 0 & 7229,8 & 3953,85 & 1554,75 \\
Mes 14 & 30 & 1968,43 & 7516,43 & 4168,13 & 1395,65 \\
Mes 15 & 30 & 1811,67 & 7255,17 & 4199,73 & 1345,17 \\
Mes 16 & 30 & 1427,49 & 6535,62 & 3792,57 & 1390,66 \\
Mes 17 & 30 & 1311,38 & 6896,9 & 3760,2 & 1402,87 \\
Mes 18 & 30 & 1311,38 & 6549,8 & 3676,68 & 1347,89 \\
Media del & 30 & 1883,9 & 8903,46 & 4053,01 & 1791,4 \\
invierno 1 & & & & & \\
Media del & 30 & 1394,85 & 8518,47 & 3624,68 & 1651,37 \\
verano 1 & & & & & \\
Media del & 30 & 1469,41 & 9198,49 & 4003,81 & 1722,78 \\
invierno 2 & & & & & \\
Media del & 30 & 1747,55 & 7407,78 & 3608,71 & 1308,22 \\
verano 2 & & & & & \\
Media del & 30 & 1920,93 & 7333,8 & 4107,24 & 1379,77 \\
invierno 3 & & & & & \\
Media del & 30 & 1350,08 & 6425,97 & 3743,15 & 1367,5 \\
verano 3 & & & & & \\
Media & 30 & 2092,64 & 7833,34 & 4054,69 & 1493,56 \\
Inviernos & & & & & \\
Media & 30 & 1699,41 & 7398,47 & 3658,85 & 1386,79 \\
Veranos & & & & & \\
Media total & 30 & 2055,72 & 7615,9 & 3856,77 & 1420,8 \\
\hline & & & & & \\
\hline
\end{tabular}

Estadísticos descriptivos. Consumos 


\begin{tabular}{cccccc} 
& $\mathrm{N}$ & Mínimo & Máximo & Media & Desv. típ. \\
\hline Mes 1 & 30 & 1887,99 & 5639,07 & 3196,36 & 927,38 \\
Mes 2 & 30 & 1560,14 & 5704,16 & 3371,85 & 1068,64 \\
Mes 3 & 30 & 1506,28 & 6649 & 3467,82 & 1270,29 \\
Mes 4 & 30 & 1128,24 & 4621,94 & 2794,7 & 1047,3 \\
Mes 5 & 30 & 1065,59 & 5528,12 & 2881,84 & 1119,32 \\
Mes 6 & 30 & 1070,23 & 6219,91 & 2840,92 & 1232,24 \\
Mes 7 & 30 & 1133,01 & 12079,38 & 3475,3 & 2087,84 \\
Mes 8 & 30 & 1035,47 & 7272,24 & 3453,76 & 1500,41 \\
Mes 9 & 30 & 1139,51 & 7272,24 & 3529,66 & 1539,1 \\
Mes 10 & 30 & 1176,66 & 6227,22 & 2985,1 & 1259,01 \\
Mes 11 & 30 & 1245,5 & 6227,22 & 2873,13 & 1137,17 \\
Mes 12 & 30 & 1291,06 & 6227,22 & 2878,33 & 1148,88 \\
Mes 13 & 30 & 1476,83 & 7341,91 & 3430,51 & 1350,14 \\
Mes 14 & 30 & 1476,83 & 7341,91 & 3457,24 & 1338,89 \\
Mes 15 & 30 & 1476,83 & 7341,91 & 3466,24 & 1386,17 \\
Mes 16 & 30 & 1206,68 & 6296,89 & 3021,22 & 1212,34 \\
Mes 17 & 30 & 1206,68 & 6296,89 & 3049,12 & 1266,54 \\
Mes 18 & 30 & 1206,68 & 6296,89 & 3049,12 & 1266,54 \\
Media del & 30 & 1687,81 & 5622,77 & 3345,35 & 1046,45 \\
invierno 1 & & & & & \\
Media del & 30 & 1088,02 & 5272,26 & 2839,15 & 1101,86 \\
verano 1 & & & & & \\
Media del & 30 & 1102,66 & 8874,62 & 3486,24 & 1658,74 \\
invierno 2 & & & & & \\
Media del & 30 & 1264,29 & 6227,22 & 2912,19 & 1162,99 \\
verano 2 & & & & & \\
Media del & 30 & 1476,83 & 7341,91 & 3451,33 & 1351,65 \\
invierno 3 & & & & & \\
Media del & 30 & 1206,68 & 6296,89 & 3039,82 & 1246,86 \\
verano 3 & & & & & \\
Media & 30 & 1532,01 & 7279,77 & 3427,64 & 1295,11 \\
Inviernos & & & & & \\
Media & 30 & 1240,72 & 5932,12 & 2930,39 & 1122,05 \\
Veranos & & & & & \\
Media total & 30 & 1490,25 & 6605,95 & 3179,01 & 1180,91 \\
\hline
\end{tabular}


Estadísticos descriptivos. Consumos

\begin{tabular}{|c|c|c|c|c|c|}
\hline \multirow[b]{2}{*}{ Sesión } & \multicolumn{4}{|c|}{ Tratamiento 8.- Rankings } & \multirow[b]{2}{*}{ Desv. típ. } \\
\hline & $\mathrm{N}$ & Mínimo & Máximo & Media & \\
\hline Mes 1 & 60 & 1421,32 & 9424,5 & 3937,27 & 1865,36 \\
\hline Mes 2 & 60 & 1189,09 & 6968,7 & 3587,06 & 1392,83 \\
\hline Mes 3 & 60 & 1203,49 & 7334,11 & 3445,64 & 1320,25 \\
\hline Mes 4 & 60 & 770,21 & 7230,9 & 2647,01 & 1301,75 \\
\hline Mes 5 & 60 & 935,87 & 7928,08 & 2697,56 & 1392,52 \\
\hline Mes 6 & 60 & 1014,23 & 7849,7 & 2673,87 & 1218,78 \\
\hline Mes 7 & 60 & 1079,43 & 8798,92 & 3226,8 & 1544,53 \\
\hline Mes 8 & 60 & 919,12 & 9065,83 & 3281,58 & 1538,49 \\
\hline Mes 9 & 60 & 863,85 & 8172,36 & 3255,06 & 1473,51 \\
\hline Mes 10 & 60 & 967,91 & 6827,68 & 2732 & 1239,31 \\
\hline Mes 11 & 60 & 869,26 & 6827,68 & 2694,73 & 1320,99 \\
\hline Mes 12 & 60 & 1003,18 & 6758 & 2837,14 & 1343,91 \\
\hline Mes 13 & 60 & 1060,85 & 7734,67 & 3316,16 & 1390,17 \\
\hline Mes 14 & 60 & 1129,98 & 7794,75 & 3344,71 & 1404,77 \\
\hline Mes 15 & 60 & 967,43 & 7748,91 & 3373,55 & 1399,51 \\
\hline Mes 16 & 60 & 546,51 & 7828,96 & 2916,24 & 1381,28 \\
\hline Mes 17 & 60 & 546,51 & 7931,14 & 2837,94 & 1389,96 \\
\hline Mes 18 & 60 & 546,51 & 7828,96 & 2836,74 & 1347,99 \\
\hline $\begin{array}{l}\text { Media del } \\
\text { invierno } 1\end{array}$ & 60 & 1271,3 & 7759,16 & 3656,65 & 1406,89 \\
\hline $\begin{array}{l}\text { Media del } \\
\text { verano } 1\end{array}$ & 60 & 1055,54 & 7333,5 & 2672,82 & 1238,52 \\
\hline $\begin{array}{l}\text { Media del } \\
\text { invierno } 2\end{array}$ & 60 & 1002,07 & 8679,04 & 3254,48 & 1496,56 \\
\hline $\begin{array}{l}\text { Media del } \\
\text { verano } 2\end{array}$ & 60 & 975,26 & 6804,45 & 2754,62 & 1270,63 \\
\hline $\begin{array}{l}\text { Media del } \\
\text { invierno } 3\end{array}$ & 60 & 1085,34 & 7759,44 & 3344,81 & 1382,94 \\
\hline $\begin{array}{l}\text { Media del } \\
\text { verano } 3\end{array}$ & 60 & 546,51 & 7863,02 & 2863,64 & 1352,93 \\
\hline $\begin{array}{c}\text { Media } \\
\text { Inviernos }\end{array}$ & 60 & 1119,57 & 7724,13 & 3418,65 & 1287,83 \\
\hline
\end{tabular}




\begin{tabular}{cccccc}
$\begin{array}{c}\text { Media } \\
\text { Veranos }\end{array}$ & 60 & 900,89 & 5930,11 & 2763,69 & 1146,19 \\
Media total & 60 & 1010,23 & 6827,12 & 3091,17 & 1185,52 \\
\hline
\end{tabular}

Estadísticos descriptivos. Beneficio

\begin{tabular}{|c|c|c|c|c|c|}
\hline \multirow[b]{3}{*}{ Sesión } & \multirow{2}{*}{\multicolumn{5}{|c|}{ Tratamiento 1.- Beneficios Básico }} \\
\hline & & & & & \\
\hline & $\mathrm{N}$ & Mínimo & Máximo & Media & Desv. típ. \\
\hline Mes 1 & 30 & 324,43 & 670,09 & 514,04 & 85,09 \\
\hline Mes 2 & 30 & 359,78 & 700,19 & 534,48 & 92,5 \\
\hline Mes 3 & 30 & 324,02 & 696,06 & 530,84 & 97,03 \\
\hline Mes 4 & 30 & 317,33 & 607,83 & 466,82 & 79,03 \\
\hline Mes 5 & 30 & 316,83 & 594,8 & 459,05 & 78,13 \\
\hline Mes 6 & 30 & 287,65 & 566,95 & 458,95 & 79,57 \\
\hline Mes 7 & 30 & 357,42 & 696,96 & 543,17 & 81,09 \\
\hline Mes 8 & 30 & 376,77 & 696,96 & 547,09 & 83,57 \\
\hline Mes 9 & 30 & 376,77 & 708,7 & 547,99 & 84,69 \\
\hline Mes 10 & 30 & 182,01 & 575,93 & 465,4 & 87,76 \\
\hline Mes 11 & 30 & 284,2 & 584,4 & 470,26 & 77,23 \\
\hline Mes 12 & 30 & 317,98 & 596,82 & 461,63 & 75,32 \\
\hline Mes 13 & 30 & 396,86 & 718,75 & 535,41 & 86,53 \\
\hline Mes 14 & 30 & 408,83 & 744,68 & 549,45 & 85,7 \\
\hline Mes 15 & 30 & 394,56 & 771,35 & 549,72 & 86,61 \\
\hline Mes 16 & 30 & 317,98 & 596 & 468,89 & 72,44 \\
\hline Mes 17 & 30 & 317,98 & 594,74 & 462,34 & 68,95 \\
\hline Mes 18 & 30 & 317,98 & 594,74 & 466,47 & 74,34 \\
\hline $\begin{array}{l}\text { Media del } \\
\text { invierno } 1\end{array}$ & 30 & 336,08 & 679,26 & 526,45 & 85,37 \\
\hline $\begin{array}{c}\text { Media del } \\
\text { verano } 1\end{array}$ & 30 & 317,98 & 578,09 & 461,61 & 75,23 \\
\hline $\begin{array}{l}\text { Media del } \\
\text { invierno } 2\end{array}$ & 30 & 370,32 & 696,96 & 546,08 & 79,48 \\
\hline $\begin{array}{c}\text { Media del } \\
\text { verano } 2\end{array}$ & 30 & 271,81 & 584,82 & 465,76 & 77,2 \\
\hline $\begin{array}{l}\text { Media del } \\
\text { invierno } 3\end{array}$ & 30 & 400,08 & 743,48 & 544,86 & 84,43 \\
\hline
\end{tabular}




\begin{tabular}{cccccc}
$\begin{array}{c}\text { Media del } \\
\text { verano 3 }\end{array}$ & 30 & 317,98 & 595,16 & 465,9 & 69,24 \\
$\begin{array}{c}\text { Media } \\
\text { Inviernos }\end{array}$ & 30 & 390,8 & 701,69 & 539,13 & 75,5 \\
$\begin{array}{c}\text { Media } \\
\text { Veranos }\end{array}$ & 30 & 317,98 & 582,31 & 464,42 & 67,92 \\
Media total & 30 & 377,27 & 638,71 & 501,78 & 67,03 \\
\hline
\end{tabular}

Estadísticos descriptivos. Beneficio

\begin{tabular}{cccccc} 
& \multicolumn{5}{c}{ Tratamiento 2.- Beneficios Consejos } \\
\cline { 2 - 6 } Sesión & $\mathrm{N}$ & Mínimo & Máximo & Media & Desv. típ. \\
\cline { 2 - 6 } Mes 1 & 23 & 392,86 & 692,74 & 544,71 & 80,9 \\
Mes 2 & 23 & 323,51 & 682,18 & 499,47 & 90,03 \\
Mes 3 & 23 & 334,56 & 1068,21 & 538,04 & 148,46 \\
Mes 4 & 23 & 284,8 & 641,37 & 459,01 & 92,44 \\
Mes 5 & 23 & 239,31 & 648,7 & 433,35 & 108,27 \\
Mes 6 & 23 & 287,49 & 658,1 & 442,77 & 109,28 \\
Mes 7 & 23 & 347,1 & 738,48 & 554,51 & 96,36 \\
Mes 8 & 23 & 233,74 & 812,81 & 528,66 & 136,24 \\
Mes 9 & 23 & 305,7 & 1069,11 & 565,57 & 156,12 \\
Mes 10 & 23 & 304,27 & 675 & 501,05 & 101,24 \\
Mes 11 & 23 & 144,74 & 691,6 & 460,6 & 126,21 \\
Mes 12 & 23 & 273,27 & 683,9 & 454,98 & 112,32 \\
Mes 13 & 23 & 356,53 & 813,37 & 554,25 & 112,83 \\
Mes 14 & 23 & 264,56 & 786,44 & 542,13 & 118,82 \\
Mes 15 & 23 & 333,65 & 1065,44 & 578,04 & 167,25 \\
Mes 16 & 23 & 219,17 & 1001,16 & 485,71 & 158,96 \\
Mes 17 & 23 & 324,66 & 994,79 & 511,17 & 151,46 \\
Mes 18 & 23 & 187,5 & 1036,01 & 477,51 & 180,91 \\
Media del & 23 & 363,28 & 716,79 & 527,4 & 80,71 \\
invierno 1 & & & & & \\
Media del & 23 & 305,76 & 638,31 & 445,04 & 88,14 \\
verano 1 & & & & & \\
Media del & 23 & 308,18 & 791,79 & 549,58 & 112,23 \\
invierno 2 & & & & &
\end{tabular}




\begin{tabular}{cccccc}
$\begin{array}{c}\text { Media del } \\
\text { verano 2 }\end{array}$ & 23 & 294,36 & 683,5 & 472,21 & 96,88 \\
$\begin{array}{c}\text { Media del } \\
\text { invierno 3 }\end{array}$ & 23 & 351,26 & 795,06 & 558,14 & 123,36 \\
$\begin{array}{c}\text { Media del } \\
\text { verano 3 }\end{array}$ & 23 & 279,79 & 1010,65 & 491,46 & 158,95 \\
$\begin{array}{c}\text { Media } \\
\text { Inviernos } \\
\text { Media }\end{array}$ & 23 & 351,28 & 749,96 & 545,04 & 87,91 \\
$\quad 23$ & 293,3 & 650,19 & 469,57 & 95,72 \\
$\quad$ Veranos & 23 & 340,05 & 700,08 & 507,31 & 85,1 \\
\hline
\end{tabular}

Estadísticos descriptivos. Beneficios

\begin{tabular}{cccccc} 
& \multicolumn{5}{c}{ Tratamiento 3.- Beneficios Contador desagregado } \\
\cline { 2 - 6 } Sesión & $\mathrm{N}$ & Mínimo & Máximo & Media & Desv. típ. \\
\hline Mes 1 & 30 & 118,93 & 712,15 & 544,91 & 115,5 \\
Mes 2 & 30 & 105,89 & 756,81 & 562,41 & 128,36 \\
Mes 3 & 30 & 357,66 & 836,84 & 602,46 & 109,97 \\
Mes 4 & 30 & 335,44 & 721,62 & 511,7 & 94,57 \\
Mes 5 & 30 & 304,71 & 965,52 & 531,29 & 128,54 \\
Mes 6 & 30 & 299,06 & 723,66 & 516,65 & 112,19 \\
Mes 7 & 30 & 346,13 & 831,04 & 575,98 & 120,33 \\
Mes 8 & 30 & 346,13 & 831,04 & 583,17 & 117,71 \\
Mes 9 & 30 & 417,91 & 1429,86 & 632,28 & 184,14 \\
Mes 10 & 30 & 323,29 & 735,28 & 536,43 & 101,29 \\
Mes 11 & 30 & 328,44 & 741,66 & 540,29 & 106,19 \\
Mes 12 & 30 & 363,5 & 741,66 & 543,34 & 96,24 \\
Mes 13 & 30 & 0 & 827,11 & 587,83 & 157,53 \\
Mes 14 & 30 & 411,4 & 827,11 & 609,57 & 107,5 \\
Mes 15 & 30 & 408,85 & 827,11 & 607,85 & 105,48 \\
Mes 16 & 30 & 347,69 & 1033,87 & 569,9 & 152 \\
Mes 17 & 30 & 347,69 & 1048,48 & 575,52 & 165,35 \\
Mes 18 & 30 & 347,69 & 1033,87 & 577,59 & 164,9 \\
Media del & 30 & 325,87 & 724,17 & 569,93 & 97,09 \\
invierno 1 & & & & &
\end{tabular}




\begin{tabular}{|c|c|c|c|c|c|}
\hline $\begin{array}{c}\text { Media del } \\
\text { verano } 1\end{array}$ & 30 & 323,81 & 696,03 & 519,88 & 99,43 \\
\hline $\begin{array}{l}\text { Media del } \\
\text { invierno } 2\end{array}$ & 30 & 394,57 & 831,04 & 597,14 & 108,49 \\
\hline $\begin{array}{l}\text { Media del } \\
\text { verano } 2\end{array}$ & 30 & 338,41 & 739,53 & 540,02 & 98,56 \\
\hline $\begin{array}{l}\text { Media del } \\
\text { invierno } 3\end{array}$ & 30 & 374,71 & 827,11 & 601,75 & 114,95 \\
\hline $\begin{array}{c}\text { Media del } \\
\text { verano } 3\end{array}$ & 30 & 347,69 & 1033,87 & 574,33 & 159,82 \\
\hline $\begin{array}{c}\text { Media } \\
\text { Inviernos }\end{array}$ & 30 & 456,98 & 774,64 & 589,61 & 87,09 \\
\hline $\begin{array}{c}\text { Media } \\
\text { Veranos }\end{array}$ & 30 & 338,19 & 726,41 & 544,74 & 102,52 \\
\hline Media total & 30 & 414,23 & 749,31 & 567,18 & 89,56 \\
\hline
\end{tabular}

Estadísticos descriptivos. Beneficios

\begin{tabular}{cccccc} 
& \multicolumn{5}{c}{ Tratamiento 4.- Beneficios Contador único } \\
\cline { 2 - 6 } Sesión & $\mathrm{N}$ & Mínimo & Máximo & Media & Desv. típ. \\
\hline Mes 1 & 30 & 329,09 & 748,39 & 540,56 & 92,39 \\
Mes 2 & 30 & 404,98 & 748,39 & 564,78 & 87,6 \\
Mes 3 & 30 & 394,76 & 767,1 & 565,26 & 97,51 \\
Mes 4 & 30 & 291,83 & 650,96 & 485,13 & 90,18 \\
Mes 5 & 30 & 252,51 & 654,28 & 490,72 & 106,56 \\
Mes 6 & 30 & 261,08 & 661,42 & 489,75 & 112,17 \\
Mes 7 & 30 & 315,87 & 793,6 & 555,06 & 125,03 \\
Mes 8 & 30 & 297,45 & 809,09 & 580,14 & 115,58 \\
Mes 9 & 30 & 300,47 & 809,09 & 584,24 & 127,14 \\
Mes 10 & 30 & 275,94 & 680,73 & 511,82 & 108,21 \\
Mes 11 & 30 & 319,5 & 680,73 & 508,91 & 101,1 \\
Mes 12 & 30 & 308,48 & 680,73 & 512,06 & 97,81 \\
Mes 13 & 30 & 372,53 & 809,09 & 586,31 & 106,87 \\
Mes 14 & 30 & 418,83 & 809,09 & 588,07 & 99,9 \\
Mes 15 & 30 & 382,03 & 809,09 & 582,25 & 108,35 \\
Mes 16 & 30 & 328,95 & 733,3 & 522,02 & 105,28 \\
Mes 17 & 30 & 298,92 & 733,3 & 521,03 & 106,12
\end{tabular}




\begin{tabular}{cccccc}
$\begin{array}{c}\text { Mes 18 } \\
\text { Media del } \\
\text { invierno 1 }\end{array}$ & 30 & 298,92 & 733,3 & 521,03 & 106,12 \\
$\begin{array}{c}\text { Media del } \\
\text { verano 1 }\end{array}$ & 30 & 268,47 & 653,17 & 488,53 & 100,19 \\
$\begin{array}{c}\text { Media del } \\
\text { invierno 2 }\end{array}$ & 30 & 311,47 & 803,93 & 573,15 & 119,31 \\
$\begin{array}{c}\text { Media del } \\
\text { verano 2 }\end{array}$ & 30 & 318,93 & 680,73 & 510,93 & 100,08 \\
$\begin{array}{c}\text { Media del } \\
\text { invierno 3 }\end{array}$ & 30 & 391,13 & 809,09 & 585,54 & 103,04 \\
$\begin{array}{c}\text { Media del } \\
\text { verano 3 }\end{array}$ & 30 & 308,93 & 733,3 & 521,36 & 105,57 \\
$\begin{array}{c}\text { Media } \\
\text { Inviernos }\end{array}$ & 30 & 386,04 & 789,21 & 571,85 & 95,23 \\
$\quad$ Media & 30 & 314,03 & 679,99 & 506,94 & 95,99 \\
$\begin{array}{c}\text { Veranos } \\
\text { Media total }\end{array}$ & 30 & 350,04 & 721,6 & 539,4 & 92,12 \\
\hline
\end{tabular}

Estadísticos descriptivos. Beneficios

\begin{tabular}{cccccc} 
& \multicolumn{5}{c}{ Tratamiento 8.- Beneficios Rankings } \\
\cline { 2 - 6 } Sesión & $\mathrm{N}$ & Mínimo & Máximo & Media & Desv. típ. \\
\hline Mes 1 & 60 & 323,85 & 772,37 & 537,62 & 104,76 \\
Mes 2 & 60 & 283,65 & 761,97 & 551,02 & 104,45 \\
Mes 3 & 60 & 294,26 & 1143,17 & 568,85 & 146,01 \\
Mes 4 & 60 & 217,8 & 1259,81 & 478,62 & 145,92 \\
Mes 5 & 60 & 144,87 & 836,04 & 447,86 & 107,33 \\
Mes 6 & 60 & 146,15 & 644,88 & 449,32 & 100,08 \\
Mes 7 & 60 & 246,24 & 765,55 & 521,58 & 124,63 \\
Mes 8 & 60 & 227,79 & 765,55 & 528,75 & 114,26 \\
Mes 9 & 60 & 292,58 & 1091,85 & 568,78 & 145,45 \\
Mes 10 & 60 & 216,59 & 1101,98 & 465,09 & 126,97 \\
Mes 11 & 60 & 262,44 & 1101,98 & 462,94 & 123,91 \\
Mes 12 & 60 & 215,61 & 685,69 & 458,93 & 96,92 \\
Mes 13 & 60 & 267,95 & 734,62 & 540,38 & 102,48 \\
Mes 14 & 60 & 242,08 & 734,34 & 542,34 & 111,87
\end{tabular}




\begin{tabular}{cccccc} 
Mes 15 & 60 & 303,64 & 1176,08 & 583,67 & 154,28 \\
Mes 16 & 60 & 215,95 & 1136,17 & 488,15 & 131,1 \\
Mes 17 & 60 & 215,95 & 1136,17 & 480,74 & 133,76 \\
Mes 18 & 60 & 215,95 & 694,43 & 471,79 & 96,6 \\
$\begin{array}{c}\text { Media del } \\
\text { invierno 1 }\end{array}$ & 60 & 351,44 & 801 & 552,49 & 101,18 \\
$\begin{array}{c}\text { Media del } \\
\text { verano 1 }\end{array}$ & 60 & 261,11 & 688,25 & 458,6 & 89,07 \\
$\begin{array}{c}\text { Media del } \\
\text { invierno 2 }\end{array}$ & 60 & 266,34 & 797,36 & 539,71 & 113,94 \\
$\begin{array}{c}\text { Media del } \\
\text { verano 2 }\end{array}$ & 60 & 231,55 & 954,73 & 462,32 & 110,88 \\
$\begin{array}{c}\text { Media del } \\
\text { invierno 3 }\end{array}$ & 60 & 271,22 & 881,59 & 555,46 & 111,56 \\
$\begin{array}{c}\text { Media del } \\
\text { verano 3 }\end{array}$ & 60 & 215,95 & 988,92 & 480,23 & 114,64 \\
$\begin{array}{c}\text { Media } \\
\text { Inviernos }\end{array}$ & 60 & 311,96 & 826,65 & 549,22 & 101,12 \\
$\begin{array}{c}\text { Media } \\
\text { Veranos }\end{array}$ & 60 & 248,2 & 827,42 & 467,05 & 93,89 \\
\begin{tabular}{c} 
Media total \\
\hline
\end{tabular} & 60 & 280,08 & 827,03 & 508,13 & 94,2 \\
\hline
\end{tabular}

\section{I.3.2. Comparativas internas al tratamiento. Wilcoxon}

Estas comparativas se realizaron para comprobar si había algún dato relevante en la capacidad de aprendizaje de alguno de los tratamientos. Como no aparece ninguna tendencia de interés, no se nombra en el resto del trabajo. En color rojo se muestran los valores no significativos $(p>0,05)$.

Comparativas internas al tratamiento (Wilcoxon). Significatividad

\begin{tabular}{lllll}
\hline \multicolumn{5}{c}{ Consumos } \\
\hline Tratamiento & Inv1 a Inv2 & Inv1 a Inv3 & Ver1 a ver2 & Ver1 a ver3 \\
1 Básico & 0,003 & 0,016 & 0,009 & 0,043 \\
2 Consejos & 0,523 & 0,236 & 0,201 & 0,429 \\
3 Cont. desag & 0,465 & 0,171 & 0,417 & 0,405
\end{tabular}




\begin{tabular}{llllll}
4 Cont. único & 0,877 & 0,992 & 0,644 & 0,339 \\
8 Ranking & $\begin{array}{l}0,001 \\
\text { Beneficios }\end{array}$ & 0,026 & 0,512 & 0,26 \\
\hline \multicolumn{1}{c}{ Tratamiento } & Inv1 a Inv2 & Inv1 a Inv3 & Ver1 a ver2 & Ver1 a ver3 \\
1 Básico & 0,043 & 0,199 & 0,239 & 0,596 \\
2 Consejos & 0,447 & 0,584 & 0,039 & 0,301 \\
3 Cont. desag & 0,309 & 0,131 & 0,032 & 0,007 \\
4 Cont. único & 0,28 & 0,047 & 0,023 & 0,03 \\
8 Ranking & 0,26 & 0,93 & 0,561 & 0,128 \\
\hline
\end{tabular}

Comparativas internas al tratamiento (Wilcoxon). La media de un periodo al siguiente... (en gris, periodos no significativos)

Consumos

\begin{tabular}{|c|c|c|c|c|c|}
\hline & Tratamiento & Inv1 a Inv2 & Inv1 a Inv3 & Ver1 a ver2 & Ver1 a ver3 \\
\hline 1 & Básico & Aumenta & Aumenta & Aumenta & Aumenta \\
\hline 2 & Consejos & Aumenta & Aumenta & Aumenta & Aumenta \\
\hline 3 & Cont. desag & Disminuye & Aumenta & Disminuye & Aumenta \\
\hline 4 & Cont. único & Aumenta & Aumenta & Aumenta & Aumenta \\
\hline \multirow[t]{3}{*}{8} & Ranking & Disminuye & Disminuye & Aumenta & Aumenta \\
\hline & & Beneficios & & & \\
\hline & Tratamiento & Inv1 a Inv2 & Inv1 a Inv3 & Ver1 a ver2 & Ver1 a ver3 \\
\hline 1 & Básico & Aumenta & Aumenta & Aumenta & Aumenta \\
\hline 2 & Consejos & Aumenta & Aumenta & Aumenta & Aumenta \\
\hline 3 & Cont. desag & Aumenta & Aumenta & Aumenta & Aumenta \\
\hline 4 & Cont. único & Aumenta & Aumenta & Aumenta & Aumenta \\
\hline 8 & Ranking & Disminuye & Aumenta & Aumenta & Aumenta \\
\hline
\end{tabular}

Comparativas internas al tratamiento (Wilcoxon). Valores medios por estación (c€)

Tratamiento Inv 1 Ver $1 \quad$ Inv 2 Ver 2 Inv 3 Ver 3 consumo

1 Básico 3287,73 2975,49 $3731,74 \quad 3143,37 \quad 3791,98 \quad 3252,22$

2 Consejos $3093,45 \quad 2592,73 \quad 3421,15 \quad 3197,63 \quad 3800,37 \quad 2820,90$

3 Cont. desag 4053,01 3624,68 4003,81 3608,71 4107,24 3743,15

4 Cont. único 3345,35 2839,15 3486,24 2912,19 3451,33 3039,82 
8 Ranking $\quad 3656,65 \quad 2672,82 \quad 3254,48 \quad 2754,62 \quad 3344,81 \quad 2863,64$

beneficio

$\begin{array}{lcllllll}1 & \text { Básico } & 526,45 & 461,61 & 546,08 & 465,76 & 544,86 & 465,90 \\ 2 & \text { Consejos } & 527,40 & 445,04 & 549,58 & 472,21 & 558,14 & 491,46 \\ 3 & \text { Cont. desag } & 569,93 & 519,88 & 597,14 & 540,02 & 601,75 & 574,33 \\ 4 & \text { Cont. único } & 556,87 & 488,53 & 573,15 & 510,93 & 585,54 & 521,36 \\ 8 & \text { Ranking } & 552,49 & 458,60 & 539,71 & 462,32 & 555,46 & 480,23\end{array}$

\section{I.3.3. Comparativas entre tratamientos. Mann-Whitney}

En este test, como en el anterior, se marca en negro los valores con una significatividad $p<0,05$; en azul si se encuentra entre 0,05 y 0,1 , y en rojo por encima de estos valores.

\begin{tabular}{cccccc}
\multicolumn{7}{c}{$\begin{array}{c}\text { Comparativas entre tratamientos } \\
\text { (Mann-Whitney) }\end{array}$} \\
\hline \multicolumn{5}{c}{ Consumos } \\
Con los óptimos \\
\hline Inv1 & $0,7-1$ & $0,7-2$ & $0,7-3$ & $0,7-4$ & $0,7-8$ \\
Ver1 & 0,001 & 0 & 0,058 & 0 & 0,009 \\
Inv2 & 0,018 & 0 & 0,018 & 0 & 0 \\
Ver2 & 0,004 & 0 & 0,058 & 0,001 & 0 \\
Inv3 & 0,058 & 0,037 & 0,058 & 0,018 & 0 \\
Ver3 & 0,001 & 0 & 0,155 & 0,018 & 0 \\
Inv & 0 & 0,007 & 0,018 & 0,001 & 0 \\
Ver & 0 & 0 & 0,058 & 0,018 & 0 \\
Todo & 0 & 0 & 0,018 & 0,004 & 0 \\
\hline
\end{tabular}

Comparativas entre tratamientos (Mann-Whitney)

\begin{tabular}{ccccccc}
\hline \multicolumn{7}{c}{ Consumos } \\
Entre sí \\
\hline $1-2$ & $1-3$ & $1-4$ & $1-8$ & $3-4$ & $3-2$ & $3-8$ \\
0,306 & 0,231 & 0,882 & 0,211 & 0,249 & 0,055 & 0,515 \\
0,06 & 0,147 & 0,679 & 0,109 & 0,067 & 0,003 & 0,003
\end{tabular}




\begin{tabular}{ccccccc}
0,151 & 0,657 & 0,308 & 0,064 & 0,214 & 0,092 & 0,037 \\
0,151 & 0,169 & 0,383 & 0,081 & 0,046 & 0,024 & 0,002 \\
0,395 & 0,367 & 0,315 & 0,111 & 0,071 & 0,099 & 0,01 \\
0,088 & 0,128 & 0,554 & 0,128 & 0,03 & 0,005 & 0,001 \\
0,342 & 0,308 & 0,535 & 0,426 & 0,095 & 0,085 & 0,079 \\
0,127 & 0,147 & 0,5 & 0,134 & 0,041 & 0,014 & 0,004 \\
0,258 & 0,243 & 0,5 & 0,182 & 0,074 & 0,026 & 0,017 \\
\hline
\end{tabular}

Comparativas entre tratamientos (Mann-Whitney)

Beneficios

Con los óptimos

\begin{tabular}{cccccc}
\cline { 1 - 1 } & $0,7-1$ & $0,7-2$ & $0,7-3$ & $0,7-4$ & $0,7-8$ \\
Inv1 & 0 & 0 & 0 & 0 & 0 \\
Ver1 & 0 & 0 & 0 & 0 & 0 \\
Inv2 & 0 & 0 & 0 & 0 & 0 \\
Ver2 & 0 & 0 & 0 & 0 & 0 \\
Inv3 & 0 & 0 & 0 & 0 & 0 \\
Ver3 & 0 & 0 & 0 & 0 & 0 \\
Inv & 0 & 0 & 0 & 0 & 0 \\
Ver & 0 & 0 & 0 & 0 & 0 \\
Todo & 0 & 0 & 0 & 0 & 0 \\
\hline
\end{tabular}

Comparativas entre tratamientos (Mann-Whitney)

Beneficios

Entre sí

$\begin{array}{lllllll}1-2 & 1-3 & 1-4 & 1-8 & 3-4 & 3-2 & 3-8\end{array}$

$\begin{array}{lllllll}0,9 & 0,058 & 0,274 & 0,27 & 0,525 & 0,076 & 0,329\end{array}$

$\begin{array}{lllllll}0,3 & 0,014 & 0,183 & 0,74 & 0,315 & 0,004 & 0,005\end{array}$

$\begin{array}{lllllll}0,99 & 0,067 & 0,353 & 0,9 & 0,525 & 0,162 & 0,035\end{array}$

$\begin{array}{lllllll}0,07 & 0,006 & 0,055 & 0,6 & 0,367 & 0,025 & 0,001\end{array}$

$\begin{array}{lllllll}0,95 & 0,038 & 0,098 & 0,5 & 0,701 & 0,178 & 0,113\end{array}$

$\begin{array}{lllllll}0,66 & 0,003 & 0,025 & 0,6 & 0,375 & 0,037 & 0,005\end{array}$

$\begin{array}{lllllll}0,943 & 0,048 & 0,193 & 0,45 & 0,6 & 0,095 & 0,155\end{array}$ 


\begin{tabular}{ccccccc}
0,886 & 0,003 & 0,057 & 0,92 & 0,193 & 0,014 & 0,001 \\
0,858 & 0,007 & 0,081 & 0,7 & 0,375 & 0,025 & 0,008 \\
\hline
\end{tabular}

M-W CONSUMOS. SIGNIFICATIVIDAD NUMÉRICA

\begin{tabular}{cccccc}
\hline \multicolumn{7}{c}{ Medias Invierno } \\
Trat. & 0 & 1 & 2 & 3 & 4 \\
1 & 0 & & & & \\
2 & 0,007 & 0,342 & & & \\
3 & 0,018 & 0,308 & 0,085 & & \\
4 & 0,001 & 0,535 & 0,829 & 0,095 & \\
8 & 0 & 0,426 & 0,737 & 0,079 & 0,973 \\
\hline
\end{tabular}

M-W CONSUMOS. SIGNIFICATIVIDAD NUMÉRICA

\begin{tabular}{cccccc}
\hline \multicolumn{7}{c}{ Medias Verano } \\
Trat. & 7 & 1 & 2 & 3 & 4 \\
1 & 0 & & & & \\
2 & 0 & 0,127 & & & \\
3 & 0,058 & 0,147 & 0,014 & & \\
4 & 0,018 & 0,5 & 0,473 & 0,041 & \\
8 & 0 & 0,134 & 0,707 & 0,004 & 0,441 \\
\hline
\end{tabular}

M-W CONSUMOS. SIGNIFICATIVIDAD NUMÉRICA

\begin{tabular}{cccccc}
\hline \multicolumn{7}{c}{ Medias totales } \\
Trat. & $0 / 7$ & 1 & 2 & 3 & 4 \\
1 & 0 & & & & \\
2 & 0 & 0,258 & & & \\
3 & 0,018 & 0,243 & 0,026 & & \\
4 & 0,004 & 0,5 & 0,667 & 0,074 & \\
8 & 0 & 0,182 & 0,791 & 0,017 & 0,745 \\
\hline
\end{tabular}


M-W BENEFICIOS. SIGNIFICATIVIDAD NUMÉRICA

\begin{tabular}{cccccc}
\hline \multicolumn{6}{c}{ Medias Invierno } \\
Trat. & 0 & 1 & 2 & 3 & 4 \\
1 & 0 & & & & \\
2 & 0 & 0,943 & & & \\
3 & 0 & 0,048 & 0,095 & & \\
4 & 0 & 0,193 & 0,333 & 0,6 & 0,369 \\
8 & 0 & 0,45 & 0,604 & 0,155 & 0,35 \\
\hline
\end{tabular}

M-W BENEFICIOS. SIGNIFICATIVIDAD NUMÉRICA

\begin{tabular}{cccccc}
\hline \multicolumn{6}{c}{ Medias Verano } \\
Trat. & 7 & 1 & 2 & 3 & 4 \\
1 & 0 & & & & \\
2 & 0 & 0,886 & & & \\
3 & 0 & 0,003 & 0,014 & & \\
4 & 0 & 0,057 & 0,127 & 0,193 & \\
8 & 0 & 0,92 & 0,887 & 0,001 & 0,035 \\
\hline
\end{tabular}

M-W BENEFICIOS. SIGNIFICATIVIDAD NUMÉRICA

\begin{tabular}{cccccc}
\hline \multicolumn{7}{c}{ Medias totales } \\
Trat. & $0 / 7$ & 1 & 2 & 3 & 4 \\
1 & 0 & & & & \\
2 & 0 & 0,858 & & & \\
3 & 0 & 0,007 & 0,025 & & \\
4 & 0 & 0,081 & 0,19 & 0,375 & \\
8 & 0 & 0,7 & 0,871 & 0,008 & 0,13 \\
\hline
\end{tabular}


M-W CONSUMOS. SIGNIFICATIVIDAD NUMÉRICA

\begin{tabular}{cccccc}
\hline \multicolumn{7}{c}{ Medias totales } \\
Trat. & $0 / 7$ & 1 & 2 & 3 & 4 \\
1 & 0 & & & & \\
2 & 0 & 0,258 & & & \\
3 & 0,018 & 0,243 & 0,026 & & \\
4 & 0,004 & 0,5 & 0,667 & 0,074 & \\
8 & 0 & 0,182 & 0,791 & 0,017 & 0,745 \\
\hline
\end{tabular}

M-W BENEFICIOS. SIGNIFICATIVIDAD NUMÉRICA

\begin{tabular}{cccccc}
\hline \multicolumn{7}{c}{ Medias totales } \\
Trat. & $0 / 7$ & 1 & 2 & 3 & 4 \\
1 & 0 & & & & \\
2 & 0 & 0,858 & & & \\
3 & 0 & 0,007 & 0,025 & & \\
4 & 0 & 0,081 & 0,19 & 0,375 & \\
8 & 0 & 0,7 & 0,871 & 0,008 & 0,13 \\
\hline
\end{tabular}

M-W CONSUMOS. DIFERENCIA NUMÉRICA (SE RESTA LA COLUMNA DE LA FILA)

\begin{tabular}{cccccc}
\hline \multicolumn{5}{c}{ Medias Invierno } \\
Trat. & 0 & 1 & 2 & 3 & 4 \\
1 & $-546,34$ & & & & \\
2 & $-711,84$ & $-165,5$ & & & \\
3 & $-95,44$ & 450,9 & 616,4 & & \\
4 & $-722,44$ & $-176,1$ & $-10,6$ & -627 & \\
8 & $-731,54$ & $-185,2$ & $-19,7$ & $-636,1$ & $-9,1$ \\
\hline
\end{tabular}


M-W CONSUMOS. DIFERENCIA NUMÉRICA. (SE RESTA LA COLUMNA DE LA FILA)

\begin{tabular}{cccccc}
\hline \multicolumn{5}{c}{ Medias Verano } \\
Trat. & 7 & 1 & 2 & 3 & 4 \\
1 & $-462,66$ & & & & \\
2 & $-715,96$ & $-253,3$ & & & \\
3 & 72,44 & 535,1 & 788,4 & & \\
4 & $-655,96$ & $-193,3$ & 60 & $-728,4$ & \\
8 & $-822,66$ & -360 & $-106,7$ & $-895,1$ & $-166,7$ \\
\hline
\end{tabular}

M-W BENEFICIOS. DIFERENCIA NUMÉRICA. (SE RESTA LA COLUMNA DE LA FILA)

\begin{tabular}{cccccc}
\multicolumn{6}{c}{ Medias Invierno } \\
\hline Trat. & 0 & 1 & 2 & 3 & 4 \\
1 & $-402,19$ & & & & \\
2 & $-396,29$ & 5,9 & & & \\
3 & $-351,69$ & 50,5 & 44,6 & & \\
4 & $-369,39$ & 32,8 & 26,9 & $-17,7$ & \\
8 & $-392,09$ & 10,1 & 4,2 & $-40,4$ & $-22,7$ \\
\hline
\end{tabular}

M-W BENEFICIOS. DIFERENCIA NUMÉRICA. (SE RESTA LA COLUMNA DE LA FILA)

\begin{tabular}{cccccc}
\hline \multicolumn{5}{c}{ Medias Verano } \\
Trat. & 7 & 1 & 2 & 3 & 4 \\
1 & $-351,98$ & & & & \\
2 & $-346,78$ & 5,2 & & & \\
3 & $-271,68$ & 80,3 & 75,1 & & \\
4 & $-309,48$ & 42,5 & 37,3 & $-37,8$ & \\
8 & $-349,38$ & 2,6 & $-2,6$ & $-77,7$ & $-39,9$ \\
\hline
\end{tabular}


M-W CONSUMOS. DIFERENCIA NUMÉRICA. (SE RESTA LA COLUMNA DE LA FILA)

\begin{tabular}{cccccc}
\hline \multicolumn{5}{c}{ Medias totales } \\
Trat. & $0 / 7$ & 1 & 2 & 3 & 4 \\
1 & $-504,45$ & & & & \\
2 & $-713,85$ & $-209,4$ & & & \\
3 & $-11,45$ & 493 & 702,4 & & \\
4 & $-689,25$ & $-184,8$ & 24,6 & $-677,8$ & \\
8 & $-777,05$ & $-272,6$ & $-63,2$ & $-765,6$ & $-87,8$ \\
\hline
\end{tabular}

M-W BENEFICIOS. DIFERENCIA NUMÉRICA. (SE RESTA LA COLUMNA DE LA FILA)

\begin{tabular}{cccccc}
\hline \multicolumn{5}{c}{ Medias totales } \\
Trat. & $0 / 7$ & 1 & 2 & 3 & 4 \\
1 & -377 & & & & \\
2 & $-371,5$ & 5,5 & & & \\
3 & $-311,6$ & 65,4 & 59,9 & & \\
4 & $-339,4$ & 37,6 & 32,1 & $-27,8$ & \\
8 & $-370,7$ & 6,3 & 0,8 & $-59,1$ & $-31,3$ \\
\hline
\end{tabular}

M-W CONSUMOS. COMPARATIVA

\begin{tabular}{|c|c|c|c|c|c|}
\hline \multirow[b]{2}{*}{ Trat. } & \multicolumn{5}{|c|}{ Medias Invierno } \\
\hline & 0 & 1 & 2 & 3 & 4 \\
\hline 1 & $<$ & & & & \\
\hline 2 & $<$ & $<$ & & & \\
\hline 3 & $<$ & $>$ & $>$ & & \\
\hline 4 & $<$ & $<$ & $<$ & $<$ & \\
\hline 8 & $<$ & $<$ & $<$ & $<$ & $<$ \\
\hline
\end{tabular}


M-W CONSUMOS. COMPARATIVA

\begin{tabular}{cccccc}
\multicolumn{5}{c}{ M-W CONSUMOS. COMPARATIVA } \\
\hline Trat. & 7 & 1 & \multicolumn{5}{c}{ Medias Verano } \\
1 & $<$ & & & 3 & 4 \\
2 & $<$ & $<$ & & & \\
3 & $>$ & $>$ & $>$ & $<$ \\
4 & $<$ & $<$ & $>$ & $<$ \\
8 & $<$ & $<$ & $<$ & $<$ & \\
\hline
\end{tabular}

M-W BENEFICIOS. COMPARATIVA

\begin{tabular}{cccccc}
\hline & \multicolumn{5}{c}{ Medias Invierno } \\
Trat. & 0 & 1 & 2 & 3 & 4 \\
1 & $<$ & & & & \\
2 & $<$ & $>$ & $>$ & & \\
3 & $<$ & $>$ & $>$ & $<$ & \\
4 & $<$ & $>$ & $>$ & $<$ & $<$ \\
8 & $<$ & $>$ & $>$ & \\
\hline
\end{tabular}

M-W BENEFICIOS. COMPARATIVA

\begin{tabular}{ccccccc}
\hline & \multicolumn{5}{c}{ Medias Verano } \\
Trat. & 7 & 1 & 2 & 3 & 4 \\
1 & $<$ & & & & \\
2 & $<$ & $>$ & $>$ & & \\
3 & $<$ & $>$ & $>$ & $<$ & \\
4 & $<$ & $>$ & $<$ & $<$ & $<$ \\
8 & $<$ & $>$ & $<$ & $<$ \\
\hline
\end{tabular}

Test de Mann-Whitney. Comparativa y significatividad. El signo < significa que el valor de la fila es menor que el de la columna.

\begin{tabular}{|l|l|}
\hline & Significatividad $>0,1$ \\
\hline & $0,05<$ significatividad $<0,1$ \\
\hline & Significatividad $<0,05$ \\
\hline
\end{tabular}


M-W CONSUMOS. COMPARATIVA

\begin{tabular}{|c|c|c|c|c|c|}
\hline \multirow[b]{2}{*}{ Trat. } & \multicolumn{5}{|c|}{ Medias totales } \\
\hline & $0 / 7$ & 1 & 2 & 3 & 4 \\
\hline 1 & $<$ & & & & \\
\hline 2 & $<$ & $<$ & & & \\
\hline 3 & $<$ & $>$ & $>$ & & \\
\hline 4 & $<$ & $<$ & $>$ & $<$ & \\
\hline \multirow[t]{3}{*}{8} & $<$ & $<$ & $<$ & $<$ & $<$ \\
\hline & \multicolumn{5}{|c|}{ M-W BENEFICIOS. COMPARATIVA } \\
\hline & \multicolumn{5}{|c|}{ Medias totales } \\
\hline Trat. & $0 / 7$ & 1 & 2 & 3 & 4 \\
\hline 1 & $<$ & & & & \\
\hline 2 & $<$ & $>$ & & & \\
\hline 3 & $<$ & $>$ & $>$ & & \\
\hline 4 & $<$ & $>$ & $>$ & $<$ & \\
\hline 8 & $<$ & $>$ & $>$ & $<$ & 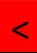 \\
\hline
\end{tabular}

Test de Mann-Whitney. Comparativa y significatividad de los totales.

\section{I.4. Cuestionarios}

\section{I.4.1. Cuestionario de concienciación medioambiental}

Se utilizó el siguiente cuestionario:

Estimado/a alumno/a, te rogamos cumplimentes esta encuesta, completamente confidencial y anónima, diseñada para estudiar diversas cuestiones relacionadas con el medio ambiente universitario. GRACIAS POR TU PARTICIPACIÓN.

1. ¿En qué lugar/es recibes habitualmente información sobre medio ambiente? (puedes marcar una respuesta o varias)

En clase.

En actividades desarrolladas en mi Centro.

En revistas o programas especializados. 
En los medios de comunicación.

No suelo recibir información sobre medio ambiente.

2. ¿En qué grado te consideras informado o informada sobre asuntos ambientales en tu centro de estudio?

Nada.

Poco.

Regular.

Bastante.

Mucho.

3. Todos los organismos públicos tienen un Área o Servicio dedicado a la protección del medio ambiente. ¿Sabes cuál es el de la Universidad?

Sí (especifica):

Sí, algo he oído pero no sé el nombre.

No.

4. ¿Sabías que existía una declaración de política ambiental en la UCO que muestra sus compromisos con el medio ambiente? En caso afirmativo, ¿cómo te has enterado?

Sí (especifica):

Sí, algo he oído pero no sé exactamente dónde.

No.

5. De los siguientes problemas actuales, puntúa los tres que más te preocupan ( 3 puntos para el que más, 2 puntos para el siguiente y 1 punto para el último)

Paro y economía.

Salud.

Medio ambiente.

Inmigración.

Vivienda. 
Seguridad ciudadana.

Desigualdad social.

Infraestructuras.

Educación.

Política.

Cultura/ Deporte.

Otros (especifica):

6. ¿Crees que tu actividad cotidiana afecta negativamente al medio ambiente?

No, nada.

Sí, un poco.

Sí, regular.

Sí, bastante.

Sí, mucho.

7. De los siguientes problemas ambientales en tu Centro, puntúa los tres que consideras más importantes ( 3 puntos para el que más, 2 puntos para el siguiente y 1 punto para el último)

Mal uso del transporte.

Inadecuada climatización.

Generación excesiva de residuos y falta de contenedores.

Mala gestión de residuos y vertidos en los laboratorios.

Mal control de plagas.

lluminación innecesaria.

Despilfarro de papel.

Ruidos.

Falta y mejora de espacios verdes.

Despilfarro de agua. 
Otros (especifica):

8. ¿Qué medio de transporte utilizas habitualmente para ir a clase? (1 respuesta)

Coche (ocupación habitual personas)

Autobús.

Moto.

Bicicleta.

Voy andando.

Tren.

9. ¿Cuál es la principal razón para utilizar ese medio de transporte? (1 respuesta)

Económica.

Distancia/tiempo.

Comodidad.

Respeto al medio ambiente.

Salud.

Seguridad.

Otros (especifica):

10. ¿Cuál es el código postal de tu vivienda?

11. De los siguientes contenedores para recogida selectiva de residuos, señala aquéllos que conoces o has utilizado en tu Centro.

ECOPUNTOS (cartuchos, pilas convencionales y pilas botón)

Móviles.

Papeleras para recogida selectiva de papel situadas en aulas.

Contenedores para residuos sólidos urbanos (materia orgánica, inertes, vidrio y papel).

Envases para residuos de laboratorio.

Otros (especifica): 
12. ¿Qué contenedores para residuos echas en falta en tu centro?:

13. ¿Utilizas los folios por las dos caras al tomar apuntes, imprimir o hacer fotocopias?

No lo hago ni lo haría.

No lo hago pero lo haría.

Sí, lo hago alguna vez.

Sí, lo hago bastantes veces.

Sí, lo hago siempre o casi siempre.

14. ¿Usas papel reciclado?

No lo hago ni lo haría.

No lo hago pero lo haría.

Sí, lo hago alguna vez.

Sí, lo hago bastantes veces.

Sí, lo hago siempre o casi siempre.

15. ¿Consideras interesante recibir formación/ información medioambiental en tu Centro? (puedes marcar una respuesta o varias)

No.

Sí, en cursos, charlas y jornadas.

Sí, en mis asignaturas.

Sí, en excursiones y visitas a empresas.

Sí, en folletos informativos, carteles, etc.

Otros (especifica):

16. ¿Participarías en posibles campañas medioambientales que se pudieran organizar (charlas, visitas, actividades de voluntariado, etc.)?

No, no creo que sirva de nada.

No, no tengo tiempo o la información/formación suficiente. 
No lo hago pero lo haría.

Sí, y no me importaría colaborar en la organización.

Sí, de hecho ya lo he hecho en alguna ocasión.

17. PARA TODOS LOS ALUMNOS Y ALUMNAS EXCEPTO LOS DE PRIMERO: ¿cómo consideras que está tu Centro desde el punto de vista ambiental con respecto al año anterior $u$ otros años?

Peor.

Está igual.

Mejor.

18. ¿Introducirías alguna mejora de carácter medioambiental en tu centro? En caso afirmativo, explica cuál/es.

Sí (especifica):

No.

A CONTINUACIÓN, PUNTÚA TU GRADO DE ACUERDO O DESACUERDO CON LAS SIGUIENTES AFIRMACIONES (1: Muy en desacuerdo; 2: En desacuerdo; 3: Indiferente; 4: De acuerdo; 5: Muy de acuerdo)

19. El ingenio humano asegurará que no hagamos de la tierra un lugar inhabitable.

20. Nos estamos aproximando al número límite de personas que la tierra puede albergar.

21. A pesar de nuestras habilidades especiales, los seres humanos todavía estamos sujetos

a las leyes de la naturaleza.

22. Las plantas y los animales tienen tanto derecho como los seres humanos a existir.

23. Los seres humanos tienen derecho a modificar el medio ambiente para adaptarlo a sus necesidades.

24. Con el tiempo, los seres humanos podrán aprender lo suficiente sobre el modo en que funciona la naturaleza para ser capaces de controlarla. 
25. La tierra tiene recursos naturales en abundancia, tan sólo tenemos que aprender a explotarlos.

26. Si las cosas continúan como hasta ahora, pronto experimentaremos una gran catástrofe ecológica.

27. El equilibrio de la naturaleza es muy delicado y fácilmente alterable.

28. La idea de que la humanidad va a enfrentarse a una crisis ecológica global se ha exagerado enormemente.

29. Los seres humanos están abusando seriamente del medio ambiente.

30. El equilibrio de la naturaleza es lo bastante fuerte para hacer frente al impacto que los países industrializados le causan.

31. Para conseguir el desarrollo sostenible, es necesaria una situación económica equilibrada en la que esté controlado el crecimiento industrial.

32. La tierra es como una nave espacial, con recursos y espacio limitados.

33. Cuando los seres humanos interfieren en la naturaleza, a menudo las consecuencias son desastrosas.

34. Los seres humanos fueron creados para dominar al resto de la naturaleza.

¿TIENES ALGUNA OBSERVACIÓN O SUGERENCIA? 


\section{Anexo II. Anexos al Experimento 2}

\section{II.1. Carta y encuesta de selección}

Los grupos I y II del experimento no 2 fueron convocados mediante la carta mostrada en la página siguiente. 
EVALUACIÓN DE TRATAMIENTOS PARA LA MEJORA DE LA EFICIENCIA ENERGÉTICA EN EL SECTOR DOMÉSTICO

La Cátedra BP de Ahorro y Eficiencia Energética de la Universitat Jaume I inicia un proyecto de investigación cuyo objetivo es evaluar diferentes métodos para la mejora de la eficiencia energética en el sector doméstico. Para ello, requerimos la participación voluntaria de 100 familias con las siguientes características:

- Familia de entre 3 y 4 miembros.

- Vivienda en Castellón de la Plana y utilizada de forma continuada durante los meses de mayo y junio.

Los participantes se dividirán en cuatro grupos de 25 familias. El primer grupo (T1) se utilizará como grupo de referencia y no se le aplicará ningún tratamiento. A los restantes tres grupos se les aplicará un método de ahorro determinado. Para los grupos T3 y T4, será necesaria la instalación de un dispositivo de medición en el cuadro eléctrico de la vivienda, y los habitantes deberán contar con un dispositivo móvil (teléfono o tableta) con sistema operativo Android, para poder visualizar su consumo en tiempo real. Si no dispone de él o no desea que se instale nada en su vivienda, igualmente puede participar como miembro de otro de los grupos.

A todos los participantes se les solicitarán las facturas eléctricas de los últimos años, lo que servirá como base para el estudio de los resultados.

Antes de iniciar el experimento los participantes deberán rellenar una encuesta sobre hábitos y características de su consumo energético. Igualmente se les convocará a una reunión en la universidad para establecer las condiciones del experimento.

La duración prevista del experimento es de dos meses.

Si Vd. está interesado en participar en el experimento puede completar la información adjunta y enviarla a la dirección mailto:administración@energyapps.escatedrabpenergia@gmail.com

Saludos y gracias por su atención 
Nombre.

Municipio

Superficie útil de la vivienda $\left(\mathrm{m}^{2}\right)$

Tfno de contacto.

e-mail de contacto

¿Le importaría que se instale en el cuadro eléctrico de su vivienda un equipo de medida? (Sin suponerle ningún coste y sin dejar ninguna huella una vez se retire)

Sí me importaría

No me importaría

¿Dispone de router WiFi en su vivienda y teléfono o tableta con el sistema operativo Android?

Sí

No

¿Conserva las facturas eléctricas de años anteriores (o tiene acceso a ellas por Internet)?

No (o no estoy dispuesto a mostrarlas)

Sí, de un año

Sí, de más de un año

Tipología de la vivienda

\begin{tabular}{|c|c|}
$\square$ Adosado / Unifamiliar & $\square$ Edificio de viviendas \\
\hline
\end{tabular}

Número de ocupantes de la vivienda (cantidad de cada tipo):

\begin{tabular}{|l|l|}
\hline Menor de 12 años & $18-65$ años \\
\hline $12-18$ años & Mayor de 65 años \\
\hline
\end{tabular}

Sistema de calefacción

\begin{tabular}{|c|c|}
\hline$\square$ Caldera de gas & $\square$ Bomba de calor \\
$\square$ Otros (especificar) & \\
\hline
\end{tabular}

Sistema de aire acondicionado

$\square$ Centralizado $\quad \square$ Bomba de calor
$\square$ Otros (especificar)




\section{Anexo III. Anexos al Experimento 3}

\section{III.1. Carta y encuesta de selección del grupo I}

Los participantes de los grupos I y II fueron convocados mediante la carta mostrada en la página siguiente. 


\section{EXPERIMENTO DE EFICIENCIA ENERGÉTICA EN VIVIENDA}

Buenos días,

Les informamos que, durante los meses de octubre, noviembre y diciembre del presente año, se llevarán a cabo en la Universitat Jaume I de Castellón una serie de estudios socio-económicos remunerados relacionados con el ahorro en el suministro eléctrico. Cada participante podrá ganar hasta un máximo de 100 euros en efectivo abonados a la conclusión del estudio, en función del ahorro energético alcanzado.

Para este estudio necesitamos participantes que reúnan las siguientes características:

- Clientes de Iberdrola (para el consumo eléctrico)

- Habitado en la misma vivienda al menos durante los años 2015 y 2016 (sin contabilizar el verano)

A los participantes se les solicitará:

- su usuario y contraseña de acceso a la oficina virtual de clientes de Iberdrola, garantizándoles previamente la confidencialidad de sus datos personales. Para el alta en la web de iberdrola se les facilitará una guía o si lo prefieren les podremos dar de alta nosotros mismos facilitándoles al momento todos los datos de la inscripción. Queremos reiterar que una vez pasado el periodo del experimento podrán cambiar la contraseña y automáticamente ya no tendremos acceso a ninguno de sus datos.

- La cumplimentación de un sencillo test de concienciación ecológica y hábitos energéticos, así como un pequeño cuestionario sobre el equipamiento de la vivienda.

- Un número de teléfono móvil o correo electrónico para el envío periódico de información. 

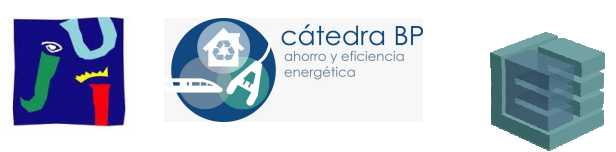

FORMULARIO DE REGISTRO

DATOS DEL PARTICIPANTE EN EXPERIMENTOS ECONÓMICOS

Nombre:

Apellidos:

$\mathrm{DNI} / \mathrm{NIE}$ :

Edad:

Fecha de nacimiento:

$\mathrm{N}^{\circ}$ Teléfono fijo:

$\mathrm{N}^{0}$ Teléfono móvil:

Email:

Superficie de la vivienda $\left(\mathrm{m}^{2}\right)$ :

Tipo de vivienda (edificio de viviendas / adosado / unifamiliar):

Localidad:

$\mathrm{N}^{\circ}$ de adultos que habitan la vivienda:

$N^{0}$ de niños que habitan la vivienda:

Tipo de calefacción (gas / estufas eléctricas / bomba de calor / otros (indicar)):

Tipo de cocina (eléctrica / gas.). 


\section{III.2. Encuesta final del experimento 3}

A continuación, debes contestar un total de 17 preguntas de test, de las cuales las dos primeras se refieren al experimento en el que has participado y el resto, a tus opiniones sobre el medio ambiente. En todas ellas excepto la primera, debes marcar una sola casilla. Gracias por tu participación.

Sobre el experimento en el que has participado:

1.- La diferencia entre los resultados de este año y del pasado, tanto si has consumido más como si has consumido menos, ¿̇a qué crees que se ha debido? (Puedes marcar varios puntos)

Cambios en el equipamiento de la vivienda

Cambios en el comportamiento de los miembros de la familia

Pura casualidad

$\square$ Otros (especificar)

2.- Te damos la posibilidad de donar a Greenpeace parte o toda tu ganancia en el experimento, o bien la cantidad de dinero que nos entregues. Si lo indicas así, lo haremos nosotros en tu nombre, en la página https://colabora.greenpeace.es/colabora/ , y te entregaremos justificante de ello:

Sí, dono todas mis ganancias en el experimento a Greenpeace

Sí, dono la siguiente parte de mis ganancias a Greenpeace: ...€

No quiero donar nada

Sobre la relación de la humanidad con el medio ambiente: 
1.- Nos acercamos al límite de población humana que la Tierra puede mantener.

Muy en desacuerdo

En desacuerdo

Indiferente

De acuerdo

Muy de acuerdo

2.-La humanidad tiene el derecho de modificar el medio ambiente para acomodarlo a sus necesidades

Muy en desacuerdo

En desacuerdo

Indiferente

De acuerdo

Muy de acuerdo

3.- Cuando la humanidad interfiere con la naturaleza, a menudo se producen consecuencias desastrosas

Muy en desacuerdo

En desacuerdo

Indiferente 
$\square$ De acuerdo

$\square$ Muy de acuerdo

4.- Gracias a la inteligencia humana, la Tierra no se convertirá nunca en un lugar inhabitable

$\square$ Muy en desacuerdo

$\square$ En desacuerdo

$\square$ Indiferente

$\square$ De acuerdo

$\square$ Muy de acuerdo

5.-La humanidad está maltratando gravemente el medio ambiente

$\square$ Muy en desacuerdo

$\square$ En desacuerdo

$\square$ Indiferente

$\square$ De acuerdo

Muy de acuerdo

6.- La Tierra está repleta de recursos naturales, sólo es necesario encontrar la forma de desarrollarlos.

Muy en desacuerdo 
En desacuerdo

Indiferente

De acuerdo

Muy de acuerdo

7.- Plantas y animales tienen el mismo derecho a vivir que las personas

Muy en desacuerdo

En desacuerdo

Indiferente

De acuerdo

Muy de acuerdo

8.- El equilibrio natural es lo bastante fuerte como para superar el impacto producido por las naciones industriales modernas

Muy en desacuerdo

En desacuerdo

Indiferente

De acuerdo

Muy de acuerdo 
9.- Pese a nuestras habilidades especiales, la humanidad sigue sometida a las leyes de la naturaleza.

$\square$ Muy en desacuerdo

$\square$ En desacuerdo

$\square$ Indiferente

$\square$ De acuerdo

$\square$ Muy de acuerdo

10.- La supuesta "crisis ecológica" que afronta la humanidad ha sido sumamente exagerada

$\square$ Muy en desacuerdo

$\square$ En desacuerdo

$\square$ Indiferente

De acuerdo

Muy de acuerdo

11.- La Tierra es como una nave espacial, con recursos y espacio limitados.

$\square$ Muy en desacuerdo

$\square$ En desacuerdo

$\square$ Indiferente 
De acuerdo

Muy de acuerdo

12.- La humanidad estaba destinada a gobernar sobre el resto de la naturaleza

Muy en desacuerdo

En desacuerdo

Indiferente

De acuerdo

Muy de acuerdo

13.- El equilibrio natural es muy delicado y de fácil perturbación

Muy en desacuerdo

En desacuerdo

Indiferente

De acuerdo

Muy de acuerdo

14.- Al final, la humanidad aprenderá suficiente sobre la naturaleza como para poder controlarla.

Muy en desacuerdo 
$\square$ En desacuerdo
$\square$ Indiferente
$\square$ De acuerdo
$\square$ Muy de acuerdo

15.- Si las cosas continúan como hasta ahora, pronto nos enfrentaremos a una catástrofe ecológica de grandes proporciones.

$\square$ Muy en desacuerdo

$\square$ En desacuerdo

$\square$ Indiferente

De acuerdo

Muy de acuerdo

\section{III.3. Comunicaciones vía mensaje de móvil o correo con los participantes del experimento 3}

\section{III.3.1. Comunicación de inicio del experimento, grupo I}

Asunto: Aviso Inicio Experimento Iberdrola

Hola, ya sabes que has sido seleccionado como participante en el experimento de ahorro eléctrico en vivienda.

El experimento da comienzo este lunes 17 de octubre, y durará previsiblemente hasta el 23 de diciembre de este año. Durante ese tiempo, debes procurar ahorrar todo lo posible en el consumo eléctrico de tu vivienda. 
Te pagaremos en función del ahorro que consigas, con un máximo de 100 euros. Es decir, si tu ahorro es de un 10\%, conseguirás 100 euros; si es de un $7,5 \%$, obtendrás 75 euros; si ahorras un 5\%, te daremos 50 euros. $Y$ así sucesivamente...

Este ahorro se calculará comparando el consumo total del 17-oct al 23dic del año 2015 con el consumo total del 17-oct al 23-dic de este año.

Recuerda que se trata de una carrera de fondo: tu comportamiento de cada día de esos dos meses y medio suma para el total. Para que sepas qué tal lo estás haciendo, cada semana te enviaré un whatsapp con tus datos hasta ese momento.

Si necesitas alguna aclaración, no dudes en preguntarme. Saludos y muchas gracias por participar.

\section{III.3.2. Comunicación de inicio del experimento, grupo II}

Asunto: Aviso Inicio Experimento Iberdrola

Hola, hoy lunes 17 de octubre da comienzo el experimento de ahorro eléctrico en vivienda. Durará previsiblemente hasta el 23 de diciembre de este año.

Simplemente, durante este tiempo estaré tomando datos de tu consumo para conocer tu comportamiento en cuanto al ahorro de energía eléctrica en tu vivienda. El ahorro se calculará comparando el consumo total del 17-oct al 23dic del año 2015 con el de las mismas fechas de este año.

Para que sepas qué tal lo estás haciendo, cada semana te enviaré un whatsapp con tus datos hasta ese momento.

Si necesitas alguna aclaración, no dudes en preguntarme. Saludos y muchas gracias por participar. 
III.3.3. Explicación de las gráficas, previa al inicio del experimento. Vía mensaje de móvil, ambos grupos

EXPERIMENTO IBERDROLA.- Hola, en unos momentos voy a enviarte unas gráficas con tus datos de consumo eléctrico. Lo haré una vez a la semana hasta el día que acabe el experimento. Verás dos gráficas: la primera son tus consumos de la semana en curso, la segunda tus datos desde el inicio del experimento hasta el día actual. Puedes usar el gráfico semanal para ver qué tal lo estás haciendo, pero ten en cuenta que cobrarás según quede, en la última semana, el segundo gráfico, el que contiene los datos desde el inicio. Si tienes alguna duda, puedes ponerte en contacto conmigo por whatsapp o en la dirección de correoal162987@uji.es.Saludos

III.3.4. Comunicación de fin del experimento, vía mensaje de móvil, ambos grupos

Hola, el 21 de diciembre finaliza el experimento de eficiencia energética en la vivienda. Por favor, permanece atento esta semana a tu correo porque recibirás un cuestionario relacionado con él para rellenarlo y reenviármelo.

Después, a partir del día 22 recibirás la última gráfica, ya con los resultados finales del experimento. Saludos y gracias por participar!

III.3.5. Resultados y solicitud de prolongación de acceso a la cuenta, vía email

Asunto: datos finales experimento

Hola, te envío la gráfica con los resultados de la última semana y los globales del experimento.

Por otra parte, y aunque tu participación en este experimento ya ha finalizado, te pedimos que esperes un par de meses antes de cambiar tu contraseña de acceso a Iberdrola. De esta forma, podríamos revisar algunas tendencias del consumo durante enero y febrero, aunque ya no influirian en tus resultados. A principios de Marzo te avisaría del final definitivo para que cambies tu contraseña. 
Saludos, feliz Navidad y gracias por tu participación.

\section{III.4. Estudio estadístico del experimento 3}

En todos los casos, en este experimento se utilizan dos formas de agrupar los datos, que coinciden con las que se utilizaron para enviar a los sujetos experimentales: consumos semanales independientes, y consumos acumulados desde el inicio del experimento. En todos los apartados siguientes, se denominan de la siguiente forma:

Grupo 0. Grupo ciego

Grupo I. Grupo con incentivo económico e información semanal por mensaje de móvil

Grupo II. Grupo de control, sin incentivo económico pero con información semanal por mensaje de móvil

Consumo semanal: Energía consumida en kWh, obtenida por suma de los consumos diarios de una única semana del experimento. Todas las semanas del año 2016 empiezan en lunes y terminan en domingo; las del año 2015 coinciden en día del mes pero no, lógicamente, en día de la semana, por lo que todas empiezan en sábado y terminan en viernes.

Consumo acumulado: Energía consumida en kWh, obtenida por suma de los consumos diarios acumulados desde el día de inicio del experimento. Todos los consumos acumulados del año 2015 empiezan el 17 de octubre del año 2015; todos los consumos acumulados del año 2016 dan comienzo el 17 de octubre del año 2016. En el año 2016, la primera semana va de lunes 17 a domingo 23; en el 2015, va de sábado 17 a viernes 23. En cualquiera de los dos casos, están representados los 7 días de la semana, por lo que no hay diferencias por contar en un caso con fin de semana y en el otro no.

\section{III.4.1. Estadísticos descriptivos de los consumos semanales y acumulados}

Los consumos semanales del Grupo I tienen las características mostradas en la Tabla III.1 
Consumos año 2015 por semanas, Grupo I.

\begin{tabular}{cccc} 
№ de semana & Media & Desviación típica & № de muestras \\
\hline 1 & 63,33 & 47,33 & 25 \\
2 & 59,48 & 37,44 & 25 \\
3 & 61,99 & 40,43 & 25 \\
4 & 61,91 & 39,17 & 25 \\
5 & 63,35 & 45,24 & 25 \\
6 & 66,51 & 45,75 & 25 \\
7 & 70 & 45,73 & 25 \\
8 & 67,01 & 42,85 & 25 \\
9 & 69,41 & 39,46 & 25 \\
\hline
\end{tabular}

Consumos año 2016 por semanas, Grupo I

\begin{tabular}{cccc} 
№ de semana & Media & Desviación típica & № de muestras \\
\hline 1 & 58,79 & 38,87 & 25 \\
2 & 56,73 & 35,35 & 25 \\
3 & 54,16 & 33,4 & 25 \\
4 & 53,72 & 31,93 & 25 \\
5 & 57,53 & 38,37 & 25 \\
6 & 61,21 & 33,88 & 25 \\
7 & 65,87 & 44,19 & 25 \\
8 & 62,64 & 39,32 & 25 \\
9 & 71,33 & 49,16 & 25 \\
\hline
\end{tabular}

Tabla III.1. Estadísticos descriptivos de los consumos semanales del Grupo I

Los consumos semanales del Grupo II tienen las características mostradas en la Tabla III.2 
Consumos año 2015 por semanas, Grupo II

\begin{tabular}{cccc} 
№ de semana & Media & Desviación típica & № de muestras \\
\hline 1 & 56,55 & 26,56 & 25 \\
2 & 53,55 & 20,26 & 25 \\
3 & 51,91 & 20,84 & 25 \\
4 & 50,68 & 19,81 & 25 \\
5 & 53,91 & 21,28 & 25 \\
6 & 63,63 & 33,09 & 25 \\
7 & 65,11 & 28,88 & 25 \\
8 & 57,95 & 27,04 & 25 \\
9 & 66,92 & 28,97 & 25 \\
\hline
\end{tabular}

Consumos año 2016 por semanas, Grupo II

\begin{tabular}{cccc} 
№ de semana & Media & Desviación típica & № de muestras \\
\hline 1 & 53,03 & 19,72 & 25 \\
2 & 52,05 & 20,76 & 25 \\
3 & 52,99 & 20,18 & 25 \\
4 & 55,05 & 20,76 & 25 \\
5 & 59,71 & 25,46 & 25 \\
6 & 68,65 & 29,23 & 25 \\
7 & 77,33 & 43,88 & 25 \\
8 & 63,17 & 30,22 & 25 \\
9 & 72,38 & 36,83 & 25 \\
\hline
\end{tabular}

Tabla III.2. Estadísticos descriptivos de los consumos semanales del Grupo II

Puede observarse cómo, en ambos casos, el promedio de consumo semanal va subiendo de semana en semana, cosa normal si tenemos en cuenta que la primera semana pertenece al mes de octubre y la última, a diciembre. Las variaciones esperables en temperatura y horas de luz entre ambas fechas hacen que los consumos sean mayores en la última que en la primera. En todos los casos, las lecturas están tomadas en kWh.

Los consumos acumulados del Grupo I de la primera a la última semanas se muestran en la Tabla III.3. Los consumos acumulados se calculan 
simplemente como la suma de los consumos de todas las semanas transcurridas.

Consumos año 2015 acumulados, Grupo I

\begin{tabular}{cccc} 
№ de semana & Media & Desviación típica & № de muestras \\
\hline 1 & 63,33 & 47,33 & 25 \\
$1-2$ & 122,81 & 83,59 & 25 \\
$1-2-3$ & 184,8 & 123,91 & 25 \\
$1 . .4$ & 246,71 & 162,59 & 25 \\
$1 \ldots .5$ & 310,06 & 207,51 & 25 \\
$1 \ldots .6$ & 376,57 & 251,47 & 25 \\
$1 \ldots . .7$ & 446,57 & 295,12 & 25 \\
$1 \ldots \ldots 8$ & 513,58 & 336,65 & 25 \\
$1 \ldots . . .9$ & 582,99 & 374,67 & 25 \\
\hline
\end{tabular}

Consumos año 2016 acumulados, Grupo I

\begin{tabular}{cccc} 
№ de semana & Media & Desviación típica & № de muestras \\
\hline 1 & 58,79 & 38,87 & 25 \\
$1-2$ & 115,52 & 73,48 & 25 \\
$1-2-3$ & 169,68 & 106,16 & 25 \\
$1 . .4$ & 223,4 & 137,08 & 25 \\
$1 \ldots$. & 280,93 & 174,99 & 25 \\
$1 \ldots .6$ & 342,14 & 206,66 & 25 \\
$1 \ldots . .7$ & 408,01 & 241,93 & 25 \\
$1 \ldots \ldots 8$ & 470,65 & 276,26 & 25 \\
$1 \ldots . . .9$ & 541,98 & 320,4 & 25 \\
\hline
\end{tabular}

Tabla III.3. Estadísticos descriptivos de los consumos acumulados a lo largo del experimento por el Grupo I

Por último, se muestra en la Tabla III.4 los consumos acumulados a lo largo del experimento por el Grupo II. 
Consumos año 2015 acumulados, Grupo II

\begin{tabular}{cccc} 
№ de semana & Media & Desviación típica & № de muestras \\
\hline 1 & 56,55 & 26,56 & 25 \\
$1-2$ & 110,11 & 44,7 & 25 \\
$1-2-3$ & 162,01 & 64,74 & 25 \\
$1 . .4$ & 212,69 & 83,3 & 25 \\
$1 \ldots . .5$ & 266,6 & 103,84 & 25 \\
$1 \ldots .6$ & 330,22 & 132,74 & 25 \\
$1 \ldots . .7$ & 395,33 & 157,39 & 25 \\
$1 \ldots \ldots .8$ & 453,28 & 182,2 & 25 \\
$1 \ldots \ldots .9$ & 520,2 & 208,29 & 25 \\
\hline
\end{tabular}

Consumos año 2016 acumulados, Grupo II

\begin{tabular}{cccc}
\hline $\begin{array}{c}\text { № de } \\
\text { semana }\end{array}$ & Media & $\begin{array}{c}\text { Desviación } \\
\text { típica }\end{array}$ & № de muestras \\
\hline 1 & 53,03 & 19,72 & 25 \\
$1-2$ & 105,08 & 40 & 25 \\
$1-2-3$ & 158,07 & 59,4 & 25 \\
$1 . .4$ & 213,12 & 78,87 & 25 \\
$1 \ldots . .5$ & 272,83 & 102,28 & 25 \\
$1 \ldots .6$ & 341,48 & 126,91 & 25 \\
$1 \ldots . .7$ & 418,81 & 164,75 & 25 \\
$1 \ldots . .8$ & 481,99 & 193,6 & 25 \\
$1 \ldots . . .9$ & 554,36 & 227,69 & 25 \\
\hline
\end{tabular}

Tabla III.4. Estadísticos descriptivos de los consumos acumulados a lo largo del experimento por el Grupo I

\section{III.4.2. Estudios de normalidad de las muestras}

Las pruebas de normalidad en la mayoría de los casos dan como resultado que las variables, en la mayoría de los casos, no presentan una distribución normal. En las Tabla III.5 y Tabla III.6 se marcan en gris los pvalores $\leq 0,05$ (distribuciones no normales). 
Pruebas de normalidad de la variable Consumo semanal

\begin{tabular}{cccc}
\hline & & Kolmogorov-Smirnov & Shapiro-Wilk \\
\hline Semana & Grupo I & 0,046 & 0,01 \\
1 & Grupo II & 0,025 & 0 \\
Semana & Grupo I & 0,062 & 0,206 \\
2 & Grupo II & 0,11 & 0,242 \\
Semana & Grupo I & 0,111 & 0,064 \\
3 & Grupo II & 0,2 & 0,212 \\
Semana & Grupo I & 0 & 0 \\
4 & Grupo II & 0,003 & 0 \\
Semana & Grupo I & 0,054 & 0 \\
5 & Grupo II & 0,023 & 0,027 \\
Semana & Grupo I & 0 & 0,004 \\
6 & Grupo II & 0,03 & 0,001 \\
Semana & Grupo I & 0,01 & 0,001 \\
7 & Grupo II & 0,004 & 0 \\
Semana & Grupo I & 0,016 & 0 \\
8 & Grupo II & 0,001 & 0 \\
Semana & Grupo I & 0,002 & 0 \\
9 & Grupo II & 0,013 & 0,014 \\
\hline
\end{tabular}

Tabla III.5. Normalidad de las muestras semanales

Pruebas de normalidad de la variable Consumo semanal acumulado

\begin{tabular}{cccc}
\hline $\begin{array}{c}\text { № de } \\
\text { semanas }\end{array}$ & & Kolmogorov-Smirnov & Shapiro-Wilk \\
\hline \multirow{2}{*}{1} & Grupo I & 0,046 & 0,01 \\
& Grupo II & 0,025 & 0 \\
\multirow{2}{*}{$1-2$} & Grupo I & 0,2 & 0,045 \\
& Grupo II & 0,2 & 0,763 \\
$1-2-3$ & Grupo I & 0,088 & 0,168 \\
& Grupo II & 0,045 & 0,456 \\
$1 . .4$ & Grupo I & 0,001 & 0,006 \\
& Grupo II & 0,022 & 0,005 \\
$1 . .5$ & Grupo I & 0,002 & 0,005 \\
& Grupo II & 0,029 & 0,002 \\
$1 . . .6$ & Grupo I & 0,001 & 0,011 \\
& Grupo II & 0,089 & 0,005
\end{tabular}




\begin{tabular}{cccc} 
& Grupo I & 0,072 & 0,5 \\
$1 \ldots . .7$ & Grupo II & 0,158 & 0,019 \\
& Grupo I & 0,2 & 0,361 \\
\multirow{2}{*}{$1 \ldots . .8$} & Grupo II & 0,078 & 0,003 \\
& Grupo I & 0,2 & 0,088 \\
$1 \ldots . . .9$ & Grupo II & 0,049 & 0,005 \\
\hline
\end{tabular}

Tabla III.6, Normalidad de las muestras acumuladas parciales

\section{III.4.3. Estudios de significatividad}

Los datos de consumo acumulados del Grupo I se muestran en la Tabla III.7, en la que se incluye la significatividad de la diferencia en cada periodo. Prácticamente todas las diferencias de consumo entre los dos años resultan ser significativas (casillas en color verde), o casi (casillas en amarillo).

Comparativa del consumo acumulado del Grupo I

\begin{tabular}{lcccc}
\hline & \multicolumn{2}{c}{ Consumos $(\mathrm{kWh})$} & Ahorro $(\%)$ & p-valor \\
\cline { 2 - 5 } & 2015 & 2016 & $\begin{array}{c}2016 \text { respecto } \\
2015\end{array}$ & (Wilcoxon) \\
\hline 1 semana & 1583,24 & 1469,74 & 7,17 & 0,382 \\
2 semanas & 3070,23 & 2888,04 & 5,93 & 0,15 \\
3 semanas & 4620,05 & 4242 & 8,18 & 0,011 \\
4 semanas & 6167,82 & 5584,98 & 9,45 & 0,005 \\
5 semanas & 7751,48 & 7023,19 & 9,4 & 0,008 \\
6 semanas & 9414,2 & 8553,55 & 9,14 & 0,032 \\
7 semanas & 11164,22 & 10200,2 & 8,63 & 0,035 \\
8 semanas & 12839,55 & 11766,17 & 8,36 & 0,037 \\
9 semanas & 14574,73 & 13549,45 & 7,03 & 0,054 \\
\hline
\end{tabular}

Tabla III.7. Comparativa del consumo acumulado del Grupo I

En cambio, la significatividad de las variaciones en el grupo II no está respaldada por el test de Wilcoxon, que no da confirmación en ninguno de los periodos, como se muestra en la Tabla III.8. Por tanto, debe concluirse que el comportamiento del Grupo II es básicamente el mismo entre los años 2015 y 2016.

Comparativa del consumo acumulado del Grupo II

\begin{tabular}{cccc}
\hline \multicolumn{2}{c}{ Consumos (kWh) } & Ahorro (\%) & p-valor \\
\cline { 2 - 4 } 2015 & 2016 & 2016 respecto & (Wilcoxon)
\end{tabular}




\begin{tabular}{lccll}
\hline 1 semana & 1413,83 & 1325,67 & 6,24 & 0,696 \\
2 semanas & 2752,68 & 2626,91 & 4,57 & 0,231 \\
3 semanas & 4050,31 & 3951,68 & 2,44 & 0,253 \\
4 semanas & 5317,24 & 5327,94 & $-0,2$ & 0,677 \\
5 semanas & 6664,91 & 6820,81 & $-2,34$ & 0,882 \\
6 semanas & 8255,54 & 8537,06 & $-3,41$ & 0,192 \\
7 semanas & 9883,33 & 10470,26 & $-5,94$ & 0,109 \\
8 semanas & 11332 & 12049,63 & $-6,33$ & 0,104 \\
9 semanas & 13005,05 & 13859,06 & $-6,57$ & 0,166 \\
\hline
\end{tabular}

Tabla III.8. Comparativa de consumos acumulados del Grupo II

En la Tabla III.9 se muestra el p-valor de la comparación de la variable Incremento del consumo entre los grupos I y II. Como se aprecia en la tabla, la variable es significativa en la mayoría de los casos (en verde $p$-valor $<0,05$, en amarillo $0,05<p$-valor $<0.1$ ). Los periodos que abarcan una única semana se llaman semana 1, semana 2, etc; los que abarcan el consumo acumulado desde el inicio del experimento, se llaman 1 semana, 2 semanas, etc.

Prueba $U$ de Mann-Whitney variable Incremento medio del consumo

\begin{tabular}{cccc}
\hline Periodo & Grupo I (kWh) & Grupo II (kWh) & p-valor \\
\hline Semana 1 & 3,53 & 4,54 &, 764 \\
Semana 2 & 1,50 & 2,75 &, 621 \\
Semana 3 & $-1,09$ & 7,83 &, 008 \\
Semana 4 & $-4,37$ & 8,19 &, 010 \\
Semana 5 & $-5,81$ & 5,82 &, 024 \\
Semana 6 & $-5,02$ & 5,29 &, 079 \\
Semana 7 & $-12,22$ & 4,13 &, 023 \\
Semana 8 & $-5,23$ & 4,37 &, 023 \\
Semana 9 & $-5,46$ & $-1,92$ &, 109 \\
\hline 1 semana & 4,54 & 3,53 &, 764 \\
2 semanas & 7,29 & 5,03 &, 677 \\
3 semanas & 15,12 & 3,95 &, 171 \\
4 semanas & 23,31 & $-0,43$ &, 045 \\
5 semanas & 29,13 & $-6,24$ &, 025 \\
6 semanas & 34,43 & $-11,26$ &, 014 \\
7 semanas & 38,56 & $-23,48$ &, 007 \\
8 semanas & 42,94 & $-28,71$ &, 007 \\
9 semanas & 41,01 & $-34,16$ &, 013 \\
\hline
\end{tabular}

Tabla III.9. Prueba de significatividad de la variable Incremento del consumo a lo largo del experimento 
La evolución semanal de la variable Consumo total presenta algunas características interesantes, por lo que se muestran los datos y sus significatividades en la Tabla III.10 y la Tabla III.11 .

Comparativa del consumo semanal del Grupo I

\begin{tabular}{ccccc}
\hline & \multicolumn{2}{c}{ Consumos (kWh) } & Ahorro (\%) & p-valor \\
\cline { 2 - 5 } & 2015 & 2016 & 2016 respecto 2015 & (Wilcoxon) \\
\hline Semana 1 & 63,33 & 58,79 & 7,17 & 0,382 \\
Semana 2 & 59,48 & 56,73 & 4,62 & 0,326 \\
Semana 3 & 61,99 & 54,16 & 12,64 & 0,002 \\
Semana 4 & 61,91 & 53,72 & 13,23 & 0,011 \\
Semana 5 & 63,35 & 57,53 & 9,18 & 0,083 \\
Semana 6 & 66,51 & 61,21 & 7,96 & 0,778 \\
Semana 7 & 70 & 65,87 & 5,91 & 0,166 \\
Semana 8 & 67,01 & 62,64 & 6,53 & 0,042 \\
Semana 9 & 69,41 & 71,33 & $-2,77$ & 0,412 \\
\hline
\end{tabular}

Tabla III.10. Comparativa del consumo semanal del Grupo I

Comparativa del consumo semanal del Grupo II

\begin{tabular}{ccccc}
\hline & \multicolumn{2}{c}{ Consumos (kWh) } & Ahorro (\%) & p-valor \\
\cline { 2 - 5 } & 2015 & 2016 & $\begin{array}{c}2016 \text { respecto } \\
2015\end{array}$ & (Wilcoxon) \\
\hline Semana 1 & 1413,83 & 1325,67 & 6,24 & 0,696 \\
Semana 2 & 1338,85 & 1301,24 & 2,81 & 0,638 \\
Semana 3 & 1297,63 & 1324,77 & $-2,09$ & 0,657 \\
Semana 4 & 1266,94 & 1376,26 & $-8,63$ & 0,3 \\
Semana 5 & 1347,67 & 1492,87 & $-10,77$ & 0,183 \\
Semana 6 & 1590,63 & 1716,25 & $-7,9$ & 0,051 \\
Semana 7 & 1627,79 & 1933,2 & $-18,76$ & 0,088 \\
Semana 8 & 1448,67 & 1579,36 & $-9,02$ & 0,427 \\
Semana 9 & 1673,05 & 1809,43 & $-8,15$ & 0,3 \\
\hline
\end{tabular}

Tabla III.11. Comparativa del consumo semanal del Grupo li 


\section{III.4.4. Otras aportaciones de los participantes}

Las respuestas concretas de cada participante a las preguntas descritas en el apartado 7.2.7 se muestran en la Tabla III.12 tal cual fueron enviadas. Estas preguntas eran:

1.- ¿Te ayudaron las gráficas que te enviaba semanalmente? En caso afirmativo, ¿cuál mirabas más?

2.- ¿Qué cambios hiciste en concreto para reducir tu consumo?

Encuesta final experimento 3

\begin{tabular}{|c|c|c|}
\hline Pregunta & Respuestas & Id \\
\hline \multirow{15}{*}{1} & Miraba el ahorro semanal & 0 \\
\hline & $\begin{array}{l}\text { Miraba el ahorro mensual (usó las gráficas para ver qué } \\
\text { gastaba más) }\end{array}$ & 4 \\
\hline & Ahorro semanal & 10 \\
\hline & Miraba su consumo respecto al año anterior & 11 \\
\hline & Ahorro semanal & 2 \\
\hline & Ahorro semanal, diferencia de un año a otro & 12 \\
\hline & Consumo y ahorro semanales & 3 \\
\hline & Ahorro semanal & 8 \\
\hline & $\begin{array}{l}\text { Me servían a nivel informativo, viéndolas sabía si lo estábamos } \\
\text { haciendo bien o no }\end{array}$ & 7 \\
\hline & Ahorro semanal y comparación con el resto de participantes & 14 \\
\hline & Ahorro experimentado & 6 \\
\hline & Miraba el ahorro comparado con la semana anterior & 16 \\
\hline & Las dos & 17 \\
\hline & Ahorro semanal & 18 \\
\hline & $\begin{array}{l}\text { Controlaba lo que consumía en la página de mi compañía } \\
\text { distribuidora; el mío lo usaba para ver el ahorro acumulado }\end{array}$ & 23 \\
\hline \multirow[t]{4}{*}{2} & Apagar el WiFi todas las noches y siempre al salir de casa & 0 \\
\hline & $\begin{array}{l}\text { Concienciar a la familia, desenchufar lo q no se usaba, apagar } \\
\text { luces, no usar el horno, cargar hasta arriba lavadora y } \\
\text { secadora }\end{array}$ & 4 \\
\hline & Cuidar el uso de las luces y los electrodomésticos & 10 \\
\hline & Apagar luces, poner menos lavadoras & 11 \\
\hline
\end{tabular}


Concienciar a la familia, la calefacción, desconectando 2

enchufes

Menos estufas/calentadores, menos luces encendidas,

Usar menos el horno, la lavadora, la tv, y cocinar menos 23

Apagar más las luces $\quad 16$

Concienciar en casa e intentar minimizar el consumo $\quad 7$

Estaban menos en casa, y cuando estaban, apagaban las luces 8 que no usaban

Cambiar televisión y nevera por mejor calificación, cambio a

LEDs

Cargar lavadoras, apagar luces e interruptores

Usar lámpara de pie en vez de halógenos, un único radiador 17 por estancia en vez de aire por conductos por toda la casa

Concienciarse de apagar luces 6

Concienciar sobre apagar luces y otros encendidos, Reducir 18 temperatura nevera, reducir uso aire acondicionado.

Concienciar a la familia, sobre todo hermano pequeño, de apagar luces y televisión cuando no se usaran. Y optimizar 3 lavavajillas y lavadora

Cambiar halógenos a LEDs

Tabla III.12. Recursos utilizados por los participantes del Grupo I para la consecución de su objetivo 